\title{
THE DYNAMICS OF LARGE-SCALE SILICIC MAGMATIC SYSTEMS: CASE STUDIES FROM MANGAKINO VOLCANIC CENTRE, TAUPO VOLCANIC ZONE, NEW ZEALAND
}

BY

George Frederick CoOper

A thesis submitted to the Victoria University of Wellington in fulfillment of the requirements for the degree of Doctor of Philosophy in Geology

Victoria University of Wellington, Wellington, New Zealand 
barba crescit caput nescit 


\begin{abstract}
This thesis research focuses on clast and crystal-specific studies to investigate the preand syn-eruptive magmatic processes of two supereruptions in the TVZ: the $1.21 \mathrm{Ma}$ Ongatiti $\left(>500 \mathrm{~km}^{3}\right)$ and the $1.0 \mathrm{Ma}$ Kidnappers $\left(\sim 1200 \mathrm{~km}^{3}\right)$, together with the smaller $\left(\sim 200 \mathrm{~km}^{3}\right)$ 1.0 Ma Rocky Hill eruption from the Mangakino Volcanic Centre (MVC).

Crystallisation histories determined through SIMS U-Pb dating of zircons reveal that the paired Kidnappers and Rocky Hill eruptions were products of a common magmatic system, which built over $200 \mathrm{kyr}$, in the time break after the Ongatiti eruption. U-Pb age spectra from the Ongatiti show a protracted crystallisation history (over $\sim 250 \mathrm{kyr}$ ), in which the majority of zircon crystallised $\sim 100$ kyr prior to eruption in a crystal mush. Zircons then ascended with melt during accumulation of the final erupted magma body in the shallow crust. Zircons remained stable in the melt dominant body but underwent little further crystallisation. Zircons from all three systems record common geochemical processes governed by the fractionating assemblage (predominantly plagioclase and amphibole). In particular, the MREE/HREE ratios and Sr concentrations of zircons from the Ongatiti record imply two contrasting source regions governed by different proportions of crystallising amphibole.
\end{abstract}

The in-situ major and trace element chemistry of glass shards and crystals from the Kidnappers fall deposit reveal that magma within the Kidnappers was stored in three discrete bodies, which were systematically tapped during the early stages of eruption. Temperature and pressure (T-P) estimates from amphibole and $\mathrm{Fe}-\mathrm{Ti}$ oxide equilibria from each magma type are similar and therefore the three magma bodies were adjacent, not vertically stacked, in the crust. Amphibole model T-P estimates range from 770 to $840{ }^{\circ} \mathrm{C}$ and 90 to $170 \mathrm{MPa}$ corresponding to pre-eruptive storage depths of $\sim 4.0-6.5 \mathrm{~km}$. The systematic evacuation of the three independent magma bodies implies that there was tectonic triggering and linkage of eruptions. The termination of fall deposition and onset of the overlying ignimbrite emplacement marks the point of widespread caldera collapse and the catastrophic evacuation of a wider variety of melt during the Kidnappers eruption.

Pumice compositions from the Kidnappers ignimbrite fall into three groups, two of which (KI-1 and KI-2) can be matched to bodies tapped during the fall phase of the eruption, with the addition of a further discrete batch of lower $\mathrm{SiO}_{2}$ (KI-3) magma. Core-rim textural and chemical variations in major crystal phases (plagioclase, amphibole and orthopyroxene) suggest each compositional group was sourced from a common mush but underwent a unique magmatic history during the development of melt-dominant bodies in the final stages prior to eruption. The field relationships and distinctive appearance of the Rocky Hill ignimbrite ( $\left.200 \mathrm{~km}^{3} \mathrm{DRE}\right)$ and the underlying Kidnappers ignimbrite suggests that the two deposits are from distinct eruption events. However, major and trace element chemistry of matrix glass, coupled with the textural 
and chemical signatures of crystals suggests the magma erupted during the Rocky Hill was generated from the same source or mush zone as the Kidnappers. The two largest melt-dominant bodies (KI-1 and KI-2) within the Kidnappers were renewed, underwent mixing and incorporation of marginal material to form two magma types (RH-1 and RH-2 in the time break prior to the Rocky Hill eruption.

Fe-Mg interdiffusion timescales in orthopyroxenes from the Kidnappers and Rocky Hill deposits suggest the establishment of the final melt-dominant bodies, through extraction of melt and crystals from a common mush, occurred within 1000 years, and peaked within centuries of each eruption. In addition, one discrete batch of Kidnappers melt has evidence for interaction with a lesser evolved melt within $50 \mathrm{yrs}$ prior to eruption. This rejuvenation event was not the eruption trigger but may have primed the magma for eruption. The difference in timescales from common zones from both the Kidnappers and Rocky Hill orthopyroxene, recording the same processes reveal the time break between the two eruptions was $\sim 20-40$ years. This work highlights the rapidity of rejuvenation and renewal of the melt-dominant bodies within the Kidnappers/Rocky Hill magmatic system.

The textural and in-situ compositional signatures of crystals from the Ongatiti ignimbrite imply the final erupted magma body was assembled from a thermally and chemically zoned mush, which extended to the base of the quartzofeldspathic crust $(\sim 15 \mathrm{~km})$. The mush was close to water saturation and was dominated by amphibole crystallisation. Melt and crystals (including the majority of zircons) were extracted from the mush and ascended to 4-6 km depths during the development of a crystal-rich (20$30 \%$ ), but melt-dominant body. Significant crystallisation of plagioclase (and lesser proportions of orthopyroxene and amphibole) occurred in an event involving the gradual heating and/or increase of water in the rhyolite, from a broadly andesitic underplated magma. Homogeneous crystal rim and matrix glass compositions imply the final erupted volume of magma was effectively mixed through convection. Eu/Eu* values of whole-rock and matrix glass suggest little crystal-melt separation occurred in the melt-dominant magma body prior to eruption.

This work has implications for understanding the generation, storage and eruption of large-scale silicic magma systems. The Ongatiti ignimbrite does not represent either an erupted mush, or a stratified magma chamber, suggesting an alternative model for the development of eruptible magma within large-scale silicic systems. The Kidnappers/Rocky Hill sequence records a complex interplay of multiple melt-dominant bodies, which were established and renewed on rapid timescales. The rapid timescales for the development of melt-dominant bodies and the systematic tapping of magmas in the Kidnappers/Rocky Hill system imply that tectonics may have had a strong external control on the eruptions at Mangakino. 


\section{Acknowledgements}

During my time in New Zealand I have had the pleasure of meeting and working with a great group of people who have all helped make this $\mathrm{PhD}$ research a truly enjoyable experience.

First and foremost, I thank my supervisor Colin Wilson for your much-admired enthusiasm for research, which has inspired me to stick at it. The interest, time and effort you have put into this work has been remarkable. You have managed to shape a lad from 'up north', who knew nothing about volcanoes into someone, who at least, knows something about volcanoes. MarcAlban Millet for your continued guidance and support both in and out of the lab, without your generous help, this work would not have happened. I look forward to working with you on home soil. Many others have shared their expertise and offered priceless advice over the course of this work- Dan Morgan, for all your help on everything diffusion, Joel Baker, Monica Handler, Richard Wysoczanski, Di Seward, July Vry, Euan Smith and Tim Little to name a few. This work has been made possible from funding provided by the Marsden Fund of the Royal Society of New Zealand, and a Victoria Doctoral Scholarship.

Aidan Allan- A true, but not literal, brother, I never quite believed we would actually get to this point. You have made this research so much fun, whether it being discussions over the latest cricket stats, a late night bento in bed, Spiffy Wednesdays, or uncontrollably laughing about 'serious' science, it's been awesome! 'Thanks Jan'.

To all my past office mates- Simon 'golden retriever' Barker, the best officemate I have ever had, Aidan Allan, Chris 'condor' Conway, Katy Chamberlain, Dave Murphy, Jiao Ruohong and Denise Tang. We have managed to have a good laugh through the good and the bad- you will all be dearly missed. To all others, past and present in the SGEES and further afield- Melissa, Katy and Alexa (my PhD sisters), John Creech and Chris Conway (los desperados), Aidan, Ramona, Matt Ryan for your awesome intensity both on and off the field, Ben 'Hammer' Hines, Jenni, Nacho, Katie Collins, Kolja, Ian Schipper, Joe Hiess, James Muirhead, Sarah Milicich, Selwyn (or is it Richard), Shaun, Emily, Loretta for our short 'academic' breaks, and to all those I have missed, you know who you are!

I would like to cordially express my upmost gratitude to all members of the Old Boys Club for some truly historic memories. It has been a pleasure to enjoy and discuss the finer sides of life with you all. Here's to more great times! To Cork, 'the greatest game on Earth', and gentlemen of the ICF, it has been a love-hate relationship, but without the 'corridor of composure' I would have found the writing of this thesis a much harder mountain to climb. Also, to Birds of Prey FC for a much needed weekly runaround and squawking session.

To my wonderful housemates of Akautangi Way, Jenni and Emily, thanks for lots of fun and games, and Becca, a true teammate who has been there for me throughout the last year, you have the patience of a saint to put up with my continual rants about the finer points of this research and life in general.

To Mum and Dad for your love and support, and subconsciously (or perhaps consciously) inspiring my passion for geology and the outdoors from an early age. And to Emily, Leia, James, Megan and Auntie Lil for your continued love from the other side of the world. 


\section{Table of Contents}

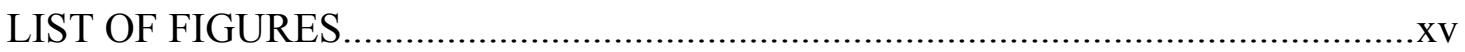

LIST OF TABLES .........................................................................................

PUBLICATIONS ARISING FROM THIS THESIS ..................................................x

\section{INTRODUCTION}

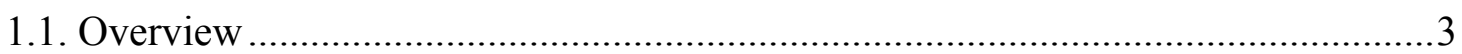

1.2. Thesis objectives and structure …............................................................. 4

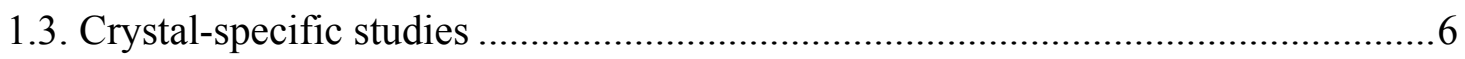

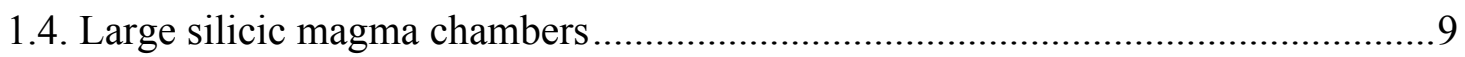

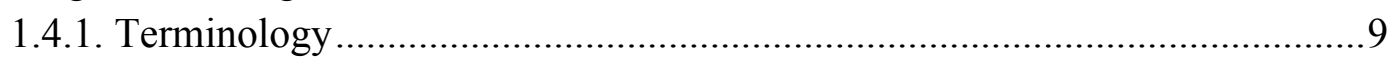

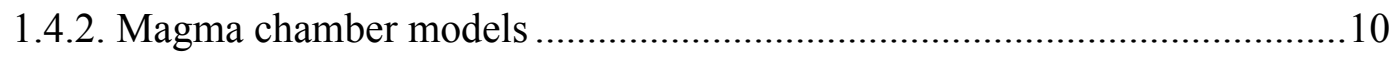

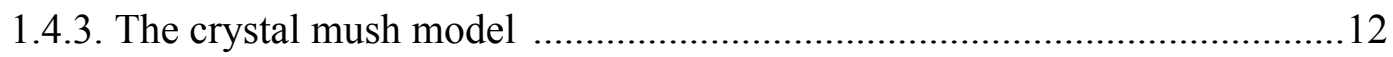

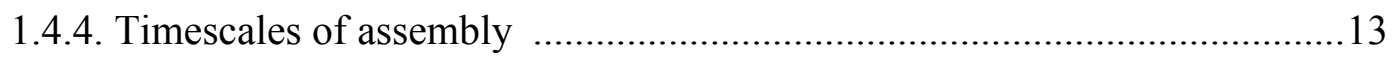

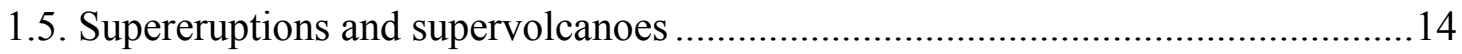

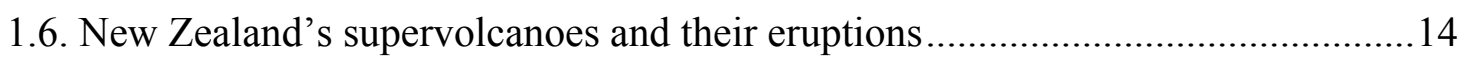

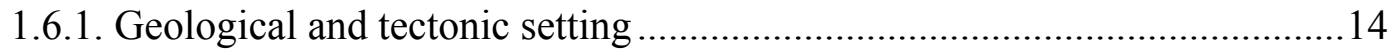

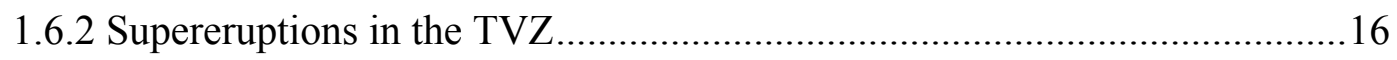

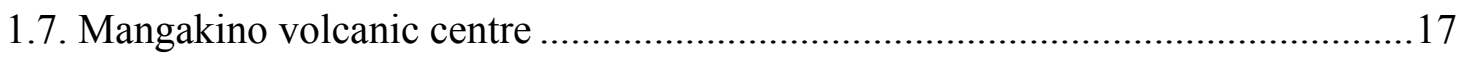

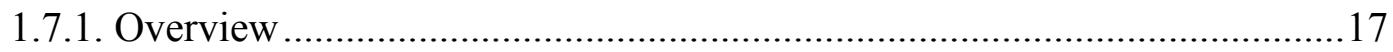

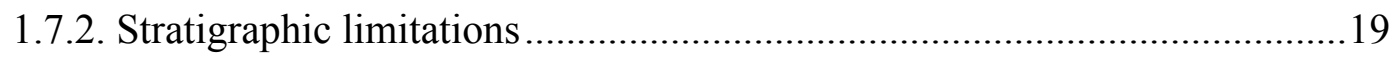

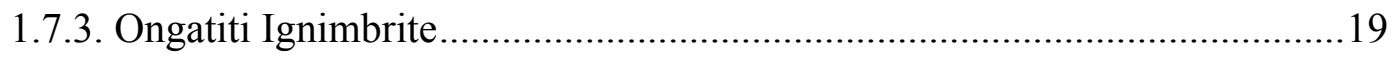

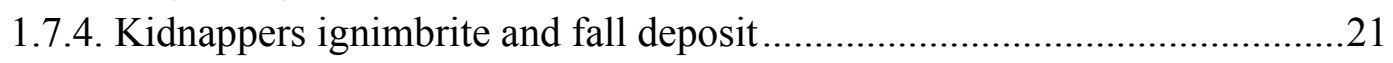

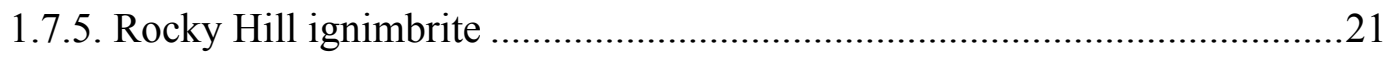

1.7.6. Previous work on Mangakino deposits ...................................................23

2. TEMPORAL EVOLUTION AND COMPOSITIONAL SIGNATURES OF TWO SUPERVOLCANIC SYSTEMS RECORDED IN ZIRCONS FROM MANGAKINO VOLCANIC CENTRE, NEW ZEALAND

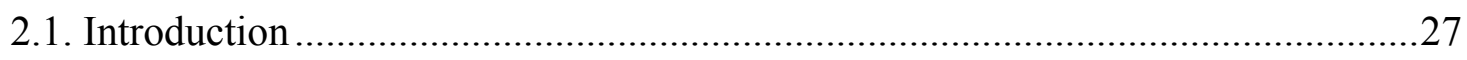

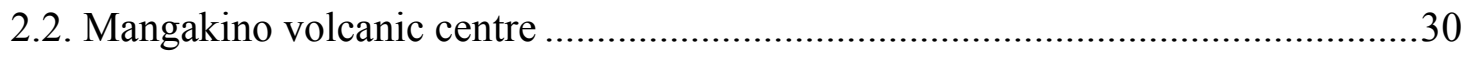

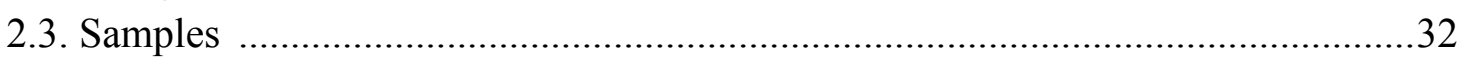

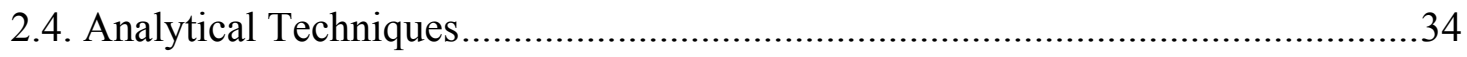

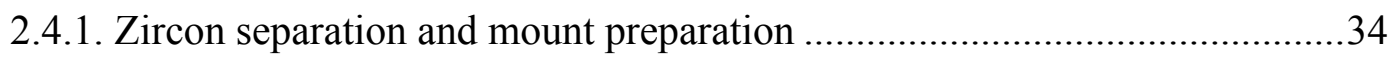

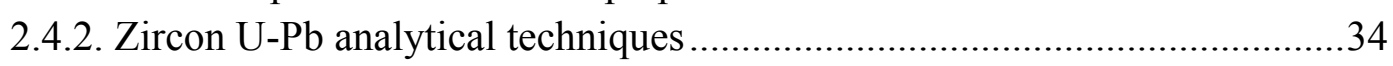

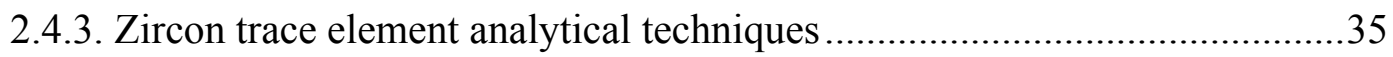

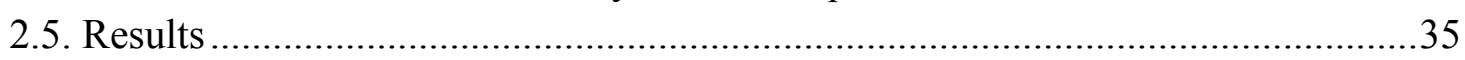

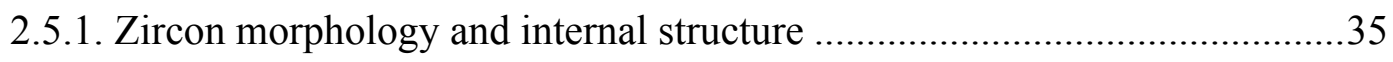

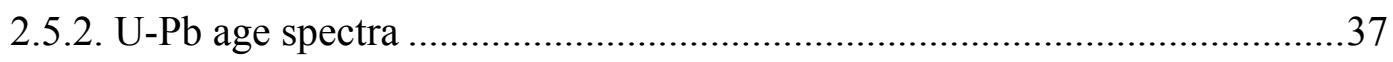

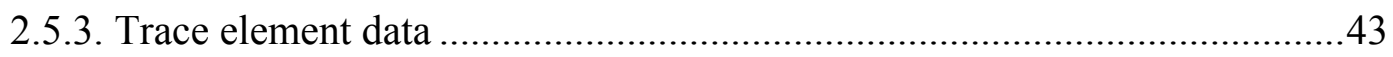




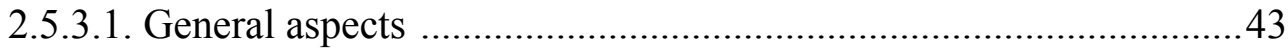

2.5.3.2. Trace element values versus age .............................................47

2.5.3.3. Trace element values versus position in crystals...........................48

2.5.3.4. Trace element values versus crystal aspect ratios .........................51

2.5.3.5. Influence of sector zoning ......................................................53

2.5.3.6. Ti concentrations and $\mathrm{Ti}$-in-zircon thermometry ...........................55

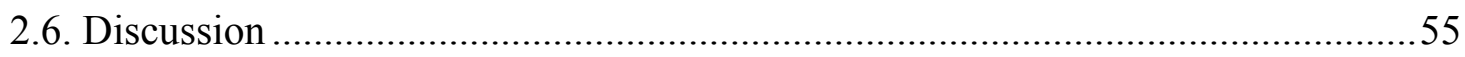

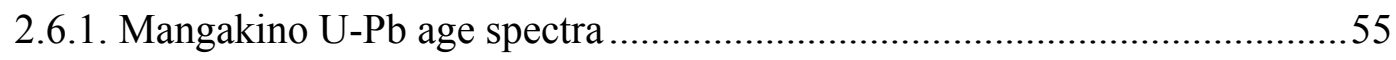

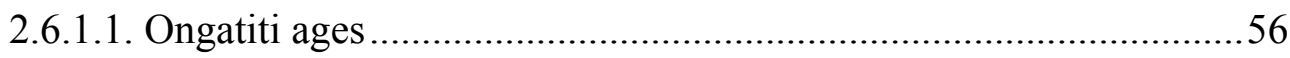

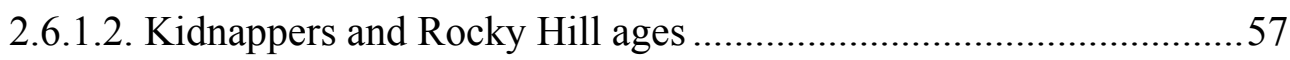

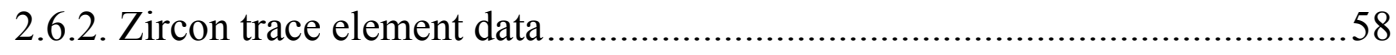

2.6.2.1. Summary of key features............................................................5

2.6.2.2. Origin of specific trace element trends........................................60

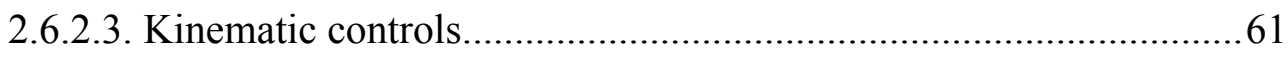

2.6.2.4. Sector zoning and zircon morphology........................................62

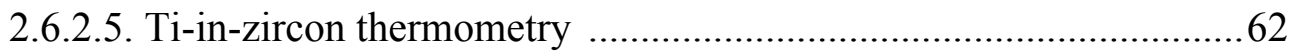

2.6.2.6. Implications for values of partition coefficients............................63

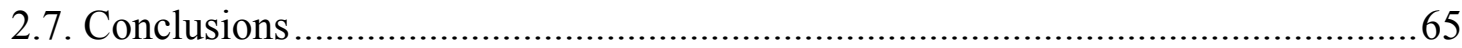

3. SYSTEMATIC TAPPING OF INDEPENDENT MAGMA CHAMBERS DURING THE 1 MA KIDNAPPERS SUPERERUPTION

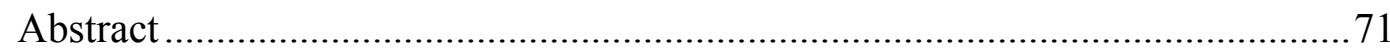

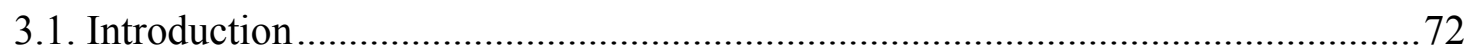

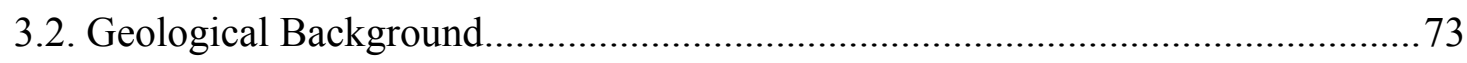

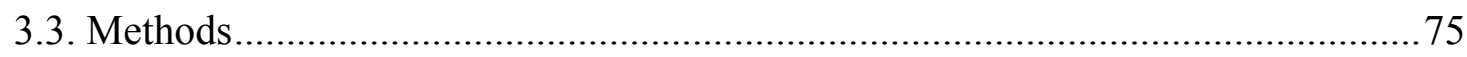

3.3.1. Sample preparation and analytical techniques ....................................... 75

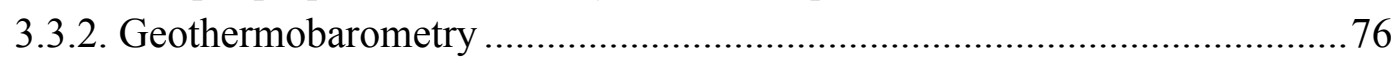

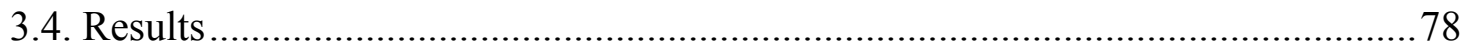

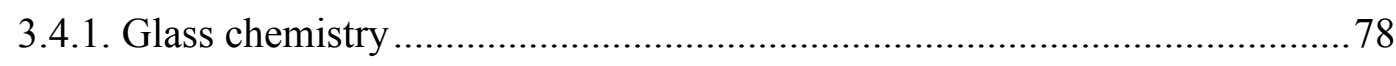

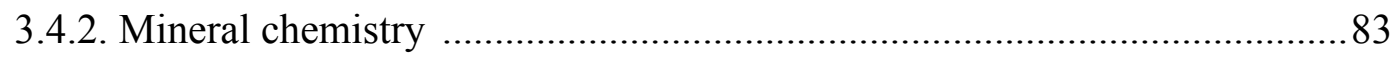

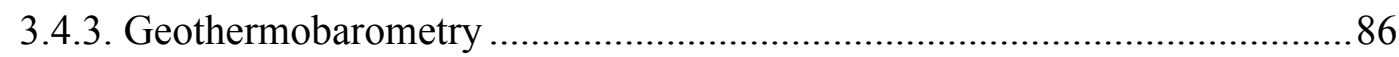

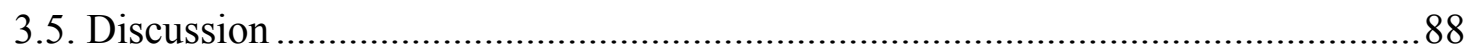

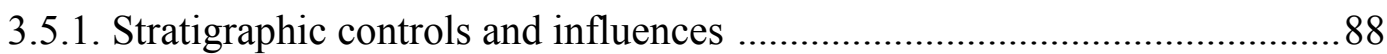

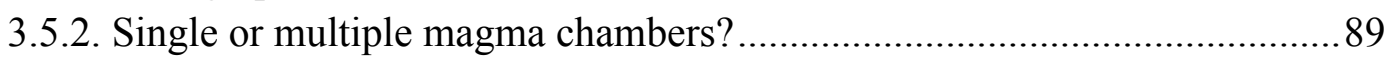

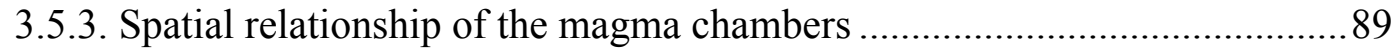

3.5.4. Temporal evolution of the Kidnappers supereruption .............................. 92

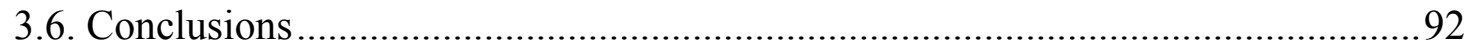

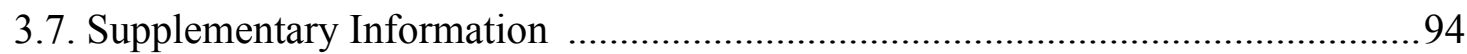

3.7.1. Major element analysis by electron microprobe (EPMA) .........................96

3.7.2 Trace element analysis by laser ablation inductively coupled plasma mass spectrometry (LA-ICP-MS) ........................................................... 96

3.7.3 Statistical treatment of glass shard chemistry .........................................98 
4. REJUVENATION AND RENEWED ERUPTION OF A SUPERVOLCANIC SYSTEM: CASE STUDY OF THE MANGAKINO CALDERA, TAUPO VOLCANIC ZONE, NEW ZEALAND

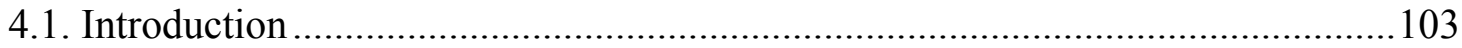

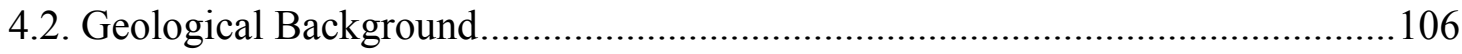

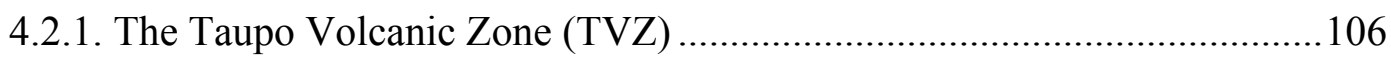

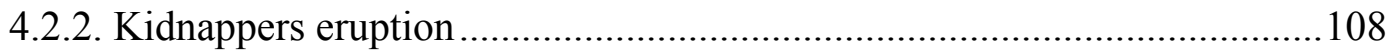

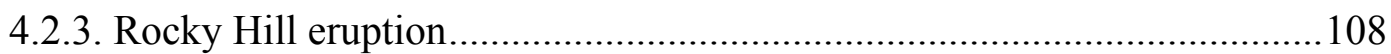

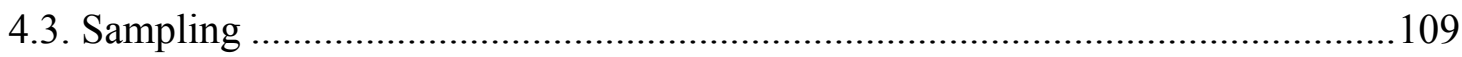

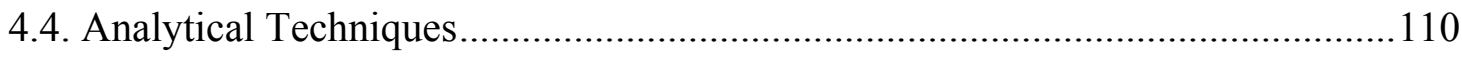

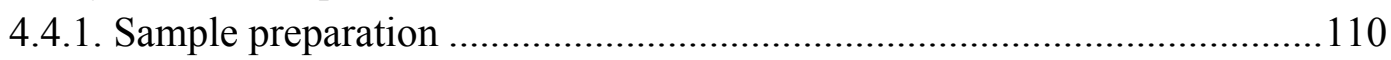

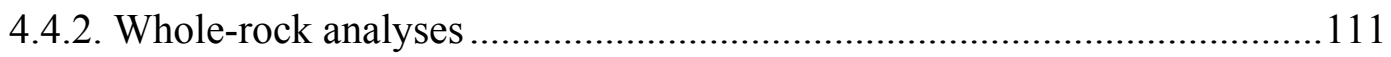

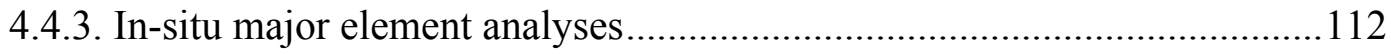

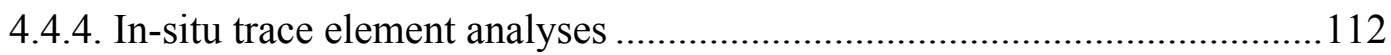

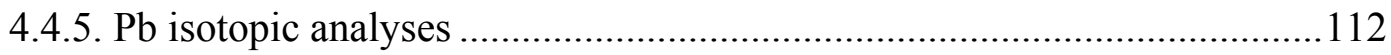

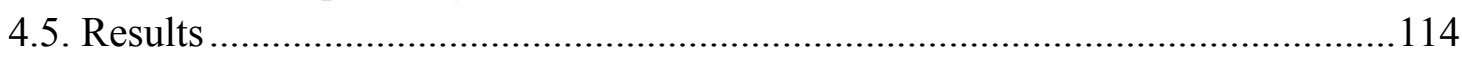

4.5.1. Whole rock pumice compositions and glass chemistry ........................... 114

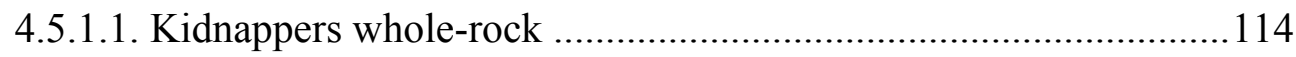

4.5.1.2. Kidnappers matrix glass ...................................................... 117

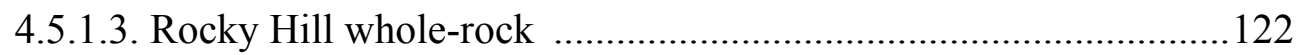

4.5.1.4. Rocky Hill matrix glass .......................................................... 122

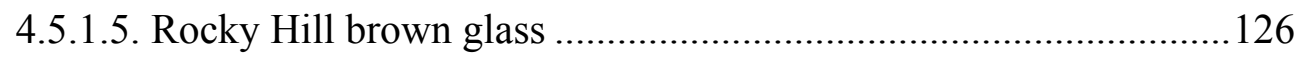

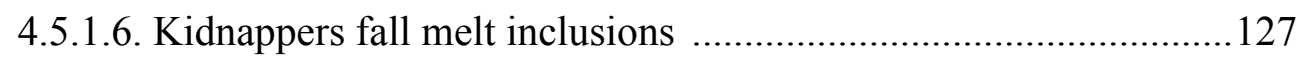

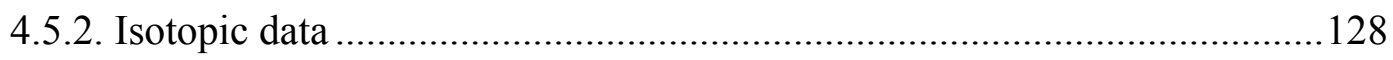

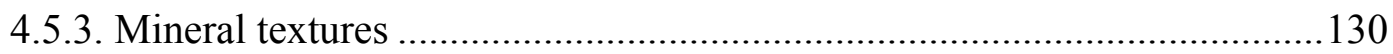

4.5.3.1. Kidnappers fall deposit mineral textures .................................... 130

4.5.3.2. Kidnappers ignimbrite pumice mineral textures ........................ 133

4.5.3.3. Rocky Hill ignimbrite pumice mineral textures .........................137

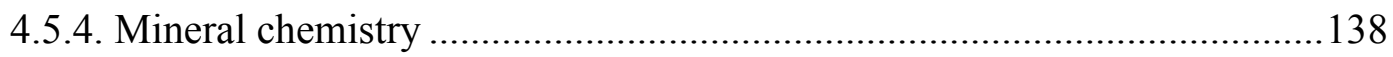

4.5.4.1. Kidnappers fall mineral chemistry .......................................... 140

4.5.4.2. Kidnappers ignimbrite pumice mineral chemistry ...................... 148

4.5.4.3. Rocky Hill ignimbrite pumice mineral chemistry ........................151

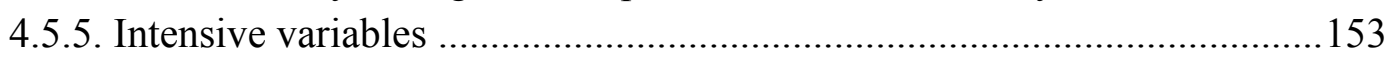

4.5.5.1. Amphibole model temperature and pressure estimates .................153

4.5.5.2. Fe-Ti oxide temperature and $f \mathrm{O}_{2}$ estimates .............................. 155

4.5.5.3. Plagioclase-melt and orthopyroxene-melt temperature estimates

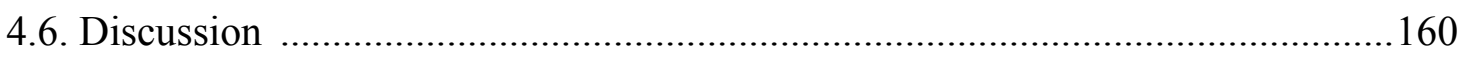

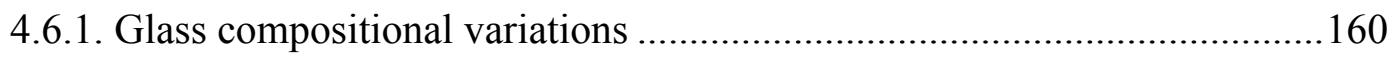

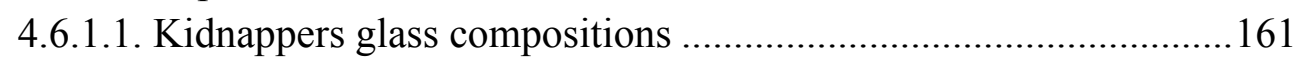

4.6.1.2. Rocky Hill glass compositions .................................................163

4.6.2. Significance of crystal signatures within compositional groups.................165

4.6.2.1. Mineral evidence supporting discrete magma batches .................. 166 
4.6.3. Consideration of geothermobarometry estimates .................................... 170

4.6.3.1. Amphibole core-to-rim P-T changes ........................................ 170

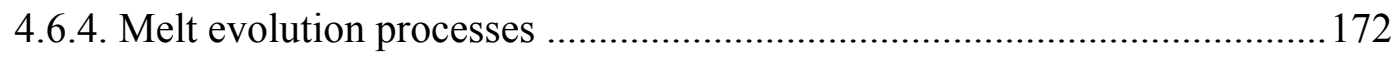

4.6.4.1. Whole rock and glass signatures ............................................. 172

4.6.4.2. Amphibole signatures ............................................................. 173

4.6.5. A magma system model for the Kidnappers and Rocky Hill eruptions ... 175

4.6.5.1. Earlier stages of the Kidnappers eruption (fall deposits) .............. 175

4.6.5.2. Later stages of the Kidnappers eruption (ignimbrite)................... 177

4.6.5.3. Prior to and during the Rocky Hill eruption................................ 179

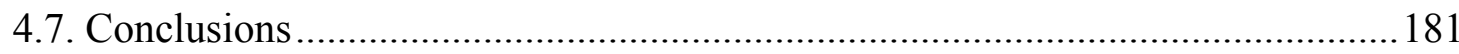

\section{ASSEMBLY AND REJUVENATION OF A LARGE SILICIC MAGMATIC SYSTEM: INSIGHTS FROM MINERAL DIFFUSIVE PROFILES IN THE KIDNAPPERS AND ROCKY HILL ERUPTION DEPOSITS}

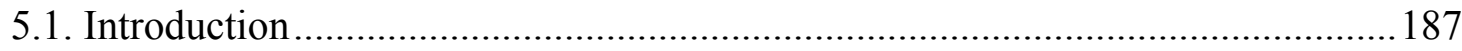

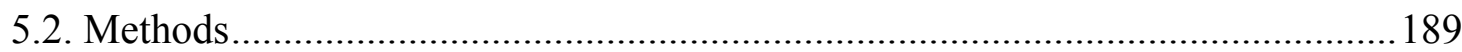

5.2.1. Orthopyroxene Fe-Mg interdiffusion .................................................. 190

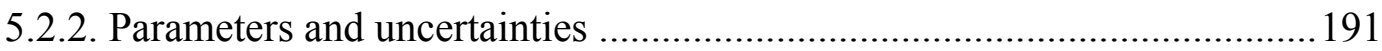

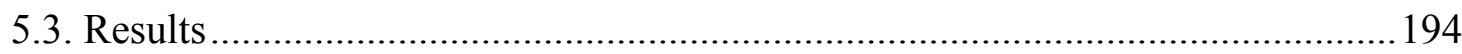

5.3.1. Textural characteristics of Kidnappers and Rocky Hill orthopyroxenes ... 194

5.3.2. Fe-Mg diffusion timescales in Kidnappers and Rocky Hill orthopyroxenes

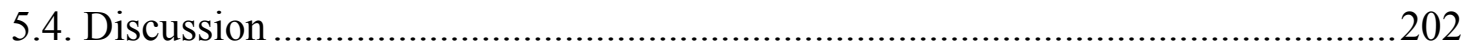

5.4.1. Implications of diffusion timescales from dark exterior zones..................202

5.4.2. Implications of diffusion timescales from core-rim boundaries ................204

5.4.3. Timescale comparisons and considerations ..........................................206

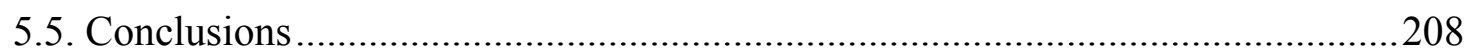

6. DEVELOPMENT, MOBILISATION AND ERUPTION OF A CRYSTAL RICH RHYOLITE: THE 1.21 MA ONGATITI ERUPTION

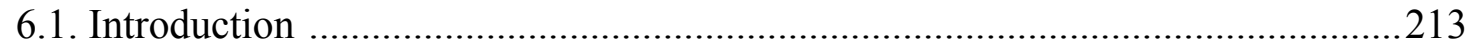

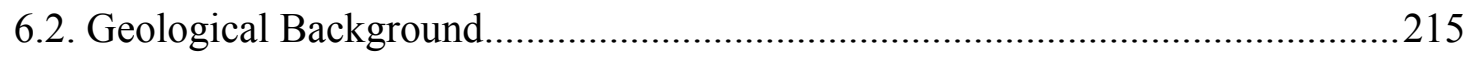

6.2.1. Mangakino Volcanic Centre and the Ongatiti ignimbrite........................22

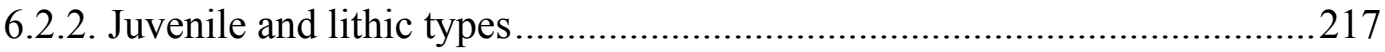

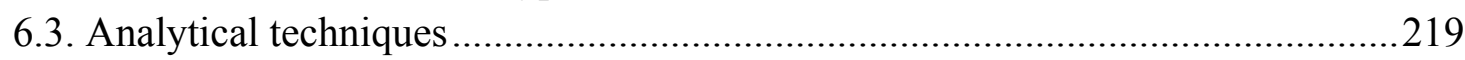

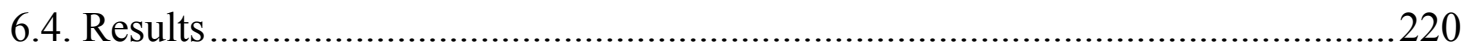

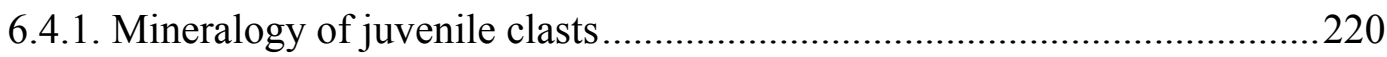

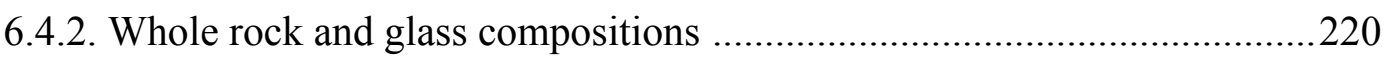

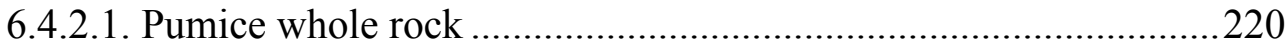

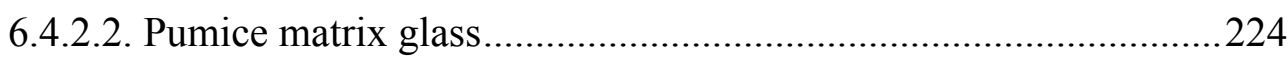

6.4.2.3. Microcrystalline clot matrix glass ........................................... 224

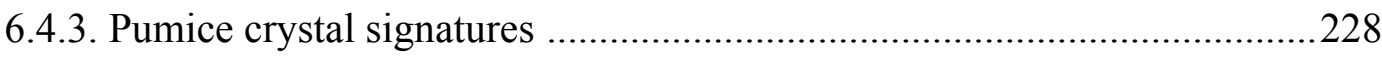




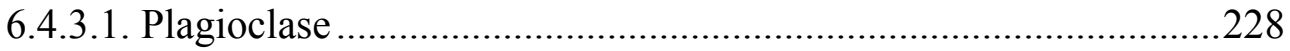

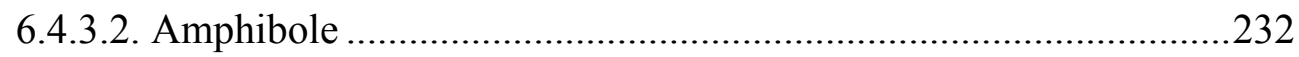

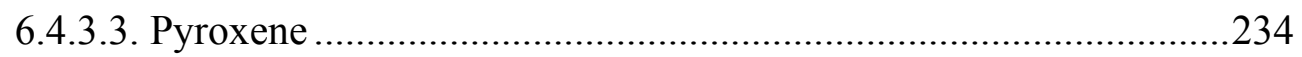

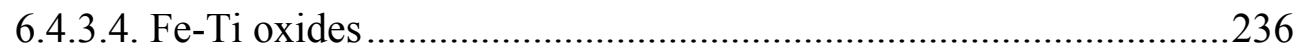

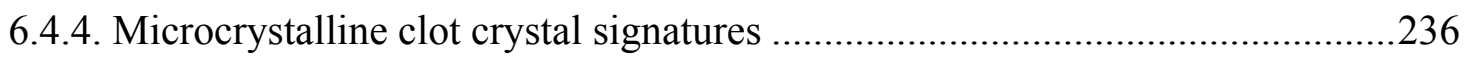

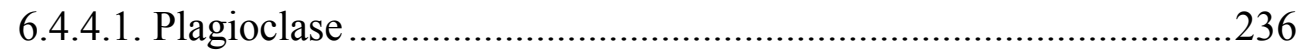

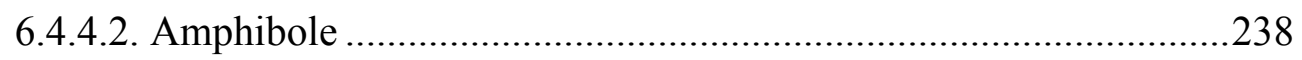

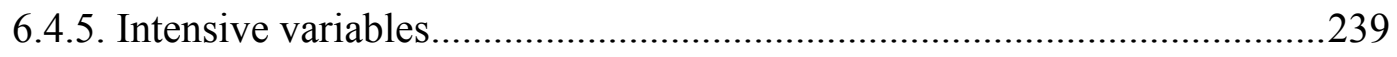

6.4.5.1. Fe-Ti oxide temperature and oxygen fugacity ............................239

6.4.5.2. Amphibole temperature and pressure .......................................239

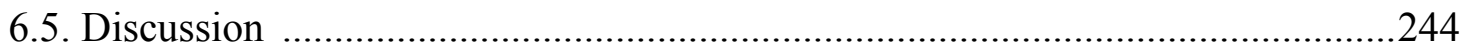

6.5.1. The role of crystal mush in the development of the Ongatiti system ........244

6.5.2. Origin of textural and chemical signatures in the Ongatiti crystals ..........245

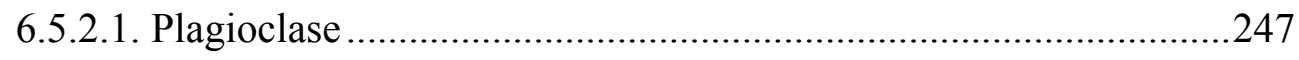

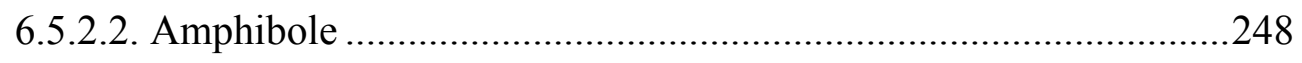

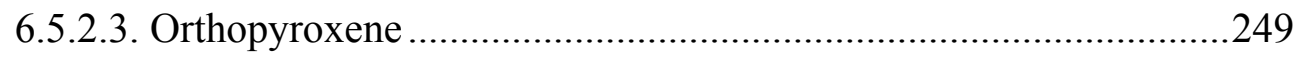

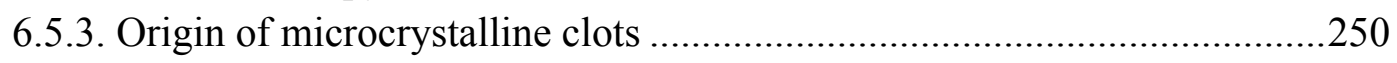

6.5.4. Heterogeneity to homogeneity in the Ongatiti magma body .....................251

6.5.5. Eruption of the Ongatiti magma body...................................................253

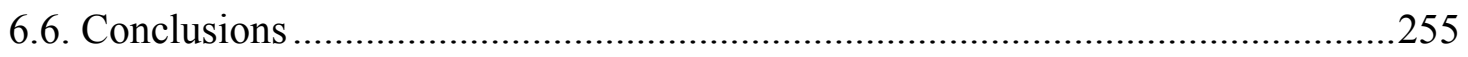

\section{SYNTHESIS AND CONCLUSIONS}

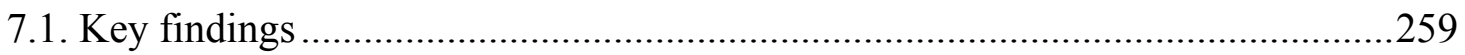

7.1.1. Over what timescales did each of the magmatic systems at Mangakino

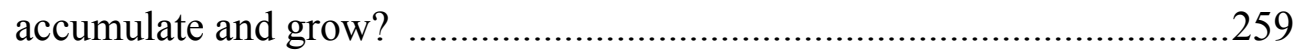

7.1.2. What magmatic processes and varying source influences can be tracked by trace elements in zircons?

7.1.3. What information can we gain from variations in mineral chemistry and zoning patterns in crystals regarding the pre-eruptive crystal growth histories and changing magmatic conditions within large silicic systems?

7.1.4. Over what depths did each magmatic system operate, and what were the sizes and pre-eruptive states of the melt-dominant bodies prior to eruption?

7.1.5. What information can be obtained from the geochemisty and/or petrology of a fall deposit, and how does it compare to the record from ignimbrites?

7.1.6. Do the Kidnappers and Rocky Hill ignimbrites share a common source and/or magma chamber? .266

7.1.7. What was the duration of the time break between the Kidnappers and Rocky Hill eruptions and what processes, such as magma recharge and mixing occurred during this time break? 
7.1.8. Does the Ongatiti ignimbrite represent an erupted crystal mush, and if so, what processes caused the transition into eruption?

7.2. Future perspectives 269

8. REFERENCES 273

\section{APPENDIX 1: ANALYTICAL TECHNIQUES}

9.1. Whole rock major and trace element analyses .297

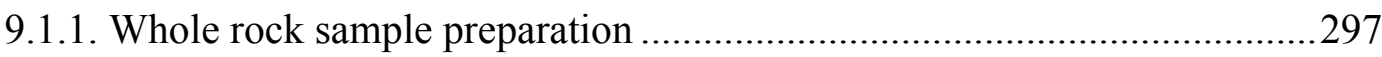

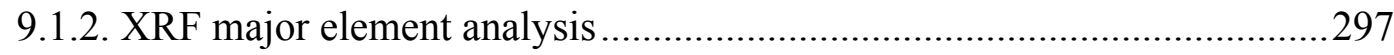

9.1.3. Precision and accuracy of major element analyses..................................297

9.1.4. Sample preparation for trace element analysis .......................................299

9.1.5. ICP-MS solution trace element analysis .................................................. 301

9.1.6. Precision and accuracy of solution trace element analyses ........................302

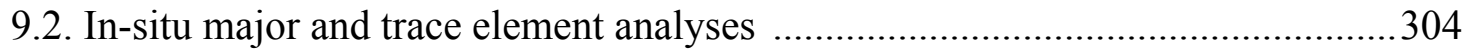

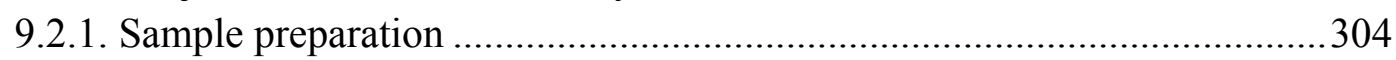

9.2.2. Electron probe (EPMA) major element analyses....................................... 304

9.2.3. Precision and accuracy of EPMA major element analyses........................305

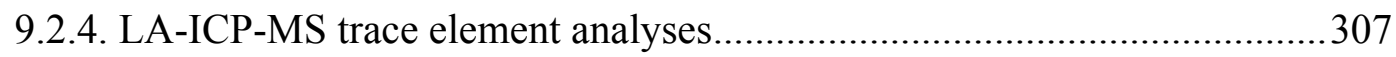

9.2.5. Precision and accuracy of LA-ICP-MS trace element analyses .................308

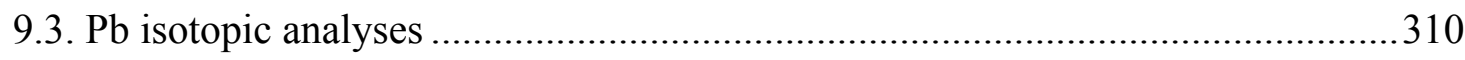

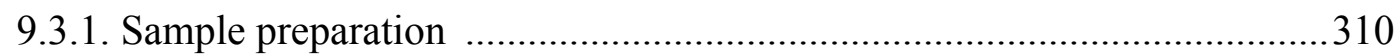

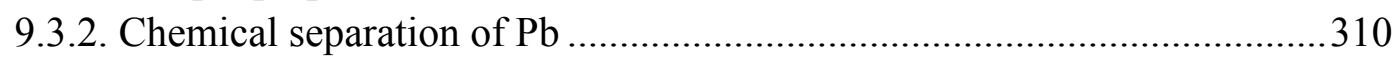

9.3.3. Mass spectrometry procedures for $\mathrm{Pb}$ isotope analysis ............................ 311

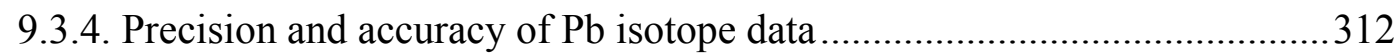

9.4. Ion probe $\mathrm{U}-\mathrm{Pb}$ geochronology and trace element analysis of zircon ................... 312

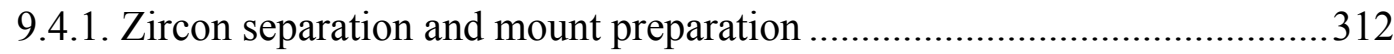

9.4.2. Zircon $\mathrm{U}-\mathrm{Pb}$ geochronology and trace element analytical techniques

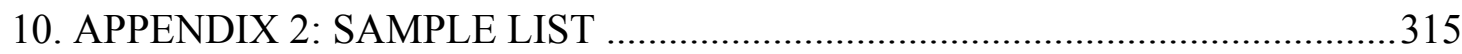

11. APPENDIX 3: DIFFUSION IMAGES AND PROFILES …................................320

12. ELECTRONIC APPENDICES - DVD

- All data used in this thesis 


\section{List of Figures}

Figure 1.1. BSE images of crystals to demonstrate antecrystic/phenocrystic components of crystals ...................................................................... 7

Figure 1.2. Schematic magma system model to illustrate terms .................................. 10

Figure 1.3. Map of caldera margins throughout the history of the TVZ ......................15

Figure 1.4. Accumulated volumes of magma erupted in caldera forming eruptions in

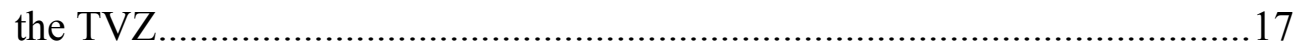

Figure 1.5. Outline map of the TVZ with extent of the Ongatiti, Kidnappers and Rocky Hill ignimbrites

Figure 1.6. Photograph of field relationship of the Kidnappers and Rocky Hill ignimbrites

Figure 2.1. Extent of the Ongatiti, Kidnappers and Rocky Hill ignimbrites and sampling locations

Figure 2.2. Histograms comparing the aspect ratio of zircon grains from Kidnappers pumices

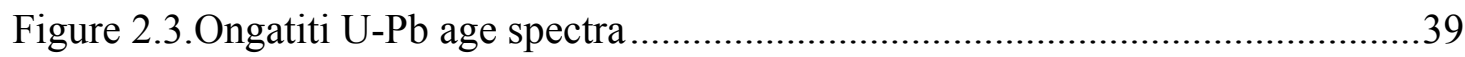

Figure 2.4. U concentrations vs. U-Pb age from each eruption ..................................40

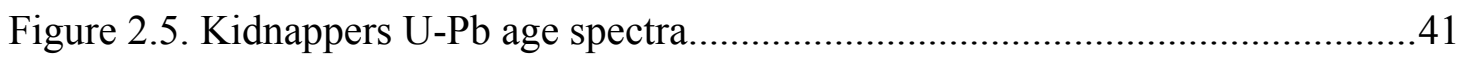

Figure 2.6. Rocky Hill U-Pb age spectra ..............................................................42

Figure 2.7. Compilation histogram off all zircons $\mathrm{U}-\mathrm{Pb}$ ages....................................4 42

Figure 2.8. Chondrite normalised REE diagram of zircon cores and rims ..................45

Figure 2.9. Summary plots of trace element data from each eruption .........................46

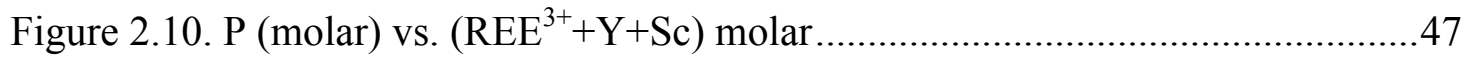

Figure 2.11. Yb concentration vs. U-Pb age of zircons from each eruption.................48

Figure 2.12. Hf concentration vs. Ti concentration and model temperatures ...............49

Figure 2.13. Major and trace element variation diagrams for Ongatiti and Kidnappers

zircons.

Figure 2.14. Chemical variation versus aspect ratio from Kidnappers zircons .52

Figure 2.15. $\mathrm{Yb}$ and $\mathrm{Hf}$ concentrations vs. $\left(\mathrm{Y}+\mathrm{Sc}+\mathrm{REE}^{3+}\right) / \mathrm{P}$ (molar) from tips and sides .53

Figure 2.16. Plots of trace elements to show effects of sector zoning .........................54

Figure 2.17. REE diagrams of zircon/melt partitioning and estimated melts . .64

Figure 3.1. Map of North Island and TVZ with extent of the Kidnappers fall deposit and ignimbrite.

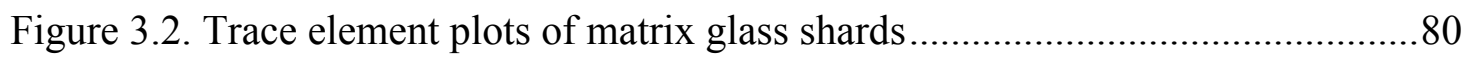

Figure 3.3. Changes in the proportion of glass times through the fall deposit .............82

Figure 3.4. Plagioclase selvage vs. host plagioclase rim compositions ........................84

Figure 3.5. Histograms and variation diagram to highlight bimodality in plagioclase rims, Fe-Ti oxide compositions and modeled temperatures. 
Figure 3.6. Amphibole apparent temperature and pressure estimates from base and top of the fall deposit

Figure 3.7. Cartoon cross section of the Kidnappers magma system

Supplementary Figure 3.1. Major and trace element variations on the ATHO-G rhyolite glass standard

Supplementary Figure 3.2. Means and errors of the three glass types for each element analysed by EPMA and LA-ICP-MS .................................................99

Supplementary Figure 3.3 Statistical treatment of major and trace element glass chemistry

Figure 4.1. Map of the North Island, New Zealand to show extent of the Kidnappers and Rocky Hill ignimbrites and sampling locations

Figure 4.2. Whole-rock and matrix glass major element compositions for Kidnappers pumices

Figure 4.3. Whole-rock and matrix glass trace element compositions for Kidnappers pumices

Figure 4.4. Major and trace element plots of Kidnappers matrix glass

Figure 4.5. Whole-rock and matrix glass major element compositions for Rocky Hill pumices

Figure 4.6. Whole-rock and matrix glass trace element compositions for Rocky Hill pumices

Figure 4.7. Major and trace element plots of Rocky Hill matrix glass

Figure 4.8. $\mathrm{K}_{2} \mathrm{O}$ vs. $\mathrm{Rb}$ for Rocky Hill matrix glass and brown glass

Figure 4.9. Comparison of quartz hosted melt inclusions and matrix glass from the

Kidnappers fall deposit

Figure 4.10. Plots of $\mathrm{Pb}$ isotope ratios from the Kidnappers fall deposit and

Kidnappers and Rocky Hill ignimbrites

Figure 4.11. Summary of plagioclase and orthopyroxene textural features from the

Kidnappers fall deposit

Figure 4.12. Summary of plagioclase textural features from the Kidnappers and Rocky Hill pumices

Figure 4.13. Summary of orthopyroxene textural features from the Kidnappers and Rocky Hill pumices

Figure 4.14. Summary of plagioclase, orthopyroxene and amphibole compositions from the Kidnappers fall deposit and Kidnappers and Rocky Hill pumices

Figure 4.15. Histograms to summarise plagioclase compositional core-rim relationships

Figure 4.16. Major and trace element plagioclase compositions from the Kidnappers fall deposit and Kidnappers and Rocky Hill ignimbrites

Figure 4.17. Major and trace element orthopyroxene compositions from the Kidnappers fall deposit and Kidnappers and Rocky Hill ignimbrites

Figure 4.18. Histograms to summarise orthopyroxene compositional core-rim relationships 
Figure 4.19. Histograms to summarise amphibole compositional core-rim relationships

Figure 4.20. Major and trace element amphibole compositions from the Kidnappers

fall deposit and Kidnappers and Rocky Hill ignimbrites

Figure 4.21. Histograms of apparent amphibole temperatures and pressures.............154

Figure 4.22. Fe-Ti oxide model temperatures and oxygen fugacities.........................157

Figure 4.23. Histograms of plagioclase-liquid and orthopyroxene-liquid model

temperatures

Figure 4.24. Schematic cross section to illustrate the effect of ponded magma on melt-dominant bodies .... 168

Figure 4.25. Cross section of the Kidnappers/Rocky Hill magma system through time

Figure 5.1. Correlation between greyscale intensity and Fe-Mg content of orthopyroxenes

Figure 5.2. Images and BSE profiles to assess the effect of image resolution and convolution uncertainties.

Figure 5.3. WDS-element map of a representative orthopyroxene crystal from the Rocky Hill (P2049)

Figure 5.4. WDS-element map of a representative orthopyroxene crystal from the Rocky Hill (P2046).....

Figure 5.5. BSE images and modeled Fe-Mg diffusion profiles of representative orthopyroxene crystals from the Kidnappers and Rocky Hill

Figure 5.6. Summary of Fe-Mg diffusion ages from dark exterior zones in the Kidnappers and Rocky Hill

Figure 5.7. Summary of Fe-Mg diffusion ages from the main core-rim boundary in the Kidnappers and Rocky Hill

Figure 5.8. Cartoon cross section of the Kidnappers/Rocky Hill magma system at two stages.

Figure 6.1. Outline map of the TVZ with extent of the Ongatiti ignimbrite and sample sites

Figure 6.2. Images of textural features of microcrystalline clots.

Figure 6.3. Whole-rock and matrix glass major element compositions for Ongatiti pumices

Figure 6.4. Chondrite normalised REE diagram for pumice and MC whole-rock and matrix glass

Figure 6.5. Matrix glass major element concentrations from pumices and MCs .......226

Figure 6.6. Matrix glass trace element concentrations from pumices and MCs .........227

Figure 6.7. Summary of textural features of Ongatiti plagioclase, amphibole and orthopyroxene.

Figure 6.8. Summary plots of plagioclase compositions from Ongatiti pumices .......230

Figure 6.9. Core-rim EPMA traverses of Ongatiti plagioclase ................................2231

Figure 6.10. Major and trace element compositions of Ongatiti amphiboles .............233 
Figure 6.11. Chondrite normalised REE diagram of amphibole cores and rims 234

Figure 6.12. Major and trace element compositions of orthopyroxene and clinopyroxene 235

Figure 6.13. Summary plots of plagioclase and amphibole compositions from MCs

Figure 6.14. Histograms to summarise contrasting compositional relationships of plagioclase cores and rims ..............................................................238

Figure 6.15. Fe-Ti oxide model temperatures and oxygen fugacities........................2240

Figure 6.16. Histograms of apparent amphibole temperatures and pressures .............241

Figure 6.17. Apparent amphibole temperatures, pressures and depths......................2242

Figure 6.18. Apparent amphibole temperatures and model melt $\mathrm{H}_{2} \mathrm{O}$ contents .........243

Figure 6.19. Semi quantitative cross section of the Ongatiti magma system .............246

Figure A1.1. Summary of solution ICP-MS data for rock powder standards 303

Figure A1.2. Summary of LA-ICP-MS data for ATHO-G, BCR-2 and BHVO-2

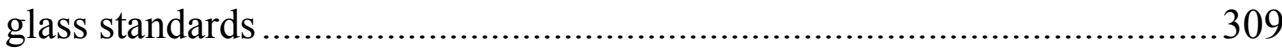

Figure A1.3. Schematic diagram to illustrate the $\mathrm{Pb}$ separation procedure.................311

Figure A3.1. Summary of modeled Fe-Mg diffusion profiles from dark exterior zones in Kidnappers orthopyroxenes 320

Figure A3.2. Summary of modeled Fe-Mg diffusion profiles from dark exterior zones in Rocky Hill orthopyroxenes 326

Figure A3.3. Summary of modeled Fe-Mg diffusion profiles from core-rim boundaries in Kidnappers orthopyroxenes .329

Figure A3.4. Summary of modeled Fe-Mg diffusion profiles from core-rim boundaries in Rocky Hill orthopyroxenes .337 


\section{List of Tables}

Table 1.1. Ignimbrites erupted from Mangakino Volcanic Centre

Table 2.1. Pumice samples used for zircon U-Pb and trace element analyses .............33

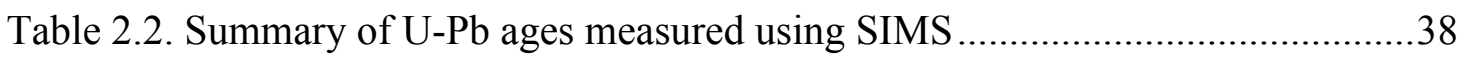

Table 2.3. Average zircon trace element concentrations .........................................44

Table 3.1. Mean major and trace element concentrations of the three glass types .......77

Table 4.1. Catalogue of samples from the Kidnappers fall deposit, Kidnappers ignimbrite and Rocky Hill ignimbrite

Table 4.2. Mean whole-rock major and trace element concentrations for each compositional group within the Kidnappers and Rocky Hill pumice

Table 4.3. Mean matrix glass major and trace element concentrations for each compositional group within the Kidnappers and Rocky Hill pumice

Table 5.1. Summary of temperatures and oxygen fugacities used to calculate diffusion timescales

Table 5.2. Summary of orthopyroxene textural populations in the Kidnappers and Rocky Hill.....

Table 6.1. Major and trace element whole-rock concentrations of Ongatiti pumices

Table 6.2. Mean matrix glass major and trace element concentrations for Ongatiti pumices 225

Table A1.1. XRF precision and accuracy for the BCR-2 standard .298

Table A1.2. XRF precision and accuracy for the BHVO-2 standard .298

Table A1.3. XRF reproducibility for the Taupo (MF-1) standard .299

Table A1.4. Repeated XRF analyses of Kidnappers pumice samples 299

Table A1.5. Solution ICP-MS data of the BHVO-2, BCR-2 and Taupo (MF-1) standards 302

Table A1.6. EPMA precision and accuracy of the ATHO-G glass standard ...............306

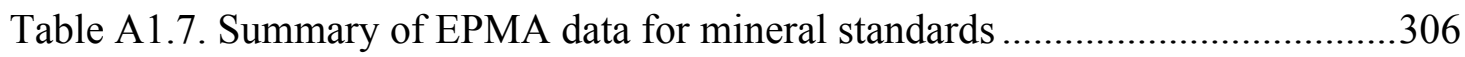

Table A1.8. Summary of LA-ICP-MS data for glass standards .................................308

Table A1.9. Precision and accuracy of $\mathrm{Pb}$ isotope measurements on the JB-2 standard

Table A1.10. Summary of data from the MAD zircon standard. 314

Table A2.1. Sample list of all juvenile material collected for this study 315 


\section{Publications arising from this thesis}

\section{Journal articles}

Cooper GF, Wilson CJN, Millet M.-A, Baker JA, Smith EGC (2012) Systematic tapping of independent magma chambers during the 1 Ma Kidnappers supereruption. Earth Planet Sci Lett 313-314:23-33

\section{Conference abstracts}

Cooper GF, Wilson CJN, Baker JA (2010) Magma forensics of a 1.0 Ma supereruption: insights from the Kidnappers fall deposit. Oral presentation given at the GeoNZ 2010 Conference, The University of Auckland, Auckland, New Zealand. 21-24 Nov

Cooper GF, Wilson CJN, Baker JA (2011) Systematic tapping of independent magma chambers during the $1 \mathrm{Ma}$ Kidnappers supereruption. Poster presented at Goldschmidt 2011 conference in Prague, Czech Republic. 11-19 Aug

Cooper GF, Wilson CJN, Baker JA, Millet M-A (2012) Rejuvenation and repeated eruption of a 1.0 supervolcanic system at Mangakino caldera, Taupo Volcanic Zone, New Zealand. Abstract V31C-2797 Poster presented at 2012 Fall Meeting, AGU, San Francisco, Calif. 3-7 Dec 
Chapter 1 


\section{Introduction}

\subsection{Overview}

Exceedingly large explosive volcanic eruptions, or 'supereruptions' are defined as those that eject $>10^{15} \mathrm{~kg}$ (or $450 \mathrm{~km}^{3}$ ) of magma, equivalent to $\sim 1000 \mathrm{~km}^{3}$ of pyroclastic material (Mason et al. 2004; Sparks et al. 2005; Self 2006; Miller and Wark 2008). Reconstructing the processes that occur in magmatic systems that feed such large explosive eruptions, and determining how they differ from 'normal'-sized silicic eruptions remains a challenge. Unravelling the complexities of these systems can be especially difficult in deposits where the limited preservation and exposure precludes detailed field-based volcanological studies. The Taupo Volcanic Zone (TVZ) in the central North Island of New Zealand is host to four of the ten Quaternary supereruptions on Earth (Wilson et al. 2009), yielding a unique opportunity to identify and quantify magma chamber processes leading up to such vast eruptions in a rifted continental arc setting.

This thesis research concentrates on crystal-specific investigations from deposits of the two older supereruptions in the TVZ: the Ongatiti (1.21 Ma) and Kidnappers (1.0 Ma) events, together with the smaller Rocky Hill eruption (1.0 Ma: ages from Houghton et al. 1995). All three deposits were erupted from the Mangakino volcanic centre (MVC), the oldest identified composite caldera volcanic centre in the TVZ (Blank 1965; Wilson et al. 1984; 1995a). Although the overall petrological characteristics of all three deposits have been outlined and some crystal chemical studies undertaken (Briggs et al. 1993; Schipper 2004), a systematic study of all the mineral phases and their associated glass (melt) compositions is undertaken for the first time in this thesis.

The Kidnappers eruption deposits ( $\left.\sim 1200 \mathrm{~km}^{3} \mathrm{DRE}\right)$ represent a crystal-poor rhyolite, in contrast to the crystal-rich Ongatiti deposits. The Kidnappers eruption generated a large, fine-grained fall deposit, followed by one of the most widespread ignimbrites on Earth (Wilson et al. 1995b; Carter et al. 2004). Despite their great volume, the deposits are poorly exposed due to their entirely non-welded nature, and so the magmatic system represents a challenge to document and reconstruct. The Kidnappers eruption was 
followed after a geologically short time interval (quantified in this thesis) by the smaller Rocky Hill eruption $\left(\sim 200 \mathrm{~km}^{3}\right)$, which is represented by a variably welded ignimbrite (Blank 1965; Wilson 1986). The Rocky Hill ignimbrite was chosen for study in order to provide insights into timescales of magma storage and post-eruptive processes, such as magma recharge, occurring after the Kidnappers supereruption.

The Ongatiti eruption deposit ( $>500 \mathrm{~km}^{3} \mathrm{DRE}$ ) represents a crystal-rich (20-30\%) rhyodacite to rhyolite and has many similarities to a class of ignimbrites termed the 'monotonous intermediates' by Hildreth (1981) (e.g., Bachmann et al. 2002; Christiansen 2005), and contrasts as such with the Kidnappers. Monotonous intermediate ignimbrites are characterised by being crystal rich (35-45\%), having nearsolidus mineral assemblages and lacking evidence for compositional zonation (Hildreth 1981; Bachmann and Bergantz 2008). Such ignimbrites are interpreted (e.g., Bachmann et al. 2002) to represent the remobilised fraction of deep-seated crystal mushes (magma bodies with $>50-60$ vol. $\%$ crystals). The Ongatiti thus provides an opportunity to study the crystal mush and magmatic root zones within a large-scale silicic magmatic system.

\subsection{Thesis objectives and structure}

This project focuses on the crystal-specific geochemistry of three eruptive deposits from the Mangakino volcanic centre, with the aim of addressing fundamental questions on the origins, rates and volumes of extremely large-scale silicic volcanism in New Zealand, with comparisons to worldwide examples. The volumes of supereruptions are 1-2 orders of magnitude larger than the widely studied Holocene rhyolitic eruptions in New Zealand, but it is unclear if there are any systematic differences between the volcanic processes during magma generation, storage and eruption. The key questions addressed in this research are as follows:

- Over what timescales did each of the magmatic systems at Mangakino accumulate and grow?

- What magmatic processes and varying source influences can be tracked by trace elements in zircons? 
- What information can we gain from variations in mineral chemistry and zoning patterns in crystals regarding the pre-eruptive crystal growth histories and changing magmatic conditions within large silicic systems?

- Over what depths did each magmatic system operate, and what were the sizes and pre-eruptive states of the melt-dominant bodies prior to eruption?

- What information can be obtained from the geochemisty and/or petrology of a fall deposit, and how does it compare to the record from ignimbrites?

- Do the Kidnappers and Rocky Hill ignimbrites share a common source and/or magma chamber?

- What was the duration of the time break between the Kidnappers and Rocky Hill eruptions and what processes, such as magma recharge and mixing occurred during this time break?

- Does the Ongatiti ignimbrite represent an erupted crystal mush, and if so, what processes caused the transition into eruption?

The above questions, and associated issues are addressed within seven interrelated chapters. Each chapter focuses on a different aspect and can serve as a self-contained study, although each progressively builds upon the preceding chapters to form a coherent single thesis. The published chapter 3 (Cooper et al. 2012) has been modified for the sake of formatting and styling, but not in terms of content, for incorporation into a consistent overall thesis design. The supplementary information from Cooper et al. (2012) has been included within Chapter 3 (section 3.7).

Chapter 1 introduces some of the overarching themes and concepts discussed within this research. Current models for the storage and evacuation of large silicic magma systems are explored. This chapter also introduces the Taupo Volcanic Zone and the eruptive deposits from the Mangakino volcanic centre, and discusses the stratigraphic and geochemical findings from previous work on these deposits.

Chapter 2 focuses on the $\mathrm{U}-\mathrm{Pb}$ age spectra and trace element records from in-situ analyses of zircons from the three studied eruptions. These data are used to constrain the timing of crystal growth, with its implications for the accumulation and growth of each magmatic system, the sources of melts and the magmatic processes recorded by the zircons. 
Chapter 3 is written around a detailed geochemical study on the glass compositions through a proximal section of the Kidnappers fall deposit to document the systematic geochemical and petrological changes through the earlier two-thirds to three quarters of the eruption. The potential causes of the systematic changes in glass chemistry are discussed and a Kidnappers magma chamber model is proposed from these findings.

Chapter 4 documents, then compares and contrasts the Kidnappers and Rocky Hill eruptions in terms of whole rock pumice compositions from the ignimbrites, glass compositions, and in-situ mineral major and trace element compositions. These data define distinct compositional groups in the pumices from both eruptions and are used to relate the pumice chemistry in the ignimbrites to the stratigraphically controlled chemistry in the volumetrically dominant Kidnappers fall deposit, described in Chapter 3. Intensive variables are also compared and a magmatic model for the evolution of the overall Kidnappers/Rocky Hill magmatic system is discussed.

Chapter 5 builds upon the chemical and textural crystal signatures characterised in Chapter 4 and uses Fe-Mg interdiffusion timescales in orthopyroxenes to constrain the timings of particular events within the Kidnappers/Rocky Hill magma system. The time break between the two eruptions is then estimated based on these findings.

Chapter 6 considers the crystal specific record from the Ongatiti ignimbrite with aim of testing popular magma storage models, such as the crystal mush model. Does the Ongatiti represent an erupted crystal mush and how does it compare to worldwide examples of monotonous intermediates such as the Fish Canyon Tuff?

Chapter 7 brings together the primary findings of this research, discussing some of the key research questions and identifies opportunities for future research to build upon the outcomes in this study.

\subsection{Crystal-specific studies}

Crystal-specific geochemical studies are the main analytical strategy used in this project. It is therefore important to define the nature of crystals that may be present in an erupted volcanic rock. Three types of crystals are commonly present within eruption products: phenocrysts (crystallised in the melt in which they now reside), antecrysts 
from precursor crystal mush, and xenocrysts (Charlier et al. 2005; Hildreth and Wilson 2007; Streck 2008). The latter may represent inputs from melting or disruption of unrelated country rocks (greywacke or older intrusive rocks), or come from different magmas of contrasting compositions injected into the magma chamber. Crystals can (and typically do) display complex growth histories (Figure 1.1) and, for example, a plagioclase may have a xenocrystic core, antecrystic inner zones and a phenocrystic rim (e.g., Charlier et al. 2008). By studying the nature of crystals present in a volcanic rock and the crystal's compositional zoning, it is possible to reconstruct crystal growth histories as well as recording magmatic events over a range of different timescales.
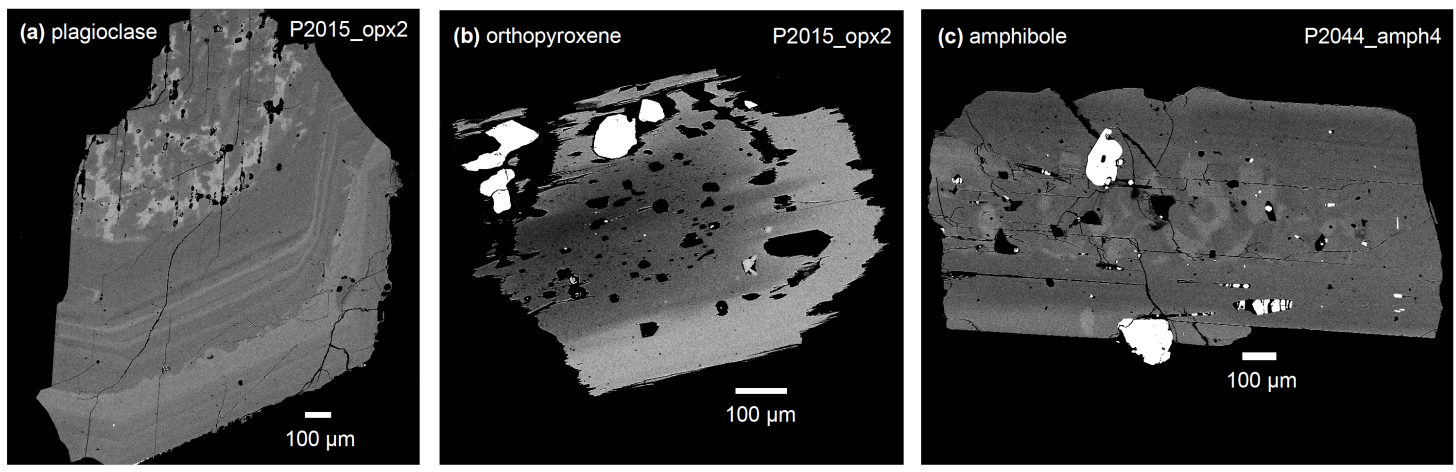

Fig. 1.1. Selected backscattered electron images (BSE) of crystals from the Kidnappers (a \& b) and Rocky Hill (c) eruptions, displaying xenocrystic/antecrystic cores with phenocrystic outer zones. (a) plagioclase with a patchy recrystallised xenocrystic core and a resorbed zone inward of the outermost rim. (b) orthopyroxene with a recrystallised core containing many melt inclusions. (c) amphibole with recrystallised core from greater temperatures and pressures than the rim which is in equilibrium with the melt.

Using imaging and quantitative chemical analysis of zones within phenocrysts, xenocrysts and antecrysts, the history of crystal growth and the generation of magma bodies can be established. By modelling of diffusive modification across originally sharp zoning boundaries it is possible to constrain timescales of magmatic events recorded in the growth history of particular mineral phases. Diffusion modelling uses the presence of concentration gradients, which dissipate or tend to equilibrate at a rate that has been experimentally calibrated (e.g., diffusion coefficient) (Morgan and Blake 2006; Chakraborty 2008; Costa 2008; Costa et al. 2008). Diffusion modelling is advantageous as it allows timescale information to be linked to textural and chemical features of the rock so that specific 'events' can be recorded (Turner and Costa 2007; Saunders et al. 2012; Allan et al. 2013). 
There are many methods of determining the intensive variables in magma bodies by the use of mineral equilibrium techniques (for reviews see Blundy and Cashman 2008; Putirka 2008). These techniques utilise major element chemistry of crystals and glass that can be routinely measured by Electron Probe MicroAnalysis (EPMA). When reconstructing temperatures and pressures, careful analysis of the textural features within crystals (through assessment of BSE imaging) is imperative, so that estimates can be linked with particular processes. In all models, it is likely that the final (immediately pre-eruptive) episode of crystal growth will be the most reliably reconstructed. This is due to the varying complexities in the interior zones and the knowledge that the outermost rims crystallised within the immediately pre-eruptive melt. The mineralogical assemblages in pumices from the Ongatiti, Kidnappers and Rocky Hill deposits allow a number of techniques to be applied within this study. Iron-titanium oxide thermometry and oxybarometry is a commonly applied technique in intermediate and felsic volcanic rocks. Iron-titanium oxides change composition much faster than silicates in response to changes in temperature or other parameters (Freer and Hauptman 1978; Hammond and Taylor 1982; Venezky and Rutherford 1999) and therefore can record thermal events that take place on timescales of days to months prior to eruption (e.g., Devine et al. 2003). The calibration of Ghiorso and Evans (2008) is applied to FeTi oxide pairs from each of the eruptive deposits analysed within this study. Amphiboles reflect the composition of the melt from which they grew and have the potential to record a temperature and pressure history throughout their growth, which allows for the reconstruction of the depths at which the crystals crystallised. Recent work by Ridolfi et al. (2010) has proposed that amphibole compositions can be used to reconstruct temperatures and pressures in calc-alkaline magmas associated with subduction-related volcanism. Using core and rim compositions and documenting the zoning within amphibole crystals allows investigation of melt compositions and temperature changes over a longer timescale than can be achieved using Fe-Ti oxide equilibrium pairs. The plagioclase-liquid and orthopyroxene-liquid thermometry models of Putirka (2008) are also used in comparison with Fe-Ti oxide and amphibole estimates in Chapter 4. For meaningful reconstruction of final pre-eruptive temperatures, the outermost rims of crystals, representing the final stages of growth, were paired with pumice matrix glass compositions, representing the melt in which the crystals resided at the time of eruption. 
The generation of large silicic magmatic systems and the timescales of accumulation and storage can also be explored through in-situ $\mathrm{U}-\mathrm{Pb}$ analysis of zircons. Zircon has the ability to retain compositional zoning through time and varying magmatic conditions, due to its refractory nature and low elemental diffusivities (Cherniak and Watson 2003). The measuring of the temporal and trace element compositional record retained in zircons provides insights into the long-term evolution of silicic systems (among many examples: Charlier et al. 2005; Simon and Reid 2005; Bindeman et al. 2006; Wilson and Charlier 2009; Claiborne et al. 2010; Watts et al. 2012; Chamberlain et al. 2013). In this study, a Sensitive High Resolution Ion Microprobe (SHRIMP) was used to obtain high precision in-situ U-Pb dating, and in-situ trace element concentrations of compositional zones within zircons.

\subsection{Large silicic magma chambers}

\subsubsection{Terminology}

Before introducing magma chamber models and processes, it is important to define what is meant by the term "magma chamber(s)" is clearly defined (Figure 1.2, after Hildreth and Wilson 2007). For the purposes of this thesis, the magma body is defined as the melt-dominant zone that is partially to fully tapped during normal eruptions. Generally in large silicic systems, the melt-dominant zone is found at depths between 4 and 11 km (Brown et al. 1998a; Wallace et al. 1999; Bachmann et al. 2002; Liu et al. 2006; Wilson et al. 2006; Hildreth and Wilson 2007; Cooper et al. 2012 [Chapter 3]). The melt-dominant zone is surrounded (but mostly underlain) by a crystal mush zone, which contains enough melt for mixing and hybridization with recharge magmas. The crystal mush may also be mobilised and tapped during exceptional eruptive events. The crystal mush zone is enclosed in turn by a rigid zone (with subordinate melt) and a crystallised margin (granitoid zone). The granitoid zone remains physically and chemically linked to melt-bearing zones and is open to resorption events. The greater magma reservoir also includes magma chamber feeder zones and the heterogeneous crustal column (dykes, pods and permeable mush), as well as partially molten lower crust and underlying mantle. 


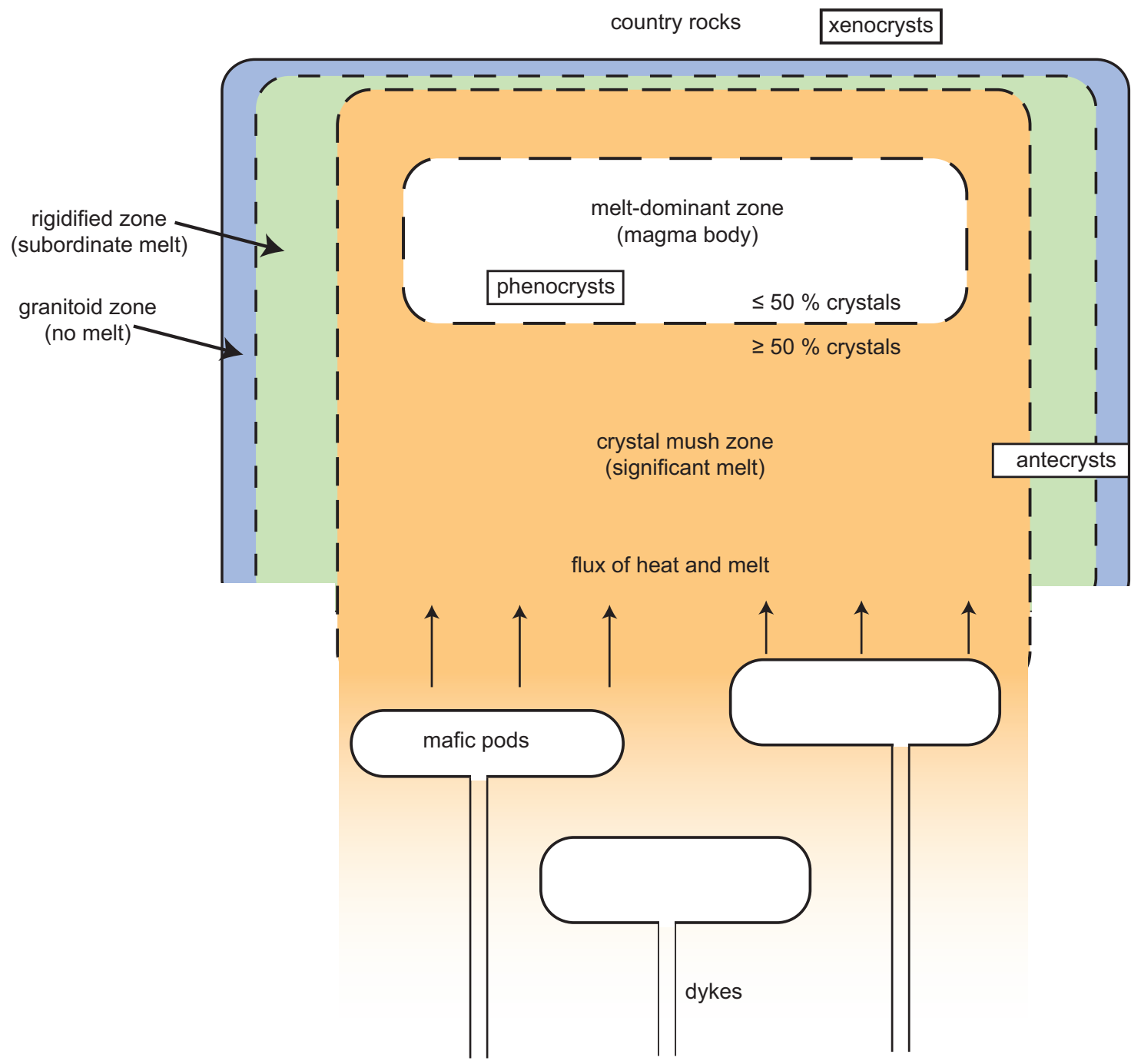

Fig. 1.2. Schematic of a magma system to illustrate terms used to describe zones in and around the magma chamber. The diagram is modified from Fig. 17 of Hildreth and Wilson (2007). Boundaries between the zones described in the text move with thermal and fluid flux and are controlled by changing melt/crystal ratios (Hildreth and Wilson 2007). The greater magma reservoir, including the magma chamber's feeder zone and heterogeneous crustal column, provides a flux of heat and magma to the magma chamber. The zones where different types of crystals (phenocrysts, xenocrysts and antecrysts) are sourced from are shown.

\subsubsection{Magma chamber models}

The great majority of generalised models of large silicic systems consider a large single unitary magma chamber (e.g., Smith 1979; Shaw 1985; Hildreth 1981, 2004; Bachmann and Bergantz 2008). Large rhyolitic eruptions are generally considered to be chemically or physically zoned, with any magma chamber zonation reversely reflected in eruption 
deposits as progressively deeper levels of a magma chamber are evacuated during an eruption (Smith 1979; Hildreth 1979, 1981; Bachmann and Bergantz 2008). More evolved and crystal-poorer magmas are typically erupted first followed by less evolved, more crystal-rich magmas. For example, the $0.76 \mathrm{Ma}$ Bishop Tuff eruption deposits show a linear gradient in crystal content, volatiles, trace element concentrations, isotopic ratios and temperatures which is thought to be the inverted record of zonation within the Bishop magma body (Hildreth 1979; Dunbar and Hervig 1992; Anderson et al. 2000; Bindeman and Valley 2002; Hildreth and Wilson 2007; Bachmann and Bergantz 2008).

Recent studies have, however, suggested that this simple model does not apply to all eruptions. Greater complexity has been observed in many worldwide examples, including those from the TVZ, New Zealand. The world's youngest supereruption (Oruanui; $25.4 \mathrm{ka}$ ) erupted compositionally variable material during a prolonged episodic eruption, although the different compositions were not systematically tapped during the eruption (Wilson et al. 2006; Allan et al. 2012; Allan 2013). Compositional variations in minerals and quartz-hosted melt inclusions show that the main meltdominant magma body was thoroughly mixed prior to eruption (Liu et al. 2006; Wilson et al. 2006). A second, horizontally separated magma body was transported laterally by diking and mixed with the Oruanui magma in the conduit during the eruption as a consequence of rifting processes (Allan et al. 2012). During paired eruptions, tectonic effects from one eruption can trigger another eruption from nearby vents. The $240 \mathrm{ka}$ Mamaku and Ohakuri ignimbrites (Gravley et al. 2007) and the 62 ka Rotoiti and Earthquake flat eruptions from the TVZ (Nairn and Kohn 1973) are examples of paired eruptions from independent magma bodies. It is also possible for single eruptions to tap two or more compositionally independent magma bodies in the shallow crust (e.g., Briggs et al. 1993; Shane et al. 2007, 2008; Cooper et al. 2012 [Chapter 3]). It is therefore necessary to consider a variety of potentially different magma chamber configurations in studies of large silicic eruptions, and not restrict interpretations to a rigid and overly simplistic view of the magmatic system(s) beneath rhyolitic volcanoes. 


\subsubsection{The crystal mush model}

A large number of geochemical studies have suggested that fractional crystallisation is the dominant process in the generation of silicic magmas (Hildreth 1981; Michael 1983; Bacon and Druitt 1988). This is particularly true of silicic volcanic rocks, which have a greater crystal fractionation signature than equivalent plutonic rocks (Halliday et al. 1991; Bachmann and Bergantz 2004). Separation of crystals and liquid must occur for magmas to evolve by crystal fractionation, but constraining a physical model to do this at the appropriate scale in large systems is problematic and the focus of much debate. The traditional view, in which crystals are separated from a volume of liquid by crystal settling and slow cooling is now thought to be an unreasonable theory for the majority of large silicic systems (Michael 1983; Cameron 1984). Gravitational settling of crystals from liquid is thought to be too slow and inefficient (Shaw 1965) for crystal-liquid segregation of the magnitude implied in large silicic systems, and within the timescales indicated by eruption sequences. Another model is the 'solidification front instability' of Marsh (2002), whereby a progressive advancement of a crystallisation front occurs from the margins to the centre of a magma body. However, it is difficult to satisfy the geological observations from large-scale rhyolites with any of these processes taken alone (Bachmann and Bergantz 2004).

Over the last decade, the crystal mush model, now widely accepted and used, has revolutionised our understanding of how large volumes of silicic magma are generated and stored within the upper crust. The crystal mush model accounts for crystal-liquid separation by the extraction of liquid from a crystal rich mush ( $>\sim 45-60 \%$ vol. crystals) (Hildreth 2004; Bachmann and Bergantz 2004). In this model, melt evolves and crystals fractionate within an intrusion of intermediate composition, with low crystallinities (< $45 \%$ ). The melt remains intermediate in composition until crystallinities of $>45-60 \%$ are reached (Marsh 1981; Brophy 1991). By the time that this critical threshold is crossed the interstitial liquid has become rhyolitic, and rheological lockup of the magma occurs. Convection is hindered, allowing extraction of high $\mathrm{SiO}_{2}$ interstitial melt through a variety of mechanisms, including microsettling and compaction (Bachmann and Bergantz 2004) and gas driven filter pressing (Sisson and Bacon 1999). Large volumes of rhyolite can then accumulate above a crystalline residue, and below a crystallising roof layer. 


\subsubsection{Timescales of assembly}

Estimates of the timing and rates of assembly of large silicic magma chambers are highly variable between systems and continue to be a focus of debate. Generalised models for production and eruption rates of caldera forming silicic systems (based on a correlation between repose time and eruptive volume) are $\sim 1 \mathrm{~km}^{3}$ per thousand years, and an intrusion rate that is an order of magnitude higher than this (Smith 1979; Shaw 1985; Reid 2008). However, mean eruption rates are an order of magnitude higher in the central TVZ, and the intrusion rate is four to six times greater than eruption rate (Wilson et al. 1984). Wilson et al. (2006) suggested that with a high heat flux from intrusion of mafic magma, 'mining' of stockpiled partly to wholly crystallised silicic plutonic rocks (crystal mush) can occur at very rapid rates. The tectonic setting of these large silicic systems is also thought to play a role in the rate at which magma can accumulate and erupt. The processes operating within a single large silicic magmatic system can occur at variable and contrasting timeframes, and perhaps the best example of this is the Oruanui eruption. Zircon model ages constrained the physical assembly of the Oruanui magma body to a period of less than ca. $3 \mathrm{kyr}$ (Wilson and Charlier 2009), but showed that the chemical processes involved in assembly of its plutonic parents occurred for at least $70 \mathrm{kyr}$ prior to the eruption (Charlier et al. 2005). In more detail, Allan et al. (2013) used Fe-Mg diffusion profiles across internal hiatus boundaries in orthopyroxene to independently constrain the timing of establishment of the final meltdominant body to be mostly within a few centuries of the eruption. In this case, the extraordinary rapidity of the accumulation processes was inferred to reflect a strong influence of extensional tectonic processes (Allan et al. 2013). At the largest scale, the Fish Canyon magma body, San Juan Volcanic Field has a multi-stage model of growth, which began with the emplacement of a long-lived, $5000 \mathrm{~km}^{3}$ dacitic magma that cooled to a near-solidus crystal mush (Bachmann et al. 2002). This mush was then reheated and partially remelted by voluminous injection of mafic magma that rejuvenated the magma system within 600 kyr of eruption (Bachmann et al. 2002; Bachmann and Bergantz 2003). This rejuvenation is expressed in the crystal record by widespread uptemperature signals in crystal rims, for example high-Al amphibole rims (Bachmann and Dungan 2002). 


\subsection{Supereruptions and supervolcanoes}

A supereruption is generally defined as an explosive eruption with a total erupted volume $>1 \times 10^{15} \mathrm{~kg}$, or $>450 \mathrm{~km}^{3}$ of magma, or $\sim 1000 \mathrm{~km}^{3}$ of pyroclastic material (Mason et al. 2004; Sparks et al. 2005; Self 2006; Miller and Wark 2008). To put these volumes into perspective $1000 \mathrm{~km}^{3}$ of pyroclastic material would cover the entire North Island of New Zealand with $\sim 8.5 \mathrm{~m}$ of debris. Historic eruptions, such as the 1980 eruption at Mt. St. Helens and the 1991 eruption from Mt. Pinatubo are 2-3 orders of magnitude smaller than a supereruption. If an eruption of this size occurred today there would be a significant loss of life, long-term devastation and destruction of social infrastructure, and long lasting climate effects from a heavy input of sulphur-rich gases to the stratosphere (Rampino and Self 1993; Sparks et al. 2005; Self 2006).

Supervolcanoes are caldera volcanoes that have produced at least one supereruption. Commonly caldera forming volcanic centres will produce numerous other eruptions of variable size (Hildreth 2004; Wolff et al. 2011; Watts et al. 2012). Supereruptions always involve high-silica magma (rhyolitic-dacitic) and, to a first order, the only difference to any other eruption is the huge volume of eruptible magma that accumulates in the upper crust. Previous studies have highlighted that supereruptions are highly variable both in composition and timescales of production and eruption, making the understanding of and possible prediction of an imminent eruption very difficult (Wilson 2008). The laterally emplaced eruption products from supereruptions (and many other smaller eruptions) do not conform to any one particular ignimbrite style and can be abruptly zoned e.g., Crater Lake (Bacon and Druitt 1988; Druitt and Bacon 1989), linearly zoned, e.g., Bishop Tuff (Hildreth and Wilson 2007), or homogeneous, e.g., Fish Canyon Tuff (Bachmann et al. 2002).

\subsection{New Zealand's supervolcanoes and their eruptions}

\subsubsection{Geological and tectonic setting}

The TVZ has been a site of intense volcanism in the central North Island of New Zealand since ca. $2 \mathrm{Ma}$. The TVZ is a NNE-trending region (300 km long and up to 60 $\mathrm{km}$ wide) of volcanism and associated extension, forming the continental continuation of the Tonga-Kermadec arc, associated with the westward subduction of the Pacific 
plate beneath the Indo-Australian plate (Cole and Lewis 1981; Cole 1990; Gamble et al. 1996). Cole et al. (1995), Wilson et al. (1995a, 2009), Houghton et al. (1995) and Rowland et al. (2010) provide comprehensive reviews of the TVZ from structural, stratigraphic, geochemical and petrologcial perspectives. The age of rift initiation is poorly constrained, but may have begun by ca. $0.9 \mathrm{Ma}$ (Wilson et al. 1995a). The nature of volcanic products erupted in the TVZ varies according to location, with andesitic volcanism dominant in the southwest and northeast (Figure 1.3). The central region is characterised by an exceptionally high heat flux (e.g., Bibby et al. 1995; Hochstein 1995). Since 1.6 Ma, in the rhyolitic dominated central part of the TVZ, $>16,000 \mathrm{~km}^{3}$ of volcanic material has been erupted in at least 25 caldera-forming and numerous smaller eruptions from eight dominantly rhyolitic volcanic centers (Houghton et al. 1995; Wilson et al. 1995a, 2009) (Figure 1.3).

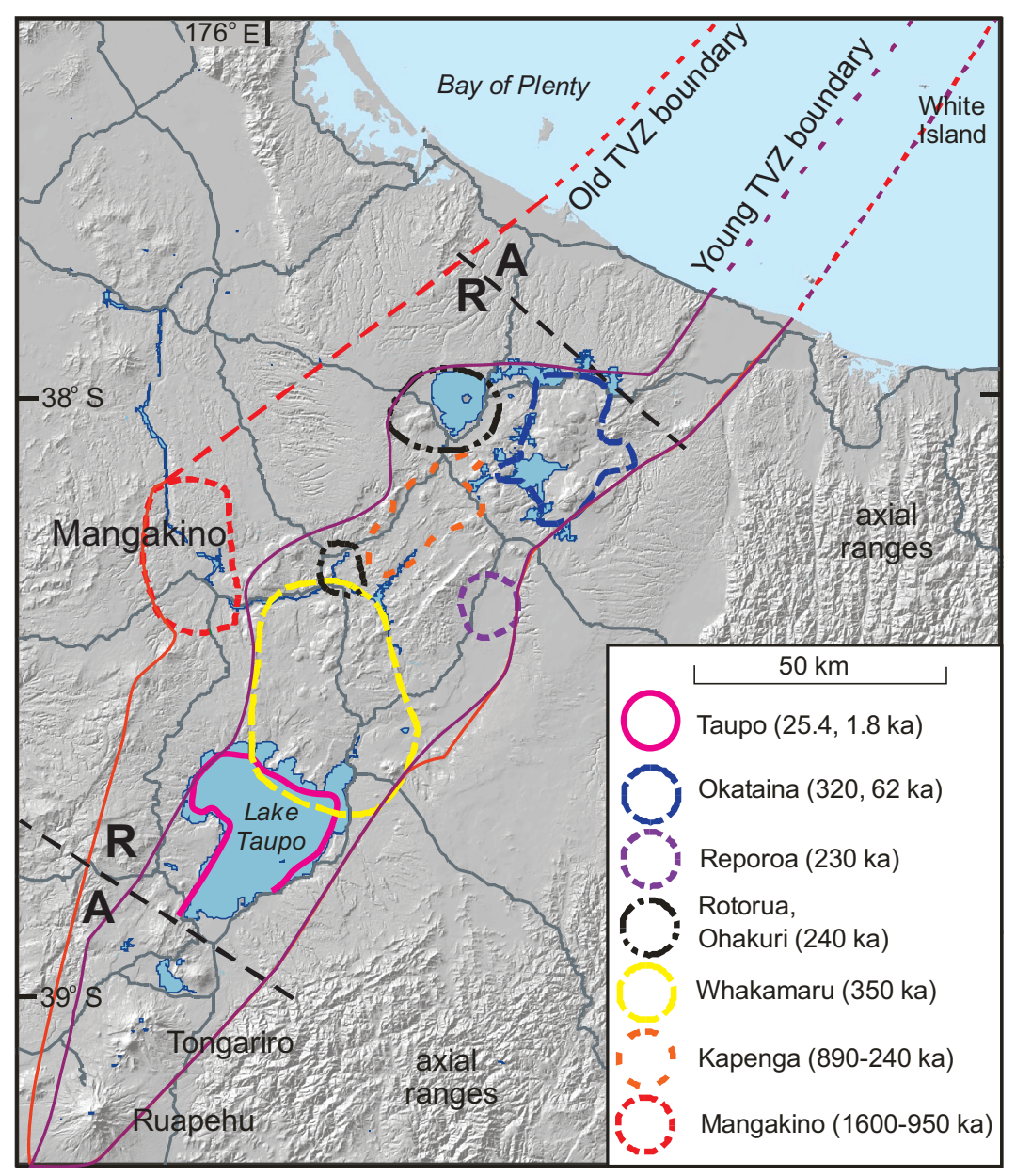

Fig. 1.3. Map of caldera margins throughout the history of the TVZ. Zones dominated by rhyolitic and andesitic volcanism are shown by $\mathrm{R}$ and A respectively. Boundaries marking the limits of the Old TVZ and Young TVZ are shown. Taupo and Okataina are the two currently active centres. After Wilson et al. (2009). 
The TVZ can be divided into the 'old TVZ' from 2.0 to $0.35 \mathrm{Ma}$ and the 'young TVZ' from 0.35 Ma to present, separated by the Whakamaru Group eruptions at $0.35 \mathrm{Ma}$, which buried the majority of the older eruptive deposits. The margin of the old TVZ extends further to the west to encompass the Mangakino volcanic centre, which lies outside the young TVZ boundary (Figure 1.3). The central TVZ is considered the most frequently active and productive Quaternary rhyolitic system on Earth (Houghton et al. 1995). Taupo and Okataina are the two active rhyolite centres, currently with hydrothermal activity.

\subsubsection{Supereruptions in the TVZ}

There have been four supereruptions in the history of the TVZ (Wilson et al. 2009). The Ongatiti (1.21 Ma) and the Kidnappers (1.0 Ma) eruptions occurred from the Mangakino centre during an intense period of activity associated with the old TVZ (Houghton et al. 1995). The Whakamaru Group eruption (0.35 Ma: Leonard et al. 2010), the largest within the TVZ, was associated with a large caldera north of the modern Lake Taupo (Wilson et al. 1986; Brown et al. 1998a). The Oruanui (25.4 ka: Vandergoes et al. 2013) the youngest supereruption on Earth, was erupted in association with a caldera now infilled by Lake Taupo (Davy \& Caldwell 1998; Wilson 2001: Figure 1.4).

The Oruanui, and to a lesser extent, the Whakamuru supereruptions have been studied in greater detail than supereruptions from the Mangakino volcanic centre, largely due to the greater quantity and quality of exposures and superior stratigraphic control. The Whakamaru Group eruptions released $>1500 \mathrm{~km}^{3}$ of magma (Figure 1.4) from multiple independent magma bodies (Brown et al. 1998a), and the associated caldera is a composite structure (Gravley et al. 2007). Variably welded ignimbrite deposits from these eruptions cover ca. $13000 \mathrm{~km}^{2}$ of central North Island (Briggs 1976; Wilson et al. 1986; Brown et al. 1998a; Matthews et al. 2012a). The Oruanui supereruption produced $\sim 530 \mathrm{~km}^{3}$ of magma (Figure 1.4) and its deposits (fall and ignimbrite) are exposed across most of the North Island (Wilson 2001; Wilson et al. 2006). The young age of this supereruption has allowed a detailed stratigraphy through the eruption deposits to 
be established (Wilson 2001), and detailed geochemical studies to be undertaken (Liu et al. 2006; Wilson et al. 2006; Allan 2013; Allan et al. 2012, 2013).

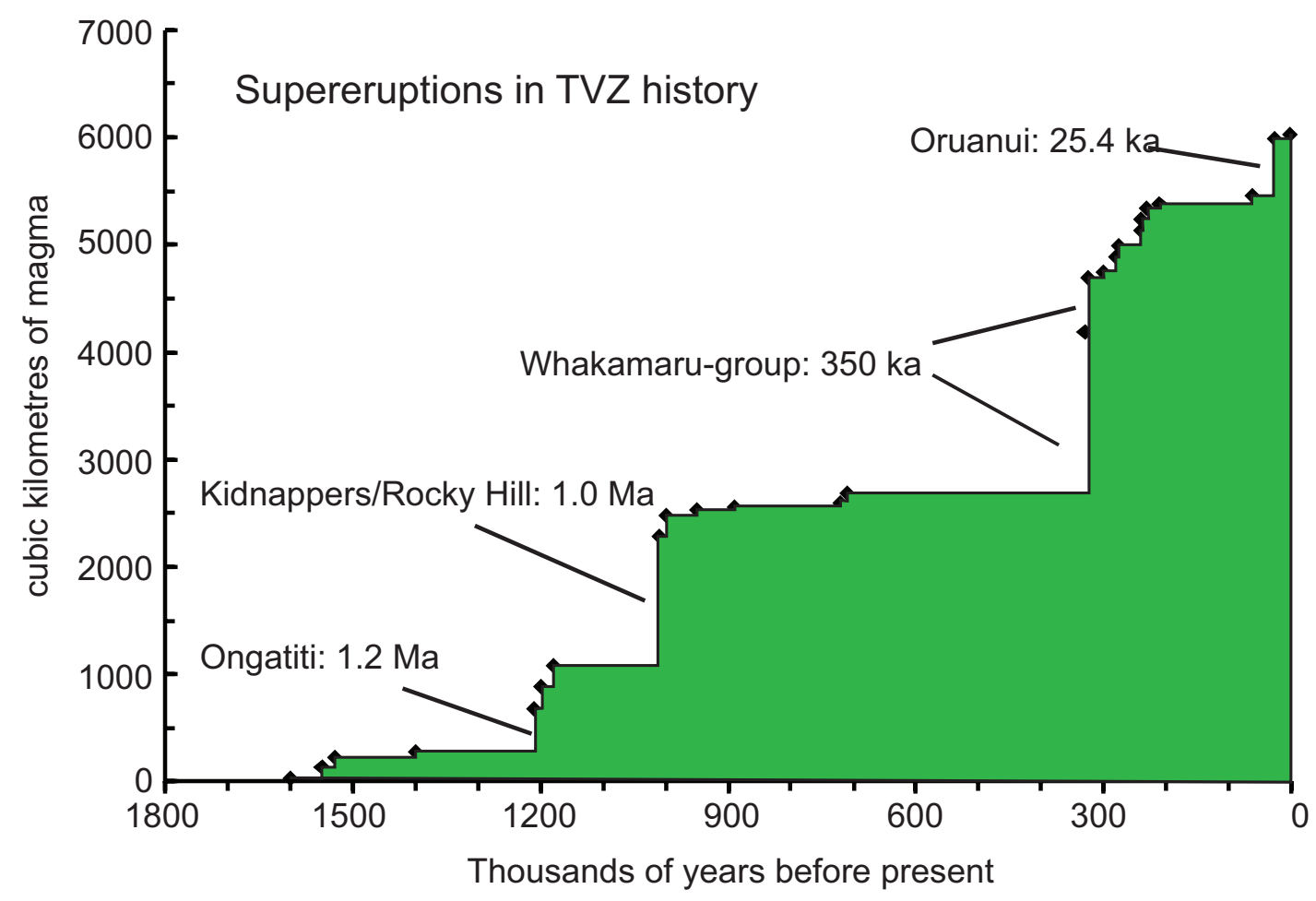

Fig. 1.4. Accumulated volumes of magma erupted in caldera-forming eruptions in the TVZ. After Wilson et al. (2009).

\subsection{Mangakino volcanic centre}

\subsubsection{Overview}

Mangakino volcanic centre, the oldest known within the TVZ, is a composite feature located on the northwestern boundary of the TVZ, and identified through geophysical anomalies and geological evidence (Blank 1965; Stern 1979; Rogan 1982; Wilson et al. 1984, 1995a; Wilson 1986). Mangakino predates and lies west of the main present-day region of high heat flow and crustal extension within the young TVZ (Briggs et al. 1993). ${ }^{40} \mathrm{Ar} /{ }^{39} \mathrm{Ar}$ age determinations from Mangakino ignimbrites show that activity occurred in two distinct periods of caldera forming eruptions - an early interval from $\sim 1.55 \mathrm{Ma}$, and a later interval from 1.21 to $0.95 \mathrm{Ma}$ (Houghton et al. 1995) (Table 1.1). Three ignimbrites are ascribed to the early interval: the Ngaroma, Unit B and Unit C 
(Table 1.1). The later interval was an intense period of volcanism when six significant ignimbrites, including the Ongatiti and the Kidnappers supereruptions, were produced.

Table 1.1. Ignimbrites erupted from Mangakino Volcanic Centre. Note that the age for Unit $C$ is known to be inaccurate, as the stratigraphic position of this ignimbrite is established between Ignimbrite B and the Ongatiti ignimbrite (Wilson 1986). Deposits labelled in bold are those considered in this thesis.

\begin{tabular}{lcc}
\hline \multicolumn{1}{c}{ Ignimbrite } & Age $(\mathrm{Ma})$ & Volume \\
\hline Marshall & $0.95 \pm 0.02$ & $>50 \mathrm{~km}^{3}$ \\
Rocky Hill & $\mathbf{1 . 0 0 \pm 0 . 0 5}$ & $\mathbf{2 0 0 \mathrm { km } ^ { 3 }}$ \\
Kidnappers & $\mathbf{1 . 0 1} \pm \mathbf{0 . 0 2}$ & $\mathbf{1 2 0 0 \mathrm { km } ^ { 3 }}$ \\
Ahuroa & $1.18 \pm 0.02$ & $>50 \mathrm{~km}^{3}$ \\
Unit D & $1.20 \pm 0.04$ & $>10 \mathrm{~km}^{3}$ \\
Ongatiti & $\mathbf{1 . 2 1} \pm \mathbf{0 . 0 4}$ & $>\mathbf{5 0 0 \mathrm { km } ^ { 3 }}$ \\
\hline Ignimbrite C & $1.68 \pm 0.07$ & \\
Ignimbrite B & $1.53 \pm 0.04$ & \\
Ngaroma & $1.55 \pm 0.05$ & $>50 \mathrm{~km}^{3}$ \\
\hline
\end{tabular}

The topographic expression of the Mangakino caldera is poorly expressed due to later infilling by eruptive deposits, but its location is defined by a major gravity low (Stern 1979; Rogan 1982) and geological field evidence (Wilson et al. 1984; Wilson 1986). A thick sequence $(>1.8 \mathrm{~km})$ of caldera-fill tuff inferred to be related to the Kidnappers/Rocky Hill eruptions has been penetrated in geothermal drillholes at Mangakino (Fagan 2007; Wilson et al. 2008). Drilling to $3.2 \mathrm{~km}$ below the surface did not penetrate the base of the $\sim 1 \mathrm{Ma}$ eruption deposits and any pre-volcanic basement is likely to be at least $4-5 \mathrm{~km}$ below the modern landscape. The stratigraphic relationships of deposits from Mangakino were originally established by Martin (1961) and Blank (1965), and later refined by Wilson (1986). Only two domes have been mapped at Mangakino (Briggs et al. 1993), although lithics of rhyolitic lava are common within Mangakino ignimbrites suggesting there was some pre- and syn-caldera effusive 
activity. Any post-caldera activity has been buried by a thick sequence of lacustrine sediments and the Whakamaru ignimbrite (Wilson et al. 2008).

\subsubsection{Stratigraphic limitations}

Ignimbrites from Mangakino volcanic centre (MVC) are poorly exposed due to burial by later eruptions from the TVZ and, in particular, the Whakamaru ignimbrite, as well as erosion during uplift of the axial ranges (Briggs et al. 1993). Therefore, stratigraphic control within these ignimbrites is limited and sampling is restricted to widely spaced exposures that are close to the eruption sources throughout the King Country, west of the modern TVZ. Any potential temporal compositional changes within any particular unit may be obscured due to poor stratigraphic control, and therefore it is necessary to sample a large range of pumice clasts from each available location so that the variability through the whole deposit can be representatively sampled. Through careful and strategic sampling it is still possible to gain novel information from Mangakino deposits with detail comparable to other TVZ supereruptions such as the Whakamaru.

\subsubsection{Ongatiti Ignimbrite}

The Ongatiti supereruption occurred at $1.21 \pm 0.04 \mathrm{Ma}$ (Houghton et. al. 1995) producing a voluminous $\left(>500 \mathrm{~km}^{3}\right)$, non-welded to partially welded crystal-rich (20-30\%) rhyodacitic to rhyolitic ignimbrite (Figure 1.5). No associated fall deposit is preserved, although it most probably is represented in the deep-sea record offshore from the North Island (e.g., Allan et al. 2008). The Ongatiti ignimbrite, to a first order, may be considered to belong to a class of ignimbrites termed the 'monotonous intermediates' (summarised by Hildreth 1981; Bachmann and Bergantz 2008). These deposits are crystal-rich (35-45\%), have near solidus mineral assemblages, and lack evidence for compositional zoning. These ignimbrites are typically, but not exclusively, dacitic in composition and include the Fish Canyon Tuff (Bachmann and Bergantz 2008), Lund Tuff (Maughan et al. 2002) and the Cerro Galan ignimbrite (Francis et al. 1989; Folkes et al. 2011). The Ongatiti ignimbrite differs from these examples as it is quartz-bearing and has higher $\mathrm{SiO}_{2}$ contents. The 'monotonous intermediates' are thought to represent remobilised, deep-seated crystal mushes ( $>30-40$ vol. \% crystals), and are therefore important for understanding crustal magmatism as they provide a link between the 
plutonic and volcanic realms (Bachmann et al. 2002). The Ongatiti ignimbrite thus provides an unusual opportunity to study these links and the root zones of a super-sized silicic magmatic system within the TVZ.

The Ongatiti ignimbrite consists of multiple flows, which were erupted in a series of directional lobes (Briggs et al. 1993) and can be subdivided into an earlier and later erupted facies (Wilson 1986). Field evidence suggests the Ongatiti eruption began with highly energetic, violent and cooler flows which generated a pumice-poor, fine grained ignimbrite before switching to less energetic and hotter flows that generated the upper pumice-rich ignimbrite (Wilson 1986; Briggs et al. 1993). The upper flow units are best defined by the presence of densely welded recycled tuff fragments that are absent from the lower unit. An overall upward coarsening of both pumice and lithic clasts is evident through the Ongatiti ignimbrite (Wilson 1986).

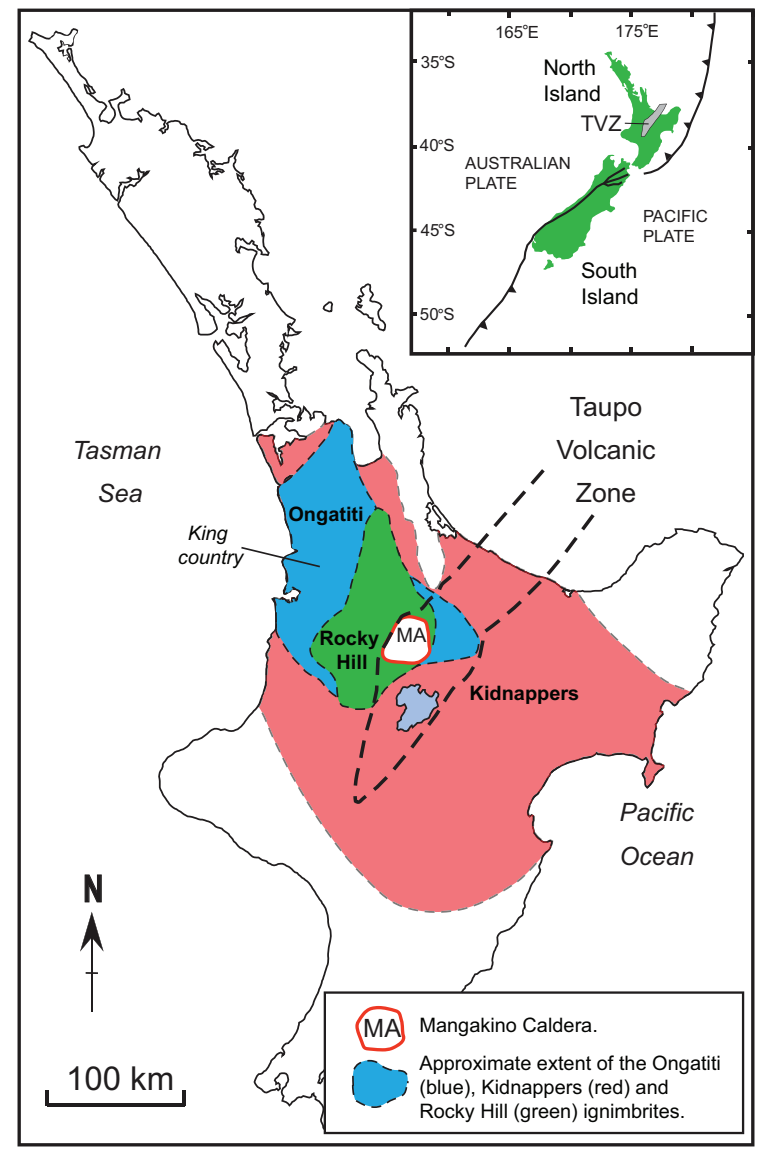

Fig. 1.5. Outline of the Taupo Volcanic Zone and plate setting (inset), with the approximate extent of the Ongatiti, Kidnappers and Rocky Hill ignimbrites.Modified from Briggs et al. (1993), Wilson et al. (1995b) and Alloway et al. (2004). 


\subsubsection{Kidnappers ignimbrite and fall deposit}

The Kidnappers eruption produced one of the largest known phreatomagmatic fall deposits in New Zealand followed by the most widespread ignimbrite on Earth (Wilson et al. 1995b; Carter et al. 2004). The total dense rock equivalent volume of the Kidnappers eruption is estimated at ca. $1200 \mathrm{~km}^{3}$ (Cooper et al. 2012 [Chapter 3]). The deposits have been dated at ca. 1 Ma by ${ }^{40} \mathrm{Ar} /{ }^{39} \mathrm{Ar}$ methods (Houghton et al. 1995; Wilson et al. 1995b). This age determination is supported by paleomagnetic evidence as the Kidnappers eruption products fall within the upper parts of normally magnetized sediments of the Jaramillo Subchron (Black 1992).

The Kidnappers fall deposit is recorded across the North Island and for $>1000 \mathrm{~km}$ eastwards across the Pacific Ocean floor (Ash A of Ninkovich 1968; Carter et al. 2004; CJN Wilson unpublished data). The fall deposit accounts for approximately two-thirds of the volume of extra-caldera erupted material (Cooper et al. 2012 [Chapter 3]). The deposit is an ash-rich phreatomagmatic fall deposit with multiple bedding, poor sorting and with beds locally rich in accretionary lapilli (Wilson 1986). Dated at ca. 1 Ma, the Potaka Tephra (e.g., Shane 1994; Carter et al. 2004; Alloway et al. 2005) is a widespread composite deposit of primary and reworked material with a collective contribution from both the Kidnappers and Rocky Hill eruptions.

The Kidnappers ignimbrite covers ca. $45,000 \mathrm{~km}^{2}$ and has a bulk volume of ca. $450 \mathrm{~km}^{3}$ (Wilson et al. 1995b) (Figure 1.5). The ignimbrite is distinctive in the field due to its completely non-welded texture, stratigraphic position over its associated fall deposit, and the high abundance of biotite that is commonly altered to a conspicuous golden hydromica. Only two definitive flow units have been observed within the ignimbrite, and stratigraphic control is very poorly constrained (Figure 1.6).

\subsubsection{Rocky Hill ignimbrite}

The Rocky Hill ignimbrite has a ${ }^{40} \mathrm{Ar} /{ }^{39} \mathrm{Ar}$ age determination that is identical within uncertainty to the Kidnappers deposits, but the ignimbrite and its juvenile components have a distinctive appearance. The ignimbrite is non- to densely welded, displaying an 
inverse thermal zonation (non-welded base and welded upper part) (Blank 1965; Wilson 1986). The pumices have a characteristic texture, including the presence of sparse but large (to $0.5 \mathrm{~cm}$ ) euhedral amphibole crystals and only minor amounts of biotite. The Rocky Hill eruption has a total dense rock equivalent volume of ca. $200 \mathrm{~km}^{3}$ (Figure 1.5). Field evidence (Wilson 1986, and pers. comm.) indicates that the top of the Kidnappers ignimbrite was eroded prior to eruption of the Rocky Hill ignimbrite, indicating the presence of a short time gap. The presence of this time gap between the supersized Kidnappers and smaller (but still substantial) Rocky Hill eruptions is a rare opportunity to study the recovery of a magmatic system after a supervolcanic event. Processes such as magma recharge during the short time interval after the Kidnappers eruption can be explored. The Rocky Hill ignimbrite commonly forms craggy outcrops, which stand proud, in comparison to the Kidnappers eruption products that are generally slope forming, vegetation covered and only exposed in slips and road cuttings (Figure 1.6). In addition to surface exposures, $>500 \mathrm{~m}$ of the Rocky Hill ignimbrite, containing pseudomorphs after large hornblende crystals, has been drilled near Mangakino township (Wilson et al. 2008).

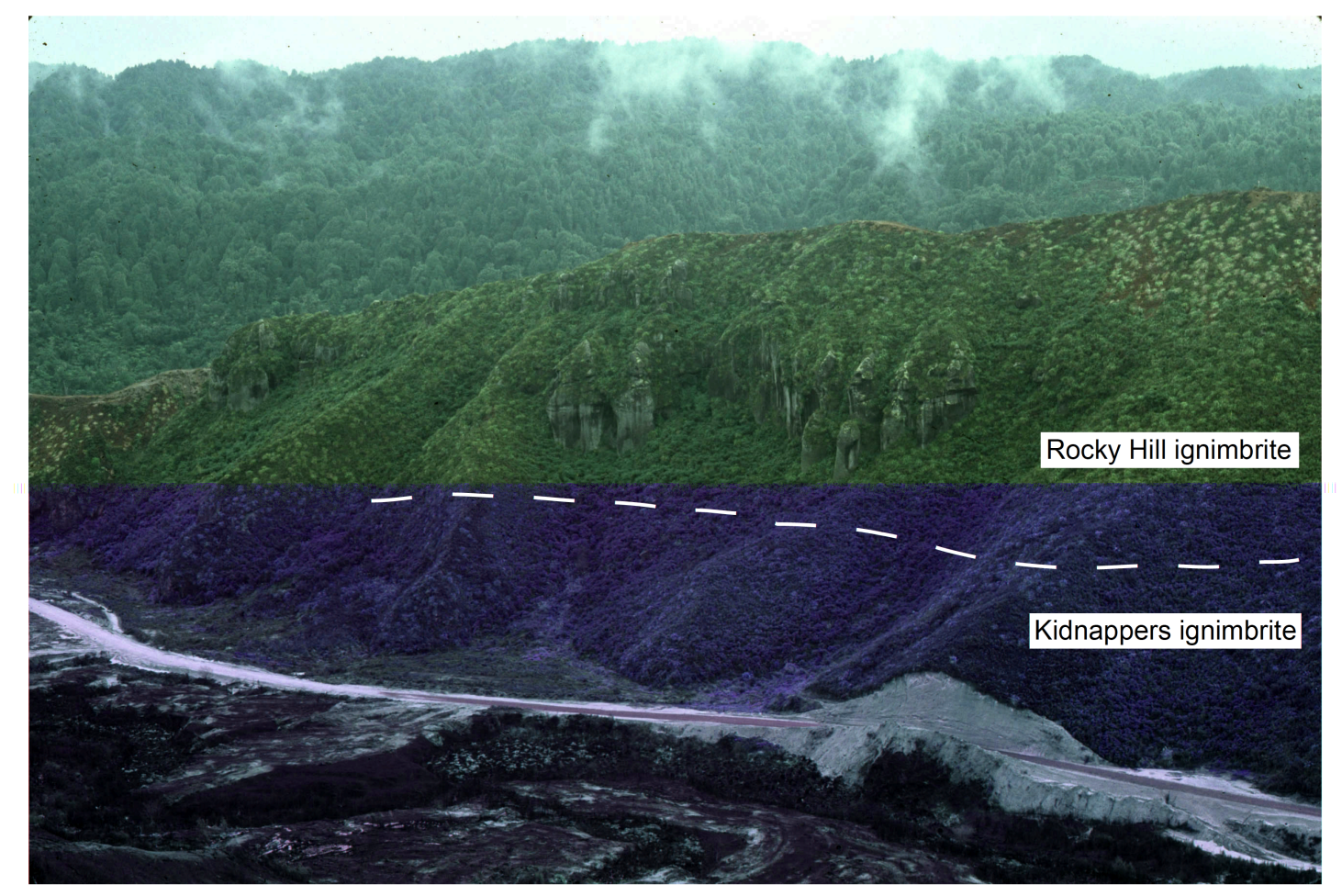

Fig. 1.6. Photograph to illustrate the field relationship of the Kidnappers and Rocky Hill ignimbrites. Rocky Hill is welded, with outcrops that stand proud whereas the Kidnappers is non welded, forms slopes, and has few outcrops. Photograph courtesy of CJN Wilson. 


\subsubsection{Previous work on Mangakino deposits}

Since early mapping studies (Martin 1961; Blank 1965; Wilson 1986), there has been relatively little published work carried out on the eruption deposits from Mangakino caldera. Reconnaissance petrological studies by Briggs et al. (1993) characterised whole rock geochemical variations, mineral chemistry, and $\mathrm{Sr}-\mathrm{Nd}$ isotope compositions on a limited set of juvenile clasts from the Ngaroma, Ongatiti, Ahuroa, Rocky Hill and Marshall ignimbrites. All these ignimbrites show a degree of compositional variation in pumices at any given stratigraphic level. Therefore, compositionally zoned magma chambers were a likely feature for the majority of the Mangakino eruptions, but any compositional zonation that existed was disrupted by pre- and syn-eruptive mixing (Briggs et al. 1993). The Marshall ignimbrites (0.95 Ma) are separated by a gradational contact (no time break), but have distinct major and trace element compositions suggesting the two units were derived from different discrete sources (Briggs et al., 1993). More recently, Schipper (2004) characterised the chemistry and mineralogy of the Kidnappers and Rocky Hill eruptions, which were found to be largely indistinguishable on the basis of whole rock and mineral chemistry, but differed in terms of phenocryst abundances and glass chemistry. The magmas tapped by the Kidnappers and Rocky Hill eruptions were therefore inferred to have co-evolved by plagioclase dominated crystal fractionation from a common chamber (Schipper 2004). With recent advancements in in-situ microanalytical geochemical techniques and extensive strategic sampling, there is an opportunity to explore the juvenile components of Mangakino eruption products in much greater detail than previous studies.

Studies by Brown \& Smith (2004), Wilson et al. (2008) and McCormack et al. (2009) have applied $\mathrm{U}-\mathrm{Pb}$ dating techniques to zircons extracted from Mangakino ignimbrites. $\mathrm{U}-\mathrm{Pb}$ ages from zircons within the Ongatiti show a peak in probability at $1.31 \mathrm{Ma}$, with no resolvable differences between ages from cores and rims (Brown \& Smith 2004). Unlike in the Whakamaru system, they found no evidence for a prolonged ( $>200 \mathrm{kyr}$ ) crystallisation history and no zircons were inherited from earlier Mangakino eruptions. A change in the xenocryst zircon age spectra in successive Mangakino eruptions is seen which is attributed to a change in location of assimilation (McCormack et al. 2009). This may be explained by changes in the crustal heat transfer as attenuation by faulting became more pervasive through the evolution of Mangakino, changing the thermal state 
in the crust. This may have led to an increase in the proportion of metasedimentary material assimilated, causing a change in xenocryst zircon age spectra (McCormack et al. 2009). However this study is somewhat limited, as zircons from whole-rock ignimbrite samples were analysed and therefore it is not known whether the zircons originated from juvenile material or were incorporated from surficial exposures of greywacke basement. A drilled core near the township of Mangakino penetrated $>1.8$ $\mathrm{km}$ of intracaldera tuff. Wilson et al. (2008) used zircon U-Pb ages to correlate this hydrothermally altered intracaldera fill to the Rocky Hill and Kidnappers ignimbrites. This thesis (Chapter 2) presents zircon age and trace element data that significantly expand the zircon $\mathrm{U}-\mathrm{Pb}$ database from the Mangakino volcanic centre.

The subsequent chapters focus on the crystal specific signatures recorded in the deposits from the Ongatiti, Kidnappers and Rocky Hill, beginning with the temporal evolution and compositions recorded in zircons from all three eruptions. The next three chapters then concentrate on the Kidnappers and Rocky Hill, starting with a detailed study through the Kidnappers fall deposit before moving on to a comparison of crystal specific signatures and timescales recorded within each of the ignimbrites. The magma system that fed the Ongatiti eruption is then explored, before conclusions are drawn from all eruptions in light of the key findings presented in this thesis. 
Chapter 2 


\section{Temporal evolution and compositional}

\section{signatures of two supervolcanic systems recorded in zircons from Mangakino volcanic centre, New}

\section{Zealand}

\subsection{Introduction}

The extremely large silicic magmatic systems that culminate in supervolcanic eruptions $\left(>10^{15} \mathrm{~kg}\right.$ or $\sim 450 \mathrm{~km}^{3}$ of magma; e.g., Sparks et al. 2005) have been proposed to develop over a wide range of timescales. Early workers (e.g. Smith 1979; Shaw 1985) favoured timescales of the order of $10^{5}$ to $10^{6}$ years for the largest systems to develop and grow their eruptible magma bodies, with the corollary that eruptive volume is proportional to the pre-eruptive repose period. Such long-term views have persisted (e.g. Christensen and DePaolo 1993; Brown and Fletcher 1999; Simon and Reid 2005; Reid 2008), but recognition of the role of recycling of earlier-formed crystals has led to recognition that physical growth of the melt-dominant body that erupts may occur at much faster rates than the geochemical processes that create the magma composition(s) concerned (Charlier et al. 2005). Such recognition is used to infer rapid rates of physical magma accumulation of only thousands of years (Miller and Wooden 2004; Miller et al. 2007; Wilson and Charlier 2009; Allan et al. 2013).

Information obtained from zircons can aid in understanding the generation of large silicic magmatic systems, the timescales of accumulation and storage, as well as the evolving magmatic conditions during storage of melt-dominant bodies. Due to its refractory nature and low elemental diffusivities (Cherniak and Watson 2003), zircon has the ability to retain compositional zoning for long periods of time and through varying magmatic conditions. Use of Sensitive High Resolution Ion Microprobe (SHRIMP) methods enable the analysis of high-precision in-situ trace element concentrations of compositional zones within zircons, as well as in-situ U-series dating. Measurement of the temporal and compositional record retained in zircons can thus provide insights into the long-term evolution of silicic systems (e.g. Claiborne et al. 2010; Charlier and Wilson 2010). 
Here new or enlarged datasets are presented of SHRIMP U-Pb age and trace element analyses of zircon from three Pleistocene eruptions (two of which were of supereruptive scale), from the Mangakino volcanic centre, Taupo Volcanic Zone (TVZ), New Zealand (Figure 2.1). Given the limited scope for detailed stratigraphic studies in these eruptive units (unlike the younger deposits from the active TVZ centres), there are three aims in this work.

(1) Characterise zircon assemblages from individual pumice clasts based on morphology and internal zonation of the grains.

(2) Examine zircon $\mathrm{U}-\mathrm{Pb}$ age spectra from each eruption individually, as well as from end-member type pumices within the same eruption.

(3) Use trace element data to trace the evolution of Mangakino magmatic systems, and link zircon chemistry to morphological and textural features.

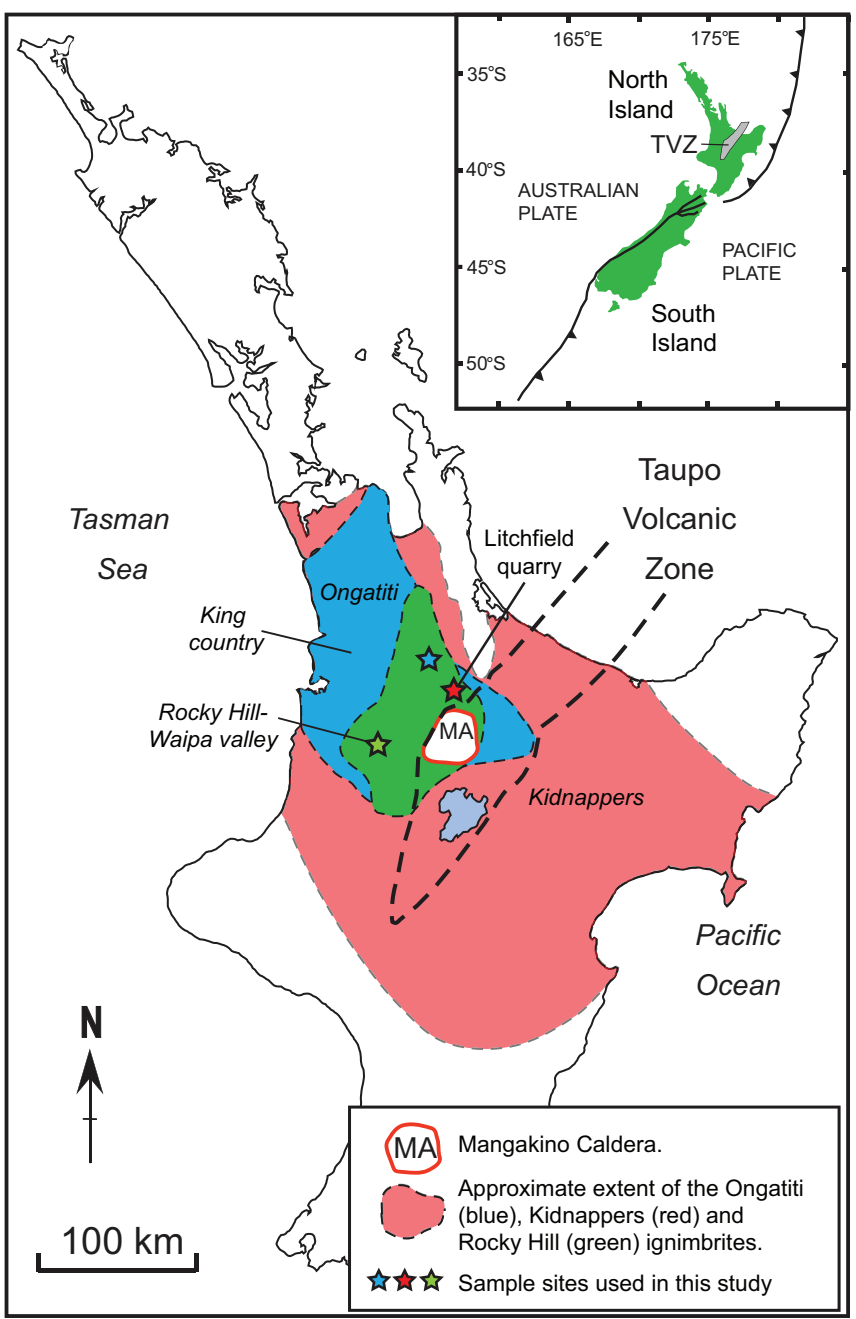

Figure 2.1. Map of the North Island, New Zealand to show the extent of the Ongatiti, Kidnappers and Rocky Hill ignimbrites and sampling locations. Modified from Briggs et al. (1993), Wilson et al. (1995b) and Alloway et al. (2004). 
Mangakino provides an excellent opportunity to compare crystallisation histories and magmatic evolution from two temporally separated supervolcanic chambers from the same general geographic source. Samples are examined from the 1.21 Ma Ongatiti, and paired 1.0 Ma Kidnappers and Rocky Hill eruptions, to address whether the latter two have a zircon $\mathrm{U}-\mathrm{Pb}$ age and/or geochemical signature that suggest that they were products of a long-lived system common to the Ongatiti, or represent a new system developed during the time break between the two sequences. In addition, the smaller Rocky Hill ignimbrite was erupted very shortly after the super-sized Kidnappers eruption, and so it is considered whether the zircons record a corresponding change in age or geochemical characteristics, or if the Rocky Hill eruption could be interpreted (in the absence of field controls) as the second stage of a single supervolcanic event.

When focusing on open magmatic systems, which can be built from the integration of discrete magma batches, it is important to define the nature of grains (or zones within grains) present in each crystal population. Three categories of crystal (or parts thereof) can be defined (e.g. Charlier et al. 2005) as present within eruption products: phenocrysts (crystallised in the melt in which they resided on eruption), antecrysts from precursor crystal mush, and xenocrysts. The last may represent inputs from melting or disruption of unrelated country rocks (greywacke or earlier [Pleistocene] intrusive rocks in the New Zealand setting), or come from different magmas of contrasting compositions injected into the magma chamber. Autocryst is a term also used to describe accessory minerals such as zircon crystals or a discrete period of crystal growth, which in a spatial and temporal sense is associated exclusively with a distinct pulse or increment of magma (Miller et al. 2007).

Previous studies using zircons from Mangakino eruption products have focused on the correlation of inherited grains to basement greywacke terranes (Brown and Smith 2004; McCormack et al. 2009), and the use of zircons for correlation of surficial ignimbrites with hydrothermally altered intracaldera fill in the Mangakino geothermal field (Wilson et al. 2008). The more extensive zircon $\mathrm{U}-\mathrm{Pb}$ age data presented here focus on magmatic, not xenocrystic grains, so that the genesis and accumulation of each system can be studied in detail. Zircon trace element data from Mangakino provides an opportunity to compare compositional signatures and potential magmatic processes with worldwide examples of large silicic volcanic systems, where comparative datasets are 
available (e.g. Reid et al. 2011; Chamberlain et al. 2013).

\subsection{Mangakino volcanic centre}

Mangakino volcanic centre is the oldest exposed composite caldera structure within the TVZ, located on and locally defining the northwestern boundary of the TVZ (Wilson et al. 1984, 1995a). The topographic expression of Mangakino caldera is poorly expressed over much of its perimeter due to burial by later eruptive deposits, but the general extent and location of the caldera collapse are defined by a major gravity low (Stern 1979; Rogan 1982) and geological field evidence (Blank 1965; Wilson 1986). ${ }^{40} \mathrm{Ar} /{ }^{39} \mathrm{Ar}$ age data from deposits inferred to be sourced from Mangakino show that activity occurred in two distinct periods of large (caldera-forming) eruptions from 1.6 to $1.5 \mathrm{Ma}$ and 1.21 to $0.95 \mathrm{Ma}$ (Houghton et al. 1995). The latter interval incorporated a particularly intense period of volcanism when six ignimbrites (all exceeding $\sim 100 \mathrm{~km}^{3}$ magma volume) were erupted, including the three reported on here.

The Ongatiti eruption occurred at $1.21 \pm 0.02 \mathrm{Ma}\left({ }^{40} \mathrm{Ar} /{ }^{39} \mathrm{Ar}\right.$ age: Houghton et al. 1995) producing a voluminous ( $>500 \mathrm{~km}^{3}$ magma), widespread ( $>150 \mathrm{~km}$ from source; Figure 2.1), non-welded to partially welded, crystal-rich rhyodacitic to rhyolitic ignimbrite (Martin 1961; Blank 1965; Briggs et al. 1993). A correlative fall deposit is present in marine cores (Allan et al. 2008), but this is inferred to be purely co-ignimbrite in origin, as no fall deposits have been found beneath or interbedded with the ignimbrite. Field evidence suggests the Ongatiti eruption began with less widely distributed flows before switching to more energetic and less hot flows (Wilson 1986). The change-over is marked by the incoming of co-eruptive welded ignimbrite clasts, inferred from their glassy, sometimes breadcrusted natures to be recycled from earlier-erupted caldera fill that was evacuated during later migration of vent positions (cf. Bishop Tuff: Wilson and Hildreth 1997). Pumice clasts span a range in composition (66-73 wt. \% $\mathrm{SiO}_{2}$ : Chapter 6), which range has previously been attributed to chemical zonation in the pre-eruptive magma chamber and related to plagioclase-dominated fractionation (Briggs et al. 1993).

The Kidnappers supereruption ( $1200 \mathrm{~km}^{3}$ magma) produced the largest known phreatomagmatic fall deposit in New Zealand followed by an exceptionally widespread ignimbrite which covers $c a$. 45,000 $\mathrm{km}^{2}$ (Wilson et al. 1995b; Carter et al. 2004; Cooper 
et al. 2012; Figure 2.1). The fall deposits are very fine grained (almost entirely devoid of lapilli-sized material) and zoned with respect to the ferromagnesian mineral assemblage and glass compositions (Cooper et al. 2012 [Chapter 3]). The ignimbrite is distinctive in the field due to its non-welded nature and an abundance of biotite that is generally weathered to a conspicuous golden hydromica. Pumice clasts in the ignimbrite span a range of $70-76$ wt. $\% \mathrm{SiO}_{2}$ (Chapter 4), and fall into three compositional groups, interpreted to represent material from independent melt-dominant bodies (Cooper et al. 2012). The ${ }^{40} \mathrm{Ar} /{ }^{39} \mathrm{Ar}$ eruption age is $1.0 \pm 0.02 \mathrm{Ma}$ (Houghton et al. 1995). Both the Kidnappers and immediately following Rocky Hill eruptions are also age constrained by both being contained within the Jaramillo normal Subchron (Ninkovich 1968; Black 1992; Tanaka et al. 1996), currently estimated to have lasted from 1.072 to $0.98 \mathrm{Ma}$ (Gradstein et al. 2012).

The Rocky Hill ignimbrite $\left(\sim 200 \mathrm{~km}^{3}\right.$ magma) has a ${ }^{40} \mathrm{Ar} /{ }^{39} \mathrm{Ar}$ age identical within uncertainties to the Kidnappers but is, however, separated from the underlying Kidnappers ignimbrite by a surface representing a period of weathering and erosion (Wilson 1986). The ignimbrite commonly forms craggy exposures, which stand proud in comparison to the Kidnappers deposits that in contrast generally are slope forming and concealed beneath vegetation. The ignimbrite is non- to densely welded, displaying an inverse thermal zonation (partially-welded base and densely welded upper part with relatively low pumice abundance) (Blank 1965; Wilson 1986; Briggs et al. 1993). Pumice clasts span 68-76 wt.\% $\mathrm{SiO}_{2}$ (Chapter 4), slightly greater than the range in the Kidnappers. Characteristic of the pumices is the presence of large (up to $5 \mathrm{~mm}$ long) euhedral hornblende crystals and biotite is very scarce (Martin 1961).

A geothermal drillhole sited within the geophysically defined Mangakino caldera penetrated $>1.8 \mathrm{~km}$ of tuff which, on the basis of consistent $\mathrm{U}-\mathrm{Pb}$ age spectra from zircons at several stratigraphic levels, is interpreted as the combined intracaldera tuff facies of the Rocky Hill and Kidnappers eruptions (Wilson et al. 2008). U-Pb zircon ages from the Kidnappers (P1722) and the Ongatiti (P1804) were also reported by Wilson et al. (2008) for comparative purposes. Here, these previous data are incorporated and significantly expanded upon. 


\subsection{Samples}

Large pumice clasts, with pre-established whole rock characteristics, were chosen so that a sufficient zircon yield could be obtained from stratigraphically or compositionally representative pumice types from each eruption deposit. Pumices from Ongatiti, Kidnappers and Rocky Hill eruptions all contain phenocrysts of plagioclase, quartz, orthopyroxene, hornblende, titanomagnetite and ilmenite, with accessory zircon and apatite. In addition, the Ongatiti contains rare K-feldspar, and the Kidnappers and Rocky Hill contain variable amounts of biotite.

Three pumices from the Ongatiti were selected for analysis based on stratigraphic position within the ignimbrite, so that a comparison between early and late flows could be made (Table 2.1). Sample P1993, a dense crystal rich pumice, is from the lower Ongatiti ignimbrite at Ranginui Station, $\sim 15 \mathrm{~km}$ west of Mangakino township (Figure 2.1). Here the exposed ignimbrite is $\sim 25 \mathrm{~m}$ thick and poorly welded. Samples P2027 and P1804, moderately crystal rich pumices, are from the upper flows along Horahora Road, where the ignimbrite is less welded and contains pumice enriched zones.

Three pumices from the Kidnappers ignimbrite were chosen based on whole-rock wt. \% $\mathrm{SiO}_{2}$ to compare zircon characteristics from compositional end-members (Table 2.1). These clasts were sampled from a pumice quarry near Litchfield, $\sim 30 \mathrm{~km}$ from source (Figure 2.1). Here the ignimbrite is $>10 \mathrm{~m}$ thick, but the upper or basal surfaces are not exposed, resulting in limited stratigraphic control. Sample P2006 is a high-SiO $\mathrm{S}_{2}$ type, biotite-rich end-member pumice (KI-2 type pumice; Chapter 4) and P1722 and P2008 are mid-SiO 2 type pumices (KI-1 type; Chapter 4) containing less biotite. These endmember type pumices are linked, respectively, to the two major glass compositional groups (types A and B) in the Kidnappers fall deposit (Cooper et al. 2012; Chapter 4). Two pumices (P1842 and P2243; Table 2.1) from the Rocky Hill ignimbrite in the Waipa Valley (Figure 2.1) were selected based on their size so that the zircon yield was sufficiently large. 


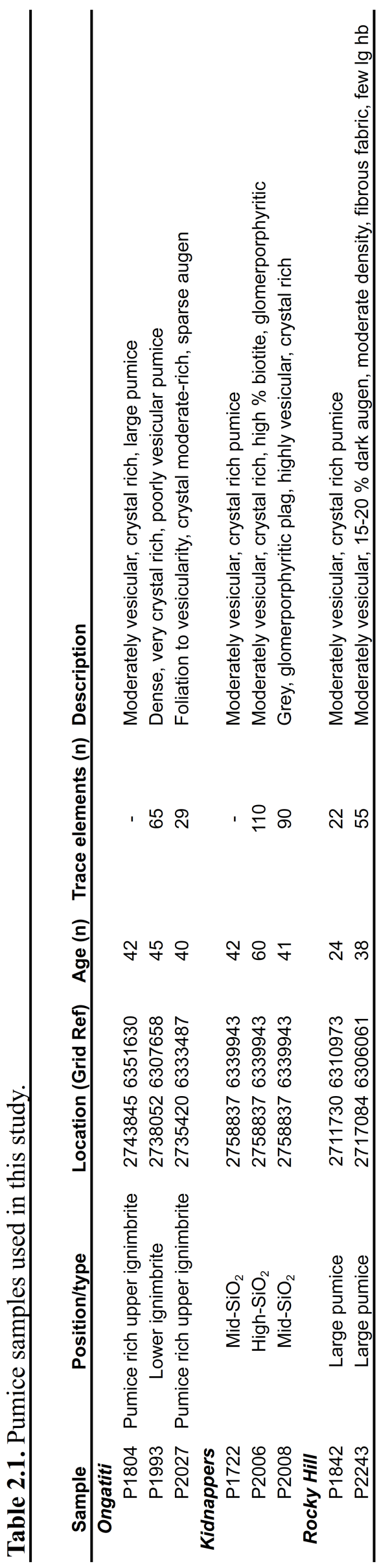




\subsection{Analytical Techniques}

\subsubsection{Zircon separation and mount preparation}

Pumices were crushed and dry sieved into size fractions $<250 \mu \mathrm{m}$ and $>250 \mu \mathrm{m}$. All material $<250 \mu \mathrm{m}$ was then wet sieved at $60 \mu \mathrm{m}$ and the fraction between 250 and 60 $\mu \mathrm{m}$ was retained. Zircons were separated from this fraction using standard heavy liquid methods and a Franz magnetic separator. Zircon grains were mounted in Epofix ${ }^{\mathrm{TM}}$ epoxy resin and polished to expose the grains to approximately mid-section. The mounts were then photographed in reflected light (RL) and imaged by cathodoluminescence (CL) on a JEOL LV5600 Scanning Electron Microscope. A large number of zircon grains $(>200)$ from each pumice sample were mounted so that representative assemblages could be assessed by RL and CL imaging before analysis. These images were used as a guide for the selection of age and trace element analysis points. The mounts were cleaned with detergent, EDTA (Stanford) or petroleum spirits (ANU), and $1 \mathrm{M} \mathrm{HCl}$ with intervening rinses in distilled water, prior to gold coating.

\subsubsection{Zircon U-Pb analytical techniques}

Age determinations on zircons were made by Secondary Ion Mass Spectrometry (SIMS) techniques on the SHRIMP-RG instruments at the joint USGS-Stanford University facility (SUMAC) and at the Research School of Earth Sciences, Australian National University (ANU). During analysis, the primary beam was rastered for 180 seconds over an area of $35 \times 45 \mu \mathrm{m}$ prior to data acquisition to remove the gold coat and any possible surface contamination. Ions were then sputtered from zircons with a 5-6 nA primary $\mathrm{O}_{2}{ }^{-}$beam focused to $\mathrm{a} \sim 25 \times 35 \mu \mathrm{m}$ spot. The mass spectrometer was cycled through peaks corresponding to ${ }^{172} \mathrm{Yb}^{16} \mathrm{O},{ }^{90} \mathrm{Zr}_{2}{ }^{16} \mathrm{O},{ }^{204} \mathrm{~Pb}$, background, ${ }^{206} \mathrm{~Pb},{ }^{207} \mathrm{~Pb}$, ${ }^{208} \mathrm{~Pb},{ }^{232} \mathrm{Th},{ }^{238} \mathrm{U},{ }^{232} \mathrm{Th}^{16} \mathrm{O}$ and ${ }^{238} \mathrm{U}^{16} \mathrm{O}$, with a total analysis time of 750 to $900 \mathrm{~s}$. Extended count times were used for ${ }^{206} \mathrm{~Pb}(20$ or $30 \mathrm{~s})$ and ${ }^{207} \mathrm{~Pb}(20 \mathrm{~s})$ and six scans were run through the mass sequence. The concentration standard was MAD (Madagascar green: Barth and Wooden 2010) at SUMAC and SL-13 at ANU and the age standard was R33 (420 Ma: ID-TIMS age from: http://earth.boisestate.edu/isotope/analytical-capabilities/id-tims-u-pb). Data reduction was done using SQUID 2 (Version 1.51: Ludwig 2009), and data plotted using Isoplot version 3.76 (Ludwig 2008). All uncertainties are reported here at 2 s.d. All R33 U-Pb age data obtained during each analytical session are presented in Electronic Appendix 1. 
A correction for initial ${ }^{230} \mathrm{Th}$ disequilibrium was calculated with the method of Schärer (1984), using the measured Th and $\mathrm{U}$ concentrations in the zircons, together with a whole-rock $\mathrm{Th} / \mathrm{U}$ value of 4.4 . The resulting age corrections range from +0.051 to +0.099 Myr. The presence of common $\mathrm{Pb}$ was evaluated by monitoring for ${ }^{204} \mathrm{~Pb}$ and ${ }^{207} \mathrm{~Pb} /{ }^{206} \mathrm{~Pb}$, and a correction applied using the recorded ${ }^{207} \mathrm{~Pb} /{ }^{206} \mathrm{~Pb}$ values and $\mathrm{a}$ common- $\mathrm{Pb}$ isotopic composition for the sample age from the average crust model of Stacey and Kramers (1975). Analyses of grains with $<20 \%$ common $\mathrm{Pb}$ were considered acceptable for the purposes of this paper; those with $>20 \%$ common $\mathrm{Pb}$ are included in the overall data set in Electronic Appendix 1, but not used to draw up the figures here.

\subsubsection{Zircon trace element analytical techniques}

SIMS analyses for trace elements were performed on the SHRIMP-RG instrument at Stanford University. Following U-Pb analysis, zircon mounts were re-polished to remove the original gold coating and sputtered pits, and recoated with gold. Sites for trace element analyses were selected on the basis of CL zoning and avoided areas where inclusions were visible in reflected light images. Preference was given for locations that had been previously analysed for U-Pb ages, although trace element spots did not coincide exactly with age spots and instead were carried out on an adjacent part of the crystal in the same CL zone. Core and rim zones of zircons were analysed where possible. Analyses were made using a 1.5-3 nA primary beam current and a $15 \times 12 \mu \mathrm{m}$ spot size. Peaks representing ${ }^{7} \mathrm{Li},{ }^{9} \mathrm{Be},{ }^{11} \mathrm{~B},{ }^{19} \mathrm{~F},{ }^{23} \mathrm{Na},{ }^{27} \mathrm{Al},{ }^{30} \mathrm{Si},{ }^{31} \mathrm{P},{ }^{39} \mathrm{~K},{ }^{40} \mathrm{Ca},{ }^{45} \mathrm{Sc},{ }^{48} \mathrm{Ti}$, ${ }^{49} \mathrm{Ti},{ }^{56} \mathrm{Fe},{ }^{89} \mathrm{Y},{ }^{93} \mathrm{Nb},{ }^{94} \mathrm{Zr}{ }^{1} \mathrm{H},{ }^{96} \mathrm{Zr},{ }^{139} \mathrm{La},{ }^{140} \mathrm{Ce},{ }^{146} \mathrm{Nd},{ }^{147} \mathrm{Sm},{ }^{153} \mathrm{Eu},{ }^{165} \mathrm{Ho},{ }^{157} \mathrm{Gd}^{16} \mathrm{O}$ ${ }^{159} \mathrm{~Tb}^{16} \mathrm{O},{ }^{163} \mathrm{Dy}{ }^{16} \mathrm{O},{ }^{166} \mathrm{Er}^{16} \mathrm{O},{ }^{169} \mathrm{Tm}^{16} \mathrm{O},{ }^{172} \mathrm{Yb}^{16} \mathrm{O},{ }^{175} \mathrm{Lu}^{16} \mathrm{O},{ }^{90} \mathrm{Zr}_{2}{ }^{16} \mathrm{O},{ }^{180} \mathrm{Hf}^{16} \mathrm{O},{ }^{206} \mathrm{~Pb}$, ${ }^{232} \mathrm{Th}^{16} \mathrm{O}$ and ${ }^{238} \mathrm{U}^{16} \mathrm{O}$ were measured for each sample in a single scan. The MAD concentration standard was measured during each analytical session to assess the effective precision of the measured trace element data (Appendix 1 and Electronic Appendix 1).

\subsection{Results}

\subsubsection{Zircon morphology and internal structure}

Zircon grains from all samples are euhedral to subhedral in shape. The most striking first order observation from Kidnappers zircon assemblages is the difference in grain 
aspect ratios between samples (Figure 2.2), as measured by the length:width ratio of the grains as exposed. (Grains that were only part exposed, as could be seen when the mount was viewed with transmitted light, were not included in this analysis.) Zircons from sample P2008 (KI-1 type; Chapter 4) display a large range in grain aspect ratio with $48 \%$ of grains with values between 6:1 and 18:1, whereas sample P2006 (KI-2 type) contains only $11 \%$ of grains of this range (Figure 2.2 ). These needle-shaped grains are up to $1 \mathrm{~mm}$ long and commonly display unzoned cores with brighter, sometimes oscillatory zoned rims when observed in CL. Such high aspect ratio (needle) grains are attributed to rapidly crystallised systems (Corfu et al. 2003). Apart from the KI-1 type Kidnappers sample, grains in all other pumice clasts have aspect ratios between $\sim 1.5: 1$ and 8:1 (see panel (b) below).

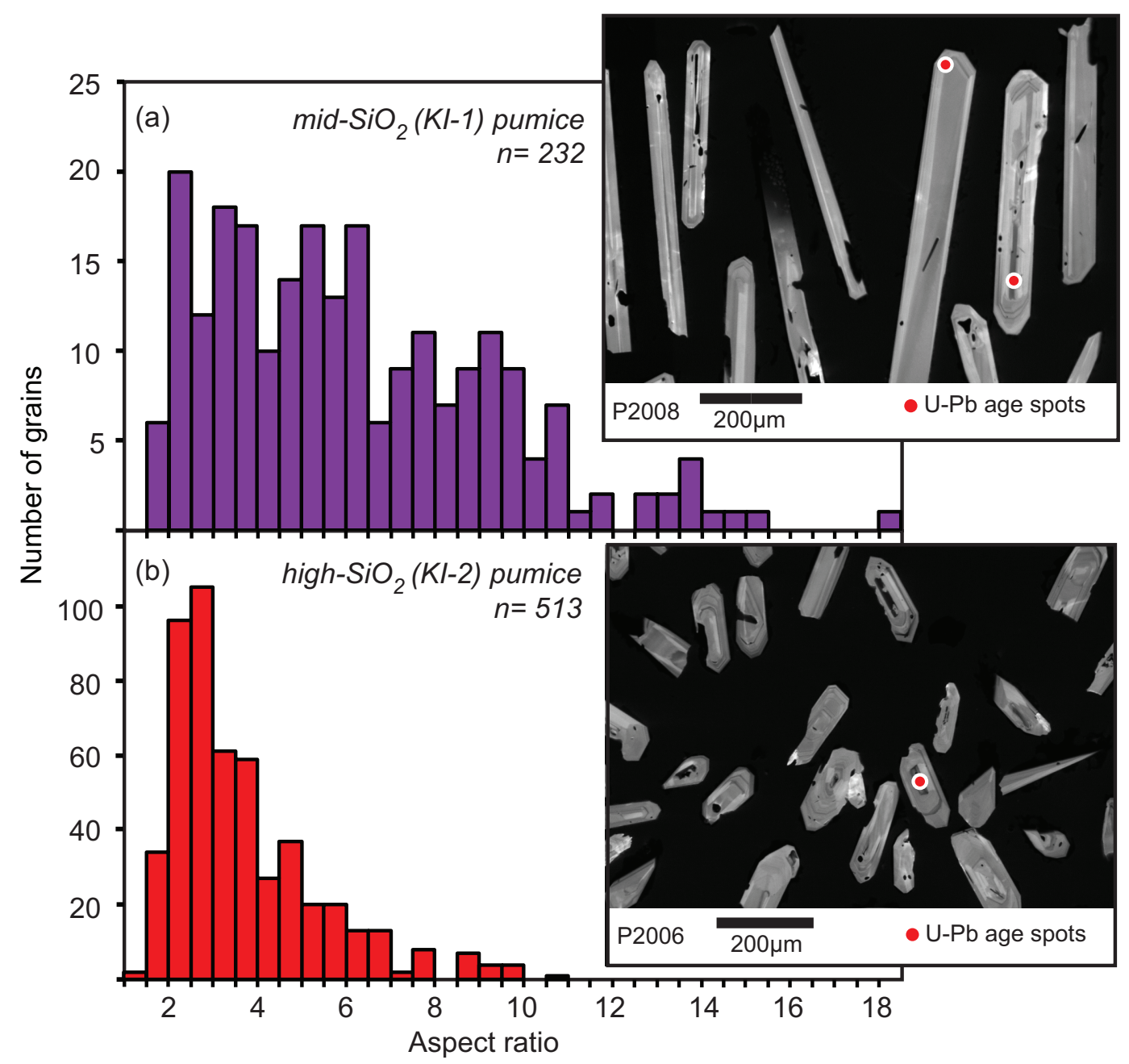

Figure 2.2. Histograms comparing the aspect ratio of zircon grains from Kidnappers pumices. (a) Aspect ratios of grains from a low- $\mathrm{SiO}_{2}$ end-member pumice (P2008; magma type KI-1 in Chapter 4), and image to show typical high aspect ratio grain morphologies. (b) Aspect ratios of grains from a high $\mathrm{SiO}_{2}$ end-member pumice (P2006; magma type KI2 in Chapter 4) and image shows typical grains within this sample. 
CL images of zircons reveal similar textures in all samples, and $>70 \%$ of grains are oscillatory zoned. Some grains contain regular zoning patterns from core to rim, whilst others have irregular and/or partly embayed boundaries that disrupt oscillatory zones. CL emission in zircon is controlled by a complex interplay of many factors and can be generated by Dy, Sm, Eu, Tb, Gd, Er and Nb, and suppressed by U, Y, Ca, P and Fe (Nasdala et al. 2003). Irregular melt inclusions, commonly of tubular form, are found within many grains, particularly along the central axis of the crystal. Zones containing or near melt and mineral inclusions were avoided to reduce the likelihood of contamination in common $\mathrm{Pb}$ and other trace elements. A proportion $(\sim 10 \%)$ of grains in all samples display CL-visible sector zoning that is common for volcanic zircons (Hoskin and Schaltegger 2003). A number of xenocrystic cores are identifiable through very dark CL intensities. These cores yield $\mathrm{U}-\mathrm{Pb}$ ages of $>100 \mathrm{Ma}$ and are thus inferred to be derived from the underlying greywacke basement. Analyses of Mangakino xenocrystic grains were the focus of McCormack et al. (2009) and were generally avoided in this study.

\subsection{2. $U-P b$ age spectra}

$126 \mathrm{U}-\mathrm{Pb}$ acceptable Quaternary age determinations were recovered from zircons from three Ongatiti ignimbrite pumices, 144 from three Kidnappers ignimbrite pumices, and 75 from two Rocky Hill ignimbrite pumices. In addition, 88 acceptable Quaternary age determinations of zircons from drillcore through material inferred to be the intracaldera equivalent of the Kidnappers and Rocky Hill ignimbrites at Mangakino geothermal field (Wilson et al. 2008), have been reprocessed in SQUID 2 and are also given here.

Summary results are in Table 2.2 and are displayed as histograms with Probability Density Function (PDF) curves (calculated using Isoplot: Ludwig 2008) in the following section.

$\mathrm{U}-\mathrm{Pb}$ ages from Ongatiti samples have populations that peak around 1.3 Ma (Figure $2.3), \sim 100 \mathrm{kyr}$ prior to the reported ${ }^{40} \mathrm{Ar} /{ }^{39} \mathrm{Ar}$ eruption age of $1.21 \pm 0.04 \mathrm{Ma}$ (Houghton et al. 1995). Weighted mean ages from each pumice are alike within 2 s.d. uncertainty. One pumice (P1804; Table 2.1) has a bimodal distribution of ages, with a minor peak close to the 1.21 Ma eruption age. Age spectra from the other two samples (P1993 and P2027; Table 2.1) have unimodal distributions. There are no age 
distinctions that can be made between samples from the lower (P1993) and upper flows (P1804, P2027). Fifteen spots return nominal U-Pb ages that are younger but within 2 s.d. uncertainty of the eruption age. These grains typically have $U$ concentrations less than 1000 ppm (Figure 2.4).

Table 2.2. Summary of mean U-Pb ages measured using SIMS.

\begin{tabular}{|c|c|c|c|c|c|c|c|}
\hline Sample & \% common ${ }^{206} \mathrm{~Pb}$ & U (ppm) & Th (ppm) & ${ }^{232} \mathrm{Th} /{ }^{238} \mathrm{U}$ & \multicolumn{2}{|c|}{$\begin{array}{l}\text { Mean age } \\
(\mathrm{Ma})\end{array}$} & MSWD \\
\hline \multicolumn{2}{|l|}{ Ongatiti } & & & & & & \\
\hline P1804 & 2.10 & 1604 & 1680 & 0.93 & 1.32 & \pm 0.03 & $2.3(1 / 42$ rejected $)$ \\
\hline P1993 & 7.95 & 542 & 546 & 0.84 & 1.31 & \pm 0.02 & $1.9(2 / 45$ rejected $)$ \\
\hline \multirow[t]{2}{*}{ P2027 } & 1.56 & 544 & 529 & 0.92 & 1.32 & \pm 0.02 & $1.2(2 / 40$ rejected $)$ \\
\hline & & & & All & 1.32 & \pm 0.01 & \\
\hline \multicolumn{8}{|l|}{ Kidnappers } \\
\hline P1722 & 2.98 & 2053 & 2387 & 1.05 & 1.12 & \pm 0.02 & $2.9(1 / 42$ rejected $)$ \\
\hline P2006 & 7.71 & 1022 & 1392 & 1.10 & 1.03 & \pm 0.01 & $1.4(2 / 60$ rejected $)$ \\
\hline \multirow[t]{2}{*}{ P2008 } & 7.76 & 530 & 564 & 0.91 & 1.02 & \pm 0.02 & 1.7 (2/42 rejected) \\
\hline & & & & All & 1.06 & \pm 0.01 & \\
\hline \multicolumn{8}{|l|}{ Rocky Hill } \\
\hline P1842 & 6.72 & 266 & 258 & 0.80 & 1.04 & \pm 0.03 & $1.6(1 / 24$ rejected $)$ \\
\hline \multirow[t]{2}{*}{ P2243 } & 4.83 & 596 & 826 & 1.03 & 1.06 & \pm 0.02 & 1.7 (2/38 rejected $)$ \\
\hline & & & & All & 1.05 & \pm 0.02 & \\
\hline
\end{tabular}

Age spectra for zircons from the three Kidnappers pumices show some variability (Table 2.2). Sample P1722 displays the oldest PDF peak with an associated weighted mean age of $1.12 \pm 0.02 \mathrm{Ma}, \sim 100 \mathrm{kyr}$ older than the ${ }^{40} \mathrm{Ar} /{ }^{39} \mathrm{Ar}$ eruption age at $1.01 \mathrm{Ma}$ (Figure 2.5a). In contrast, the peak from P2006 is unimodal (Figure 2.5b) with a younger PDF peak and associated weighted mean age of $1.03 \pm 0.01 \mathrm{Ma}$. The PDF curve of P2008 displays a subtle bimodality with a primary peak very close to eruption age and a secondary peak at $\sim 1.07 \mathrm{Ma}$ (Figure $2.5 \mathrm{c}$ ). A high proportion of grains within P2008, and to a lesser extent P2006, return ages that are younger but within uncertainty of the ${ }^{40} \mathrm{Ar} /{ }^{39} \mathrm{Ar}$ eruption age. These anomalous ages may be attributed to a higher number of analysed grains with low $U$ concentrations $(<1000 \mathrm{ppm})$ in these samples compared to P1722 where high U grains were preferentially targeted (Figure 2.4). Both samples from the Rocky Hill ignimbrite show bimodal age distributions with peaks at 1.0 $\mathrm{Ma}$ and 1.1 $\mathrm{Ma}$ (Figure 2.6) and intermediate weighted mean values (Table 2.2). Rocky Hill age determinations younger than the ${ }^{40} \mathrm{Ar} /{ }^{39} \mathrm{Ar}$ eruption age can also be related to grains with low $\mathrm{U}$ concentrations ( $<500 \mathrm{ppm}$ ) (Figure 2.4). 


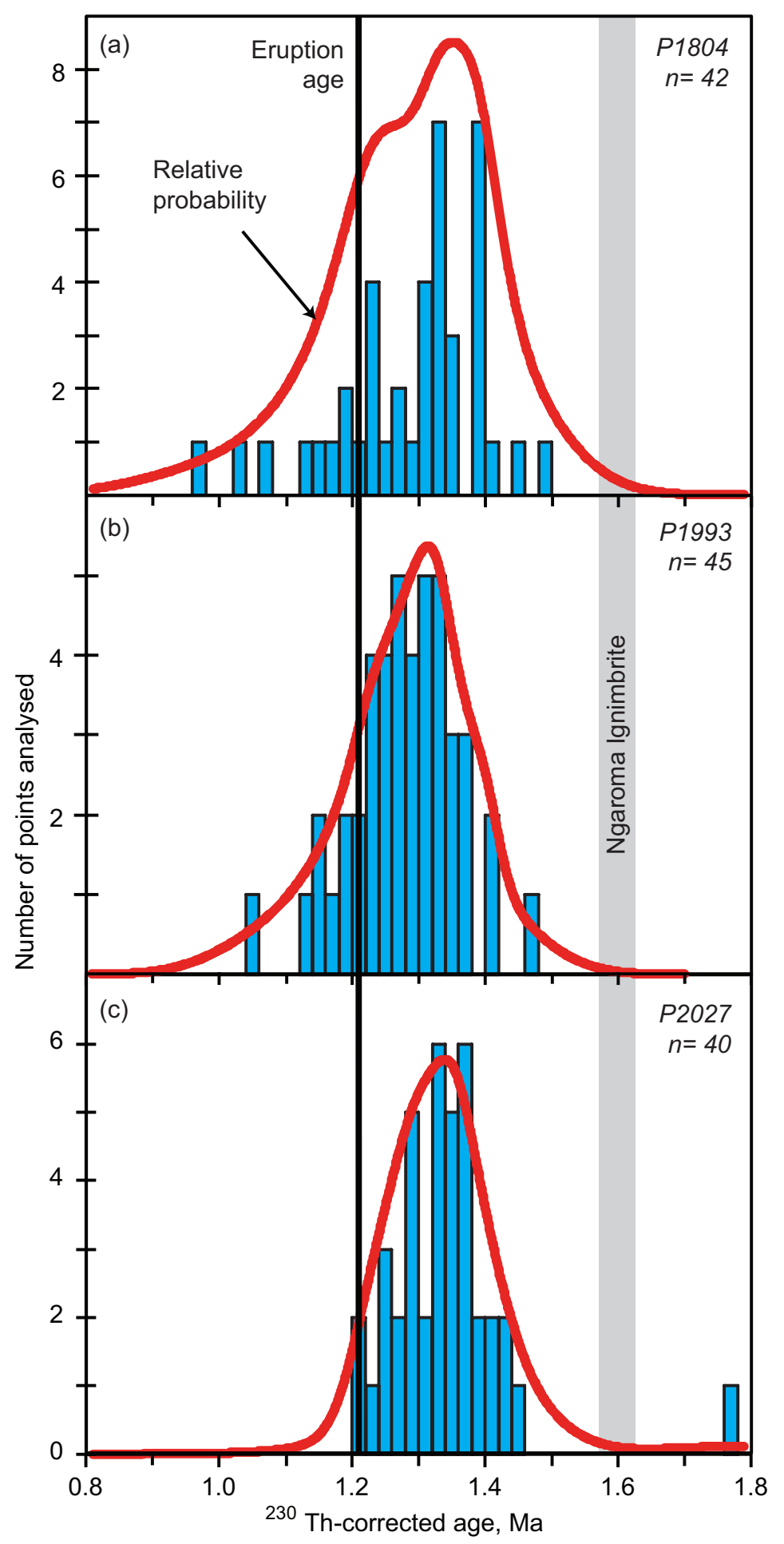

Figure 2.3. Histograms and probability density curves (created using Isoplot: Ludwig, 2008) for analysed zircons from three pumices within the Ongatiti ignimbrite. Eruption age line marks the ${ }^{40} \mathrm{Ar} /{ }^{39} \mathrm{Ar}$ age at $1.21 \mathrm{Ma}$ (Houghton et al. 1995). (a) Grains from P1804, from the upper parts of the ignimbrite. This data was previously presented in Wilson et al. (2008), but has been reprocessed with the SQUID-2 program. (b) Grains from P1993, from the lower, and (c) P2027 from the upper parts of the ignimbrite, respectively. 


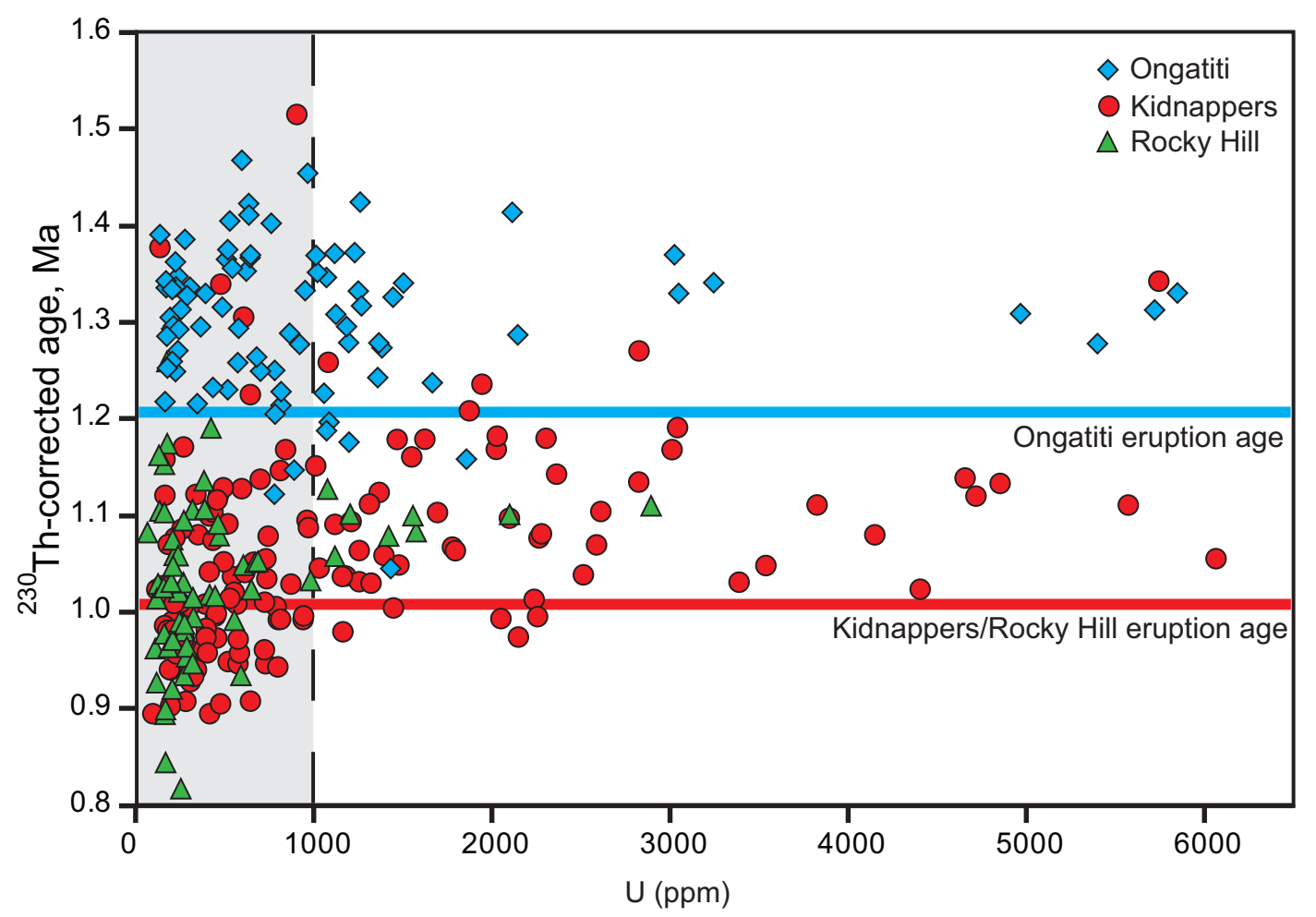

Figure 2.4. $\mathrm{U}$ concentrations (ppm) vs. U-Pb age (Ma) from common analytical spots for each of the Rocky Hill, Kidnappers and Ongatiti ignimbrites. The ${ }^{40} \mathrm{Ar} /{ }^{39} \mathrm{Ar}$ eruption ages for the Ongatiti and Kidnappers/Rocky Hill eruption are marked by coloured lines and the vertical dashed line indicates a division between 'low U' $(<1000 \mathrm{ppm})$ and 'high U' $(>1000 \mathrm{ppm})$ zircons. Grey shaded area highlights grains with $<1000 \mathrm{ppm} U$ which often return ages younger than the ${ }^{40} \mathrm{Ar}{ }^{39} \mathrm{Ar}$ eruption age.

The overall $\mathrm{U}-\mathrm{Pb}$ age distributions from the three studied ignimbrites are shown in Table 2.2 and Figure 2.7. The weighted mean age of all the Ongatiti data is $1.32 \pm 0.01$ $\mathrm{Ma}$, and the age distribution covers a range of $\sim 250 \mathrm{kyr}$ prior to the ${ }^{40} \mathrm{Ar} /{ }^{39} \mathrm{Ar}$ eruption age (Figure 2.7). On the basis of their age distributions, the Kidnappers and Rocky Hill are indistinguishable, with overlapping PDF curves and a primary peak just prior to eruption age. Weighted mean ages from the Kidnappers and Rocky Hill are within uncertainty of each other (Table 2.2) and ages from both eruptions span a range of 200 kyr prior to eruption age. The Kidnappers age spectra show a larger tail to older ages $(>1.2 \mathrm{Ma}$ ), which cover a similar range to the Ongatiti age peak at $1.32 \mathrm{Ma}$ (Figure 2.7). 


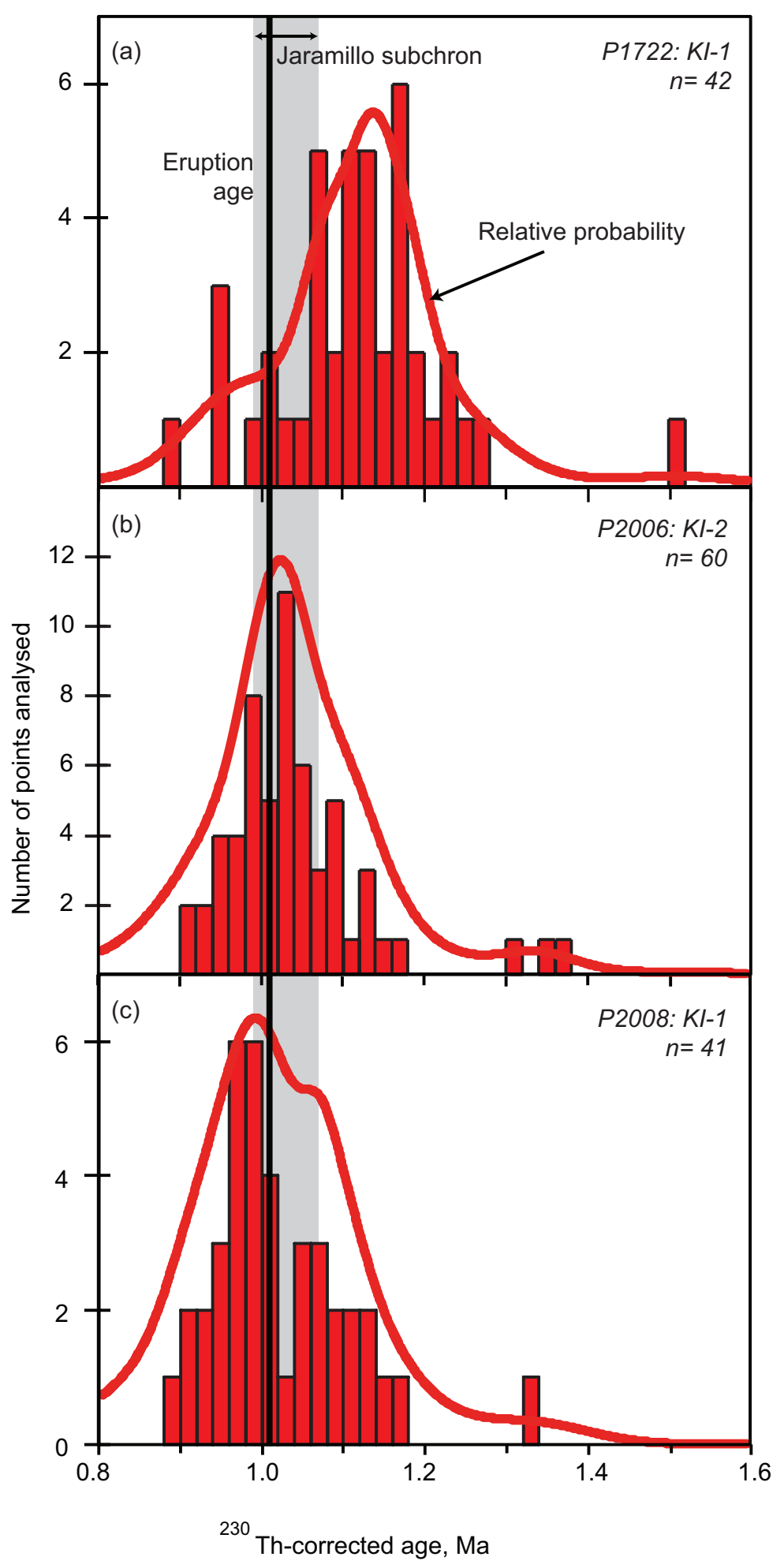

Figure 2.5. Histograms and probability density curves for analysed zircons from individual pumices within the Kidnappers ignimbrite. Eruption age denotes the ${ }^{40} \mathrm{Ar} /{ }^{39} \mathrm{Ar}$ age at 1.01 Ma from Houghton et al. (1995). Grey shaded area represents the duration of the Jaramillo Subchron (normal magnetic polarity), within which both the Kidnappers and Rocky Hill ignimbrites were erupted (Black 1992). (a) Grains analysed from P1722, a mid-SiO ${ }_{2}$ pumice (magma type KI-1: Chapter 4). This data was previously presented in Wilson et al. (2008), but has been reprocessed with the SQUID-2 program. (b) Grains from P2006, a high-SiO ${ }_{2}$ end-member pumice (magma type KI-2), and (c) P2008, a low$\mathrm{SiO}_{2}$ pumice (magma type KI-1). 


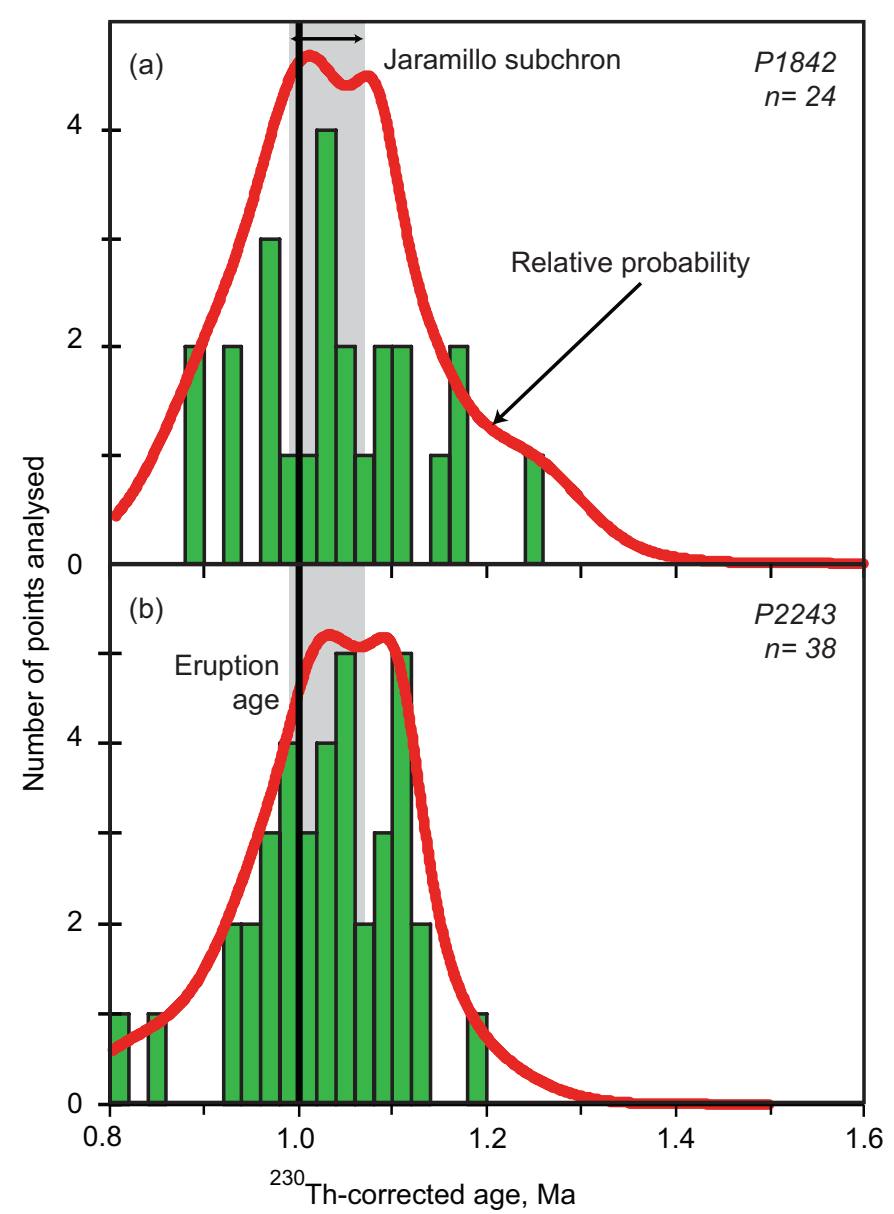

Figure 2.6. Histograms and probability density curves for analysed zircons from individual pumices within the Rocky Hill ignimbrite. Eruption age denotes the ${ }^{40} \mathrm{Ar} /{ }^{39} \mathrm{Ar}$ age at 1.0 Ma from Houghton et al. (1995). Grey shaded area represents the Jaramillo Subchron (normal magnetic polarity), within which both the Kidnappers and Rocky Hill ignimbrites were erupted (Black 1992). Grains from P1842 (a) and P2243 (b) are shown.

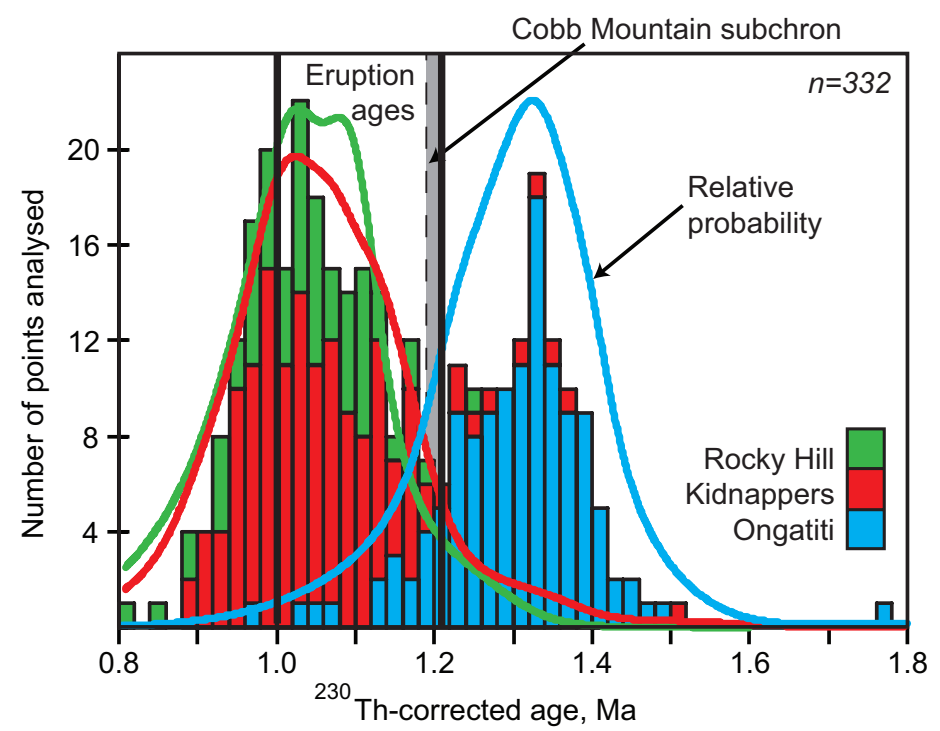

Figure 2.7. Compilation histogram and probability density curves from all Mangakino zircons analysed in this study. Eruption ages, marked with black lines, are as in previous figures. Grey shaded area marks the Cobb Mountain Subchron, within which the Ahuroa ignimbrite was erupted (Tanaka et al. 1996; see text for context). 


\subsubsection{Trace element data}

A total of 496 zircon trace element analyses were obtained: 116 from 2 Ongatiti ignimbrite pumices; 293 from 2 Kidnappers ignimbrite pumices; and 87 from 2 Rocky Hill ignimbrite pumices. Average trace element concentrations from each sample are given in Table 2.3. The analytical uncertainties on zircon trace element data (Mazdab and Wooden 2006) generally vary with count statistics, but also reflect to some extent heterogeneities in the MAD standard. The majority of measured elements, including the Rare Earth Elements (REE) reproduce to $< \pm 11 \% 2$ s.d. (Table 2.3), those lowconcentration elements ( $\mathrm{Li}, \mathrm{Be}, \mathrm{F}, \mathrm{Na}, \mathrm{Ca}, \mathrm{La}$ and $\mathrm{Eu}$ ) show worse reproducibilities ( $\pm 38-66 \%$ : Appendix 1). Selected elements were used to monitor contamination from melt and/or mineral inclusions: $\mathrm{Ca}, \mathrm{Al}, \mathrm{Na}, \mathrm{K}, \mathrm{La}$ for feldspar and glass; Ca, P, F for apatite; Fe for Fe-Ti oxides; and $\mathrm{Ca}, \mathrm{Fe}, \mathrm{La}$ for allanite.

\subsubsection{General aspects}

Chondrite-normalised patterns from the Ongatiti, Kidnappers and Rocky Hill eruptions are typical of magmatic zircons (Hoskin and Schaltegger 2003; Hanchar and van Westrenen 2007) with a depletion in light REE (LREE) and an increase in concentration by five orders of magnitude from La to Lu (Figure 2.8). The shape of the chondrite normalised REE patterns from all studied eruptions are almost identical, with pronounced positive $\mathrm{Ce}$ anomalies and modest negative Eu anomalies (Figure 2.8). The REE concentrations within zircons from a single pumice sample range over an order of magnitude and are, in general, more enriched within crystal cores (Figure 2.8).

The overall trends in elemental concentrations and ratios in zircons are remarkably similar between the three studied eruptions (Figure 2.9). The ranges and trends in ratios commonly used to track magmatic evolution (Th/U, Eu/Eu*, $\mathrm{Yb} / \mathrm{Gd})$ are almost identical, reflecting the similar fractionating mineral assemblages in the melts for each eruption. $\mathrm{Eu} / \mathrm{Eu}^{*}$ decreases with increasing melt fractionation (measured by higher $\mathrm{Hf}$ concentrations), indicative of zircon growth in a system undergoing plagioclase crystallisation (Figure 2.9a). Typical trends of decreasing $\mathrm{Nd} / \mathrm{Yb}$ and increasing $\mathrm{Ce} / \mathrm{Sm}$ (used here in preference to $\mathrm{Ce} / \mathrm{Ce}$ * because of the very low and variable abundances of La in these zircons) with increasing Hf are also observed (Figure 2.9b, c). 

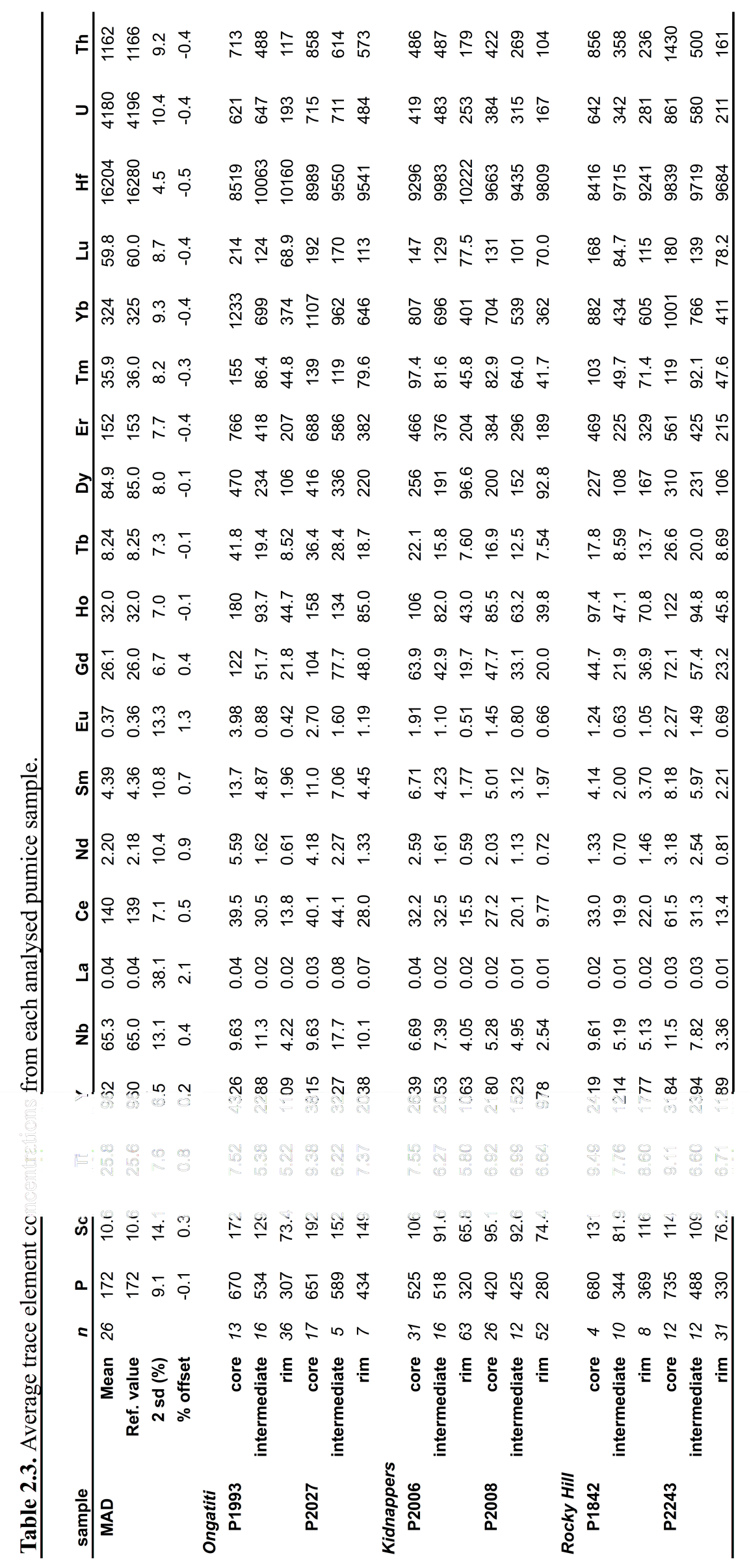


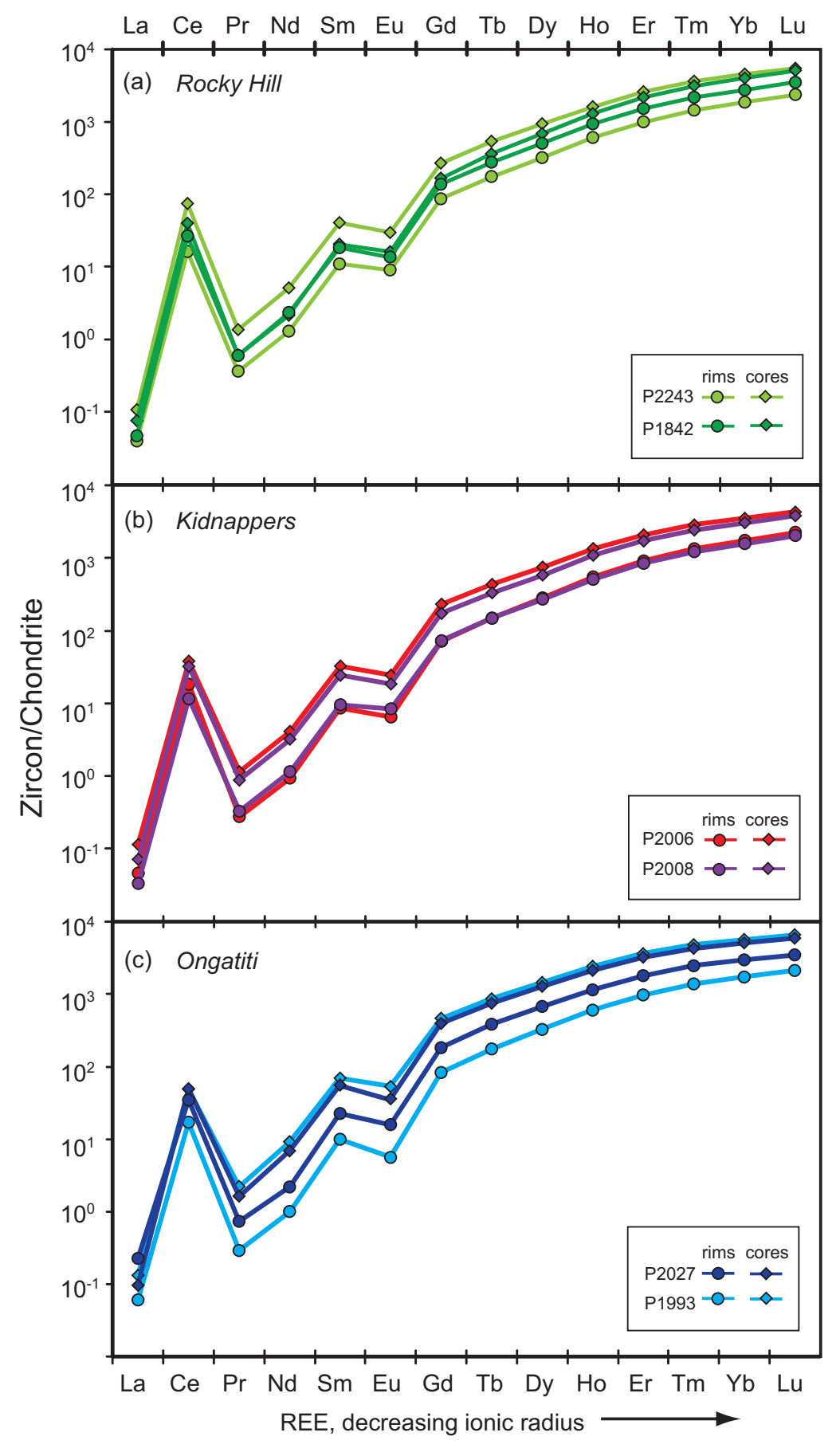

Figure 2.8. Chondrite-normalised REE diagram for zircon cores (diamonds), and rims (circles) from the (a) Rocky Hill, (b) Kidnappers and (c) Ongatiti pumices showing mean values from each sample. Lines are coloured according to each pumice sample. Chondrite normalisation values are from Anders and Grevesse (1989). 

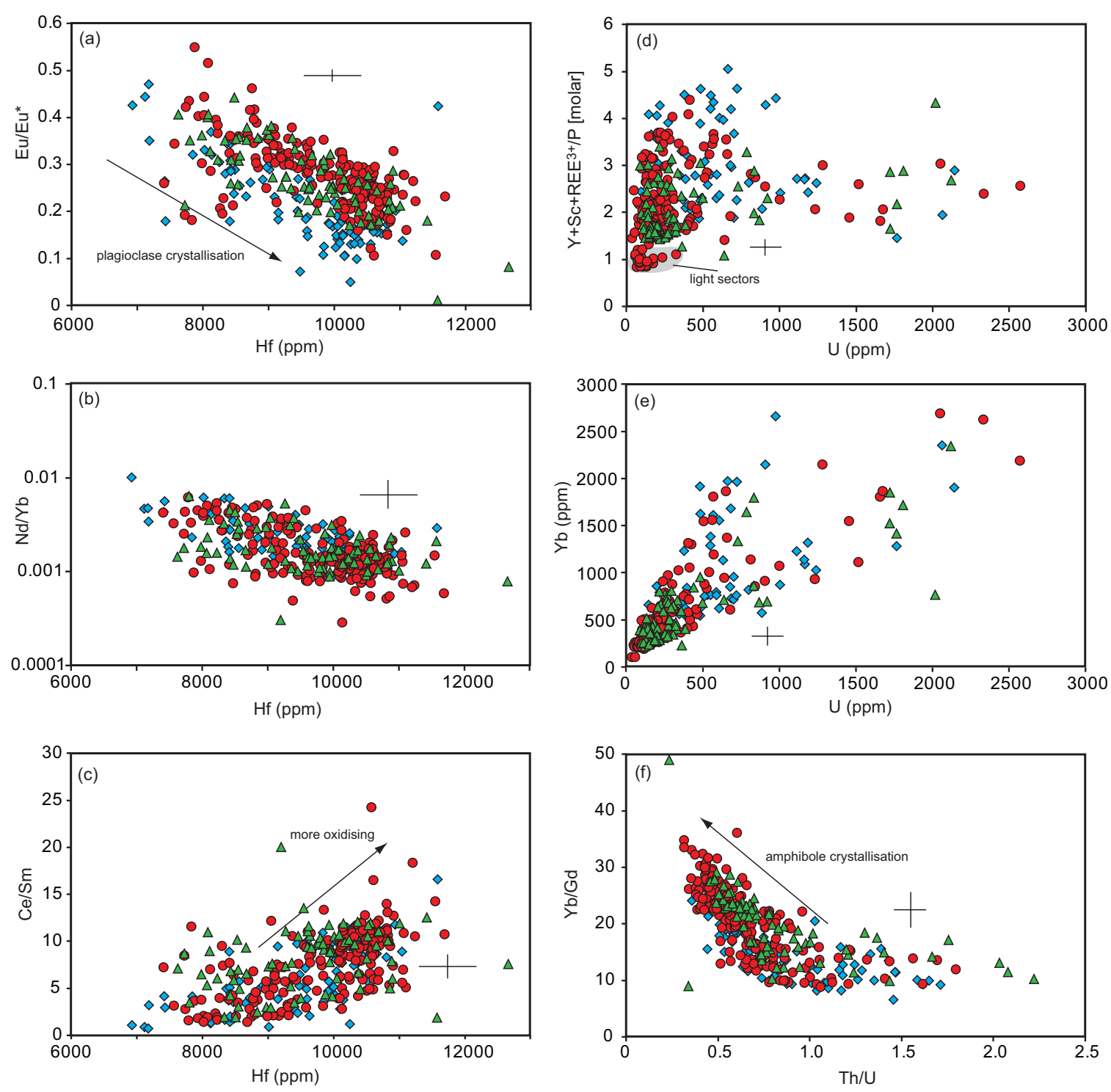

Figure 2.9. Summary plots of general trace element data of zircons from each eruption. Symbols are as in Figure 2.4. See text for discussion.

It is typical for $\mathrm{U}$ to co-vary with the molar $\left(\mathrm{Y}+\mathrm{Sc}+\mathrm{REE}^{3+}\right) / \mathrm{P}$ ratio and with $\mathrm{Yb}$ (Belousova et al. 2002; Clairbourne et al. 2010; Barth and Wooden 2010; Barth et al. 2012, Chamberlain et al. 2013). Here, the trend in $\mathrm{U}$ versus molar $\left(\mathrm{Y}+\mathrm{Sc}+\mathrm{REE}^{3+}\right) / \mathrm{P}$ ratio shows much scatter with a divergence in the data at $>500 \mathrm{ppm} U$ (Figure 2.9d). Two diverging trends also show on a plot of $U$ versus $\mathrm{Yb}$ at $\mathrm{U}>500$ ppm (Figure 2.9e). Concentrations of heavy REE (HREE) increase relative to MREE (the $\mathrm{Yb} / \mathrm{Gd}$ ratio used here) with decreasing $\mathrm{Th} / \mathrm{U}$. The majority of $\mathrm{Th} / \mathrm{U}$ values are from $0.4-1.0$ with a tailoff to higher values $(\sim 2)$ and there is a sharp increase in $\mathrm{Yb} / \mathrm{Gd}$ at $\mathrm{Th} / \mathrm{U}$ values $<\sim 0.8$ (Figure 2.9f). All analyses from Ongatiti and Rocky Hill have values of the molar 
$\left(\mathrm{Y}+\mathrm{Sc}+\mathrm{REE}^{3+}\right) / \mathrm{P}$ ratio of $>1$, mostly between 2:1 and 4:1 (Figure 2.10). The majority of Kidnappers analyses cover the same range, but a number of analyses have a $\left(\mathrm{Y}+\mathrm{Sc}+\mathrm{REE}^{3+}\right) / \mathrm{P}$ of $\sim 1$, following the 'xenotime substitution' of Hoskin and Schaltegger (2003) (Figure 2.10). In addition to these general fractionation trends, the Mangakino zircons show geochemical variations from core to rim and with age, as well as variations which appear to be influenced by the shape of the grains (aspect ratio) and sector zoning, discussed below.

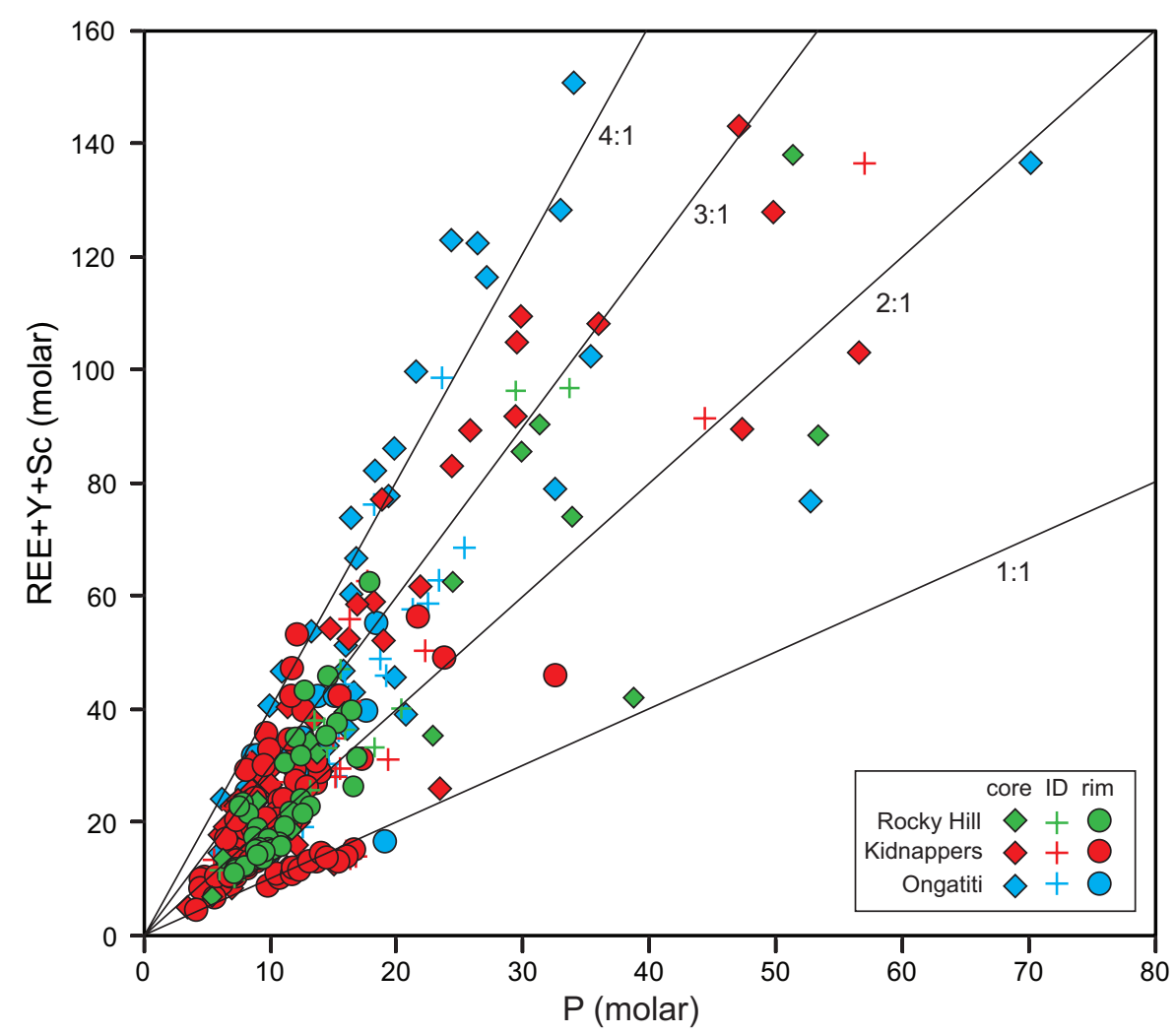

Figure 2.10. $\mathrm{P}$ (molar) vs. $\mathrm{REE}^{3+}+\mathrm{Y}+\mathrm{Sc}$ (molar) to show the range of $\left(\mathrm{REE}^{3+}+\mathrm{Y}+\mathrm{Sc}\right) / \mathrm{P}$ ratios of zircons from all samples. Symbols represent cores, intermediate domains (ID) and rims.

\subsubsection{Trace element values versus age}

Where possible, the sites for trace element determinations were positioned close to U$\mathrm{Pb}$ analytical spots to assess any temporal variations. As discussed in section 2.6.2, there is a greater spread in zircon ages at lower concentrations of $U$ (Figure 2.4). A greater spread in ages is also found in zircons with lower concentrations of REE, Y, Nb, and Th. For example, a plot of $\mathrm{Yb}$ versus age (Figure 2.11) show that the largest range in concentrations is observed in zircons close to the mean age, and the youngest ages correspond to $\mathrm{Yb}<\sim 700 \mathrm{ppm}$. Yb concentrations $>1000 \mathrm{ppm}$ are dominantly found in the cores and intermediate domains (IDs) of zircons (Figure 2.11). 


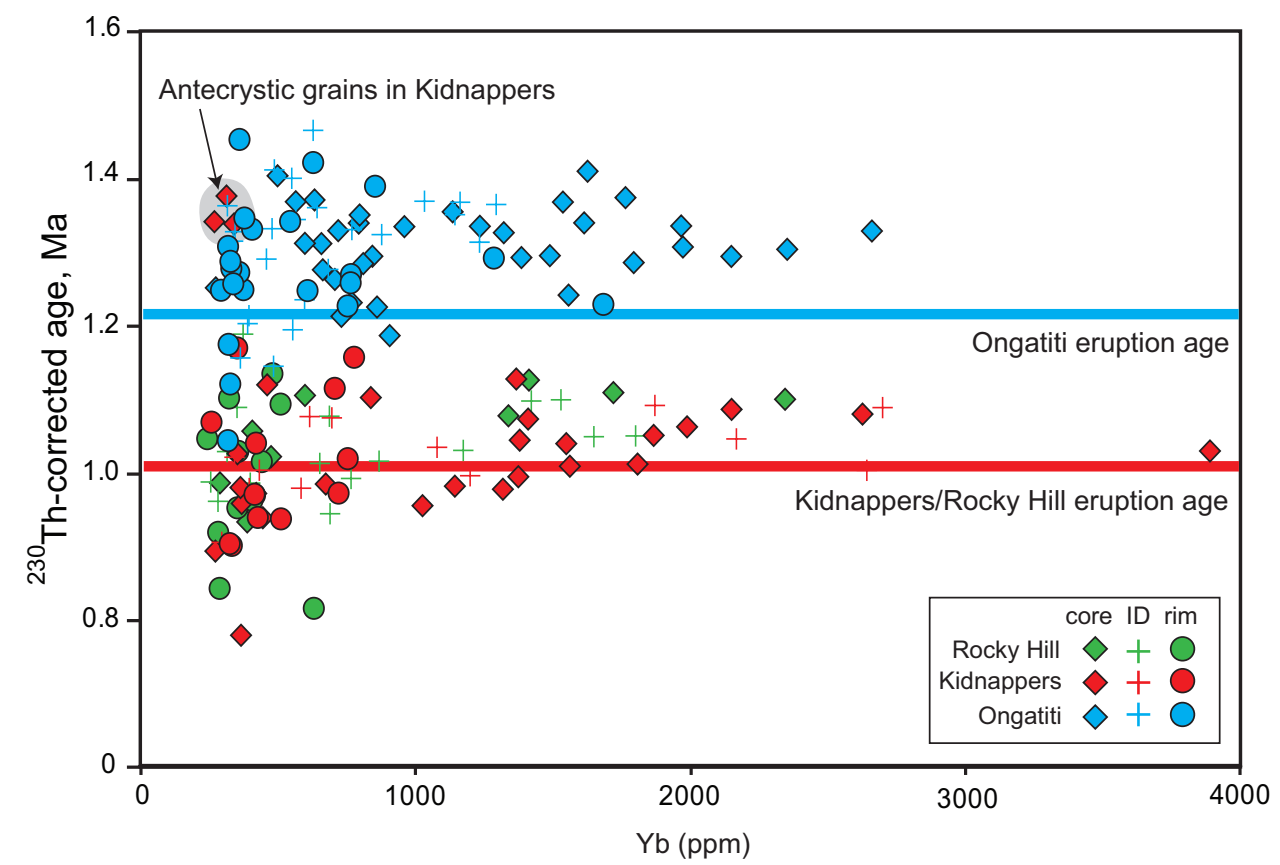

Figure 2.11. $\mathrm{Yb}$ (ppm) vs. U-Pb age (Ma) for zircons from the Ongatiti, Kidnappers and Rocky Hill deposits. Coloured lines indicate the ${ }^{40} \mathrm{Ar} /{ }^{39} \mathrm{Ar}$ eruption ages for the Ongatiti and Kidnappers/Rocky Hill eruptions.

\subsubsection{Trace element values versus position in crystals}

Contrasts in the trace element concentrations and element ratios of cores, intermediate domains and rims of crystals have the potential to track chemical changes within evolving magmatic systems. To a first order, zircon cores contain a larger range and higher absolute concentrations of trace elements (apart from Hf) than zircon rims (Figure 2.8 and Figure 2.11). This trend is observed in all three deposits and is consistent with the crystallisation of zircon from evolving melts undergoing crystal fractionation involving the other crystal phases in the respective magmas (in particular plagioclase, amphibole and orthopyroxene [Chapters 4 and 6]). There is no systematic trend, however, in ages and location of analytical spots in cores versus rims of grains. A decrease in REE concentrations from core to rim is shown by zircons from each of the six pumice samples studied (Table 2.3; Figure 2.8). Intermediate domains generally have REE concentrations in between those from cores and rims, with the exception of zircons from Rocky Hill (sample P1842) in which concentrations are lower than the mean rim values (Table 2.3). Ongatiti zircons show the greatest spread in REE concentrations with rims from sample P1993 having the lowest concentrations of REE ( $\sim 2$ lower than rims from P2027) (Figure 2.8c). 


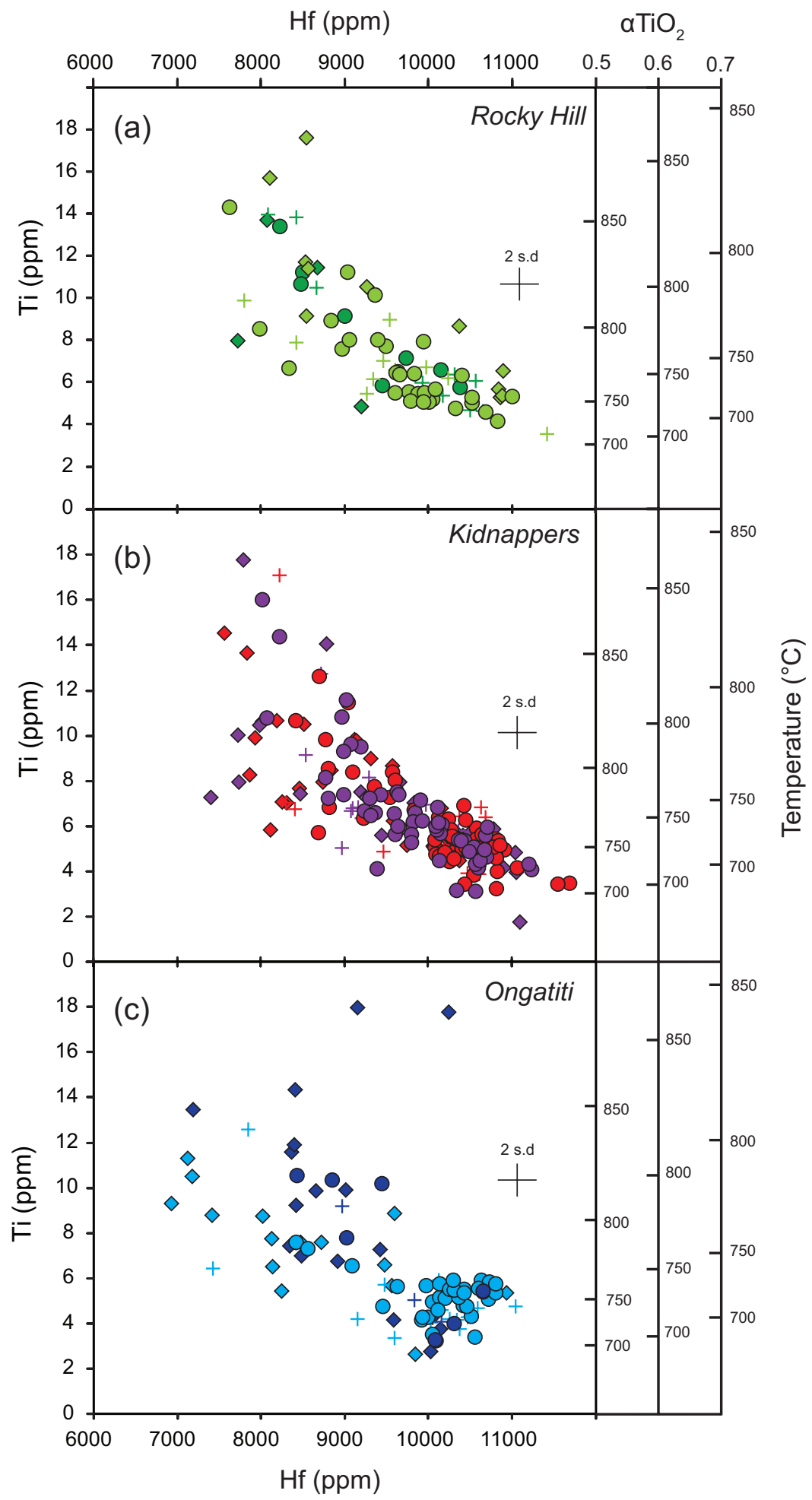

Figure 2.12. Hf vs. Ti concentration (left scale) and calculated temperatures (right scale) from each of the Mangakino eruptions. Diamonds represent cores, crosses are intermediate domains, and circles are rim analyses. Colours represent each sample as in Figure 2.8. Temperatures were calculated using the Ti-in-zircon thermometer of Ferry and Watson (2007) at a range of $\alpha \mathrm{TiO}_{2}(0.5-0.7)$. 
Concentrations of Hf are between 7000 and 11000 ppm and are very similar between Mangakino eruptions (Figures 2.9 and 2.12). Zircon Ti concentrations in the Rocky Hill and Kidnappers are between $\sim 3$ and $18 \mathrm{ppm}$. The majority of rim analyses from all samples cluster from 9000-11000 ppm Hf and 3-8 ppm Ti (Figure 2.12a, b). A spread of cores, intermediate domains and rims extend back to higher Hf and Ti concentrations. Ti concentrations in the Ongatiti cover a smaller range ( 3-14 ppm) (Figure 2.12c). Zircon rims from sample P1993 (Table 2.1) group very tightly (Hf: 10000-11000 ppm, Ti: 3-6 ppm), with cores extending to lower Hf (7000 ppm) and higher Ti (12 ppm) concentrations. In contrast, concentrations from sample P2027 have a greater scatter and do not display a clear core to rim trend (Figure 2.12c).

Concentrations of $\mathrm{Sc}$ in all samples show a strong covariance with $\mathrm{Th} / \mathrm{U}$ values and have similar divergent trends as when plotted against $\mathrm{Yb} / \mathrm{Gd}$ (Figure 2.13a). Sc concentrations range from 30 to $\sim 500 \mathrm{ppm}$ in the Ongatiti and decrease with increasing $\mathrm{Yb} / \mathrm{Gd}$. When Sc concentrations from the Ongatiti are plotted against REE, in particular Ce (Figure 2.13b), two positive divergent trends are present within both samples. Although not commonly utilised in zircon trace element studies, Be concentrations were measured routinely as part of the trace element run table. In all but one sample, Be concentrations are very low (a few ppm), as is normally expected, but in Ongatiti sample P1993, Be concentrations in cores and intermediate domains reach up to 380 ppm (Figure 2.13c). These elevated Be concentrations show coherent positive trends when plotted against other tracers of melt evolution (P, Hf, Ti and REE, and Th/U).

Core-to-rim decreases in light REE (e.g. Sm: Figure 2.13d) and increases in Hf and HREE/MREE (e.g. Yb/Gd: Figure 13e) are found in all samples. Zircon rims from the Kidnappers samples show a sharp rise in $\mathrm{Yb} / \mathrm{Gd}$ values with decreasing Th/U (Figure 2.13e), and extend to higher $\mathrm{Yb} / \mathrm{Gd}$ values (35) than those found in the Rocky Hill (27) and Ongatiti (25) samples (Table 2.3). Two parallel trends in high $\mathrm{Th} / \mathrm{U}(>0.8)$ cores, at $\mathrm{Yb} / \mathrm{Gd}$ values of 8-14 are observed in Kidnappers zircons (labeled A and B in Figure 2.13e). When $\mathrm{Th} / \mathrm{U}$ is plotted against other trace element ratios such as $\mathrm{Y} / \mathrm{P}$, the parallel trends in core values become divergent, forming two edges of the dataset that defines a wedge shape (Figure 2.13f). 
Ongatiti
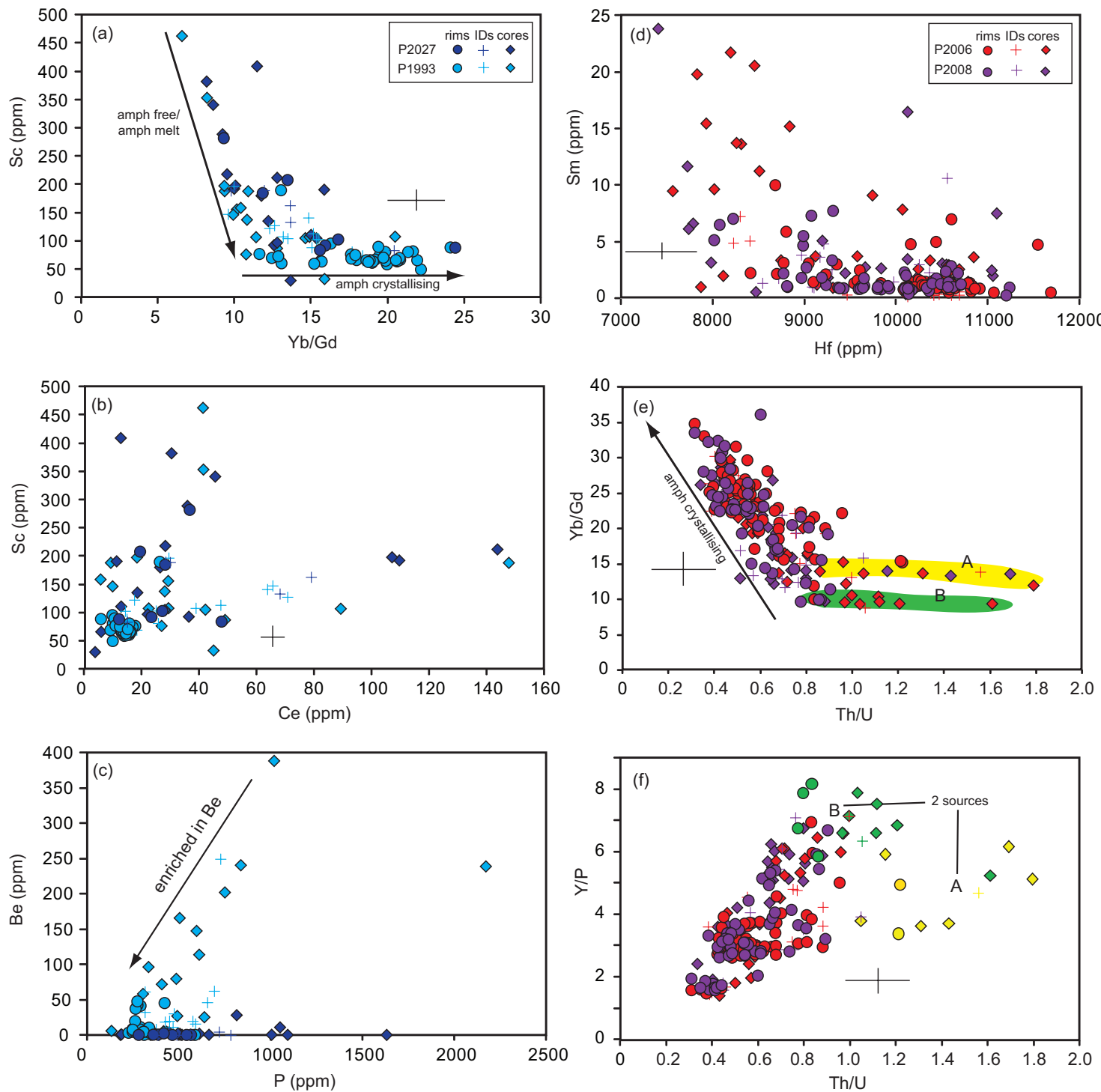

Kidnappers
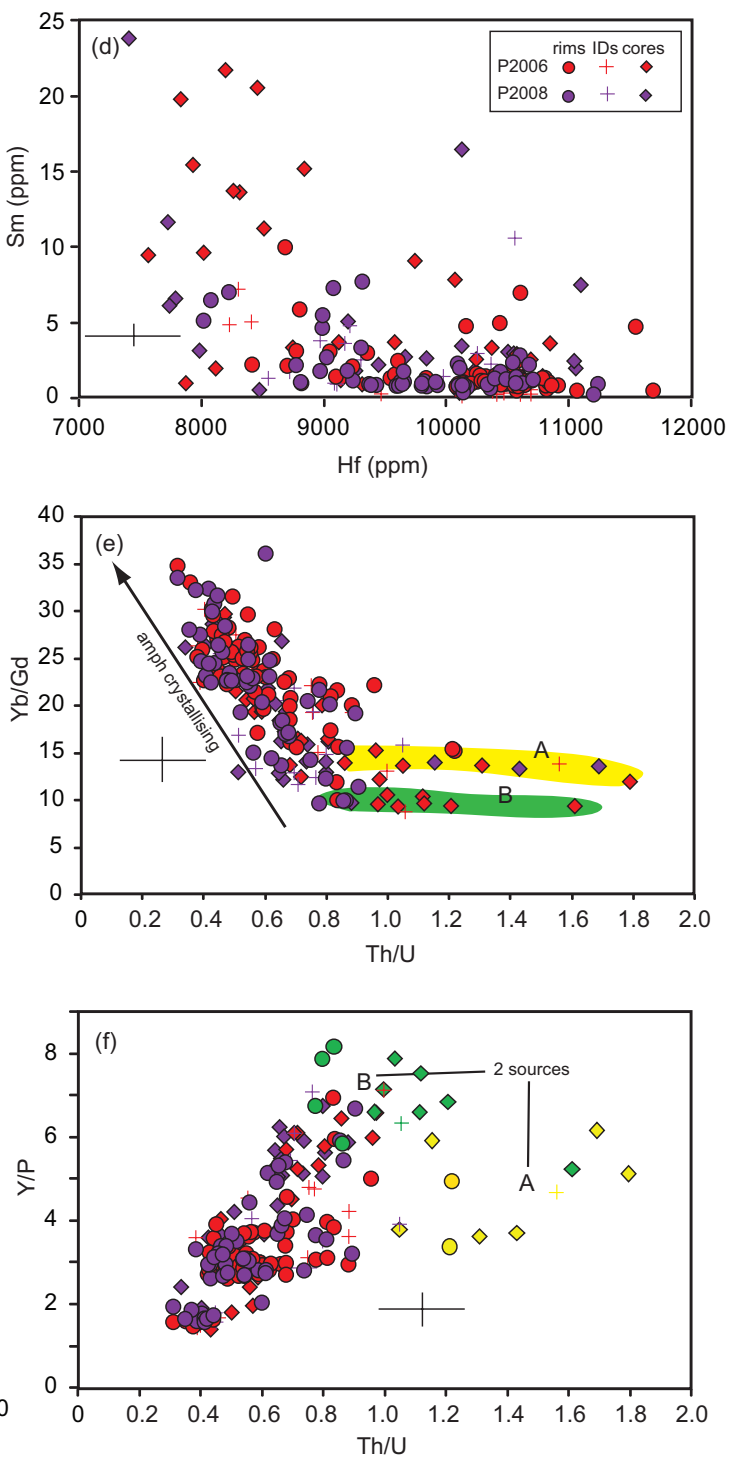

Figure 2.13. Selected trace element variation diagrams to show specific trends observed in Ongatiti (a-c) and Kidnappers (d-f) zircons. Two parallel trends in panel (e), labeled A (yellow) and B (green) at $\mathrm{Th} / \mathrm{U}>0.8$ and low $\mathrm{Yb} / \mathrm{Gd}$ are coloured yellow and green in (f). Diamonds represent cores, crosses are intermediate domains, and circles are rim analyses. Colours represent each sample as in Figure 2.8.

\subsubsection{Trace element values versus crystal aspect ratios}

The variations in Kidnappers zircon aspect ratios are unusually large, and the question arises as to whether any features of the trace-element data vary commensurately.

Analyses from higher aspect ratio grains (length:width of $>6$ ) display a reduced range in $\mathrm{Y}, \mathrm{REE}, \mathrm{P}, \mathrm{Sc}, \mathrm{Nb}$ and $\mathrm{U}$ concentrations when compared with low aspect ratio grains (length:width of 1-5) (Figure 2.14). This trend may be a consequence of the difference in zoning styles between low and high aspect grains. Low aspect ratio grains contain a greater proportion of zones, internal domains and cores, which generally have the 
highest elemental concentrations (Table 2.3 and Figure 2.14), and will therefore skew data towards higher concentrations and larger compositional ranges. In addition, the tips and sides of high aspect ratio grains within the Kidnappers sample P2008 show significant offsets in trace element concentrations, even in cases where the tip and side appear to be within the same CL zone (Figure 2.15). The majority of tips have similar molar $\left(\mathrm{Y}+\mathrm{Sc}+\mathrm{REE}^{3+}\right) / \mathrm{P}$ values (1.5-2.2) as lower aspect ratio zircon rims, with a small number $>2.6$ (Figure 2.15a). Sides have $\left(\mathrm{Y}+\mathrm{Sc}+\mathrm{REE}^{3+}\right) / \mathrm{P}$ and $\mathrm{Y}$ values either lower $\left(\left(\mathrm{Y}+\mathrm{Sc}+\mathrm{REE}^{3+}\right) / \mathrm{P}: \sim 1, \mathrm{Y}: 100-200\right)$, or higher $\left(\left(\mathrm{Y}+\mathrm{Sc}+\mathrm{REE}^{3+}\right) / \mathrm{P}: \sim 2.6, \mathrm{Y}: 300-500\right)$ than tips from the same grains (Figure 2.15a). Apart from one grain, all tie-lines between side and tip pairs from the same crystal have steep positive gradients on a $\left(\mathrm{Y}+\mathrm{Sc}+\mathrm{REE}^{3+}\right) / \mathrm{P}$ versus $\mathrm{Yb}$ plot (Figure 2.15a). In contrast, the offset is not consistent when $\left(\mathrm{Y}+\mathrm{Sc}+\mathrm{REE}^{3+}\right) / \mathrm{P}$ values from tips and sides are plotted against $\mathrm{Hf}$, but sides are generally enriched in Hf compared to their corresponding tips (Figure 2.15b).

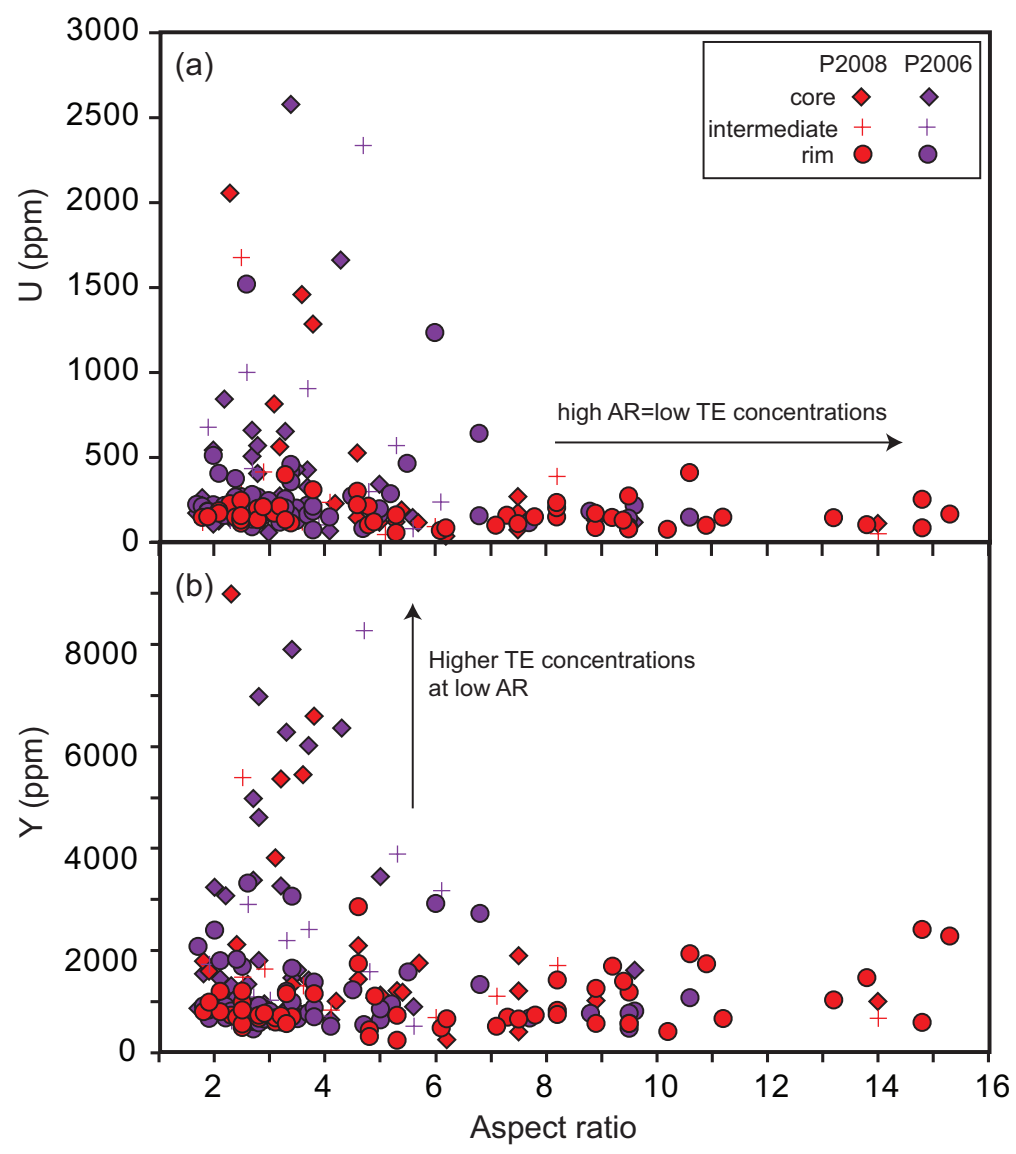

Figure 2.14. Summary plots of chemical variation versus aspect ratio (length/width) from Kidnappers zircons. Symbols and colours are as in Figure 2.12. Analyses from cores, intermediate domains and rims are separated by symbol shape. 


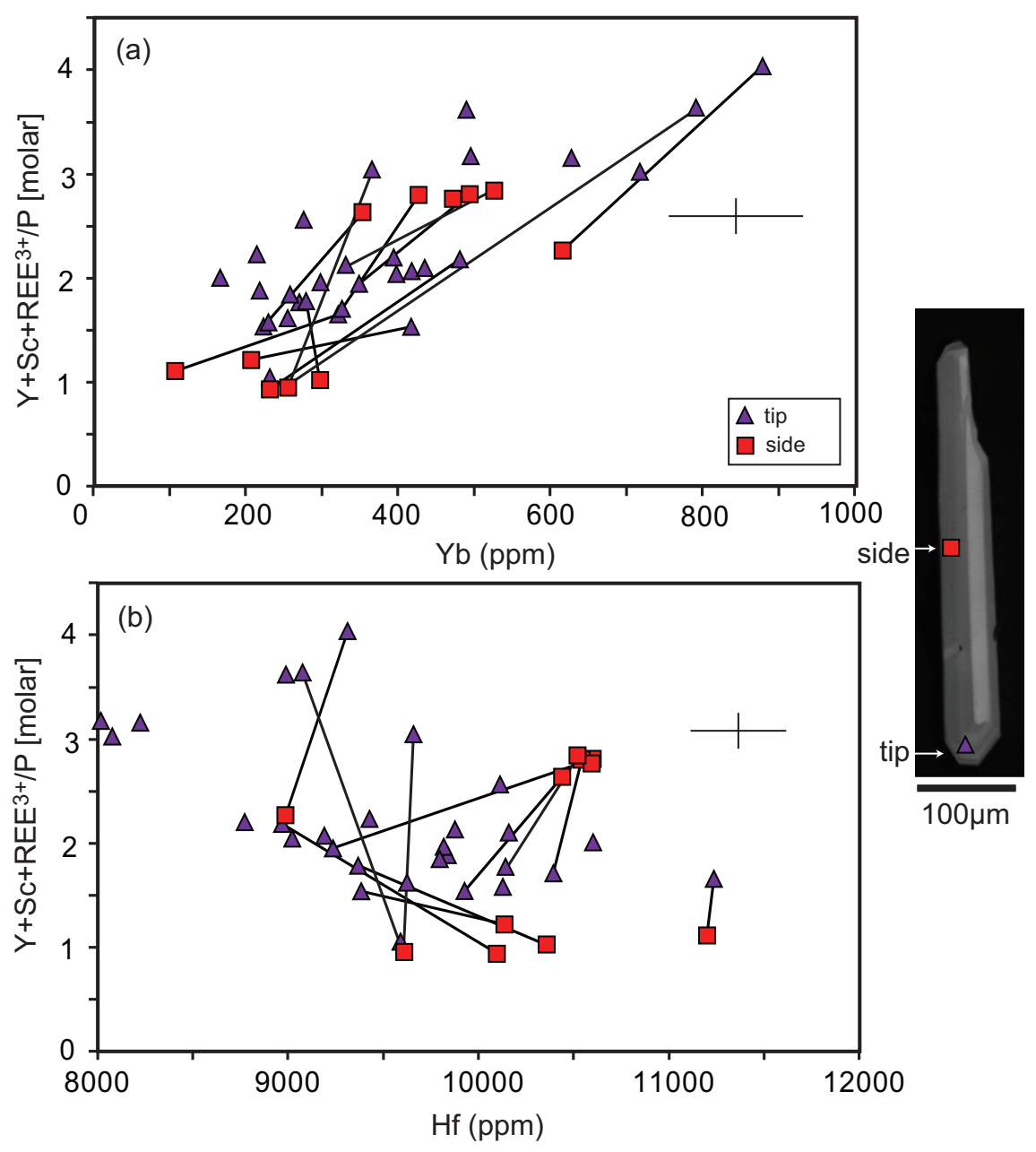

Figure 2.15. $\mathrm{Yb}(\mathrm{a})$ and $\mathrm{Hf}(\mathrm{b})$ concentrations (ppm) versus $\left(\mathrm{Y}+\mathrm{Sc}+\mathrm{REE}^{3+}\right) / \mathrm{P}[\mathrm{molar}]$ for tips (triangles) and sides (squares) of high aspect zircon grains from Kidnappers sample P2008. Tie lines show pairs of analyses from the same grain. Accompanying CL image shows a typical grain where sides and tips were targeted.

\subsubsection{Influence of sector zoning}

The sector zoning best expressed in grains from Kidnappers sample P2006 is reflected in the concentrations of trace elements. Lighter CL zones, along the sides of crystals ( $a$ and $b$ axes) and dark CL zones from the tips ( $c$ axis) were analysed within single grains and fall into two distinct compositional groups, particularly with respect to the molar $\left(\mathrm{Y}+\mathrm{Sc}+\mathrm{REE}^{3+}\right) / \mathrm{P}$ ratio (Figure 2.16). Light sectors have $\left(\mathrm{Y}+\mathrm{Sc}+\mathrm{REE}^{3+}\right) / \mathrm{P}$ values that follow the 'xenotime substitution' mechanism $\sim 1.0$, and do not vary with $\mathrm{Yb}$ or $\mathrm{Hf}$ values. In contrast, dark sectors have $\left(\mathrm{Y}+\mathrm{Sc}+\mathrm{REE}^{3+}\right) / \mathrm{P}$ values of $\sim 1.5$, overlying the main population of rims which span from 1.5-2.0, between 200 and $400 \mathrm{ppm} \mathrm{Yb}$ (Figure 2.16b). Light sectors have large variations in Hf content (>2000 ppm) when 
compared to dark sectors ( $\sim 500 \mathrm{ppm})$, and dark sectors may be more or less enriched in Hf compared to light sectors (Figure 2.16b). The influence of sector zoning is less consistent with respect to other elements such as Ti, which shows both minor enrichments and depletions (Figure 2.16c).
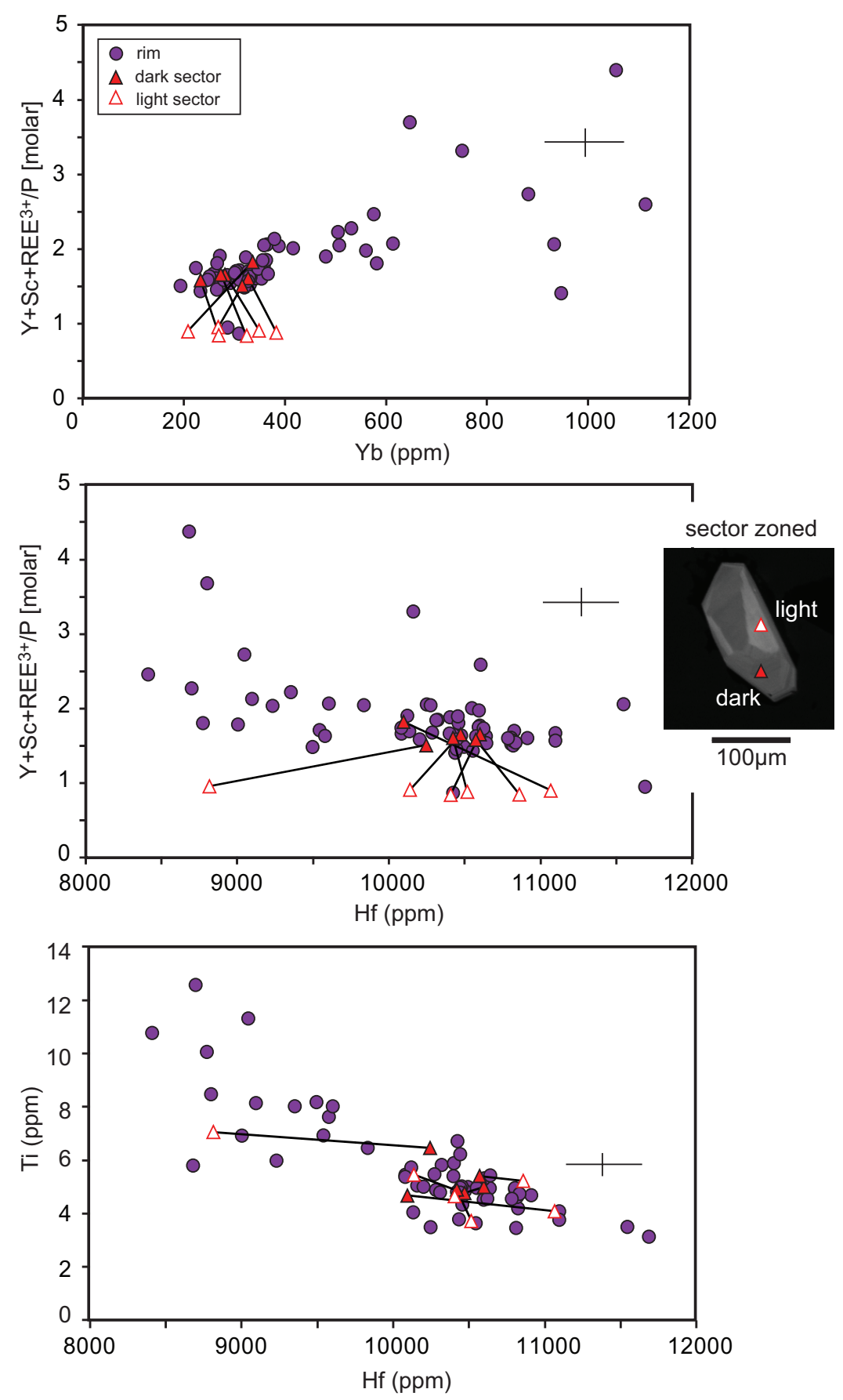

Figure 2.16. Plots of selected trace elements to show the effects of sector zoning in zircons from Kidnappers sample P2006. Circles show normal rim analyses and tie lines between light sectors (open triangles) and dark sectors (red triangles) show analyses from the same grain. Accompanying CL image show a typical grain where light and dark sectors were targeted. 


\subsubsection{Ti concentrations and Ti-in-zircon thermometry}

Ti concentrations in Mangakino zircons typically show decreasing values with increasing melt fractionation (increasing Hf), which may reflect decreasing magmatic temperatures (Watson and Harrison 2005; Watson et al. 2006; Ferry and Watson 2007; Fu et al. 2008) or changing melt compositions as the system evolves or partitions into the zircon structure (Figure 2.12). A range of model temperatures was estimated using the formulation of Ferry and Watson 2007. The $\alpha \mathrm{TiO}_{2}$ was estimated using Fe-Ti oxides in equilibrium (Ghiorso and Evans 2008), which returned a range of $\alpha \mathrm{TiO}_{2}$ values, averaging $\sim 0.6$. The formulation of Ghiorso and Gualda (2013) can yield a large variation in calculated $\alpha \mathrm{TiO}_{2}$, and questions the use of a constant $\alpha \mathrm{TiO}_{2}$ value in thermometry estimates. Here Ti-in-zircon temperatures were also calculated using the minimum and maximum $\alpha \mathrm{TiO}_{2}$ values of 0.5 and 0.7 estimated from $\mathrm{Fe}$-Ti oxides (Figure 2.12). All eruptions have model temperatures at $0.6 \alpha \mathrm{TiO}_{2}$ from $\sim 700{ }^{\circ} \mathrm{C}$ at high Hf (>10000 ppm) to $\sim 850^{\circ} \mathrm{C}$ at low Hf (7000-8000 ppm) (Figure 2.12). Rims have a smaller range in temperatures than cores, clustering between $\sim 700{ }^{\circ} \mathrm{C}$ to $\sim 800{ }^{\circ} \mathrm{C}$ $\left(750{ }^{\circ} \mathrm{C}\right.$ in Ongatiti). The range in temperatures is strongly dependent on the adopted $\alpha \mathrm{TiO}_{2}$ value, particularly at high $\mathrm{Ti}$ concentrations and can vary by up to $\sim 50{ }^{\circ} \mathrm{C}$ (Figure 2.12), greatly limiting the precision of any model temperature estimates.

\subsection{Discussion}

\subsubsection{Mangakino U-Pb age spectra}

$\mathrm{U}-\mathrm{Pb}$ age data represent cores, intermediate domains and rims from grains where it was possible to place the beam on 'clean' areas within a single CL zone. Generally, a single age analysis was performed on each selected grain and therefore age zonation was not directly assessed as part of this study. Zones with adequate $U$ concentrations (qualitatively assessed by CL intensity) were often targeted to obtain smaller age uncertainties (Dobson et al. 2008). Although yielding dark CL tones, high U cores were generally avoided as they were commonly found to incorporate abundant microinclusions of melt and/or crystals. This selection process has the potential to skew the data to higher or lower ages depending on the selected grain and/or zone. The effect of preferentially selecting higher $\mathrm{U}$ grains for $\mathrm{U}-\mathrm{Pb}$ analysis is evident in the data from P1722 (Figure 2.5a) where the peak age is $>100$ kyr prior to the eruption age. U-Pb spectra from all eruptions return a proportion of ages that are younger than the ${ }^{40} \mathrm{Ar} /{ }^{39} \mathrm{Ar}$ 
eruption ages, which tend to be from zircon grains containing low concentrations of $U$ $(<1000 \mathrm{ppm})$ (Figure 2.4). This feature of the age spectra has previously been observed within Ongatiti samples (Wilson et al. 2008). Although a number of low U grains appear younger than eruption age, the majority of grains within Mangakino pumice samples contain low concentrations of $U$ and therefore cannot be excluded in age determinations to avoid sampling bias. U-Pb analysis by SIMS permits considerations of analytical selection described above and these effects would not be apparent using the higher precision bulk ID-TIMS method, which is weighted by average grain U (and $\mathrm{Pb}$ ) concentrations.

\subsubsection{Ongatiti ages}

Ongatiti zircon age spectra show little variance between samples (Figure 2.3) and have an overall unimodal age distribution (Figure 2.7). Ongatiti U-Pb ages are consistent with a zircon growth history of no more than $\sim 250 \mathrm{kyr}$. Apart from a minor younger secondary peak, the Ongatiti age mode is $\sim 100 \mathrm{kyr}$ prior to eruption age. Some workers suggest that protracted crystallisation histories may reflect recycling of partially (crystal mush) or completely crystalline plutons associated with earlier magmatic episodes (Brown and Smith 2004; Charlier et al. 2005; Pamukcu et al. 2013). It is unlikely that the 1.32 Ma peak age is due to inheritance from magmatism associated with an earlier eruption, as the previous large eruption from Mangakino was the Ngaroma at $1.60 \pm$ $0.03 \mathrm{Ma}$ (Houghton et al. 1995). A similar lack of residual zircon inheritance has been found in eruptives from the Yellowstone system (Vazquez and Reid 2002). The distinctly older $\mathrm{U}-\mathrm{Pb}$ age peak could also represent the remobilization of crystal mush as the Ongatiti shows some characteristics of a monotonous intermediate (Hildreth 1981; Bachmann et al. 2002; Bachmann and Bergantz 2008) in its rhyodacitic bulk composition and crystal-rich nature. The $\mathrm{U}-\mathrm{Pb}$ age spectra suggest zircon crystallised in an early event, $\sim 100 \mathrm{kyr}$ prior to the eruption, and then remained stable in a mush with little crystallisation and/or dissolution. A late stage rejuvenation event then remobilised the mush material and triggered the eruption without significant further crystal growth. This interpretation is consistent with textural and chemical variations of other crystal phases from the Ongatiti (Chapter 6). Alternatively, the published $1.21 \pm 0.04 \mathrm{Ma}$ ${ }^{40} \mathrm{Ar} /{ }^{39} \mathrm{Ar}$ eruption age (Houghton et al. 1995) may require some revision. Briggs et al. (2005) reported a ${ }^{40} \mathrm{Ar} /{ }^{39} \mathrm{Ar}$ age of $1.32 \pm 0.02 \mathrm{Ma}$ (plateau age); $1.34 \pm 0.04 \mathrm{Ma}$ 
(isochron age) for the Ongatiti ignimbrite at a distal location in the Tauranga Basin. The $1.32 \pm 0.01 \mathrm{Ma}$ Ongatiti age in this study is closely similar to the $1.31 \pm 0.03 \mathrm{Ma}$ (Brown and Smith 2004), 1.30 Ma (Wilson et al. 2008) and 1.29 $\pm 0.14 \mathrm{Ma}$ (McCormack et al. 2009) weighted mean estimates from previous U-Pb dating work. These age data suggest that either the Ongatiti eruption age may be earlier than currently thought, or that the deposit dated by Briggs et al. (2005) may be an earlier eruptive expression of the Ongatiti magma system.

\subsubsection{Kidnappers and Rocky Hill ages}

Kidnappers zircon age spectra show a subtle bimodality and some variance in ages is shown between pumice from mid-SiO 2 (KI-1) and high-SiO ${ }_{2}$ (KI-2) compositional groups (see Chapter 4). This variance may reflect minor differences in the crystallisation histories of the discrete melt-dominant bodies operating in the Kidnappers system. Subtle bimodal age peaks, on eruption age at $\sim 1.0 \mathrm{Ma}$ and older than 1.1 Ma in sample P2008 may represent two populations of grains found within this sample. The younger age peak, representing autocrysts growing at the time of eruption coincides with the unimodal peak of sample P2006. The younger age peak reflects a high number of low $U$ grains (Figure 2.4), often with high aspect ratios (Figure 2.14). The older age peaks in the other Kidnappers samples are closer to those observed in the Rocky Hill samples. Rocky Hill U-Pb age spectra are very similar between samples (Figure 2.6) and are indistinguishable from the Kidnappers spectra (Figure 2.7). The Rocky Hill weighted mean age of $1.05 \pm 0.02 \mathrm{Ma}$ is within uncertainty of the $1.04 \pm 0.07$ Ma figure reported in McCormack et al. (2009).

The Kidnappers and Rocky Hill have similar pumice whole rock and glass chemistries as well as common textural and chemical variations in all other mineral phases (see Chapter 4), suggesting the deposits were erupted from the same magmatic system. The indistinguishable age spectra between the Kidnappers and Rocky Hill support this interpretation. The subtle bimodality in both eruptions (peaks on eruption age at $\sim 1 \mathrm{Ma}$ and at $\sim 1.1 \mathrm{Ma}$ ) suggest two pulses of crystallisation occurred within the parental magmatic system. The older zircon population could be considered as inherited (compare the $\sim 95 \mathrm{ka}$ model age population in magmas of the Oruanui system: Wilson and Charlier 2009); however, the greater uncertainties on the U-Pb ages presented here make this less clear-cut. The relatively high age uncertainties cause any bimodal 
distribution to blur and the peak ages to shift (cf. Figure 16 of Wilson and Charlier 2009).

Kidnappers and Rocky Hill age determinations span $\sim 200$ kyr prior to eruption suggesting the Kidnappers/Rocky Hill magma system began to build and crystallise zircon after the Ongatiti ignimbrite was erupted (Figure 2.7). A small proportion (5/143) of grains with ages of $>1.2 \mathrm{Ma}$ are present within the Kidnappers, overlapping the Ongatiti eruption age. The ages of these grains imply they are antecrystic (or xenocrystic) and may have originated or crystallised during the growth of the older Ongatiti and/or the intervening Ahuroa/Unit D magmatic systems. The closely successive eruptions of the Unit D/Ahuroa deposits at $1.18 \pm 0.02 \mathrm{Ma}$ (Wilson 1986; Houghton et al. 1995) were the last events from Mangakino prior to the Kidnappers, and there appears to be no substantive inheritance of zircons from these or earlier episodes. McCormack et al. (2009) reported a change in the xenocrystic zircon assemblage between the Rocky Hill and earlier Mangakino ignimbrites (Ahuroa, Ongatiti, Ngaroma), which they attributed to a physical change in the location of crustal assimilation.

\subsubsection{Zircon trace element data}

\subsubsection{Summary of key features}

To a first order, Mangakino zircons have the potential to track magma evolution, as decreases in mean REE concentrations from cores to rims are observed in all samples (Figure 2.8). Commonly used monitors of magma evolution by fractional crystallisation during zircon growth include $\mathrm{Yb} / \mathrm{Gd}, \mathrm{Th} / \mathrm{U}$ and $\mathrm{Hf}$ (Grimes et al. 2009; Claibourne et al. 2010; Carley et al. 2011). The Eu-anomaly (Eu/Eu*) and Ce-anomaly (Ce/Ce*, or alternatively in this chapter $\mathrm{Ce} / \mathrm{Sm}$ ) have been also proposed as a means to track changes in the oxidation state (Trail et al. 2011, 2012). Here, zircon Eu/Eu* values are almost certainly dominantly controlled by melt evolution driven by feldspar fractionation. Ti concentrations have been used to model temperatures of the magmatic systems from which the zircon grew (Watson and Harrison 2005; Watson et al. 2006; Ferry and Watson 2007; Fu et al. 2008). No systematic changes or shifts in zircon chemistry are observed from the Ongatiti to the Kidnappers/ Rocky Hill samples, suggesting that each system is undergoing similar magmatic processes, dominated by a similar fractionating mineral assemblage (plagioclase, amphibole and orthopyroxene: 
chapters 4 and 6). All zircon assemblages in this study have typical and consistent evolutionary trends of decreasing Ti (down-temperature) and increasing Hf (Figure 2.12). The majority of zircon rims from all eruptions show a tight trend in Ti and $\mathrm{Hf}$ concentrations, and are inferred to have grown within the final eruptible melt-dominant bodies or their parental mush zones (chapters 4 and 6). A proportion of zircons (particularly cores) at higher $\mathrm{Ti}$ and $\mathrm{Hf}$, which do not follow this trend, may represent an antecrystic component sourced from a crystal mush.

A relative enrichment in zircon HREE over MREE during growth is a common feature from each eruption (Figures 2.9 and 2.13). In other magmatic systems, this trend has been suggested to record the crystallisation of accessory minerals such as apatite and titanite (e.g. Hoskin et al. 2000) or control by garnet (e.g. Barth et al. 2013). The Ongatiti, Kidnappers and Rocky Hill eruptive deposits, however, contain abundant amphibole. Here, it is proposed that in the case of Mangakino systems, amphibole is the primary driver of changes in HREE/MREE. Amphibole preferentially incorporates MREE over HREE ( $\mathrm{Yb} / \mathrm{Gd}$ of $\sim 0.45$ in Kidnappers amphibole: Chapter 4), therefore the fractional crystallisation of amphibole will deplete the melt in MREE, leaving a greater proportion of HREE available in the melt to partition into zircon. A number of zircon cores do not have enrichment in HREE and thus may be inherited from a source not undergoing significant amphibole crystallisation. These cores are coincident with the higher Ti cores (Figure 2.12). The sharp increases in $\mathrm{Yb} / \mathrm{Gd}$ and decreases in $\mathrm{Y} / \mathrm{Yb}$ at $\mathrm{Th} / \mathrm{U}<\sim 0.8$ (Figures 2.9 and 2.13) coincide with the tightening of Ti data at $\sim 9000$ ppm Hf (Figure 2.12) and may therefore represent the transition to zircon growing alongside amphibole.

Values of $\mathrm{Eu} / \mathrm{Eu}^{*}$ decrease with increasing $\mathrm{Hf}$ and decreasing $\mathrm{Th} / \mathrm{U}$ with a straight trend in all cases (Figure 2.9), consistent with all Mangakino zircons having co-crystallised with plagioclase. Ce-anomalies in zircon have been found to increase with decreasing temperature and/or increasing oxygen fugacity (Claiborne et al. 2010; Trail et al. 2011, 2012). Here $\mathrm{Ce} / \mathrm{Sm}$ values are used in place of the Ce-anomaly, which has greater uncertainties due to low concentrations of $\mathrm{La}$ in zircon. The $\mathrm{Ce} / \mathrm{Sm}$ ratio in Mangakino zircons rises with increasing Hf concentrations (Figure 2.9), coinciding with a trend to lower Ti contents, and therefore lower apparent temperatures. These trends suggest, not surprisingly and in tune with the records from major phases (chapters 4 and 6), that the 
zircon records at Mangakino show that the parental magmatic systems became both cooler and more oxidising as they evolved.

\subsubsection{Origin of specific trace element trends in zircons}

Trace element data from Mangakino samples, in particular those from the Kidnappers eruption, suggest there are two populations of inherited grains or cores (A and B) from more than one source (Figure 2.13e). Data from groups A and B, first distinguished on the basis of horizontal parallel trends in cores on a plot of $\mathrm{Th} / \mathrm{U}$ vs. $\mathrm{Yb} / \mathrm{Gd}$, commonly define two edges of a triangular shape to the total datasets (Figure 2.13f). A similar spread is also observed in the Ongatiti and Rocky Hill data. This distribution can be explained by three-component mixing and the incorporation of zircons from two sources. Variable sources of crystal inputs within the Kidnappers system is consistent with the interpretation of open system behaviour and the evidence of multiple meltdominant bodies (Chapter 4). Alternatively, this distribution (particularly with respect to $\mathrm{Y} / \mathrm{P}$ ) can also be explained by zircon grains that were either crystallising in the presence or absence of crystallising apatite.

Concentrations of Sc decrease with increasing $\mathrm{Yb} / \mathrm{Gd}$ (Figure 2.13a) and $\mathrm{Hf}$, and with decreasing $\mathrm{Th} / \mathrm{U}$, suggesting that $\mathrm{Sc}$ has the potential to be used as a tracker of magmatic evolution, particularly in systems where amphibole is crystallising. Sc concentrations in Mangakino amphibole are high ( 300 ppm: chapters 4 and 6$)$ leading to high amphibole/melt partition coefficients (29-42). Significant amounts of amphibole crystallisation may thus be the main driver controlling Sc concentrations in zircon. Sc concentrations also increase with absolute REE concentrations and divergent trends are often observed (Figure 2.13f), inferred here to reflect zircons crystallising either with or without accompanying amphibole. This inference is supported by the trace-element records in Ongatiti plagioclase and amphibole, which suggest that an amphibole dominated source was present at depths down to $\sim 15 \mathrm{~km}$ and a plagioclase dominated mush was present between 4-6 km depth (Chapter 6). Melt plus associated zircons from the amphibole-dominated source interacted with the shallow mush to establish the final erupted melt-dominant body. Therefore crystal components (or interiors of grains) are present which record a history of crystallisation either with or without significant proportions of amphibole. 
Ongatiti sample P1993 contains zircons with elevated Be (up to $\sim 400 \mathrm{ppm}$ ). Be concentrations form distinct trends when plotted against evolutionary monitors such as $\mathrm{Hf}, \mathrm{Th} / \mathrm{U}$ and $\mathrm{Yb} / \mathrm{Gd}$, as well as REE, $\mathrm{Y}$ and $\mathrm{P}$ (Figure 2.12c), and decrease as the host system became more evolved. It is not apparent what the cause of the Be enrichment is. The observed Be concentrations are not an artifact of the analytical procedure, as this sample was measured during the same session as other samples, which do not have any grains enriched in Be. It is also unlikely that either melt or microlite inclusions were included in particular ion probe spots as similar Be concentrations would be expected in analyses from other samples, and additional elements would show anomalously high concentrations. Similarly high Be zircons are present within the Huckleberry Ridge Tuff, Yellowstone, from samples which appear to be from sources that are geographically adjacent (CJNW unpublished data).

\subsubsection{Kinematic controls}

A consideration for any kinematic controls on the incorporation of trace elements into zircon needs to be made when using zircon to trace magmatic evolution. The dominant mechanism for the incorporation of REE in zircon is commonly assumed to be the 'xenotime' substitution mechanism, where $(\mathrm{Y}[+\mathrm{Sc}]+\mathrm{REE})^{3+}+\mathrm{P}^{5+}=\mathrm{Zr}^{4+}+\mathrm{Si}^{4+}$, to maintain charge balance (Speer 1982; Hinton and Upton 1991; Hoskin et al. 2000; Finch et al. 2001; Hoskin and Schaltegger 2003). If the incorporation of REEs is controlled by simple 'xenotime' substitution, the ratio of $(\mathrm{Y}+\mathrm{REE}) / \mathrm{P}$ should be close to 1 (note that only SHRIMP-RG data includes Sc determinations). All analyses from Ongatiti and Rocky Hill, and the vast majority of Kidnappers zircons have (Y+REE)/P in excess of 1 (generally $1.5-5.0$ ) (Figure 2.10), and therefore additional substitution mechanisms or alternative processes must be controlling the incorporation of REE. It is possible that $\mathrm{Li}, \mathrm{Mg}, \mathrm{Al}$ and $\mathrm{Fe}$ cations may be incorporated into interstitial sites by complex 'xenotime-type' substitutions to maintain local charge neutrality (Hoskin et al. 2000), but commensurate concentrations of these elements are not present. $\mathrm{Sc}^{3+}$ concentrations in Mangakino zircons range from $\sim 30$ to $\sim 500 \mathrm{ppm}$, and increase with REE and Y. Sc thus appears to behave like other $3^{+}$cations (Figure 2.13) and therefore is included here in calculations using total $3^{+}$(molar). When Sc is included in xenotime calculations, the $\left(\mathrm{REE}^{3+}+\mathrm{Y}+\mathrm{Sc}\right) / \mathrm{P}$ ratio increases by $2-16 \%$ and the general mismatch with simple 'xenotime substitution' is increased. $\left(\mathrm{REE}^{3+}+\mathrm{Y}+\mathrm{Sc}\right) / \mathrm{P}$ ratios close to 1 are found in light sectors and sides of a proportion of high aspect ratio grains (Figures 2.15 
and 2.16), implying that a single zircon grain can have multiple substitution mechanisms in operation, dependent on morphology or internal texture, and as found in the Bishop Tuff zircons (Chamberlain et al. 2013).

\subsubsection{Sector zoning and zircon morphology}

Sector zoning recognised under CL is not a common texture in Mangakino zircons in comparison to grains within other systems such as the Bishop Tuff (Chamberlain et al. 2013). It is, however, possible that sector zoning is more prevalent even though not detectable under CL. It is apparent from the trace element data presented here that different absolute concentrations of trace elements are incorporated in the sides and tips of the same crystal, within what appears to be the same growth zone (Figure 2.15). The sector zoning (or side-tip variations), particularly evident in Kidnappers samples, may be caused by disequilibrium effects associated with the rapid crystal growth of high aspect grains (Luo and Ayers 2009). If the rate of zircon growth is greater than the rate of diffusive supply of particular elements, re-equilibrium with the melt will not be achieved (Watson 1996). These kinematic effects, particularly in rapidly grown grains, pose problems for the use of zircon to track magma evolution and therefore the use of parameters insensitive to these effects is required. High aspect ratio grains commonly have low concentrations of $\mathrm{U}(<500 \mathrm{ppm})$, which in turn give the lowest $\mathrm{U}-\mathrm{Pb}$ ages. The rapid growth of high aspect ratio grains is consistent with late-stage zircon growth (in particular, that forming the eruption-age mode within the Kidnappers) within the meltdominant bodies just prior to eruption.

\subsubsection{Ti-in-zircon thermometry}

Ti-in-zircon apparent temperatures for grains that have grown within the melt-dominant body cover a large range from $700-800{ }^{\circ} \mathrm{C}$ in the Kidnappers/Rocky Hill system and from $700-750{ }^{\circ} \mathrm{C}$ in the Ongatiti using $\alpha \mathrm{TiO}_{2}$ of 0.6 (Figure 2.12). Cores from all eruptions extend the temperature range to $>850^{\circ} \mathrm{C}$. These higher $\mathrm{Ti}$ (and model temperature) cores, likely reflect the hotter temperatures within the crystal mush. The Ti in zircon model temperatures from rims are somewhat lower than the majority of temperature estimates from amphibole rims (Ridolfi et al. 2010) and Fe-Ti oxides (Ghiorso and Evans 2008), which suggest temperatures in the melt-dominant bodies were between $770-840{ }^{\circ} \mathrm{C}$ in the Kidnappers/Rocky Hill (Chapter 4), and 780-860 ${ }^{\circ} \mathrm{C}$ in the Ongatiti (Chapter 6). A single value for the activity of $\mathrm{TiO}_{2}$ in magma $\left(\alpha \mathrm{TiO}_{2}\right)$ is 
commonly adopted in Ti-in-zircon temperature calculations, but Fe-Ti oxide equilibrium pairs returned variable $\alpha \mathrm{TiO}_{2}$ figures (0.5-0.7) and therefore Ti-in-zircon temperatures were also calculated using a minimum and maximum $\alpha \mathrm{TiO}_{2}$. When a minimum $\alpha \mathrm{TiO}_{2}$ of 0.5 is adopted, the upper temperature estimates become closer to other temperature estimates, however the lower temperature bound remains unreasonably low at $\sim 700^{\circ} \mathrm{C}$. The range of Ti concentrations $(\sim 2-18 \mathrm{ppm})$, and associated range in temperature estimates $\left(\sim 700-850^{\circ} \mathrm{C}\right)$ observed in Mangakino zircons is relatively large when compared to other large silicic systems such as the Bishop Tuff (2-8 ppm; Chamberlain et al. 2103) and Oruanui (2-14 ppm; CJN Wilson et al., unpublished data).

\subsubsection{Implications for values of partition coefficients}

The partitioning of many trace elements in zircon is dependent on structural strain associated with coupled substitutions (Finch et al. 2001; Hanchar and van Westrenen 2007) and on temperature (Watson and Harrison 2005; Watson et al. 2006; Ferry and Watson 2007; Fu et al. 2008; Luo and Ayers 2009). There are a large number of published partition coefficients from natural and experimental samples, which vary over several orders of magnitude for REEs (Hanchar and van Westrenen 2007). Zircon chemistry (REEs) paired with corresponding pumice chemistry can be used to calculate zircon/melt partition coefficients if the zircons have grown from the melt in which they now reside. To obtain meaningful partition coefficients, zircon rim and matrix glass analyses were targeted in this study, as trace element concentrations from cores are not a reflection of the melt in which the grains now reside. The range in REE partition coefficients varies over two orders of magnitude within a single sample (Figure 2.17a). Minor differences in the partitioning of REE between lower and higher aspect ratio grains (Figure 2.17a), tips and sides, and different sector zones are found. These variances may be due to a difference in substitution mechanisms operating between light and dark sectors and between tips and sides of high aspect ratio grains, as implied from offsets in the molar $\left(\mathrm{Y}+\mathrm{Sc}+\mathrm{REE}^{3+}\right) / \mathrm{P}$ ratio (Figures 2.15 and 2.16). 

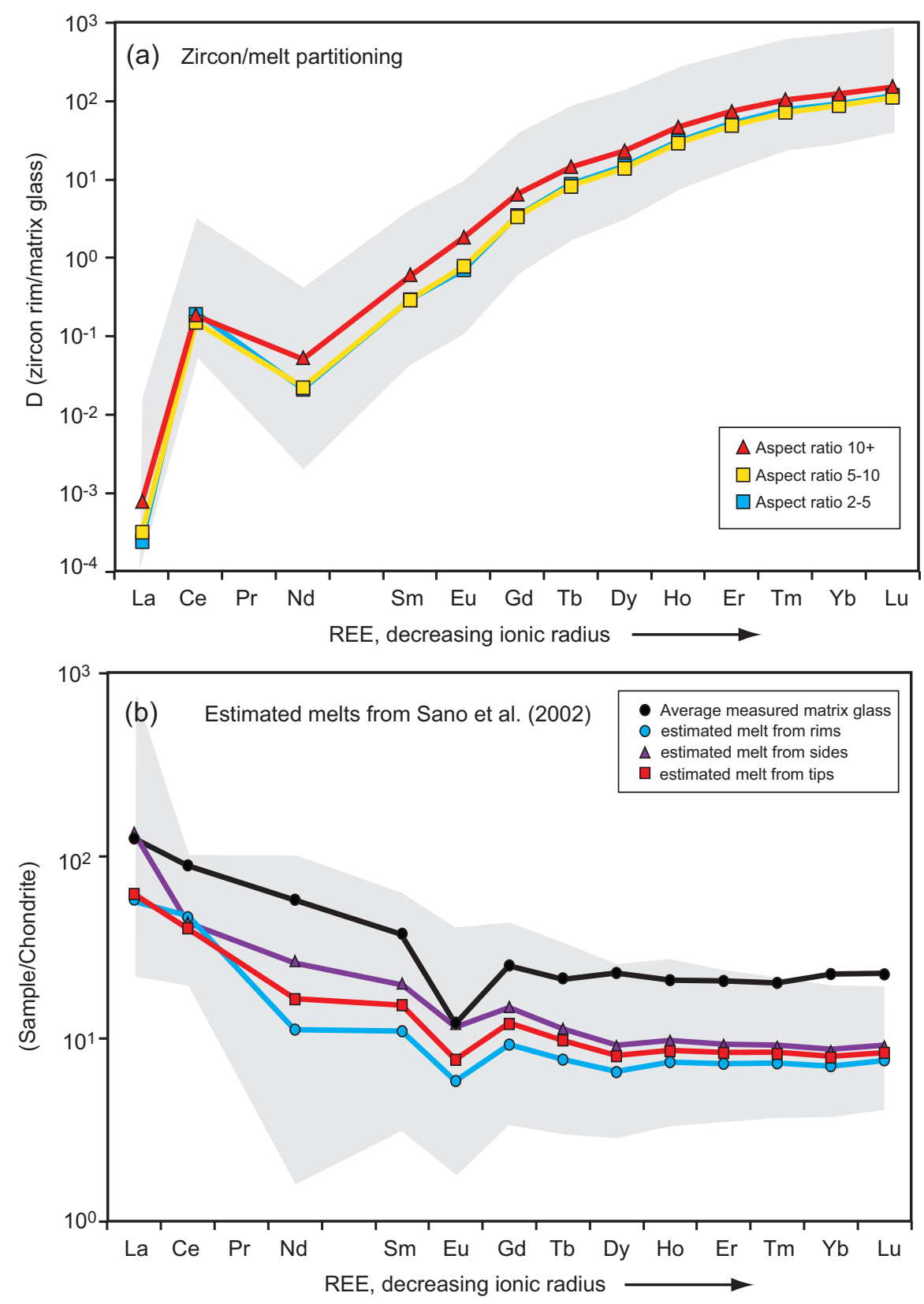

Figure 2.17. (a) REE diagram of zircon/melt partitioning to show the range of partition coefficients calculated from zircon rims and associated matrix glass (grey shaded area) from Kidnappers sample P2008. The three lines are representative zircon/melt relationships from grains with the different aspect ratios marked. (b) Chondrite-normalised REE diagram to compare the measured melt values with estimated melt using partition coefficients from Sano et al. (2002). Grey shaded area is the full range of melt estimates using zircon rims from Kidnappers sample P2008. The average values from rims, sides and tips are shown for comparison and average measured glass values are shown by the black line.

The widely used partition coefficients of Sano et al. (2002), which have been found to closely reconstruct melt compositions (Hanchar and van Westrenen 2007), were used to compare with the ones calculated in this study. The range in melt REE concentrations 
estimated from these published values varies over $\sim 1-2$ orders of magnitude (Figure $2.17 \mathrm{~b}$ ) and values shown in analyses from the tips and sides of high aspect ratio grains differ (Figure 2.17b). However, the REE patterns remain very similar and therefore only differences in absolute concentrations are present between sides and tips. In general the estimated melt from rims has lower absolute REE concentrations when compared to the measured matrix glass compositions, particularly in HREE. The estimated melt has a similar pattern to measured glass, with the exception of a less pronounced Eu anomaly (Figure 2.17b). Disparities are also found in reproducing LREE, particularly La which has very low abundances in zircon, making accurate measurement difficult. The large range in partition coefficients from this study and melt estimates from Sano et al. (2002) questions the reliability of their use. It is clear that before establishing and/or using published partition coefficients for melt reconstruction or mapping magmatic history, the kinematic and morphological controls on the incorporation of trace elements within single zircon grains must be considered.

\subsection{Conclusions}

This study provides evidence for the timing of assembly and establishment of two supervolcanic systems at Mangakino volcanic centre, as well as the magmatic processes in operation during zircon growth. Demonstration of additional factors governing zircon trace element variations are also presented which raise important considerations for zircon studies in other silicic systems. The key findings presented here are:

1. A remarkable variation in zircon morphology is present. High aspect ratio zircons (from 6:1-18:1), up to $1 \mathrm{~mm}$ in long are found within the Kidnappers, which are attributed to rapid crystallisation just prior to eruption.

2. $\mathrm{U}-\mathrm{Pb}$ ages from the Ongatiti ignimbrite show a protracted history over $\sim 250 \mathrm{kyr}$ prior to eruption with the peak crystallisation occurring $\sim 100 \mathrm{kyr}$ prior to eruption. This record is consistent with the chemical and textural records from other crystal phases for the rejuvenation of a $\sim 1.31$ Ma crystal mush prior to eruption at $1.21 \pm 0.04 \mathrm{Ma}$ (Chapter 6$)$. The age data show no overlap with an earlier eruptive unit from Mangakino and suggest that the whole silicic system accumulated over the $\sim 250 \mathrm{kyr}$ period.

3. U-Pb age data spectra from the Kidnappers and Rocky Hill ignimbrites span over $200 \mathrm{kyr}$ prior to eruption and are indistinguishable from each other. The age and trace element data imply that their respective zircons grew within a 
common magmatic system, consistent with the textural and chemical record from other mineral phases (Chapter 4). A bimodality in age spectra is present in zircons from both deposits which represent two more focused periods of crystallisation prior to eruption. The younger pulse likely occurred through growth in the melt-dominant bodies and is closely linked to the rapidly grown needle-shaped grains present in the Kidnappers. Little overlap with ages from the Ongatiti ignimbrite is present and suggest a new magmatic system was completely established at Mangakino in the $\sim 200$ kyr interval between the two supervolcanic eruptions.

4. The protracted $\mathrm{U}-\mathrm{Pb}$ timescales presented here represent the formation of the systems as a whole (i.e. the development and crystallization history of the parental crystal mushes or sources). In contrast, the timescales from diffusion modeling (Chapter 5) represent processes during the establishment and priming of the final eruptible melt-dominant bodies.

5. Many of the patterns in trace element characteristics in zircons from Mangakino are controlled by the fractionation of plagioclase and amphibole. Plagioclase is the dominant mineral phase in each eruption, reflected in the development of $\mathrm{Eu} / \mathrm{Eu}^{*}$ anomalies with other indicators of increasing evolution/fractionation in all analysed zircons at Mangakino. Amphibole has a strong control on the chemistry of the systems at Mangakino (Chapters 4 and 6), particularly in the Ongatiti, the zircons in which record evidence for an amphibole-dominated source region. Zircons presented in this study record enrichments in HREE/MREE with evolution and diverging trends in Sc (enriched in amphibole), which are inferred to represent crystals grown in the presence or absence of crystallising amphibole. Lesser-evolved chemical signatures in Ongatiti zircon cores provide evidence for three-component mixing and the presence of grains from two sources.

6. In addition to the magmatic signatures recorded in zircons, the morphology of grains and the presence of sector zoning are also found to have a strong control on the incorporation of trace elements. Analyses from the tips and sides of high aspect ratio grain rims reveal significant differences in the concentration of several trace elements, which imply varying substitution mechanisms play a role within a single crystal. This affect is also identified by the presence of sector zones, visible under CL (Chamberlain et al. 2013). Careful consideration of 
varying kinematic controls is therefore needed before zircons can be used to track magmatic histories and reconstruct melt compositions from which the grains grew. 


\section{Chapter 3}

Published as: Cooper GF, Wilson CJN, Millet M-A, Baker J, Smith EGC (2012) Systematic tapping of independent magma chambers during the 1 Ma Kidnappers supereruption. Earth Planet Sci Lett 213-214:23-33 


\title{
3. Systematic Tapping Of Independent Magma Chambers During The 1 Ma Kidnappers Supereruption
}

\begin{abstract}
The 1.0 Ma Kidnappers supereruption ( $1200 \mathrm{~km}^{3}$ DRE) from Mangakino volcanic centre, Taupo Volcanic Zone, New Zealand, produced a large phreatomagmatic fall deposit followed by an exceptionally widespread ignimbrite. Detailed sampling and analysis of glass shards and mineral phases have been undertaken through a proximal $4.0 \mathrm{~m}$ section of the fall deposit, representing the first two-thirds of erupted extracaldera material. Major and trace element chemistries of glass shards define three distinct populations (types A, B and C), which systematically change in proportion through the fall deposit and are inferred to represent three magma types. Type B glass and biotite first appear at the same level ( $\sim 0.95 \mathrm{~m}$ above base) in the fall deposit suggesting later tapping of a biotite-bearing magma. Plagioclase and Fe-Ti oxide compositions show bimodal distributions, which are linked to type A and B glass compositions. Temperature and pressure (T-P) estimates from hornblende and Fe-Ti oxide equilibria from each magma type are similar and therefore the three magma bodies were adjacent, not vertically stacked, in the crust. Most hornblende model T-P estimates range from 770 to $840{ }^{\circ} \mathrm{C}$ and 90 to $170 \mathrm{MPa}$ corresponding to storage depths of 4.0-6.5 km. Hornblende model T-P estimates coupled with in situ trace element fingerprinting imply that the magma bodies were individually well mixed, and not stratified. Compositional gaps between the three glass compositional types imply that no mixing between these magmas occurred. We interpret these data, coupled with the systematic changes in shard compositional proportions through the fall deposit, to reflect that three independent melt-dominant bodies of magma contributed large (A, $\left.\sim 270 \mathrm{~km}^{3}\right)$, medium $\left(\mathrm{B}, \sim 90 \mathrm{~km}^{3}\right)$ and small $\left(\mathrm{C}, \sim 40 \mathrm{~km}^{3}\right.$ ) volumes (as reflected in the fall deposits) and were systematically tapped during the eruption. We propose that the systematic evacuation of the three independent magma bodies implies that there was tectonic triggering and linkage of eruptions. Our results show that supereruptions can be generated by near simultaneous multiple eruptions from independent magma chambers rather than the evacuation of a large single unitary magma chamber.
\end{abstract}




\subsection{Introduction}

Reconstructing the pre- and syn-eruptive processes that occur in silicic magma chambers during exceptionally large explosive eruptions (particularly 'supereruptions', $>10^{15} \mathrm{~kg} \approx 450 \mathrm{~km}^{3}$ of magma; e.g., Sparks et al. 2005; Self 2006; Miller and Wark 2008) continues to be a fundamental challenge in understanding how such vast bodies of magma are generated, stored and ultimately erupted. Generalised models for large silicic magma chambers (e.g., Smith, 1979; Hildreth 1981, 2004; Shaw 1985; Bachmann and Bergantz 2008) envisage them to be single unitary bodies, with crystalricher roots ('mush zones') that are not erupted except under unusual circumstances. Those eruptions involving rhyolitic compositions of any significant size $\left(>1 \mathrm{~km}^{3}\right)$ in the high-silica rhyolite grouping of Hildreth (1981) are generally considered to be zoned in chemical or physical properties, with those zonations inversely reflected in the deposits (Smith 1979; Bachmann and Bergantz 2008). Crystal-poorer, more evolved magmas typically are erupted first, followed by crystal-richer, less evolved magmas, with gradients in crystal content matching gradients in chemical and mineralogical properties (e.g., Hildreth and Wilson 2007). Where compositions cluster into discrete groups, such distinct magmas are generally inferred to be genetically related and modelled as layers in single chambers (e.g. Schuraytz et al. 1989; Streck and Grunder 1997).

Recent studies have shown, however, that such models may be too simple for many examples, both small and large. The 25.4 ka Oruanui rhyolite shows compositional variability, but the different compositions were not systematically tapped during the eruption, and compositional variations in mineral and quartz-hosted melt inclusions show that the melt-dominant body was thoroughly stirred prior to eruption (Liu et al. 2006; Wilson et al. 2006). Single eruptions may tap two or more compositionally independent magma bodies in the shallow crust (e.g. Briggs et al. 1993; Smith et al. 2004; Shane et al. 2007, 2008), and paired eruptions can occur where the tectonic adjustment from one eruption serves to trigger another eruption from nearby vents (e.g., Nairn and Kohn 1973; Gravley et al. 2007).

In addition, in arriving at compositional information about silicic eruption deposits, there is a wide variability in the quality of material available. Ideally, individual juvenile clasts (pumice, in most cases) are sampled from all stratigraphic levels, but this 
ideal is seldom achievable. In particular, the fine-grained products of phreatomagmatic eruptions pose challenges because of the scarcity of large-enough pumice clasts and the volumetric dominance of fine-grained widespread fall deposits that are prone to erosion. Here we present field and geochemical data from the $\sim 1$ Ma Kidnappers eruption deposits in the Taupo Volcanic Zone (TVZ) of New Zealand. In this case, the stratigraphic controls are limited to the observation that at all localities the ignimbrite (non-welded and with fresh pumice) overlies and hence postdates the substantially larger fall deposit (in which clasts $>1-2 \mathrm{~cm}$ are absent). We thus use glass and mineral chemistry from the fall deposit to track compositional variations in the eruption products and infer the existence of multiple magma bodies that were systematically tapped during the first two-thirds of the eruption.

\subsection{Geological background}

The TVZ has been the dominant focus of volcanism in the central North Island of New Zealand since $\sim 2 \mathrm{Ma}$. It is a $<60 \mathrm{~km}$ wide, NNE-trending region of volcanism and associated extension forming the southern, continental continuation of the TongaKermadec arc, associated with westward subduction of the Pacific plate beneath the Indo-Australian plate (Cole and Lewis 1981; Figure 3.1). In the $\sim 120 \mathrm{~km}$ long, rhyolite-dominated central TVZ, $>16,000 \mathrm{~km}^{3}$ has been erupted since $\sim 1.6 \mathrm{Ma}$ in at least 25 caldera-forming and numerous other smaller eruptions from eight volcanic centres (Houghton et al. 1995; Wilson et al. 1995a, 2009).

The Kidnappers eruption is the second largest TVZ eruption known, dated at $\sim 1$ Ma by a variety of techniques, including ${ }^{40} \mathrm{Ar} /{ }^{39} \mathrm{Ar}$ dating and linking to the geomagnetic polarity timescale through its occurrence towards the top of normally magnetized deposits of the Jaramillo Subchron (Black 1992; Wilson et al. 1995b). Kidnappers deposits consist of three components. There is a voluminous phreatomagmatic fall deposit, recorded across the North Island and for $>1000 \mathrm{~km}$ eastwards across the Pacific Ocean floor (Ash A of Ninkovich 1968; Carter et al. 2004; CJNW unpublished data: Figure 3.1). This fall deposit is overlain by an exceptionally widespread non-welded 


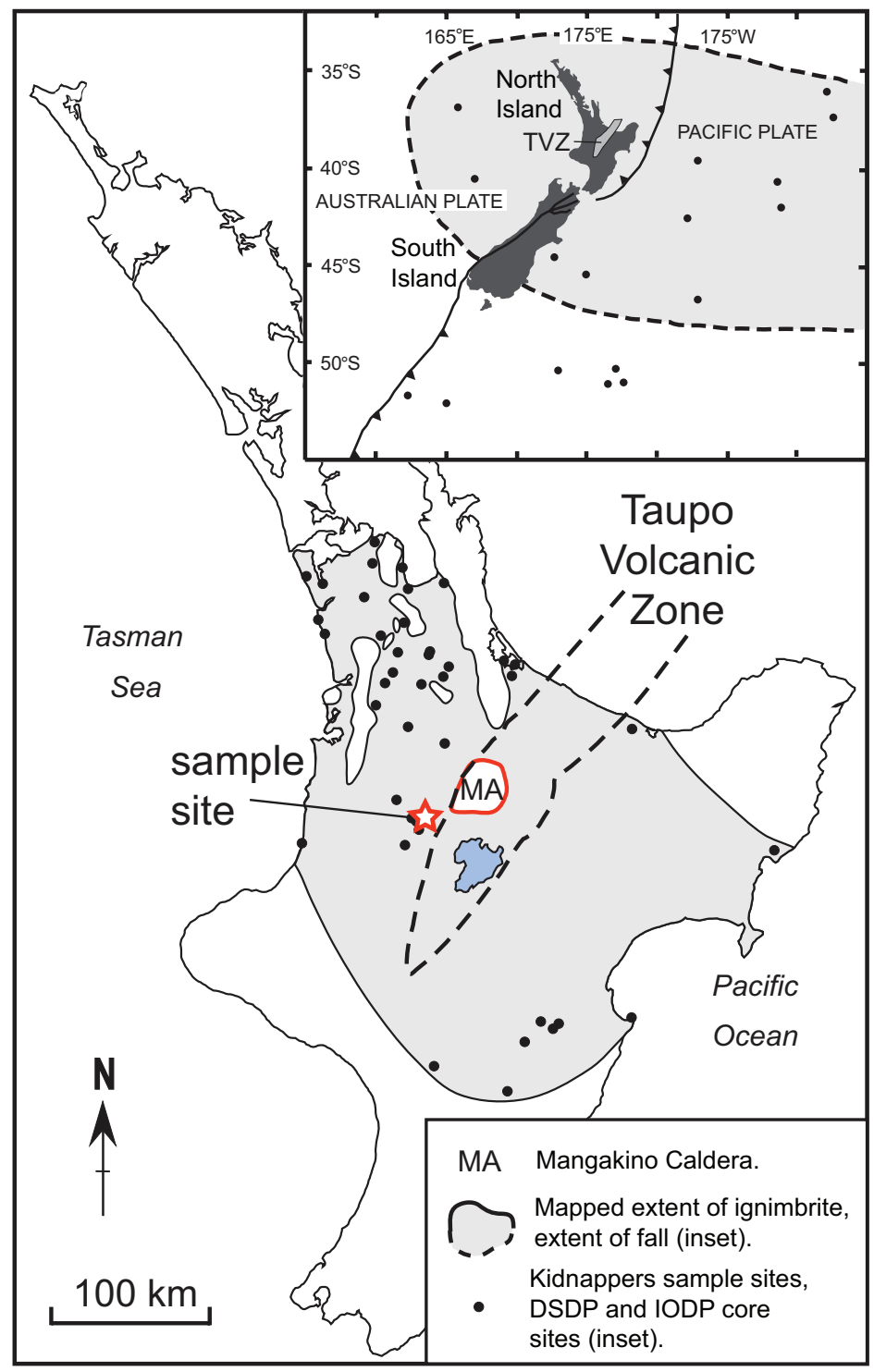

Fig. 3.1. Map of North Island, New Zealand, showing the Taupo Volcanic Zone (TVZ) and approximate location of Mangakino caldera (MA) on the western margin of the TVZ. The star marks the proximal fall deposit location. Shaded area defines the mapped extent of the Kidnappers ignimbrite (updated from Wilson et al. 1995b). Inset shows approximate extent of the Kidnappers fall deposit estimated from the offshore core record (adapted from Carter et al. 2004).

ignimbrite that covers $\sim 45,000 \mathrm{~km}^{2}$ (Wilson et al. 1995b; Figure 3.1). In addition, a $>1.8 \mathrm{~km}$ thickness of poorly-welded but hydrothermally altered tuff, inferred from $\mathrm{U}-\mathrm{Pb}$ age determinations on zircon to relate to this eruption, has been drilled near Mangakino township (Wilson et al. 2008), within the area identified as a composite collapse caldera for this and other eruptions from the Mangakino volcanic centre (Stern 1979; Rogan 1982; Wilson et al. 1984). The Kidnappers eruption was followed by a short period of erosion before eruption of the Rocky Hill ignimbrite, also from Mangakino, and we 
infer that the two eruptions collectively contributed to a composite deposit of primary and reworked volcaniclastic material that is mapped as the Potaka Tephra (e.g., Shane 1994; Carter et al. 2004; Alloway et al. 2005).

Volumes of the Kidnappers eruption products are problematic to estimate because of extensive erosion and/or burial of the deposits. Limited thickness data from on land (CJNW unpublished data) and marine cores (Carter et al. 2004) show that the fall deposit is similar in size to the $340 \mathrm{ka}$ Whakamaru eruption fall deposit for which a bulk volume of $\sim 700 \mathrm{~km}^{3}$ ( $\sim 00 \mathrm{~km}^{3}$, DRE) is estimated by Froggatt et al. (1986). The Kidnappers ignimbrite bulk volume is estimated at $\sim 450 \mathrm{~km}^{3}$ (equivalent to $\sim 200 \mathrm{~km}^{3}$, DRE) by Wilson et al. (1995b). An unknown (but clearly substantial) volume of material is represented by intracaldera material (Wilson et al. 2008) and if generalized models (e.g. Lipman 1984; Mason et al. 2004) suggesting an approximately 1:1 relationship for the relative volumes of intra- versus extra-caldera material are adopted, then an overall dense-rock equivalent volume for the Kidnappers eruption of $\sim 1200 \mathrm{~km}^{3}$ is inferred. At worse, these estimates may carry an uncertainty of $\pm 50 \%$ (cf. Hildreth 1981, Figure 3.1). The fall deposit thus accounts for about two thirds of the extracaldera volume of material.

A $4.0 \mathrm{~m}$ section of the Kidnappers fall deposit, located approximately $30 \mathrm{~km}$ southwest of the Mangakino caldera rim on Pukemako Road at NZMG grid reference $2723847 \mathrm{~m}$ E, 6289997m N (Figure 3.1), was sampled for this study. This site was chosen because the fall deposit here is the thickest that has been found. It rests on a thick palaeosol developed on the $1.18 \mathrm{Ma}$ Ahuroa ignimbrite and is overlain quasi-conformably by the slightly erosive base of the Kidnappers ignimbrite. The fall deposit is multiply bedded and poorly sorted, with upward increases in the abundance of accretionary lapilli and pumice sizes (to a maximum of 1-2 $\mathrm{cm}$ long).

\subsection{Methods}

\subsubsection{Sample preparation and analytical techniques}

Bulk samples from 11 selected levels in the $4.0 \mathrm{~m}$ fall deposit section were disaggregated and rinsed in water, then wet sieved into $>1 \mathrm{~mm}, 1 \mathrm{~mm}-500 \mu \mathrm{m}, 500-250$ $\mu \mathrm{m}, 250-125 \mu \mathrm{m}, 125-63 \mu \mathrm{m}$ and $<63 \mu \mathrm{m}$ fractions. Glass shards were floated off in 
water to provide an initial separation of glass and minerals. Separated fractions were rinsed in Milli-RO 6 water and dried at $105^{\circ} \mathrm{C}$ for several hours. Plagioclase, quartz, orthopyroxene and amphibole crystals were handpicked from the $>1 \mathrm{~mm}$ and $1 \mathrm{~mm}-500$ $\mu \mathrm{m}$ sieve fractions. Fe-Ti oxide equilibrium pairs included within orthopyroxene were targeted for electron microprobe analysis (EPMA). Biotite is prominent as golden hydromica in the majority of samples but is almost entirely too weathered for reliable analysis and, therefore, biotite chemistry has been excluded from this study. Glass shards from the 250-125 $\mu \mathrm{m}$ fraction were selected for analysis for both EPMA and laser ablation inductively coupled plasma mass spectrometry (LA-ICP-MS) analysis. At least 25 grains of each mineral phase from every sample were mounted in epoxy resin blocks. Six glass samples were mounted in 6 pre-drilled holes within each epoxy block. A $25 \mathrm{~nm}$ carbon coating was applied before major element analysis by EPMA.

Major and trace elements in glass and crystals were analysed by EPMA and LA-ICPMS at Victoria University of Wellington as described in the Supplementary Information (section 3.7). In the use of EPMA data on glass shards that have variable concentrations of water from secondary hydration, a key question is to what extent scatter in data values reflects analytical uncertainties versus actual variability in glass compositions. This question is of particular importance in the use of glass shards for tephra fingerprinting (as here) or correlation (Lowe 2011, for review). To test the contrasts between analytical uncertainties and variability in glass compositions EPMA and LAICP-MS data of the ATHO-G standard were compiled to provide a robust estimate of analytical variability (Table 3.1; Supplementary Figure 3.1).

\subsubsection{Geothermobarometry}

Amphibole apparent temperature and pressure estimates and mineral formulae were calculated following the methods of Ridolfi et al. (2010) from samples at 9 horizons within the fall section. Using core and rim compositions and documenting the zoning within amphiboles allows investigation of apparent temperature changes over longer timescales than can be achieved by using Fe-Ti oxides alone. Uncertainties on apparent temperature estimates are $\pm 22{ }^{\circ} \mathrm{C}\left(\sigma_{\text {est }}\right)$ which do not vary with pressure (Ridolfi et al. 2010). Uncertainties on the barometer increase with pressure and decrease with temperature, and can range from 11-24\% (Ridolfi et al. 2010). 
Table 3.1. Mean major and trace element concentrations of the three glass types. Mean ATHO-G and $2 \mathrm{sd} \%$ values are shown for comparison. All standard reference values used were taken from GeoRem preferred reference values (http://georem.mpch-mainz.gwdg.de/).

\begin{tabular}{|c|c|c|c|c|c|c|c|c|c|c|}
\hline Element & Type A & 2 sd \% & Type B & 2 sd \% & Type C & 2 sd \% & ATHO-G & 2 sd \% & Ref. value & $\%$ Diff. \\
\hline$n$ & 650 & & 286 & & 84 & & 336 & & & \\
\hline $\mathrm{SiO}_{2}$ & 77.84 & 1 & 77.92 & 1 & 77.61 & 2 & 75.57 & 3 & 75.60 & 0 \\
\hline $\mathrm{TiO}_{2}$ & 0.12 & 45 & 0.10 & 36 & 0.13 & 58 & 0.24 & 13 & 0.26 & -8 \\
\hline $\mathrm{Al}_{2} \mathrm{O}_{3}$ & 12.47 & 3 & 12.52 & 2 & 12.71 & 3 & 12.27 & 2 & 12.20 & 1 \\
\hline $\mathrm{FeO}$ & 1.22 & 14 & 1.04 & 16 & 1.30 & 16 & 3.29 & 10 & 3.27 & 1 \\
\hline MgO & 0.11 & 28 & 0.09 & 36 & 0.12 & 49 & 0.10 & 32 & 0.10 & 1 \\
\hline $\mathrm{CaO}$ & 0.96 & 6 & 0.77 & 8 & 1.06 & 7 & 1.69 & 4 & 1.70 & 0 \\
\hline $\mathrm{Na}_{2} \mathrm{O}$ & 3.71 & 12 & 3.50 & 20 & 3.57 & 52 & $4.51^{a}$ & 7 & 3.75 & 17 \\
\hline $\mathrm{K}_{2} \mathrm{O}$ & 3.55 & 7 & 4.02 & 15 & 3.48 & 9 & 2.63 & 4 & 2.64 & 0 \\
\hline Total & 94.57 & & 93.91 & & 94.08 & & 100.38 & 2.20 & 99.24 & 1 \\
\hline$n$ & 105 & & 63 & & 20 & & 12 & & & \\
\hline $\mathrm{Li}$ & 51.7 & 16 & 42.9 & 65 & 50.7 & 24 & 30.4 & 4 & 28.6 & 7 \\
\hline MgO & 0.146 & 18 & 0.111 & 24 & 0.170 & 27 & 0.123 & 6 & 0.103 & 14 \\
\hline $\mathrm{CaO}$ & 0.936 & 17 & 0.746 & 21 & 1.05 & 15 & 1.69 & 6 & 1.70 & -2 \\
\hline Sc & 8.66 & 24 & 7.67 & 23 & 8.58 & 32 & 9.62 & 7 & 5.00 & 43 \\
\hline $\mathrm{TiO}_{2}$ & 0.143 & 11 & 0.112 & 23 & 0.157 & 20 & 0.271 & 5 & 0.255 & 7 \\
\hline $\mathbf{v}$ & 2.82 & 185 & 1.30 & 92 & 7.71 & 307 & 3.53 & 8 & 3.91 & -10 \\
\hline MnO & 0.040 & 9 & 0.038 & 16 & 0.043 & 9 & 0.103 & 2 & 0.106 & -3 \\
\hline $\mathrm{Cu}$ & 3.98 & 93 & 2.60 & 91 & 7.15 & 205 & 16.5 & 18 & 18.6 & -10 \\
\hline $\mathrm{Zn}$ & 38.9 & 37 & 38.4 & 34 & 36.7 & 46 & 149 & 6 & 141 & 5 \\
\hline $\mathbf{R b}$ & 136 & 9 & 149 & 8 & 135 & 10 & 62.7 & 4 & 65.3 & -4 \\
\hline $\mathrm{Sr}$ & 66.1 & 16 & 50.4 & 24 & 76.3 & 17 & 93.1 & 3 & 94.1 & -3 \\
\hline $\mathbf{Y}$ & 24.3 & 21 & 22.2 & 24 & 25.8 & 33 & 92.8 & 4 & 94.5 & -3 \\
\hline $\mathrm{Zr}$ & 119 & 19 & 87.6 & 36 & 136 & 25 & 513 & 4 & 512 & 0 \\
\hline $\mathrm{Nb}$ & 8.97 & 9 & 8.65 & 13 & 9.01 & 10 & 62.4 & 5 & 62.4 & 4 \\
\hline Mo & 1.50 & 48 & 1.78 & 38 & 1.29 & 52 & 3.98 & 19 & 4.80 & -14 \\
\hline Cs & 6.98 & 12 & 7.67 & 10 & 7.12 & 19 & 0.921 & 14 & 1.08 & -19 \\
\hline $\mathrm{Ba}$ & 826 & 9 & 839 & 13 & 833 & 8 & 547 & 4 & 547 & 0 \\
\hline La & 25.7 & 18 & 25.7 & 19 & 26.3 & 22 & 54.4 & 4 & 55.6 & -2 \\
\hline $\mathrm{Ce}$ & 52.9 & 8 & 54.0 & 10 & 53.3 & 9 & 123 & 3 & 121 & 1 \\
\hline Pr & 5.54 & 16 & 5.43 & 17 & 5.71 & 19 & 14.2 & 6 & 14.6 & -1 \\
\hline Nd & 21.4 & 18 & 20.0 & 21 & 22.0 & 21 & 61.9 & 5 & 60.9 & 2 \\
\hline $\mathrm{Sm}$ & 4.20 & 25 & 3.91 & 32 & 4.22 & 22 & 14.7 & 11 & 14.2 & 4 \\
\hline Eu & 0.559 & 35 & 0.433 & 45 & 0.609 & 42 & 2.72 & 12 & 2.76 & -2 \\
\hline Gd & 3.76 & 28 & 3.23 & 31 & 3.95 & 47 & 14.2 & 11 & 15.3 & -6 \\
\hline $\mathrm{Tb}$ & 0.577 & 27 & 0.517 & 36 & 0.634 & 40 & 2.42 & 7 & 2.51 & -4 \\
\hline Dy & 4.04 & 23 & 3.70 & 33 & 4.27 & 35 & 16.6 & 6 & 16.2 & 2 \\
\hline Ho & 0.850 & 26 & 0.756 & 28 & 0.875 & 36 & 3.33 & 9 & 3.43 & -1 \\
\hline $\mathrm{Er}$ & 2.59 & 25 & 2.40 & 31 & 2.70 & 32 & 10.4 & 11 & 10.3 & 3 \\
\hline $\mathrm{Tm}$ & 0.414 & 36 & 0.372 & 33 & 0.440 & 53 & 1.50 & 13 & 1.52 & 1 \\
\hline $\mathrm{Yb}$ & 2.75 & 31 & 2.68 & 28 & 2.92 & 38 & 10.4 & 13 & 10.5 & 0 \\
\hline Lu & 0.442 & 37 & 0.417 & 36 & 0.458 & 37 & 1.54 & 12 & 1.54 & -2 \\
\hline Hf & 3.74 & 24 & 3.00 & 35 & 4.15 & 29 & 13.6 & 12 & 13.7 & -3 \\
\hline $\mathrm{Ta}$ & 0.780 & 24 & 0.843 & 22 & 0.833 & 31 & 4.00 & 11 & 3.90 & 3 \\
\hline w & 1.74 & 36 & 1.92 & 27 & 1.89 & 46 & 8.78 & 16 & 9.30 & -1 \\
\hline $\mathrm{Pb}$ & 20.0 & 12 & 21.6 & 17 & 21.6 & 50 & 5.31 & 11 & 5.67 & -5 \\
\hline Th & 13.7 & 18 & 14.5 & 20 & 14.0 & 23 & 7.51 & 6 & 7.40 & 1 \\
\hline U & 3.14 & 10 & 3.44 & 12 & 2.97 & 15 & 2.34 & 11 & 2.37 & -1 \\
\hline
\end{tabular}

For magnesiohornblendes, at $90 \mathrm{MPa}(3.4 \mathrm{~km}$ depth) uncertainties are $\sim 11 \mathrm{MPa}(\sim 0.4$ $\mathrm{km})$ and at $300 \mathrm{MPa}(11 \mathrm{~km})$ uncertainties are as high as $\sim 60 \mathrm{MPa}(\sim 2.5 \mathrm{~km})$. 
Fe-Ti oxide temperature estimates were calculated using the method of Ghiorso and Evans (2008) from 6 horizons within the fall section. Co-existing Fe-Ti oxides have the ability to respond by diffusion on geologically rapid time scales and thus record magmatic temperatures on the order of days prior to eruption (Hammond and Taylor 1982; Venezky and Rutherford 1999). Fe-Ti oxides (ilmenite and magnetite) are present as both discrete crystals and hosted within orthopyroxene and amphibole. Discrete FeTi oxide crystals were not analysed due to the increased difficulties of determining equilibrium relationships and considerable oxidation of these crystals. Only coexisting Fe-Ti inclusions within the same host orthopyroxene phenocrysts were targeted to ensure textural equilibrium (Blundy et al. 2006). All chosen Fe-Ti oxide pairs were then tested for equilibrium following the method of Bacon and Hirschmann (1988) before use in thermometry calculations. The Ghiorso and Evans (2008) calibration has uncertainties of $\pm 44{ }^{\circ} \mathrm{C}$ average absolute deviation (Blundy and Cashman 2008).

\subsection{Results}

\subsubsection{Glass chemistry}

Between 47 and 111 individual matrix glass shards from each of 11 horizons within the fall deposit were analysed for major element chemistry by EPMA. Less than 100 shards were analysed where glass was more finely vesiculated, as these shards were often $<20$ $\mu \mathrm{m}$ in wall thickness. Sampling bias was tested by estimating the proportion of finely vesiculated glass shards from BSE images at each stratigraphic horizon. The proportion of finely vesiculated shards varies from $<10 \%$ in samples 4107, 4117, 4132 and 4134 to $\sim 70 \%$ in 4129 . Changes in the proportion of these shards are not systematic with stratigraphic height. While most major elements exhibit relatively uniform compositions, three compositional populations are identifiable, most clearly distinguished by $\mathrm{CaO}$ content (Figure 3.2a; Table 3.1): type A (0.90-1.00 wt. \% CaO), type $\mathrm{B}(0.72-0.82$ wt. \% CaO), and type $\mathrm{C}(1.00-1.10$ wt. \% CaO). These glass populations are also evident from $\mathrm{FeO}, \mathrm{K}_{2} \mathrm{O}, \mathrm{TiO}_{2}$ and $\mathrm{MgO}$ contents, although greater compositional overlaps characterise these elements. Each glass type is compositionally homogeneous in terms of major elements when analytical uncertainties assessed from the ATHO-G glass standard are considered (Supplementary Figure 3.1a). 
Relative proportions of the three glass types present at each horizon reveal a sequential and systematic change through the fall deposit (Figure 3.3). The base of the fall deposit, resting on the palaeosol, contains $100 \%$ type A glass and it is thus assumed that crystals from this basal horizon are associated with the type A glass end-member. Although density-driven mineral and glass fractionation during transport in the ash cloud and settling may have affected the absolute proportions of crystals to glass, it is not considered to have affected the eruptive ordering at the scale of the sampling resolution. The appearance (at $\sim 0.95 \mathrm{~m}$ above base) and increase of type B glass corresponds with the first occurrence and increase, respectively, of biotite in the fall section. Quartz abundance also increases in tune with the increasing proportions of type B glass. Type B glass becomes dominant at the top of the fall deposit, immediately below the ignimbrite (Figure 3.3). Type $\mathrm{C}$ glass appears above the base, is subordinate throughout the fall section and is absent at the top of the section (Figure 3.3). Type C glass is more closely linked in stratigraphic ordering and abundance, and in major element characteristics to type A than type B glasses. Overall approximate proportions of each glass type (1032 analyses) through the entire fall deposit thickness are: $68 \%$ type A, $22 \%$ - type B and $10 \%$ - type C.

Glass shards within selected horizons were targeted for LA-ICP-MS analysis on the basis of the $\mathrm{CaO}$ compositional groups described above. Trace element concentrations and, in particular, those of $\mathrm{Sr}$ (Figure 3.2b) and $\mathrm{Zr}$ in the selected samples further distinguish the three glass groups. Sr and Zr co-vary with light REE, Ba and Th in all glass populations suggesting these elements are behaving compatibly within each group. Each compositional group is slightly offset, suggesting minor differences in starting compositions, and compatible behavior in La during fractional crystallisation. These trends are consistent with a co-variation in Mg concentrations. Each group covers a similar range in composition but is distinguished by higher (type C) and lower (type B) $\mathrm{Sr}$ and $\mathrm{Zr}$ concentrations. Sr concentrations range from 53 to $76 \mathrm{ppm}$ in type A, 38 to $60 \mathrm{ppm}$ in type $\mathrm{B}$ and from 62 to $90 \mathrm{ppm}$ in type $\mathrm{C}$ glass shards. $\mathrm{Zr}$ concentrations range from 91 to $143 \mathrm{ppm}$ in type A, 66 to $107 \mathrm{ppm}$ in type B and from 112 to $172 \mathrm{ppm}$ in type C glass shards. All glass types show parallel trends and variations within each group that exceed the 2 sd analytical uncertainties (Supplementary Figure 3.1b; Table 

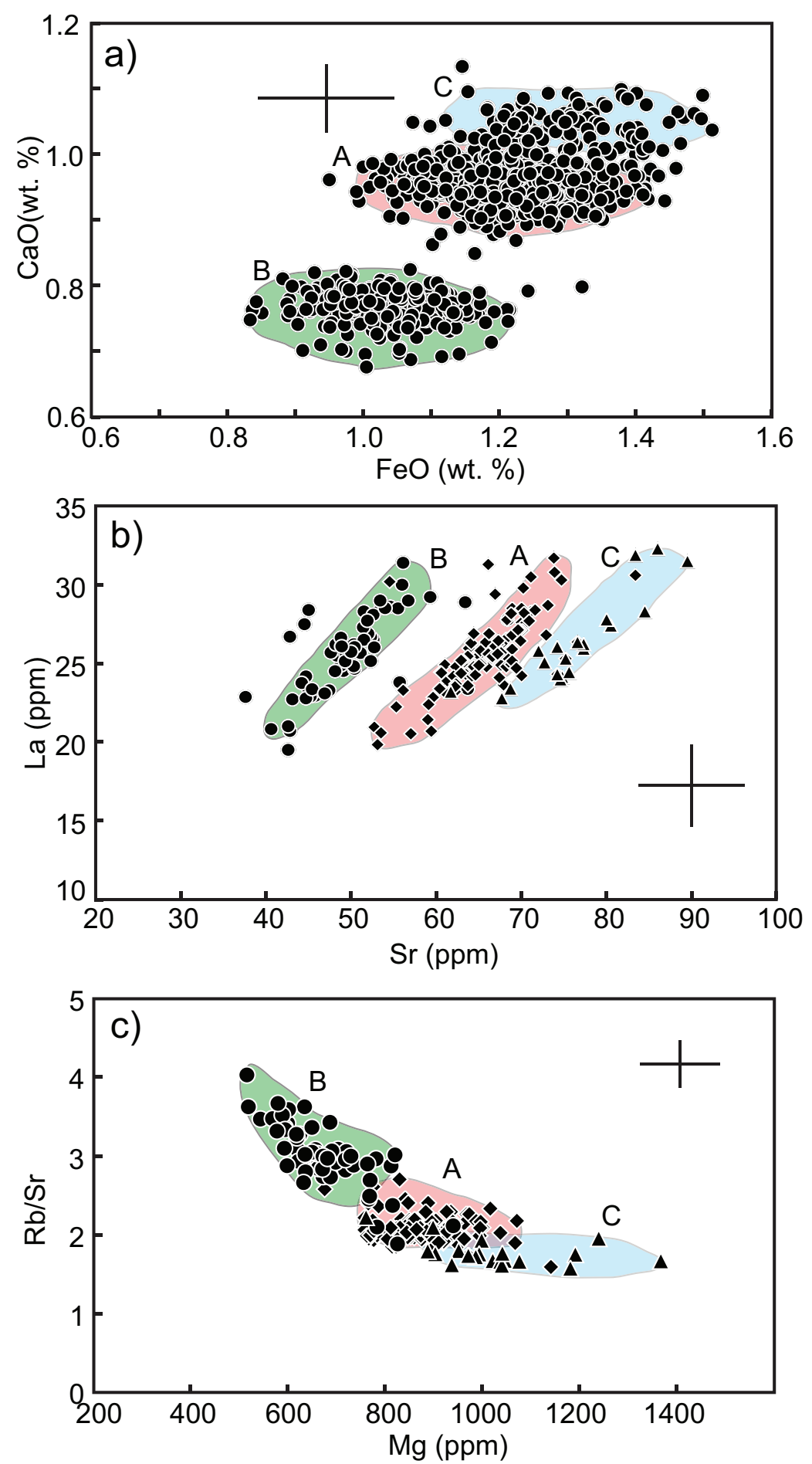

Fig. 3.2. Selected major and trace element plots of matrix glass shards from the Kidnappers fall deposit. The three compositional groups are first defined on the basis of $\mathrm{CaO}$ content, therefore all analyses within (a) are shown by circles. $\mathrm{CaO}$-defined groups are shown by diamonds (type A), circles (type B) and triangles (type C) in trace element plots (b, c). Coloured envelopes highlight the three groups within each plot. Crosses represent the $2 \mathrm{sd}$ error on individual analyses. 
3.1) of these trace elements. Each glass type therefore shows some internal heterogeneity with respect to trace element chemistry. Type $\mathrm{C}$ glass overlaps type A glass in all major and trace element plots, although the trends do not suggest that mixing has occurred between these groups (Figure 3.2b). $\mathrm{Mg}$ versus $\mathrm{Rb} / \mathrm{Sr}$ ratios (Figure 3.2c) display distinct groups that follow a typical differentiation trend. Type $\mathrm{C}$ glass has the least evolved and group B glass the most evolved trace element chemistries with the greatest range in $\mathrm{Rb} / \mathrm{Sr}$. We interpret this range to largely reflect the extent of plagioclase fractional crystallization experienced by the magma types. Positive trends of Th with $\mathrm{Sr}$ and $\mathrm{Zr}$, and no trend in $\mathrm{U}$ versus $\mathrm{Sr}$ and $\mathrm{Zr}$ suggest that $\mathrm{Th}$ is being preferentially fractionated. The presence of minor accessory allanite and/or monazite, in which Th and REE are highly compatible may explain these trends, although these have not been observed within this deposit. Rare earth element (REE) concentrations are typical of TVZ rhyolitic glasses (Allan et al. 2008) and are very similar in all groups. Chondrite normalized REE patterns all exhibit light REE enrichment and flat middle to heavy REE profiles. The average europium anomaly $\left(\mathrm{Eu} / \mathrm{Eu}^{*}\right)$ shows only minor differences between the three groups. Average major and trace element compositions of each glass type are presented in Table 3.1.

To assess the distinction between the three glass types, a mean and standard deviation, as well as the standard deviation of the mean was calculated for each element analysed by EPMA and LA-ICP-MS. The mean and $2 s_{\mathrm{m}}$ (standard deviation of the mean) of all glass types are significantly separated for all major elements, excluding $\mathrm{SiO}_{2}$ and $\mathrm{Al}_{2} \mathrm{O}_{3}$ and a number of trace elements (Supplementary Figure 3.2). Ellipses defining 95\% of data within a group assuming a 2-variable Gaussian distribution show no overlap between types $\mathrm{A}$ and $\mathrm{B}$ glass for $\mathrm{CaO}$ and $\mathrm{Zr}$ (Supplementary Figure 3.2). Ellipses of type $\mathrm{A}$ and $\mathrm{C}$ show a degree of overlap for the majority of paired element plots, however often the $95 \%$ confidence region of the bivariate mean (2 SE) of each group falls outside the 95\% ellipse of the other (Supplementary Figure 3.3). A more detailed discussion of this statistical study is included within the Supplementary Information file. On the basis of these results we consider each glass type to show significant statistical distinctions. 


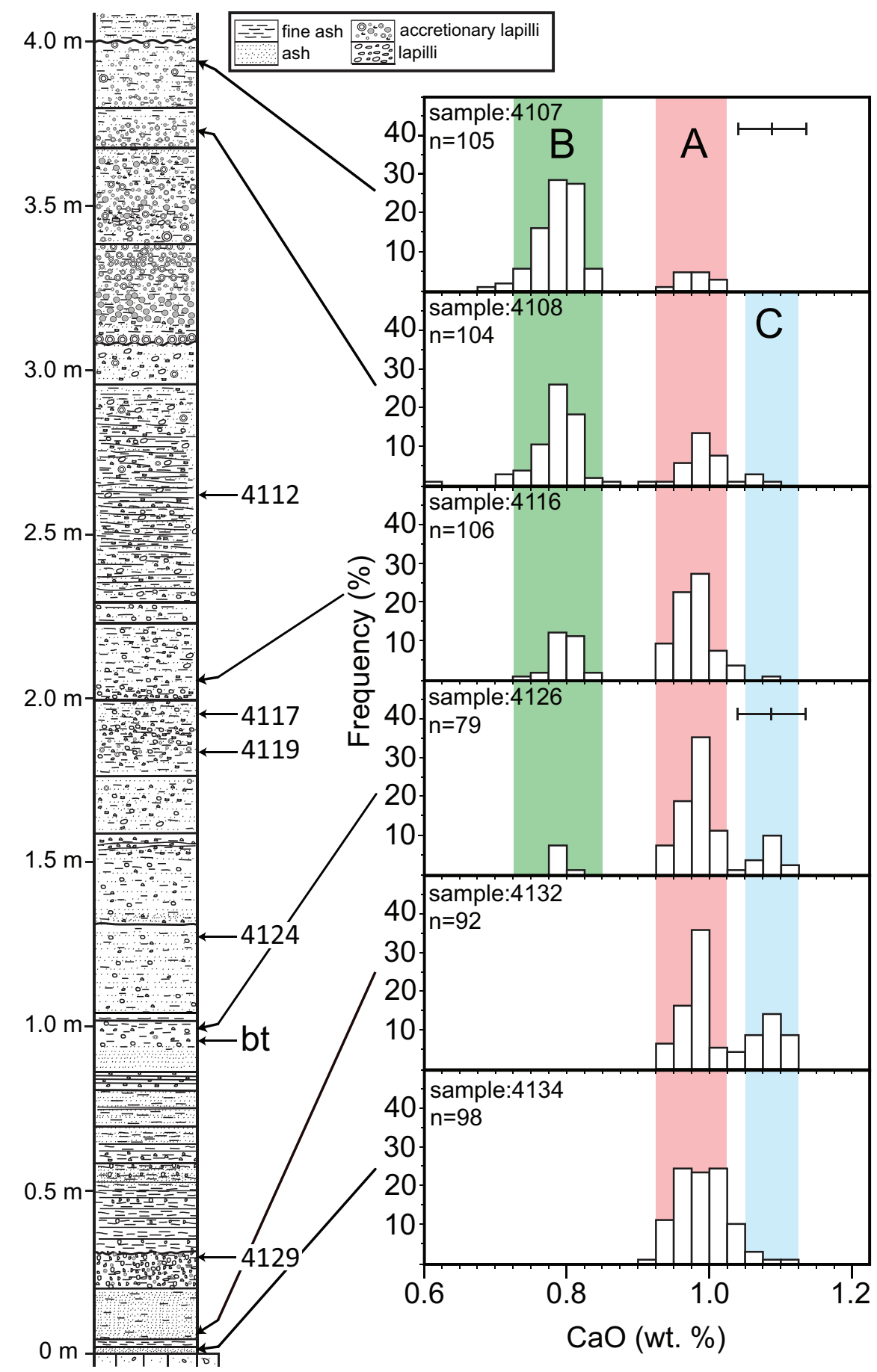

Fig. 3.3. Changes in the proportion of glass types through the $4.0 \mathrm{~m}$ section of the Kidnappers fall deposit. A simplified stratigraphic log of the proximal section is shown (following fieldwork by C.J.N. Wilson). Six selected histograms of $\mathrm{CaO}$ analyses at each horizon are displayed. Three modes in $\mathrm{CaO}$ through the deposit are highlighted, defining the three glass types (A, B, C). Note the first appearance of biotite (bt) and type B glass at $\sim 0.95 \mathrm{~m}$ and the gradual increase in the proportions of type B glass through the top $3.0 \mathrm{~m}$ of the deposit. The 2 sd error on a single analyses is represented by error bars. All 11 sampled horizons are labelled with sample numbers. 


\subsubsection{Mineral chemistry}

The fall deposit has a phenocryst assemblage of plagioclase + amphibole + quartz + orthopyroxene + ilmenite + magnetite \pm biotite with apatite and zircon occurring as accessory minerals. Biotite first appears at $\sim 0.95 \mathrm{~m}$ from the base. Quartz abundances increase upwards through the fall deposit.

Plagioclase phenocrysts are commonly $>1 \mathrm{~mm}$ in size, and at all horizons through the fall deposit display multiple zoning, suggesting that all the crystals have had complex growth histories. Plagioclase rim compositions throughout the deposit display a bimodal distribution with respect to $\mathrm{An}\left(\mathrm{mol} \%\right.$ ), at $\mathrm{An}_{32.5}$ and $\mathrm{An}_{37.5}$ (Figure 3.5a) and Or (mol $\%)$ at $\mathrm{Or}_{2.75}$ and $\mathrm{Or}_{3.75}$. Plagioclase rim compositions from the base of the fall deposit (i.e., where the type A glass overwhelmingly dominates) show a unimodal distribution at $\mathrm{An}_{37.5}$ and $\mathrm{Or}_{2.75}$ and a narrower range in major and trace element compositions compared to samples where types A and B are present. At least two groups are evident when plagioclase rim compositions are plotted against glass selvage chemistries (Figure 3.4). Higher $\mathrm{An}, \mathrm{Mg} /$ lower Or rim compositions correspond to plagioclase growing within the type $\mathrm{A}$ end member melt and the lower $\mathrm{An}, \mathrm{Mg} /$ higher Or rim compositions are from the type B melt composition (Figure 3.4). A number of higher $\mathrm{An}$ and $\mathrm{Mg}$ values may correspond to plagioclase associated with type $\mathrm{C}$ glass. Plagioclase core compositions show considerable overlap throughout the fall deposit and vary between $\mathrm{An}_{64-28}$ and $\mathrm{Or}_{3.90-0.85}$.

Orthopyroxene shows considerable compositional overlap throughout the fall deposit with no clear change between horizons or bimodality evident. Bright cores were occasionally observed in BSE images, although no zonation between the cores and rims are observed. Orthopyroxene rims, in general, show a tight compositional range between $\sim \mathrm{En}_{42-48}$ and $\mathrm{Wo}_{1.65-3.00}$. Cores show a similarly narrow range of compositions between $\sim \mathrm{En}_{43-50}$ and $\mathrm{Wo}_{1.75-3.50}$ with a wider scatter to $\mathrm{En}_{65}$ and $\mathrm{Wo}_{1.2-5.6}$.

Amphibole crystals are found within all horizons throughout the fall deposit and commonly display compositional zonation when viewed by BSE. Amphibole rims and the majority of cores classify as magnesiohornblendes; 14 cores are tschermakitic pargasite in composition, and 4 cores are magnesiohastingsites. Amphibole cores and 
rims between horizons show considerable compositional overlap. Amphibole rims cluster between 47.5 and $43.5 \% \mathrm{SiO}_{2}$, and cores display the same clustered composition, although some cores have $\mathrm{SiO}_{2}$ contents as low as $41.5 \mathrm{wt} \%$. Chondritenormalised REE patterns have strongly negative $\mathrm{Eu} / \mathrm{Eu}$ * from 0.16 to 0.61 (mean $=$ 0.27). Average amphibole $\mathrm{Eu} / \mathrm{Eu}^{*}$ values are slightly lower than glass $\mathrm{Eu} / \mathrm{Eu}^{*}$ but cover a similar range of values.
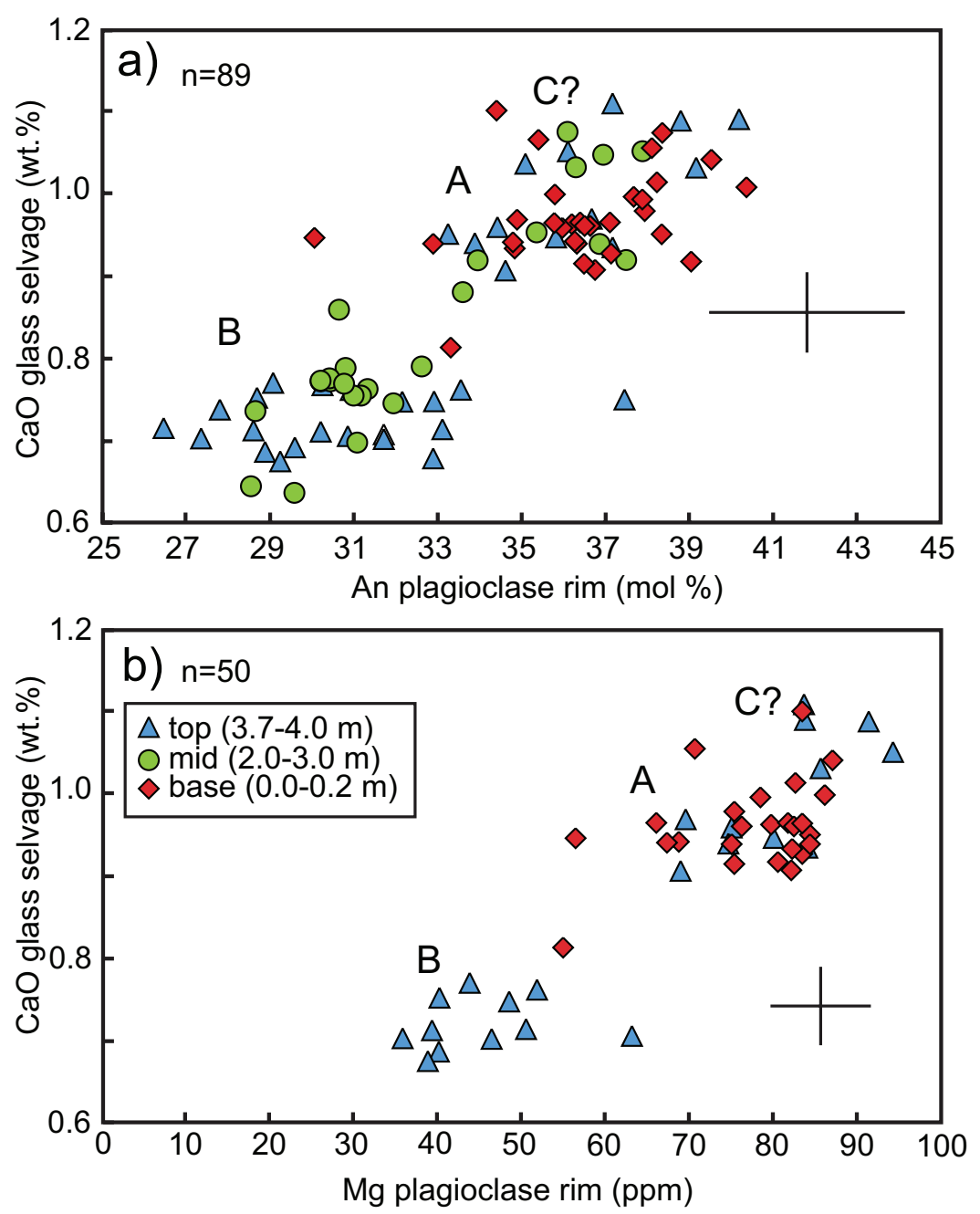

Fig. 3.4. (a) and (b) Plagioclase glass selvages (filled symbols) versus host plagioclase rim $\mathrm{An}$ and $\mathrm{Mg}$ throughout the fall deposit. Crosses represent the 2 sd error on each analysis. 

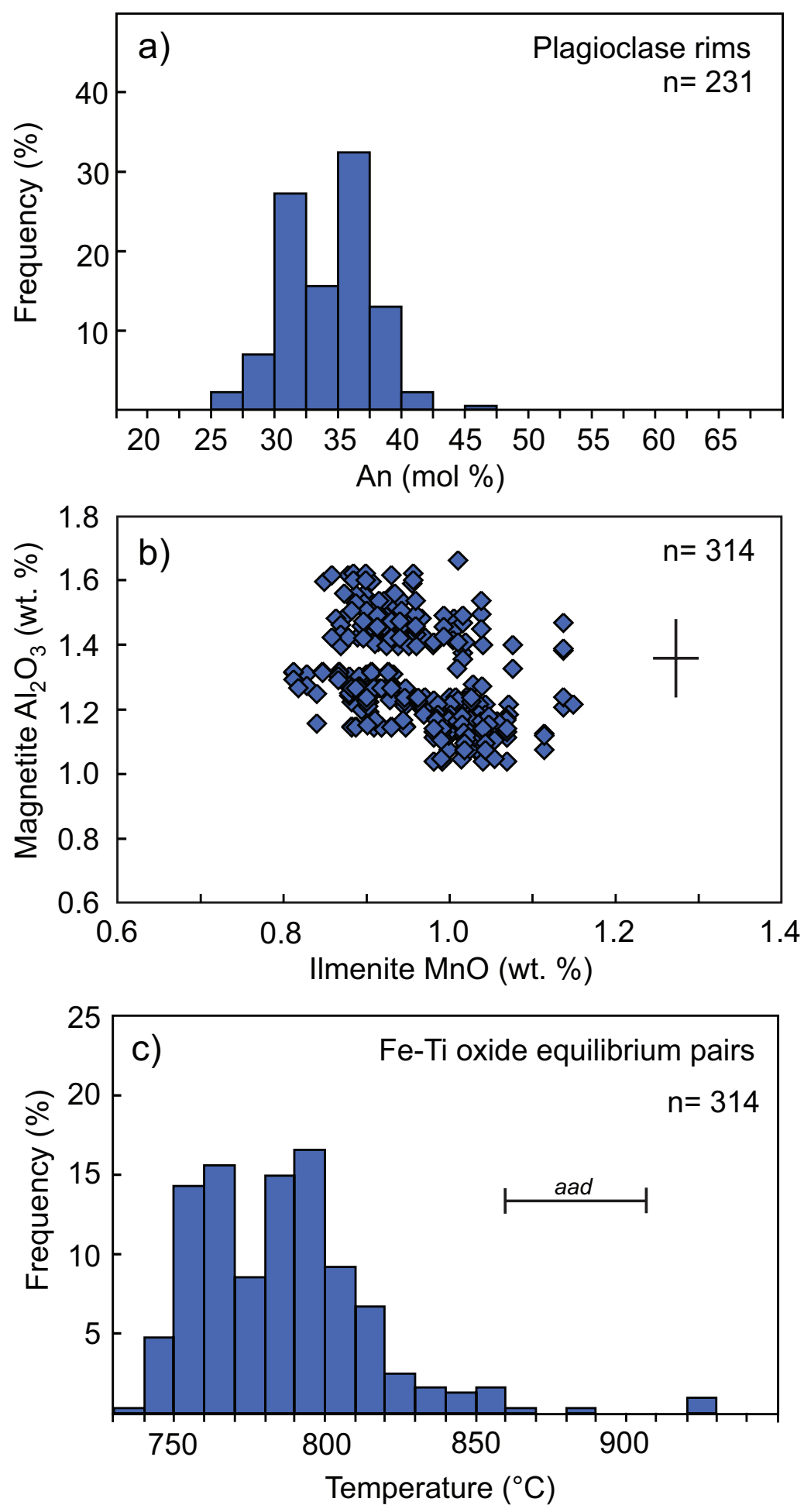

Fig. 3.5. (a) Histogram of total plagioclase rim An values showing the bimodal distribution, with modes at $\mathrm{An}_{32.5}$ and $\mathrm{An}_{37.7}$ (b) Plot of ilmenite $\mathrm{MnO}$ versus magnetite $\mathrm{Al}_{2} \mathrm{O}_{3}$ for $\mathrm{Fe}-\mathrm{Ti}$ oxide equilibrium pairs (defined by Bacon and Hirschmann 1988). Equilibrium pairs cluster into two groups, reflecting the bimodal temperature estimates in (c). (c) Total Fe-Ti oxide temperatures calculated using the method of Ghiorso and Evans (2008). A bimodal distribution is displayed, with modes at 760 and $790{ }^{\circ} \mathrm{C}$. The error bar represents the average absolute deviation (aad) from Blundy and Cashman (2008). 
Magnetite compositions fall in the range of $X^{\prime}$ usp $_{0.27-0.46}$ and show a bimodal distribution with respect to $\mathrm{Al}_{2} \mathrm{O}_{3}$. Ilmenite has a compositional range of $X^{\prime}{ }^{\prime} \operatorname{llm}_{0.87-0.93}$ and shows a bimodal distribution with respect to $\mathrm{MnO}$. Magnetite-ilmenite equilibrium pairs included within the same host orthopyroxene fall into two compositional groups (Figure 3.5b). The two compositional groups are reflected in bimodal Fe-Ti oxide temperatures (Figure 3.5c; Section 3.4.3).

\subsubsection{Geothermobarometry}

Hornblende cores from 9 horizons within the fall section display mean apparent temperatures between 797 and $810^{\circ} \mathrm{C}$ and mean apparent pressures between 117 and $148 \mathrm{MPa}$. Hornblende rims display mean temperatures between 782 and $795{ }^{\circ} \mathrm{C}$ and mean pressures from 105 to $120 \mathrm{MPa}$. Hornblende apparent temperatures and pressures do not show any systematic change through the fall deposit (Figure 3.6a,b). Both mean and modal temperatures and pressures from each horizon sampled are the same within analytical uncertainties. All amphiboles fall half way between their maximum thermal stability curve and the upper limit of consistent amphiboles and therefore pressure estimates have uncertainties between 11 and 24\% (Ridolfi et al. 2010). Amphibole trace element compositions, in particular $\mathrm{Sr}$ concentrations and $\mathrm{Eu} / \mathrm{Eu}^{*}$ anomalies, covary with these independently derived apparent temperature and pressure estimates. Hornblende $\mathrm{Eu} / \mathrm{Eu}^{*}$ values from the base of the deposit (accompanying the type A glass composition) and the top of the deposit (dominated by glass type B) both tightly cluster between 0.2 and 0.3 at $750-840{ }^{\circ} \mathrm{C}$ and $80-170 \mathrm{MPa}$ and extend to $\sim 0.6$ at higher temperatures and pressures (Figure 3.6c, d).

Fe-Ti oxide temperature estimates show a bimodal distribution throughout the deposit with modes at $\sim 760$ and $790{ }^{\circ} \mathrm{C}$ (Figure 3.5c). Temperature modes change from between ca. 780 and $810{ }^{\circ} \mathrm{C}$ at the base to $\sim 770$ and $800{ }^{\circ} \mathrm{C}$ at the top. The mean temperature at the base is $810{ }^{\circ} \mathrm{C}$ compared with $785^{\circ} \mathrm{C}$ at the top of the section. Caution must be placed on the subtle differences in absolute Fe-Ti oxide temperature estimates as they all fall within the uncertainties $\left(44{ }^{\circ} \mathrm{C}\right.$ average absolute deviation [Blundy and Cashman 2008]) of the Ghiorso and Evans (2008) calibration. However, we consider the bimodal distribution in both Fe-Ti oxide chemistry (Figure 3.5b) and 
temperature estimates (Figure 3.5c) recorded within 314 equilibrium pairs to be significant.
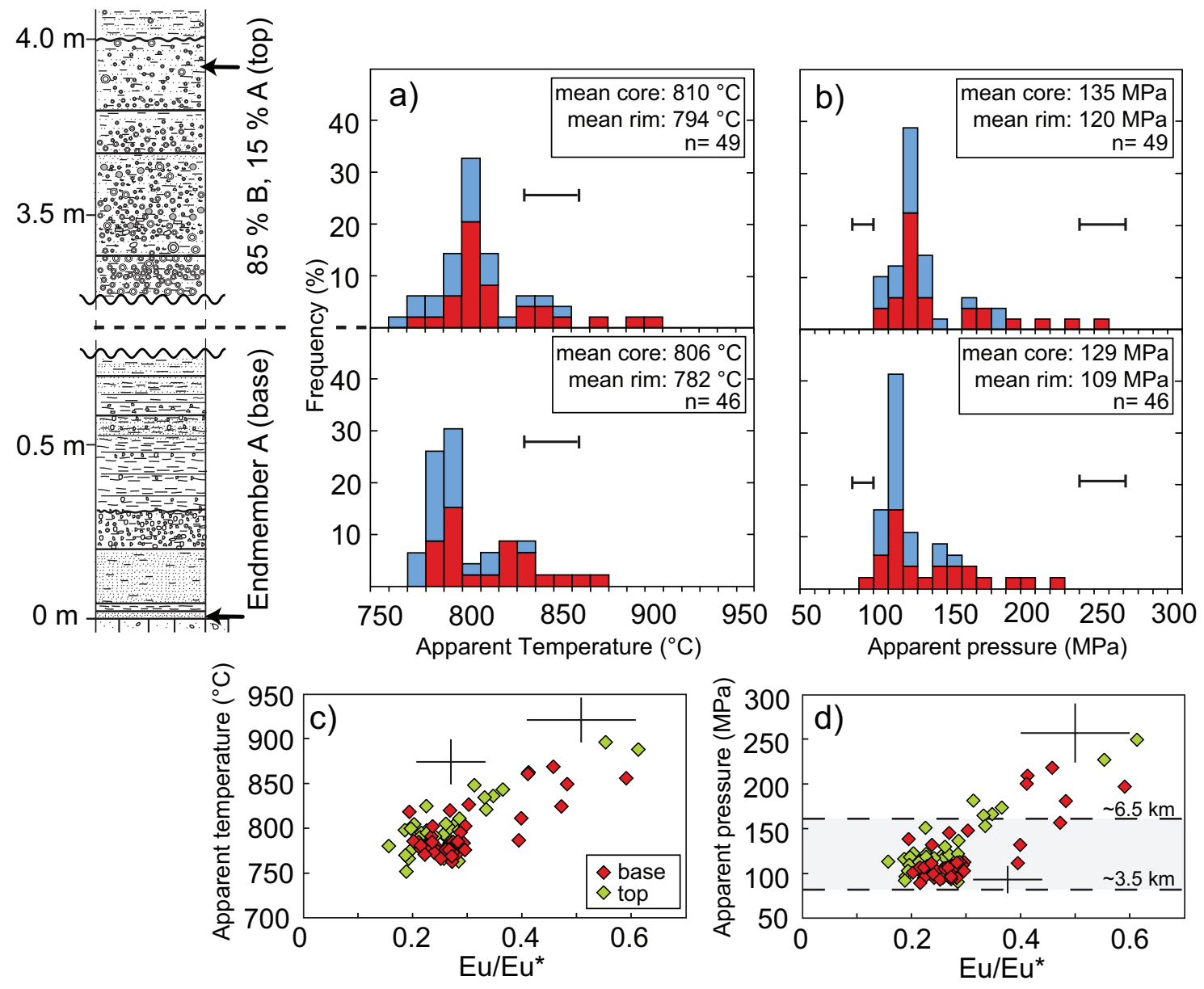

Fig. 3.6. Plots comparing amphibole apparent temperature and pressure estimates from the base of the fall (type A end member) and the top of the fall (primarily type B). All apparent temperatures and pressures were calculated using the method of Ridolfi et al. (2010). (a) and (b) Stacked frequency histograms of apparent temperatures (a) and pressures (b) from the base and top of the fall. Core (red) and rim (blue) temperatures and pressures cover a similar range and have similar means in the base and top of the fall. Error bars represent uncertainties on apparent temperature and pressure estimates from Ridolfi et al. (2010). (c) and (d) Amphibole Eu/Eu* versus amphibole temperatures (c) and pressures (d) from the base (red diamonds) and top (green diamonds) of the fall. Dashed lines correspond to approximate depths recorded by most amphiboles (inferred as magma chamber depths). Crosses represent the $2 \mathrm{sd}$ on $\mathrm{Eu} / \mathrm{Eu} *$ and the maximum error on T-P estimates. 


\subsection{Discussion}

\subsubsection{Stratigraphic controls and influences}

The proximal Kidnappers fall section allows for unambiguous stratigraphical control in sampling and therefore detailed mineralogical and geochemical changes through the first approximately two-thirds of the eruption can be recorded. Stratigraphic control within the overlying ignimbrite is minimal, due to a scarcity of marker planes and the wide spacing of exposures. The material within the fall section is limited in turn, however, as pumices reach only $\sim 1-2 \mathrm{~cm}$ in length; therefore glass shards and (glassselvedged) free crystals were analysed at multiple horizons. This approach assumes that the shards and crystals at each horizon are representative of the magma(s) being withdrawn at that particular stage of the eruption. Although the grain size of the deposit is very fine, poorly vesiculated glass shards $>125 \mu \mathrm{m}$ occur through most of the deposit and could be readily analysed by both EPMA and LA-ICP-MS. The proportion of finely vesiculated shards was estimated at each stratigraphic horizon and does not show any correlation with the proportion of glass types observed. The systematic changes in glass chemistry displayed through the deposit are therefore not due to sampling bias. A caveat to analyzing glass shards is that mixing on scales larger than the shard size may be obscured. However no mixed or mingled pumices have been observed in the overlying ignimbrite or any other eruptive deposit from Mangakino volcanic centre (Briggs et al. 1993).

Although the Kidnappers fall deposit contains multiple layers and evidence for changing intensities of eruption, no time breaks are observed within the deposit at any location (Wilson 1986, and unpublished data). The deposit displays a uniformity with a fine grain size, high abundance of accretionary lapilli and scarcity of foreign lithic fragments throughout, and was generated by large-scale magma interaction with surficial water (Self and Sparks 1978; Wilson et al. 1995b). In addition, the Kidnappers ignimbrite is un-welded throughout at all but one location (where it is sintered only), implying that virtually all of the extra-caldera deposits were heavily influenced by magma-water interaction. We infer that all the compositions represented in the fall deposits were erupted in a common style and came from vents that were closely enough spaced to have experienced the same 'wet' eruptive style, and have been dispersed by a single mega-plume. 


\subsubsection{Single or multiple magma chambers?}

The majority of models for compositional zonation within deposits of large silicic eruptions involve a single melt-dominant body (Hildreth 1981; Bachmann and Bergantz 2008 for reviews). Some examples involve a number of different magma compositional 'batches', which are either injected into, differentiate in-situ within, or have a close association with a larger, dominant magma chamber (e.g., Schuraytz et al. 1989; Streck and Grunder 1997; Brown et al. 1998a; Nairn et al. 2004). However, geochemical data from the Kidnappers fall deposit suggest a contrasting model for magma storage and production of a supereruption. There are a number of lines of evidence suggesting three magma chambers were tapped during this eruption:

1. The fall deposit does not follow a typical stratified magma chamber evacuation model, where more evolved material is erupted and deposited first, followed by eruption and deposition of progressively less evolved material (Hildreth 1981; Schuraytz et al. 1989; Streck and Grunder 1997). In the Kidnappers case, type A glass is deposited first, closely followed by the least evolved glass (C) followed by the appearance and progressive increase in the more evolved (B) glass. This 'non-classical' sequence is also evident from mineralogical changes through the deposit, with the appearance and increase in biotite, and an increase in quartz abundance with the increased presence of type B glass, and is also seen in the $340 \mathrm{ka}$ Whakamaru eruption deposits (Brown et al. 1998a). This suggests that either a zoned magma chamber was tapped by multiple vents or that multiple magma chambers were present. No significant shift in temperature and pressure estimates were observed from the base to the top of the fall with changes in chemistry which would be expected if a unitary stratified chamber was tapped by a single vent progressively withdrawing magma from greater depths.

2. Glass shard chemistry suggests that no mixing occurred between the three melts during the first two-thirds of the eruption as represented by the fall deposit. Major element plots show types A, B and C glasses as discrete compositional groups with no apparent mixing trends between groups. However, parallel covariant trace element trends suggest that each melt type underwent parallel, but independent evolution with respect to fractionating plagioclase and zircon (Figure 3.2). The absence of mixing between these melt types strongly suggests that the magma batches were separately stored, with no interaction prior to or 
during eruption. This suggestion is supported by the corresponding chemistries of plagioclase rims and selvages (Figure 3.4), indicating the growth of crystals within a particular individual magma host. The major and trace element chemistry of type $\mathrm{C}$ glass partially overlaps that of type A but appears to be a distinct group with no mixing (Figure 3.7). We propose that type $\mathrm{C}$ is from a smaller body of magma with similar conditions to the type A chamber. Type $\mathrm{C}$ glass appears and disappears in the fall deposit, and is always present with Type $\mathrm{A}$, and therefore it is possible that $\mathrm{A}$ and $\mathrm{C}$ erupted from a common vent (Figure 3.7).

3. Bimodal distributions in An content of plagioclase rims and Fe-Ti oxide-derived magma temperatures suggest there are at least two populations of crystals which have grown within predominantly types A and B melts. The bimodality of plagioclase rim compositions coupled with selvage chemistries (Figure 3.4) is observed in the fall deposit coincidentally with the appearance of type B glass and biotite providing further evidence for the involvement of at least two distinct magma types, each with its own distinctive crystal populations. Bimodal Fe-Ti oxide magma temperatures may represent subtle differences in conditions between each chamber prior to initiation of the eruption. It should be noted that the subtle differences and, in some cases, overlap in the chemistry of the crystal populations derived from the three melt types is consistent with the fact that only small compositional differences characterise these melts.

The approximate volumes of each magma type erupted can be estimated from the relative proportions of the three glass types averaged over the thickness of the fall deposit multiplied by the $400 \mathrm{~km}^{3}$ first-order estimate for the volume of the fall material. From this, erupted magma volumes were $\sim 270 \mathrm{~km}^{3}$ for type A, $\sim 90 \mathrm{~km}^{3}$ for type $\mathrm{B}$ and $40 \mathrm{~km}^{3}$ for type $\mathrm{C}$ (Figure 3.7 ). The type $\mathrm{C}$ glass disappears below the top of the fall deposit suggesting that the body from which it was erupted may have been fully evacuated during fall deposition. The magma bodies from which the three melts were derived also appear to display little or no evidence for stratification. Most hornblende $\mathrm{Eu} / \mathrm{Eu}^{*}$ values show a tight cluster in apparent pressure (90-170 $\mathrm{MPa}$ ) and temperature (750-840 ${ }^{\circ} \mathrm{C}$ ), providing independent evidence that the eruptible volume of magma was homogeneous (Figures 3.6 and 3.7). A number of hornblende cores have higher $\mathrm{Eu} / \mathrm{Eu}$ * that correlates with an increase in pressure (170-250 MPa) and temperature (840-900 
$\left.{ }^{\circ} \mathrm{C}\right)$ suggesting the contribution of crystals from greater depths $(8-11 \mathrm{~km})$. There is therefore the possibility of a crystal-rich source beneath the magma chambers with less evolved compositions. Minor compositional heterogeneity within glass types is also evident (Figure 3.2), beyond that attributable solely to analytical uncertainties (Supplementary Figure 3.1). However, mean glass compositions of types A and B glass at each sampled horizon do not show any significant change $(<10 \%)$ upwards through the fall deposit. The lack of a systematic compositional change within each melt type suggests the tapping of unzoned or homogeneous magma bodies (cf. Oruanui: Wilson et al. 2006).

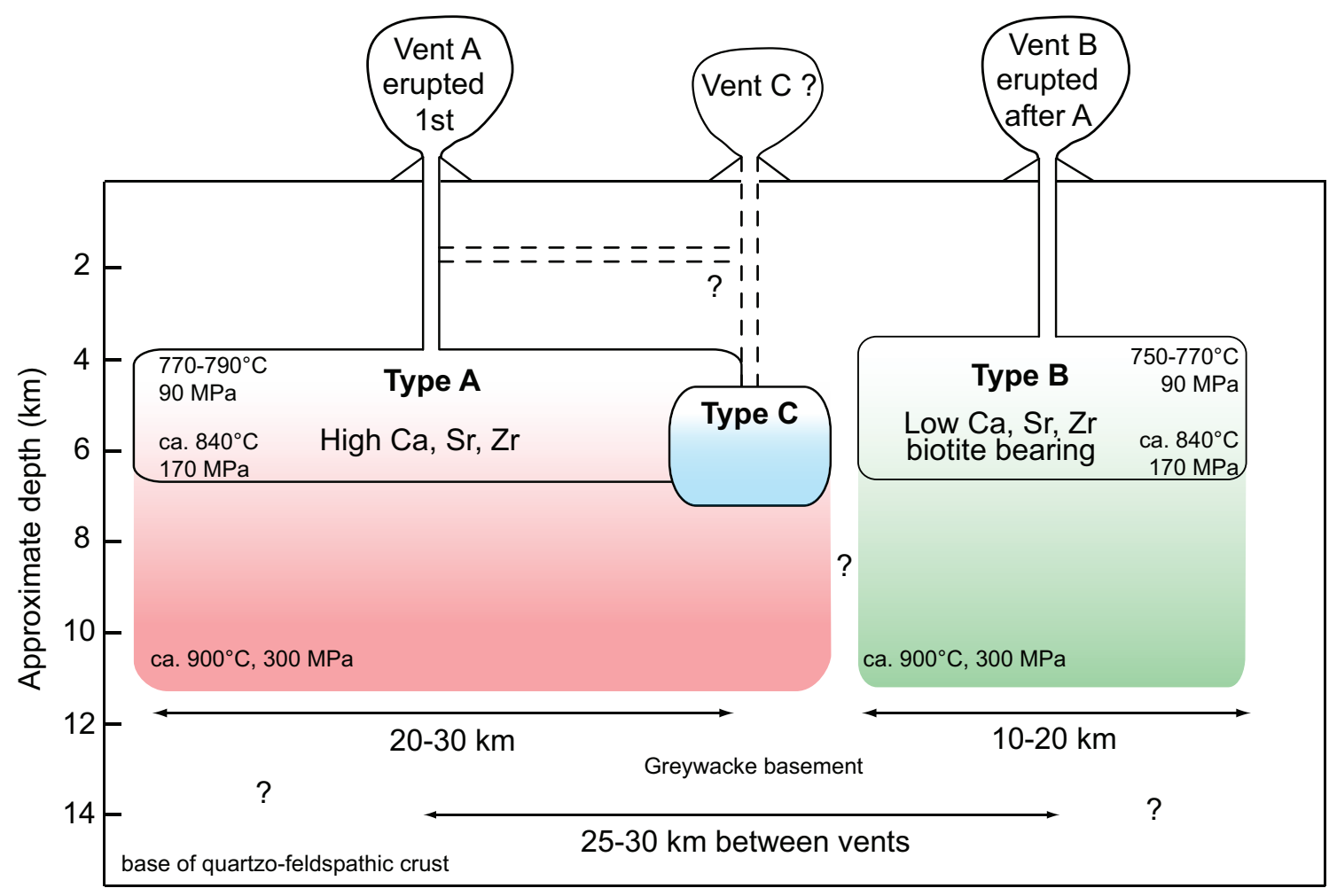

Fig. 3.7. Cartoon cross-section of the Kidnappers magma system, just prior to, or on the onset of eruption. Three independent melt-dominant bodies are found at approximately the same depth ( $4.0 \pm 0.5$ to $7.0 \pm 1.8 \mathrm{~km})$, estimated from amphibole apparent temperature and pressure calculations (see text and Figure 3.6 for explanation). Shaded boxes extending beneath the two melt-dominant bodies represent a deeper zone, inferred to be the source of amphiboles yielding 7-11 km model depth estimates. Types $\mathrm{C}$ and $\mathrm{A}$ material erupted synchronously, therefore the type $\mathrm{C}$ magma may have erupted from either the same vent as, or a separate vent to, that for magma type A (dashed lines). Vertical and horizontal scales are the same, but the horizontal dimensions are approximate only, to be consistent with the estimated volumes erupted of the respective magma types. See text for discussion. 


\subsubsection{Spatial relationship of the magma chambers}

Differences in the physicochemical conditions of the magma chambers can be used to constrain their positions in the crust and the spatial relationships between them. Similar apparent pressure estimates from amphiboles that crystallized from all three melt types thoughout the fall deposit imply that the three magma chambers were laterally adjacent in the crust, rather than vertically stacked at different depths. The majority of hornblende T-P estimates for melts $\mathrm{A}$ and $\mathrm{B}$ range from $770-840 \pm 22{ }^{\circ} \mathrm{C}$ and $90-170$ MPa corresponding to magma chamber depths between $\sim 3.5 \pm 0.4$ and $6.5 \pm 1.5 \mathrm{~km}$ (Figure 3.7), requiring the chambers to have occupied similar crustal depths. No shifts in T-P estimates are observed at horizons where type $\mathrm{C}$ is present and therefore the type C melt originated from a similar depth to type A and B melts (Figure 3.7). A tail of higher T-P estimates at all horizons indicates a contribution of crystals from beneath the melt-dominant bodies (up to $\sim 11.0 \pm 2.5 \mathrm{~km}$ ). The estimated depths are within the range of the majority of magma chamber depths for supereruptions worldwide. The meltdominant portions of magma chambers of the Oruanui (Liu et al. 2006; Wilson et al. 2006), Whakamaru (Brown et al. 1998a), Bishop (Wallace et al. 1999; Hildreth and Wilson 2007) and Fish Canyon (Bachmann et al. 2002) were all located between 4-11 km depth.

The vertical dimensions of the magma chambers associated with glass types A and B are inferred to be broadly similar due to the similar maximum and minimum temperature and pressure estimates throughout the fall section for crystals derived from the respective glass types. The precise number and location of the vents and the horizontal separation between the three chambers is not possible to constrain due to caldera collapse and burial of surface features. If all the vents were contained within the same large-scale caldera structure as might be indicated by the fact that all melt types were phreatomagmatically erupted, a maximum spread of 25-30 km can be inferred from the areal extent of the residual gravity low associated with Mangakino volcanic centre (Stern 1979; Wilson et al. 1984).

\subsubsection{Temporal evolution of the Kidnappers supereruption}

The synchronous tapping of three, independent but closely spaced magma bodies of similar size (within an order of magnitude) is unique in models for large silicic 
eruptions. The Kidnappers supereruption began with evacuation from magma chamber A prior to the initiation of tapping of magma chamber $\mathrm{C}$ for a short period of time before the tapping of magma chamber B began. Magma type B glass increases in importance sequentially through the fall deposit, suggesting a progressive increase in the proportion of material being erupted coming from chamber B. The observed systematic tapping of the three magma chambers raises questions over trigger mechanisms. Paired eruptions such as the 240 ka Mamaku-Ohakuri ignimbrites from the TVZ are thought to have had a tectonic control related to large scale rifting events (Gravley et al. 2007). Field relationships there demonstrate that the Mamaku and Ohakuri ignimbrites were erupted from two geographically separated sources with each system active sequentially, then at times simultaneously. Compositional contrasts between the two magma bodies are minor, however. In the case of the Kidnappers eruption, material from the three melt-dominant bodies makes up one coherent fall deposit, and therefore it is not possible to distinguish the eruption deposits from any individual chamber on field evidence alone. Simultaneous eruption of discrete magmas has been suggested for other eruptions from Mangakino. The Marshall ignimbrites at 0.9 Ma display two distinct chemical and isotopic groups which have been proposed to have erupted from discrete magmas from slightly different sources (Briggs et al. 1993). It is therefore possible that multiple discrete magma bodies characterise the Mangakino volcanic centre. The closely successive 61 ka Rotoiti and Earthquake Flat eruptions display no significant time break (Nairn and Kohn 1973) and their sources are only $\sim 15$ $20 \mathrm{~km}$ apart. Even with their close proximity, their chemistries and zircon crystallization age patterns suggest that their magma bodies developed independently (Davis 1985; Charlier et al. 2003). In this case, faulting related to the Rotoiti calderaforming eruption triggered the smaller Earthquake Flat eruption. In the case of the Kidnappers, it is plausible that the tapping of magma chamber B and/or magma chamber $\mathrm{C}$ was triggered by tectonic readjustment following partial drainage of magma chamber A.

Similarities in eruptive relationships may be drawn between the Kidnappers and the Whakamaru supereruptions from the TVZ (Brown et al. 1998a). The Whakamaru eruption (340 ka) produced $>1500 \mathrm{~km}^{3}$ of magma and two independent magma bodies were tapped during the event (Brown et al. 1998a). The Whakamaru caldera has been suggested to comprise multiple collapses (nested caldera) (Gravley et al. 2007) and this 
morphological style may have also resulted from the Kidnappers supereruption, but later burial of caldera structures precludes further interpretation. The Kidnappers fall deposit is one coherent unit with no field separation of the three magma types and therefore plumes from the two or three vents have completely merged prior to deposition. The interaction and mixing of plumes implies that the vents are in close proximity to each other and may also have contributed towards the exceptionally wide dispersal of the fall deposits.

\subsection{Conclusions}

A detailed major and trace element study of the glass shards and minerals from the fall deposit of the 1.0 Ma Kidnappers supereruption delineates three distinct compositional types of magma and establishes their ordering of evacuation. Such information could not be obtained from individual clasts (pumice fragments) in this case because of the fine-grained nature of the fall deposit, and so this opens up new possibilities for investigating deposits where macroscopic clasts are not available. Such an approach has previously been applied to some vitric co-ignimbrite deposits (e.g. Perkins and Nash 2002; Cathey and Nash 2004), but in studies of glass compositions from single fall units, compositional groupings were still ascribed to layers within a unitary system. From our data we conclude the following.

(1) Three independent magma bodies were tapped during the Kidnappers eruption reflected in three glass types $(\mathrm{A}, \mathrm{B}, \mathrm{C})$ recorded within the fall deposit on the basis of both major and trace element compositions. Volumes of the three corresponding magma types erupted to form the fall deposit are (in $\mathrm{km}^{3}$ ), are $\sim 270$ (type A), $\sim 90$ (type B) and $\sim 40$ (type C). We suggest that all three magma types underwent independent evolution with no interaction or mixing prior to eruption. The ranges in glass chemistry observed are largely a reflection of variable fractionation of plagioclase and zircon, and minor heterogeneity is found within each compositional group. Bimodality in plagioclase rim compositions and Fe-Ti oxides suggest growth from at least two different melts. The effectively complete overlap in apparent pressures recorded in amphibole compositions imply that the magma bodies were separated horizontally in the crust and could not have formed as discrete, vertically arranged layers within a single magmatic system.

(2) The tapping of the three magma chambers was systematic, reflected in a sequential change in the proportion of glass types through the fall section. The Kidnappers 
eruption began with the evacuation of type A material, closely followed by the associated type $\mathrm{C}$ material (least evolved) before type B magma (most evolved) began to be tapped. The first appearances of type B glass and biotite coincide; this, and their subsequently increasing proportions along with that of quartz provides further evidence for the evacuation of a distinct magma type. Material from the three erupting chambers make up one composite fall unit and therefore this eruption sequence cannot be inferred from field evidence alone. This study highlights the importance of strategic sampling of fall units in the reconstructing of magma chambers and eruption sequences.

(3) The systematic tapping of the three magma chambers and inferences on the horizontal separation of the magma bodies strongly imply a tectonic control. The Kidnappers draws similarities to other New Zealand examples, such as the MamakuOhakuri and the Rotoiti-Earthquake Flat eruptions where paired eruptions were triggered or accompanied by regional faulting. However, the magmas in the Kidnappers eruption are unique in that the three eruptions were synchronous and all of large scale. The locations of vents are not constrained but are inferred to have been in close proximity due to the complete mixing of fall material and interaction of all materials with water (from a common caldera lake?) during the eruption. 


\subsection{Supplementary Information}

\subsubsection{Major element analysis by electron microprobe (EPMA)}

Backscattered electron (BSE) imaging and quantitative major element analyses were carried out using a JEOL JXA-8230 Superprobe at Victoria University of Wellington. Glass shards were analysed using an accelerating voltage of $15 \mathrm{kV}$ and a beam current of $8 \mathrm{nA}$ with a defocused ( $20 \mu \mathrm{m}$ diameter) electron beam with $30 \mathrm{~s}$ measurements on peak and $15 \mathrm{~s}$ measurements on backgrounds either side of the peak. $\mathrm{Na}_{2} \mathrm{O}$ and $\mathrm{K}_{2} \mathrm{O}$ were measured first during each analysis to minimise alkali migration. Minerals were analysed using an accelerating voltage of $15 \mathrm{kV}$ and a beam current of $12 \mathrm{nA}$ with a focused beam, with $30 \mathrm{~s}$ measurements on peak and $15 \mathrm{~s}$ measurements on backgrounds either side of the peak.

The electron microprobe was calibrated regularly using a series of natural and synthetic standards. Natural standards were chosen to be suitably matrix-matched to each mineral phase being analysed. The natural standards used for both calibration and monitoring instrumental drift during each run were plagioclase NMNH 115900, Engels amphibole, hypersthene USNM 746, magnetite NMNH 96189, ilmenite NMNH 96189 and ATHOG rhyolitic glass. The ATHO-G reference standard was measured routinely during analytical sessions of glass measurements to monitor any analytical drift (typically 4-5 points on ATHO-G for every 20-30 points on unknowns) (Supplementary Figure 3.1).

\subsubsection{Trace element analysis by laser ablation inductively coupled plasma mass} spectrometry (LA-ICP-MS)

The trace element compositions of glass shards and amphibole from selected horizons were determined using a New Wave deep UV (193 nm solid state) laser ablation system coupled to an Agilent 7500CS ICP-MS at Victoria University of Wellington. All data were acquired as static spot analyses with a beam diameter of $35 \mu \mathrm{m}$, a laser repetition rate of $5 \mathrm{~Hz}, 85 \%$ laser power and using helium as the carrier gas. The ICP-MS raw csv data files were processed using Igor Pro v. 6.21 and the Iolite v. 6.23 software add on (Hellstrom et al. 2008). Data was processed using an internal standard data reduction scheme (Woodhead et al. 2007). $\mathrm{SiO}_{2}$ was determined by EMPA prior to LA-ICP-MS analysis such that ${ }^{29} \mathrm{Si}$ was used as the internal standard, which is more appropriate than 
${ }^{43} \mathrm{Ca}$ given the low Ca content of the rhyolitic glasses in these samples. NIST 612 was used as the calibration standard for calculating trace element abundances of rhyolitic glass. BCR-2 was used as the calibration standard for analyses of amphibole. ATHO-G and BHVO-2-G were analysed as secondary standards during each analytical run to allow assessment of the precision and accuracy of trace element analyses when the instrument was calibrated using NIST 612 (ATHO-G) and BCR-2 (BHVO-2-G), respectively. All standard reference values used were taken from GeoRem preferred reference values (http://georem.mpch-mainz.gwdg.de/) (Table 3.1).
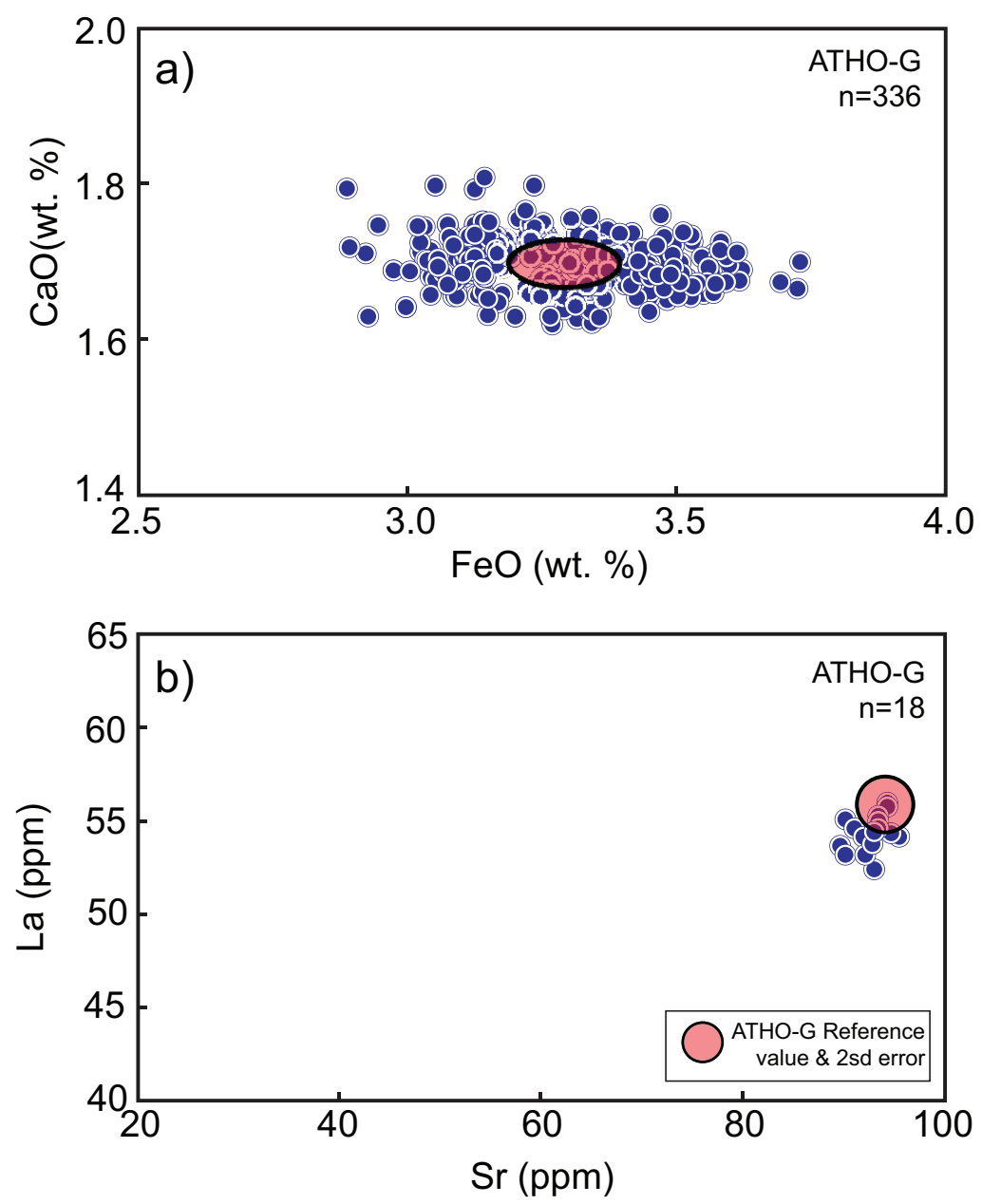

Supp. Fig. 3.1. (a) All ATHO-G electron microprobe analyses during the course of this study. The ATHO-G reference values are from GeoRem preferred values (http://georem.mpch-mainz.gwdg.de/). The red ellipse indicates the 2 sd error on the preferred reference value. ATHO-G $\mathrm{FeO}$ and $\mathrm{CaO}$ values form an ellipse centered on the reference value. Note that the size of the ellipse is similar to the $\mathrm{FeO}$ versus $\mathrm{CaO}$ ellipses of matrix glass shards shown in Fig. 3(a). (b) ATHO-G La and Sr concentrations during LA-ICP-MS of glass shards. Symbols as in (a). 


\subsubsection{Statistical treatment of glass shard chemistry}

For elements analysed by EPMA and LA-ICPMS, and for each glass type (A, B and C), a mean and standard deviation, $s$, was calculated, as well as the standard deviation of the mean $s_{\mathrm{m}}$ :

$$
s_{\mathrm{m}}=s / \sqrt{ } \text { (number of samples for the element in the subgroup) }
$$

These are displayed in Supplementary Figure 3.2 with 95\% error bars for the mean, being $\pm 1.96 \mathrm{~s}_{\mathrm{m}}$. For the purpose of demonstrating the differences between each group across all elements, each element's mean and standard deviation have been scaled by its overall mean, so that the overall mean plots at 1 . These statistics are presented in a different way in Supplementary Figure 3.3. It is assumed that each element pair in each group belongs, jointly, to a bivariate Normal distribution, with the means as given above. In general, lines of equal probability for such a distribution are ellipses, with the ellipse being inclined to the axes where there is correlation between the two variables. The axes of the ellipse were calculated as the eigenvectors of the sample covariance matrix of the paired data, with the semi-axes being the square roots of the corresponding eigenvalues. Extreme outliers were rejected before statistic treatment of the data.

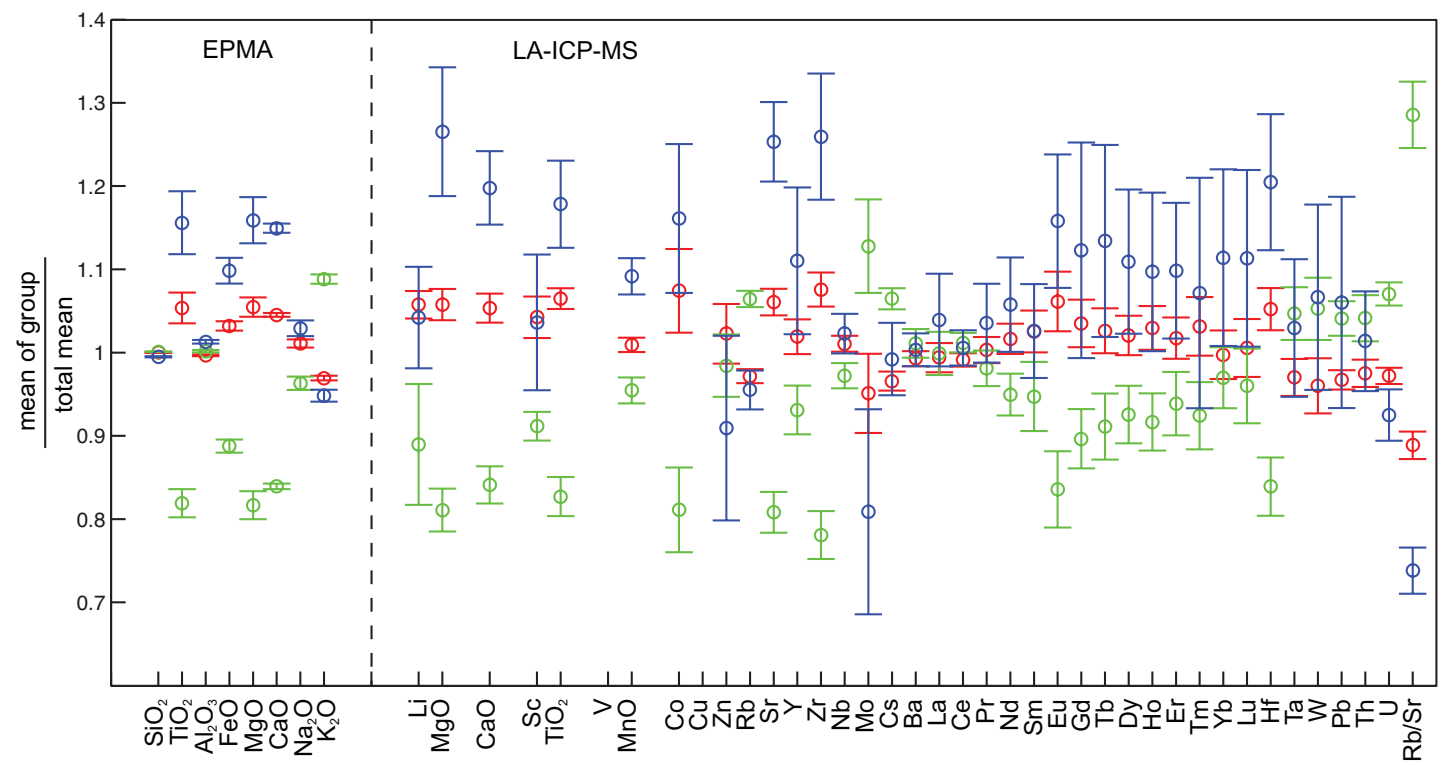

Supp. Fig. 3.2. Means (circles) and $95 \%$ error bars for the mean $\left( \pm 1.96 s_{\mathrm{m}}\right)$ of glass types A (red), B (green) and C (blue) for each element analysed by EPMA and LA-ICP-MS. Glass types originally defined by $\mathrm{CaO}$. Each elements mean and standard deviation have been scaled by its overall mean, so that the overall mean plots at 1 . 

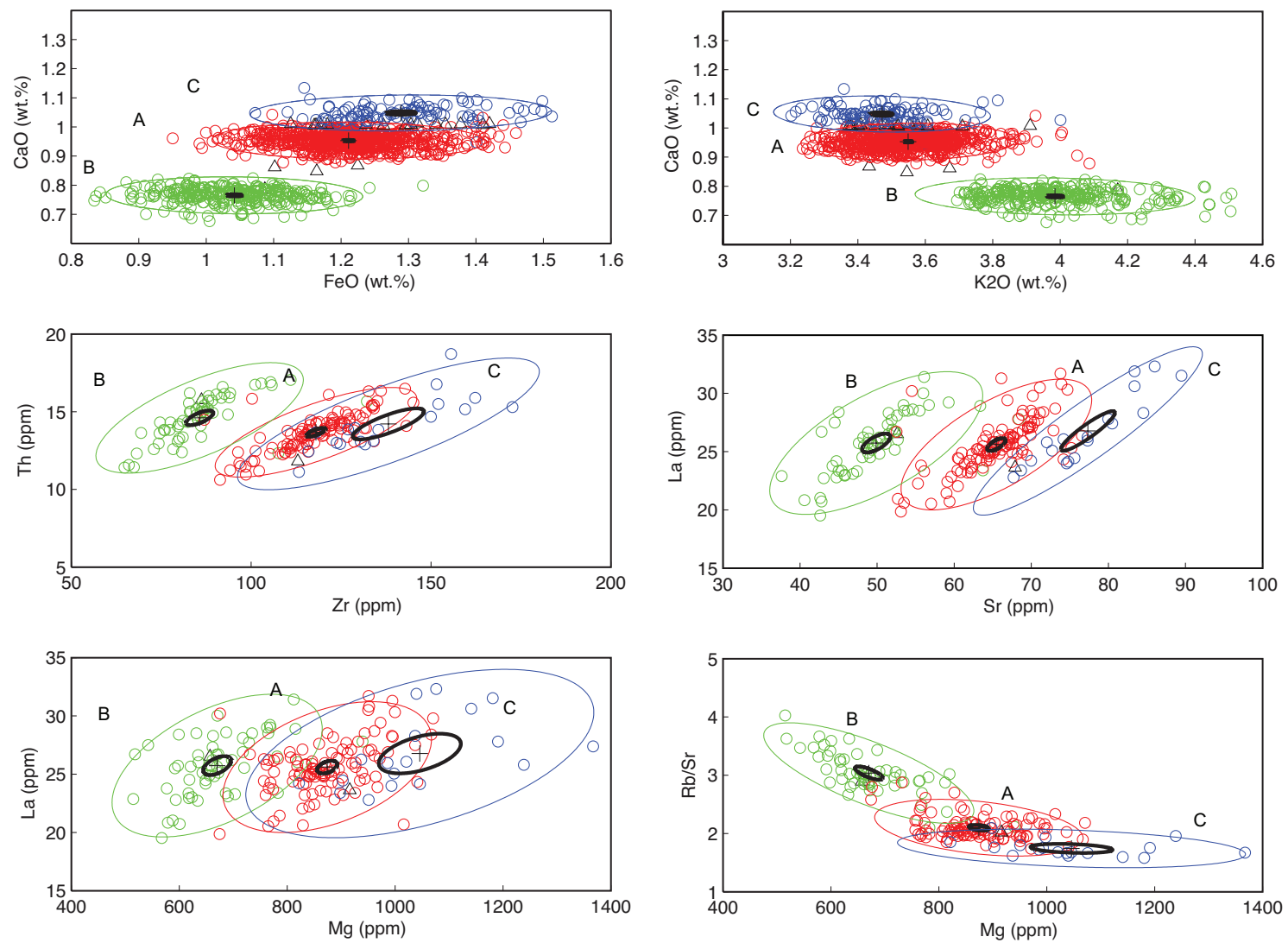

Supp. Fig. 3.3. Six selected plots to display the statistical treatment of major and trace element glass chemistry. The outer (coloured) ellipse contains (approximately) 95\% of the data assuming a 2-variable Gaussian distribution; the inner ellipse (black) is a $95 \%$ confidence region (2 SE) for the bivariate mean (black cross). See text for discussion. 
Chapter 4 


\section{Rejuvenation and renewed eruption of a supervolcanic system: Case study of the Mangakino caldera, Taupo Volcanic Zone, New Zealand}

\subsection{Introduction}

Reconstructing the processes that occur in silicic magma systems prior and during exceptionally large explosive eruptions, and understanding how such vast parental bodies of magma are generated, stored and ultimately erupted is challenging.

Worldwide, examples of supereruptions (caldera forming events in which $>10^{15} \mathrm{~kg} \approx$ $450 \mathrm{~km}^{3}$ of magma are erupted: e.g., Sparks et al. 2005; Self 2006; Miller and Wark 2008) have been shown to have many complexities. Detailed and integrated analytical approaches along with reliable field observations are therefore needed when studying these catastrophic events. The timing of generation and establishment of large silicic systems is a key issue when studying exceptionally large silicic eruptions. Constraining timescales of accumulation and generation of a magmatic system can be made from age determinations of accessory minerals such as zircon or allanite (Vazquez and Reid 2004; Charlier et al. 2005; Simon and Reid 2005; Bachmann et al. 2007; Wilson and Charlier 2009). The U-Pb age spectra from the Kidnappers and Rocky Hill ignimbrites have almost identical distributions, suggesting that the growth of zircon occurred within a common magmatic system (Chapter 2). The age spectra show that crystal growth in the Kidnappers/Rocky Hill system occurred over a period of $\sim 200$ kyr prior to eruption at $\sim 1 \mathrm{Ma}$ (Chapter 2).

The proposed nature and storage of large silicic magma bodies, and how chemical zonation (if any) is accommodated within these magma systems varies considerably. Hildreth (1981) presented the classic high-silica rhyolite magma chamber model, where chemical or physical magma chamber zonation is inversely reflected in the eruption deposits (Smith 1979; Bachmann and Bergantz 2008). This model appears to be valid in explaining the compositional variation within the Bishop Tuff, Long Valley, California (760 ka), which is considered to arise from a single stratified magma body. In this case crystal-poorer, more evolved magmas are erupted first, followed by crystal-richer, less 
evolved magmas, with gradients in crystal content matching gradients in both chemical and mineralogical properties (e.g., Hildreth and Wilson 2007). Many large TVZ rhyolitic deposits have significant compositional variations within the same eruptive unit (e.g. Briggs et al. 1993; Brown et al. 1998a, Milner et al. 2003; Wilson et al. 2006; Deering et al. 2011; Allan et al. 2013). These variations are, however, not always systematic; the compositions may be reversely ordered, or be distributed such that multiple discrete magma bodies are inferred to have been tapped within single eruptive events.

Tectonics has been shown to play a role in the triggering of large silicic eruptions in the TVZ, for example the $25.4 \mathrm{ka}$ Oruanui ignimbrite (Allan et al. 2012), the $240 \mathrm{ka}$ Mamaku-Ohakuri ignimbrites (Gravley et al. 2007) and the Rotoiti and Earthquake Flat eruptions (Nairn and Kohn 1973; Charlier et al. 2003). The rise and underplating of mafic magmas can also play a role in generating and mobilising eruptible melt, and is often considered to be a potential trigger mechanism for eruption (Sparks et al. 1977; Pallister et al. 1992). An injection of hotter, lower viscosity, volatile rich magma is accompanied by a thermal, material and volatile exchange. This interaction leads to a decrease in the viscosity of silicic magma, potentially inducing it to erupt. Alternatively, mafic underplating may provide the heat needed to cause significant convective stirring in a melt-dominant body (Couch et al. 2001).

With the possible exception of Toba (Chesner and Rose 1991), single caldera eruptions are rarely isolated, but are coupled with numerous smaller pre- and post-caldera eruptions from a common volcanic centre. The Yellowstone caldera complex has at least 25 lava domes associated with the third post-caldera sequence (Girard and Stix 2010; Pritchard and Larson 2012; Watts et al. 2012). The Valles caldera, New Mexico, is considered as the 'type' resurgent caldera (Self et al. 1986; Kennedy et al. 2012), from which two large units, the Otowi (Lower Bandelier: 1.61 Ma) and Tshirege (Upper Bandelier: 1.25 Ma) were erupted (Smith and Bailey 1968; Wolff et al. 1999; Phillips et al. 2007). After eruption of the Bandelier Tuffs, a series of smaller rhyolitic lavas and accompanying tephras were erupted from 1.25-0.52 Ma (Gardner et al. 2010; Wolff et al. 2011). The Cerro Toledo Rhyolite, comprising domes and tephras, are also found between the two episodes of the Bandelier Tuff, allowing the evolution of magma over 
this time interval to be tracked (Stix and Gorton, 1993; Spell et al. 1996; Gardner et al. 2010). A large number of pre-caldera (Glass Mountain) and post-caldera sequence rhyolite domes are associated with the Long Valley Caldera from which the Bishop Tuff was erupted (Metz and Mahood 1985, 1991; Hildreth 2004). In each of these systems, pre- and post-caldera activity, short timescales $\left(<10^{4}\right.$ years $)$ before and after the climactic eruption is in the form of small-volume explosive activity, resurgent dome lavas and intrusions. There are, however, no documented examples of silicic systems with another major caldera-forming eruption within a short interval after a supereruption. The Kidnappers and Rocky Hill caldera-forming events from Taupo Volcanic Zone (TVZ), New Zealand are both inferred to have been sourced from the Mangakino volcanic centre (Wilson 1986) and were erupted in close succession (both within the Jaramillo subchron and with identical ages at $\sim 1 \mathrm{Ma}$ ). They collectively provide windows into the short-term processes involved in the development and posteruptive state of a supervolcanic system, and the timescales over which they take place.

This chapter presents an extensive geochemical and petrological dataset from the Kidnappers fall deposit, and the Kidnappers and Rocky Hill ignimbrites in order to compare and contrast the deposits, with the aim of addressing the following questions: (1) Can distinctions between these eruptions be found in the systematic study of minerals and glass to corroborate the field evidence, or do the Kidnappers and Rocky Hill events geochemically and mineralogically appear to be essentially phases of the same eruption? (2) How many melt compositions were involved in the Kidnappers and Rocky Hill eruptions and did their variability change? (3) Are similarities present in the geochemical and mineralogical data to support zircon $\mathrm{U}-\mathrm{Pb}$ age spectra (see Chapter 2) that suggest that the Kidnappers and Rocky Hill were erupted from a common system? (4) Are there any geochemical signatures present within each eruption that give insights into potential trigger mechanisms and rejuvenation processes? (5) Did conditions operating within the Mangakino magmatic system (in particular temperature, pressure, oxygen fugacity and $\mathrm{H}_{2} \mathrm{O}$ contents) remain constant or change between eruptive events? Significant glass chemical variations within the large Kidnappers fall deposit have previously been documented and used to infer that three independent magma bodies were systematically tapped in the earlier stages of the Kidnappers eruption (Cooper et al. 2012 [Chapter 3]). The question then arises as to whether the subsequent ignimbrites 
of the Kidnappers and Rocky Hill eruptions also show evidence for the multiple chambers in their pumice chemistries, and whether or not they mixed and/or were chemically stratified.

There is a wide variability in the type and quality of analysable material available to interrogate the compositional record in large silicic eruptions. Fall deposits, where a stratigraphic ordering is present, provide an opportunity to track compositional variations through time (Perkins and Nash 2002, Cathey and Nash 2004, Nash and Perkins 2012; Cooper et al. 2012 [Chapter 3]). However, large enough pumice clasts for individual analyses are often scarce (or absent in the fall deposits of the Kidnappers and the Rocky Hill), and therefore the relationships between mineral, glass and whole-rock compositions cannot be studied. The Kidnappers, and to a lesser extent the Rocky Hill ignimbrite is poorly exposed and both deposits lack all but the broadest of stratigraphic controls. However, the majority of pumices are large enough and unaltered allowing the whole-rock, glass and mineral relationships of individual clasts to be analysed. In some cases, such as the deposits from the Snake River Plain, the evolution of the eruptions can only be tracked from the distal fall, which is complete and unaltered in comparison to the flow deposits (e.g. Perkins et al. 1995; Perkins and Nash 2002; Cathey and Nash 2004). In this chapter, glass from pumices within the Kidnappers and Rocky Hill ignimbrites is compared to the three glass types previously identified in the Kidnappers fall deposit (Cooper et al. 2012 [Chapter 3]). The mineral compositional data from the fall deposit (organised by stratigraphic ordering) is also compared alongside the data from pumices (organised by whole-rock chemistry). These data provide a record through the full (preserved) stratigraphic history of the Kidnappers eruption and allow comparison of the information that can be gained from the different deposit types.

\subsection{Geological Background}

\subsubsection{The Taupo Volcanic Zone (TVZ)}

The TVZ is a NNE-trending locus of volcanism and associated extension forming the southern, continental termination of the Tonga-Kermadec arc, itself associated with westward subduction of the Pacific plate beneath the Indo-Australian plate (Cole and Lewis, 1981). The TVZ has been the dominant focus of volcanism in the central North 
Island of New Zealand since $\sim 2 \mathrm{Ma}$, and is divided into three segments on the basis of the dominant magma composition and magma fluxes. Within the $\sim 120 \times 60 \mathrm{~km}$ rhyolite-dominated central TVZ, $>16,000 \mathrm{~km}^{3}$ of magma has been erupted since $\sim 1.6$ Ma in at least 25 caldera-forming and numerous other smaller eruptions from eight volcanic centres (Houghton et al. 1995; Wilson et al. 1995a, 2009). This chapter reports data from two large-scale silicic eruptions from the Mangakino volcanic centre (MVC) on the north-western margin of the TVZ (Figure 4.1).

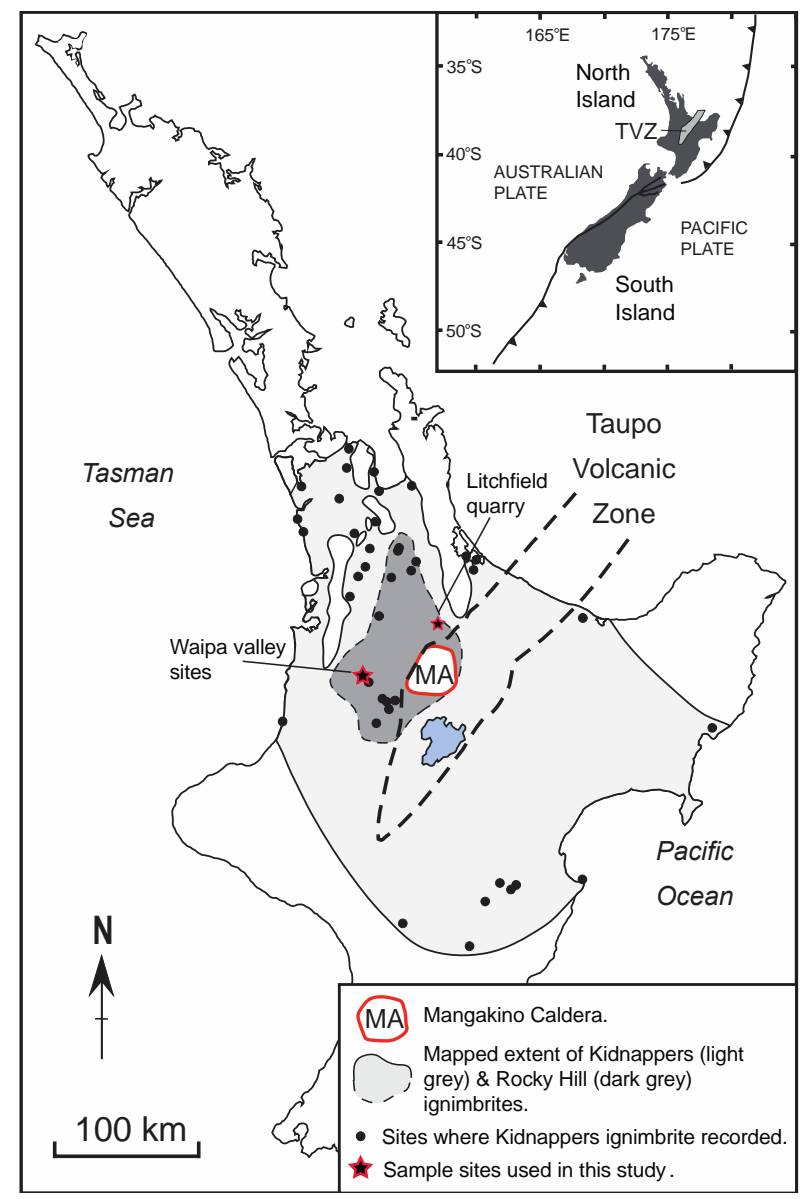

Fig. 4.1. Map of the North Island, New Zealand to show the extent of the Kidnappers and Rocky Hill ignimbrites and sampling locations. The thick dashed line marks the boundary of the old TVZ. Extent of the Kidnappers fall deposit is shown in Figure 3.1. Modified from Briggs et al. (1993) and Wilson et al. (1995b).

The MVC was recognised from the presence of a major negative gravity anomaly, in addition to geological field evidence that linked some extensive welded ignimbrites to a source in this area (Blank 1965; Stern 1979; Rogan 1982; Wilson et al. 1984; Wilson 1986). The stratigraphic relationships of deposits from Mangakino were originally 
established by Martin (1961) and Blank (1965) and later refined by Wilson (1986). Mangakino volcanic centre is a composite feature and can be subdivided into two clustered periods of caldera forming eruptions (Houghton et al. 1995), the first between 1.62 and $1.51 \mathrm{Ma}$, and the second between 1.23 and $0.91 \mathrm{Ma}$. The latter includes the Kidnappers and Rocky Hill eruptions, as well as the older 1.21 Ma Ongatiti eruption (considered in chapters 2 and 6).

\subsubsection{Kidnappers eruption}

The Kidnappers eruption is dated at $\sim 1 \mathrm{Ma}$ by ${ }^{40} \mathrm{Ar} /{ }^{39} \mathrm{Ar}$ techniques on plagioclase, and constrained by its deposition towards the top of the normally magnetized Jaramillo Subchron (Black 1992; Houghton et al. 1995; Wilson et al. 1995b). The Kidnappers is the second largest TVZ eruption known and it generated three components: (1) a voluminous phreatomagmatic fall deposit, recorded across the North Island and for $>1000 \mathrm{~km}$ eastwards across the Pacific Ocean floor (Ash A of Ninkovich 1968; Carter et al. 2004; Cooper et al. 2012 [Chapter 3]); (2) an exceptionally widespread nonwelded ignimbrite that covers $\sim 45000 \mathrm{~km}^{2}$ (Wilson et al. 1995b; Figure 4.1); and (3) $>1.3 \mathrm{~km}$ of poorly-welded, hydrothermally altered tuff within the source collapse structure (Wilson et al. 2008). A DRE volume for the Kidnappers eruption of $1200 \mathrm{~km}^{3}$ $\pm 50 \%$ is estimated (Cooper et al. 2012 [Chapter 3]). Geochemical investigation of the Kidnappers fall deposit revealed three magma chambers were sequentially tapped during the early stages of the Kidnappers eruption (Cooper et al. 2012 [Chapter 3]). The pre-eruptive chambers were horizontally separated, at depths of between 4 and $12 \mathrm{~km}$, within what became an inferred common composite caldera. Their systematic tapping was used to infer that there was a tectonic control to the observed eruptive behaviour. The eruption of discrete magma batches from separate sources has also been proposed for the Marshall and Ahuroa ignimbrite eruptions from the MVC (Briggs et al. 1993).

\subsubsection{Rocky Hill eruption}

The Kidnappers eruption was followed by a short period of quiescence and erosion before deposition of the Rocky Hill ignimbrite. The Rocky Hill age determined by ${ }^{40} \mathrm{Ar} /{ }^{39} \mathrm{Ar}$ dating is the same within uncertainty as that of the Kidnappers at $\sim 1 \mathrm{Ma}$, but field relationships and deposit characteristics demonstrate that the Rocky Hill 
ignimbrite is a younger, separate eruption. The Rocky Hill eruption generated a partially to densely welded ignimbrite ( $200 \mathrm{~km}^{3}$, DRE) with minor amounts of distinctively large hornblende (4-5 $\mathrm{mm}$ long) in the juvenile fraction. No co-eruptive fall deposit has been found beneath the Rocky Hill ignimbrite. The ignimbrite forms prominent outcrops and extends at least $85 \mathrm{~km}$ from source (Briggs et al. 1993; Figure 4.1). It grades from a partially welded, pumice- and crystal-rich base to a densely welded upper part with lower pumice abundance (Blank 1965; Wilson 1986; Moyle 1989). In addition, $>0.5 \mathrm{~km}$ thickness of welded ignimbrite with distinctive hornblende pseudomorphs and an indistinguishable zircon crystallisation age spectrum is found in drillholes within the composite collapse caldera (Wilson et al. 2008). It is inferred, however, from glass compositions and field characteristics that the Kidnappers and Rocky Hill eruptions collectively contribute to a composite deposit of primary and reworked volcaniclastic material that is mapped throughout New Zealand as the Potaka Tephra (e.g., Shane 1994; Carter et al. 2004; Alloway et al. 2005).

\subsection{Sampling}

Sampling of the Kidnappers fall deposit is discussed in Chapter 3. Representative juvenile clasts from the Kidnappers and Rocky Hill ignimbrites were sampled for use within this study. Due to the non-welded nature of the Kidnappers ignimbrite and its burial by later deposits, exposure is limited. The majority of Kidnappers pumice was sampled from an exposed section of pumice rich incipiently sintered ignimbrite in a pumice quarry near Litchfield (NZMG grid reference 2758837m E 6339943m N), 30 $\mathrm{km}$ from source, and a small number were from a farm pumice pit at $2748206 \mathrm{~m} \mathrm{E}$ $6369073 \mathrm{~m} \mathrm{~N}$ (Figure 4.1). The basal contact at the Litchfield pumice pit is absent and therefore there is no control on stratigraphic sampling. Here, the ignimbrite is $>10 \mathrm{~m}$ thick, and contains pumice clasts up to $\sim 60 \mathrm{~cm}$ long. Kidnappers pumice is typically light grey in colour and contain discrete crystals (rather than crystal clots). Biotite is present in the vast majority of pumice clasts (although commonly weathered to a golden hydromica), and pumices have a remarkably similar physical appearance throughout the Kidnappers ignimbrite, regardless of their major-element composition (Section 4.5.1). 
Due to its welded nature, the Rocky Hill ignimbrite commonly forms rocky exposures and large boulder-like outcrops within the King Country (see Chapter 1). Pumice samples were taken from several locations west of Mangakino caldera within the Waipa Valley (Figure 4.1), 50 km from source, at $2716434 \mathrm{~m} \mathrm{E,} 6304665 \mathrm{~m} \mathrm{~N}$ and 2714700 m E, 6308230 m N. The eponymous Rocky Hill type locality (Martin, 1961; Blank, 1965) was sampled at $2711731 \mathrm{~m} \mathrm{E}, 6310973 \mathrm{~m} \mathrm{~N}$ and $2711707 \mathrm{~m} \mathrm{E}, 6310890 \mathrm{~m} \mathrm{~N}$. Most pumice within the ignimbrite is glomeroporphyritic, with both spherical crystal clots (commonly with brown glass selvedges) and schlieren. Large (to 4-5 mm) amphibole phenocrysts are ubiquitous within Rocky Hill pumice. The overall colour of pumice clasts varies from white $(\sim 70 \%)$ to dark grey or brown $(\sim 30 \%)$, either with or without streaking. Due to the welded nature of the ignimbrite, pumice clasts are often flattened and elongated, with textures that are commonly dense, fibrous or woody with elongated vesicles.

\subsection{Analytical Techniques}

Analytical techniques are presented in full in Appendix 1 alongside analyses of standards as a record of the overall reproducibility of all data. Here, techniques and analytical operating conditions specific to this study are summarised.

\subsubsection{Sample preparation}

Preparation methods for the material sampled through the Kidnappers fall deposit is discussed in Chapter 3. Pumice clasts from the ignimbrites were cleaned in water and any adhering ignimbrite matrix was removed. A proportion of material was cut off and dried at $105{ }^{\circ} \mathrm{C}$ for $\sim 24$ hours before crushing into small chips using a Boyd crusher, or mortar and pestle. 100-200 g of these pumice chips were powdered in an agate Tema mill for use in whole-rock major element (XRF) and trace element (solution ICP-MS) chemistry.

The remaining portions of the pumices, to be used for glass chemistry, mineral chemistry and isotopic work, were selected on the basis of major element chemistry and textural characteristics so that a full range of pumice types were represented. Pumice 
fragments were gently crushed using a Boyd crusher and/or with a mortar and pestle to 'pop' the crystals out of matrix glass. The crushed sample was then sieved into $>1 \mathrm{~mm}$, $1 \mathrm{~mm}-500 \mu \mathrm{m}, 500-250 \mu \mathrm{m} .250-125 \mu \mathrm{m}, 125-63 \mu \mathrm{m}$ and $<63 \mu \mathrm{m}$ fractions. Matrix glass, from selected size fractions, was floated off in water to provide an initial separation of glass and minerals. The phenocryst phases of plagioclase, quartz, amphibole, orthopyroxene and biotite were handpicked from the $>1 \mathrm{~mm}$ and $1 \mathrm{~mm}-500$ $\mu \mathrm{m}$ sieve fractions. Where available, at least 25 grains from each mineral phase within pumice samples were selected and mounted in epoxy resin blocks. Fe-Ti oxide (ilmenite and magnetite) equilibrium pairs contained as inclusions within orthopyroxene and amphibole were targeted for electron probe micro-analysis (EPMA). Glass shards from the $250-125 \mu \mathrm{m}$ sieve fraction were mounted into 6 pre-drilled holes within each epoxy block. A $25 \mathrm{~nm}$ carbon coating was applied to each polished block before EPMA analysis.

\subsubsection{Whole-rock analyses}

Whole-rock major element analysis $\left(\mathrm{SiO}_{2}, \mathrm{TiO}_{2}, \mathrm{Al}_{2} \mathrm{O}, \mathrm{Fe}_{2} \mathrm{O}_{3}, \mathrm{MnO} . \mathrm{MgO}, \mathrm{CaO}, \mathrm{Na}_{2} \mathrm{O}\right.$, $\mathrm{K}_{2} \mathrm{O}, \mathrm{P}_{2} \mathrm{O}$ ) were carried out by XRF using a Philips PW2400 Sequential Wavelength Dispersive X-ray Fluorescence Spectrometer at the University of Canterbury and Spectrachem Analytical (CRL Energy Ltd), Lower Hutt. Samples were held at $1000{ }^{\circ} \mathrm{C}$ for 1 hour and then weighed to determine the Loss On Ignition (LOI). Standards BCR-2, BHVO-2, and Taupo MF pumice (an in-house rhyolitic standard) were included within each analytical session as unknowns so that the accuracy and reproducibility could be monitored.

Whole-rock trace element analysis was carried out by solution inductively coupled mass spectrometry (ICP-MS), using methods outlined in Appendix 2. Measurements were made on an Agilent 7500CS ICP-MS at Victoria University of Wellington. 43 elements were analysed: Li, B, Mg, Ca, Sc, Ti, V, Cr, Mn, Co, Ni, Cu, Zn, Ga, Rb, Sr, Y, Zr, Nb, Mo, Cs, Ba, La, Ce, Pr, Nd, Sm, Eu, Gd, Tb, Dy, Ho, Er, Tm, Yb, Lu, Hf, Ta, W, Tl,

$\mathrm{Pb}$, Th, U. BHVO-2 was used as the calibration standard whereas BCR-2 and Taupo MF pumice were used as secondary standards. ${ }^{43} \mathrm{Ca}$ is used as an internal standard. Igor Pro and the Iolite software add on (Hellstrom et al. 2008) were used to remove the 
background from sample signals and calculate average count rates for each measured samples.

\subsubsection{In-situ major element analyses}

Backscattered electron (BSE) imaging and quantitative major element analyses of glass and crystals were carried out using a JEOL JXA-8230 Superprobe at Victoria University of Wellington. Minerals were analysed with a $15 \mathrm{kV}$ accelerating voltage and a $12 \mathrm{nA}$ focused beam. Glass was analysed with a $15 \mathrm{kV}$ accelerating voltage and an $8 \mathrm{nA}$ beam current with a defocused beam $(20 \mu \mathrm{m})$. Measurements of $30 \mathrm{~s}$ on the peak and $15 \mathrm{~s}$ on backgrounds either side of the peak were used for the majority of analyses. When analyzing $\mathrm{Na}_{2} \mathrm{O}$ of glass, the peak and background times were reduced to 10 s to minimise $\mathrm{Na}_{2} \mathrm{O}$ migration.

\subsubsection{In-situ trace element analyses}

The trace element compositions of minerals and glass were determined using a New Wave deep UV (193 nm solid state) laser ablation system coupled to a Agilent 7500CS ICP-MS at Victoria University of Wellington. All data were acquired as static spot analyses with a beam diameter of $35 \mu \mathrm{m}$, a laser repetition rate of $5 \mathrm{~Hz}, 85 \%$ laser power and using helium as the carrier gas. Calibration standards used were NIST 612 for rhyolitic glass and plagioclase, and BCR-2 for amphibole and orthopyroxene and

${ }^{29} \mathrm{Si}$ was used as an internal standard. ATHO-G and BHVO-2-G were analysed as secondary standards during each analytical session when the instrument was calibrated using NIST 612 and BCR-2, respectively. All standard reference values used were taken from GeoRem preferred reference values (http://georem.mpch-mainz.gwdg.de/).

\subsubsection{Pb isotopic analyses}

All $\mathrm{Pb}$ isotopic compositions were measured using a $\mathrm{Nu}$-Plasma multi-collector inductively coupled mass spectrometer (MC-ICP-MS) at Victoria University of Wellington, after $\mathrm{Pb}$ separation methods outlined in Appendix 2. $\mathrm{Pb}$ samples were introduced into the MC-ICP-MS via a desolving nebulizer system (DSN-100). Pb isotope measurements were corrected for instrumental mass bias and drift by sample- 
standard bracketing using NBS-981 $\left({ }^{208} \mathrm{~Pb} /{ }^{204} \mathrm{~Pb}=36.7262,{ }^{207} \mathrm{~Pb} /{ }^{204} \mathrm{~Pb}=15.5000\right.$ and ${ }^{206} \mathrm{~Pb} /{ }^{204} \mathrm{~Pb}=16.9416$ (Baker et al. 2004) and JB-2 was used to monitor accuracy and reproducibility $\left(2 \mathrm{sd}=109 \mathrm{ppm}\right.$ for ${ }^{208} \mathrm{~Pb} /{ }^{204} \mathrm{~Pb}, 93 \mathrm{ppm}$ for ${ }^{207} \mathrm{~Pb} /{ }^{204} \mathrm{~Pb}$ and $50 \mathrm{ppm}$ for $\left.{ }^{206} \mathrm{~Pb} /{ }^{204} \mathrm{~Pb}\right)$.

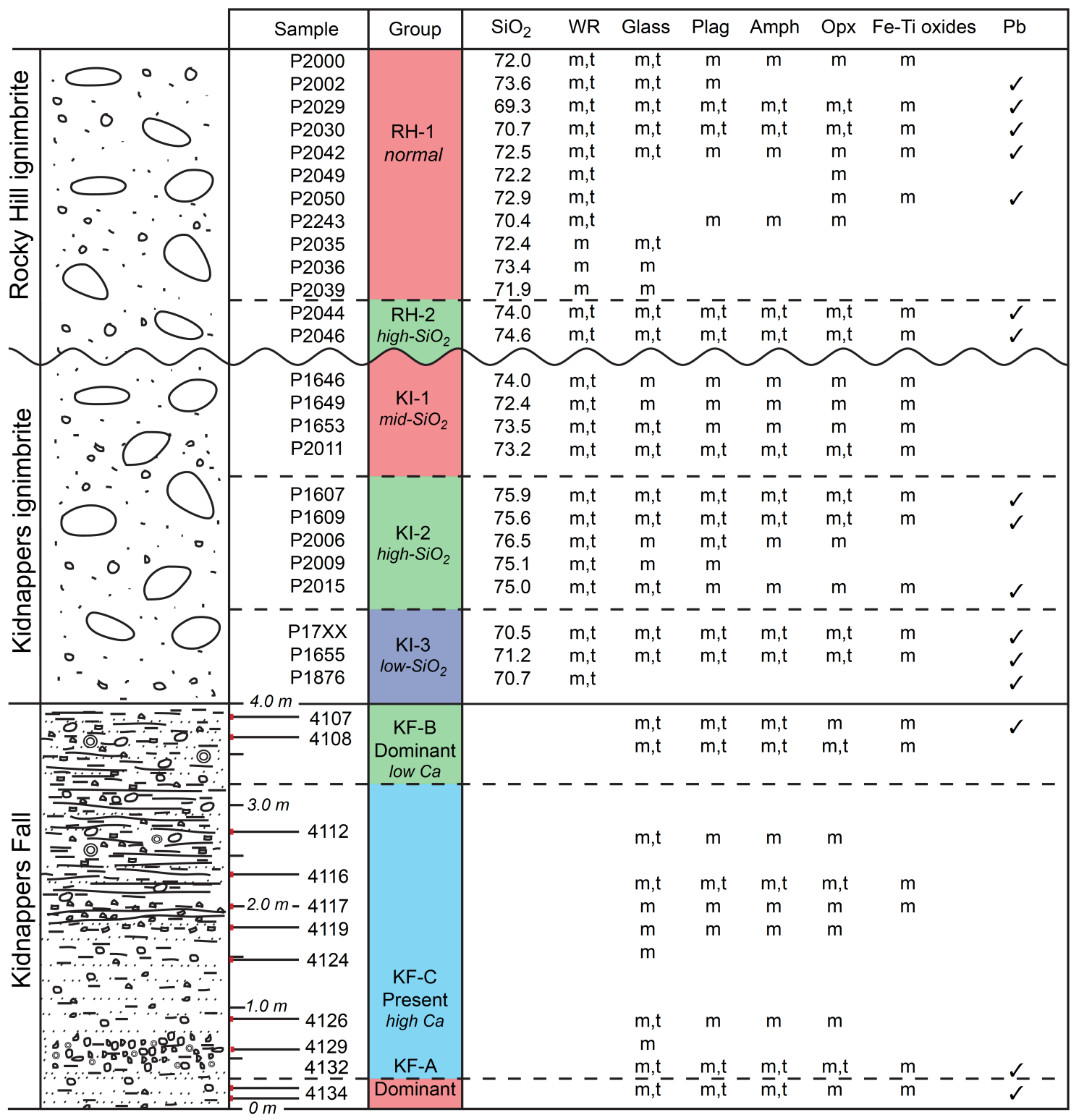

Table 4.1. Catalogue of samples from the Kidnappers fall deposit, Kidnappers ignimbrite and Rocky Hill ignimbrite chosen for crystal specific studies and glass analyses. Kidnappers Fall samples are ordered in stratigraphic height through the proximal fall deposit (Chapter 3).

Pumice from the ignimbrites are arranged by whole-rock compositional groups $\left(\mathrm{SiO}_{2}\right.$ wt. \%) and are without stratigraphic control. The colours assigned to compositional groups are used in all figures throughout this chapter. Note that the stratigraphic heights covered by 'other' (light blue) contain material from KF-C, as well KF-A and KF-B fall deposit compositional groups. Major element analyses are indicated with an ' $\mathrm{m}$ ', and trace element analyses are denoted by a ' $\mathrm{t}$ '. $\mathrm{Pb}$ denotes that $\mathrm{Pb}$ isotope data is presented. 


\subsection{Results}

In the following section, whole-rock and glass data from Kidnappers and Rocky Hill ignimbrite pumices are presented first. The Kidnappers fall matrix glass is presented in full in Cooper et al. (2012 [Chapter 3]) and used here as a comparison between pumice glass from the overlying ignimbrites. Glass from quartz hosted melt inclusions from the fall deposit are also presented as a comparison. Then mineral characteristics, chemistry, and geothermobarometry estimates from the fall deposit and both ignimbrites are presented. Table 4.1 displays all samples used for glass and crystal specific work in this study. All data used in this chapter are presented in electronic appendices (EA.3-EA.9).

\subsubsection{Whole rock pumice compositions and glass chemistry}

All pumice analysed in this study are rhyolitic and make up $>99 \%$ of all juvenile material by weight. Lithic clasts are present within both ignimbrites but have not been analysed. Because pumice within the Kidnappers (and to a lesser extent the Rocky Hill) is of very similar appearance, whole rock compositions were determined first. Endmember types were then determined on the basis of their chemistry before selected clasts were chosen for glass and crystal-specific analyses. All pumices analysed show some degree of secondary hydration (0-5 \% LOI), but pumices generally had a glassy and 'fresh' appearance.

\subsubsection{Kidnappers whole-rock pumice in ignimbrite}

Forty two pumice clasts were analysed for major elements by XRF and 21 for trace elements by solution ICP-MS. There are significant variations in whole rock major and trace element compositions, for example 70.5-76.5 wt. \% $\mathrm{SiO}_{2}, 3.3-5.0$ wt. \% $\mathrm{K}_{2} \mathrm{O}$, 12.2-15.7 wt. \% $\mathrm{Al}_{2} \mathrm{O}_{3}$ (Figure 4.2). 23-72 ppm Zn, 82-191 ppm Sr, 69-197 ppm Zr and 84-164 ppm Rb (Figure 4.3). LOI values are between 0 and 3.4 wt. \% and secondary hydration does not appear to affect any element concentrations (i.e. no correlations with LOI values). Major element data are relatively well spread across this compositional range, but the data do cluster into three different groups based on major elements (particularly $\mathrm{SiO}_{2}, \mathrm{MgO}, \mathrm{TiO}_{2}$ and $\mathrm{CaO}$ ) (Figure 4.2). The majority of Kidnappers pumices can therefore be divided into a dominant mid-SiO ${ }_{2}$ type (72-74 wt. \% $\mathrm{SiO}_{2}$ : $\mathrm{KI}-1)$, 

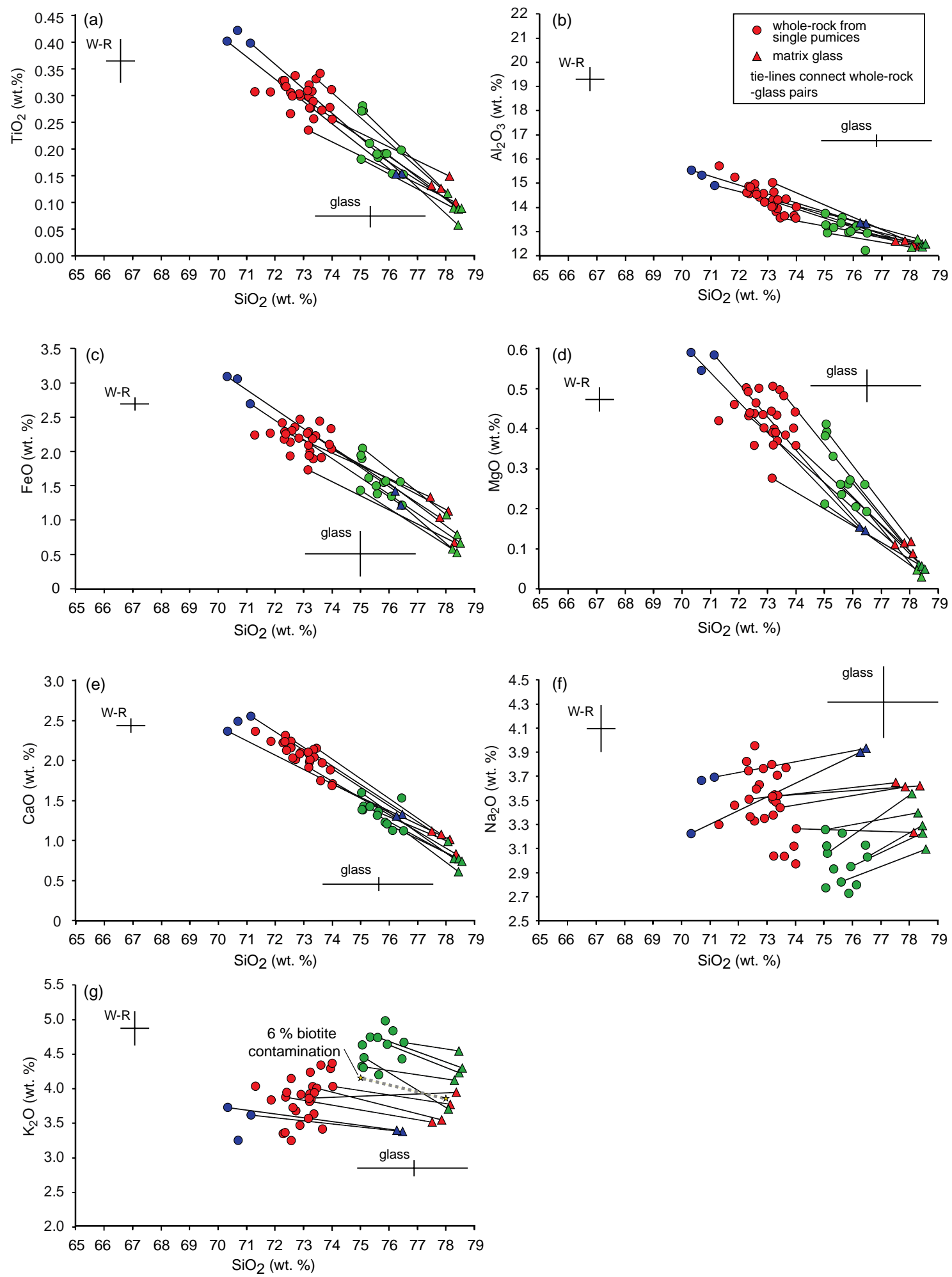

Fig. 4.2. Plots of whole-rock (circles) and matrix glass (triangles) major oxide abundances against silica for all analysed Kidnappers single pumice clasts. Tie lines connect whole-rock-glass pairs. Crosses represent whole-rock 2 sd XRF uncertainties (left hand side) and 2 sd EPMA matrix glass uncertainties (right hand side) (Electronic Appendix). Colours of the symbols indicate the compositional groups assigned to each pumice $(\mathrm{KI}-1=$ red, KI-2=green, KI-3=blue; see Table 4.1) 
Table. 4.2. Mean whole rock major and trace element concentrations for each compositional group within Kidnappers and Rocky Hill pumice. The 2 sd of each concentration within each compositional group are shown. The number of pumices (n) analysed by XRF and solution ICP-MS within each group are displayed.

\begin{tabular}{|c|c|c|c|c|c|c|c|c|c|c|}
\hline & \multicolumn{6}{|c|}{ Kidnappers pumice } & \multicolumn{4}{|c|}{ Rocky Hill pumice } \\
\hline & \multicolumn{2}{|c|}{$\begin{array}{c}\mathrm{KI}-1 \\
72-74 \text { wt. } \% \mathrm{SiO}_{2}\end{array}$} & \multicolumn{2}{|c|}{$\begin{array}{c}\mathrm{KI}-2 \\
>74.5 \text { wt. } \% \mathrm{SiO}_{2}\end{array}$} & \multicolumn{2}{|c|}{$\begin{array}{c}\mathrm{KI}-3 \\
<72 \text { wt. } \% \mathrm{SiO}_{2}\end{array}$} & \multicolumn{2}{|c|}{$\begin{array}{c}\text { RH-1 } \\
<74 \text { wt. } \% \mathrm{SiO}_{2}\end{array}$} & \multicolumn{2}{|c|}{$\begin{array}{c}\text { RH-2 } \\
>74 \text { wt. } \% \mathrm{SiO}_{2}\end{array}$} \\
\hline & Mean & $\pm 2 s d$ & Mean & $\pm 2 s d$ & Mean & $\pm 2 s d$ & Mean & $\pm 2 s d$ & Mean & $\pm 2 s d$ \\
\hline \multicolumn{11}{|l|}{ Major elements } \\
\hline XRF & \multicolumn{2}{|c|}{$n=27$} & \multicolumn{2}{|c|}{$n=12$} & \multicolumn{2}{|c|}{$n=3$} & \multicolumn{2}{|c|}{$n=37$} & & \\
\hline $\mathrm{SiO}_{2}$ & 73.0 & 1.30 & 75.6 & 1.07 & 70.8 & 0.63 & 71.4 & 2.99 & 75.0 & 1.79 \\
\hline $\mathrm{TiO}_{2}$ & 0.30 & 0.05 & 0.21 & 0.09 & 0.41 & 0.03 & 0.32 & 0.07 & 0.24 & 0.11 \\
\hline $\mathrm{Al}_{2} \mathrm{O}_{3}$ & 14.4 & 1.06 & 13.1 & 0.77 & 15.3 & 0.69 & 16.3 & 2.39 & 14.0 & 1.45 \\
\hline $\mathrm{Fe}_{2} \mathrm{O}_{3} \mathrm{~T}$ & 2.42 & 0.41 & 1.77 & 0.56 & 3.28 & 0.50 & 2.45 & 0.86 & 1.83 & 0.50 \\
\hline $\mathrm{MnO}$ & 0.06 & 0.01 & 0.04 & 0.01 & 0.08 & 0.03 & 0.05 & 0.02 & 0.04 & 0.01 \\
\hline $\mathrm{MgO}$ & 0.43 & 0.11 & 0.28 & 0.15 & 0.57 & 0.05 & 0.39 & 0.13 & 0.30 & 0.12 \\
\hline $\mathrm{CaO}$ & 2.07 & 0.34 & 1.34 & 0.30 & 2.47 & 0.18 & 2.04 & 0.41 & 1.62 & 0.28 \\
\hline $\mathrm{Na}_{2} \mathrm{O}$ & 3.48 & 0.51 & 2.99 & 0.36 & 3.53 & 0.51 & 3.79 & 0.40 & 3.40 & 0.28 \\
\hline $\mathrm{K}_{2} \mathrm{O}$ & 3.85 & 0.61 & 4.58 & 0.48 & 3.54 & 0.51 & 3.21 & 0.50 & 3.50 & 1.06 \\
\hline $\mathrm{P}_{2} \mathrm{O}_{5}$ & 0.03 & 0.08 & 0.02 & 0.01 & 0.05 & 0.09 & 0.06 & 0.12 & 0.07 & 0.12 \\
\hline Totals normalised to & $100 \%$, vc & atile free & & & & & & & & \\
\hline $\mathrm{FeO} \mathrm{T}$ & 2.17 & 0.37 & 1.59 & 0.51 & 2.95 & 0.45 & 2.21 & 0.78 & 1.64 & 0.45 \\
\hline LOI & 1.96 & 1.74 & 2.57 & 0.87 & 2.76 & 0.97 & 3.55 & 1.50 & 3.22 & 0.94 \\
\hline Trace elements & & & & & & & & & & \\
\hline Solution ICP-MS & & & & & & & $n=$ & & & \\
\hline $\mathrm{Li}$ & 15.2 & 11.7 & 15.5 & 12.6 & 14.5 & 14.7 & 22.7 & 20.0 & 10.7 & 4.5 \\
\hline B & 3.71 & 2.44 & 3.12 & 1.19 & 2.72 & 0.56 & 3.43 & 1.72 & 2.81 & 0.38 \\
\hline MgO wt. \% & 0.363 & 0.134 & 0.248 & 0.155 & 0.530 & 0.024 & 0.378 & 0.117 & 0.257 & 0.131 \\
\hline $\mathrm{Sc}$ & 6.56 & 2.34 & 4.67 & 2.38 & 9.78 & 0.50 & 6.93 & 1.34 & 5.25 & 1.46 \\
\hline $\mathrm{TiO}_{2}$ wt. $\%$ & 0.256 & 0.055 & 0.188 & 0.106 & 0.371 & 0.028 & 0.313 & 0.068 & 0.215 & 0.036 \\
\hline v & 17.6 & 6.7 & 10.7 & 8.9 & 25.2 & 2.1 & 20.0 & 3.9 & 15.1 & 2.8 \\
\hline $\mathrm{Cr}$ & 2.15 & 1.78 & 1.16 & 0.80 & 2.39 & 1.59 & 1.96 & 0.64 & 2.27 & 2.37 \\
\hline $\mathrm{Mn}$ & 392 & 36 & 301 & 97 & 722 & - & 361 & 173 & - & - \\
\hline Co & 2.35 & 1.16 & 1.71 & 0.68 & 3.77 & 2.29 & 2.94 & 1.26 & 1.95 & 0.79 \\
\hline $\mathrm{Ni}$ & 0.836 & 0.232 & 0.543 & 0.173 & 1.12 & 0.29 & 1.23 & 0.77 & 1.20 & 1.50 \\
\hline $\mathrm{Cu}$ & 3.81 & 2.88 & 3.91 & 2.05 & 4.39 & 1.43 & 4.67 & 2.16 & 7.85 & 6.34 \\
\hline $\mathrm{Zn}$ & 35.7 & 11.6 & 33.2 & 12.9 & 55.3 & 29.1 & 43.9 & 24.5 & 39.0 & 27.6 \\
\hline $\mathrm{Ga}$ & 16.6 & 1.6 & 15.6 & 1.2 & 18.0 & 0.8 & 18.1 & 1.9 & 15.3 & 3.3 \\
\hline $\mathbf{R b}$ & 109 & 26 & 144 & 28 & 103 & 7 & 97.8 & 14 & 112 & 23 \\
\hline $\mathrm{Sr}$ & 153 & 34 & 96 & 30 & 187 & 14 & 153 & 36 & 116 & 3 \\
\hline$Y$ & 23.9 & 4.5 & 25.1 & 3.8 & 27.9 & 2.2 & 22.8 & 4.4 & 24.7 & 4.5 \\
\hline $\mathrm{Zr}$ & 104 & 28 & 85.0 & 33.9 & 172 & 42 & 116 & 17 & 89.7 & 19.0 \\
\hline $\mathrm{Nb}$ & 8.22 & 0.74 & 8.31 & 1.57 & 9.64 & 0.36 & 9.79 & 1.05 & 7.82 & 2.05 \\
\hline Mo & 1.43 & 0.66 & 1.60 & 0.57 & 1.46 & 0.45 & 1.35 & 0.49 & 1.76 & 0.23 \\
\hline Cs & 6.37 & 2.11 & 8.95 & 2.23 & 5.09 & 1.29 & 5.94 & 1.04 & 6.55 & 1.31 \\
\hline $\mathrm{Ba}$ & 729 & 79 & 791 & 116 & 718 & 132 & 747 & 109 & 692 & 163 \\
\hline La & 23.3 & 5.3 & 26.5 & 2.5 & 24.6 & 3.9 & 22.9 & 4.5 & 24.5 & 8.8 \\
\hline $\mathrm{Ce}$ & 47.0 & 7.2 & 52.3 & 5.3 & 52.5 & 9.6 & 48.4 & 10.9 & 47.1 & 12.0 \\
\hline $\mathrm{Pr}$ & 5.51 & 1.54 & 6.07 & 0.69 & 5.93 & 0.85 & 5.19 & 0.99 & 5.72 & 1.42 \\
\hline $\mathrm{Nd}$ & 20.6 & 5.8 & 22.0 & 3.0 & 22.7 & 2.9 & 19.0 & 3.7 & 20.8 & 4.9 \\
\hline $\mathrm{Sm}$ & 4.22 & 1.19 & 4.38 & 0.74 & 4.79 & 0.48 & 3.82 & 0.72 & 4.22 & 0.92 \\
\hline $\mathrm{Eu}$ & 0.93 & 0.23 & 0.71 & 0.16 & 1.14 & 0.12 & 0.86 & 0.15 & 0.78 & 0.00 \\
\hline Gd & 4.13 & 1.04 & 4.21 & 0.62 & 4.81 & 0.45 & 3.81 & 0.68 & 4.24 & 0.53 \\
\hline Tb & 0.631 & 0.161 & 0.634 & 0.113 & 0.739 & 0.099 & 0.596 & 0.114 & 0.628 & 0.08 \\
\hline Dy & 3.96 & 0.88 & 4.03 & 0.68 & 4.69 & 0.42 & 3.77 & 0.68 & 4.02 & 0.55 \\
\hline Ho & 0.826 & 0.165 & 0.842 & 0.142 & 0.971 & 0.089 & 0.783 & 0.145 & 0.827 & 0.137 \\
\hline $\mathrm{Er}$ & 2.46 & 0.48 & 2.58 & 0.41 & 2.86 & 0.24 & 2.35 & 0.42 & 2.52 & 0.52 \\
\hline $\mathrm{Tm}$ & 0.380 & 0.071 & 0.407 & 0.056 & 0.432 & 0.029 & 0.363 & 0.060 & 0.388 & 0.081 \\
\hline $\mathrm{Yb}$ & 2.54 & 0.42 & 2.76 & 0.33 & 2.83 & 0.12 & 2.42 & 0.42 & 2.67 & 0.57 \\
\hline Lu & 0.384 & 0.062 & 0.424 & 0.058 & 0.428 & 0.010 & 0.367 & 0.055 & 0.394 & 0.080 \\
\hline $\mathrm{Hf}$ & 3.14 & 0.62 & 2.89 & 0.90 & 4.68 & 0.84 & 3.62 & 0.62 & 2.74 & 0.05 \\
\hline $\mathrm{Ta}$ & 0.677 & 0.205 & 0.751 & 0.142 & 0.715 & 0.182 & 0.788 & 0.117 & 0.777 & 0.322 \\
\hline w & 1.17 & 0.58 & 1.42 & 0.68 & 1.20 & 0.76 & 1.24 & 0.61 & 1.55 & 0.56 \\
\hline $\mathrm{Ti}$ & 1.28 & 0.65 & 1.48 & 0.48 & 1.42 & 0.80 & 1.36 & 0.62 & 1.96 & 1.27 \\
\hline $\mathrm{Pb}$ & 12.7 & 2.4 & 13.5 & 2.7 & 18.6 & 6.9 & 15.9 & 4.3 & 14.3 & 7.0 \\
\hline Th & 10.5 & 1.3 & 13.4 & 1.3 & 9.75 & 0.73 & 11.8 & 1.7 & 11.3 & 4.1 \\
\hline$U$ & 2.35 & 0.33 & 2.90 & 0.22 & 2.29 & 0.14 & 2.35 & 0.30 & 2.50 & 0.59 \\
\hline $\mathrm{Eu} / \mathrm{Eu}^{\star}$ & 0.67 & 0.10 & 0.50 & 0.09 & 0.73 & 0.03 & 0.67 & 0.15 & 0.57 & 0.10 \\
\hline
\end{tabular}


a high $\mathrm{SiO}_{2}$ variant (>74.5 wt. \% $\mathrm{SiO}_{2}$ : KI-2) and a low $\mathrm{SiO}_{2}$ variant $\left(<72\right.$ wt. \% $\mathrm{SiO}_{2}$ : KI-3) (Table 4.1). Representative whole-rock major and trace element compositions from the Kidnappers compositional groups are shown in Table 4.2. Trace elements Ni, $\mathrm{Zn}, \mathrm{Sr}$ and $\mathrm{Zr}$ behave compatibly with increasing $\mathrm{SiO}_{2}$, whereas $\mathrm{Ba}$ and $\mathrm{Rb}$ behave incompatibly (Figure 4.3). Rb/Sr ratios within Kidnappers pumices range from 0.5 to 2.0, with a sharp increase from 1.0 to 2.0 at $>75.0$ wt. $\% \mathrm{SiO}_{2}$ and $>4.5 \mathrm{~K}_{2} \mathrm{O}$ in KI-2 samples (Figure 4.3). The higher $\mathrm{Rb} / \mathrm{Sr}$ trend in $\mathrm{KI}-2$ pumices trend toward the average composition of biotite rich granitoid xenoliths from the Kidnappers ignimbrite analysed in Brown et al. (1998b) (Figure 4.3e). Eu/Eu* ranges between 0.74-0.47 and decreases with decreasing $\mathrm{Al}_{2} \mathrm{O}_{3}$. Y shows much scatter when plotted against $\mathrm{Al}_{2} \mathrm{O}_{3}$ with no apparent trend (Figure 4.3f). Much of the whole-rock compositional variations in the Kidnappers can be attributed to the varying crystal cargo within each clast. Also, the relative differences in the compositions of average Kidnappers matrix glass (see section 4.5.1.2 for full glass data) mirror that of the three whole-rock compositional groups (e.g. low- $\mathrm{SiO}_{2}$ whole rock group corresponds to low-SiO 2 (KI-3) glass group, collectively named KI-3: Figures 4.2 and 4.3; Table 4.1). The variance of whole rock geochemistry is therefore partially governed by the chemistry of the matrix glass, i.e. the melt phase.

\subsubsection{Kidnappers matrix glass}

Eleven representative pumices from the Kidnappers ignimbrite were chosen for analysis of their matrix glass. Representative major and trace element glass compositions from each compositional group are shown in Table 4.3. Each pumice clast from which matrix glass was analysed has a slightly different matrix glass major element chemistry (Electronic Appendix 3), and average concentrations cover a significant range from the least to most evolved pumice. Tie lines drawn between major element whole rock and average matrix glass compositions have gradients in common with the overall whole rock data, apart from $\mathrm{K}_{2} \mathrm{O}$ and $\mathrm{Na}_{2} \mathrm{O}$ which share a similar range in concentrations between whole rock and glass (Figure 4.2). The apparent $\mathrm{K}_{2} \mathrm{O}$ addition can be resolved with $\sim 6 \%$ contamination of biotite into the melt-dominant bodies. Tie lines between $\mathrm{Rb} / \mathrm{Sr}$ and $\mathrm{SiO}_{2}$ of $\mathrm{KI}-1$ glass and $\mathrm{KI}-1$ whole-rock are steeper than in any other samples due to higher glass $\mathrm{Rb} / \mathrm{Sr}$ values (Figure 4.3 ), and suggest the involvement of biotiterich material. 

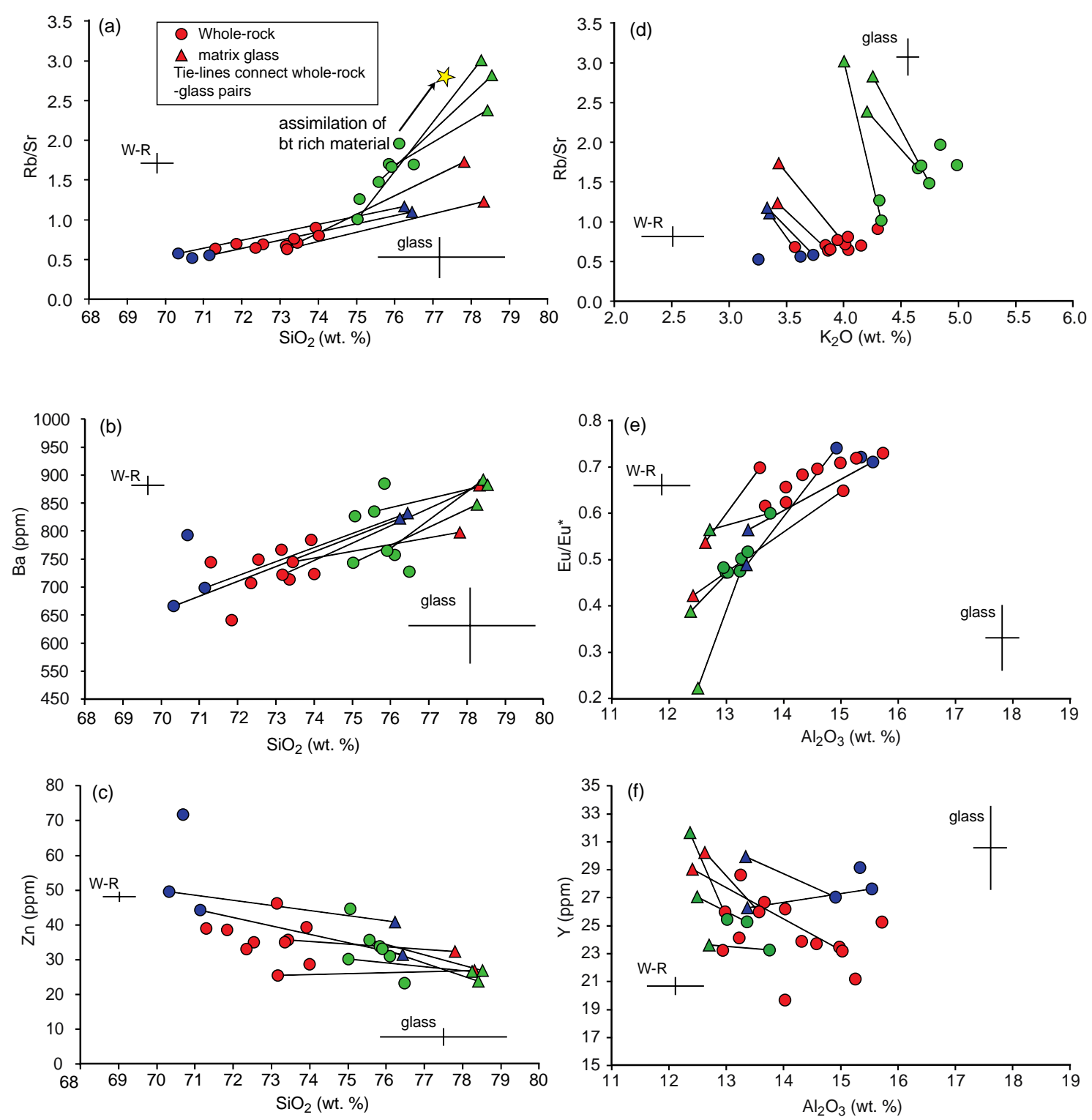

Fig. 4.3. Plots of selected trace elements versus silica (a-c), $\mathrm{K}_{2} \mathrm{O}$ (d) and $\mathrm{Al}_{2} \mathrm{O}_{3}$ (e,f) for pumice whole-rock and matrix glass from Kidnappers pumice. Tie-lines connect wholerock-glass pairs. Crosses represent 2 sd whole-rock solution ICPMS uncertainties (Electronic Appendix). Colours of the symbols indicate the compositional groups assigned to each pumice (KI-1=red, KI-2=green, KI-3=blue; see Table 4.1). 
Table. 4.3. Mean matrix glass major and trace element concentrations for each compositional group within Kidnappers and Rocky Hill pumice. The 2 sd of each concentration within each group are shown. The number of individual matrix glass shards analysed by EPMA and LA-ICP-MS are displayed.

\begin{tabular}{|c|c|c|c|c|c|c|c|c|c|c|}
\hline & \multicolumn{6}{|c|}{ Kidnappers matrix glass } & \multicolumn{4}{|c|}{ Rocky Hill matrix glass } \\
\hline & \multicolumn{2}{|c|}{$\mathrm{KI}-1$} & \multicolumn{2}{|c|}{$\mathrm{KI}-2$} & \multicolumn{2}{|c|}{$\mathrm{KI} 3$} & \multicolumn{2}{|c|}{$\mathrm{RH}-1$} & \multicolumn{2}{|c|}{ RH-2 } \\
\hline & Mean & $\pm 2 s d$ & Mean & $\pm 2 s d$ & Mean & $\pm 2 s d$ & Mean & $\pm 2 s d$ & Mean & $\pm 2 s d$ \\
\hline \multicolumn{11}{|l|}{ Major elements } \\
\hline EPMA & \multicolumn{2}{|c|}{$n=125$} & \multicolumn{2}{|c|}{$n=193$} & \multicolumn{2}{|c|}{$n=76$} & \multicolumn{2}{|c|}{$n=412$} & \multicolumn{2}{|c|}{$n=95$} \\
\hline $\mathrm{SiO}_{2}$ & 77.9 & 0.7 & 78.4 & 0.5 & 76.3 & 1.0 & 77.9 & 0.6 & 78.3 & 0.5 \\
\hline $\mathrm{TiO}_{2}$ & 0.136 & 0.042 & 0.081 & 0.047 & 0.153 & 0.039 & 0.137 & 0.036 & 0.096 & 0.024 \\
\hline $\mathrm{Al}_{2} \mathrm{O}_{3}$ & 12.5 & 0.3 & 12.5 & 0.3 & 13.4 & 0.3 & 12.6 & 0.2 & 12.5 & 0.2 \\
\hline $\mathrm{Fe}_{2} \mathrm{O}_{3} \mathrm{~T}$ & 1.15 & 0.54 & 0.62 & 0.51 & 1.38 & 0.59 & 0.94 & 0.56 & 0.63 & 0.52 \\
\hline MnO & 0.031 & 0.039 & 0.025 & 0.036 & 0.047 & 0.044 & 0.017 & 0.032 & 0.017 & 0.028 \\
\hline MgO & 0.104 & 0.043 & 0.046 & 0.057 & 0.153 & 0.063 & 0.057 & 0.082 & 0.045 & 0.069 \\
\hline $\mathrm{CaO}$ & 1.06 & 0.11 & 0.73 & 0.22 & 1.31 & 0.17 & 0.95 & 0.13 & 0.74 & 0.06 \\
\hline $\mathrm{Na}_{2} \mathrm{O}$ & 3.48 & 0.50 & 3.39 & 0.50 & 3.91 & 0.40 & 3.61 & 0.26 & 3.53 & 0.37 \\
\hline $\mathrm{K}_{2} \mathrm{O}$ & 3.64 & 0.37 & 4.25 & 0.73 & 3.40 & 0.38 & 3.77 & 0.35 & 4.13 & 0.23 \\
\hline Raw uncorrected total & 95.0 & & 95.7 & & 96.4 & & 95.8 & & 95.9 & \\
\hline \multicolumn{11}{|l|}{ Trace elements } \\
\hline LA-ICP-MS & $n=$ & & $n=$ & 29 & & & $n=$ & & & 29 \\
\hline $\mathbf{L i}$ & 42.1 & 20.5 & 36.7 & 16.9 & 34.8 & 17.0 & 47.2 & 20.5 & 52.3 & 13.7 \\
\hline $\mathrm{Na}_{2} \mathrm{O}$ wt. $\%$ & 3.65 & 0.56 & 3.36 & 0.66 & 3.72 & 1.67 & 4.01 & 1.08 & 3.88 & 0.75 \\
\hline MgO wt. \% & 0.145 & 0.168 & 0.102 & 0.095 & 0.268 & 0.178 & 0.076 & 0.120 & 0.083 & 0.066 \\
\hline CaO wt. \% & 1.01 & 0.51 & 0.88 & 0.41 & 1.38 & 0.61 & 1.06 & 0.30 & 0.87 & 0.41 \\
\hline Sc & 9.64 & 7.35 & 6.10 & 11.53 & 10.5 & 6.5 & 9.69 & 4.03 & 7.02 & 1.75 \\
\hline $\mathrm{TiO}_{2}$ wt. $\%$ & 0.17 & 0.05 & 0.12 & 0.04 & 0.23 & 0.09 & 0.18 & 0.13 & 0.12 & 0.01 \\
\hline V & 2.08 & 2.36 & 1.35 & 2.12 & 2.76 & 2.77 & 3.06 & 3.41 & 1.34 & 0.50 \\
\hline $\mathrm{Mn}$ & 204 & 116 & 242 & 122 & 356 & 134 & 146 & 57 & 154 & 64 \\
\hline Co & 1.04 & 1.89 & 0.540 & 2.044 & 1.21 & 2.66 & 1.07 & 1.82 & 0.28 & 1.17 \\
\hline $\mathrm{Ni}$ & 1.47 & 6.13 & 1.30 & 6.65 & 1.75 & 5.78 & 0.75 & 4.04 & 0.84 & 5.14 \\
\hline $\mathrm{Cu}$ & 5.66 & 24.84 & 4.66 & 35.89 & 6.26 & 42.51 & 9.15 & 28.06 & - & - \\
\hline $\mathrm{Zn}$ & 28.4 & 21.2 & 25.7 & 18.4 & 36.2 & 22.8 & 27.3 & 34.0 & 21.5 & 21.5 \\
\hline Ga & 16.4 & 5.8 & 15.8 & 4.5 & 15.6 & 5.3 & 17.0 & 5.6 & 15.6 & 3.0 \\
\hline $\mathbf{R b}$ & 153 & 58 & 169 & 35 & 131 & 56 & 133 & 45 & 158 & 18 \\
\hline $\mathrm{Sr}$ & 79.1 & 28.1 & 64.4 & 32.60 & 117 & 49 & 100 & 36 & 72.64 & 30.12 \\
\hline$Y$ & 32.5 & 42.1 & 27.1 & 14.0 & 28.1 & 15.6 & 29.8 & 13.4 & 27.5 & 8.9 \\
\hline $\mathrm{Zr}$ & 140 & 60 & 102 & 55 & 201 & 86 & 164 & 72 & 101 & 28 \\
\hline $\mathrm{Nb}$ & 9.98 & 2.89 & 9.49 & 2.71 & 10.5 & 2.4 & 10.8 & 4.6 & 8.92 & 1.39 \\
\hline Mo & 2.16 & 3.91 & 1.84 & 2.36 & 1.68 & 1.99 & 1.72 & 0.86 & 1.87 & 1.19 \\
\hline Cs & 8.16 & 3.58 & 8.51 & 2.78 & 6.41 & 2.24 & 7.42 & 1.82 & 8.51 & 3.08 \\
\hline $\mathrm{Ba}$ & 856 & 204 & 868 & 184 & 827 & 164 & 860 & 215 & 930 & 159 \\
\hline La & 30.7 & 20.6 & 29.3 & 11.9 & 28.1 & 9.1 & 31.2 & 14.0 & 30.6 & 9.0 \\
\hline $\mathrm{Ce}$ & 57.0 & 14.9 & 54.9 & 10.0 & 54.4 & 11.4 & 56.2 & 14.3 & 57.5 & 10.2 \\
\hline $\mathrm{Pr}$ & 6.71 & 6.03 & 6.09 & 1.92 & 5.92 & 2.11 & 6.15 & 2.12 & 6.24 & 1.49 \\
\hline $\mathrm{Nd}$ & 27.4 & 36.3 & 23.4 & 14.2 & 25.6 & 9.4 & 24.5 & 9.2 & 23.9 & 7.2 \\
\hline $\mathrm{Sm}$ & 5.81 & 11.08 & 4.51 & 3.42 & 4.93 & 3.31 & 4.93 & 2.02 & 4.77 & 2.02 \\
\hline $\mathrm{Eu}$ & 0.694 & 1.095 & 0.631 & 0.710 & 0.818 & 0.496 & 0.662 & 0.291 & 0.507 & 0.235 \\
\hline Gd & 5.17 & 8.47 & 3.83 & 3.93 & 4.63 & 4.04 & 4.69 & 2.40 & 4.16 & 1.72 \\
\hline $\mathrm{Tb}$ & 0.804 & 1.392 & 0.613 & 0.518 & 0.772 & 0.436 & 0.731 & 0.369 & 0.681 & 0.253 \\
\hline Dy & 5.85 & 8.02 & 4.28 & 3.03 & 5.35 & 3.35 & 4.91 & 2.30 & 4.48 & 1.60 \\
\hline Ho & 1.21 & 1.63 & 1.01 & 0.66 & 1.15 & 0.91 & 1.06 & 0.57 & 0.93 & 0.38 \\
\hline $\mathrm{Er}$ & 3.45 & 4.04 & 2.93 & 2.07 & 2.85 & 2.38 & 3.18 & 1.53 & 2.95 & 1.14 \\
\hline $\mathrm{Tm}$ & 0.518 & 0.706 & 0.427 & 0.448 & 0.540 & 0.385 & 0.495 & 0.246 & 0.501 & 0.208 \\
\hline $\mathrm{Yb}$ & 3.74 & 4.10 & 2.96 & 2.23 & 2.70 & 2.85 & 3.48 & 1.82 & 3.35 & 1.27 \\
\hline Lu & 0.573 & 0.688 & 0.513 & 0.385 & 0.537 & 0.418 & 0.550 & 0.254 & 0.571 & 0.299 \\
\hline $\mathrm{Hf}$ & 4.11 & 2.47 & 3.38 & 2.11 & 5.47 & 3.45 & 5.02 & 2.48 & 3.68 & 1.37 \\
\hline $\mathrm{Ta}$ & 0.903 & 0.565 & 0.941 & 0.602 & 0.859 & 0.495 & 0.993 & 0.422 & 0.979 & 0.304 \\
\hline W & 2.10 & 1.52 & 2.25 & 1.76 & 1.74 & 1.52 & 2.23 & 1.87 & 2.21 & 0.88 \\
\hline $\mathrm{Pb}$ & 17.5 & 3.2 & 17.1 & 6.1 & 20.3 & 6.2 & 21.5 & 7.0 & 19.1 & 4.3 \\
\hline Th & 16.0 & 6.3 & 16.3 & 6.8 & 13.7 & 5.4 & 16.4 & 6.1 & 17.4 & 4.8 \\
\hline U & 3.55 & 1.49 & 3.73 & 1.31 & 3.08 & 0.75 & 3.36 & 0.67 & 3.71 & 0.79 \\
\hline $\mathrm{Rb} / \mathrm{Sr}$ & 2.81 & 4.95 & 1.00 & 14.73 & 2.73 & 10.40 & 1.82 & 1.18 & 2.79 & 1.83 \\
\hline $\mathrm{Eu} / \mathrm{Eu}^{*}$ & 0.45 & 0.47 & 0.45 & 0.56 & 0.53 & 0.27 & 0.43 & 0.19 & 0.36 & 0.23 \\
\hline
\end{tabular}


Average matrix glass values range from 76.3-78.5 wt. \% $\mathrm{SiO}_{2}, 3.4-4.6$ wt. $\% \mathrm{~K}_{2} \mathrm{O}$ and 0.6-1.3 wt. \% $\mathrm{CaO}$, and the overall eruption is characterised by glass heterogeneity (Figure 4.4). Matrix glass within all but two of the individual pumice samples is homogeneous with respect to major elements, apart from $\mathrm{FeO}$ which spans a range beyond analytical uncertainty in all pumice samples. However, matrix glass from KI-3 pumices (Table 4.1) have major element heterogeneity beyond analytical uncertainties (Figure 4.4), for example a range in $\mathrm{SiO}_{2}$ of $\sim 2$ wt. $\%, \mathrm{CaO}$ of $\sim 0.4$ wt. $\%$ and $\mathrm{FeO}$ of $\sim$ 1.5 wt. \%. Similarly to major elements, some glass trace element concentrations are also heterogeneous at a single pumice scale (cf. the compositional uniformity of the Oruanui glasses; Allan et al. 2013). This is particularly evident in elements compatible in plagioclase and zircon. Zr varies by $>100$ ppm in glass from KI-1 and KI-2 pumices, and $\sim 150$ ppm in KI-3 pumices. Sr varies over $\sim 60$ ppm in glass from KI-1 and KI-2 pumices and $\sim 80 \mathrm{ppm}$ in KI-3 pumices (Figure 4.4).

In addition to the elemental variability mentioned above, there are compositional gaps in matrix glass across the suite of analysed pumice samples (Figure 4.4). The glass chemistry shows clustering into three groups (best defined by $\mathrm{SiO}_{2}$ versus $\mathrm{CaO}$ and $\mathrm{Zr}$ versus Th), which correspond in almost all cases to the three groups seen in whole rock compositions (Figure 4.3). Matrix glass from the lower $\mathrm{SiO}_{2} \mathrm{KI}-3$ group shows separate, sub-parallel trends when compared to the KI-1 and KI-2 groups on all major and trace element plots (Figure 4.4). Compositional fields covered by KI-1 and KI-2 groups glasses overlap and display a common and continuous trend in $\mathrm{FeO}$ and $\mathrm{Rb} / \mathrm{Sr}$ (Figure 4.4). The three matrix glass groups within the Kidnappers ignimbrite pumices span a larger range than the three compositionally distinct glass types found in the underlying Kidnappers fall deposit (Cooper et al. 2012 [Chapter 3]: Figure 4.4). The compositional groups in the fall deposit, named type $\mathrm{A}$, type $\mathrm{B}$ and type $\mathrm{C}$ in Cooper et al. (2012 [Chapter 3]) are labelled here as KF-A, KF-B and KF-C for ease of comparison. KI-1 overlaps both the KF-A and KF-C compositional fields on all plots apart from $\mathrm{SiO}_{2}$ vs. $\mathrm{Mg}$, and extends to higher trace element concentrations ( $\mathrm{Zr}, \mathrm{Sr}, \mathrm{La}$, Th). KI-2 overlaps KF-B but extends to lower $\mathrm{CaO}$ and $\mathrm{FeO}$ concentrations as well as higher trace element concentrations ( $\mathrm{Zr}, \mathrm{Sr}, \mathrm{La}, \mathrm{Th}) . \mathrm{KI}-3$ does not overlap any of the Kidnappers Fall groups and therefore represents a magma unique to the later stages of the Kidnappers eruption. The KI-3 pumice glasses have significantly higher $\mathrm{Al}_{2} \mathrm{O}_{3}$ 
concentrations ( 13.4 wt. \%) compared with all other Kidnappers glass from both the fall and ignimbrite, which have indistinguishable $\mathrm{Al}_{2} \mathrm{O}_{3}$ ( 12.5 wt. \%) (Figure 4.4b).
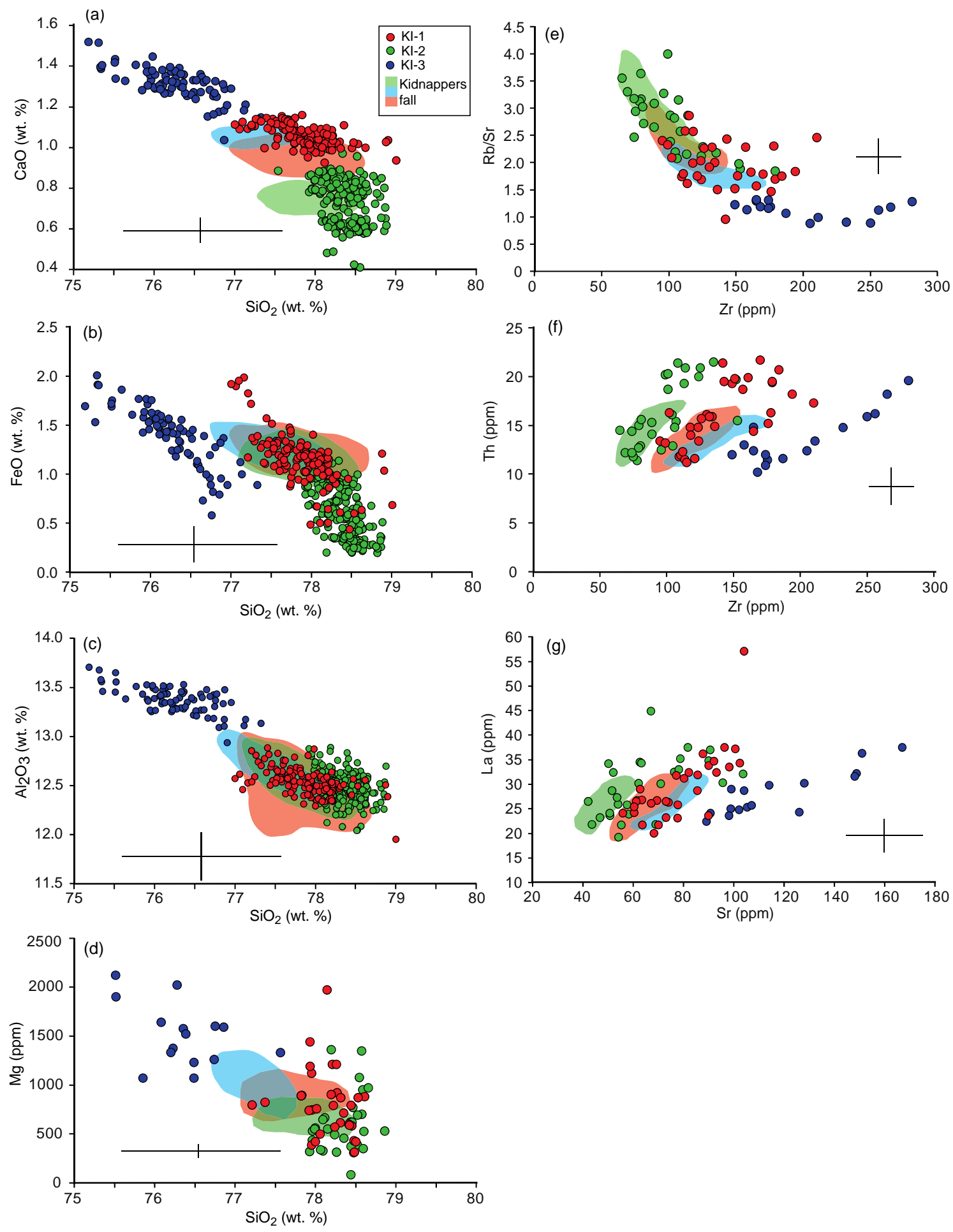

Fig. 4.4. Selected major and trace element plots of Kidnappers matrix glass. Each data point represents a single matrix glass analysis. Spots are divided into three groups based on whole-rock compositional groups (KI-1, KI-2 and KI-3; Table 4.1), and shaded areas highlight the compositional range covered by the glass compositional groups in the Kidnappers fall deposit, identified in Chapter $3(\mathrm{KF}-\mathrm{A}=$ red, KF-B=green, KF-C=light blue (KF-C contains KF-C glass and variable proportions of KF-A and KF-B; see Chapter 3 and Table 4.1). 


\subsubsection{Rocky Hill whole-rock}

Forty four pumice clasts were analysed for major elements by XRF and 12 for trace elements by solution ICP-MS. In comparison to the Kidnappers whole-rock data, similar and/or slightly larger major element variations are displayed (e.g. 65.0-76.2 wt. $\% \mathrm{SiO}_{2}$ : Figure 4.5). $\mathrm{K}_{2} \mathrm{O}$ concentrations are generally lower (2.1-4.9 wt. \%) and $\mathrm{Na}_{2} \mathrm{O}$ concentrations are generally higher in Rocky Hill pumices. $\mathrm{Al}_{2} \mathrm{O}_{3}$ concentrations extend to considerably higher values (13.1-21.3 wt. \%) (Figure 4.5b). $\mathrm{Al}_{2} \mathrm{O}_{3}$ has a weak positive correlation $\left(\mathrm{R}^{2}=0.25\right)$, and $\mathrm{SiO}_{2}$ a weak negative correlation $\left(\mathrm{R}^{2}=0.25\right)$ with LOI values (0-5 wt. \%) and thus the highest $\mathrm{Al}_{2} \mathrm{O}_{3}$ concentrations may be an artifact of secondary hydration. and associated leaching and chemical alteration. $\mathrm{MgO}$ concentrations at the less-evolved end of the compositional range ( $<71 \mathrm{wt}$. \% $\mathrm{SiO}_{2}$ ) are lower than observed in Kidnappers samples (Figure 4.5d). Trace elements are slightly less variable than in the Kidnappers (e.g., 25-64 ppm Zn, 115-177 ppm Sr, 83-127 ppm $\mathrm{Zr}$ and 86-120 ppm Rb: Figure 4.5). A continuity of values is shown across the range in major element concentrations and therefore Rocky Hill pumices cannot be subdivided based on whole rock chemistry. Trace elements such as Ni, Zn, Sr and Zr behave compatibly whereas $\mathrm{Rb}$ behaves incompatibly (Figure 4.6). Ba is less incompatible in the Rocky Hill than the Kidnappers samples. Rb/Sr ratios within Rocky Hill pumice span a more restricted range (0.5-1.0) and form a sub parallel trend when plotted against $\mathrm{K}_{2} \mathrm{O} . \mathrm{Eu} / \mathrm{Eu}^{*}$ ratios also cover a smaller range (0.76-0.53) with a sharp drop in pumices with $<16$ wt.\% $\mathrm{Al}_{2} \mathrm{O}_{3}$ (Figure 4.6). Unlike in the Kidnappers, $\mathrm{Y}$ has a tighter correlation with $\mathrm{Al}_{2} \mathrm{O}_{3}$.

\subsubsection{Rocky Hill matrix glass}

Nine pumices from the Rocky Hill were chosen for matrix glass analysis on the basis of whole rock composition (Table 4.1). Representative data are shown in Table 4.3. Apart from $\mathrm{K}_{2} \mathrm{O}$ and $\mathrm{Na}_{2} \mathrm{O}$, tie lines drawn between major element whole rock and average matrix glass compositions have the same slopes (over similar lengths) as within the Kidnappers suggesting a similar degree of crystal content effects (Figure 4.5). Unlike in the Kidnappers, $\mathrm{K}_{2} \mathrm{O}$ tie lines have positive and $\mathrm{Na}_{2} \mathrm{O}$ tie lines negative slopes with increasing $\mathrm{SiO}_{2}$ (Figure 4.5). Rocky Hill matrix glass has higher $\mathrm{Rb} / \mathrm{Sr}$ and $\mathrm{K}_{2} \mathrm{O}$ values than its corresponding whole rock value (Figure 4.6). 

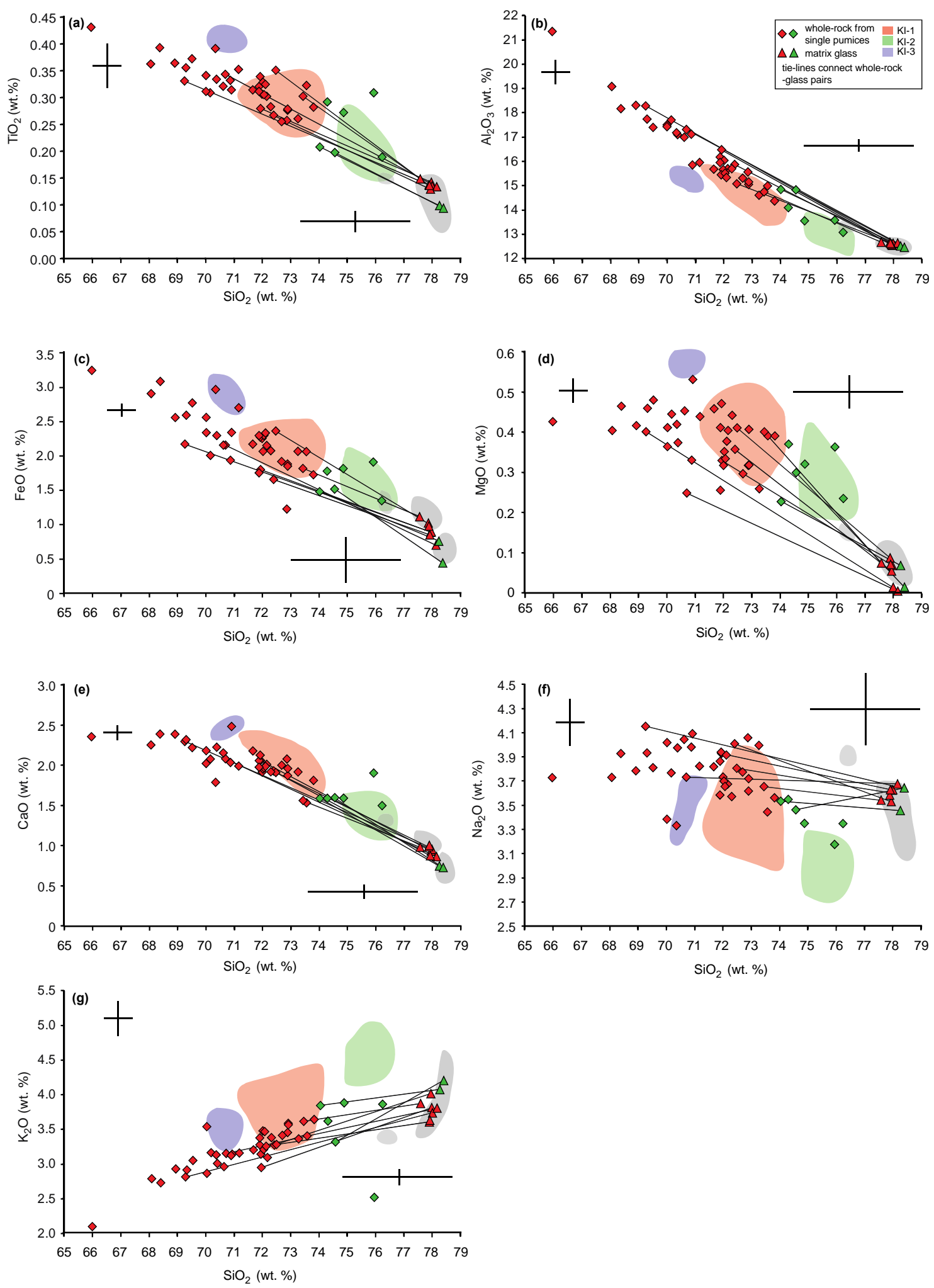

Fig. 4.5. Plots of whole-rock (diamonds) and matrix glass (triangles) major oxide abundances against silica for all analysed Rocky Hill single pumice clasts. Tie lines connect whole-rock-glass pairs. Red diamonds represent RH-1 pumices and green diamonds are RH-2 pumices. The range of Kidnappers data is shown by the coloured areas for whole-rock analyses and grey areas for glass analyses (see Figure 4.2). Crosses represent whole-rock $2 \mathrm{sd}$ XRF uncertainties (left hand side) and 2 sd EPMA matrix glass uncertainties (right hand side) (Appendix 1). 

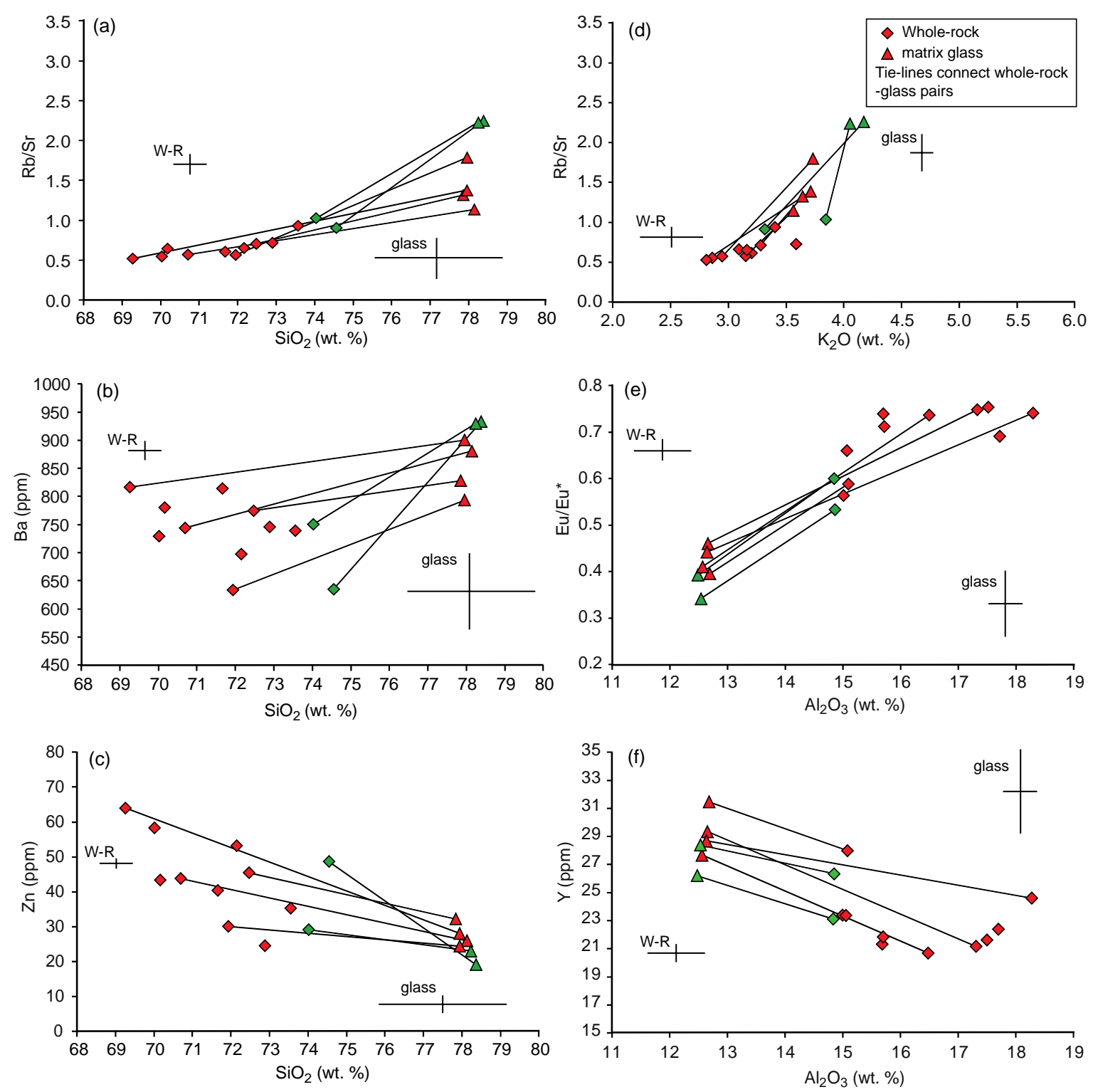

Fig. 4.6. Plots of selected trace elements versus silica (a-c), $\mathrm{K}_{2} \mathrm{O}(\mathrm{d})$ and $\mathrm{Al}_{2} \mathrm{O}_{3}(\mathrm{e}$,f) for pumice whole-rock and matrix glass from Rocky Hill pumices. Tie-lines connect wholerock-glass pairs. Crosses represent 2 sd whole-rock solution ICPMS uncertainties (Electronic Appendix). Colours of the symbols indicate the compositional groups to which pumices are assigned (RH-1=red, $\mathrm{RH}-2=$ green; see Table 4.1).

Matrix glass displays less variation in major element chemistry than within the Kidnappers. Average values range from 77.6-78.4 wt. \% $\mathrm{SiO}_{2}$, 3.6-4.2 wt. \% $\mathrm{K}_{2} \mathrm{O}$ and 0.7-1.0 wt.\% $\mathrm{CaO}$. The matrix glass within each pumice is homogeneous with respect to major elements, apart from $\mathrm{FeO}$ that ranges over 0.8 wt. \% in each sample (Figure 4.7). Two discrete matrix glass groups are present within Rocky Hill pumice, and therefore pumice clasts can be classified into a 'normal' type ( $\mathrm{RH}-1$ : higher $\mathrm{CaO}$ and lower $\mathrm{SiO}_{2}$ ) and high-SiO $\mathrm{Si}_{2}$ type (RH-2: lower $\mathrm{CaO}$ : Figure 4.7a). 

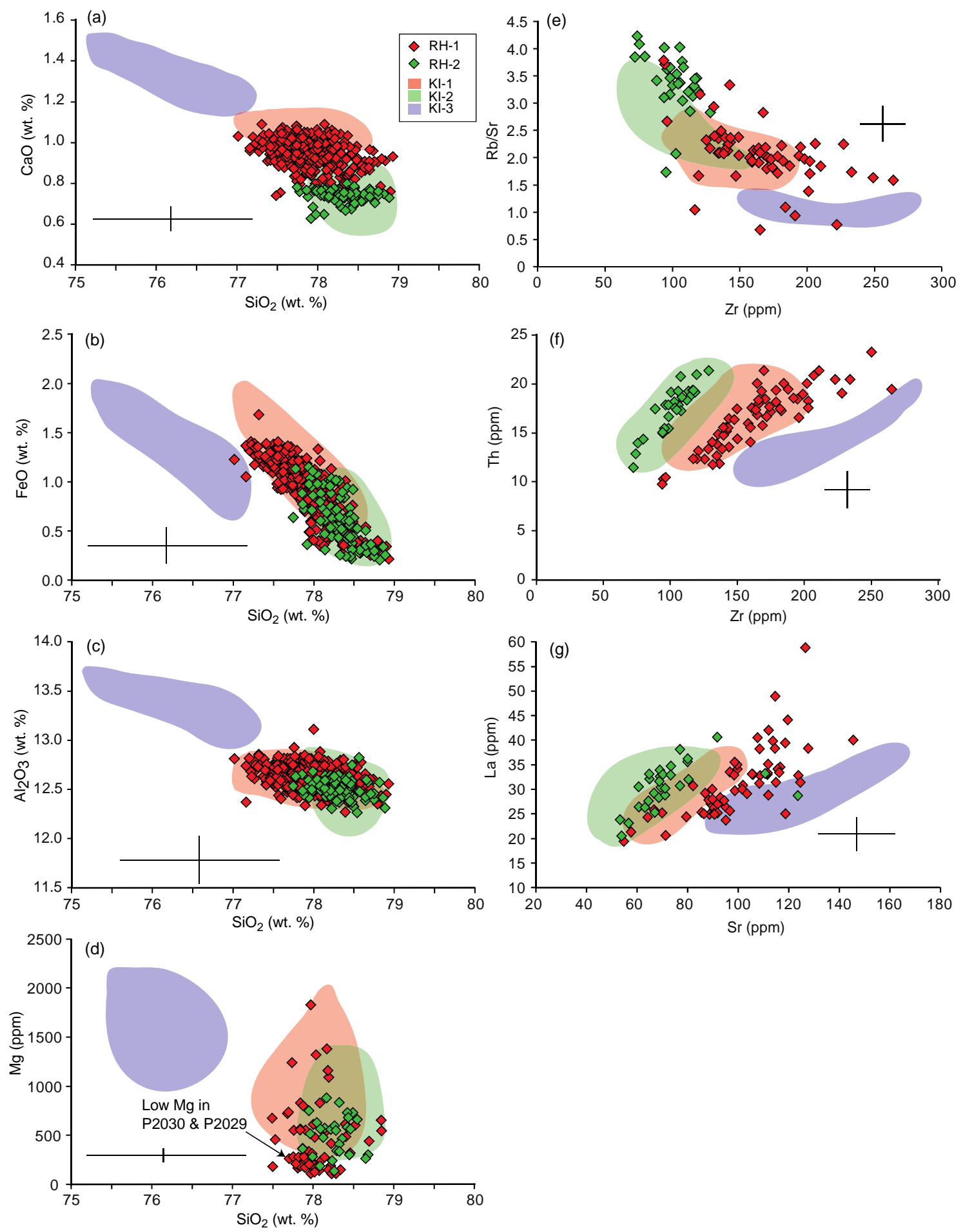

Fig. 4.7. Plots of selected major and trace elements of Rocky Hill matrix glass. Each data point represents a single matrix glass analysis. Spots are divided into two groups based on whole-rock compositional groups. Coloured shaded areas represent the corresponding ranges covered by matrix glass compositional groups within Kidnappers pumice (KI$1=$ red, KI-2=green, KI-3=blue; see Figure 4.2). 
Although these groups have distinct matrix glass compositions, associated whole-rock compositions show a large range with no compositional gaps. An arbitrary value of 74 wt. $\% \mathrm{SiO}_{2}$ is therefore used as a whole-rock cut off between $\mathrm{RH}-1$ and $\mathrm{RH}-2$ pumices. Interestingly, the two glass compositional groupings ( $\mathrm{RH}-1$ and $\mathrm{RH}-2)$, but with a more restricted range in matrix $\mathrm{CaO}$ contents are very similar to the glass compositional groups (KF-A and KF-B) within the Kidnappers fall deposit (Cooper et al. 2012 [Chapter 3]). Matrix glass FeO and trace element concentrations in the Rocky Hill, however, cover a larger range. Heterogeneity within Rocky Hill glass is more pronounced in trace element concentrations, particularly $\mathrm{Zr}$ and $\mathrm{Sr}$ (Figure 4.7). $\mathrm{Zr}$ varies over $\sim 150 \mathrm{ppm}$ (normal type pumice) and $\sim 80 \mathrm{ppm}$ (high-SiO 2 pumice), and $\mathrm{Sr}$ over $\sim 100 \mathrm{ppm}$ (normal type pumice) and $\sim 40 \mathrm{ppm}$ (high-SiO $\mathrm{S}_{2}$ pumice). Matrix glass major element compositions are slightly more restricted, but overlie the KI-1 and KI-2 Kidnappers groups. Unlike in the Kidnappers, all Rocky Hill pumices within each of the RH-1 and RH-2 groups (Table 4.1) have indistinguishable major element matrix glass compositions (Figure 4.7). Trace element concentrations from the dominant RH-1 type matrix glass overlie and extend the KI-1 Kidnappers group but do not show the same trends as the KI-3 group. Rocky Hill pumice samples P2029 and P2030 from group RH1 (Table 4.1) have matrix glass $\mathrm{Mg}$ concentrations of $<500 \mathrm{ppm}$, lower than any values within the Kidnappers (Figure 4.7d). Trace element concentrations within group RH-2 are nearly identical to those in the KI-2 group, apart from higher and more restricted $\mathrm{Rb} / \mathrm{Sr}$ ratios. The two Rocky Hill glass groups form sub parallel trends on plots of $\mathrm{Sr}$ versus $\mathrm{La}$ and $\mathrm{Zr}$ versus Th with limited or no overlap.

\subsubsection{Rocky Hill brown glass}

In hand sample, brown glass can be seen sheathing crystal clots within several Rocky Hill pumice clasts (Figure 4.8). BSE imaging reveals the brown glass to have a lower vesicularity with thicker bubble walls than the matrix glass, but is not devitrified. The brown glass is commonly compositionally distinct with, on average, higher $\mathrm{Na}_{2} \mathrm{O}(5.1$ wt. \%) and $\mathrm{CaO}\left(1.2\right.$ wt. \%) but lower $\mathrm{K}_{2} \mathrm{O}$ (1.4 wt. \%), Rb (66 ppm), Ba (716 ppm) and $\mathrm{Li}(19 \mathrm{ppm})$ than the matrix glass (Figure 4.8; Electronic Appendix 4). The distinctly lower concentrations of fluid mobile elements imply that the brown glass has been affected by fluids. $\mathrm{SiO}_{2}$ and all other elements are indistinguishable from matrix glass 
compositions. Brown glass selvedges are common in RH-1 type pumice, but have only been found in one RH-2 type pumice sample.

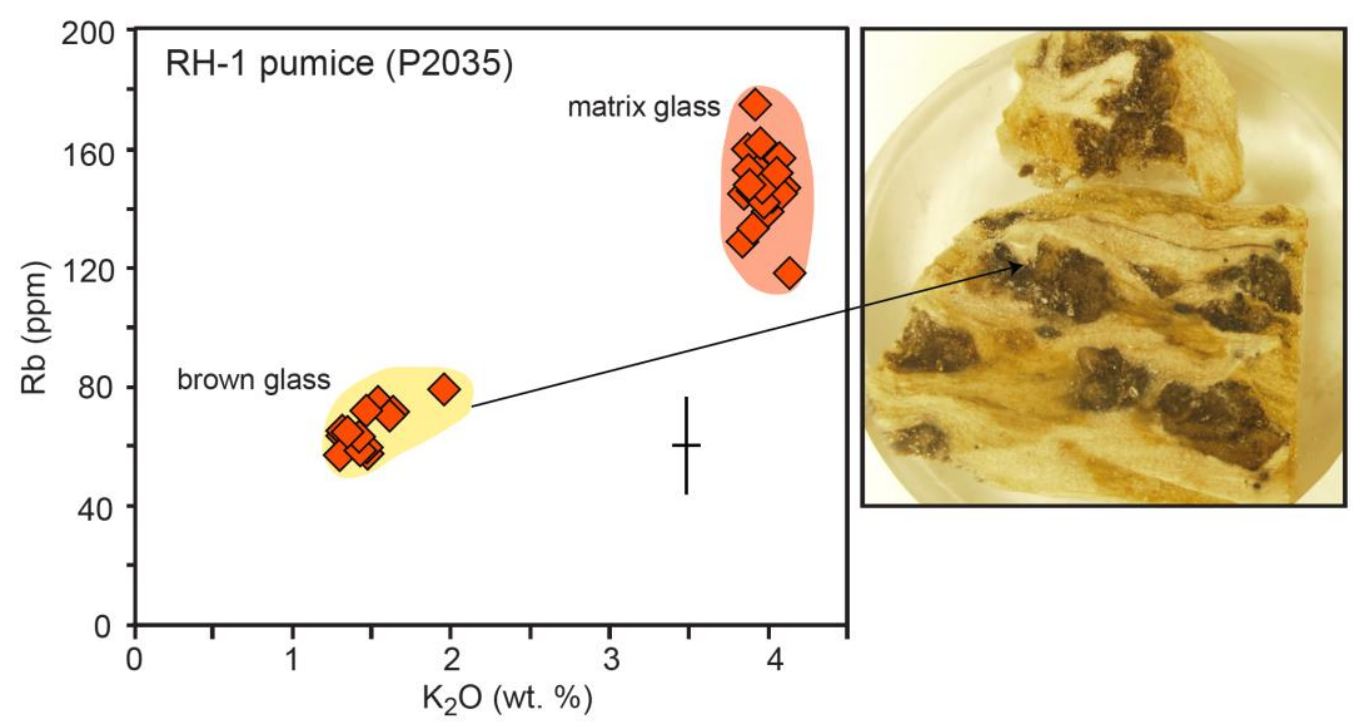

Fig. 4.8. $\mathrm{K}_{2} \mathrm{O}$ versus $\mathrm{Rb}$ for Rocky Hill matrix glass and brown glass from a single pumice clast. Photograph of a pumice chip shows the textural relationship between matrix glass and brown glass, which is found in association with crystal clots.

\subsubsection{Kidnappers fall melt inclusions}

In addition to matrix glass, quartz hosted melt inclusions were analysed throughout the Kidnappers fall deposit. Melt inclusions are common within Kidnappers fall quartz and plagioclase phenocrysts and range in size from $10-200 \mu \mathrm{m}$ in diameter. Major and trace element compositions of quartz-hosted melt inclusions show considerable overlap with the Kidnappers fall glass populations (cf. Liu et al. 2006; Figure 4.9). Closed inclusions show weak groupings on trace element plots such as $\mathrm{Zr}$ versus Th. However, these groupings are not separated to the same extent as matrix glass compositions. The compositions of open (reentrant) inclusions and selvages overlap those of the closed melt inclusions. Melt inclusions extend to higher $\mathrm{Rb} / \mathrm{Sr}$ values, but show a more restricted range in $\mathrm{Zr}, \mathrm{Sr}$ and $\mathrm{Ba}$ concentrations than are observed in matrix glass shards. Closed melt inclusions extend to lower concentrations of a number of elements including $\mathrm{Mg}, \mathrm{Ca}, \mathrm{Mn}, \mathrm{Ba}$ and $\mathrm{Sr}$. 

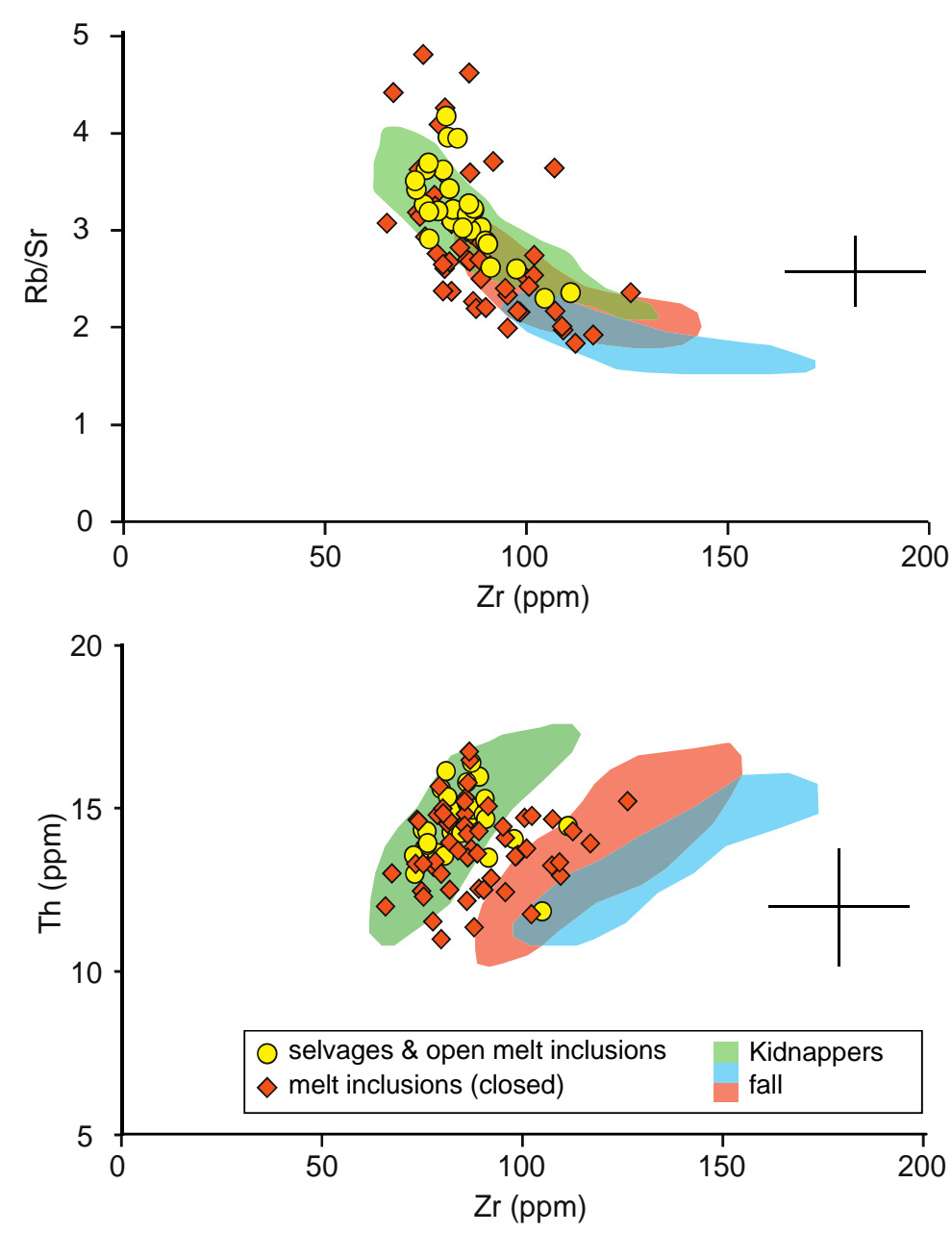

Fig. 4.9. Plots to compare the composition of quartz hosted melt inclusions to the compositions of matrix glass in the Kidnappers fall deposit (Chapter 3) (coloured shaded areas; Table 4.1). Circles represent analyses of selvages and open melt inclusions. Diamonds represent analyses of closed melt inclusions.

\subsubsection{Isotopic data}

Pumices from the Kidnappers (6 clasts) and Rocky Hill (7 clasts) ignimbrites, as well as Kidnappers fall material (4 samples) were selected for $\mathrm{Pb}$ isotopic analysis to cover the full compositional range in both eruptions (Table 4.1). Whole rock pumice samples were used for the ignimbrites and both whole rock samples and glass separates were measured in Kidnappers fall samples. The range in $\mathrm{Pb}$ isotope data for all analysed samples is relatively small and only minor differences between eruptions are evident (Figure 4.10). All Kidnappers and Rocky Hill data lie within the field defined by other TVZ rhyolites (Allan 2008), and within the Torlesse terrane field (Figure 4.10). 

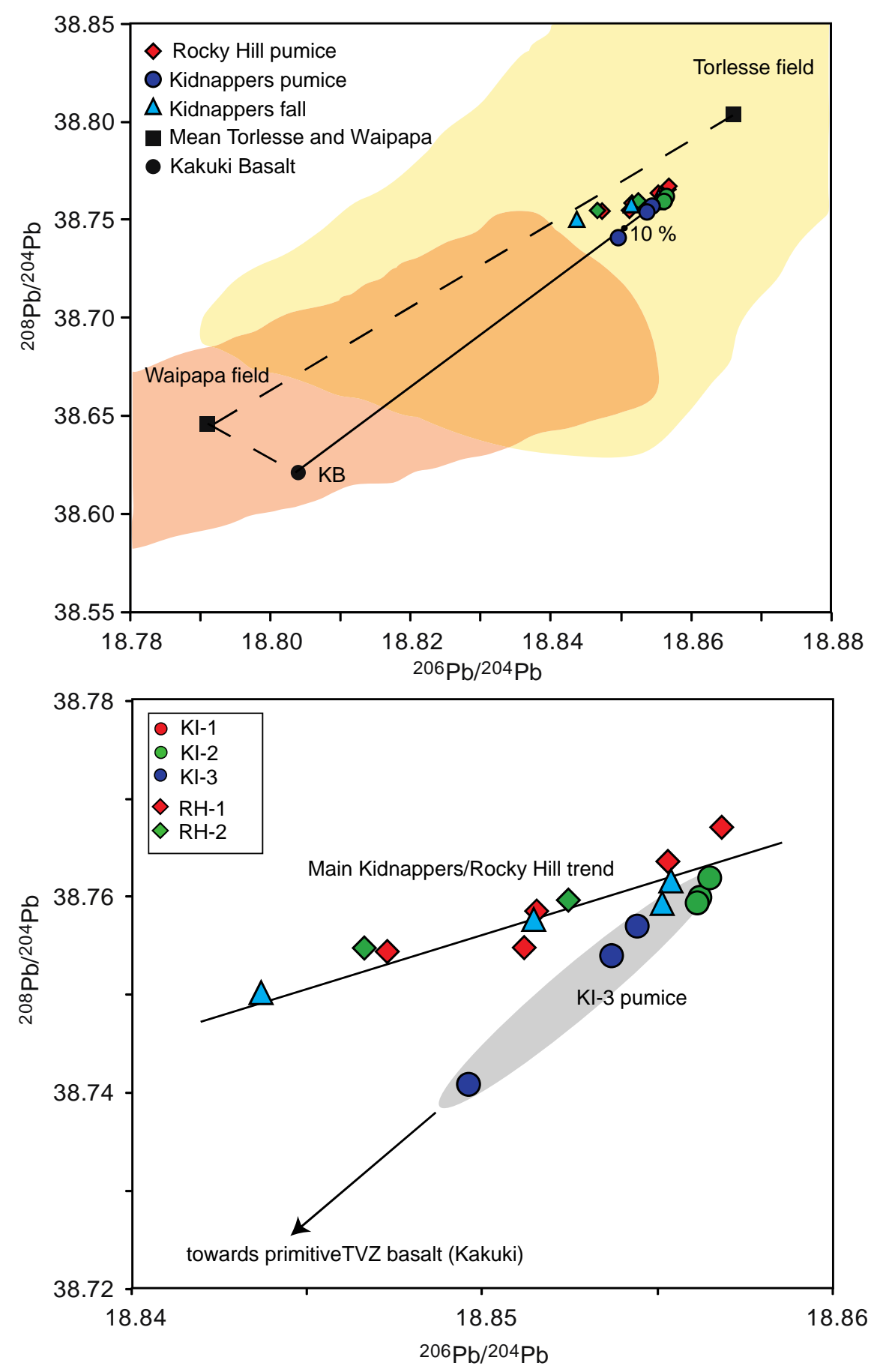

Fig. 4.10. Plots of $\mathrm{Pb}$ isotope ratios from the Kidnappers fall samples and from pumices in the Kidnappers and Rocky Hill ignimbrites. Grey shaded fields mark the range of $\mathrm{Pb}$ isotopic compositions reported for the Waipapa and Torlesse greywacke crustal lithologies, modified from Allan (2008).

The majority of $\mathrm{Pb}$ isotopic signatures within TVZ rhyolites are explained by crustal contamination, whereby primitive TVZ basalts are variably contaminated by metagreywacke crust of the Waipapa and/or Torlesse composite terranes (e.g. McCulloch et al. 1994; Adams et al. 2009; Leonard et al. 2010). The Waipapa composite terrane 
outcrops west of the TVZ (and in the Mangakino area), whereas the Torlesse composite terrane is found to underlie a significant proportion of, and to the east of the modern TVZ. (e.g. Charlier et al. 2010). It is apparent that the melt erupted from Mangakino has been significantly contaminated by Torlesse crust and therefore the Torlesse must extend someway beneath the western margin of the old TVZ (cf. McCormack et al. 2009). KI-3 pumices (Table 4.1) display a slightly different vector than all other analysed samples, and appear to trend towards the field of TVZ basalts (McCulloch et al. 1994) (Figure 4.10).

\subsubsection{Mineral textures}

All pumices analysed from both ignimbrites contain the phenocryst assemblage, in variable proportions, of plagioclase + quartz + orthopyroxene + hornblende + magnetite + ilmenite, plus accessory zircon and apatite. Material from the Kidnappers fall deposit contains the same assemblage (Chapter 3). Biotite comes in part way through the Kidnappers fall deposit (in association with the B-type glass: Chapter 3), is present in nearly all Kidnappers pumices, but is sparse within Rocky Hill pumices. High-SiO 2 (KI2) end-member pumices contain a smaller proportion of orthopyroxene and a greater proportion of amphibole when compared with the low- $\mathrm{SiO}_{2}(\mathrm{KI}-1)$ pumices.

Before the mineral chemistry is presented, mineral textures of pumices from the Kidnappers and Rocky Hill ignimbrites are discussed and compared with mineral characteristics from the earlier Kidnappers fall phase. Three types of crystals are commonly present within eruption products: phenocrysts (grown in the melt which they now reside), antecrysts (from a precursor melt or crystal mush) and xenocrysts (Hildreth and Wilson 2007, Streck 2008). The latter may be from the melting or disruption of unrelated country rocks, old intrusive rocks or different magmas of contrasting compositions injected into the magma body.

\subsubsection{Kidnappers fall deposit mineral textures}

Nine samples through the fall deposit were chosen for crystal specific investigations (Table 4.1). Mineral chemistries from the Kidnappers fall deposit are briefly discussed 
in Chapter 3. Here the data are presented differently to make direct comparisons to the mineral characteristics in the two ignimbrites. The mineral assemblage at each horizon (apart from the KF-A dominant base) reflects a mixture of material from at least two compositional groups. Thus, the mineral textures and chemistry from the fall deposit cannot always be definitively matched with the glass compositional groups. In particular, crystals from KF-C cannot be separated from the other groups and so KF-C material is presented within the 'other' group in the following section (Table 4.1). Consideration of these limitations needs to be placed on the discussion of proportions of mineral textures at each stratigraphic height, as unlike from pumice samples, variations in concentrations in loose ash samples may not be a true representation of the crystal cargo in each melt.

Plagioclase is the dominant crystal phase in all sampled heights through the deposit. Plagioclases are commonly $>1 \mathrm{~mm}$ in size and are variably and complexly zoned at all horizons. Plagioclase at each analysed fall horizon (Table 4.1) was classified based on the characteristics of the outermost rim. Around $25 \%$ of plagioclase at all stratigraphic heights display patchy cores, often with a sieve texture. In general, plagioclase rims can be divided into three populations based on a change in BSE intensity between interior domains and outermost rims: light rims, dark rims and non-distinct rims (no colour change or fine oscillatory zoning to the outermost rim) (Figure 4.11). Grains displaying non-distinct rims are the dominant population (42-92\%), and grains with light rims are subordinate at each stratigraphic horizon (3-12\%). The most notable observation is the near absence of plagioclase with dark rims at the base of the deposit (where KF-A dominates). This suggests dark rimmed grains may be almost exclusively from the KFB compositional group which first appears $\sim 1 \mathrm{~m}$ from the base of the deposit.

Orthopyroxene is up to $\sim 1 \mathrm{~mm}$ in size and occurs as subhedral crystals that are commonly fractured with ragged terminations. Fe-Ti oxide inclusions are nearly ubiquitous in orthopyroxene, and apatite and zircon inclusions are sometimes present. Orthopyroxene crystals at each analysed fall horizon (Table 4.1) were classified into four populations based on simplified textural characteristics evident from BSE imaging: 


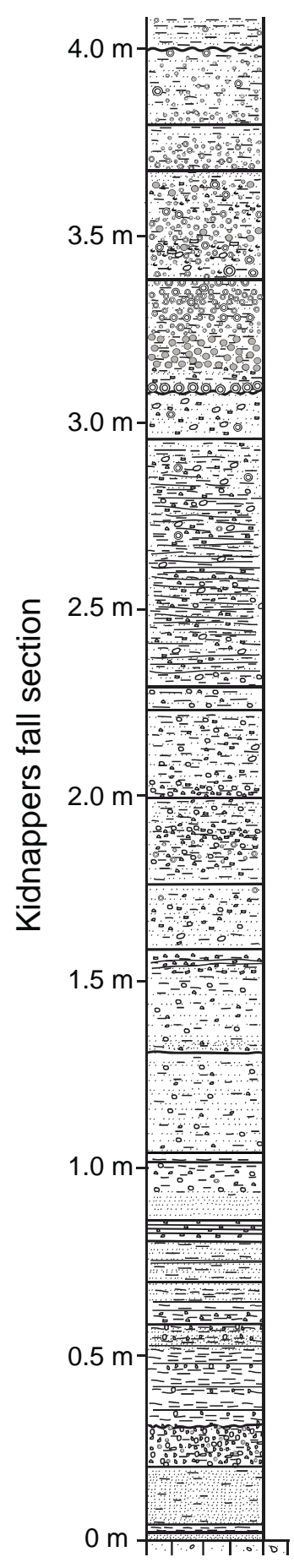

(a) Plagioclase
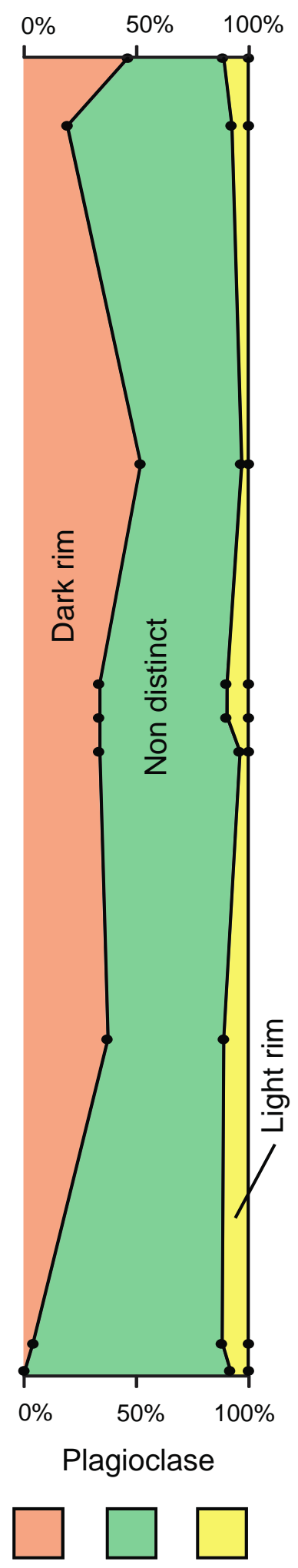

Dark

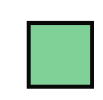

Non distinct

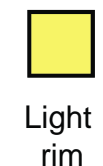

(b) Orthopyroxene
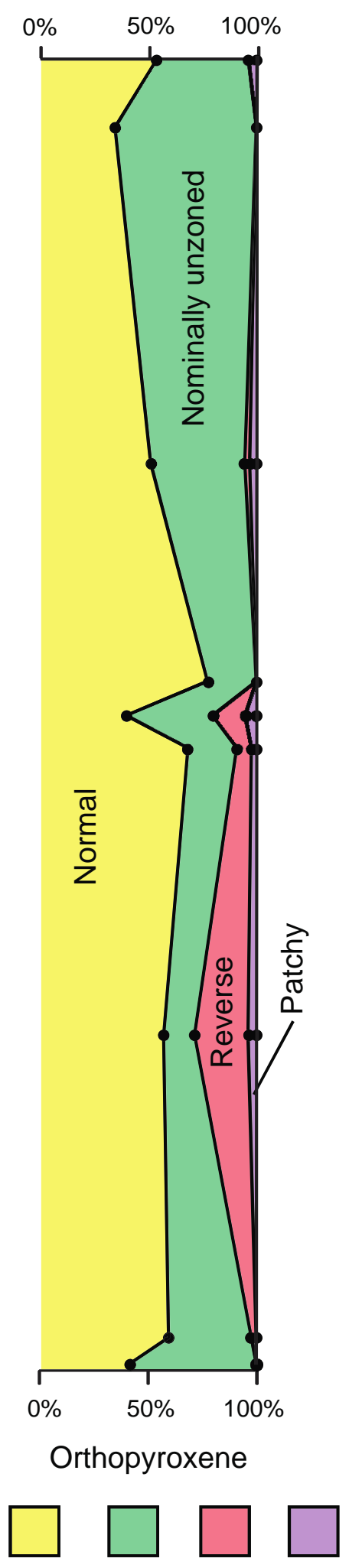

Normal Unzoned Reverse Patchy

Fig. 4.11. Summary of textural features of plagioclase and orthopyroxene grains from samples through the Kidnappers fall deposit (Cooper et al. 2012 [Chapter 3]). These textures are discussed in the text with representative images in Figure 4.12 and Figure 4.13. 
grains in which interiors follow general normal (1) and reverse (2) zoning patterns, (3) grains which are nominally unzoned and (4) grains which have a patchy appearance with no clear zoning relationship (Figure 4.11). No significant stratigraphic variations in the proportions of normally zoned, nominally unzoned and patchy grains are recorded through the fall deposit (Figure 4.11). Reversely zoned grains are only present in any significant quantity (up to $25 \%$ ) from just above the base to $\sim 2 \mathrm{~m}$ in the fall deposit (Figure 4.11). The least evolved KF-C glass type is only present within the same horizons, suggesting these grains may be associated with this melt type.

Quartz forms euhedral, bipyramidal, but often broken crystals up to $\sim 2 \mathrm{~mm}$ across. Variable and complex zoning within quartz is evident from cathodoluminescence (CL) imaging. Euhedral prismatic amphibole crystals are up to $\sim 2 \mathrm{~mm}$ long and commonly contain inclusions of Fe-Ti oxides and apatite. Amphiboles do not display consistent textural core-to-rim relationships or systematic zoning patterns and it is therefore not feasible to characterise these grains based on zoning visible in BSE imagery. A subordinate population of amphibole grains have patchy recrystallised cores and may represent an antecrystic or xenocrystic component. Biotite occurs as golden coloured, weathered euhedral to subhedral books or flakes up to $1 \mathrm{~mm}$ across. Magnetite and ilmenite occur as discrete crystals but are also common as inclusions within orthopyroxene and amphibole. Discrete oxides in the fall deposit have some degree of weathering and alteration and therefore oxide inclusions were targeted for geochemical analysis (Section 4.5.4.1).

\subsubsection{Kidnappers ignimbrite pumice mineral textures}

Ten representative Kidnappers pumice samples were chosen for crystal specific investigations (Table 4.1). Plagioclase, the dominant crystal phase in all pumices, forms subhedral to euhedral, invariably fractured crystals up to $2 \mathrm{~mm}$ long, with weakly defined but complex zoning (Figure 4.12). Around $20 \%$ of plagioclase across all pumice types display bright patchy cores, which often have a sieve texture. These cores may be either antecrystic or xenocrytic, undergoing resorption and recrystallisation when placed into the melt-dominant body. Plagioclase interior domains show variable 


\section{Kidnappers plagioclase rim characteristics}
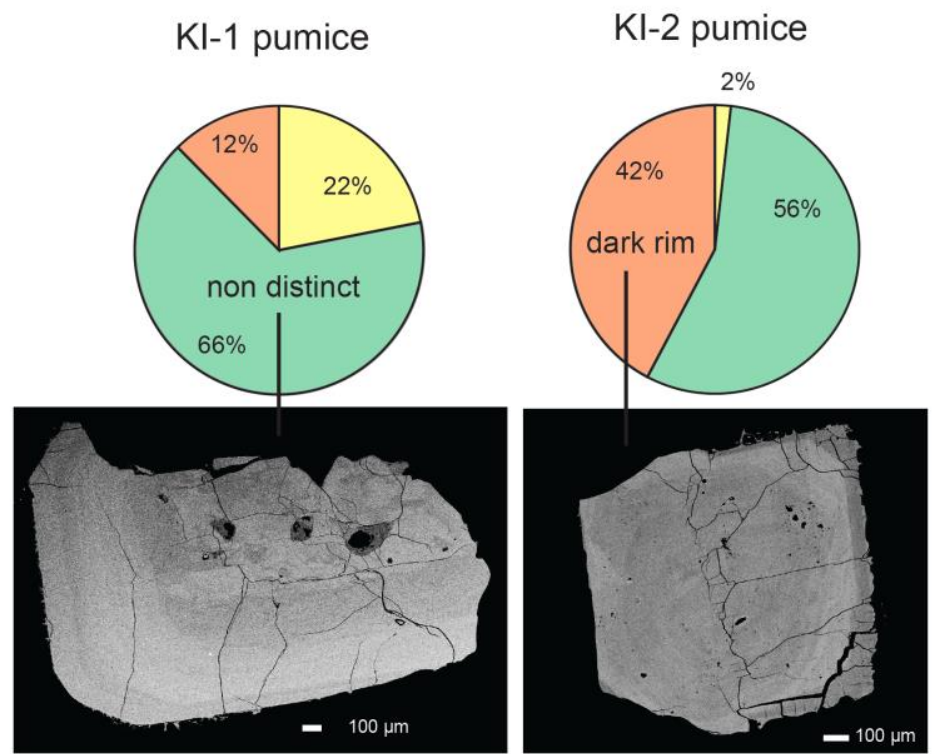

KI-3 pumice

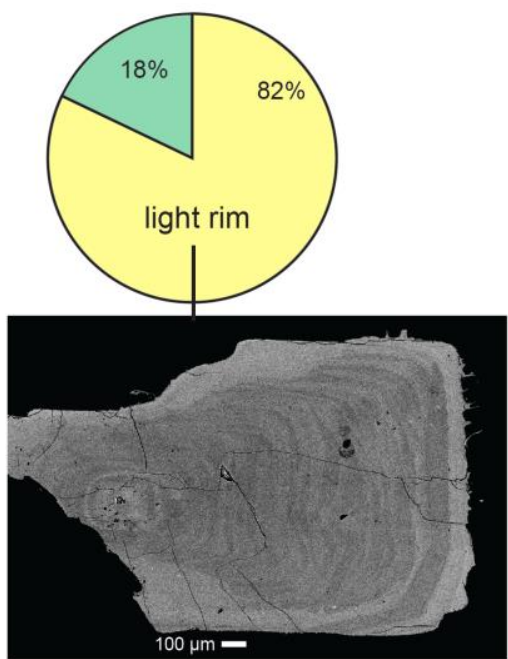

Rocky Hill plagioclase rim characteristics

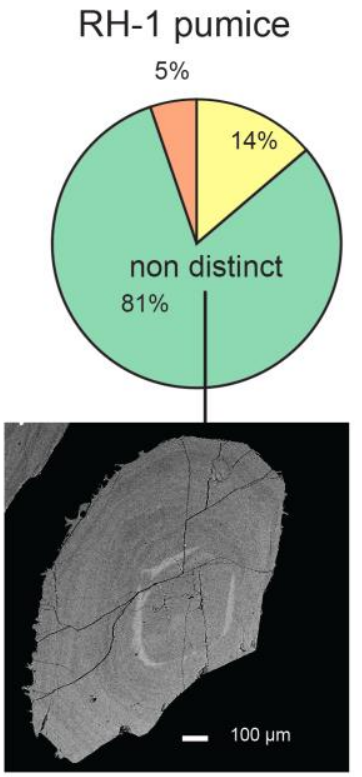

$\mathrm{RH}-2$ pumice

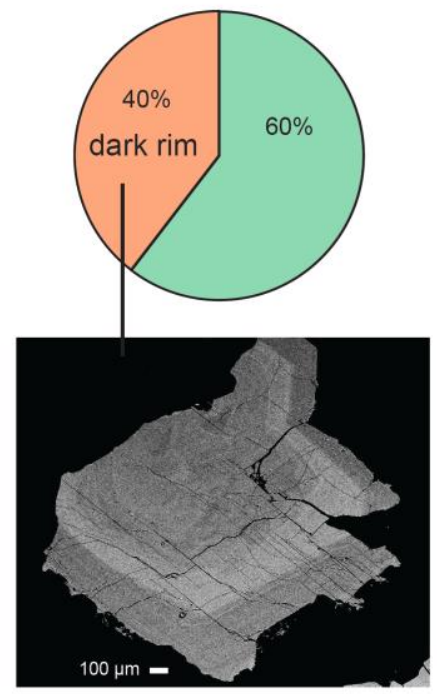

Fig. 4.12. Summary of textural features (based on BSE imaging) of Kidnappers and Rocky Hill plagioclase grains from each pumice compositional group. Plagioclase grains are divided into three populations based on the BSE intensity change from intermediate domains to outermost rims. 'Light rims' and 'dark rims' are grains that have prominent outermost rims that are either lighter or darker than their interior domains. 'Non-distinct rims' do not show a significant change in brightness from their associated interior domains. 
zoning patterns with a number of resorption episodes both within and between samples, making textural classification difficult. To compare textures to their counterparts in the fall deposit, plagioclase rims can be divided into the same three populations: light rims, dark rims and non-distinct rims (Figure 4.12). Within KI-3 pumice, grains with light rims dominate ( $82 \%$ ) and grains with dark rims are absent, whereas in KI-2 pumice 42 $\%$ of grains have a prominent dark rim and only $2 \%$ have light rim (Figure 4.12). Twelve percent of the plagioclase crystals within KI-1 pumice have dark rims and $22 \%$ have light rims. The dominance of light grains in KI-3 is not observed at any horizon in the Kidnappers fall deposit (3-12\% of total plagioclase grains) and is unique to the Kidnappers ignimbrite.

Orthopyroxene (up to $1 \mathrm{~mm}$ ) occurs as subhedral crystals that commonly are fractured with ragged terminations, and contain nearly ubiquitous Fe-Ti oxide, common apatite and rare zircon inclusions. Orthopyroxene crystals were classified into the same four populations as within the fall deposit. However, a further distinction can be made of crystals that show a dark exterior zone that may overprint any of the textures (Figure 4.13). This dark zone can be superimposed onto each of the four textural groups described above and is either found within $100 \mu \mathrm{m}$ of the grains outermost rim, or as the outermost rim itself (Figure 4.13). This zone is only present in a small number of reversely zoned grains ( $\sim 1 \mathrm{~m}$ from base) in the Kidnappers fall deposit, but is more common within the ignimbrite. Systematic changes are observed in the proportions of each textural type within each whole-rock compositional group. Orthopyroxenes displaying normal zoning increase from $34 \%$ in KI-3 pumice to $76 \%$ within KI-2 pumice. Nominally unzoned grains decrease in proportion from 51 to $15 \%$, and reversely zoned grains decrease from 8 to $1 \%$ between KI-3 and KI-2 pumice types (Figure 4.13). Patchy grains, representing significant recrystallisation do not follow a particular trend and are commonly subordinate to other textural types. The most striking contrast within each compositional group is the high proportion (41\%) of grains with a dark (high $\mathrm{Mg}$ ) exterior zone in $\mathrm{KI}-3$ pumice versus $2 \%$ in KI-2 pumice samples (Figure 4.13). 


\section{Orthopyroxene textural characteristics}

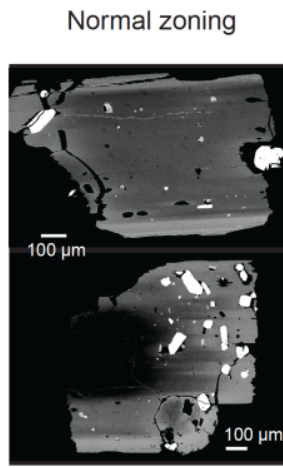

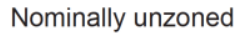

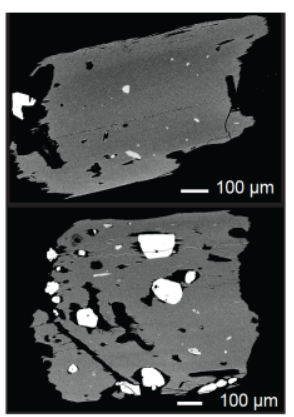

Reverse zoning

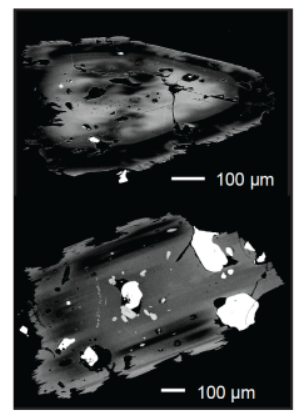

Patchy

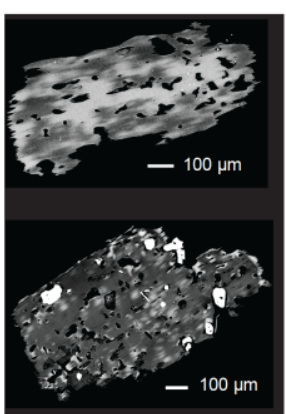

\section{Kidnappers}

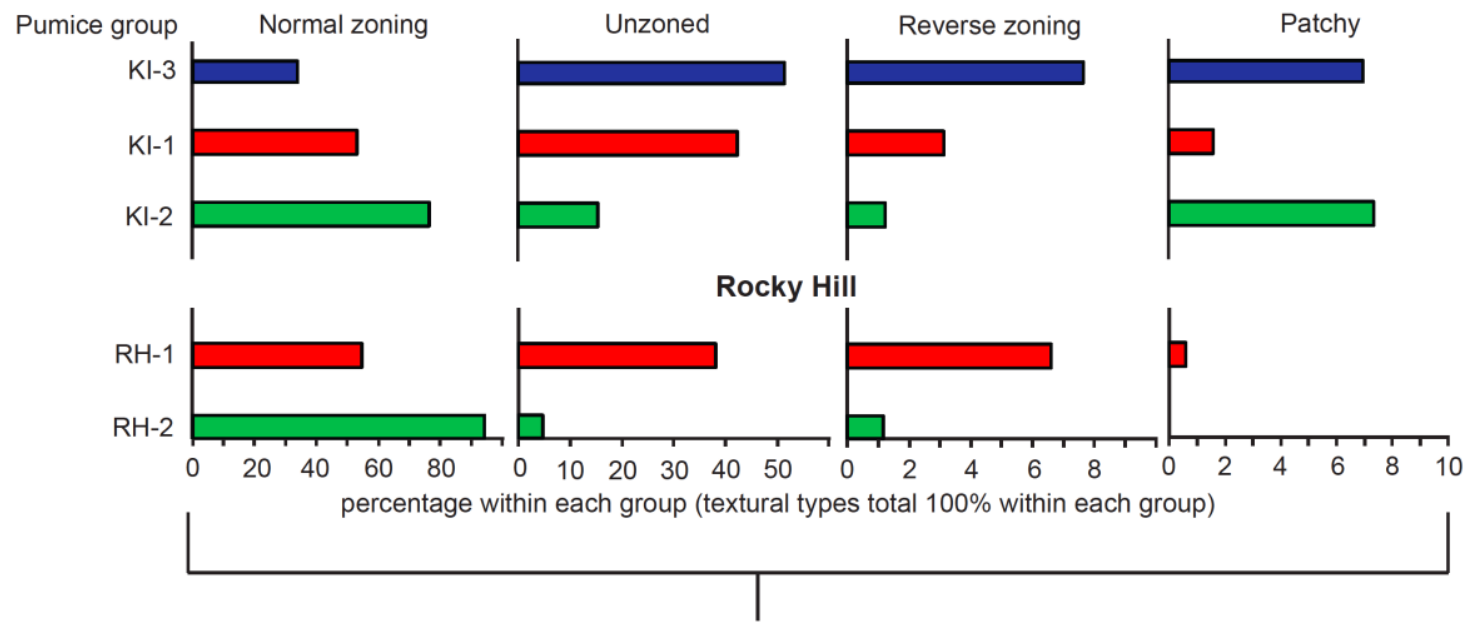

Dark exterior zone (superimposed on the above textures)
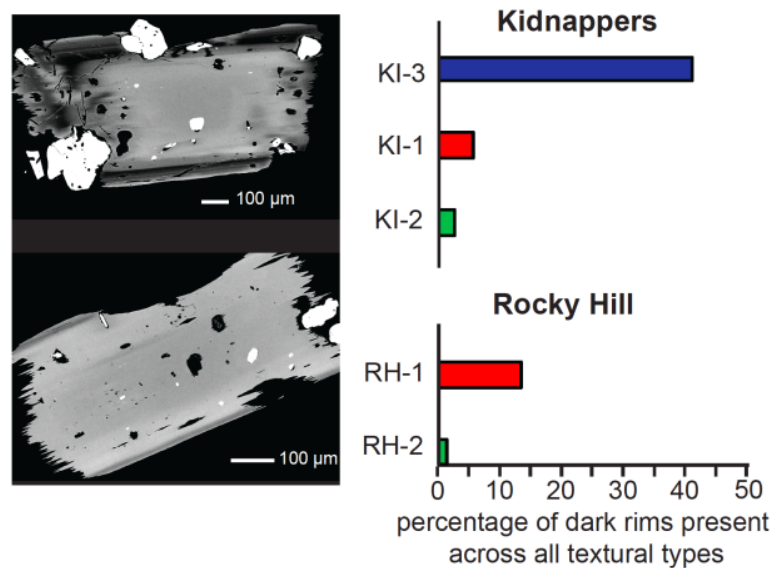

Fig. 4.13. Summary of textural features (based on BSE imaging) of Kidnappers and Rocky Hill orthopyroxene grains from each pumice compositional group. Normally zoned orthopyroxenes are those with have darker (higher En) cores and lighter (lower En) outer zones. Nominally unzoned grains do not show any significant compositional zonation, although some streaky discontinuous zoning may be present. Reversely zoned grains have lighter (lower En) cores and darker (higher En) outer zones. Patchy grains display a range of compositions but zoning is discontinuous and no core-rim relationships are observed. Bar charts show the proportions of grain populations within each compositional group. A dark exterior zone (e) may be superimposed on any of the four textures, and the proportions of grains with dark exteriors (as a percentage of total orthopyroxene grains) are shown. 
Quartz forms euhedral, bipyramidal, but often broken crystals up to $2 \mathrm{~mm}$ across. Variable zoning within quartz is evident from CL imaging. Euhedral prismatic amphibole crystals are up to $2 \mathrm{~mm}$ long and commonly contain inclusions of $\mathrm{Fe}-\mathrm{Ti}$ oxides and apatite. As with the Kidnappers fall deposit, it is difficult to classify the textural characteristics of amphibole grains. A subordinate population of amphibole grains have patchy recrystallised cores and may represent an antecrystic or xenocrystic component. Biotite occurs mostly as golden coloured, weathered euhedral to subhedral books or flakes up to $1 \mathrm{~mm}$ across. Where fresh enough to analyse, it does not display any clear zoning characteristics. Magnetite and ilmenite occur as discrete crystals but are also common as inclusions within orthopyroxene and amphibole. Accessory zircon is ubiquitous in all pumices. In any one clast, zircon varies from tabular to needle shaped up to $1 \mathrm{~mm}$ in length and with length-to-width aspect ratios of up to 1:18 in a KI1 type pumice and 1:11 in a KI-2 type pumice (see Chapter 2).

\subsubsection{Rocky Hill ignimbrite pumice mineral textures}

Nine representative pumice samples were chosen for crystal specific work (Table 4.1). Plagioclase occurs as euhedral crystals up to $2 \mathrm{~mm}$ long, but commonly fractured. Broken and/or exploded plagioclase crystals are common within crystal clots. Plagioclase crystals display weak, variable and complex zoning, and can be classified into three populations based on rim characteristics. A greater proportion ( 30\%) of Rocky Hill plagioclase display patchy or sieve textured cores, when compared to the Kidnappers. Plagioclase from high-SiO $\mathrm{S}_{2}$ Rocky Hill (RH-2) pumices have almost identical proportions of dark (40\%) and non-distinct (60\%) rims as those from high$\mathrm{SiO}_{2}$ Kidnappers (KI-2) pumices (Figure 4.12). Plagioclase rim characteristics from RH-1 pumice are similar to those within the KI-1 group, with 5\% dark and $14 \%$ light rims. In contrast to the Kidnappers (KI-3 group), no pumices from the Rocky Hill contain plagioclase where light rims dominate.

Orthopyroxene crystals (up to $1 \mathrm{~mm}$ long) are subhedral, commonly fractured with ragged terminations, and near ubiquitous inclusions of Fe-Ti oxides. A systematic change in the proportion of orthopyroxene textural types with whole-rock $\mathrm{SiO}_{2}$ is also observed within the Rocky Hill (Figure 4.13). Crystals with normal zoning are $55 \%$ of 
the orthopyroxene population in RH-1 pumice, increasing to $94 \%$ in $\mathrm{RH}-2$ pumice. Concurrently, unzoned grains decrease from $38 \%$ to $5 \%$, and reversely zoned grains decrease from $7 \%$ to only $1 \%$, respectively. Grains with a dark (high $\mathrm{Mg}$ ) exterior zone decrease in abundance from $13 \%$ in $\mathrm{RH}-1$ pumices to $1 \%$ in $\mathrm{RH}-2$ pumices. These proportional changes are similar to those between KI-1 to KI-2 pumices in the Kidnappers ignimbrite (Figure 4.13).

Quartz crystals are up to $2 \mathrm{~mm}$ across, mostly euhedral but sometimes broken, with variable zoning evident in CL imagery. Amphibole occurs distinctively as larger euhedral prismatic crystals up to 4-5 mm long, commonly containing inclusions of $\mathrm{Fe}$ Ti oxides and apatite. As with the Kidnappers, it is difficult to classify the textural characteristics of the amphibole grains. Biotite is less abundant than within the Kidnappers, but occurs as 'fresher' euhedral to subhedral books up to $1 \mathrm{~mm}$ across. Magnetite and ilmenite occur as discrete phenocrysts and are also very common as inclusions within orthopyroxene and amphibole. Zircon is ubiquitous within Rocky Hill pumices but without the same extreme ranges in aspect ratio as in the Kidnappers (Chapter 2).

\subsubsection{Mineral chemistry}

In the following section, the major and trace element concentrations of minerals are presented and compared to the textural characteristics outlined above. The total range of analysed minerals from each fall stratigraphic horizon, and each pumice compositional group are presented in Figure 4.14.

Fig. 4.14. (opposite) Summary plots of mineral composition for plagioclase, orthopyroxene and amphibole from the Kidnappers fall deposit (a-c) versus stratigraphic height in the fall deposit where sampled (see Table 4.1), Kidnappers ignimbrite (d-f) and Rocky Hill ignimbrite (g-i) versus the compositions of their host pumices. Dashed lines mark divisions between glass compositional groups in the Kidnappers fall deposit and pumice compositional groups within the Kidnappers and Rocky Hill ignimbrites. 

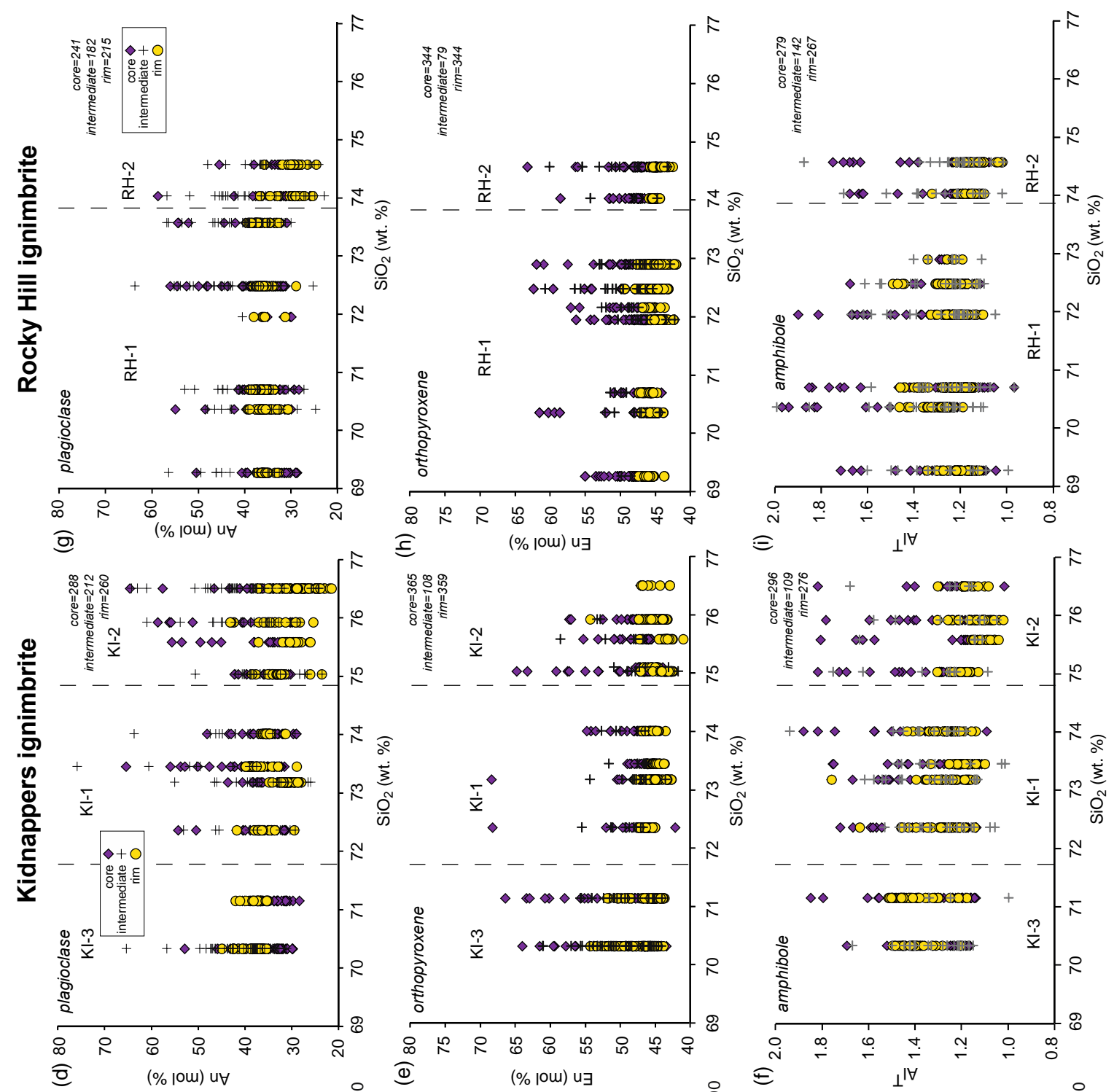
E $(\% \mid \mathrm{OW}) \mathrm{u} \exists$
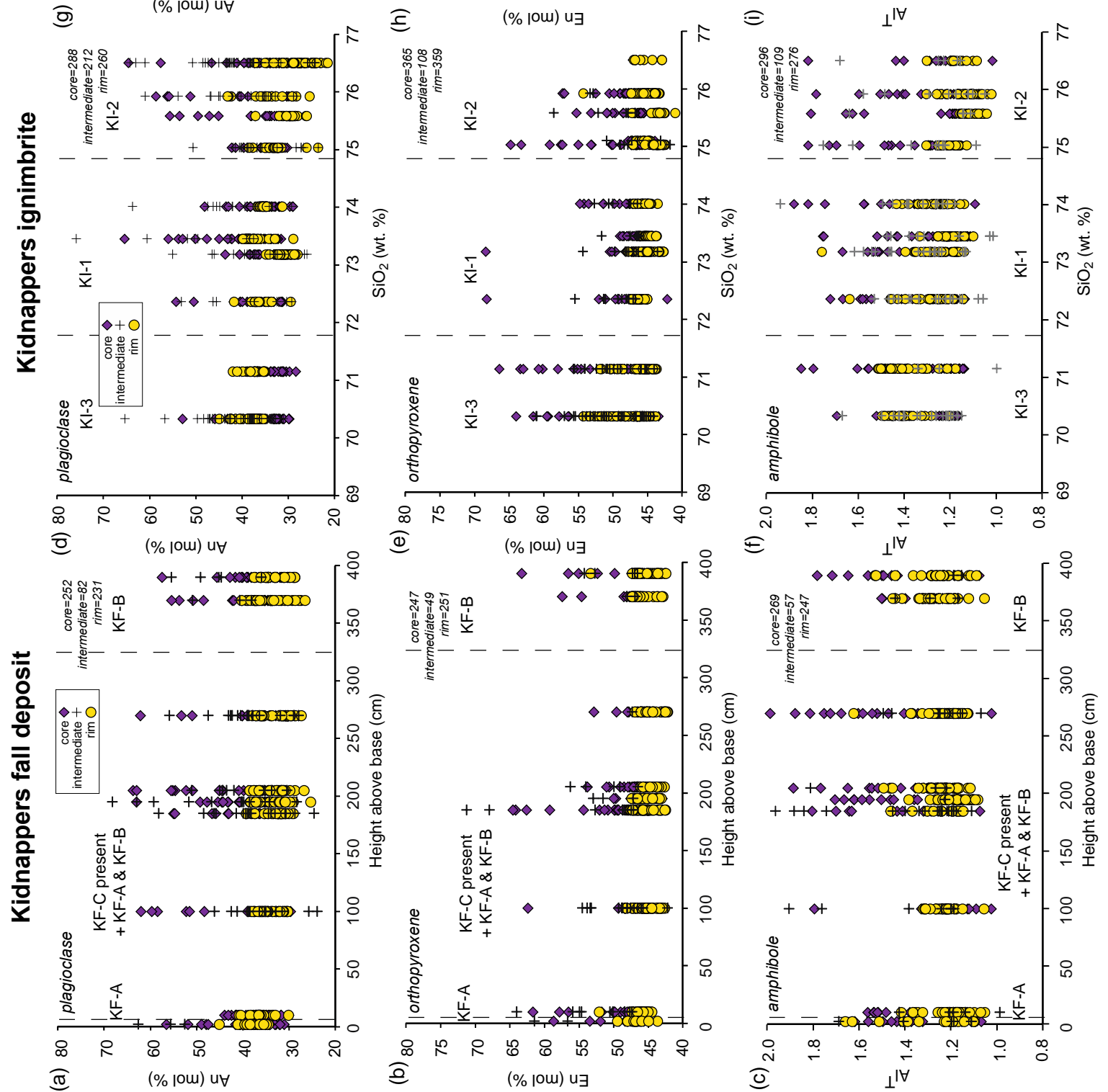


\subsubsection{Kidnappers fall mineral chemistry}

Overall, plagioclase compositions from the Kidnappers fall range from $\mathrm{An}_{68}$ to $\mathrm{An}_{24}$ and $\mathrm{Or}_{0.8}$ to $\mathrm{Or}_{4.8}$ (Figure 4.14a). Plagioclase core compositions show considerable overlap from horizons where KF-A or KF-B material dominates (Table 4.1) and vary between $\mathrm{An}_{64-28}$ and $\mathrm{Or}_{3.90-0.85}$. Plagioclase rim values cover a range of $\sim \mathrm{An}_{10}$ and cores show a greater range from $\sim \mathrm{An}_{30}-\mathrm{An}_{60}$ at each stratigraphic height (Figure 4.14a).

Minimum plagioclase rim anorthite values vary with stratigraphic height from $\sim \mathrm{An}_{35}$ at the base to $\sim \mathrm{An}_{26}$ at the top of the deposit (Figure 4.14a). Total plagioclase rim compositions throughout the deposit display a bimodal distribution with respect to An and $\mathrm{Or}\left(\mathrm{mol} \%\right.$ ), at $\mathrm{An}_{32.5} \mathrm{Or}_{3.75}$ and $\mathrm{An}_{37.5} \mathrm{Or}_{2.75}$ (Figure 4.15). Rim compositions where KF-A material is dominant have a unimodal distribution at $\mathrm{An}_{37.5}$ and $\mathrm{Or}_{2.75}$ and are linked to KF-A glass selvages (Chapter 3). Broader ranges and bimodal distributions in major and trace element compositions of rims are found in samples where the other fall deposit melt types (KF-B and KF-C) are present (Figure 4.15). The lower An (and Mg) plagioclase population at $\mathrm{An}_{32.5} \mathrm{Or}_{3.75}$ (Figure 4.16) is therefore associated with the KFB melt composition but there is no specific plagioclase composition that can be definitively linked to KF-C glass compositions (Chapter 3). Plagioclase rims associated with the KF-B group have a range in Ba between $\sim 300$ and 650 ppm and have core-torim increases in $\mathrm{Ba}$ (Figure 4.16). Rims from the KF-A group cover a smaller range $(\sim 300-500 \mathrm{ppm})$ and show no significant core-to-rim changes. Plagioclase rims in the KF-A group range from 60 to $100 \mathrm{ppm} \mathrm{Mg}$, and have no core-to-rim shifts in $\mathrm{Mg}$ concentrations. In comparison, concentrations in KF-B rims extend to lower values ( 40-100 ppm) and have some grains with core-to-rim decreases in Mg (Figure 4.16).

Orthopyroxene compositions in total range between $\mathrm{En}_{65}-\mathrm{En}_{42}$ and $\mathrm{Wo}_{5.6}-\mathrm{Wo}_{1.2}$ (Figure 4.14b). Minimum rim values are essentially uniform (within analytical uncertainty) from $\sim \mathrm{En}_{44}$ at the base to $\sim \mathrm{En}_{43}$ at the top of the fall deposit but show no systematic changes through all other horizons (Figure 4.14b). Rim concentrations range by $\sim \mathrm{En}_{5}$ in each pumice. The majority of cores range in compositions between $\sim \mathrm{En}_{43-50}$ and $\mathrm{Wo}_{1.75-}$ 3.50 with a wider scatter to $\mathrm{En}_{65}$ and $\mathrm{Wo}_{1.2-5.6}$ (Figure 4.17). Orthopyroxene cores from 
horizons where the KF-A and KF-B glass compositions dominate show considerable compositional overlap, with a bimodal distribution at $\sim \mathrm{Wo}_{2.2}$ and $\sim \mathrm{Wo}_{2.5}$ (Figure 4.18)
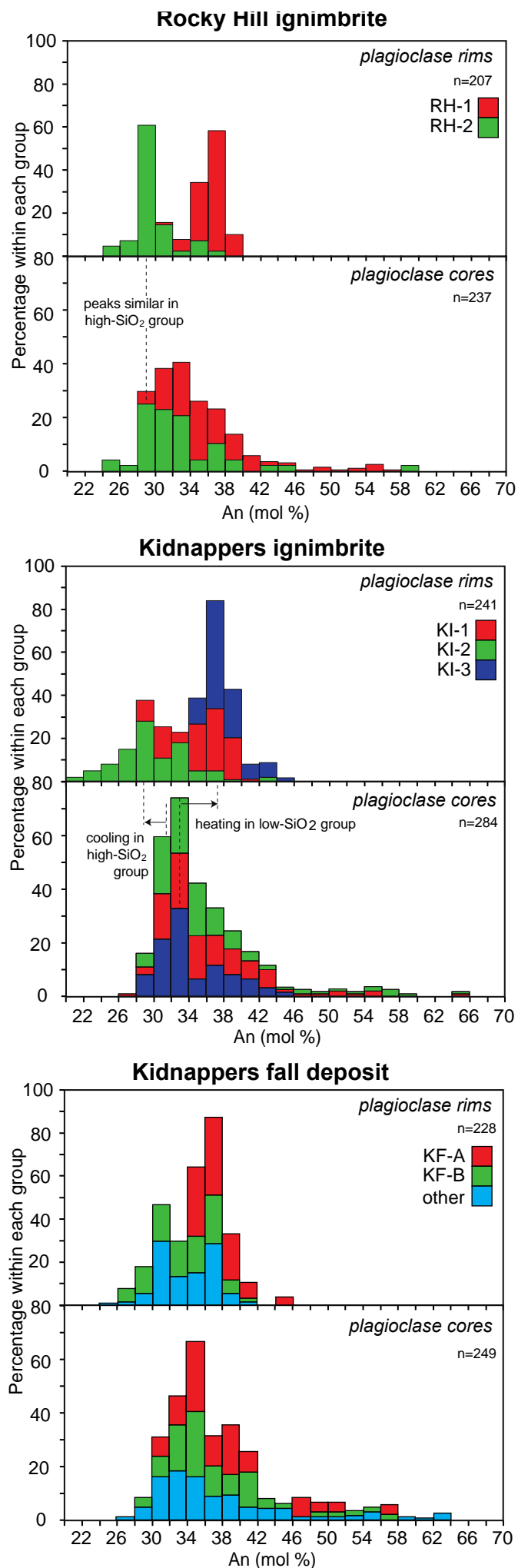

Fig. 4.15. Stacked histograms to summarise the compositional (An \%) relationships between plagioclase cores and rims from the each compositional group in the Kidnappers fall deposit, Kidnappers ignimbrite and Rocky Hill ignimbrite. Colour designations for each compositional group are the same as in Table 4. 


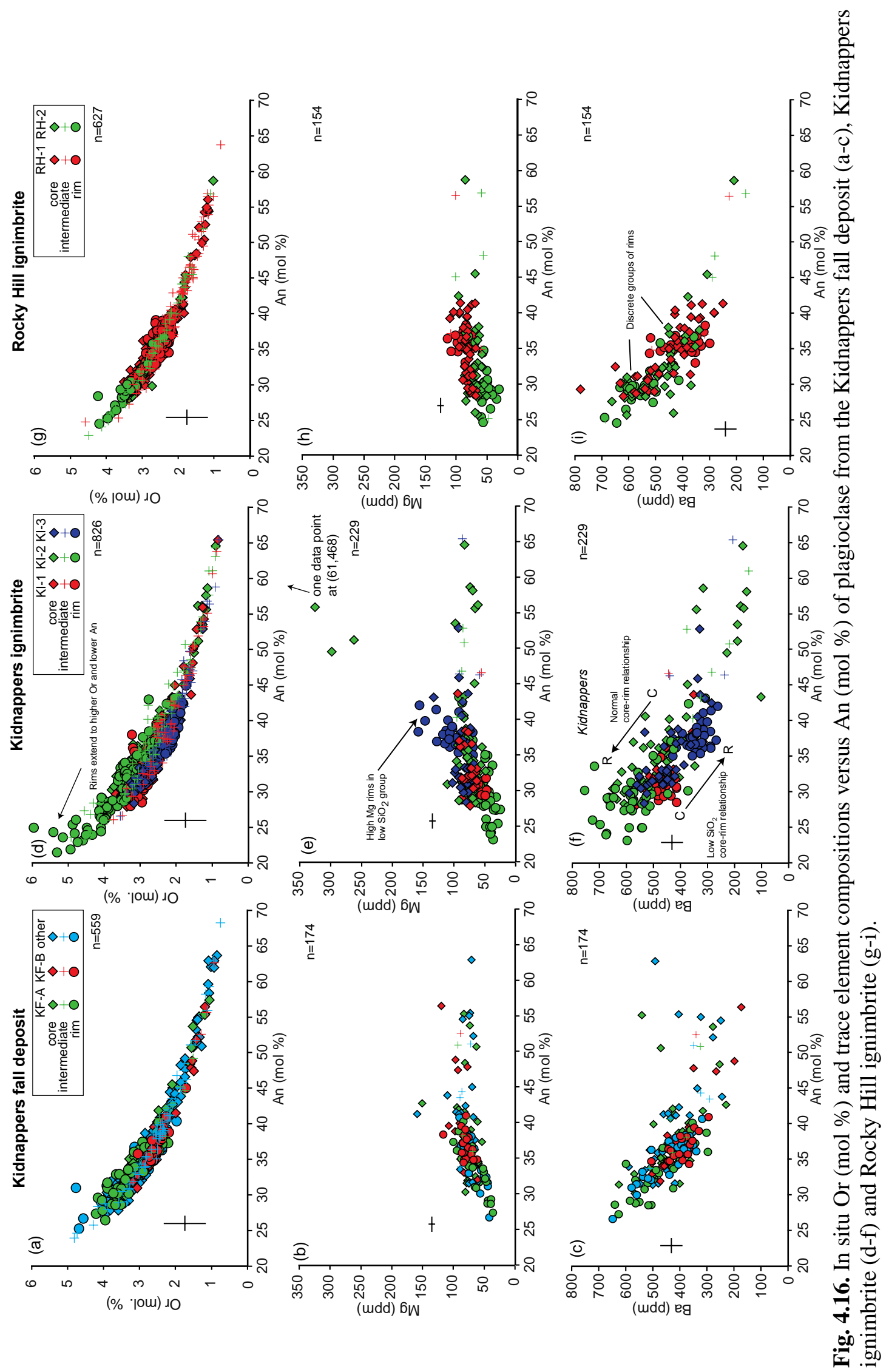




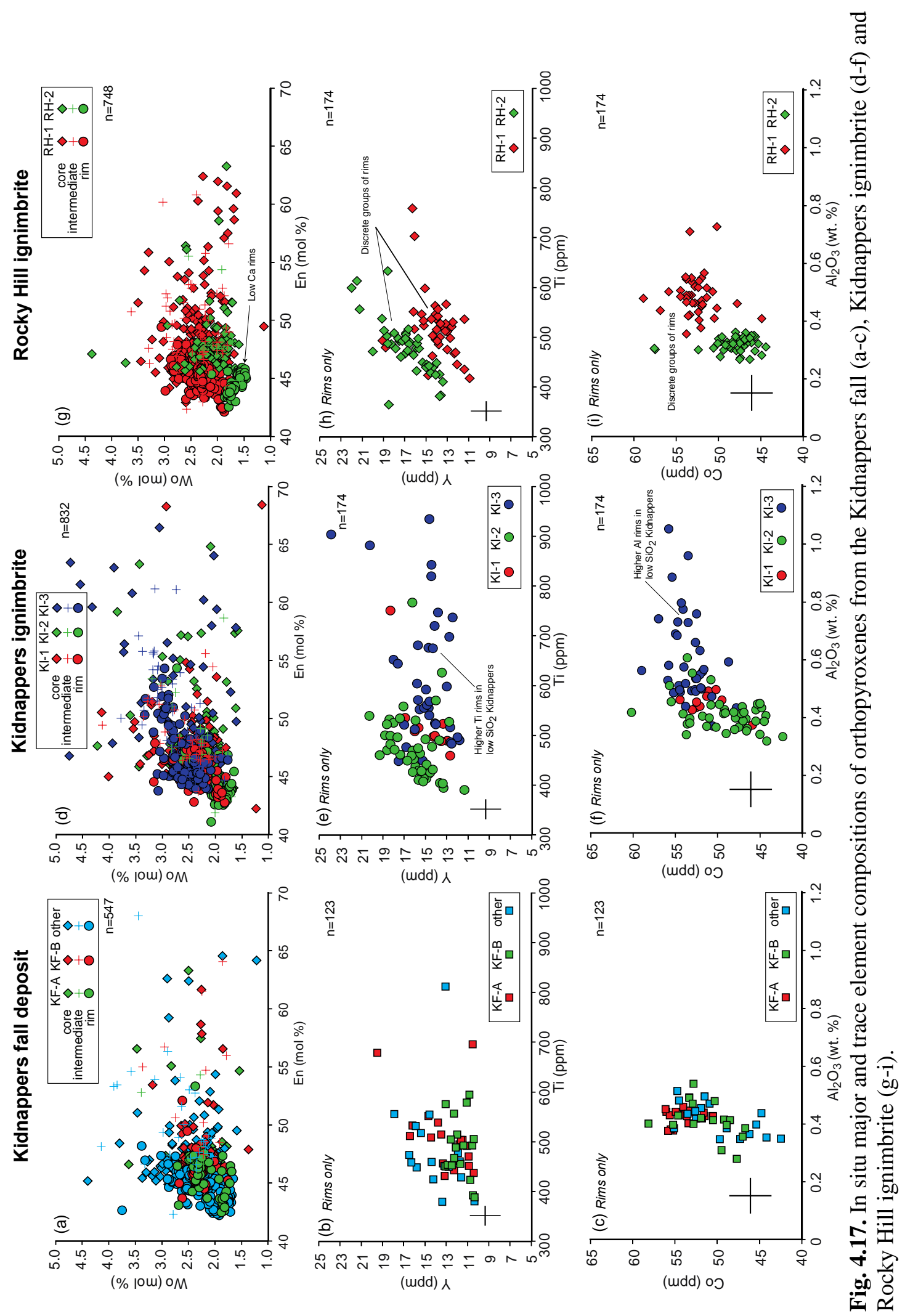



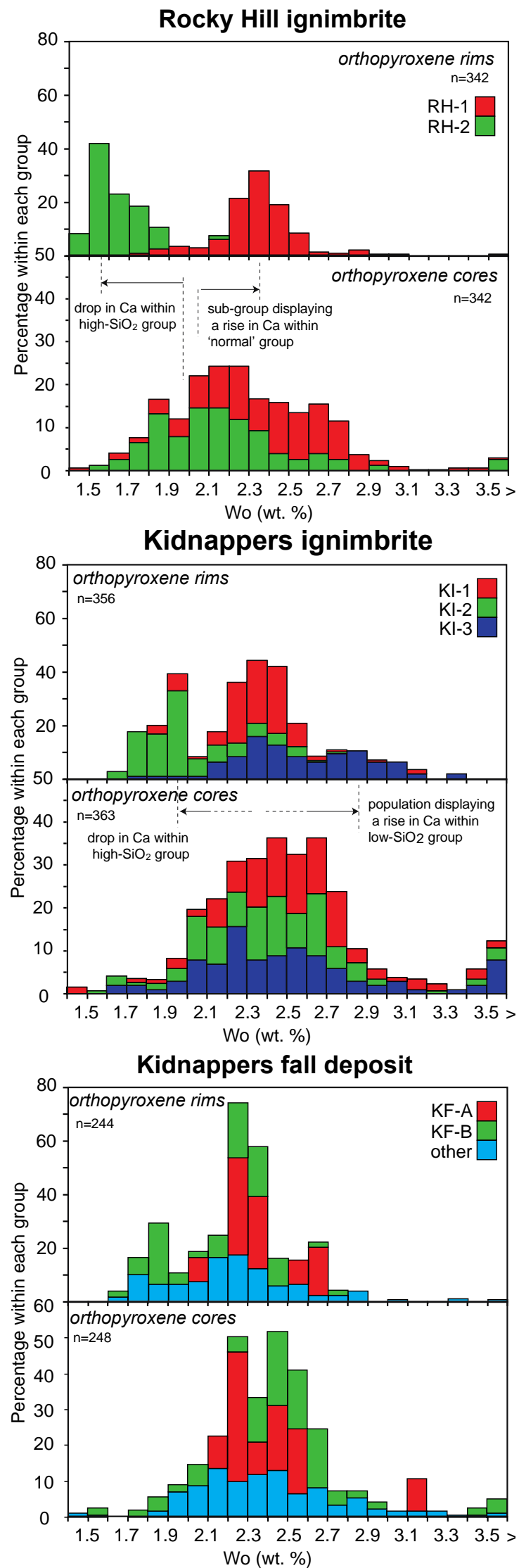

Fig. 4.18. Stacked histograms to summarise the compositional (Wo \%) relationship between orthopyroxene cores and rims from the Kidnappers fall deposit, Kidnappers ignimbrite and Rocky Hill ignimbrite. Colour designations are as in Figure 4.15. 
Grains from where the KF-B glass dominates show a unimodal distribution forming the $\mathrm{Wo}_{2.5}$ peak. Orthopyroxene rims, in general, show a tight compositional range between $\sim \mathrm{En}_{42-48}$ and $\mathrm{Wo}_{1.6-3.0}$ (Figure 4.17). Orthopyroxene rims also have a bimodal distribution with peaks at $\mathrm{Wo}_{2.2}$ and $\mathrm{Wo}_{1.8}$ (Figure 4.18). A proportion of grains from KF-B dominated horizons display a significant core-to-rim drop in $\mathrm{Ca}\left(\mathrm{Wo}_{2.5}-\mathrm{Wo}_{1.8}\right)$ (Figure 4.18). Significant core-to-rim shifts in chemistry are absent in grains from horizons where KF-A glass dominates. No clear distinctions in trace element concentrations from horizons dominated by KF-A and KF-B glasses are observed, with overlapping rim concentrations in all elements (Figure 4.17). Orthopyroxenes from the KF-A-dominant group have a more restricted range in concentrations and in general, slightly higher Co concentrations (50-57 ppm) than in all fall horizons where more than one compositional group is present (Figure 4.17).

Amphibole rims and the majority of cores plot in the field of magnesiohornblendes; 14 cores are tschermakitic pargasite in composition, and 4 cores are magnesiohastingsites (terminology of Leake et al. 2004). Amphibole cores and rims show considerable compositional overlap between different stratigraphic horizons and no systematic change with stratigraphic ordering is observed (Figure 4.14c). Total amphibole compositions range from $\mathrm{Al}^{\mathrm{T}}=0.99-1.99$ (Figure 4.14c). Amphibole core and intermediate domain compositions cover the whole of this range but rims have a smaller range $\left(\mathrm{Al}^{\mathrm{T}}\right.$ 1.05-1.62). Rims compositions range by $\sim 0.3 \mathrm{Al}^{\mathrm{T}}$ at the base and $\sim 0.2 \mathrm{Al}^{\mathrm{T}}$ at all other stratigraphic heights (Figure 4.14c). Cores at all horizons average $\sim 1.3 \mathrm{Al}^{\mathrm{T}}$. Rim values from the base (KF-A glass dominated) and top (KF-B glass dominated) parts of the fall deposit are very similar, with means at 1.2 and $1.26 \mathrm{Al}^{\mathrm{T}}$ respectively. No consistent core-to-rim shifts in $\mathrm{Al}^{\mathrm{T}}$ are present in any samples, but a number of grains associated with KF-B material show a core-to-rim decrease in $\mathrm{TiO}_{2}$ (Figure 4.19). When $\mathrm{Al}^{\mathrm{T}}$ is plotted against other site-specific cation proportions such as $(\mathrm{Na}+\mathrm{K})^{\mathrm{A}}$, a slight inflection in the data array is observed at $\mathrm{Al}^{\mathrm{T}} \sim 1.2$ (Figure 4.20). Inflections are also visible when $\mathrm{Mn}$ and $\mathrm{Zr}$ are plotted against amphibole $\mathrm{Eu} / \mathrm{Eu}^{*}$ (total range from 0.7 to 0.2 ) (Figure 4.20), used here as a quantitative measure of the degree of evolution of the host melt (Allan et al. 2013). 

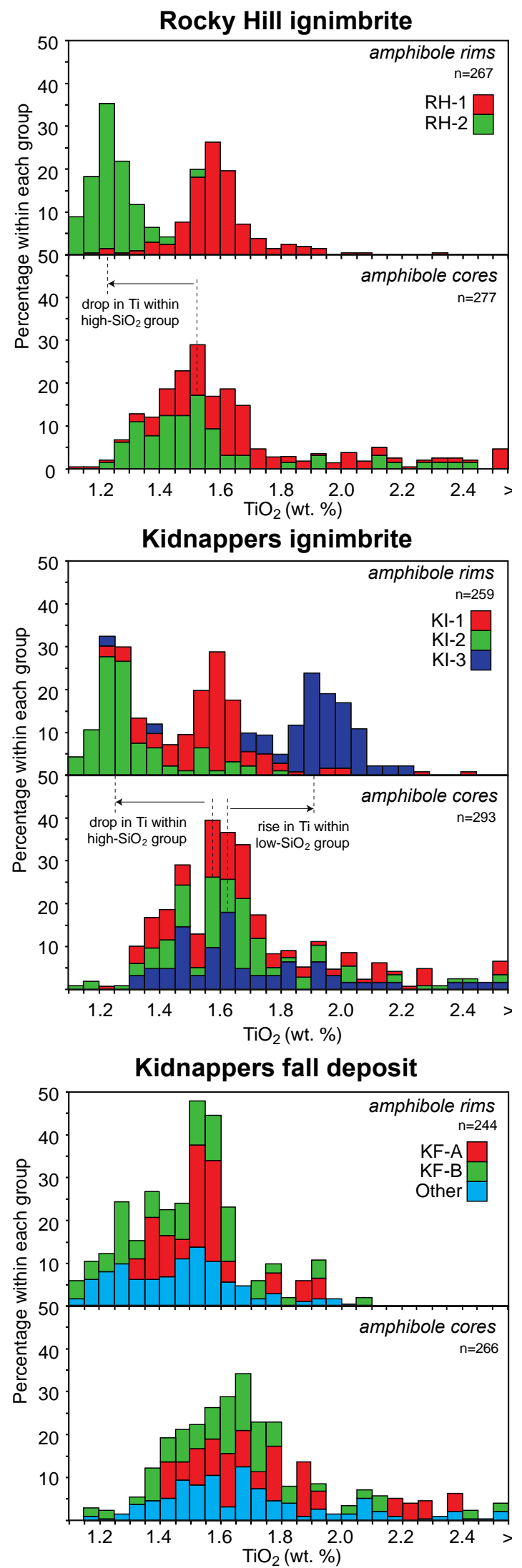

Fig. 4.19. Stacked histograms to summarise the compositional relationships between amphibole cores and rims from the Kidnappers fall deposit, Kidnappers ignimbrite and Rocky Hill ignimbrite. Colour designations are as in Figure 4.18. 


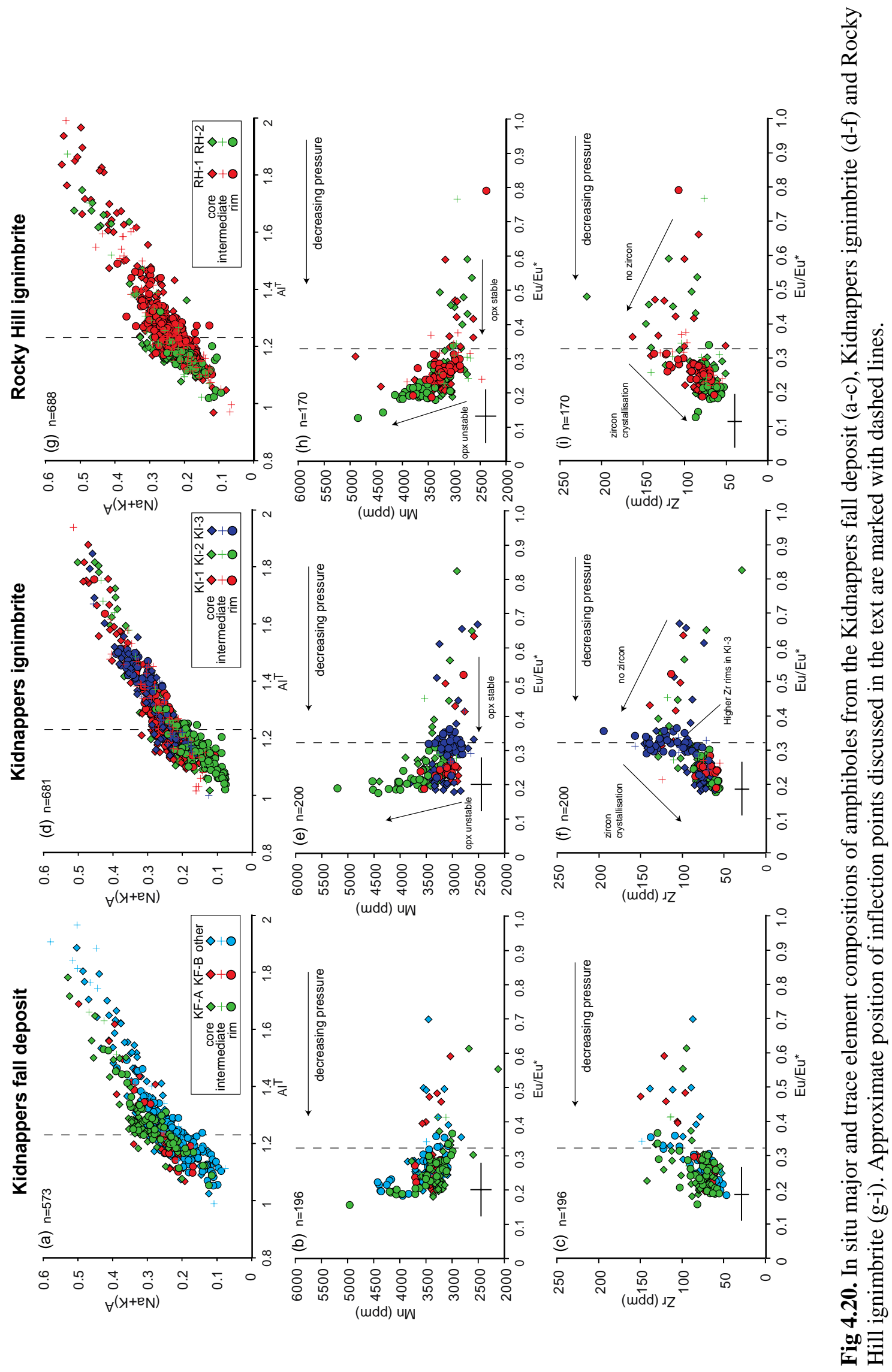


Cores with $\mathrm{Eu} / \mathrm{Eu}^{*}>0.3$ do not show a systematic trend in trace element concentrations. In contrast, cores and rims with $\mathrm{Eu} / \mathrm{Eu}<0.3$ show sharp increases in $\mathrm{Mn}$ (from 3000$4500 \mathrm{ppm}$ ), and decreases in $\mathrm{Zr}$ (from 150-50 ppm) with decreasing Eu/Eu* (Figure 4.20). When in-situ trace element signatures from common analytical spots are paired with model pressure estimates using the formulations of Ridolfi et al. (2010) there is a near linear positive relationship between $\mathrm{Eu} / \mathrm{Eu}^{*}$ and pressure, suggesting that the most evolved amphibole compositions grew at the lowest pressures. The hinge point in traceelement variations at $\mathrm{Eu} / \mathrm{Eu}^{*} \sim 0.3$ corresponds to an apparent pressure of $\sim 120 \mathrm{MPa}$ and depths of 4.5-4.0 km (see Section 4.5.5).

Magnetite compositions fall in the overall range of $\mathrm{X}_{\mathrm{usp} 0.27-0.46}$ and show a bimodal distribution with respect to $\mathrm{Al}_{2} \mathrm{O}_{3}$. Ilmenite has a compositional range of $\mathrm{X}_{\mathrm{ilm} 0.87-0.93}$ and shows a bimodal distribution with respect to $\mathrm{MnO}$. Magnetite-ilmenite equilibrium pairs (paired on the basis of the criteria of Bacon and Hirschmann, 1988) included within the same host orthopyroxene fall into two compositional groups which are reflected in the bimodal distribution of total Fe-Ti oxide temperatures (see Chapter 3 and Section 5.5.5).

\subsubsection{Kidnappers ignimbrite pumice mineral chemistry}

The Kidnappers pumices from which mineral chemistries were analysed are listed in Table 4.1. Plagioclase compositions range from $\mathrm{An}_{65}$ to $\mathrm{An}_{21}$ and $\mathrm{Or}_{0.8}$ to $\mathrm{Or}_{6.0}$ (Figure 4.14d). Plagioclase cores from each of the whole rock compositional groups have similar mean compositions between $\mathrm{An}_{35}$ and $\mathrm{An}_{37}$, and $\mathrm{Or}_{2.6}$ and $\mathrm{Or}_{2.8}$. Plagioclase rim compositions within each pumice can be grouped into three populations based on minimum An values, from $\mathrm{An}_{21}-\mathrm{An}_{25}(\mathrm{KI}-2) \mathrm{An}_{28}-\mathrm{An}_{31}(\mathrm{KI}-1)$ and $\mathrm{An}_{35}-\mathrm{An}_{36}(\mathrm{KI}-3)$, corresponding to the three whole rock compositional groups (Figure 4.14d). Rim compositions vary by $\sim \mathrm{An}_{10-15}$ within each pumice sample (Figure $4.14 \mathrm{~d}$ ). Average rim compositions within each group vary: grains from KI-3 pumices have $\mathrm{An}_{38} \mathrm{Or}_{2.2}$ rims, those from KI-1 pumices have $\mathrm{An}_{35} \mathrm{Or}_{2.7}$ rims, and those from KI-2 pumices have $\mathrm{An}_{30}$ $\mathrm{Or}_{3.7}$ rims (Figure 4.15). Plagioclases from KI-3 pumices show a core-to-rim increase in An and decrease in Or proportions (Figure 4.15) which is reflected by the dominance $(82 \%)$ within this group of light plagioclase rims when viewed under BSE imaging (Figure 4.12). The opposite is the case for plagioclase from the KI-2 samples (Figure 
4.15). Plagioclase trace elements display similar patterns, with KI-3 grains showing core to rim increases in $\mathrm{Mg}$ and $\mathrm{Sr}$ and a decrease in $\mathrm{Ba}$, the reverse of the trend in $\mathrm{KI}-1$ and KI-2 grains (Figure 4.16). A clear compositional gap in rim concentrations of $\mathrm{Mg}$, $\mathrm{Ba}$ and $\mathrm{Sr}$ is present between KI-3 type and KI-1 and KI-2 rims (Figure 4.16). A population of plagioclase cores from the high $\mathrm{SiO}_{2}$ group (KI-2) at $>\mathrm{An}_{50}$ have higher $\mathrm{Mg}$ and $\mathrm{Sr}$ concentrations and lower Ba concentrations than are found within any other plagioclase grains (Figure 4.16).

Orthopyroxene compositions range from $\mathrm{En}_{68}$ to $\mathrm{En}_{41}$ and $\mathrm{Wo}_{5.2}$ to $\mathrm{Wo}_{1.1}$ (Figure 4.14e). Cores from each of the pumice compositional groups have very similar mean compositions between $\mathrm{En}_{48}-\mathrm{En}_{49}$ and $\mathrm{Wo}_{2.54}-\mathrm{Wo}_{2.45}$. Mean rim compositions, in contrast, vary systematically with whole rock and glass composition, thus: $\mathrm{En}_{47} \mathrm{Wo}_{2.5}$, (KI-3), $\mathrm{En}_{45} \mathrm{Wo}_{2.3}(\mathrm{KI}-1)$, and $\mathrm{En}_{44} \mathrm{Wo}_{2.1}$ (KI-2: Figure 4.17). Rim concentrations range by $\sim \mathrm{En}_{10}$ within KI-3 pumices, but by only $\sim \mathrm{En}_{5}$ within KI-1 and KI-2 pumices (Figure 4.14e). A significant core to rim drop in mean $\mathrm{Ca}$ of 1.2 to $1.0 \mathrm{wt} \%\left(\mathrm{Wo}_{2.5}\right.$ to $\left.\mathrm{Wo}_{2.0}\right)$ is found in crystals within the KI-2 group, and $\sim 40 \%$ of crystals (those with dark exterior zones under BSE imaging: Figure 4.18) from the KI-3 group display a rimward rise in $\mathrm{Ca}$ (Figure 4.17). These contrasts are reflected in textural characteristics, with a dominance of normal zoning (light rims under BSE) in the KI-2 group, and a significant proportion of reversely zoned (dark exterior zone) crystals in the KI-3 group (Figure 4.11). Trace elements within crystal interiors have a large spread in concentrations and commonly have no clear trends when plotted against each other. However, crystal rim concentrations typically plot into distinct fields that link to the whole-rock composition of their host pumice (Figure 4.17). The rims of grains from KI-1 and KI-2 pumices form parallel trends and discrete groups on a plot of $\mathrm{TiO}_{2}$ versus $\mathrm{Y}$ (Figure 4.17), with grains from the KI-3 pumices forming an extension of the KI-1 field back to higher trace element concentrations. These distinctions are more apparent than in the Kidnappers fall deposit where rim compositions from each horizon overlap with respect to trace elements. Rim compositions were tested for crystal-melt equilibrium using a method similar to that of Roeder and Emslie (1970). A Rhodes diagram (Rhodes et al. 1979; Putirka. 2008) was used, which visually compares observed Fe-Mg exchange coefficients with $\mathrm{K}_{\mathrm{D}}(\mathrm{Fe}-\mathrm{Mg})_{\text {opx-liquid, }}$, on a plot of $100 * \mathrm{Mg} \#$ liquid versus $100 * \mathrm{Mg} \#$ opx. 
All rim compositions reflect equilibrium with their corresponding matrix glass compositions, which also plot into three groups.

Amphibole cores plot in the field of magnesiohornblende and tschermakite-pargasite and outermost rims are all in the magnesiohornblende field. Total amphibole compositions range from $\mathrm{Al}^{\mathrm{T}} 0.99$ to 1.94 (Figure 4.14f). Amphibole core compositions have a large scatter $\left(\mathrm{Al}^{\mathrm{T}}\right.$ 1.02-1.88) but mean $\mathrm{Al}^{\mathrm{T}}$ values are very similar between whole rock compositional groups (1.27 [KI-2] to 1.31 [KI-3]: Figure 4.14f). Rim concentrations range by $\sim 0.2 \mathrm{Al}^{\mathrm{T}}$ in $\mathrm{KI}-1$ and $\mathrm{KI}-3$ pumices, but are more restricted $\left(\sim 0.1 \mathrm{Al}^{\mathrm{T}}\right)$ in $\mathrm{KI}-2$ pumices. $\mathrm{Rim} \mathrm{Al}^{\mathrm{T}}$ values cluster between $\sim 1-1.5$ but, along with other elemental concentrations such as $\mathrm{TiO}_{2}$ (Figure 4.19), vary with whole rock groupings, averaging 1.15 (KI-2), 1.26 (KI-1) and $1.42 \mathrm{Al}^{\mathrm{T}}$ (KI-3 pumice). KI-3 group amphiboles show a significant core-to-rim increase in $\mathrm{Al}^{\mathrm{T}}$, whereas the $\mathrm{KI}$-2 group shows the opposite (Figure 4.20). $\mathrm{TiO}_{2}$ concentrations in amphibole cores are similar in each group ( 1.6 wt. \%), but rim compositions are distinct in each group, $\sim 1.2$ (KI-2), $\sim 1.6(\mathrm{KH}-1)$ and $~ 2.0 \mathrm{wt} \%$ (KH-3) (Figure 4.19). The 'up temperature' signature recorded in the lesser-evolved end-member samples and the 'down temperature' signature recorded in more evolved samples are comparable to those observed in other mineral phases, even though no consistent corresponding textural characteristics are observed. When $\mathrm{Al}^{\mathrm{T}}$ is plotted against other site-specific cation proportions such as $(\mathrm{Na}$ $+\mathrm{K})^{\mathrm{A}}$ (Figure 4.20) and $\mathrm{Mg} /\left(\mathrm{Mg}+\mathrm{Fe}^{3+}\right)$, an inflection in data is observed at $\mathrm{Al}^{\mathrm{T}}=\sim 1.2$. At $\mathrm{Al}^{\mathrm{T}}$ values $<1.2$, a sharp drop in $(\mathrm{Na}+\mathrm{K})^{\mathrm{A}}$ and increase in $\mathrm{Mg} /\left(\mathrm{Mg}+\mathrm{Fe}^{3+}\right)$ occurs, particularly evident in rims from KI-2 type pumices. This inflection is more prominent in amphiboles from the ignimbrite than those in the Kidnappers fall deposit (Figure 4.20). These trends suggest a change in chemistry of the melt from which amphibole grew, with a decrease in $\mathrm{Na}$ and $\mathrm{K}$ and increase in $\mathrm{Mg}$ in the higher silica melts. There is also an inflection point where several trace element concentrations, such as Mn and $\mathrm{Zr}$, are plotted against amphibole $\mathrm{Eu} / \mathrm{Eu}^{*}$ (total range from 0.8 to 0.2) (Figure 4.20). A sharp increase in Mn concentrations (from 3000 to 5000 ppm) occurs with $\mathrm{Eu} / \mathrm{Eu}^{*}$ decreasing from 0.3 to 0.2 (Figure 4.20). In contrast, Mn concentrations in amphibole cores do not vary with $\mathrm{Eu} / \mathrm{Eu}^{*}$ at values $>0.3$. Over the same amphibole $\mathrm{Eu} / \mathrm{Eu} *$ range (0.3-0.2), there is a sharp decrease in $\mathrm{Zr}$ concentrations (from $\sim 150$ to $50 \mathrm{ppm}$ ). From 
$\mathrm{Eu} / \mathrm{Eu}^{*}$ of 0.8 to 0.3 , however, $\mathrm{Zr}$ concentrations in amphibole cores show a steady increase in $\mathrm{Zr}$ (from $~ 50$ to $150 \mathrm{ppm}$ ) (Figure 4.20).

Magnetite and ilmenite occurring as inclusions in a high proportion of orthopyroxenes, and to a lesser extent in amphiboles, were analysed. Magnetites range from Usp $24-51$ and ilmenites from $\mathrm{Ilm}_{85-90}$. Magnetites from the KI-3 group extend to higher wt. \% $\mathrm{TiO}_{2}$, and have a mean Usp value of 35, compared to 31 in the KI-1 and KI-2 groups. Mean ilmenite compositions are between $\operatorname{Ilm}_{87-89}$ and do not vary considerably between compositional groups.

\subsubsection{Rocky Hill ignimbrite pumice mineral chemistry}

The Rocky Hill pumices from which mineral chemistry was analysed are listed in Table 4.1. Plagioclase compositions range from $\mathrm{An}_{64}$ to $\mathrm{An}_{23}$ (Figure 4.14g). Rim compositions vary by $\sim \mathrm{An}_{10}$ within each pumice (Figure $4.14 \mathrm{~g}$ ). Cores have similar mean compositions between $\mathrm{RH}-1\left(\mathrm{An}_{36} \mathrm{Or}_{2.5}\right)$ and $\mathrm{RH}-2$ pumices $\left(\mathrm{An}_{33} \mathrm{Or}_{2.9}\right)$. Mean rim compositions from RH-1 plagioclase are almost identical to their associated cores $\left(\mathrm{An}_{36} \mathrm{Or}_{2.4}\right)$, but RH-2 rims show more evolved compositions $\left(\mathrm{An}_{30} \mathrm{Or}_{3.3}\right.$ : Figure 4.15). The lower-An rim compositions reflect growth and equilibrium with the RH-2 glass and are consistent with an increase in the proportion of BSE-dark rims within this group (Figure 4.13). All core-to-rim trends recorded in grains from $\mathrm{RH}-1$ and $\mathrm{RH}-2$ groups are very similar to trends in the KI-1 and KI-2 groups, respectively (Figures 4.15 and 4.16). Rocky Hill plagioclase trace element compositions cover a very similar range to those within the Kidnappers. RH-2 type grains display core-to-rim decreases in $\mathrm{Mg}$ and $\mathrm{Sr}$ and increases in Ba whereas cores from RH-1-type grains have concentrations both higher and lower than their associated rims (Figure 4.16). A clear gap in $\mathrm{Mg}, \mathrm{Ba}$ and $\mathrm{Sr}$ concentrations is seen between RH-1 type and RH-2 rims, corresponding with the discrete modes in rim An \% (Figure 4.16). The separation between RH-1 and RH-2 rim compositions is more prominent than within the KI-1 and KI-2 groups (Figure 4.16).

Orthopyroxene compositions range from $\mathrm{En}_{63}-\mathrm{En}_{42}$ and $\mathrm{Wo}_{4.38}-\mathrm{Wo}_{1.46}$ (Figure 4.14h). Cores from both compositional groups have very similar mean compositions between $\mathrm{En}_{48}-\mathrm{En}_{49}$ and $\mathrm{Wo}_{2.4}-\mathrm{Wo}_{2.1}$ (Figure 4.17). Rim concentrations within each pumice range 
by $<\operatorname{En}_{5}$ (Figure $4.14 \mathrm{~h}$ ). Rims have the same mean $\mathrm{En}_{45}$ values, however, rims from the $\mathrm{RH}-2$ group show a tight clustering around $\mathrm{Wo}_{1.6}$ compared with $\mathrm{Wo}_{3.4}$ within $\mathrm{RH}-1$ grains (Figure 4.18), in contrast to the Kidnappers samples. This consistent core-to-rim drop in $\mathrm{Ca}$ is reflected in the dominance of normal zoned orthopyroxenes within the RH-2 group (Figure 4.13). Trace element concentrations of crystal rims from the RH-1 and RH-2 groups fall into distinct clusters, which overlie rim compositions of KI-1 and KI-2 groups respectively, within the Kidnappers (Figure 4.17). Like in plagioclase, the separation between RH-1 and RH-2 orthopyroxene rim compositions is more clear than between the KI-1 and KI-2 groups (Figure 4.17). The trend towards higher elemental concentrations observed in crystals from the Kidnappers low-SiO 2 (KI-3) group is not represented within Rocky Hill grains (Figure 4.17).

Rocky Hill amphiboles are commonly complexly zoned, with cores plotting in the field of magnesiohornblende and tschermakite-pargasite and rims in the magnesiohornblende field. Total amphibole compositions cover a similar range as in the Kidnappers $\left(\mathrm{Al}^{\mathrm{T}}\right.$ of 0.97-1.99) (Figure 4.14i). Core compositions cover this range $\left(\mathrm{Al}^{\mathrm{T}}\right.$ of 0.97-1.97) and mean $\mathrm{Al}^{\mathrm{T}}$ values are almost identical between whole-rock groups (1.29 in RH-1 group; 1.27 in RH-2 group: Figure 4.14i). Rim concentrations range by $\sim 0.2 \mathrm{Al}^{\mathrm{T}}$ in $\mathrm{RH}-1$ pumices, but only $\sim 0.1 \mathrm{Al}^{\mathrm{T}}$ in $\mathrm{RH}-2$ pumices (4.14i). Mean amphibole rim compositions within the RH-1 group are similar to associated cores $\left(\mathrm{Al}^{\mathrm{T}}\right.$ of 1.24), but show a significant drop within the $\mathrm{RH}-2$ group $\left(\mathrm{Al}^{\mathrm{T}}=1.13\right)$. $\mathrm{TiO}_{2}$ concentrations in RH-2 amphibole cores have a mode at $\sim 1.5 \mathrm{wt}$. \%, but rim compositions drop to a mode of $\sim 1.2$ wt. \%, whereas RH-1 amphiboles do not show systematic changes in $\mathrm{TiO}_{2}$ concentrations, both cores and rims having modes close to $\sim 1.6 \mathrm{wt}$. \% (Figure 4.19). The core-to-rim trends observed within Rocky Hill grains are closely similar to those observed within KI-1 and KI-2 groups in the Kidnappers, respectively (Figure 4.19). Very few amphiboles show a core-to-rim increase in $\mathrm{Al}^{\mathrm{T}}$ as seen in the KI-3 group. The hinge point in trace element data observed in Kidnappers amphiboles at $\mathrm{Al}^{\mathrm{T}}$ of $\sim 1.2$ is, however, not as well developed in Rocky Hill amphiboles, although data show closely similar trends against Eu/Eu* (Figure 4.20). 
Magnetite inclusions within orthopyroxene are in the range of Usp $23-50$ and ilmenite inclusions fall between $\mathrm{Ilm}_{80-91}$. Mean Fe-Ti oxide compositions do not vary significantly between compositional groups and are between $\mathrm{Usp}_{29-32}$ and $\mathrm{Ilm}_{87-88}$.

\subsubsection{Intensive variables}

Major element concentrations from a number of mineral phases, in some cases coupled with glass compositions, can be used to derive estimates of temperature and pressure (see Putirka 2008, for review). Amphibole model temperatures, pressures and water contents were estimated using the methods of Ridolfi et al. (2010) from each pumice clast in the ignimbrites, and each horizon in the Kidnappers fall deposit selected for crystal specific work (Table 4.1). Amphiboles have the potential to record a history of changing melt composition and magmatic conditions throughout the growth of the crystal. Such information can then be compared with information from Fe-Ti oxide equilibrium pairs and mineral-melt formulations which reflect the magma temperature just prior to eruption.

\subsubsection{Amphibole model temperature and pressure estimates}

Kidnappers fall deposit: Amphibole cores from horizons dominated by KF-A and KF-B glass compositions have overlapping ranges in model temperatures. Amphibole rim temperatures from KF-A dominated horizons peak at $\sim 780^{\circ} \mathrm{C}$, and in $\mathrm{KF}-\mathrm{B}$ dominated horizons at $\sim 790{ }^{\circ} \mathrm{C}$, and there is a total range between 770 and $900{ }^{\circ} \mathrm{C}$ (Figure 4.21). Amphibole core model pressures are almost identical at any stratigraphic position in the fall deposit, with a peak between 100 and $120 \mathrm{MPa}$ and a tail to $260 \mathrm{MPa}$. Rim model pressures also peak between 100 and $120 \mathrm{MPa}$, but cover a smaller range than cores, from 80 to $160 \mathrm{MPa}$ in both KF-A and KF-B dominated fall material (Figure 4.21). These temperature and pressure estimates are used in Chapter 3 to infer that the three discrete melts were held at comparable depths and therefore horizontally separated.

Kidnappers ignimbrite: Amphibole core model temperatures show little difference between samples, with a peak at $790-800{ }^{\circ} \mathrm{C}$ and a tail off to $\sim 920{ }^{\circ} \mathrm{C}$ (Figure 4.21). 
Rocky Hill ignimbrite
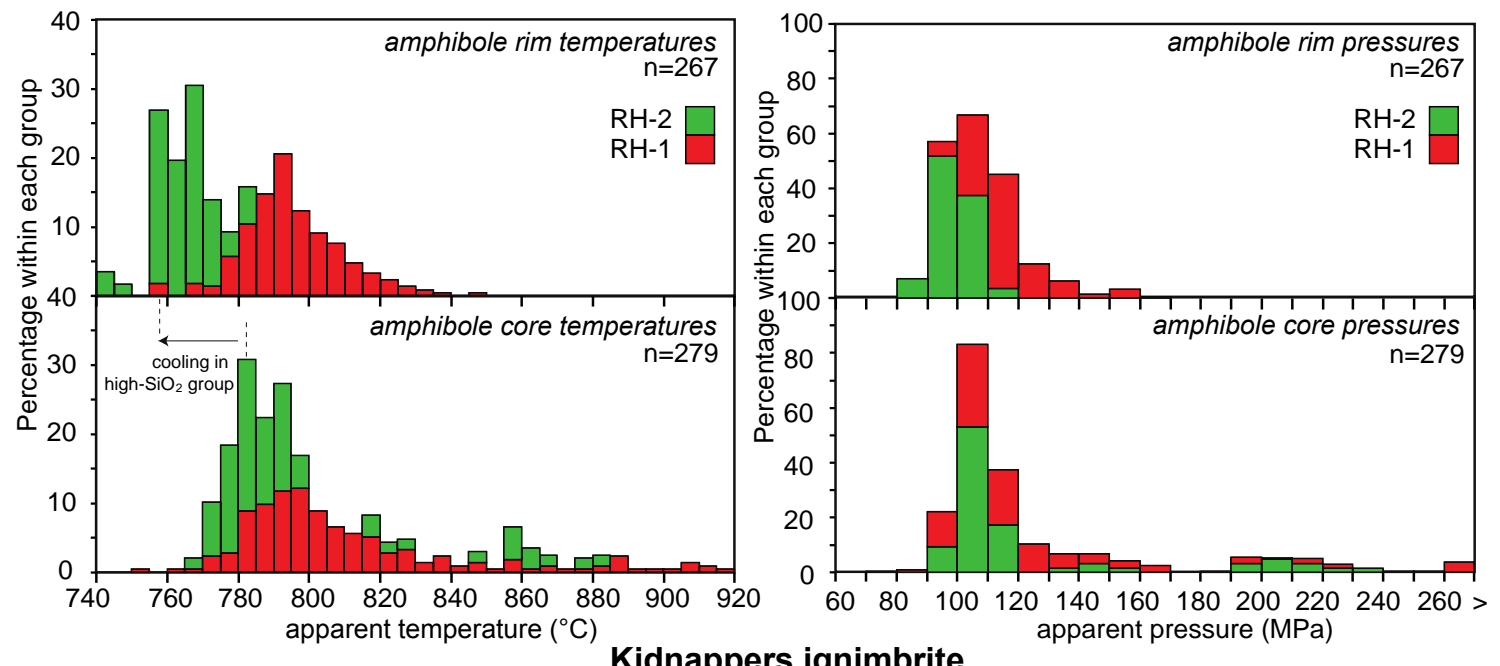

Kidnappers ignimbrite
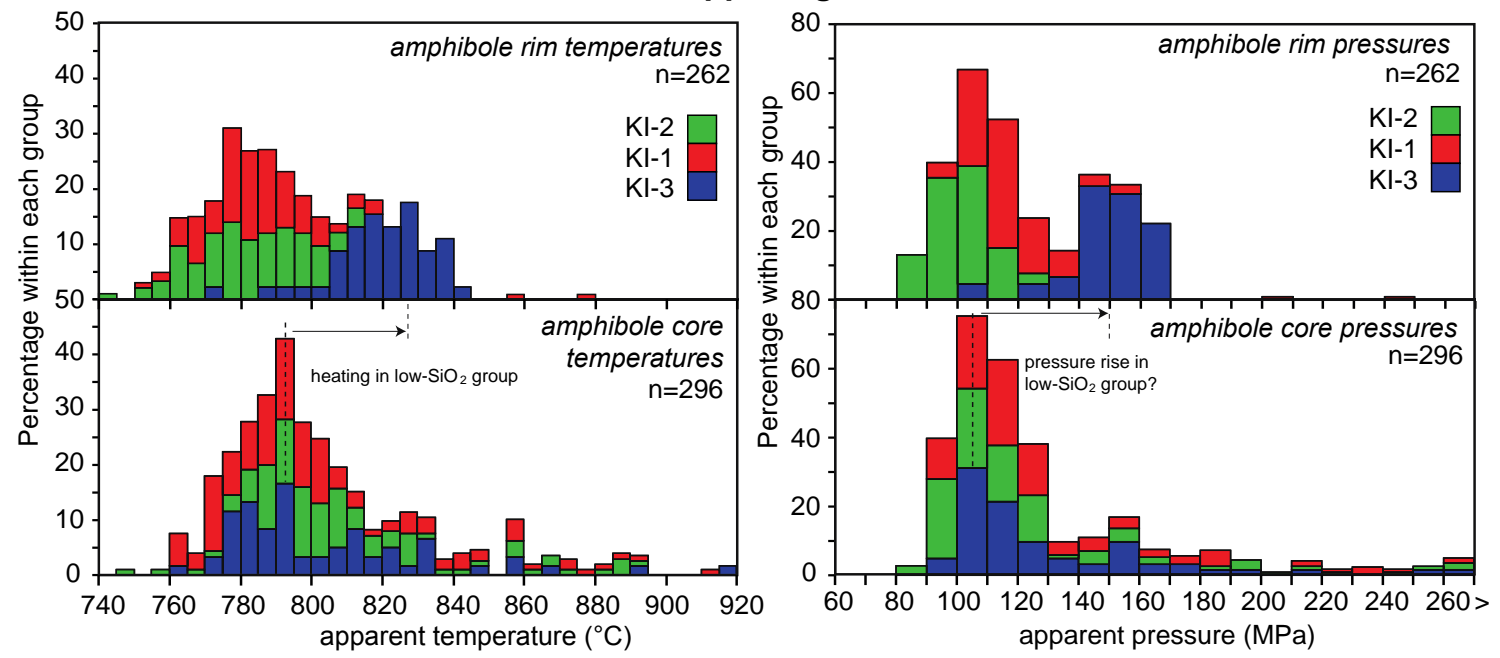

Kidnappers fall deposit
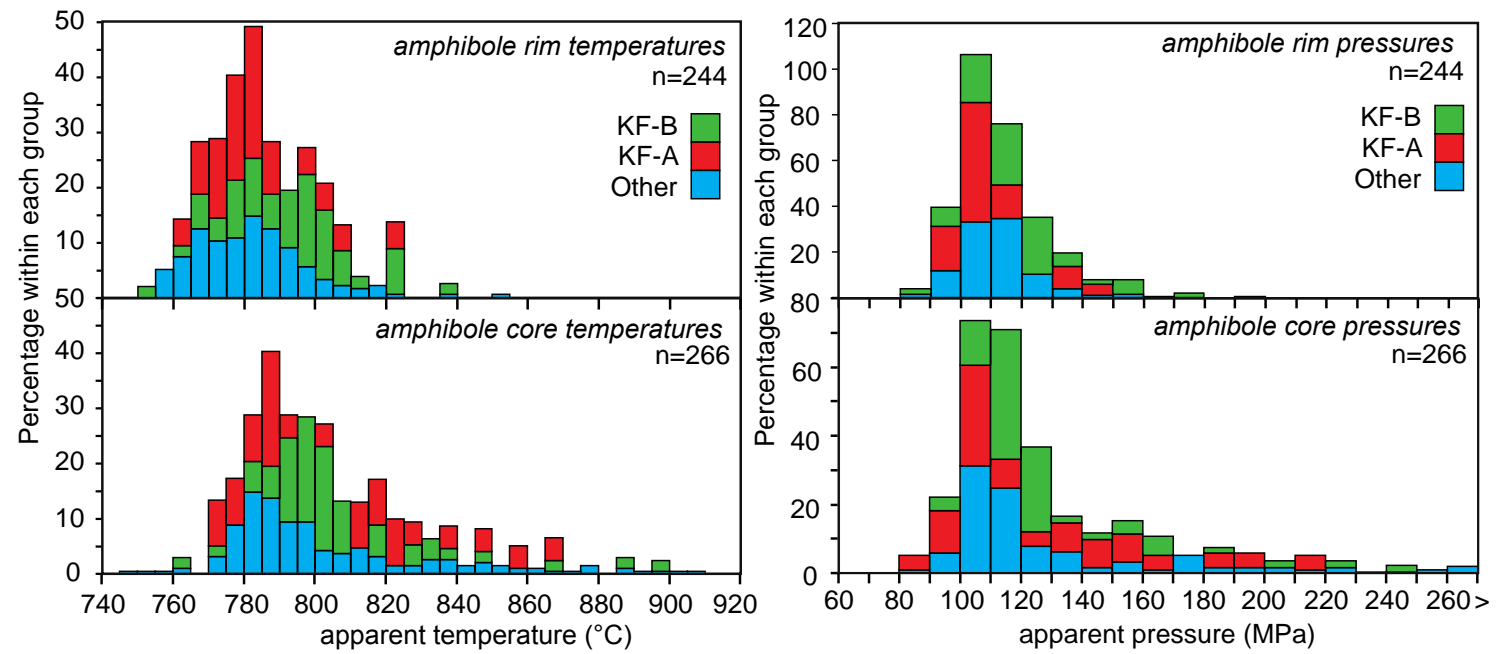

Fig. 4.21. Stacked histograms of amphibole core and rim apparent temperatures $\left({ }^{\circ} \mathrm{C}\right)$ and pressures (MPa) from each compositional group within Kidnappers and Rocky Hill pumices and horizons where the KF-A and KF-B glass compositional groups dominate the material within the fall deposit (Table 4.1). Apparent amphibole temperatures and pressures were calculated using the method of Ridolfi et al. (2010). 
Rim temperatures from crystals in KI-1 and KI-2 pumice groups have broad peaks between $780-800^{\circ} \mathrm{C}$, similar to associated core temperatures. In contrast, amphiboles from the KI-3 pumice group show a core-to-rim temperature increase, with peak rim model temperatures of $810-840^{\circ} \mathrm{C}$. This pattern is reflected in model pressures, with cores displaying peak pressures of 90-130 MPa and a tail to $270 \mathrm{MPa}$ (Figure 4.21). Rim model pressures from KI-1 and KI-2 pumice groups are tightly clustered, similar to associated core pressures (80-130 MPa), whereas rim model pressures from the KI-3 group are higher (130-170 MPa) than in their respective cores. The model temperature and pressure estimates from the KI-1 and KI-2 groups are almost identical to those in the fall deposit, but KI-3 has a higher model T-P signal (Figure 4.21).

Rocky Hill ignimbrite: Amphibole core model temperatures are similar between pumice compositional groups, with the majority between 770 and $820{ }^{\circ} \mathrm{C}$ and a tail to $\sim 920{ }^{\circ} \mathrm{C}$ (Figure 4.21). Rim model temperatures from the RH-1 pumices are indistinguishable from core temperatures $\left(780-820^{\circ} \mathrm{C}\right)$, but within the $\mathrm{RH}-2$ group rim temperatures are cooler $\left(760-780{ }^{\circ} \mathrm{C}\right)$. The $\mathrm{RH}-2$ rim temperatures are lower, and the core-to-rim drop in temperature is more significant than in the otherwise similar high-SiO ${ }_{2}(\mathrm{KI}-2)$

Kidnappers group. Model pressures from cores display narrow ranges between 90 and $120 \mathrm{MPa}$ with a minor tail to $270 \mathrm{MPa}$ (Figure 4.21). Model pressures from the majority of rims are very similar to those recorded in the cores (RH-1: 90-140 MPa; RH-2: 80-120 MPa).

\subsubsection{Fe-Ti oxide temperature and $\mathrm{fO}_{2}$ estimates}

Fe-Ti oxide model temperature and oxygen fugacity estimates were calculated using the method of Ghiorso and Evans (2008). Magnetite and ilmenite pairs included within the same host orthopyroxene and, but to a lesser extent, amphibole were targeted to ensure textural equilibrium (Blundy et al. 2006). Before use in thermometry calculations, all Fe-Ti oxide pairs were tested for equilibrium using the method of Bacon and Hirschmann (1988). The Ghiorso and Evans (2008) calibration has been estimated to have uncertainties of $\pm 44{ }^{\circ} \mathrm{C}$ average absolute deviation (Blundy and Cashman. 2008). 
Kidnappers fall deposit: Total Fe-Ti oxide temperature estimates show a bimodal distribution throughout the fall deposit with peaks at $\sim 760$ and $790{ }^{\circ} \mathrm{C}$ (Figure 4.22). Temperature ranges change from between $\sim 780$ and $860{ }^{\circ} \mathrm{C}$ (mean of $810{ }^{\circ} \mathrm{C}$ ) where $\mathrm{KF}-\mathrm{A}$ glass dominates to between $\sim 770$ and $820^{\circ} \mathrm{C}$ (mean of $785^{\circ} \mathrm{C}$ ) where $\mathrm{KF}-\mathrm{B}$ glass dominates. The temperature ranges covered in KF-A and KF-B dominant horizons are similar to the ranges covered in KI-1 and KI-2 ignimbrite groups (Figure 4.22). Grains from all other horizons display a bimodality due to variable proportions of magmas yielding KF-A and KF-B (and KF-C) glass types present. All Fe-Ti oxide temperature estimates fall within the uncertainties of the Ghiorso and Evans (2008) calibration. However, when the number of analyses are taken into account (311 pairs), coupled with the bimodal Fe-Ti chemistry, the significance of differences in modeled temperatures is increased (Cooper et al. 2012 [Chapter 3]). $\log f \mathrm{O}_{2}$ estimates fall on the NNO buffer curve and cover a range from -11.6 to -15.5 (Figure 4.22 ). Values vary slightly with stratigraphic height from a mean of -13.7 at the base (KF-A dominant) to -14.2 at the top (KF-B dominant).

Kidnappers ignimbrite: The oxide pairs show a larger range in model temperatures from $760-970{ }^{\circ} \mathrm{C}$, extending the range seen in the fall deposit. Differences in model temperatures are recorded from each pumice group (Figure 4.22). KI-3 oxides have a large spread with a mean of $860^{\circ} \mathrm{C}$. KI-1 and KI-2 group oxides have a slightly smaller range in model temperatures, with means of $830{ }^{\circ} \mathrm{C}$ and $800{ }^{\circ} \mathrm{C}$, respectively (Figure 4.22). The temperature ranges within each compositional group, and in each individual pumice (Table 4.1), are larger than the range in amphibole rim model temperatures. The range in $\mathrm{Fe}-\mathrm{Ti}$ oxides may be recording a rapid change in temperature immediately prior to eruption, which is probably not recorded in amphiboles as the timescale may be too short for the re-equilibration of amphibole compositions (De Angelis et al. 2013). Alternatively, these differences may be a reflection of the relatively large $\mathrm{Fe}$-Ti oxide model uncertainties, coupled with a high number of modeled equilibrium pairs, resulting in a large spread in temperatures. $\log f \mathrm{O}_{2}$ estimates fall on the NNO buffer curve and cover a range from -10.8 to -14.9 (Figure 4.22), and mean $f \mathrm{O}_{2}$ estimates from each group are -12.5 (KI-3) -13.1 (KI-2) and -13.9 (KI-2 pumice). Two KI-2 pumice samples (P1607 and P1609: Table 4.1) contained a large number of magnetite/ilmenite 
pairs that are not in $\mathrm{Mg} / \mathrm{Mn}$ equilibrium, but those pairs that were in equilibrium returned very similar temperatures to other KI-2 oxide pairs.

\section{Rocky Hill ignimbrite}
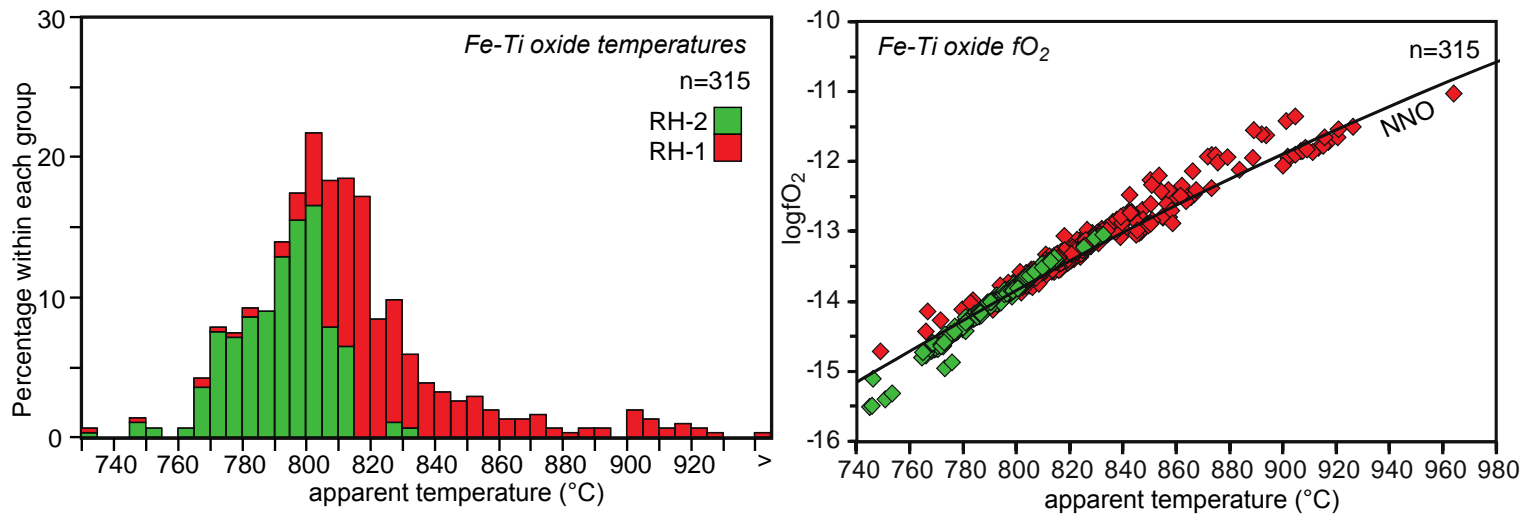

Kidnappers ignimbrite
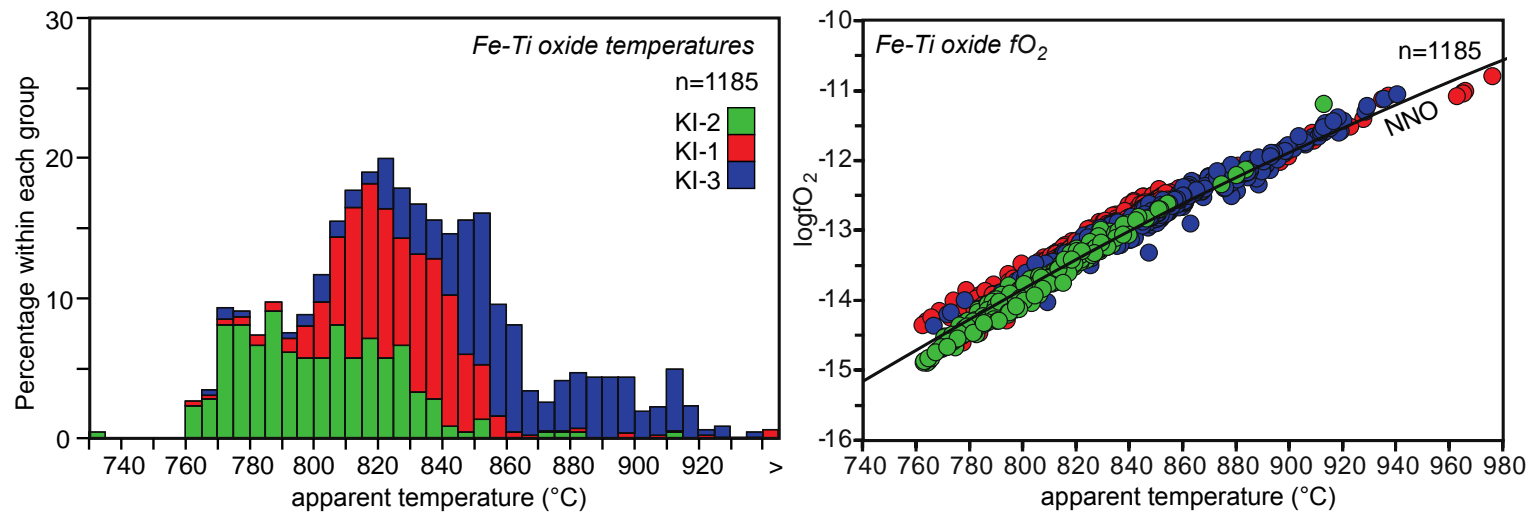

Kidnappers fall deposit
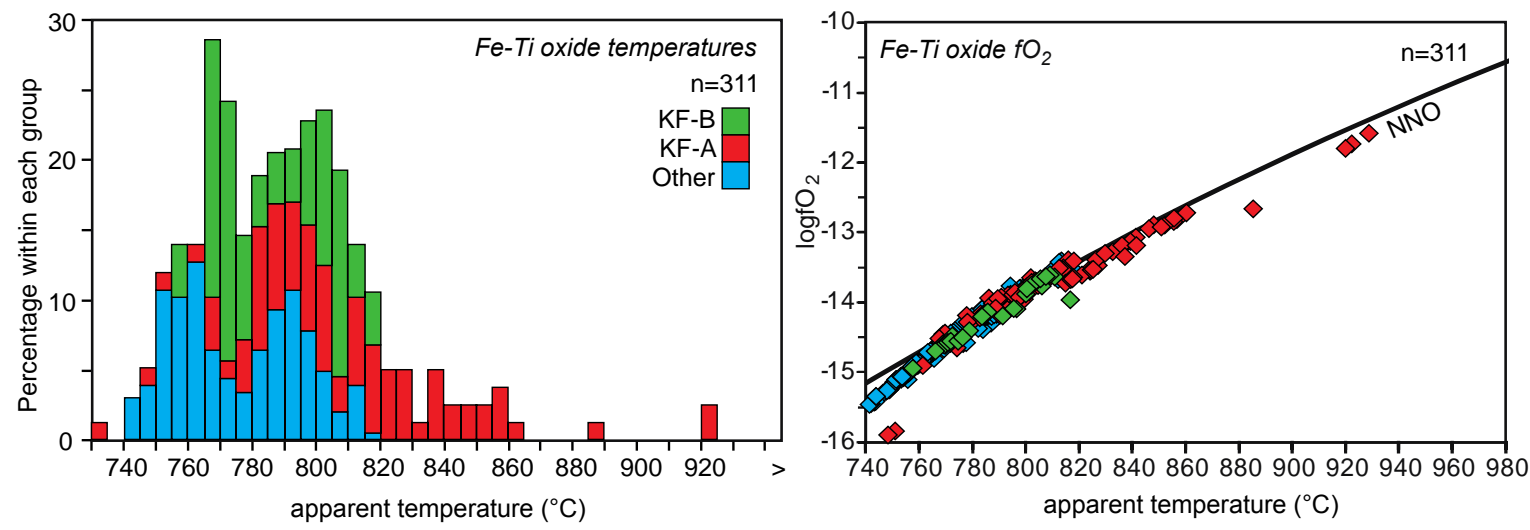

Fig. 4.22. Fe-Ti oxide model temperatures and oxygen fugacities calculated using the methods of Ghiorso and Evans (2008). Apparent temperatures from all Fe-Ti oxide equilibrium pairs in each compositional group are displayed as stacked histograms. Calculated oxygen fugacity values $\left(\log f \mathrm{O}_{2}\right)$ vs. temperature $\left({ }^{\circ} \mathrm{C}\right)$ from each compositional group are shown in plots.

Rocky Hill ignimbrite: Model temperature estimates cover a similar range to the Kidnappers ignimbrite of $750-960{ }^{\circ} \mathrm{C}$ and also show variations with whole-rock 
compositions (Figure 4.22). Mean temperatures from the RH-1 group pumices are 830 ${ }^{\circ} \mathrm{C}$ compared to $790{ }^{\circ} \mathrm{C}$ in $\mathrm{RH}-2$ group (Figure 4.22). Log $f \mathrm{O}_{2}$ estimates cover a range from -11.0 to -15.5 , with mean values of -13.2 from $\mathrm{RH}-1$ group and -14.0 in $\mathrm{RH}-2$ group samples. The temperature and $f \mathrm{O}_{2}$ estimates from $\mathrm{RH}-1$ and $\mathrm{RH}-2$ are very similar to those in the KI-1 and KI-2 groups, respectively.

\subsubsection{Plagioclase-melt and orthopyroxene-melt temperature estimates}

Plagioclase-melt and orthopyroxene-melt equilibrium model temperatures were calculated following Putirka (2008) (Figure 4.23). Due to the presence of multiple melt compositions within Mangakino eruptives (e.g. Cooper et al. 2012 [Chapter 3]) it is important to use melt (glass) compositions that are directly associated with crystal populations. An average matrix glass composition for each pumice that the plagioclase and orthopyroxene were extracted from was used in these estimates. Only rim compositions were used so as to maximise the likelihood of equilibrium between crystals and melt. Due to the difficulty of definitively matching loose crystals to glass shard compositional groups within the Kidnappers fall deposit, plagioclase-melt and orthopyroxene-melt temperatures were estimated from Kidnappers ignimbrite pumices only. The plagioclase-melt thermometer in particular is strongly sensitive to the $\mathrm{H}_{2} \mathrm{O}$ wt. $\%$ of the melt, which was calculated for each pumice using average water content model estimates in amphibole rims (Ridolfi et al. 2010) from the same clast. Average values used in all temperature estimates range from 5.2-5.7 wt. \% $\mathrm{H}_{2} \mathrm{O}$. Tests for orthopyroxene-liquid equilibrium between orthopyroxene rims and matrix glass were made using a Rhodes diagram (Putirka 2008). This simple test compares the observed Fe-Mg exchange coefficient with a constant value $\left(\mathrm{K}_{\mathrm{D}}\right)$, calculated from the cation fraction of $\mathrm{Si}$ in the melt.

Model temperatures from the Kidnappers plagioclase cover a smaller range, and are generally lower than amphibole and Fe-Ti oxide estimates, between $745-815^{\circ} \mathrm{C}$ (Figure 4.23). KI-3 group plagioclase rims have a narrow peak with a mean of $805^{\circ} \mathrm{C}, \mathrm{KI}-1$ group rims have a mean of $780{ }^{\circ} \mathrm{C}$ and $\mathrm{KI}-2$ rims display bimodal values with a mean of $760{ }^{\circ} \mathrm{C}$ (Figure 4.23). Model temperatures for the Rocky Hill are more restricted into 
two tight modes representing grains from RH-1 $\left(775-795^{\circ} \mathrm{C}\right.$; mean of $\left.785^{\circ} \mathrm{C}\right)$ and $\mathrm{RH}-$ $2\left(760-775^{\circ} \mathrm{C}\right.$; mean of $\left.765^{\circ} \mathrm{C}\right)$ compositional groups.
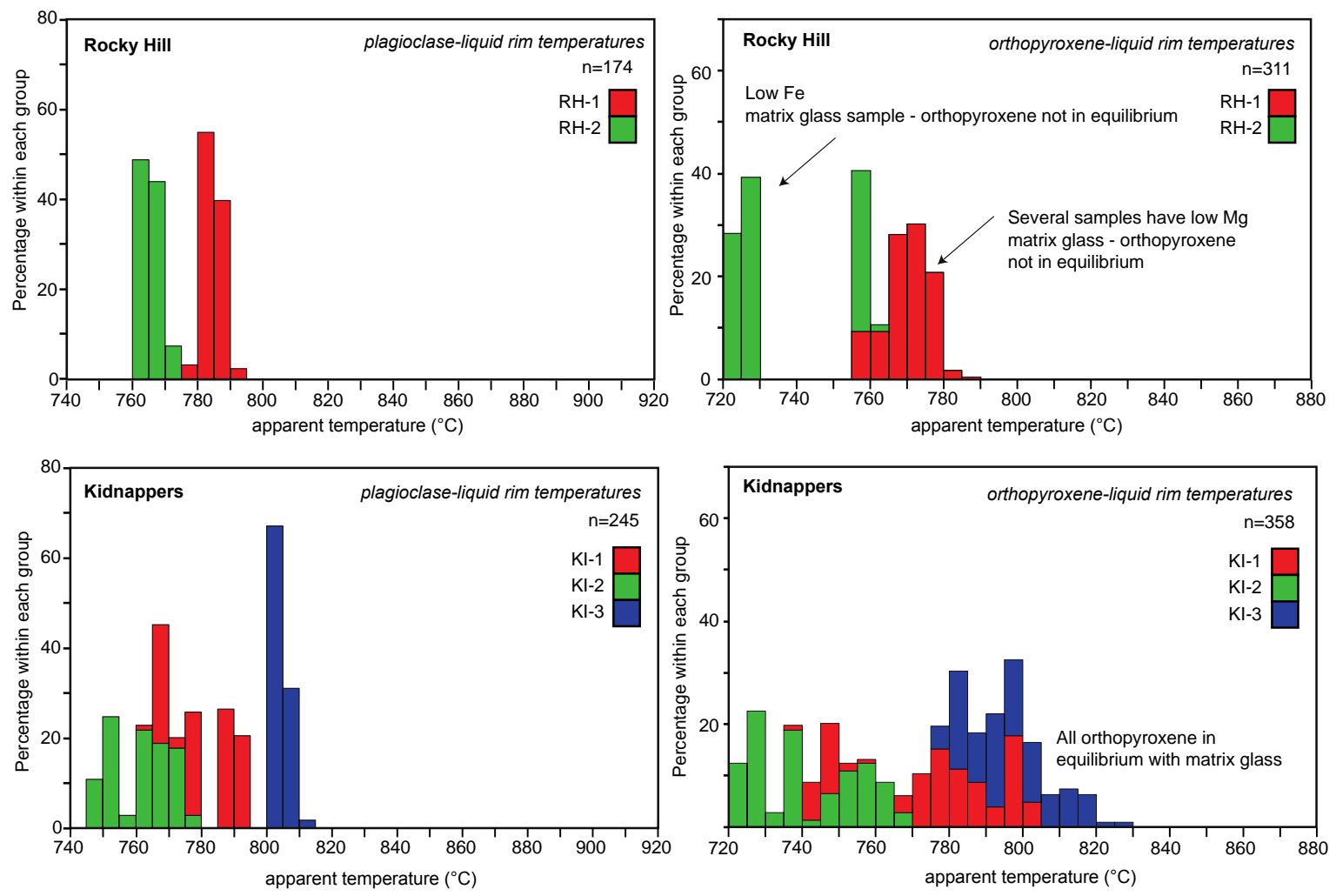

Fig. 4.23. Stacked histograms of plagioclase-liquid and orthopyroxene-liquid model temperatures from each compositional group within the Kidnappers and Rocky Hill pumices only. Apparent temperatures were calculated using the methods of Putirka (2008). Temperatures were calculated using only the rims of plagioclase and orthopyroxene grains, with matrix glass compositions from the same pumice clast.

All Kidnappers orthopyroxene-melt pairs are in equilibrium. Model temperatures show a slightly larger range than those from the plagioclase-liquid thermometer (Figure 4.23). KI-2 group crystals display multiple modes from $720-770{ }^{\circ} \mathrm{C}$ (mean of $750{ }^{\circ} \mathrm{C}$.), KI-1 group crystals have three peaks between 740 and $800{ }^{\circ} \mathrm{C}$ (mean of $775{ }^{\circ} \mathrm{C}$ ), and KI-3 group crystals have a broad distribution with a mean of $795^{\circ} \mathrm{C}$. In contrast, fifty percent of Rocky Hill pumice samples contain orthopyroxene that is not in equilibrium with the melt. Two samples (P2029 and P2030: Table 4.1) from RH-1 pumice have significantly lower Mg matrix glass concentrations (Figure 4.7) and melt-rim pairs are far from equilibrium. One RH-2 pumice (P2046: Table 4.1) has significantly lower average matrix glass $\mathrm{Mg}$ and $\mathrm{Fe}$ concentrations (Figure 4.7) and orthopyroxene-melt pairs are also out of equilibrium. No reliance can be placed on temperature calculations from these samples. Those samples in which crystal rims are in equilibrium with the melt 
record mean model temperatures of $770{ }^{\circ} \mathrm{C}$ in the $\mathrm{RH}-1$ group and $760{ }^{\circ} \mathrm{C}$ in the $\mathrm{RH}-2$ group (Figure 4.23).

The ranges in plagioclase-liquid and orthopyroxene-liquid model temperatures are smaller in both eruptions when compared to other thermometry techniques. In part this due to the use of only crystal rims (not cores) but is also an artifact of the thermometry models, which are strongly reliant on melt and $\mathrm{H}_{2} \mathrm{O}$ concentrations. The use of average matrix glass values and average modeled $\mathrm{H}_{2} \mathrm{O}$ concentrations reduces the number of variables in temperature calculations, thus reducing the range of modeled temperatures. The absolute temperature variations are therefore not likely a true reflection of magmatic conditions and so less reliance is placed on plagioclase- and orthopyroxeneliquid estimates in this study. However, the relative temperature differences between pumice compositional groups are consistent with amphibole and $\mathrm{Fe}-\mathrm{Ti}$ oxide temperature estimates.

\subsection{Discussion}

Contrasting but complementary information can be gained from the study of fall deposits with stratigraphic control, and from ignimbrites that have limited stratigraphic control but where relationships between mineral, glass and pumice compositions can be evaluated. Information from the fall deposit has shown that Kidnappers melt-dominant bodies were independent and systematically tapped (Cooper et al. 2012 [Chapter 3]). These conclusions would be more difficult to reach if only data from the overlying ignimbrite were used. In contrast, mineral characteristics, coupled with associated pumice whole-rock and glass data from the Kidnappers ignimbrite confirm that each melt-dominant body has a distinctive history. The following discussion incorporates the information from each deposit to build a picture of the evolution of the Kidnappers/Rocky Hill magmatic system.

\subsubsection{Glass compositional variations}

It is important to establish the variations in pumice matrix glass chemistry as the basis for crystal specific investigations. This is essential when examining eruptive deposits 
such as the Kidnappers and Rocky Hill ignimbrites (where stratigraphic control is limited), so that crystal characteristics can be given additional context from the eruption deposits as a whole. Matrix glass major and trace element compositions reflect variations present within the magmatic body just prior to eruption. Glass from the Kidnappers and Rocky Hill eruptions is unusual in the fact that chemical heterogeneity is displayed over a complete range of scales, from chamber-wide, through single-clast, to millimetre scales. Although some tephra correlation studies of eruptions from rhyolitic centres in the TVZ have found evidence for compositional variations in glass (e.g. the Okataina Volcanic Centre: Shane et al. 2003. 2008), this level of heterogeneity is unusual in most TVZ rhyolitic eruptions (Sutton et al. 1995; Allan et al. 2008). The glass heterogeneity presented here has implications for tephrochronological studies that rely on crystal/glass separates or the compositional uniformity of melts (Shane et al. 2008) such as U-series, ${ }^{40} \mathrm{Ar}-{ }^{39} \mathrm{Ar}$ and fission track dating. Also, characterisation of compositional heterogeneity may not be possible when a limited set of distal samples from restricted dispersal sectors are used (Lowe 2011). The present study is unique in the fact that the detailed compositional variations with stratigraphic ordering in the Kidnappers fall deposit can be compared to the record from Kidnappers ignimbrite pumices, which contain information on glass, whole-rock and mineral relationships. The full range of matrix glass compositions is found at any given stratigraphic height within the ignimbrite. In contrast, glass compositions within the Kidnappers fall deposit display a systematic variation with stratigraphic ordering. Therefore, the switch from the fall eruption to the ignimbrite is inferred to have been accompanied by wider scale caldera collapse, which disrupted the systematic withdrawal of discrete magma bodies, and the catastrophic evacuation of all magma batches occurred.

\subsubsection{Kidnappers glass compositions}

Three definable matrix glass compositional groups, each with a trace element heterogeneity have been documented within the Kidnappers fall deposit, which represents the first two-thirds of the total erupted material (Cooper et al. 2012 [Chapter 3]). The pumice matrix glass data from the Kidnappers ignimbrite significantly expands the range of glass chemistry seen in the fall deposit to both more- and less-evolved compositions (Figure 4.4). Each pumice analysed from within the Kidnappers ignimbrite compositional groups (Figure 4.2) also displays a slightly different average 
matrix glass composition. Apart from $\mathrm{FeO}$, matrix glass compositions from individual pumices in both the KI-1 and KI-2 pumice groups are homogeneous within analytical uncertainty with respect to major element concentrations. In contrast, trace element concentrations, particularly $\mathrm{Zr}$ and $\mathrm{Sr}$, in each compositional group show variations beyond analytical uncertainty, explained by a fractionating assemblage of plagioclase and zircon. The range in matrix glass $\mathrm{SiO}_{2}$ and $\mathrm{FeO}$ within each of the two KI-3 pumice clasts (Table 4.1) is also greater than analytical uncertainty (Figure 4.4). KI-3 group glass is therefore heterogeneous with respect to major element concentrations. The KI-3 group forms a separate sub-parallel trend to KI-1 and KI-2 groups suggesting that no mixing has occurred between glass types, and it is not represented within the Kidnappers Fall deposit. Therefore it is inferred that the KI-3 group represents a discrete magma batch, which was only tapped after additional caldera collapse and during emplacement of the ignimbrite. KI-1 and KI-2 type pumice glasses are compositionally similar, but extend to a greater range of compositions to the KF-A (and KF-C) and KF-B type glass in the Kidnappers fall deposit, respectively. It is inferred that the KI-1 and KF-A, and the KI-2 and KF-B material was erupted from the same two melt-dominant bodies previously identified (types A and B of Cooper et al. 2012 [Chapter 3]). During the earlier stages of eruption of the fall deposit, more restricted volumes of melt were tapped, and hence greater glass homogeneity is observed in the fall compositional groups. After the onset of ignimbrite deposition, more variable (and heterogeneous) melt was tapped from these melt-dominant bodies. Overlapping matrix glass compositions in the KI-1 and KI-2 pumice groups suggest that these melts did not necessarily remain physically separated as they were in the earlier stages of the eruption. However, their crystal populations with distinctive textural characteristics imply that these groups underwent different crystallisation histories (section 4.6.2). The KF-C glass (Type C of Cooper et al. 2012 [Chapter 3]) is not represented as a discrete compositional field in the Kidnappers ignimbrite (KI-1 compositions overlap both KFA and KF-C groups). The KF-C melt diminished before the total fall material was deposited (Cooper et al. 2012 [Chapter 3]), and was therefore either fully drained, or incorporated into the KF-A/KI-1 melt-dominant body.

The ranges in $\mathrm{FeO}$ observed within all pumice samples could be attributed to late stage microlite growth, in particular Fe-Ti oxides. However no microlites are observed within 
any matrix glass at high BSE magnifications. An alternative explanation for the larger range in $\mathrm{FeO}$ and $\mathrm{SiO}_{2}$ in $\mathrm{KI}-3$ glass may be a consequence of this discrete (KI-3) magma body interacting with another melt of a less evolved composition (see section 4.6.2).

Quartz hosted melt inclusions from the Kidnappers fall deposit do not display any significant differences in composition with respect to the fall matrix glass (Figure 4.9). This suggests an absence of compositional gradients, or shifts in chemistry of the melts from which the quartz has grown (cf. Liu et al. 2006). Most melt inclusions overlie KFB glass compositions indicating a greater proportion of quartz from the more evolved KF-B melt, which is coupled with greater biotite proportions in this group. These data suggest that quartz originated in evolved mush, or grew within melts that resemble the final melt-dominant body and did not originate at depth from a lesser evolved crystal mush/source (as also seen in the Oruanui system: Allan 2013).

\subsubsection{Rocky Hill glass compositions}

Major element matrix glass concentrations in Rocky Hill pumices have a slightly more restricted range than glass within Kidnappers pumices (Figure 4.7), although, trace element concentrations extend to slightly higher values within the $\mathrm{RH}-1$ group in comparison to KI-1. In general, the $\mathrm{RH}-1$ glass predominantly overlies the KI-1 compositional field and the RH-2 group overlaps the KI-2 group. Unlike in the Kidnappers, each pumice clast within each of the Rocky Hill compositional groups has indistinguishable chemistry. The reduction in major element diversity could reflect convective stirring, which removed any existing compositional variability and/or stratification. Such stirring could reflect the aftermath of caldera collapse and subsidence accompanying the Kidnappers event (e.g. Marshall and Sparks 1984; Folch et al. 2001; Kennedy and Stix 2007; Kennedy et al. 2008). Another possible explanation is that smaller and compositionally more restricted (i.e. well mixed) sources were tapped during the Rocky Hill eruption. This idea is supported by model temperature and pressure estimates, which have somewhat narrower unimodal distributions in comparison to those from the Kidnappers. Also, crystal rim compositions within the Rocky Hill plot into tighter and more discrete groups reflecting a reduction in the 
compositional variability of the melt. The relatively large range in $\mathrm{Sr}$ and $\mathrm{Zr}$ within each group can be explained by the same fractionating assemblage of plagioclase and zircon as observed in the Kidnappers. The two glass compositional groupings (RH-1 and RH2) within the Rocky Hill are remarkably similar to the KF-A and KF-B Kidnappers fall groups. If we infer that these respective groups in each eruption originated from common melt-dominant bodies, the separation between these distinct bodies remained after the Kidnappers eruption, or was re-established by similar processes during the time break between the two events (see Chapter 5).

There are some differences, however, between the Kidnappers and Rocky Hill. Glass compositions in the range of the KI-3 group are not represented within Rocky Hill pumices (Figure 4.7) and therefore this magma batch was absent from the later eruption. In turn, the matrix glasses of two Rocky Hill pumices (P2029 and P2030: table 4.1) have particularly low Mg concentrations (Figure 4.7). These compositions are not observed in any Kidnappers samples and may suggest an additional process operated to generate a new magma batch in the short ( $20-40$ years: see Chapter 5$)$ timeframe in between these eruptions. A decrease of $\mathrm{Mg}$ in the melt could have arisen from the crystallisation of orthopyroxene and amphibole, such as the large examples of the latter which are characteristic of Rocky Hill pumice. An additional glass type also commonly found within single Rocky Hill pumice clasts is the brown glass selvedges (Figure 4.8). This glass has fluid-affected compositions (low $\mathrm{K}_{2} \mathrm{O}, \mathrm{Rb}$ and $\mathrm{Li}$, high $\mathrm{Na}_{2} \mathrm{O}$ ) and may indicate the incorporation of pre-altered chamber-margin material. Alternatively, crystallisation of biotite (enriched in $\mathrm{K}_{2} \mathrm{O}$ and $\mathrm{Rb}$ ) into a crystal rich rind at the chamber margin could strip these fluid mobile elements from localised marginal glass, resulting in the observed brown glass. These elemental changes are similar to many of those observed across a single, layered biotite-rich and biotite-poor granitoid lithic clast from the Rotoiti eruption (Brown et al. 1998b). Biotite-rich granitoid lithics are present within the Kidnappers ignimbrite and have been sampled at the Litchfield Quarry site (though previously identified as Ongatiti ignimbrite: Brown et al. 1998b; Krippner et al. 1998). These granitoids are inferred to be comagmatic, representing the crystallising margins of the magma body. The brown glass is predominantly found in association with large, often shattered plagioclase grains. Such selvedges are rarely observed within Kidnappers pumices, consistent with the eruptions being distinct events. The evacuation 
of magma and caldera collapse during the Kidnappers eruption has the potential to cause stirring, mixing and incorporation of marginal material into the remaining meltdominant bodies (Marshall and Sparks, 1984; Folch et al. 2001; Kennedy and Stix. 2007; Kennedy et al. 2008). If the same bodies were renewed prior to the Rocky Hill eruption, this material could have been incorporated, but not fully mixed in with the melt.

\subsubsection{Significance of crystal signatures within compositional groups}

Whole rock and glass data both point towards distinct compositional groups being present within the products of both the Kidnappers and Rocky Hill eruptions. The chemistry and textural characteristics of minerals suggest each distinct compositional group underwent a slightly different history, giving rise to unique features and consistent with the idea that discrete magma batches were tapped by both eruptions (Section 4.6.1. and Cooper et al. 2012 [Chapter 3]). Similarities of crystal signatures between the Kidnappers and Rocky Hill samples suggest growth within a common mush system, undergoing the same chamber-wide processes and fractionating assemblages. The total range in chemistry and P-T estimates from phenocryst phases in both eruptions is relatively small. Minor tail-offs in model amphibole P-T histograms (Figure 4.21) could be taken to indicate a relatively small contribution of crystals with lesser-evolved core compositions derived from a deeper, hotter source. The dominant mush source from which the crystals and melt were derived had a similar composition to the eruptible melt-dominant bodies. This similarity is in part due to the dominance of greywacke crust within the TVZ, which has a strong control on the generation and final composition of all silicic melts in the TVZ (McCulloch et al. 1994; Graham et al. 1995).

It is important to first consider the relative sizes of magma batches represented by each compositional group. On the basis of whole-rock data, 3 out of 42 Kidnappers pumices belong to the KI-3 group, suggesting that this compositional group comprises $<10 \%$ of the total juvenile material within the ignimbrite. The KI-3 group is not represented in the Kidnappers fall deposit, which comprises $\sim 2 / 3$ of the total erupted extra caldera material, and this discrete magma batch therefore represents $<3 \%$ of the overall erupted magma. The KI-1 group is the dominant composition within the Kidnappers ignimbrite 
( 27 out of 42 pumices), and thus comprises $\sim 65 \%$ of ignimbrite juvenile material, with the KI-2 group making up the remaining $\sim 30 \%$. The volume estimates of KI-1 and KI2 are broadly similar to the proportions of KF-A ( 68\%) and KF-B ( 22\%) glass material estimated in the Kidnappers fall deposit. If we infer that these respective groups in the fall and flow originated from common melt-dominant bodies (KF-A=KI1; KF-B=KI-2) then total contributions of erupted magma from the two largest meltdominant bodies are $\sim 65 \%\left(780 \mathrm{~km}^{3}\right.$ DRE) and $\sim 25 \%\left(300 \mathrm{~km}^{3} \mathrm{DRE}\right)$. The two other less voluminous melts, KI-3 and KF-C are $\sim 3 \%\left(40 \mathrm{~km}^{3} \mathrm{DRE}\right)$ and $\sim 7 \%\left(80 \mathrm{~km}^{3}\right.$ DRE). At worse, these estimates may carry an uncertainty of $\pm 50 \%$ (cf. Hildreth 1981 , his Fig. 1). Estimates of the sizes of the same magma bodies during the Rocky Hill are more problematic to establish due to the continuous range in whole-rock compositions making a definitive cut off between RH-1 and RH-2 difficult. It is reasonable to assume, however, that the RH-1 group (similar to KI-1 and KF-A) remains the dominant magma type in the Rocky Hill ignimbrite.

\subsubsection{Mineral evidence supporting discrete magma batches}

A unique geochemical signature is particularly evident in the KI-3 group, which has whole-rock, glass and isotopic characteristics that are not found within the earlier erupted Kidnappers fall, or later erupted Rocky Hill deposits. The majority of crystals from the KI-3 group also display 'up-temperature' core-to-rim relationships in all phases, which are coupled with the dominance of BSE-light rims in plagioclase and BSE-dark rims in orthopyroxene (Figures 4.12 and 4.13). Thermometry estimates are also consistent with a temperature increase in the late stages of crystal growth due to late stage interaction with a less evolved, hotter magma. The increased range and unique trends in major and trace element glass chemistry within this group also point towards interaction with a less evolved endmember that did not mix with, or had very little influence on the other compositional groups. $\mathrm{Al}_{2} \mathrm{O}_{3}$ concentrations, as well as other compatible elements ( $\mathrm{Ti}, \mathrm{Mg}, \mathrm{Mn}, \mathrm{Sr}, \mathrm{Zr}, \mathrm{Eu}$ ) of glass are significantly higher within the KI-3 group, whereas $\mathrm{SiO}_{2}$ (and $\mathrm{Ba}, \mathrm{Rb}$ ) are lower (Figure 4.4), coupled with core-torim Al increases in all phases, particularly amphibole and orthopyroxene (Figures 4.16 and 4.17) suggesting that any lesser evolved melt was enriched in $\mathrm{Al}$ and other compatible elements. This melt, such as a high Al basalt or derivative andesite, could have interacted with the KI-3 melt by ponding at the base of the dominant body (Figure 
4.24). $\mathrm{Pb}$ isotopes from $\mathrm{KI}-3$ pumice samples trend differently to all other samples (Figure 4.10$)$. This trend could be explained by contamination $(\sim 10 \%)$ of a primitive basalt, although the lesser evolved melt could be another TVZ basalt or andesite, which have large geochemical and isotopic variations (Gamble et al. 1993). Therefore the lesser-evolved component cannot be defined further at this stage. An involvement of mafic magma has been suggested in many other large silicic magma systems (Bergantz and Dawes 1994; Bachmann et al. 2002, Girard and Stix 2009, 2010) and is a common process in younger silicic systems within the TVZ (Blake et al. 1992; Brown et al. 1998a; Leonard et al. 2002; Wilson et al. 2006; Shane et al. 2007; Matthews et al. 2012a). Alternatively, the mafic intrusion may have rejuvenated a proportion of mush by gas sparging and upward heat transfer (the mafic 'wind' of Bachmann and Bergantz. 2006). Heating of a crystal rich source zone or crystal mush can remobilise a proportion of crystals and liquid to become eruptible melt. This process occurred on a smaller scale in the Kos Plateau Tuff (Keller 1969; Bachmann 2010) and much larger scale in the Fish Canyon Tuff (Lipman et al. 1997; Bachmann et al. 2002), but is usually associated with crystal rich (>35-40 vol.\%) ignimbrites with little or no compositional heterogeneity. (the 'monotonous intermediates' of Hildreth 1981). A mafic interaction with the KI-3 magma would invoke a chemical and temperature change within this particular, relatively small-volume, separated body. However a similar interaction with a much larger volume of magma may not have a chamber-wide affect (Figure 4.24). Therefore, greater proportions of crystals within a smaller, separate magma batch will record this mafic interaction or chemical change compared to a larger volume in which other processes dominate. An example of this effect is evident in the textures of KI-3 plagioclase ( $>80 \%$ have BSE-light rims: Figure 4.12 ) and orthopyroxene ( $>40 \%$ of grains have BSE-dark outer zones: Figure 4.13), which have significantly higher proportions of 'up-temperature' grains than the other compositional groups (Figure 4.21). The thermal pulse from the input of a hotter, more mafic magma during the late stages of crystal growth may have the potential to 'prime' this volume of magma for eruption (cf. Matthews et al. 2012a, b). The significance of this process and the timescales over which it occurred are further discussed in Chapter 5.

Although KI-1 and KI-2 glass compositional fields overlap on several major and trace element plots (Figure 4.4), crystal signatures from pumices in these groups show unique 


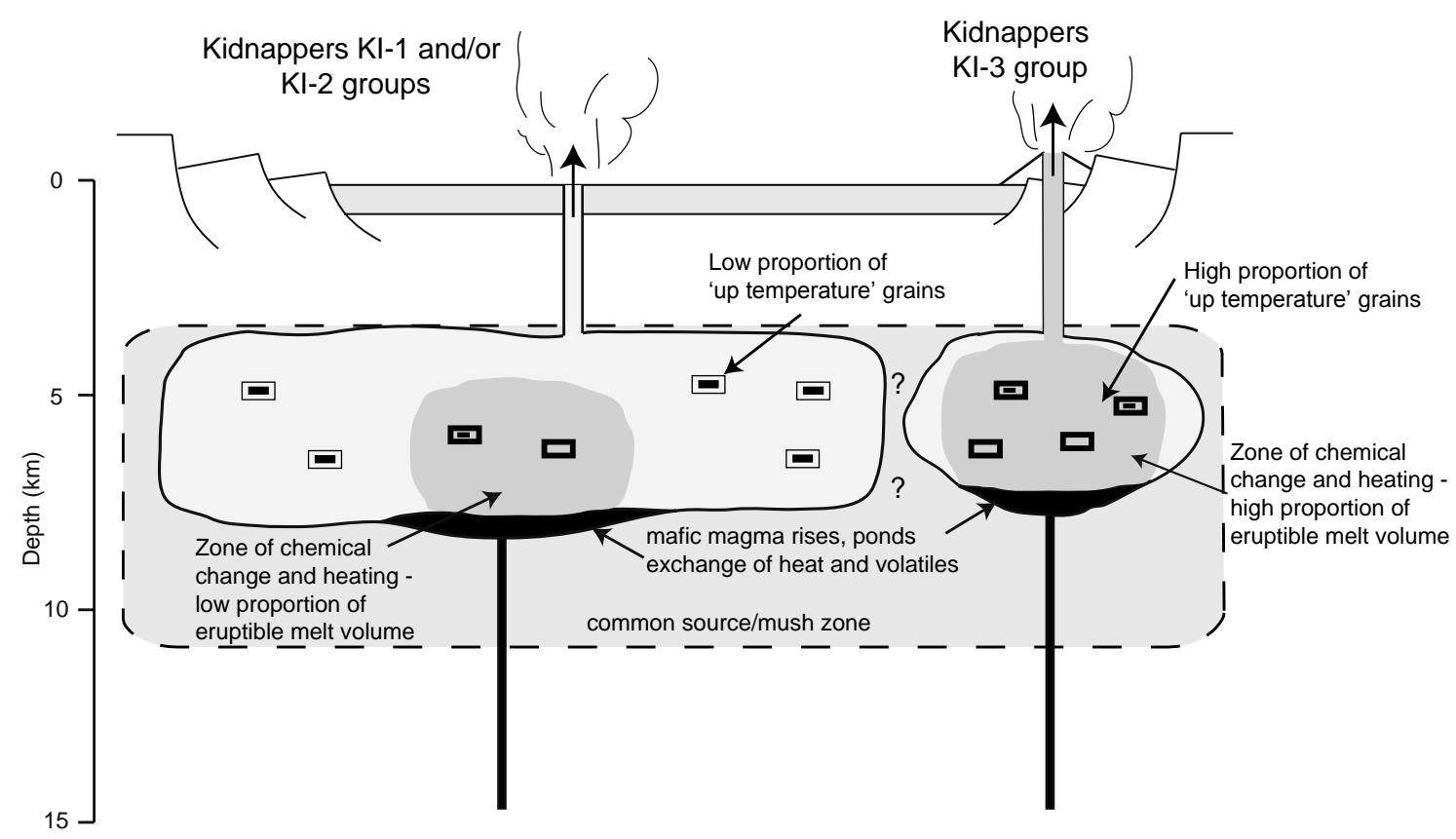

Fig. 4.24. Schematic cross section to illustrate the effect of ponded mafic magma below melt-dominant bodies of different volumes. Similar volumes of mafic magma will chemically and thermally effect a greater proportion of a smaller eruptible melt volume (such as KI-3 melt), compared with a larger volume (KI-1 or KI-2 melts). Therefore a greater proportion of the erupted crystal cargo will record these physiochemical changes. Depths shown are estimated from amphiboles using the method of Ridolfi et al. (2010). Lateral extents of the melt-dominant bodies are schematic only.

characteristics suggesting growth within discrete magma batches. In general, minerals from KI-1 pumices have no significant core-to-rim changes in chemistry whereas those from KI-2 have 'down temperature' signals (plagioclase with lower An plagioclase, orthopyroxene with lower Wo rims, and amphibole with lower $\mathrm{Al}^{\mathrm{T}}$ and $\mathrm{TiO}_{2}$ rims). Contrasting proportions of mineral textures are also found between KI-1 and KI-2 groups. KI-1 plagioclases are dominated by grains with non distinct rims (66\%), compared to dark rims (12\%) whereas within KI-2, $42 \%$ of the plagioclases have dark rims (Figure 4.12). Distinctions in orthopyroxene grains are more subtle, KI-1 orthopyroxenes are $53 \%$ normally zoned and $42 \%$ unzoned, compared with $76 \%$ normally zoned and only $15 \%$ unzoned in KI-2 (Figure 4.13). The proportions of mineral textures through the fall deposit cannot be definitively linked to melt types, but the appearance of dark plagioclase coincides with the appearance of KF-B glass, consistent with evidence that the KI-2 and KF-B groups originate from the same discrete melt, or share common magmatic processes. At the base of the fall deposit (KFA dominant), dark plagioclase rims are nearly absent, and therefore share similarities 
with KI-1 pumices. These crystal textures and compositions suggest the KI-1/KF-A melt-dominant body largely remained under similar conditions in the lead-up to eruption, with no significant physiochemical changes. In comparison, crystals from the KI-2/KF-B group suggest this volume of magma evolved though cooling and crystal growth and fractionation. Alternatively, the down temperature crystal signatures may represent the injection of material from a crystal mush into a melt-dominant body prior to eruption.

Crystal signatures from the RH-1 and RH-2 groups are very similar to those in KI-1 and KI-2 respectively. RH-1 crystals show little core-to-rim changes in chemistry and have very similar proportions of non-distinct plagioclase rims and unzoned orthopyroxene grains as KI-1. RH-2 crystals are dominated by 'down temperature' chemical and textural signals as in KI-2. This evidence supports the idea that the two main meltdominant bodies tapped in the Kidnappers were erupted again in the Rocky Hill, or that similar processes re-established two new magma batches within the same source systems.

There are many studies of large silicic eruptions that contain multiple melt batches with unique compositional signatures that cannot easily be related by any differentiation or fractional crystallisation process within a single magma body (Fridrich and Mahood, 1987; Schuraytz et al. 1989; Briggs et al. 1993; Cambray et al. 1995; Mills et al. 1997). However many of these studies propose models whereby the discrete melt batches are held within a single large magma chamber, with barriers to mixing between compositional groups. For example, the Timber Mountain Group in the Southwestern Nevada Volcanic Field contains two large volume tuffs erupted at 11.6 and $11.45 \mathrm{Ma}$ (Mills et al. 1997). Cambray et al. (1995) and Mills et al. (1997) show evidence from whole-rock chemistry, phenocryst chemical variation, glass chemistry and temperature estimates, to suggest the presence of distinct magma batches in both eruptions. These workers suggest that the melt evolved in discrete magma batches before coming together within a single magma chamber, with no mixing between them, just prior to eruption. This scenario, however, requires highly complex withdrawal dynamics and barriers to mixing, and may be reevaluated in light of the Kidnappers/Rocky Hill system 
with a more simple magma system model, whereby the synchronous tapping of separated melt-dominant bodies takes place.

\subsubsection{Consideration of geothermobarometry estimates}

To complement the textural and chemical variations with crystals (Sections 4.6.2), model amphibole temperatures and pressures were calculated to highlight core-to-rim changes within each melt-dominant body. The similarities of model temperature and pressure estimates from amphibole cores from each compositional group within both the Kidnappers and Rocky Hill eruptive deposits (Figure 4.21) indicate that amphibole crystallised under common conditions for a period of time prior to eruption. It is thus inferred that the Kidnappers/Rocky Hill system as a whole, including the source zone or crystal mush, operated at similar depths in the crust ( 4-10 km). These depths are comparable to other large-scale silicic systems (Brown et al. 1998a; Wallace et al. 1999; Bachmann et al. 2002; Liu et al. 2006; Wilson et al. 2006; Hildreth and Wilson 2007). Each melt-dominant body is also found to operate at similar depths between 3.5 and 6.5 $\mathrm{km}$. The similarities in temperature and pressure estimates also imply that the meltdominant bodies tapped throughout the Kidnappers and Rocky Hill eruptions were largely horizontally separated. However, small amphibole core-to-rim shifts in apparent pressure and temperature (P-T) are present within the compositional groups, and temperature estimates from other phases record final pre-eruptive conditions that vary between compositional groups. These differences support the idea that discrete batches of eruptible melt underwent unique evolutionary pathways and were held at slightly different P-T conditions (and possibly depths) for a period of time prior to eruption.

\subsubsection{Amphibole core-to-rim P-T changes}

Within the Kidnappers KI-3 group pumices, amphiboles record apparent core-to-rim increases in both model temperature $\left(\sim 40{ }^{\circ} \mathrm{C}\right)$ and pressure ( 40 MPa: Figure 4.21). The former can be explained by an input of hotter, less evolved magma, as discussed above, but it is less easy to explain a rise in model pressures. The Al-in-amphibole barometer of Ridolfi et al. (2010) is based on simple regression of $\mathrm{Al}_{\text {tot }}$ from experiments at a known pressure and therefore all variability in $\mathrm{Al}$ content is expressed as a pressure change. It is likely, however, that significant changes in $\mathrm{Al}$ concentrations in the melt 
may also drive increased amphibole $\mathrm{Al}_{\text {tot }}$ values without an accompanying change in pressure (e.g., Coombs et al. 2013). Such changes may be particularly relevant in smaller magma bodies in which rapid, chamber-wide changes in melt chemistry are possible (see section 6.4.2 and Figure 4.24). No consistent core-to-rim increases in temperature and pressure are recorded in the Kidnappers fall deposit or the Rocky Hill ignimbrite, suggesting that this process, also recorded by the textures and chemistry plagioclase and orthopyroxene, is unique to the later stages (and flow deposits) of the Kidnappers eruption.

Both core and rim model temperature and pressure estimates from pumices in the KI-1 group and the RH-1 group, as well as from the KF-1 glass dominated horizons in the Kidnappers fall cover the same range. No significant or consistent core-to-rim shifts in either model temperature or pressure are observed within these groups, which indicates that the common melt from which these crystals grew remained under very similar P-T conditions, depths and with similar Al concentrations over the time taken for the crystals to grow.

Amphiboles from KI-2 and RH-2 group pumices from the Kidnappers and Rocky Hill ignimbrites display a small core-to-rim decrease in model temperature $\left(\sim 20-30{ }^{\circ} \mathrm{C}\right)$ and pressure ( 10 MPa) estimates (Figure 4.21). A number of amphiboles from the KF-B dominated horizons in the Kidnappers fall deposit also show a small core-to-rim temperature decrease, but no measurable shift in model pressure is evident. These P-T shifts are smaller than the uncertainty on the Ridolfi et al. (2010) model but confidence in these model data is increased when the number of analyses showing this consistent change is taken into account. These trends within the KI-2 and RH-2 (and KF-B glass) groups imply that crystals moved to slightly lower P-T conditions and shallower depths (4-6 km) prior to eruption. Unlike in KI-3 group amphiboles, the core-to-rim decrease in $\mathrm{Al}_{\text {tot }}$ may be considered to realistically represent a change in the pressure, particularly when the proportion of KI-2 (and $\mathrm{RH}-2$ ) material is considered ( $25 \%$ of total volume within the Kidnappers ignimbrite), as it is harder to envisage a rapid drop in $\mathrm{Al}$ concentration within this volume of melt. There is no significant differences in the $\mathrm{Eu} / \mathrm{Eu}^{*}$ values in glass and amphiboles from KI-2 (and RH-2) and the other 
compositional groups to suggest that plagioclase crystallisation was the cause of these trends. The core-to-rim textural and chemical variations, coupled with a drop in model temperatures and pressures within the crystals may represent the extraction of melt and crystals from a Kidnappers/Rocky Hill mush or source zone and establishment of the final melt-dominant body at shallower levels $(3.5-5.0 \mathrm{~km})$, in similar fashion to the Oruanui system (Allan et al. 2013). The similarities of model temperatures and pressures through the Kidnappers fall and ignimbrite suggest the tapping of material at the same depths before and after caldera collapse. Therefore the increased glass compositional diversity within the Kidnappers ignimbrite compared with the fall deposit may largely represent lateral, and not vertical chemical variations within the erupted melt volumes.

\subsubsection{Melt evolution processes}

In general, overall compositional trends from the Kidnappers and Rocky Hill deposits are similar, and are inferred to represent processes occurring in a common magmatic system. Evolutionary trends within products of the Kidnappers/Rocky Hill magma system are strongly controlled by a common crystallising assemblage (in particular plagioclase and amphibole). Differences between the signatures of the two eruptions, do however exist, and highlight some distinctions.

\subsubsection{Whole rock and glass signatures}

The general trends in whole rock and glass compositions of the Kidnappers and Rocky Hill are very similar, with overlaps in almost every major and trace element. However, whole-rock to glass tie lines show disparities between the behaviour of alkalis (Figures 4.2 and 4.5). $\mathrm{K}_{2} \mathrm{O}$ tie-lines within Kidnappers samples have negative slopes and the ranges in concentrations are similar between associated glass and whole-rock pairs. In comparison, tie-lines within the Rocky Hill have positive slopes and whole rock $\mathrm{K}_{2} \mathrm{O}$ concentrations are lower than in either the corresponding glass or Kidnappers wholerock concentrations. These contrasting patterns are consistent with a fractional crystallisation trend in the Rocky Hill. Whole-rock $\mathrm{K}_{2} \mathrm{O}$ concentrations in the Kidnappers (particularly KI-2) are, however, greater than would be expected from fractional crystallisation alone and indicate some $\mathrm{K}_{2} \mathrm{O}$ addition. This addition could be 
explained by assimilation of $\sim 6 \%$ of biotite-rich material (high in $\mathrm{K}_{2} \mathrm{O}$ ) into Kidnappers melts. This process is also consistent with higher $\mathrm{Rb}$ concentrations (enriched in biotite), and increasing $\mathrm{Rb} / \mathrm{Sr}$ ratios in Kidnappers whole rock (Figure 4.3) data. This whole-rock KI-2 compositional array trends towards the composition of Kidnappers bioite-rich granitoids analysed by Brown et al. (1998b), and suggests the incorporation or melting of comagmatic marginal material into the higher $\mathrm{SiO}_{2}(\mathrm{KI}-2)$ melt-dominant body (Figure 4.3).

Values of whole rock $\mathrm{Al}_{2} \mathrm{O}_{3}$ wt. \% extend to considerably higher concentrations in Rocky Hill pumices with little accompanying change in glass values (Figure 4.5), consistent with an increase in abundance of Al-rich phases (plagioclase, amphibole) within Rocky Hill pumice. Whole-rock Eu/Eu* values in Kidnappers pumices decrease with decreasing $\mathrm{Al}_{2} \mathrm{O}_{3}$ and form a near-continuous trend towards the respective glass compositions (Figure 4.6). This trend implies that the majority of plagioclase present in the Kidnappers crystallised from the melt in which it is now found. In contrast, whole rock $\mathrm{Al}_{2} \mathrm{O}_{3}$ values in the Rocky Hill are significantly higher at the same $\mathrm{Eu} / \mathrm{Eu}^{*}$ values as the whole-rock Kidnappers and their respective glass compositions. Also, the wholerock compositional array does not trend toward its respective glass compositions (Figure 4.6), which may imply that an additional plagioclase component is present in Rocky Hill pumices. The plagioclase-bearing clots with their brown glass sheaths, found in many Rocky Hill pumices, are inferred to be this component, representing contaminant material from crystal richer margins (roof and/or sidewall). However, this inference is used with caution as Rocky Hill whole-rock $\mathrm{Al}_{2} \mathrm{O}_{3}$ weakly correlates with LOI values, and thus the highest $\mathrm{Al}_{2} \mathrm{O}_{3}$ concentrations and the trends discussed above may to some extent be an artifact of higher degrees of secondary hydration and alteration within Rocky Hill pumices. Whole rock Y concentrations in the Kidnappers do not correlate with $\mathrm{Al}_{2} \mathrm{O}_{3}$, whereas in the Rocky Hill they form a tightly defined trend. $\mathrm{Y}$ is enriched in amphibole $(\mathrm{Y} a \mathrm{aph} / \mathrm{Y}$ melt $=10)$ compared to the other major crystal phases (electronic appendices EA.6 and EA.7) and thus the Rocky Hill data imply that there was a strong amphibole crystallisation control operating in the magma system after the Kidnappers event but prior to the Rocky Hill eruption. 


\subsubsection{Amphibole signatures}

Inflections observed within amphibole major and trace element data with increasing evolution are explained here by changes affecting the overall melt-dominant bodies. The sharp drop in $(\mathrm{Na}+\mathrm{K})^{\mathrm{A}}$ with decreasing $\mathrm{Al}^{\mathrm{T}}$ (at 1.2), particularly evident in KI-2 type rims (Figure 4.20), is inferred to reflect continued plagioclase and/or biotite crystallisation ( $\mathrm{Na}+\mathrm{K}$ removal). These phases are particularly common in high-SiO${ }_{2} \mathrm{KI}-$ 2 type pumices. The same inflection is less evident though in amphiboles from the Rocky Hill which, in general, has lower biotite proportions. Both Kidnappers and Rocky Hill amphibole $\mathrm{Mg} /\left(\mathrm{Mg}+\mathrm{Fe}^{3+}\right)$ and $\mathrm{Mn}$ values increase with decreasing $\mathrm{Al}^{\mathrm{T}}$ (at 1.2), which is interpreted to reflect orthopyroxene instability (cf. Allan et al. 2013). Inflections in amphibole $\mathrm{Mn}$ and $\mathrm{Zn}$ concentrations with both $\mathrm{Eu} / \mathrm{Eu}^{*}$ and model pressures also are consistent with orthopyroxene instability in the more evolved $\left(\mathrm{Eu} / \mathrm{Eu}^{*}<0.3\right)$, lower (model) pressure melts (Figure 4.20). The breakdown of orthopyroxene, preferentially enriched in $\mathrm{Mg}, \mathrm{Mn}$ and $\mathrm{Zn}$, increases the availability of these elements in the melt. This inference is supported by qualitative differences in orthopyroxene proportions from KI-2 (amph>opx) and KI-3 (opx>amph) group pumices in the Kidnappers. This feature and the Mn inflection trend within Kidnappers/Rocky Hill amphiboles is opposite to those observed in the Oruanui rhyolite, where orthopyroxene was stable at lower pressures in the melt-dominant body (Allan et al. 2013). Zr concentrations in Kidnappers/Rocky Hill amphiboles show a change also at the same point as $\mathrm{Mn}$ does $\left(\mathrm{Eu} / \mathrm{Eu}^{*}=0.3\right.$ : Figure 4.20), in response to the onset of zircon crystallisation and subsequent removal of $\mathrm{Zr}$ from the melt. The upward trend in $\mathrm{Zr}$ concentrations in a minority of amphibole cores from $\mathrm{Eu} / \mathrm{Eu}^{*} 0.8-0.3$ suggest an antecrystic amphibole component which originally grew in zircon undersaturated conditions. The changes at $\mathrm{Eu} / \mathrm{Eu}^{*}<0.3$, model pressures $<120 \mathrm{MPa}$, and depths of 4.5-4.0 km could reflect a change into crystal growth in the final erupted melt-dominant bodies. Amphibole compositions, particularly cores, yielding higher model pressures are inferred to represent an antecrystic component derived from a deeper source zone or mush. The inflection at $\mathrm{Eu} / \mathrm{Eu}^{*}<0.3$ is particularly evident in the KI-2 and RH-2 compositional groups, which also have a large proportion of 'down temperature' core-to-rim textural and chemical changes, as well as core-to-rim decreases in model amphibole temperature and pressure estimates (Figure 4.21). These data support the idea of a decompression event, representing significant extraction of 
melt and crystals from a mush/source zone to establish the melt-dominant body at shallower levels. This process was rapid, occurring on short timescales (centuries) prior to eruption, as also recorded in the Oruanui eruption (Allan et al. 2013; see Chapter 5). In light of the evidence for the rapid extraction of melt and crystals from a crystal mush, magma system models involving melts with contrasting chemistry and complex magma chamber zonation (e.g. Duffield and Ruiz 1992; Schuraytz et al. 1989) may be reevaluated. The Taylor Creek Rhyolite, New Mexico consists of 20 domes and lava flows erupted over a few thousand years or less, inferred to be erupted from a single large ( $30 \mathrm{~km}$ diameter) reversely zoned magma chamber (Duffield and Ruiz 1992). However, sustaining a large magma chamber over thousands of years, with multiple tapping of small volumes of melt, but never a large pyroclastic eruption seems problematic. The establishment of many small-scale melt batches, formed and erupted over rapid timescales from a large crystal-rich mush source (e.g. Girard and Stix 2010) could also explain the trends observed within these systems and represent a physically more plausible scenario.

\subsubsection{A magma system model for the Kidnappers and Rocky Hill eruptions}

Although both the Kidnappers and Rocky Hill eruptive products show much geochemical and petrological diversity, there are some striking similarities between the two events. It is inferred that the melt-dominant bodies tapped in both events had a common source zone and involved varying proportions of the same melts. The following outlines the evolution of the Kidnappers/Rocky Hill magma system, built around the scenarios presented in Figure 4.25.

\subsubsection{Earlier stages of the Kidnappers eruption (fall deposits)}

During the eruption of the Kidnappers fall deposit, three discrete, horizontally separated melt-dominant bodies (type KF-A, KF-B and KF-C) are inferred to have been tapped from three vent systems to yield the simultaneous and sequential compositional changes in the fall deposit (Cooper et al. 2012 [Chapter 3]) (Figure 4.25). No interaction or mixing took place between the independent melt-dominant bodies during this early phase. The erupted volumes of melt were homogeneous, with little or no evidence for stratification and were stored at depths of $\sim 3.5$ to $6.5 \mathrm{~km}$. The horizontal separation of 


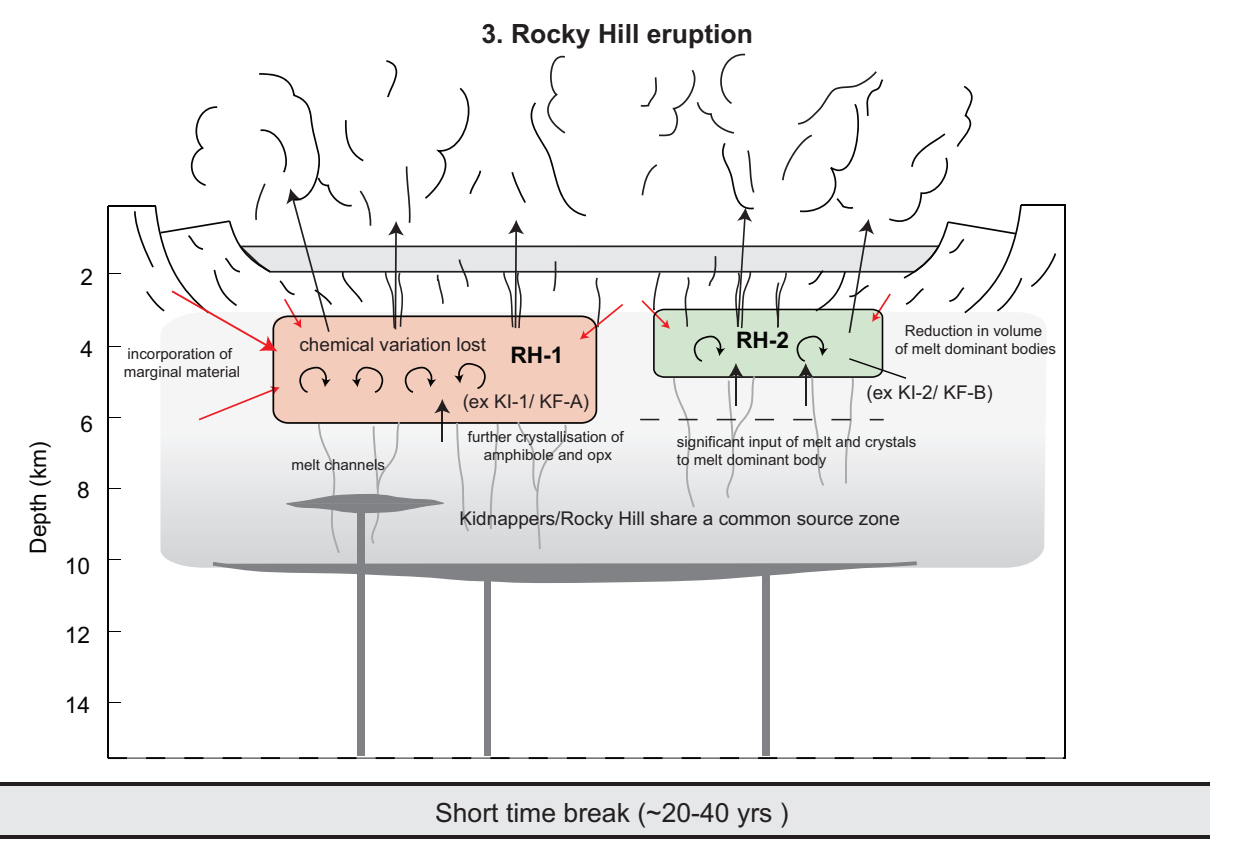

2. Wider scale caldera collapse and eruption of flow deposits

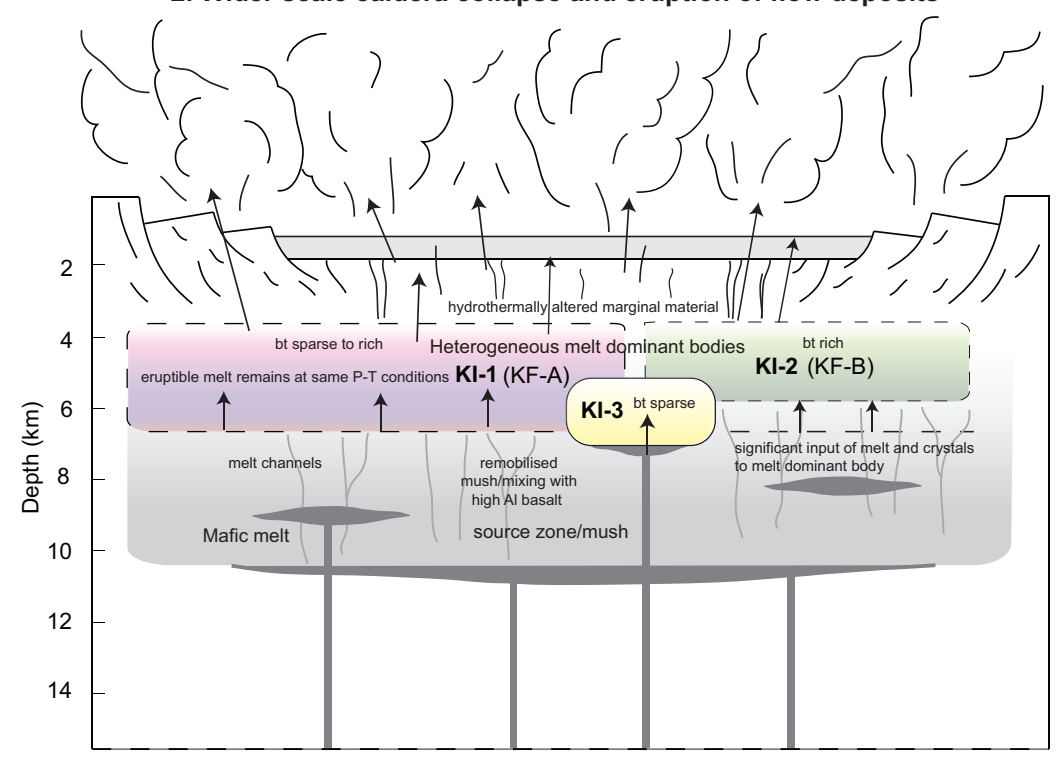

1. Eruption of the Kidnappers fall deposit

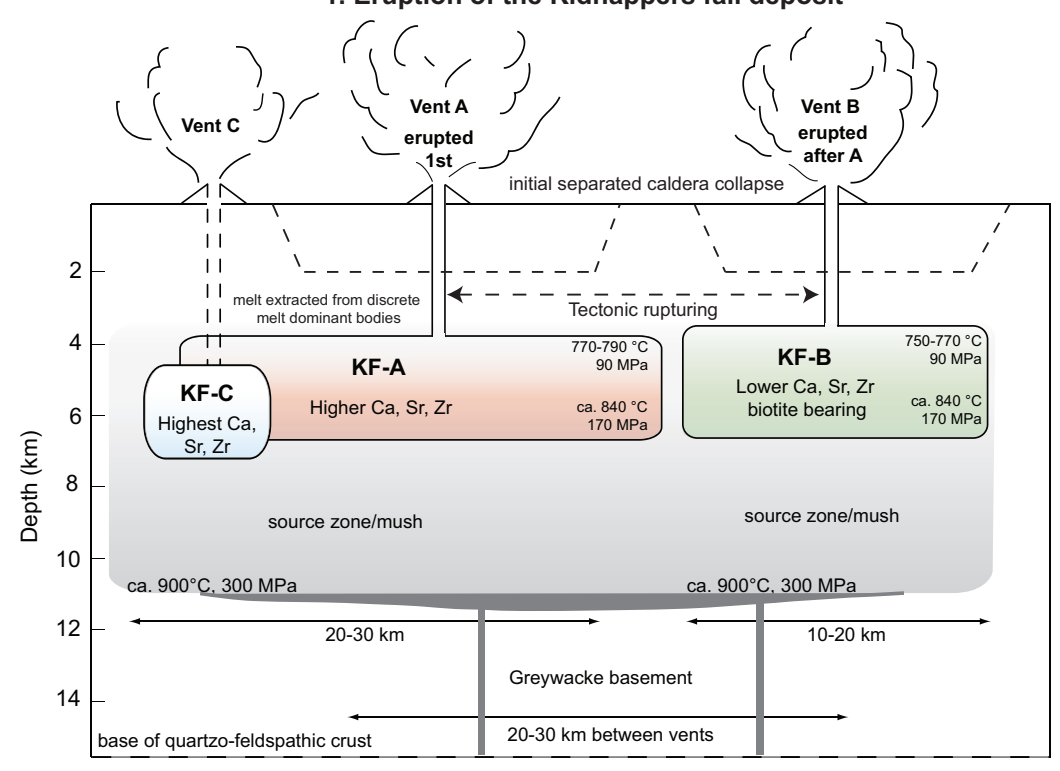


Fig. 4.25. (opposite) Semi quantitative cross sections of the Kidnappers/Rocky Hill magma system through time. (1) During the early stages of the Kidnappers eruption, material was erupted from at least two independent magma chambers (plus the possible minor KF-C magma) as a phreatomagmatic fall (Cooper et al. 2012 [Chapter 3]). Caldrera collapse probably commenced during the fall phase. (2) Eruption and deposition of material deposited as flows was coincidental with wholesale caldera collapse. During this period, a wider range of compositions were tapped from two, heterogeneous melt-dominant bodies which had little exchange of crystals or melt. A third smaller volume of melt underwent late stage heating and mixing with a more primitive, mafic melt, but did not mix with the other Kidnappers magmas. (3) After a short time break ( 20-40 years [Chapter 5]) the Rocky Hill eruption commenced. Two smaller homogeneous melt-dominant bodies, broadly similar to Type A and B of the early Kidnappers were tapped. Collapse of the chamber roof and margins incorporated altered material to the melt. Depths are estimated from amphiboles using the method of Ridolfi et al. (2010). The horizontal extents in (1) are approximately estimated from the volume of erupted material and the general size of the gravity anomaly that defines the Mangakino caldera.

the melt-dominant bodies is poorly constrained but vents are estimated to have been 20$30 \mathrm{~km}$ apart, based on the size of Mangakino caldera and the crude estimates of erupted volumes. The systematic tapping of the three horizontally separated melt-dominant bodies may have been controlled by tectonic processes following the partial drainage of magma chamber A (Cooper et al. 2012 [Chapter 3]). Due to the exceptionally large volumes of magma that was evacuated during this stage, it is likely that caldera collapse accompanied the eruption of the Kidnappers fall deposit. The initial caldera collapse may have been related to each geographically separated vent (cf. Gravley et al. 2007), and therefore deposition of the fall deposit remained systematic.

\subsubsection{Later stages of the Kidnappers eruption (ignimbrite)}

Draining of the melt-dominant bodies and tectonic readjustment is inferred to have caused further and more widespread caldera collapse and a consequent increase in the eruption intensity to generate pyroclastic flows and deposit the Kidnappers ignimbrite. This may be analogous to the collapse sequence observed in the $240 \mathrm{ka}$ MamakuOhakuri paired eruptions (Gravley et al. 2007). Here, initial caldera collapse associated with each ignimbrite, formed the Rotorua and Ohakuri calderas, spaced $\sim 30 \mathrm{~km}$ apart. Subsequent collapse of the area between the two calderas then occurred within years to decades after the event. Within the Kidnappers, it is possible that tectonic rupturing occurred between the initially separated calderas formed during eruption of the fall deposit, leading to wider scale caldera collapse and an increase in the eruption intensity. 
It is inferred that caldera collapse at this stage initiated the evacuation of a wider diversity of material from three distinct batches of melt plus crystals (Figure 4.25). The three Kidnappers compositional groups record unique characteristics with different histories. The mid-SiO 2 (KI-1) pumice group is similar in its relevant characteristics to glass KF-A and KF-C in the fall deposits (Cooper et al. 2012 [Chapter 3]) and is therefore inferred to represent material from the same melt-dominant body. Changes in the KF-C glass proportions in the fall deposit suggest this body may have been mixed into the KF-A/KI-1 magma body, or been entirely drained during the fall phase alone. Thus the KI-1 pumice group may represent a somewhat greater diversity of material from the magma body defined by the earlier KF-A glass compositions. Both glass KF-A and the corresponding KI-1 pumices are volumetrically dominant, suggesting this meltdominant body was the largest tapped during the Kidnappers event. No significant coreto-rim shifts in amphibole model P-T estimates are observed, and thus the final eruptible magma is inferred to have been stored over a stable depth range and without any significant temperature changes prior to evacuation.

The Kidnappers high-SiO 2 (KI-2) pumice type is correlated with the KF-B glass in the fall deposits (Cooper et al. 2012 [Chapter 3]), but extends to more evolved matrix glass and associated crystal compositions. The KI-2 pumices are therefore inferred to have been evacuated from a source common to the KF-B fall glass material, but they tapped more diverse magma compositions than those represented in the fall deposits. Core-torim amphibole model P-T estimates suggest a proportion of this magma rose to slightly shallower depths shortly before eruption (see Chapter 5). This rise was accompanied by core-to-rim down-temperature (and pressure) compositional shifts in plagioclase, orthopyroxene and amphibole, and lower Fe-Ti oxide model temperatures. This process is inferred to represent the extraction of large volumes of crystals and melt from a crystal mush and the establishment of the final erupted melt-dominant body.

The KI-2 group magma has distinctive characteristics, giving evidence for the operation of contrasting processes when compared to the KI-1 magma. Overlapping compositions between KI-2 and KI-1 glasses suggest that mixing between the melts may possibly have occurred, although exchange of the crystal cargo was minimal. It is possible that 
syn-eruptive tectonic disruption could have allowed these once-discrete melt-dominant bodies to interact. The KI-2 group magma contains a greater proportion of biotite, suggesting a greater involvement of lower temperature, biotite rich marginal material at shallower levels, represented in whole-rock and glass compositional trends.

The KI-3 pumice compositions from the Kidnappers ignimbrite are distinct from any represented in the fall deposit glass compositions, and therefore are inferred to represent tapping of an additional, smaller magma body in the later stages of the eruption (Figure 4.25). This composition does not recur within the Rocky Hill composition spectrum, and thus is unique to the Kidnappers ignimbrite. Matrix glass and crystal chemistries suggest that this melt originated from a common source to other Kidnappers material but underwent interaction with a lesser evolved melt, and did not mix syn-eruptively with the larger melt-dominant bodies discussed above. Evidence from Fe-Mg diffusion profiles across up-temperature orthopyroxene rims show that interaction with the lesser evolved melt occurred within 50 years of eruption (See Chapter 5 for details).

Each compositional group within the Kidnappers is found at the same stratigraphic position within the ignimbrite, and was sampled at exposures where there were no signs of any significant time breaks (e.g. flow unit boundaries). Thus, it is inferred that the evacuation of the diverse magmas involved in the later stages of the Kidnappers eruption was simultaneous. It is unlikely that the tapping of these magmas occurred from a few discrete geographically separated vents, as suggested for the early eruption stages (Cooper et al. 2012 [Chapter 3]). It is therefore suggested that the extraction occurred in a catastrophic fashion accompanying caldera collapse (Druitt and Sparks 1984; Lipman 2000; Cole et al. 2005), with the possibility of multiple, ring fracture controlled vents.

\subsubsection{Prior to and during the Rocky Hill eruption}

The data presented here suggest that in the $\sim 20-40$ year time break between the Kidnappers and Rocky Hill eruptions (Chapter 5), two independent melt-dominant magma bodies were reestablished (Figure 4.25). Glass compositions within the RH-1 and RH-2 Rocky Hill pumice compositional groups (Figure 4.7) closely resemble KF- 
A/KI-1 and KF-B/KI-2 glasses, respectively, in the Kidnappers ignimbrite and fall material (Figure 4.4). The melt-dominant bodies tapped during the Rocky Hill are thus inferred to have been derived from the same source regions involved in generation of the KI-1 and KI-2 magmas in the Kidnappers. Crystal core-to-rim textural and compositional changes, and core-to-rim shifts in amphibole P-T model estimates, suggest that the RH-1 and RH-2 Rocky Hill pumice groups underwent magmatic processes in common to the KI-1 and KI-2 Kidnappers pumice groups, respectively. In respect of major element glass compositions (Figure 4.7), plagioclase and orthopyroxene rim compositions (Figure 4.16), and model temperature and pressure estimates (Figure 4.21), the Rocky Hill melt-dominant bodies are inferred to have been more homogeneous than those in the Kidnappers. This homogeneity may be a consequence of: (1) smaller volumes being tapped in the Rocky Hill; (2) a significant volume of new melt plus an inherited population of zircons (Chapter 2) being generated or extracted from the mush/source zone; (3) Post-Kidnappers caldera collapse and tectonic readjustment may have stirred any remaining magma (Marshall and Sparks, 1984; Folch et al. 2001; Kennedy et al. 2008). Further tectonic readjustments after the Kidnappers eruption may have also led to the incorporation of significant amounts of fluid and/or biotite influenced marginal material (crystal clots plus brown glass selvedges: section 4.5.1) into the reestablished melt-dominant bodies, just prior to, or possibly during the Rocky Hill eruption. The reestablished bodies were more crystal rich, which may in part be due to the draining of significant proportions of eruptible melt and a new influx of crystals from the inferred common mush zone. An increase in the proportion (30\%) of plagioclase with patchy or sieve textured cores, compared to $20 \%$ in the Kidnappers supports the inference that additional crystals were brought up from a deeper mush. The presence of larger amphiboles within the Rocky Hill pumices suggests further growth occurred of amphibole within the melt-dominant bodies, or that there was incorporation of larger grains from a surrounding crystal mush.

Evidence from orthopyroxene diffusion timescales across boundaries representing a common up temperature signal (Chapter 5), coupled with the field interpretations for a geologically short time break (Wilson 1986), suggest that this time break was 20-40 yrs. Such a short time gap between two such large eruptions has not previously been recognised in large silicic systems globally, and the cause(s) for the gap are not wholly 
clear. It is conceivable that longer-term tectonic readjustment after the eruption of the Kidnappers fall deposit may have itself been the trigger mechanism for the firstly systematic, and then repeated evacuation of magma through the Kidnappers and Rocky Hill eruptions (cf. Gravley et al. 2007). Allan et al. (2013) suggest that rifting and extensional processes in the mush bearing crust prior to the Oruanui eruption promoted melt channels, whereby melt (and crystals) could be extracted to establish meltdominant bodies over rapid timescales. A similar scenario is suggested in this system to explain the rapid renewal of melt-dominant bodies following the Kidnappers and prior to the Rocky Hill eruption. The evidence from Taupo, as well as from the older Mangakino volcanic centre suggest that parallel magma systems are able to operate in the crust within the conditions of the TVZ. Caldera collapse and subsidence is thought to have exerted a strong control on the eruption of the lower and upper Bandelier Tuffs (Self et al. 1986; Kennedy et al. 2012), but the time break between the renewal of activity, and replenishment within this system is $\sim 0.37$ Myr (Stix et al. 1988; Stix and Gorton, 1993). Similarly long timescales are seen in the Timber Mountain Caldera Complex between the Rainer Mesa (11.6 Ma) and Ammonia Tanks (11.4 Ma) caldera forming events, proposed to have been derived from a common parent (Broxton et al. 1989). The scenario at Mangakino for the $20-40$ year time break between the two large silicic eruptions has not been seen in any other examples. This is in part due to the limitations in the temporal resolution available from dating studies and the ambiguity of field studies in such cases. Kidnappers and Rocky Hill field evidence, extensive textural and geochemical characterisation of crystals, coupled with orthopyroxene Fe-Mg diffusion timescales (Chapter 5) has allowed this short time gap to be resolved. The renewal of magma and re-eruption processes acting on these short timescales has not generally been looked for in the geological record. Systems in which tectonics has a strong control, such as those in the TVZ, may have the potential to reveal similar processes to those recorded here in the Kidnappers/Rocky Hill system.

\subsection{Conclusions}

The Mangakino volcanic centre was a highly active system at $1 \mathrm{Ma}$, producing 1200 $\mathrm{km}^{3}$ of magma in the Kidnappers event followed by another $\sim 200 \mathrm{~km}^{3}$ during the Rocky Hill event, after a time break of only $\sim 20-40$ yrs. From the dataset presented in this chapter and elsewhere in this thesis, the following conclusions are drawn. 
(1) The general similarity of crystal compositions and textures, glass chemistry, isotopic signatures, and zircon age spectra (Chapter 2) between both eruptions provides unequivocal evidence that both eruptions came from a common system. The system represented a source of crystals (and melt) with broadly similar chemistries giving rise to the compositional similarity of the Kidnappers fall deposit and subsequent Kidnappers and Rocky Hill ignimbrites.

(2) Subtle variations in pumice mineralogy and whole-rock compositions, glass chemistry and crystal textures (plus diffusion timescales: Chapter 5) confirm that the Kidnappers and Rocky Hill are distinct events and not the products of one zoned eruption. The renewal of compositionally similar melt-dominant bodies between the Kidnappers and Rocky Hill events, and the short timescales involved (Chapter 5) highlights the rapidity of rejuvenation at Mangakino.

(3) The systematically zoned Kidnappers fall deposit provides evidence for the tapping of three discrete magma bodies whereas the Kidnappers ignimbrite is more compositionally diverse. The change from fall to flow marks a change in the scale and siting of caldera collapse and the simultaneous evacuation of discrete but compositionally diverse melts. Compositional heterogeneity within the Kidnappers and Rocky Hill ignimbrites is found both at the chamber-wide and pumice scale, and the full compositional spectrum can be found at any particular level within each ignimbrite. Therefore, the evacuation of a single stratified magma chamber cannot be applied to the Kidnappers/Rocky Hill system.

(4) The magmatic system involved multiple melt-dominant bodies, which were apparently drained during the Kidnappers event, and in a short timescale ( 20$40 \mathrm{yrs}$ ), the two largest bodies were reestablished from a common source region or mush prior to re-eruption during the Rocky Hill event.

(5) Lesser-evolved melts, such as high-Al basalts or derivative andesites, interacted with the system, which mobilised proportions of the final erupted melt through heating and volatile/chemical exchange. This interaction may have played a role in priming a proportion of magma within $\sim 50$ years of the Kidnappers eruption (Chapter 5).

(6) Caldera collapse episodes had significant control on the intensity and timing of eruptions at Mangakino. During eruption of the Kidnappers fall deposit, the systematic tapping of discrete magmas suggests caldera collapse remained 
separate and confined to each single melt-dominant body (Figure 4.25). The change in deposition during the Kidnappers eruption from fall material to the onset of pyroclastic flows marks a change in the scale and siting of caldera collapse. The rapid rejuvenation of more homogeneous melt-dominant bodies and the triggering of the Rocky Hill eruption, over a short timescale of 20-40 years, may also be attributed to stirring after caldera collapse and/or a strong extensional tectonic control at Mangakino. Regional rifting may have created localised melt channels through the crystal mush allowing extracted melt to ascend rapidly to reestablish or renew the melt-dominant bodies on such a short time scale (cf. Allan et al. 2013; Chapter 5).

This work on the Kidnappers and Rocky Hill adds to the growing evidence for complex, large silicic magma systems, which show a large compositional diversity. Multiple discrete batches of magma have been found to play a role in many large silicic eruptions, particularly within the TVZ (Briggs et al. 1993; Brown et al. 1998a; Gravley et al. 2007; Allan et al. 2012). The complexities of these systems can in several cases reflect a close relationship with the regional extension tectonics of the TVZ, which strongly controls the triggering and movement of magma before and during eruption. Here, it is suggested that tectonics played an important role in the evacuation of magmas from Mangakino during the Kidnappers and Rocky Hill eruptions. Independent melts were systematically tapped during the Kidnappers eruption, suggesting faulting may have sequentially triggered the evacuation of melt from each chamber (Cooper et al. 2012 [Chapter 3]). Further and wider scale caldera collapse was then coincidental with the evacuation of a larger variety of magmas from the system. Regional rifting, causing localised faulting and the opening of pathways for melt to ascend may then have aided the rapid renewal of melt-dominant bodies prior to the Rocky Hill. This study has found evidence that a large silicic system can rebuild and erupt a second large volume ignimbrite in a geologically short timescale after a supervolcanic eruption. 
Chapter 5 


\section{Assembly and rejuvenation of a large silicic magmatic system: insights from mineral diffusive profiles in the Kidnappers and Rocky Hill eruption deposits}

\subsection{Introduction}

Establishing the timescales of magmatic processes in the lead up to a large eruption provides important insights into the dynamics of large-scale magmatic systems. However, establishing timescales can be difficult, especially in deposits such as the Kidnappers and Rocky Hill where limited preservation and exposure precludes detailed field-based volcanological studies (Chapter 4). One method of determining timescales is from elemental diffusion modelling across sharp chemical boundaries or zones within crystals (Martin et al. 2008; Kahl et al. 2011; Saunders et al. 2012; Allan et al. 2013). Modelled timescales represent the time elapsed at magmatic temperatures following periods of renewed growth and formation of crystal zonation within individual grains. Crystals have the potential to record a history of magmatic processes throughout their growth (Morgan et al. 2004; Kahl et al. 2011). Crystal zonation can arise from perturbations in magmatic variables such as melt composition, temperature, pressure, or oxidation state. Such variations may themselves arise from larger-scale magmatic processes including magma mixing and/or recharge, or the ascent and decompression of significant volumes of magma.

The texture and chemical composition of discrete crystal zones can be used to discriminate between different magmatic processes responsible for the zonation (Kahl et al., 2011; Saunders et al. 2012; Allan et al., 2013). This is an essential step when deciphering how particular magmatic processes are reflected in the crystal record and how significant these processes may be. Crystals may have either grown within the final melt-dominant body (phenocrysts), or be incorporated from the longer lived parental magmatic system (antecrysts), or be inherited from older unrelated sources (xenocrysts) (Charlier et al. 2005; Hildreth and Wilson 2007, Streck 2008). Each crystal interior may have a diverse and complex growth history, but zoning features that are common 
(typically the crystal rims [Allan et al. 2013]) to a substantial proportion of all crystals may be present. Therefore, a distinction between localised and system-wide crystal histories can be made. Within Chapter 4, crystals from the Kidnappers and Rocky Hill eruption deposits were classified based on texture and chemistry to establish the overarching features of grains, interpreted to relate to chamber-wide processes. The textural and crystal chemical record from major phases (plagioclase, amphibole, orthopyroxene), coupled with thermobarometric model constraints suggest that both eruptions were sourced from a common overall magmatic system, and were subject to common processes as the multiple melt-dominant bodies were assembled prior to each eruption (Chapter 4).

Insights into the longevity, assimilation and crystallistion history of the magmatic system can be gained through radiometric dating of accessory mineral phases such as zircon or allanite (see review in Chapter 2). Zircons invariably record long timescales, due to their refractory nature and low elemental diffusivities (Cherniak and Watson 2003) and can readily be recycled in systems and subjected to varying magmatic conditions. These protracted timescales may have little or no relevance to the processes that govern the physical assembly and development of the melt-dominant magma body that ultimately erupts. In contrast, key overarching zonation boundaries within the crystal cargo may reflect chamber-wide processes such as the physical establishment of melt-dominant bodies, decompression from a crystal mush or mafic recharge/rejuvenation, which may ultimately lead to eruption (Streck 2008). Provided there is information about the diffusion rates of the element(s) of interest in the mineral species present, common and overarching boundaries may be targeted for diffusion modelling (Costa et al. 2003; Martin et al., 2008; Matthews et al. 2012b; Ruprecht and Cooper 2012; Allan et al. 2013). The estimated diffusion timescales of the processes that may ultimately lead to an eruption are invariably more rapid (centuries or less) than those recording the growth and crystallisation history of the magmatic system. Thus, the timescales of large-scale magmatic processes and the methods by which to resolve them are disparate.

The field relationships and appearance of the Kidnappers and Rocky Hill deposits suggest that the two large-scale silicic eruptions were distinct events, with a short time 
break of weathering and erosion in between (Wilson 1986; Chapter 4). The Kidnappers fall deposit and ignimbrite and the Rocky Hill ignimbrite have identical ${ }^{40} \mathrm{Ar} /{ }^{39} \mathrm{Ar}$ ages within uncertainty at 1.0 Ma. U-Pb zircon age spectra from both eruptions are also indistinguishable, suggesting growth and crystallisation within a common magmatic system (Chapter 2). The time break between the two eruptions is therefore not currently resolvable by radiometric methods and may be closer to the estimated timescales made available by diffusion methods.

In this chapter, Fe-Mg interdiffusion across key zones in orthopyroxene crystals is applied from both the Kidnappers and Rocky Hill in order to determine the timescales of magmatic processes operating within a large silicic magmatic system, which gave rise to two very large silicic eruptions within spatial and temporal proximity. In this case, it is particularly relevant to identify common zones that record the same processes in both eruptions, with the aim of assessing the differences in model timescales in the lead up to eruption. Orthopyroxene is the ideal choice within this system, as simple and common zoning patterns are present, which are comparable with the histories recorded in the other major phases (Chapter 4). Here, the diffusive timescales for the establishment of the final erupted melt-dominant bodies and the rejuvenation of the Kidnappers and Rocky Hill system through mafic interaction are estimated. In addition, diffusion timescales are used to estimate the time break between these two large-scale silicic eruptions. If a particular zone in orthopyroxenes from both eruptions represents a common process, then the timing of this process may be estimated by modelling the extent of Fe-Mg interdiffusion across the chemical boundary in question. Any difference in the estimated timescales from common zones within the Kidnappers and Rocky Hill crystals thus supplies an estimate of the time break between successive eruptions from the same system.

\subsection{Methods}

Methods for the separation and mounting of crystals for EPMA analysis, and analytical operating conditions are outlined in Chapter 4 and Appendix 1. The procedures specific to diffusion modelling within this study are discussed below. 


\subsubsection{Orthopyroxene Fe-Mg interdiffusion}

High resolution backscattered electron (BSE) images of each orthopyroxene crystal were taken to investigate crystal zonation features and mark the location of individual analyses. The oldest (cores) and the youngest (rims) portion of each crystal were targeted for analysis by EPMA. If crystals contained any prominent zonation between cores and outermost rims, then these zones, referred to here as intermediate domains, were also analysed to ensure complete coverage of the compositional range within each crystal. A strong negative linear relationship $\left(\mathrm{R}^{2}=0.95\right)$ is observed between BSE greyscale values and the $\mathrm{Mg} /(\mathrm{Mg}+\mathrm{Fe})$ content of orthopyroxene, and therefore the zoning observed in BSE images is inferred to be an accurate reflection of the $\mathrm{Fe}-\mathrm{Mg}$ content (Figure 5.1).

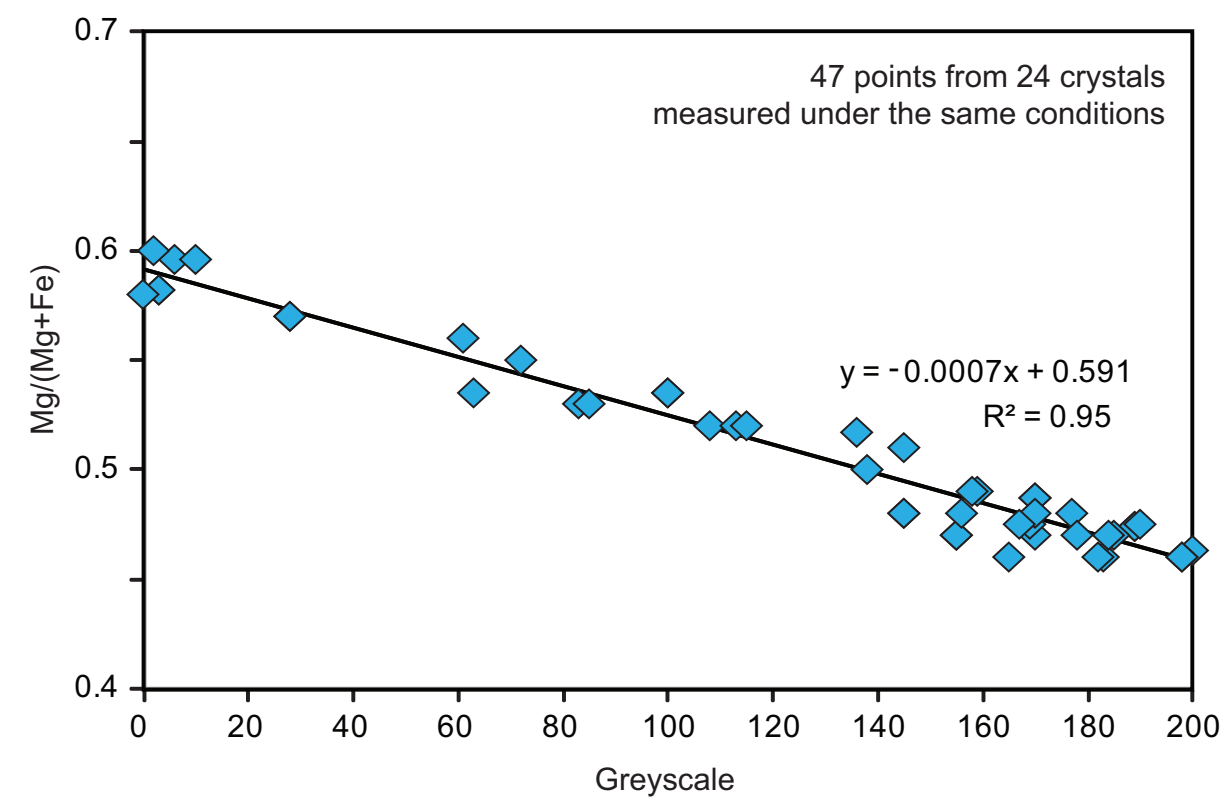

Figure 5.1. Plot to show the strong correlation between greyscale and the $\mathrm{Mg}$ and $\mathrm{Fe}$ content of orthopyroxenes. The correlation was measured over 24 crystals, imaged under identical settings and analysed within a single analytical session on a JEOL JXA8230 electron microprobe at Victoria University of Wellington.

This relationship allows the gradients in $\mathrm{Fe}$ and $\mathrm{Mg}$ concentrations to be investigated at a much higher spatial resolution than is possible from spot analyses alone (Morgan et al. 2004; Martin et al. 2008; Saunders et al. 2012; Allan et al. 2013). It is assumed that the boundaries chosen for modelling initially had step-wise concentration gradients, which over time at magmatic temperatures were modified by Fe-Mg interdiffusion, and that 
diffusion ceased upon quenching on eruption, resulting in sigmoidal concentration gradients. Image J (http://rsb.info.nih.gov/ij/), a free Java based image processing programme was used to extract spatially resolved profiles of backscattered electron intensity across crystal zonation boundaries. The linear relationship between the Fe- $\mathrm{Mg}$ content of the orthopyroxenes and intensity of backscattering (greyscale value: Figure $5.1)$ is used to quantify $\mathrm{Mg} /(\mathrm{Mg}+\mathrm{Fe})$ profiles from BSE images.

In this study I have adopted the method used by Allan et al. (2013) to calculate the orthopyroxene Fe-Mg diffusion coefficient. This method is based on the parameterisation of Ganguly and Tazzoli (1994) which Allan et al. (2013) modified to incorporate an oxygen fugacity dependence such that:

$$
D_{F e-M g}=\left(-5.54+2.6 \mathrm{X}_{F e}-\frac{12530}{T}\right) \times\left(\frac{\mathrm{fO}_{2}(\text { sample }, T)}{\mathrm{fO}_{2}(\mathrm{IW} \text { buffer }, T)}\right)^{\frac{1}{6}}
$$

where $\mathrm{X}_{\mathrm{Fe}}$ is the compositional parameter $\mathrm{Fe} /(\mathrm{Fe}+\mathrm{Mg})$ of the orthopyroxene, $\mathrm{T}$ is the temperature in Kelvins and $f \mathrm{O}_{2}$ is oxygen fugacity, calculated at magmatic temperature for the sample or the Iron-Wustite (IW) buffer, as appropriate. The Fe-Mg content was measured for each orthopyroxene grain by EPMA and then extrapolated across the diffused boundary using greyscale values in the ImageJ software. BSE images were rotated so that greyscale profiles across areas perpendicular to zone boundaries could be measured. Finite-difference software was used to generate a database of simulated diffusion profiles, which obey composition-dependent diffusion under a 1-D (linear) diffusion geometry; these were then adapted to the samples via application of scaling laws using Excel (DJ Morgan, in prep.).

\subsubsection{Parameters and uncertainties}

It is essential to consider the sources and magnitude of uncertainties of diffusion modelled ages (Chakraborty, 2008; Costa and Morgan, 2010). The calculations for $D_{\mathrm{Fe}-}$ $\mathrm{Mg}$ are very insensitive to pressure, but highly sensitive to temperature and oxygen fugacity (see Allan et al. 2013, their Fig. 8). Here we adopt different temperature and 
$f \mathrm{O}_{2}$ values for each compositional group within the Kidnappers and Rocky Hill based on a range of unique characteristics discussed in Chapter 4 . The best estimate for the final magmatic temperature of each of the compositional groups is shown in Table 5.1, which are based on estimates from co-crystallising amphibole rims using the Ridolfi et al. (2010) formulation. A significant number of crystals have up-temperature signals within the low- $\mathrm{SiO}_{2} \mathrm{Kidnappers} \mathrm{group} \mathrm{(KI-3)} \mathrm{and} \mathrm{therefore} \mathrm{the} \mathrm{temperature} \mathrm{adopted} \mathrm{for}$ this group is somewhat higher than other groups (Table 5.1). In the other compositional groups where down-temperature signals dominate, rim temperatures are likely to be lower than the temperature at which the orthopyroxene core-rim boundary initially formed. Therefore, the modelled timescales using lower-bound temperatures produce maximum age estimates. Oxygen fugacity estimates used in modelling were determined using the Fe-Ti oxide equilibrium model of Ghiorso and Evans (2008). Estimates of $f \mathrm{O}_{2}$ yielded by this model are generally more reducing than other available models such as those presented by Sauerzapf et al. (2008) and Ridolfi et al. (2010). However, adoption of these lower bound $f \mathrm{O}_{2}$ values results in smaller estimates of $D_{\mathrm{Fe}-\mathrm{Mg}}$ and hence longer (maximum) estimated timescales (Allan et al. 2013). For uncertainty calculations on single model-age determinations, temperature uncertainties of $\pm 30^{\circ} \mathrm{C}$ and $\pm 0.3 \log$ units for oxygen fugacity were used.

Table 5.1. Summary of temperatures and oxygen fugacities used to calculate orthopyroxene diffusive timescales from each compositional group.

\begin{tabular}{|c|c|c|}
\hline Group & Temperature & $\mathrm{fO}_{2}(\Delta \mathrm{NNO})$ \\
\hline \multicolumn{3}{|l|}{ Kidnappers } \\
\hline $\mathrm{KI}-3\left(\mathrm{low}-\mathrm{SiO}_{2}\right)$ & $820^{\circ} \mathrm{C}$ & 0.1 \\
\hline $\mathrm{KI}-1\left(\mathrm{mid}-\mathrm{SiO}_{2}\right)$ & $785^{\circ} \mathrm{C}$ & 0.0 \\
\hline $\mathrm{KI}-2$ (high-SiO $\left.{ }_{2}\right)$ & $780^{\circ} \mathrm{C}$ & 0.2 \\
\hline \multicolumn{3}{|l|}{ Rocky Hill } \\
\hline $\mathrm{RH}-1$ (normal) & $795^{\circ} \mathrm{C}$ & 0.1 \\
\hline $\mathrm{RH}-2$ (high-SiO ${ }_{2}$ ) & $765^{\circ} \mathrm{C}$ & 0.0 \\
\hline
\end{tabular}

The uncertainties associated with profile shapes (i.e. the compositional integrity of the 
BSE images) and the profile lengths (based upon the absolute reliability of the magnification provided by microprobe imaging) were also taken into account, and a value of $\pm 3 \%$ adopted, following Allan et al. (2013). The validity of crystal zonation boundaries that display sigmoidal profiles over short length scales $(<\sim 5 \mu \mathrm{m})$, implying very short timescales of $\leq 3$ years at the conditions relevant to this study (Table 5.1), need to be considered with caution. Such boundaries may reflect a tangible record of very short-lived processes in the magma, but may potentially also be an artifact of pixel size and effects of convolution in the BSE imaging.
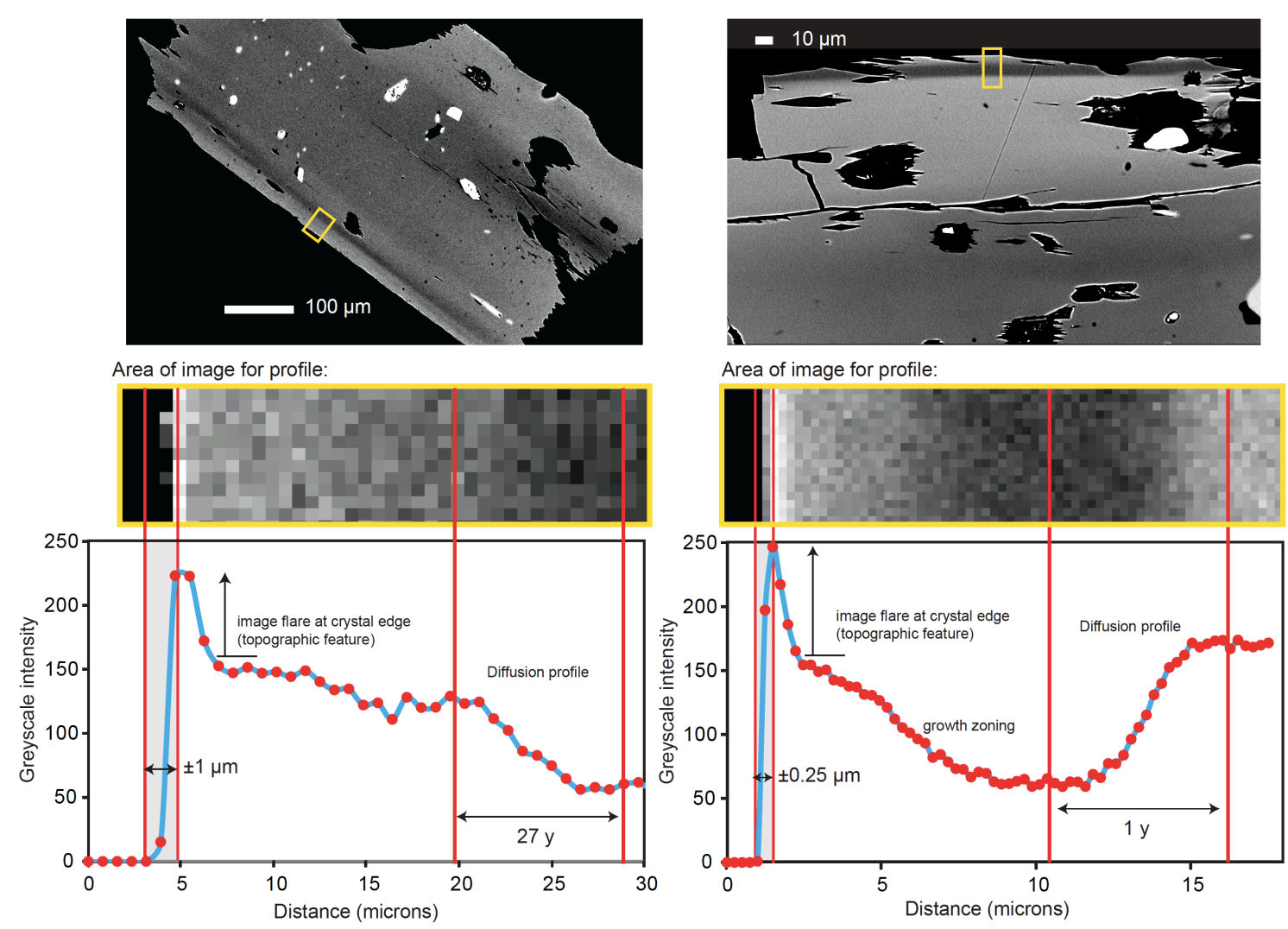

Figure 5.2. Images and BSE profiles to assess the effect of uncertainties due to image resolution and associated convolution. (a) Image at x120 magnification and imaged at faster scan speeds (Fine 1) which imparts a larger pixel size on the area of the profile. (b) Image at x370 magnification and slower scan speeds (Fine 2) resulting in smaller pixels. The effect of smearing across a sharp stepwise boundary is shown.

Convolution can be particularly problematic where image pixel size is very small $(\sim 0.25$ $\mu \mathrm{m})$ compared to the spatial resolution and excitation volume of the electron beam $(\sim 1$ $\mu \mathrm{m})$, potentially smearing out a sharp stepwise boundary and in essence generating an artificial diffusion profile (Morgan et al. 2004). To test for this effect, the resolution limit is estimated by taking a BSE profile across sharp features (in this case the edge of 
the crystals and into the glass selvedge) at different image magnification and resolution (Figure 5.2). The lower magnification (x120) and resolution image shows a $\pm 1 \mu \mathrm{m}$ smearing over the edge of the boundary (assumed to be stepwise), and at higher magnification (x370) and resolution this effect is reduced to $\pm 0.25 \mu \mathrm{m}$ (Figure 5.2). These lengths are $\sim 12 \%$ and $\sim 5 \%$, respectively, of the diffusion profile length. These effects are much less significant than the uncertainties associated with temperature and oxygen fugacity estimates. However, to account for possible convolution effects, the youngest ages ( $0-3$ years) are described uniformly here as 'less than 3 years'.

\subsection{Results}

\subsubsection{Textural characteristics of Kidnappers and Rocky Hill orthopyroxenes}

The zoning within individual orthopyroxene crystals is complex. There are, however, some key overarching textural features that allow crystals to be classified into distinct populations (see Chapter 4 and Table 5.2). Four main orthopyroxene crystal populations (referred to here as normal, unzoned, reverse and patchy) are present within the Kidnappers and Rocky Hill based on simplified textural characteristics observed in BSE images (see Figure 4.13 for proportions). In addition, these populations can have a dark outer zone (within $100 \mu \mathrm{m}$ of the outermost rim, or as the outermost rim) that may overprint any of the above textures. Within this chapter, boundaries from both normal and reverse grains are utilised for modelling. Normal grains exhibit a general normal zoning pattern, with dark cores (higher $\mathrm{Mg \# )}$ ) and lighter rims (lower $\mathrm{Mg \# ),} \mathrm{whereas}$ reverse grains have darker zones towards the outside of the crystal. Also, any grain with an overprinted dark outer zone is of particular interest for modelling timescales, as they are found in both eruptions, and likely represent a late-stage heating possibly related to the involvement of more mafic magma (Chapter 4).

The textural classification of orthopyroxene grains provides a context from which inferred timescales can be linked. There are however textural features that disturb the main zoning features described above and may inhibit the modelling of timescales across certain boundaries. A careful assessment of the zoning features and selection of individual orthopyroxene grains is therefore needed before attempting to model meaningful timescales. To assess both the primary zonation and diffusion affected 
Table 5.2. Summary of orthopyroxene textural populations within each of the compositional groups from the Kidnappers and Rocky Hill (see Chapter 4 for representative images of crystal populations).

\begin{tabular}{|c|c|c|c|c|c|}
\hline Group & Normal & Reverse & Unzoned & Patchy & Dark outer \\
\hline \multicolumn{6}{|l|}{ Kidnappers } \\
\hline $\mathrm{KI}-3\left(\mathrm{low}-\mathrm{SiO}_{2}\right)$ & $34.0 \%$ & $7.6 \%$ & $51.4 \%$ & $6.9 \%$ & $41.0 \%$ \\
\hline $\mathrm{KI}-1\left(\right.$ mid-SiO$\left.{ }_{2}\right)$ & $53.1 \%$ & $3.1 \%$ & $42.2 \%$ & $1.6 \%$ & $5.5 \%$ \\
\hline $\mathrm{KI}-2\left(\right.$ high-SiO$\left.{ }_{2}\right)$ & $76.2 \%$ & $1.2 \%$ & $15.2 \%$ & $7.3 \%$ & $2.4 \%$ \\
\hline \multicolumn{6}{|l|}{ Rocky Hill } \\
\hline RH-1 (normal) & $54.7 \%$ & $6.6 \%$ & $38.1 \%$ & $0.6 \%$ & $13.2 \%$ \\
\hline $\mathrm{RH}-2\left(\right.$ high $\left.\mathrm{SiO}_{2}\right)$ & $94.3 \%$ & $1.1 \%$ & $4.6 \%$ & $0.0 \%$ & $1.1 \%$ \\
\hline
\end{tabular}

zonation, elemental mapping of selected crystals using EPMA was carried out (Figures 5.3 and 5.4). Al has a very slow diffusion rate (Sautter et al. 1988), Ca is slow, and Fe and $\mathrm{Mg}$ have relatively fast diffusion rates, allowing the influence of elements with contrasting diffusion rates to be assessed. $\mathrm{Al}$ can be considered immobile over timescales of $<10,000$ years at the magmatic temperatures applicable to the Kidnappers/Rocky Hill system (Smith and Barron 1991). Thus, Al potentially records the original growth zonation of the orthopyroxene. Blurring in Al content across boundaries parallel to the c-axis is evident, which cannot be attributed to diffusion (Figure 5.3). Therefore, growth must have a strong control parallel to the c-axis compared to the sharper boundary along the a-axis, which has negligible kinetic growth effects. Grains commonly contain multiple inclusions of magnetite, ilmenite, apatite and melt. Fe-rich, streaky and discontinuous zonation commonly extends outward from the inclusions for several tens of microns parallel to the crystallographic $c$-axis (Figures 5.3 and 5.4), but over much shorter lengths parallel to the $a$ - and $b$-axes. These streaky zones are often, but not always, visibly associated with inclusions and may represent the result of diffusion from an inclusion above or beneath the plane of the polished surface. Similar textures have been observed in orthopyroxenes from the Oruanui eruption deposits (Allan et al. 2013) and deposits from historic eruptions of Usu volcano, Japan (Tomiya and Takahashi 2005). Tomiya and Takahashi (2005) inferred that the streaks are a result of anisotropic diffusion and that the $c$-axis diffused faster than $a$ - or $b$ - axes, whereas Allan et al. (2013) demonstrated that the $c$-axis was dominated by growth 

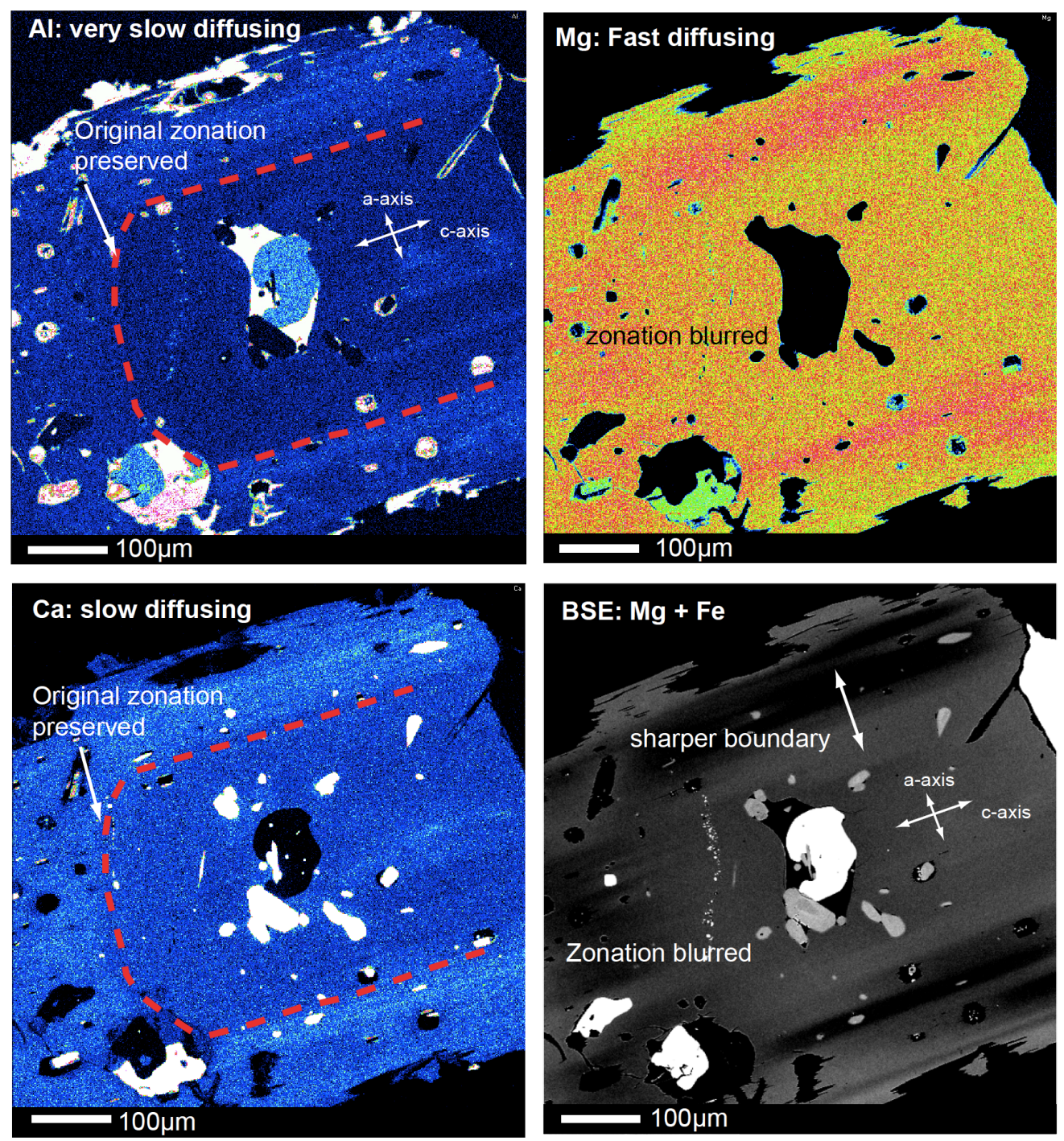

Figure 5.3. Element maps of a representative orthopyroxene crystal from the Rocky Hill (pumice P2049; group RH-1) with a dark exterior zone. Elements with very slow (Al) and slow $(\mathrm{Ca})$ diffusion rates preserve the original zonation to a greater extent than faster diffusing $\mathrm{Mg}$. The map of $\mathrm{Mg}$ content and BSE image show increased blurring of the dark zone, parallel to the $c$-axis, compared to across the $a$-axis, inferred to reflect a component of growth zonation along the $c$-axis.

effects, plus a component of diffusion. $\mathrm{Ca}$, with slow diffusion rates highlights the affect of dissolution, formation of melt inclusions, and recrystallisation (Figure 5.4). Ca-poor haloes around melt inclusions within the orthopyroxene core of the example in Figure 5.4 represent secondary zonation caused by dissolution and formation of Ca-rich melt inclusions, before crystallisation resumed. A number of cores, which are riddled with melt inclusions thus record a departure from equilibrium for a period of time and dissolution of the crystal before growth was resumed. 

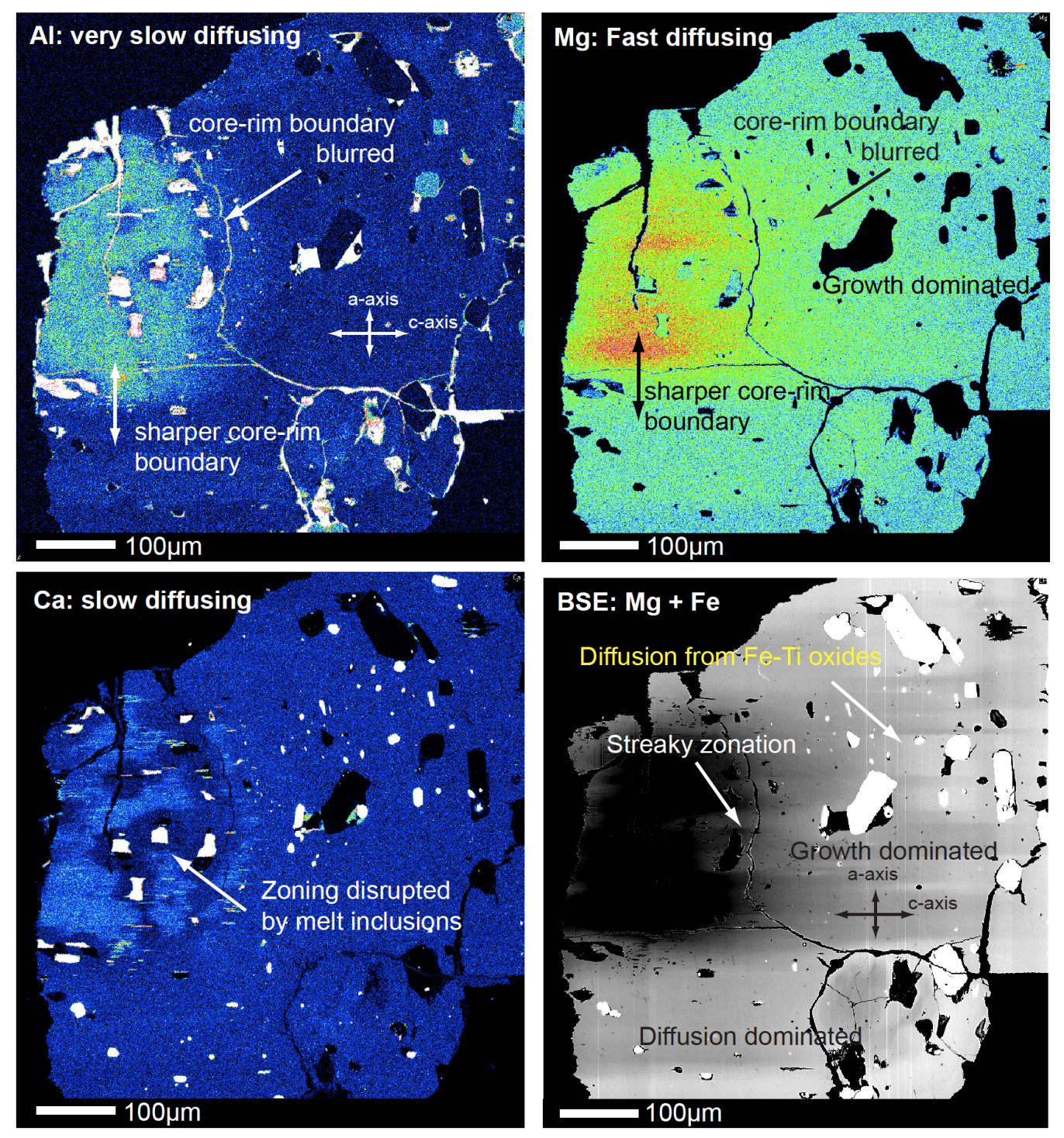

Figure 5.4. Element maps of a representative normally zoned orthopyroxene crystal with a dark core from the Rocky Hill (pumice P2046; group RH-2). The Al map shows blurring of the core-rim boundary parallel to the $c$-axis compared to along the $a$-axis, suggesting a strong growth control parallel to the $c$-axis. Slowly diffusing $\mathrm{Ca}$ shows dissolution of the core, and formation of melt inclusions during recrystallisation.

\subsubsection{Fe-Mg diffusion timescales in Kidnappers and Rocky Hill orthopyroxenes}

Within Kidnappers orthopyroxenes, timescales were modelled across the boundaries both between cores and rims, and between intermediate domains and dark outer zones (the latter common in low-SiO 2 (KI-3) Kidnappers samples). The corresponding boundaries were also modelled within Rocky Hill orthopyroxenes. Commonly, however, in the Rocky Hill grains the dark outer zones are overgrown by an additional light outer rim, and therefore the intervening boundary was also modelled in these cases 
(Figure 5.5). Core-rim boundaries cover a spectrum from those with very dark cores found in the interior of the crystal, to broader cores where the boundary is found towards the exterior of the crystal (Figure 5.5). All modelled diffusion ages across the full range of core-rim boundaries were grouped together, as definite textural distinctions are difficult to establish. Due to the kinetic/growth influence in orthopyroxene parallel to the $c$-axis (Figure 5.3 and 5.4), all modelled boundaries were parallel to the $a$ - or $b$ axes, which display concentration gradients that are consistent with diffusive modification. Selected examples of diffusion profiles modelled across the types of boundaries described above are shown in Figure 5.5 and all the modelled Fe-Mg profiles with corresponding BSE images are summarised in Appendix 3. All diffusion ages in this study (presented in Electronic Appendix 10) are calculated using lowerbound temperature and oxygen fugacity estimates to yield maximum ages. The core-rim age data generally forms straight lines on plots of rank order versus log age (Figure 5.6), suggesting that older ages are exponentially less likely. This may be the result of an exponential acceleration in the recorded process towards eruption (cf. Allan et al. 2013). However, these trends may also be the result of older boundaries being overwritten or due to the magma volume increasing through time, which would systematically dilute grains recording older processes. Alternatively an unknown exponential process may govern the data.

All dark exterior zones from Kidnappers orthopyroxenes were modelled from within the low-SiO 2 (KI-3) pumice group (Chapter 4). Modelled diffusion timescales from dark exterior zones within the Kidnappers exponentially increase from $\sim 50$ years and display several minor age peaks. Peaks in the Probability Density Function (PDF) curve are at less than $\sim 3$ and $\sim 1$ year prior to eruption (Figure 5.6). Three modelled profiles that returned ages of less than one year were excluded in the PDF curve calculation for clarity. Notably fewer orthopyroxene grains with dark exterior zones are found within the Rocky Hill (Table 5.2). The grains displaying this texture in the Rocky Hill are assumed to be inherited from a melt-dominant body tapped during the Kidnappers eruption (Chapter 4). 
Dark exterior zones
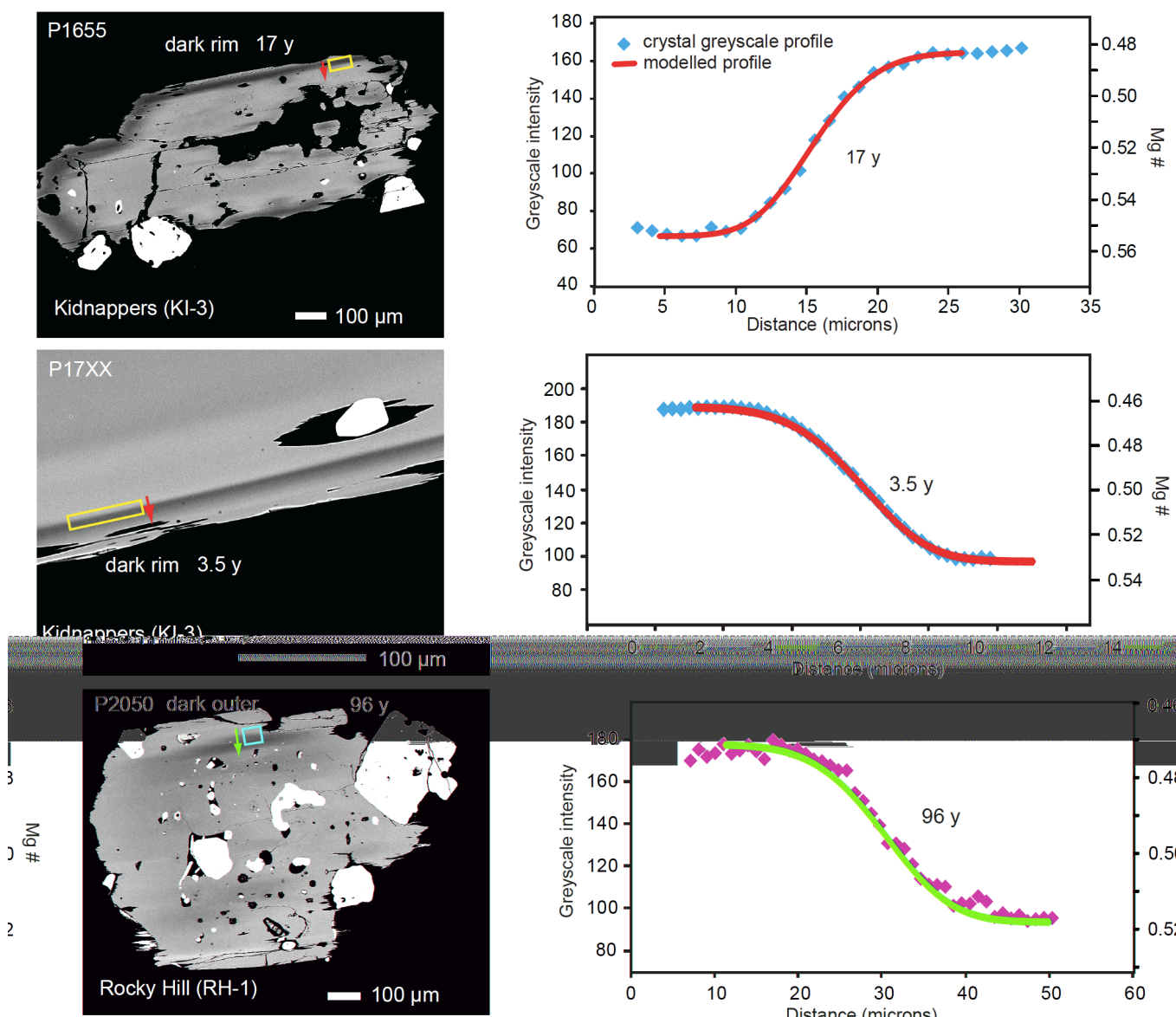

Core-rim boundary
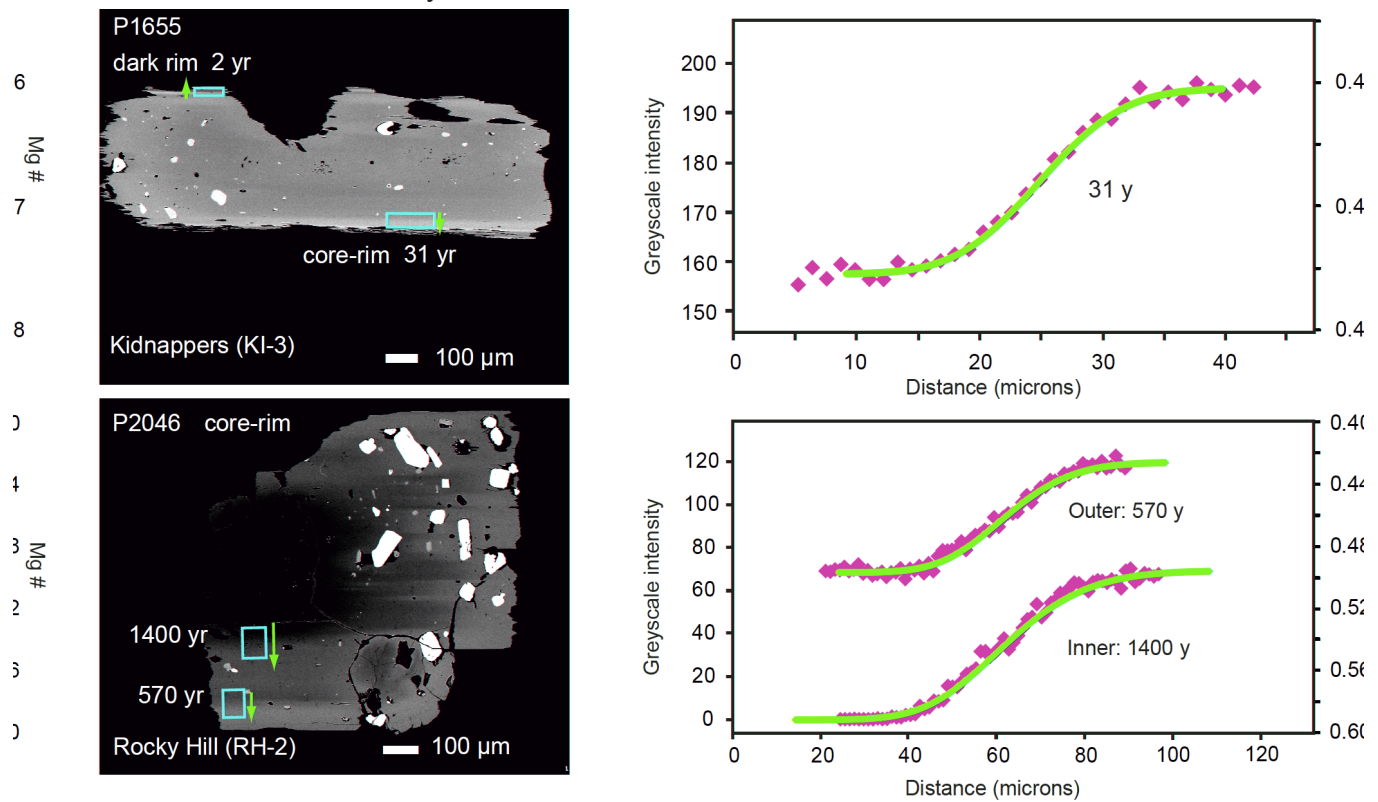

Figure 5.5. Selected examples of orthopyroxene BSE images from pumices within the Kidnappers (group KI-3) and Rocky Hill (groups RH-1 and RH-2) with corresponding modelled Fe-Mg diffusion profiles taken across boundaries (highlighted areas). Profiles of greyscale intensity are taken from rotated BSE images, and are converted to $\mathrm{Mg} \#$. The red line shows each modelled profile of an initially sharp compositional boundary over the time presented for each profile, using the parameters in Table 5.1. 

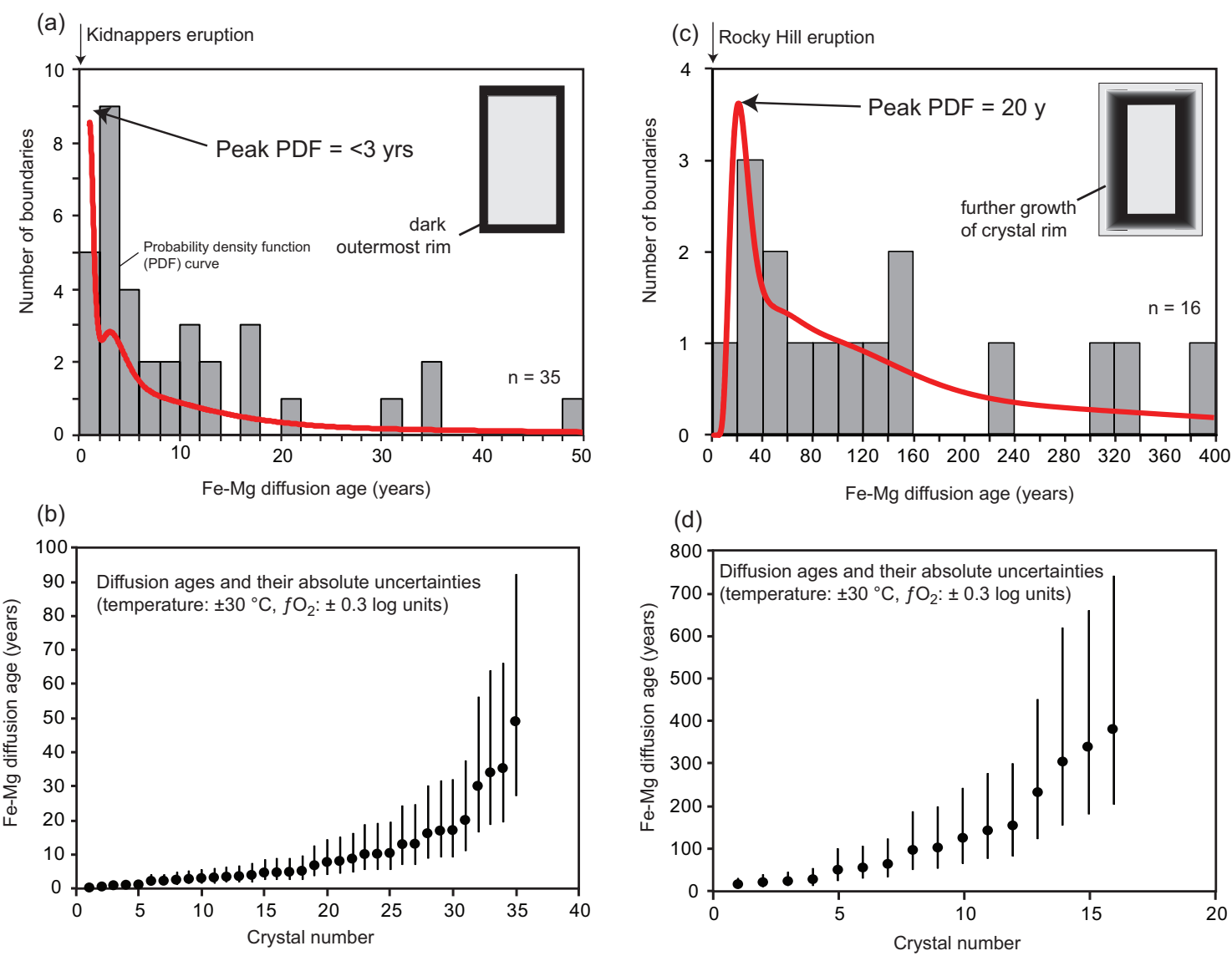

Figure 5.6. Histograms showing the range and frequency of maximum $\mathrm{Fe}-\mathrm{Mg}$ interdiffusion ages determined for dark exterior zones in the Kidnappers (panel a) and Rocky Hill (panel c) (see Figure 5.3 for examples). Three modelled ages of $<1$ year were excluded in calculation of the PDF curve in panel (a) for clarity. Individual ages and their absolute uncertainties are plotted for the Kidnappers (panel b) and Rocky Hill (panel d). Schematic crystals within each plot represent the modelled boundaries from each eruption. Commonly, the dark zone in the Kidnappers, representing a rejuvenation event, is at the outermost rim. Within the Rocky Hill, further growth of the remnant crystals causes the dark zone to be inward of the rim and more diffuse.

Timescales from dark exterior zones within the Rocky Hill date back considerably further than those from the Kidnappers. Modelled ages are between 380 and 16 years and the PDF curve has a peak at $\sim 20$ years before eruption (Figure 5.6). Thus, the peak PDF age difference between the Kidnappers ( $<3$ years) and Rocky Hill ( $\sim 20$ years) is $\sim$ 20 years by this methodology. 

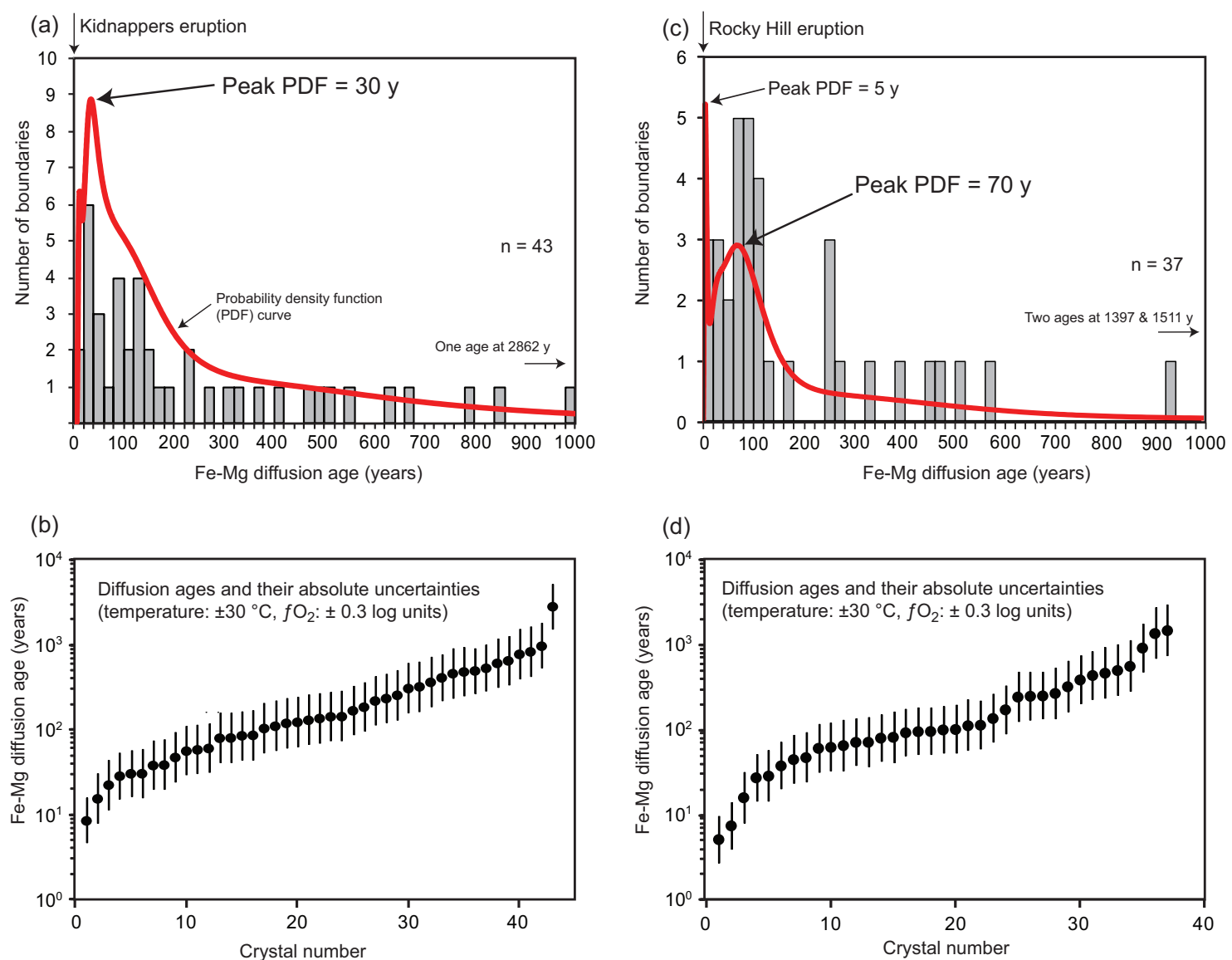

Figure 5.7. Histograms showing the range and frequency of maximum $\mathrm{Fe}-\mathrm{Mg}$ interdiffusion ages determined from the main core-rim boundaries from the Kidnappers (a) and Rocky Hill (c) (see Figure 5.3 for examples). The PDF curve represents a population probability of all age determinations with associated uncertainties $\left( \pm 30^{\circ} \mathrm{C}\right.$ and $\pm 0.3 \log$ units of oxygen fugacity). Individual ages and their absolute uncertainties are plotted for the Kidnappers (b) and Rocky Hill (d).

Modelled diffusion timescales from core-rim boundaries within the Kidnappers deposits show an exponential increase from $\sim 1000$ yrs, to a peak at $\sim 30$ years before eruption (Figure 5.7). The histogram shows several peaks within the range of data between 100150 years and at $\sim 30$ years prior to eruption. Modelled ages from analogous core-rim boundaries within the Rocky Hill also show an exponential increase from $\sim 600$ years, to a peak in the probability density function (PDF) curve at $\sim 70$ years before eruption (Figure 5.7). An additional second peak within $\sim 5$ years of eruption is also present within Rocky Hill grains. Thus, the difference in peak PDF age between the Kidnappers ( $\sim 30$ years) and the Rocky Hill ( $\sim 70$ years) is 40 years, providing another estimate for the time break between the eruptions. Only three modelled boundaries across very dark cores from both eruptions return significantly older ages ( $>1000$ years) prior to 
eruption. Granularity within the distribution of estimated timescales is seen in all datasets (Figures 5.6 and 5.7), however further inferences to relate these minor peaks to particular processes is not possible without significantly expanding the number of modelled ages.

\subsection{Discussion}

\subsubsection{Implications of diffusion timescales from dark exterior zones}

Dark exterior zones in orthopyroxene grains from the low-SiO $\mathrm{Kidnappers}_{2} \mathrm{KI}-3$ ) pumice group represent mixing with, or rejuvenation from interaction with a lesser evolved and/or hotter melt (Chapter 4). The presence of a higher proportion of amphibole and plagioclase crystals with up-temperature rims within this group are consistent with the orthopyroxene textural signal. Amphibole rims within this group commonly have higher $\mathrm{Al}$ concentrations and plagioclase rims have a higher An content (Chapter 4). Matrix glass from KI-3 pumice also has significantly higher Al concentrations than within the other two Kidnappers compositional groups, suggesting interaction with a hotter, Al-richer (and hence inferred less evolved) melt (Figure 5.8). Therefore, modelled timescales across the interior domain to dark exterior zone boundary reflect the time before eruption when interaction with this less evolved melt occurred. This interaction caused the rejuvenation of a volume of crystals and melt, and began only $\sim 50$ yrs before eruption (Figure 5.8). Over the following 50 years, the influence of the lesser evolved melt exponentially increased within the KI-3 melt volume up to a few years before eruption (PDF peak at $\sim 3$ years; Figure 5.6). The interaction recorded in Kidnappers grains occurred very shortly before eruption, and may therefore be considered as a potential eruption triggering mechanism. However the proportion of material with signatures of interaction with the less-evolved melt is relatively small ( $\sim 3 \%$ of total erupted Kidnappers material). The magmatic rejuvenation is therefore unlikely to have had a system wide influence. It is inferred that mafic interaction, possibly through underplating, essentially primed a volume of material for eruption through thermal rejuvenation and volatile exchange, rather than being the eruption trigger itself. 


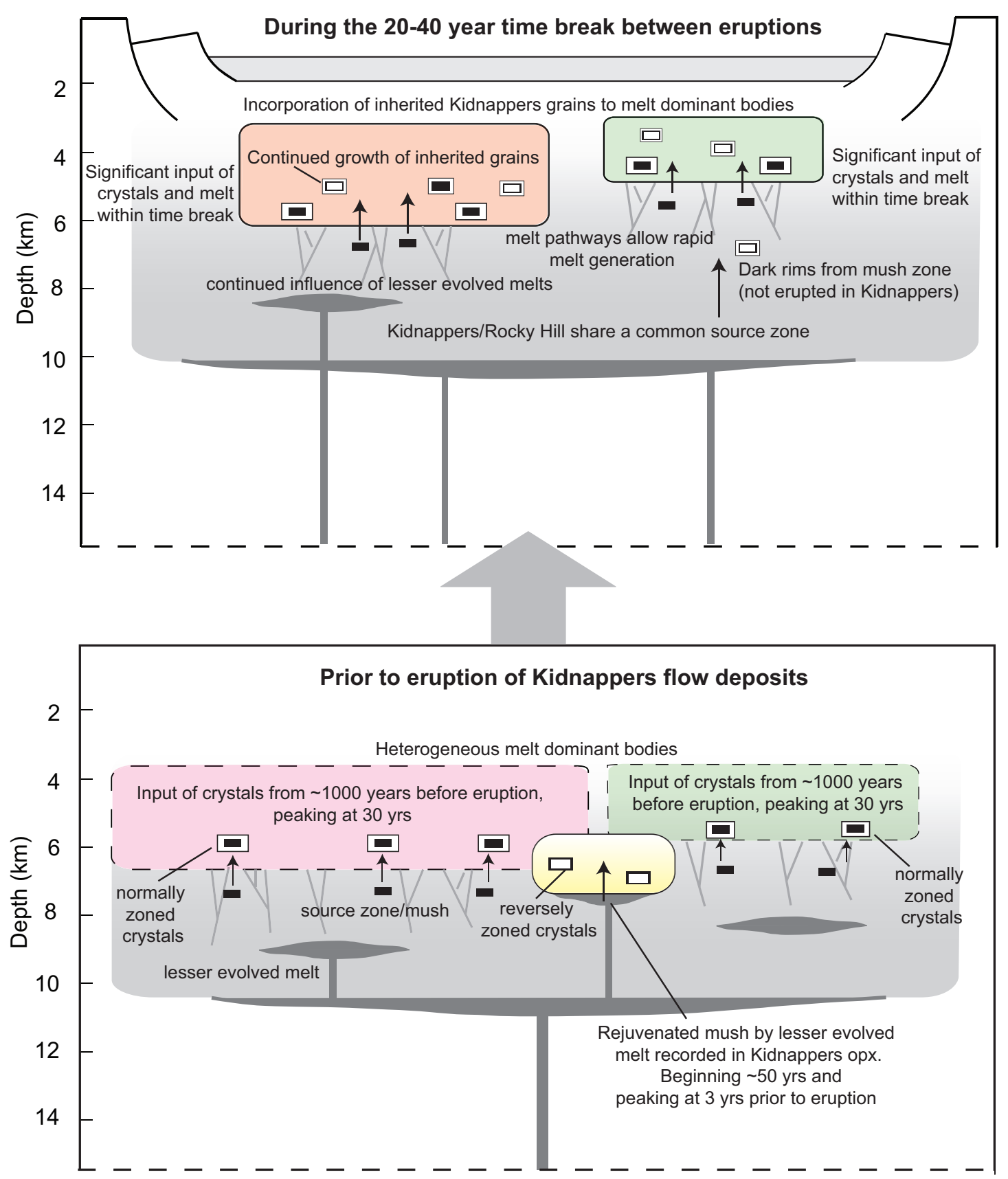

Figure 5.8. Cartoon cross section of the Kidnappers/Rocky Hill magma system at two stages: (1) prior to eruption of the Kidnappers and (2) during the short time break between eruptions. The magmatic processes inferred from crystal textures and chemistry (discussed in the text), over the timescales modelled from Fe-Mg interdiffusion in orthopyroxene are shown. Diagram is adapted from Figure 4.23 in Chapter 4 to include established timing constraints.

Geochemical and petrological evidence from Kidnappers and Rocky Hill deposits suggest that both eruptions were derived from a common overall magmatic system (Chapter 4). Consequently, orthopyroxene grains with a dark exterior zone in the Rocky 
Hill can be inferred to record the same processes as seen within the Kidnappers crystals. The corresponding population of orthopyroxenes in the Rocky Hill deposits can thus be considered as inherited from unerupted magma generated prior to the Kidnappers event. Consistent with this inference, the majority of modelled ages from the dark exterior zone in Rocky Hill orthopyroxenes, including those from the dark zone to outermost rim boundary, are older than those within the Kidnappers. The offset in the date of this common zonation ( $\sim 20$ years) can therefore represent an approximate estimate for the time break between the two eruptions. The textures and chemical zoning within the majority of Rocky Hill orthopyroxenes, and the other mineral phases do not contain any evidence for a trigger mechanism for the eruption analogous to that seen in the Kidnappers KI-3 pumice group.

\subsubsection{Implications of diffusion timescales from core-rim boundaries}

Prominent core-rim boundaries within orthopyroxene from the Kidnappers/Rocky Hill magma systems are inferred to represent a transition from storage in a crystal mush to crystallisation and storage within the melt-dominant bodies that were finally erupted (Chapter 4). Timescales modelled across Kidnappers core-rim boundaries cover a large range, but only one crystal returns an age $>1000$ years before eruption. $60 \%$ of diffusion profiles date to within 200 years of the eruption and suggests that a significant input of orthopyroxene grains (those displaying normal zonation; Table 5.2) to the final melt-dominant body occurred within centuries of the eruption (Figure 5.8). This process peaked only $\sim 30$ years prior to the Kidnappers eruption (Figure 5.7). The FeMg modelled ages across Kidnappers/Rocky Hill orthopyroxene core-rim boundaries cover remarkably similar timescales to those inferred from corresponding crystal boundaries found within the Oruanui (Allan et al. 2013), which are also inferred to represent the timing of physical extraction and establishment of the melt-dominant body. In the Oruanui case, $\sim 90 \%$ of crystals record this common history (Allan et al. 2013), but within the Kidnappers the proportion of crystals recording this process is lower and varies between compositional groups (Table 5.2), suggesting that additional magmatic controls were operating within the system. The proportion of nominally unzoned grains within the Kidnappers ranges between 15 and $51 \%$, and these may be crystals that have entirely grown within a melt-dominant body over a short timescale prior to eruption. Alternatively, grains lacking zonation could reflect an input of crystals 
to melt-dominant bodies right at the point of eruption, with insufficient time to grow a discernible rim. It is also possible that grains that appear unzoned under BSE imaging (a reflection of $\mathrm{Fe}$ and $\mathrm{Mg}$ content), may be zoned in respect to other elements such as $\mathrm{Al}$ and $\mathrm{Ca}$. Contrasting diffusion rates may thus have smoothed out the original $\mathrm{Fe}$ and $\mathrm{Mg}$ zonation, but the $\mathrm{Al}$ and $\mathrm{Ca}$ zonation remains (Figures 5.3 and 5.4).

Core-rim boundaries within Rocky Hill orthopyroxenes record a similar range of timescales as in Kidnappers grains. The Rocky Hill core-rim model ages, which reflect the timing of movement of orthopyroxene grains to the final erupted melt-dominant body, have a bimodal distribution with peak PDF ages at $\sim 70$ and $\sim 5$ years (Figure 5.7). The $\sim 70$ year peak is inferred to correspond to the input of grains occurring at $\sim 30$ years prior to the Kidnappers eruption. The $\sim 5$ year peak is younger than $>90 \%$ of the timescales recorded from dark exterior zones within the Rocky Hill. Therefore significant proportions of the two melt-dominant bodies evacuated in the Rocky Hill eruption were assembled within the 20-40 year time break between it and the Kidnappers eruption (Figure 5.8). This process of rejuvenation is particularly marked in orthopyroxenes from the high- $\mathrm{SiO}_{2}$ Rocky Hill (RH-2) pumice group, where $94 \%$ of grains have normal zonation. This dominant zonation pattern in the high-SiO $2(\mathrm{RH}-2)$ pumice group is coupled with lower amphibole rim model temperature and pressure estimates, low-An plagioclase rims, and lower Ca homogeneous glass. These distinctive characteristics of the $\mathrm{RH}-2$ pumice group support the idea that a significant proportion of this melt was newly generated, with most of the orthopyroxene grains recording a post-Kidnappers magmatic history. Grains which return core-rim model ages greater than a few hundred years may be inherited from the Kidnappers eruption, and record earlier processes within the common magma system.

Differences in the model timescales from the core-rim boundaries between both eruptions support the evidence for the short intervening time break between these eruptions. There is a $\sim 40$ year difference in core-rim model age peaks between the two eruptions, which is within uncertainties with the $\sim 20$ year time break observed across dark outer zones. It is not possible, however, to definitively estimate the time break between the Kidnappers and Rocky Hill eruptions with diffusion timescales alone. It is possible that the crystals and melt present in the Rocky Hill were entirely generated 
after the Kidnappers eruption (i.e. there are few inherited grains). In such an alternative scenario, the time gap would be $>600$ years $(99 \%$ of Rocky Hill grains record age of $<600$ years). However, two lines of field evidence support a shorter time gap. (1) The contact between the two ignimbrite deposits has no associated soil horizon. (2) The associated fall material (referred to as the Potaka Tephra: Shane 1994; Carter et al. 2004), both onshore and in marine cores appears to be a single composite deposit of reworked Kidnappers and Rocky Hill material (Cooper et al. 2012 [Chapter 3]).

\subsubsection{Timescale comparisons and considerations}

The parameters (temperature and oxygen fugacity) used in Fe-Mg diffusion modelling calculations have a large bearing on the modelled ages. All ages within this study represent maximum estimates and therefore the timescales of processes discussed above are upper-bound limits. However, because different temperature and oxygen fugacity estimates were used for each compositional group (Table 5.1), gaps in modelled ages could be a result of the parameters used in each of the calculated ages. In Rocky Hill orthopyroxenes, analogous zones were modelled at conditions that reflected the outer rim growth of crystals and not necessarily the original conditions under which the dark zone formed. Therefore, using lower temperature estimates $\left(765-795^{\circ} \mathrm{C}\right)$ in Rocky Hill samples may artificially produce larger age estimates. For example, if $820^{\circ} \mathrm{C}$ and 0.1 $\triangle \mathrm{NNO}$ were used to calculate a Rocky Hill Fe-Mg diffusion age that yielded $96 \mathrm{yrs}$ (Figure 5.5) when modelled at $795^{\circ} \mathrm{C}$ and $0.1 \triangle \mathrm{NNO}$, then the calculated age would be younger at 53 years. The latter modelled age value is, however, still larger than any ages modelled in the Kidnappers and therefore the disparities in ages calculated using different temperature and oxygen fugacity estimates are not large enough to preclude any of the conclusions drawn in this study.

The Fe-Mg interdiffusion timescales obtained from orthopyroxenes are much shorter than the proposed timescale of development of the Kidnappers/Rocky Hill system from $\mathrm{U}-\mathrm{Pb}$ zircon age spectra (Chapter 2). Zircon age spectra from the Kidnappers and Rocky Hill suggest the system was developed over $200 \mathrm{kyr}$ before eruption, with a peak crystallisation age mode within uncertainty of the eruption age at 1.0 Ma. This age difference is a consequence of the process that is being recorded by each technique. U- 
$\mathrm{Pb}$ zircon age spectra provide a record for the maximum assembly of the magma system, and more specifically the time when zircon began crystallising within the system. In contrast, orthopyroxene Fe-Mg interdiffusion from the Kidnappers and Rocky Hill records processes occurring one or two orders of magnitude faster than maximum zircon accumulation timescales. Therefore the larger scale Kidnappers/Rocky Hill magmatic system, from which the final erupted melt was derived, assembled and grew over $200 \mathrm{kyr}$ prior to eruption, with the rate of assembly peaking just before eruption. Melt-dominant bodies, comprising of crystals and melt extracted from a larger mush zone were largely established within less than 1000 years before eruption, with a significant input of material within centuries-decades of each eruption. It is difficult to definitively establish if the history recorded in orthopyroxene crystals can be applied to the system as a whole, or to other phases (plagioclase, amphibole and quartz) present in the Kidnappers and Rocky Hill deposits. However, a significant proportion of plagioclase textures (compositional zones) and apparent amphibole temperatures and pressures from each compositional group in both eruptions (Chapter 4) suggest a history consistent with that recorded in orthopyroxenes.

Timescales of the assembly of the Kidnappers/Rocky Hill system, as well as the establishment of melt-dominant bodies are similar to contrasting timescales recorded in the $\sim 350$ ka Whakamaru ignimbrite, TVZ, New Zealand. Here zircon U-Pb age spectra indicate magmatic residence times of $250 \mathrm{kyr}$ prior to eruption, with periods of crystallisation closer to eruption following magmatic events (Brown and Fletcher 1999). Matthews et al. $(2012 \mathrm{a}, \mathrm{b})$ investigated the timescales of quartz crystallisation in the Whakamaru on the basis of Ti diffusion in quartz. They reported that a significant chemical change occurred in the Whakamaru system not long before eruption ( $\sim 10-85$ years), thought to represent a rapid thermal pulse or pressure change causing late-stage magma chamber recharge. Like the dark exterior zones within orthopyroxene, and uptemperature plagioclase and amphibole rims in the KI-3 compositional group seen in the Kidnappers deposits, this late stage quartz signal was attributed by Matthews et al. $(2012 a, b)$ to open-system processes and the rejuvenation of magma from the interaction of underplated mafic magma. Similar $(<100$ years before eruption) timescales of rejuvenation are also found in both the $\sim 50$ ka Earthquake Flat eruption, Okataina, New 
Zealand and the $\sim 74$ ka Younger Toba Tuff supereruption, Sumatra (Matthews et. al. 2012b).

The relative rapidity of acceleration of the magmatic system towards eruption implied by the orthopyroxene timescales within the Kidnappers and Rocky Hill suggest that dynamic, open-system processes occurred in a short time before eruption, and raises questions as to what the trigger mechanism for each eruption is. There is growing evidence for a strong tectonic control on magmatic systems within the TVZ (Gravley et al. 2007; Rowland et al. 2010; Allan et al. 2012; Cooper et al. 2012 [Chapter 3]). Rifting related processes acting on the system could allow extraction and movement of melt through the development of melt channels (Figure 5.8; Allan et al. 2013) much more rapidly than typical melt extraction mechanisms (Bachmann and Bergantz 2004). It is hard to envisage how an exceptionally large silicic system can erupt $\sim 1200 \mathrm{~km}^{3}$ of material, before shutting down for only $\sim 20-40$ years before the evacuation of another $\sim 200 \mathrm{~km}^{3}$ of material in the Rocky Hill event without an external control. Rifting related processes thus may have exerted a dominating control on both the triggering and the shutdown of the Kidnappers and Rocky Hill eruptions.

\subsection{Conclusions}

This work has major implications for our understanding of magmatic processes related to large silicic eruptions. Orthopyroxene crystals from the Kidnappers and Rocky Hill contain textural and chemical features that record rapid, open-system processes. Fe-Mg interdiffusion modelling of textural zones within these orthopyroxenes reveals the following processes occurred within centuries of each eruption:

(1) Interaction of a lesser evolved melt with some part of the Kidnappers magma system occurred within 50 years of eruption. This interaction, possibly through underplating, was not widespread enough to trigger the eruption, but it may have primed (or remobilised) a volume of crystal mush, contributing towards generation of the KI-3 pumice magma just prior to eruption.

(2) Movement of melt and associated crystals to assemble the final melt-dominant bodies occurred within centuries of the Kidnappers eruption. This process was 
most prevalent only $\sim 30$ years prior to eruption. A similar record has been found in the Oruanui eruption deposits (Allan et al. 2013).

(3) The short time break between the Kidnappers and Rocky Hill eruptions is estimated to be of the order of 20-40 yrs from the difference in Fe-Mg interdiffusion ages from dark exterior zones and core-rim boundaries between samples from the two eruptions. Significant additional extraction of crystals and melt to regenerate two melt-dominant bodies subsequently evacuated during the Rocky Hill eruption happened within the 20-40 yr post-Kidnappers time break, highlighting the rapidity of magmatic rejuvenation at Mangakino.

The processes involved in generating the final melt-dominant bodies, shutting the eruption down, and rejuvenating the system once again over the inferred short timescales before and after the Kidnappers supereruption strongly suggest the presence of an additional external control. No petrological or geochemical information represented in the crystal record can explain why or how evacuation of magma from the Kidnappers system ceased before restarting during the Rocky Hill event. Here, the diffusion modelling provides additional support for a wider role for tectonic controls operating on the magmatic system at Mangakino during the 1.0 Ma eruptions (previously proposed in Cooper et al. 2012 [Chapter 3]). Other examples (e.g. Gravley et al. 2007; Allan et al. 2012) have added to the growing body of evidence that suggests an extensional tectonic regime in the TVZ is able to impart a strong influence on the timing and tempo of silicic volcanism. 
Chapter 6 


\section{Development, mobilisation and eruption of a crystal rich rhyolite: the $1.21 \mathrm{Ma}$ Ongatiti ignimbrite}

\subsection{Introduction}

Models to explain the processes involved in generation, storage and eruption of largescale silicic magma bodies vary enormously. There is, however, a tendency for large felsic (dacite to rhyolite) volcanic ignimbrites to be pigeonholed into two categories (Bachmann and Bergantz 2008; Huber et al. 2012): the crystal-rich monotonous intermediates of broadly dacitic composition (after Hildreth 1981) and crystal-poor compositionally zoned rhyolites. In the overall mush model (Hildreth 2004; Bachmann and Bergantz 2004: see Chapter 1) these two categories are considered to be remobilised mush crystal cumulates, and the fractionated melt (plus entrained and newly grown crystals) that has accumulated to form a melt-dominant body. The work reported in this thesis and the studies on the Oruanui eruption by Wilson et al. (2006) and Allan (2013) imply that this model may be too simplistic. The melt-dominant bodies erupted for the Oruanui, Kidnappers and Rocky Hill ignimbrites, although compositionally variable, were not compositionally zoned. Within the Kidnappers/Rocky Hill system, two large $\left(>100 \mathrm{~km}^{3}\right)$ and two small $\left(10-100 \mathrm{~km}^{3}\right)$ separate melt-dominant bodies are inferred to have been generated from a common mush/source zone.

In the New Zealand record, there are two super-sized eruption deposits that are crystalrich and might ostensibly be interpreted as examples of remobilised mushes. The Whakamaru system (Brown et al. 1998a) is inferred to represent, in large part, a very crystal-rich body that was reactivated over a short (centuries to millenia) period prior to eruption (Matthews et al. 2012a,b). The Ongatiti ignimbrite from Mangakino is also crystal-rich (20-30\%), of rhyodacite to low-silica rhyolite composition, and shows compositional variability, but not consistent zonation (Briggs et al. 1993). Both these deposits, however, are quartz-bearing and have higher $\mathrm{SiO}_{2}$ contents than the examples of monotonous intermediates widely cited in the literature, such as the Fish Canyon Tuff (Bachmann et al. 2002; Bachmann and Dungan 2002), the Cerro Galan ignimbrite 
(Francis et al. 1989; Folkes et al. 2011), the Atana ignimbrite (Lindsay et al. 2001) and the Lund Tuff (Maughan et al. 2002).

The question then arises as to the origins of the magma bodies that fed eruptive units like the Whakamaru and Ongatiti ignimbrites. Do they simply represent a remobilised crystal mush, activated by thermal rejuvenation, but where the parental mush was more evolved and quartz-bearing? Alternatively, do they represent melt-dominant bodies that had cooled and crystallised to close to the point of critical crystallinity or rheological lock-up at > 50 vol. \% crystals (Marsh, 1981; Brophy 1991; Vigneresse et al. 1996; Petford 2003; Huber et al. 2010a) before being rejuvenated and provoked into eruption? The Oruanui melt-dominant body is inferred to have been generated extremely rapidly, but the compositional record from crystal zonation implies a cooling from $\sim 820^{\circ} \mathrm{C}$ to $\sim 770{ }^{\circ} \mathrm{C}$ over the same short period, of no more than $\sim 1600$ years (Allan et al. 2013). It is possible that over another few thousand years, the Oruanui melt-dominant body (had it not erupted) would have cooled below the rheological 'lock-up' point and become a melt-bearing mush body, but of rhyolitic composition. The extraordinarily rapid generation and 'de-generation' of eruptible melt-dominant bodies implied by the Oruanui (and other young eruptions at Taupo: Sutton et al. 2000) suggest that evolved, hot melt-bearing mush bodies may be commonly present in silicic volcanic systems. What would such a crystal-rich rhyolitic mush look like if 'defrosted' (Mahood 1990) or 'reactivated' (Bachmann et al. 2002; Huber et al. 2010b)?

The clues to understanding the genesis of the New Zealand 'monotonous rhyolites' lie in the compositions and textures of crystals that reflect the processes of heating and cooling, and the records of interstitial melt compositions. Although these deposits are near homogeneous at a large scale, a record of significant compositional variability and a complex history of open-system magmatic processes may be recorded within the mineral assemblage (e.g. Charlier et al. 2007). The addition of heat is ubiquitous in any remobilisation processes, commonly inferred to be the result of underplating by less evolved to wholly mafic compositions (Pallister et al. 1991; Murphy et al. 2000; Couch et al. 2001; Bachmann et al. 2002; Bachmann and Bergantz 2003; Hildreth and Wilson 2007). In addition, however, that heat may be introduced with inputs of volatiles ('gas sparging' or mafic 'wind' of Bachmann and Bergantz 2006) and/or melts of contrasting (generally less-evolved) composition that will be reflected in changes of composition in 
the interstitial melts/glasses and the crystals that dissolve in, or crystallise from those melts.

In this chapter data from the 1.21 Ma Ongatiti ignimbrite ( $\left.>500 \mathrm{~km}^{3} \mathrm{DRE}\right)$ from Mangakino volcanic centre, Taupo Volcanic Zone (TVZ) are presented to explore the processes that gave rise to this large-volume crystal-rich supereruption. The homogeneity of the Ongatiti ignimbrite is evaluated using whole-rock and glass major and trace element chemistry of juvenile clasts (pumices). The development of the magma system is then investigated by; the identification of textural populations in the major mineral phases; the in-situ geochemical history of each crystal population; and the estimation of changing intensive variables. The origins of each mineral phase and the involvement of a lesser-evolved source are explored though the study of textural and geochemical signatures of crystals and glass in microcrystalline clots, which are commonly found within pumices. The histories of the major crystal phases are evaluated in the light of a protracted crystallisation record in Ongatiti U-Pb zircon age spectra (see Chapter 2). On this basis, and the fact that the bulk rock compositional trends are consistent with fractionation of an assemblage that includes zircon, the dominant proportion of crystallisation within the Ongatiti system occurred $\sim 100 \mathrm{kyr}$ prior to eruption.

\subsection{Geological Background}

\subsubsection{Mangakino Volcanic Centre and the Ongatiti ignimbrite}

The Mangakino volcanic centre (MVC) is a composite caldera structure located on and in part defining the northwestern margin of the TVZ (Figure 6.1; see also Chapter 1 for background). Activity at Mangakino can be subdivided into two intense periods of large eruptions, accompanied by caldera collapse, between 1.62 and $1.51 \mathrm{Ma}$, and 1.23 and $0.91 \mathrm{Ma}$ (Houghton et al. 1995). The younger period includes the eruption of the Ongatiti ignimbrite, as well as those of the Kidnappers and Rocky Hill ignimbrites (Chapter 4).

The Ongatiti eruption occurred at $1.21 \pm 0.04 \mathrm{Ma}$ (Houghton et al. 1995) producing a voluminous ( $>500 \mathrm{~km}^{3} \mathrm{DRE}$ ), widespread, crystal-rich, rhyodacitic to rhyolitic 
ignimbrite. The ignimbrite is widely distributed to the north (as far as Auckland (Alloway et al. 2004)) and to the west (as far as Port Waikato), and is reported at depth beneath the Waiotapu geothermal field (Wilson et al. 2010) (Figure 6.1). No associated fall deposit is preserved on land, although it most probably is represented in the deepsea record offshore from the North Island (e.g., Allan et al. 2008).

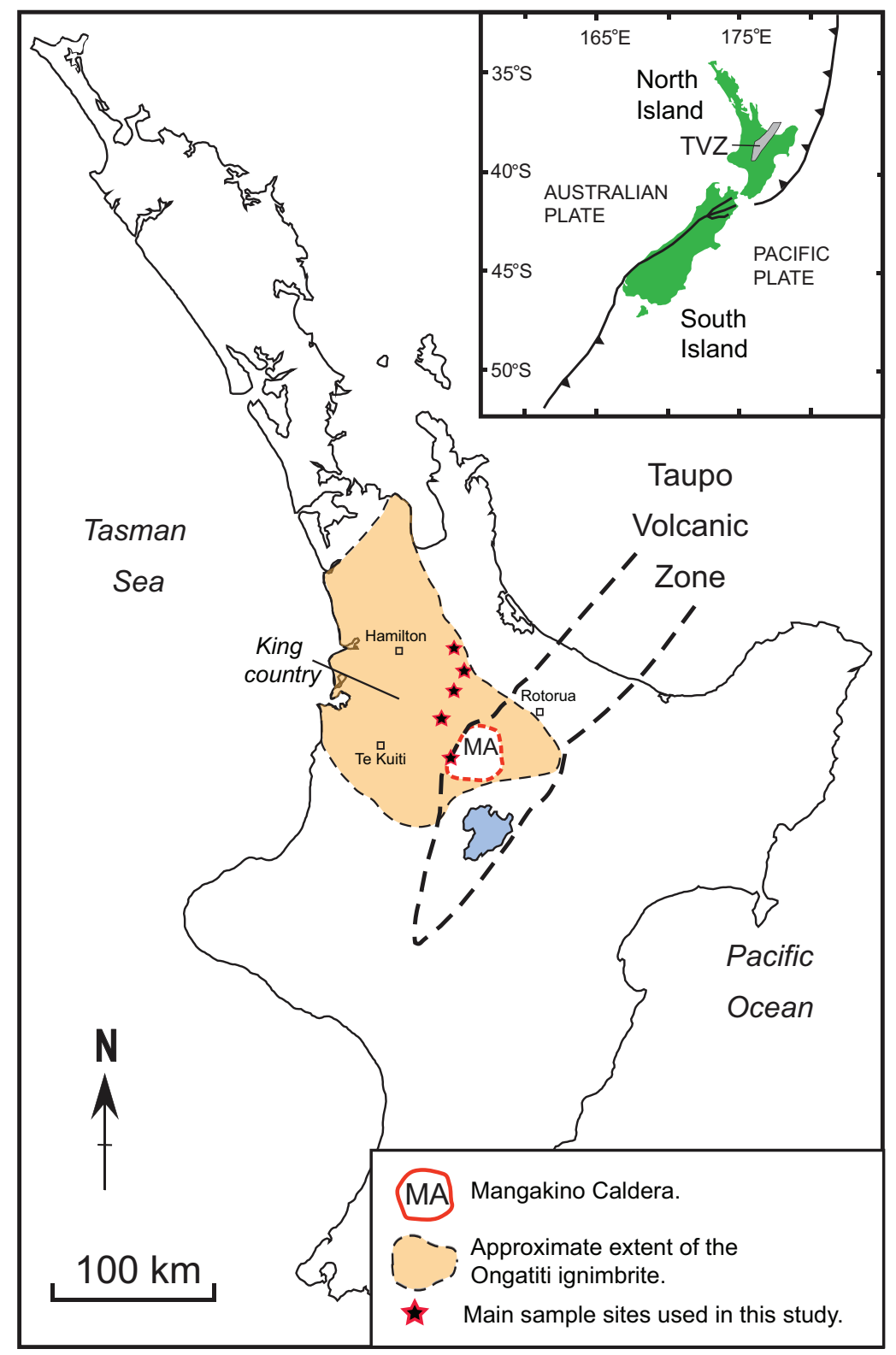

Fig. 6.1. Outline of the Taupo Volcanic Zone (TVZ) and its plate tectonic setting (inset), with the approximate extent of the Ongatiti ignimbrite.

The ignimbrite is non-welded to partially welded, and consists of multiple flows, which were erupted in a series of directional lobes (Briggs et al. 1993). The deposit can be subdivided into an earlier erupted facies (Eu I), and a later erupted facies (Eu II). The 
latter contains densely welded recycled tuff fragments, which are absent in deposits of the earlier flows (Wilson 1986). The eruption commenced with highly energetic, violent and cooler flows, generating a pumice-poor, fine grained ignimbrite. Later flows were hotter but less energetic and less violent, generating an upper pumice-rich ignimbrite (Wilson 1986; Briggs et al. 1993). An upward increase in size of pumice and lithic clasts is shown through the Ongatiti ignimbrite (Wilson 1986).

\subsubsection{Juvenile and lithic types}

Representative juvenile clasts displaying a wide variety of textures were sampled throughout King Country for this study. The ignimbrite was sampled at locations covering both the lower (Eu I) and upper (Eu II) flow units, where large pumices with as little post-depositional alteration as possible could be found. The Eu I material was primarily sampled from Ranganui Station, $\sim 15 \mathrm{~km}$ west of Mangakino township, and on Duncan Road. Here the ignimbrite is $\sim 25 \mathrm{~m}$ thick and welded, forming craggy outcrops. Sample sites for the Eu II material include Tokahaere Rock, Hinuera Quarry and along Horahora Road, north of Mangakino (see Appendix 2 for full sample list and grid references).

Pumice textures vary greatly throughout the ignimbrite from crystal rich $(\sim 30 \%)$ and dense clasts to highly vesicular clasts with fewer crystals. Pumices from the Eu I ignimbrite are poorly-highly vesicular and crystal rich (20-30 \%) containing crystal schlieren, and many are flattened to fiamme. Several crystal moderate- to crystal-rich (20-30 \%) pumices display an 'adobe-type' (after Hildreth and Wilson 2007) texture, with a coarsely fibrous lineated fabric and crystal schlieren. Pumice from the upper flows are typically crystal-moderate to -rich, with a drawn out planar fabric and an abundance of glomerocrysts. In addition to 'normal' pumices, individual clasts (up to 24 $\mathrm{cm}$ ) of microcrystalline material occur within the upper (Eu II) ignimbrite. Many pumices within Eu II also contain clots of visually identical material up to $9 \mathrm{~cm}$ in size. Both individual clasts and clots are crystal rich (20-50\%) with a subordinate vesiculated glassy matrix, the crystals being almost entirely plagioclase and amphibole grains with a consistent size $(\sim 1 \mathrm{~mm})$ giving the material a distinctive 'salt and pepper'like appearance (Figure 6.2). 

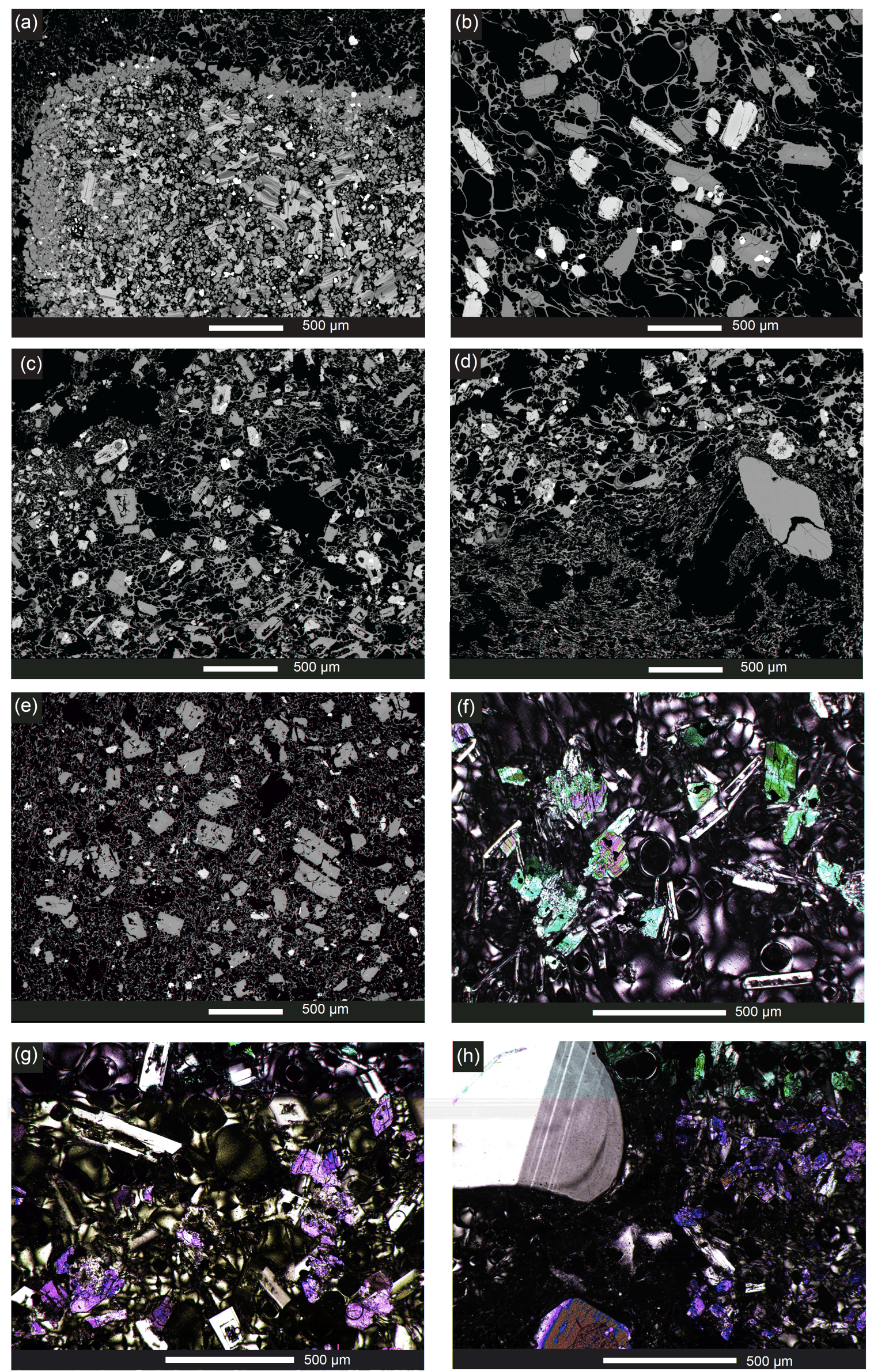
Fig. 6.2. (opposite) Textural features of microcrystalline clots (MCs). (a) BSE image of a biotite rich xenolith with a quartz rich rind within a pumice clast from Eu II ignimbrite. (b) BSE image of the highly vesiculated texture within a small $\mathrm{MC}$ with $\sim 50 \%$ plagioclase (darker grey) and $\sim 50 \%$ amphibole (lighter grey). Note the consistent crystal sizes. (c) BSE image of a MC with hopper/skeletal plagioclase. (d) BSE image from the edge of the MC shown in panel (c) to show the relationship to the host pumice. Note that the pumice is more microscopically vesicular and contains larger crystals. (e) BSE image of a plagioclase rich MC with smaller amphibole in a microvesicular matrix. (f) and (g) Photomicrographs under crossed polars show needle shaped skeletal and hopper plagioclase crystals. (h) Photomicrograph under crossed polars to demonstrate the contrast in crystal size between plagioclase and amphibole within the host pumice (left) and an amphibole dominated MC (right).

A wide range of lithic types are found within the Ongatiti ignimbrite, including andesite and rhyolite lavas, densely welded ignimbrite (some vitric and breadcrusted, and inferred to be recycled Ongatiti material), biotite granite and granodiorite porphyry (Brown et al. 1998b; Krippner et al. 1998). The high proportion of lava clasts suggests that the volcanic pile engulfed by the Ongatiti vents comprised a significant volume of rhyolitic and andesitic lava from earlier dome building episodes (Krippner et al. 1998). The compositional and isotopic data from granitoid lithic fragments are similar to the range displayed in the Ongatiti ignimbrite, suggesting that the granitoids may be geochemically related, although lacking any interstitial glass phase and with common biotite, which is absent in the general mineral assemblage of Ongatiti pumices (Brown et al. 1998b; Krippner et al. 1998).

\subsection{Analytical techniques}

All analytical techniques for major and trace element whole rock analyses were carried out using the procedures outlined in Appendix 1. Instrument conditions for Electron Probe MicroAnalysis (EPMA) and trace elements by solution and laser ICP-MS were the same as those used for the Kidnappers and Rocky Hill samples (Chapter 4) and are detailed in Appendix 1. For imaging, a series of thin sections were made so that the textural relationship of normal pumice and the microcrystalline clots described above could be made. For in-situ analysis of crystals and glass within microcrystalline clots, a series of polished epoxy mounts were made using $\sim 2 \mathrm{~cm}$ chips of this material. 


\subsection{Results}

\subsubsection{Mineralogy of juvenile clasts}

Pumices from the Ongatiti ignimbrite contain, in a general order of abundance plagioclase, quartz, orthopyroxene, amphibole, titanomagnetite, ilmenite and accessory zircon and apatite. A number of pumices also contain sparse, light green clinopyroxene. Microcrystalline clasts and clots (abbreviated to MC in the following text) within normal pumice contain almost entirely plagioclase and amphibole grains in a highly vesiculated glassy matrix (Figure 6.2). A full spectrum from plagioclase dominated (Figure 6.2e) to amphibole dominated (Figure 6.2h) assemblages is seen within the MC material. The plagioclase and, but to a lesser extent, amphibole display a range of disequilibrium textures including sieve textures, high aspect ratio skeletal grains and hopper textures (Figure 6.2). Rare, xenocrystic material containing a high proportion of biotite was also observed within Ongatiti pumice from the upper (Eu II) flows and may represent incorporation of biotite bearing granitoid material (Krippner et al. 1998) (Figure 6.2a).

\subsubsection{Whole rock and glass compositions}

\subsubsection{Pumice whole rock}

Selected individual pumices covering a range of textures were chosen for whole-rock major element XRF and trace element solution ICP-MS analysis (Table 6.1). The majority of pumices within the Ongatiti ignimbrite are rhyodacitic to rhyolitic in composition (Figure 6.3), from 66-73 wt. \% $\mathrm{SiO}_{2}, 14-20$ wt. $\% \mathrm{Al}_{2} \mathrm{O}_{3}$, and 2.5-4.2 wt. \% $\mathrm{K}_{2} \mathrm{O}$ (values calculated to $100 \%$, volatile-free). Tie lines between major element whole rock and average matrix glass concentrations have gradients in common with the whole rock array, with the exceptions of $\mathrm{Al}_{2} \mathrm{O}_{3}$ and $\mathrm{Na}_{2} \mathrm{O}$ (Figure 6.3). These two tie lines have a shallower negative slope than whole rock trends and suggest other processes, in addition to fractional crystallisation, may have been in operation. There is a much larger range in whole rock compositions than associated matrix glass, which can be considered homogeneous within the uncertainties of the analytical technique (Figure 6.3). Due to the crystal rich nature of pumices, the range in whole-rock compositions is thus entirely a reflection of the crystal assemblage and crystallinity of each individual pumice. 
Table 6.1. Major (XRF) and trace element (solution-ICP-MS) whole-rock concentrations of selected pumices from both the lower (Eu I) and upper (Eu II) parts of the Ongatiti ignimbrite. Element oxides are normalised to $100 \%$ and original LOI and Totals are given for convenience. Representative 2 sd uncertainties of both techniques are presented in Appendix 1.

Eu I Eu I Eu I Eu II Eu II Eu II Eu II Eu II Eu II Eu II Eu II Eu II Eu II Sample no. P1991 P1992 P1994 P2027 P2018 P2023 P2028 P2026 P2024 P2019 P2021 P2022 P2025

\begin{tabular}{|c|c|c|c|c|c|c|c|c|c|c|c|c|c|}
\hline \multicolumn{14}{|c|}{ Major elements by XRF (Normalised to $100 \%$, volatile free) } \\
\hline $\mathrm{SiO}_{2}$ & 71.3 & 71.6 & 72.4 & 71.1 & 71.2 & 69.9 & 68.9 & 73.0 & 66.0 & 70.5 & 70.5 & 69.6 & 71.5 \\
\hline $\mathrm{TiO}_{2}$ & 0.34 & 0.36 & 0.35 & 0.34 & 0.33 & 0.36 & 0.36 & 0.35 & 0.40 & 0.34 & 0.37 & 0.36 & 0.34 \\
\hline $\mathrm{Al}_{2} \mathrm{O}_{3}$ & 15.9 & 15.8 & 15.0 & 16.2 & 15.2 & 16.9 & 18.2 & 14.3 & 20.4 & 15.9 & 15.7 & 16.4 & 16.2 \\
\hline $\mathrm{Fe}_{2} \mathrm{O}_{3}$ & 3.16 & 3.52 & 2.86 & 2.75 & 3.05 & 2.75 & 2.76 & 2.89 & 3.77 & 3.12 & 3.51 & 3.64 & 2.07 \\
\hline $\mathrm{MnO}$ & 0.06 & 0.06 & 0.03 & 0.03 & 0.06 & 0.05 & 0.05 & 0.04 & 0.09 & 0.07 & 0.07 & 0.05 & 0.04 \\
\hline MgO & 0.15 & 0.10 & 0.09 & 0.17 & 0.31 & 0.46 & 0.45 & 0.29 & 0.47 & 0.41 & 0.38 & 0.39 & 0.31 \\
\hline $\mathrm{CaO}$ & 1.94 & 1.86 & 1.96 & 2.15 & 2.15 & 2.16 & 2.20 & 1.69 & 2.30 & 2.24 & 2.12 & 2.40 & 2.09 \\
\hline $\mathrm{Na}_{2} \mathrm{O}$ & 4.04 & 3.68 & 4.43 & 3.62 & 4.10 & 4.24 & 4.31 & 3.28 & 4.09 & 3.83 & 3.89 & 3.91 & 4.11 \\
\hline $\mathrm{K}_{2} \mathrm{O}$ & 2.93 & 2.93 & 2.94 & 3.67 & 3.65 & 3.04 & 2.79 & 4.21 & 2.47 & 3.57 & 3.39 & 3.22 & 3.37 \\
\hline $\mathrm{P}_{2} \mathrm{O}_{5}$ & 0.13 & 0.02 & 0.01 & 0.01 & 0.01 & 0.04 & 0.01 & 0.01 & 0.01 & 0.01 & 0.01 & 0.01 & 0.03 \\
\hline (LOI) & 1.53 & 2.67 & 1.08 & 1.67 & 1.57 & 3.04 & 2.51 & 1.51 & 4.78 & 1.57 & 2.19 & 3.04 & 2.83 \\
\hline Total & 99.48 & 99.94 & 99.93 & 99.69 & 99.96 & 99.45 & 99.96 & 98.99 & 99.80 & 99.95 & 99.64 & 99.96 & 99.49 \\
\hline \multicolumn{14}{|c|}{ Trace elements by Solution ICP-MS } \\
\hline $\mathbf{L i}$ & 21.2 & 23.1 & 20.5 & 10.7 & 9.92 & 11.3 & 10.9 & 12.8 & 11.2 & 18.0 & 20.0 & 15.4 & 19.7 \\
\hline B & 2.54 & 2.49 & 2.33 & 3.05 & 2.83 & 2.88 & 2.61 & 3.15 & 2.81 & 3.39 & 2.98 & 3.49 & 3.25 \\
\hline MgO & 0.17 & 0.13 & 0.10 & 0.15 & 0.28 & 0.42 & 0.44 & 0.30 & 0.48 & 0.43 & 0.39 & 0.40 & 0.31 \\
\hline Sc & 6.81 & 7.51 & 8.28 & 6.55 & 8.53 & 7.64 & 7.84 & 8.52 & 8.18 & 8.61 & 9.15 & 13.2 & 8.16 \\
\hline $\mathrm{TiO}_{2}$ & 0.37 & 0.40 & 0.32 & 0.31 & 0.30 & 0.33 & 0.35 & 0.32 & 0.38 & 0.32 & 0.35 & 0.37 & 0.33 \\
\hline V & 25.4 & 26.2 & 24.7 & 25.9 & 29.0 & 22.3 & 22.0 & 24.5 & 34.9 & 29.3 & 27.9 & 28.4 & 24.9 \\
\hline $\mathrm{Cr}$ & 2.13 & 1.76 & 2.19 & 2.97 & 1.75 & 2.12 & 2.22 & 1.86 & 2.44 & 2.87 & 2.26 & 2.13 & 2.45 \\
\hline MnO & 0.06 & 0.06 & 0.03 & & & & & & & 0.07 & 0.06 & 0.05 & 0.04 \\
\hline Co & 4.25 & 3.30 & 2.31 & 2.78 & 3.24 & 2.59 & 2.60 & 3.23 & 4.43 & 3.34 & 3.20 & 3.38 & 1.77 \\
\hline $\mathrm{Ni}$ & 1.59 & 0.89 & 1.07 & 1.05 & 0.73 & 0.89 & 1.00 & 0.90 & 1.36 & 0.93 & 0.88 & 1.17 & 0.71 \\
\hline $\mathrm{Cu}$ & 8.68 & 5.95 & 8.94 & 4.35 & 3.77 & 4.50 & 4.45 & 5.81 & 4.05 & 3.48 & 3.03 & 4.14 & 3.30 \\
\hline $\mathrm{Zn}$ & 76.8 & 66.8 & 56.6 & 42.9 & 49.8 & 49.3 & 52.7 & 43.3 & 60.1 & 60.5 & 61.6 & 60.1 & 42.0 \\
\hline Ga & 19.0 & 20.7 & 18.2 & 18.5 & 18.7 & 19.4 & 20.2 & 17.3 & 21.7 & 19.2 & 19.4 & 21.0 & 18.8 \\
\hline $\mathbf{R b}$ & 94.3 & 94.5 & 94.2 & 81.2 & 87.7 & 85.4 & 83.0 & 104 & 71.3 & 103.6 & 99.4 & 86.7 & 94.6 \\
\hline $\mathrm{Sr}$ & 154 & 150 & 155 & 155 & 155 & 163 & 162 & 119 & 174 & 169 & 161 & 186 & 164 \\
\hline$Y$ & 20.2 & 15.2 & 19.1 & 23.0 & 27.4 & 26.9 & 24.6 & 29.4 & 24.9 & 31.1 & 26.5 & 32.1 & 31.9 \\
\hline $\mathrm{Zr}$ & 90.7 & 74.5 & 65.4 & 91.0 & 101 & 94.0 & 96.4 & 106 & 103 & 102 & 106 & 113 & 98.9 \\
\hline $\mathrm{Nb}$ & 10.3 & 10.9 & 9.03 & 9.02 & 9.08 & 9.59 & 10.3 & 9.58 & 11.2 & 9.01 & 9.78 & 10.1 & 9.36 \\
\hline Mo & 0.68 & 0.99 & 0.89 & 1.52 & 1.67 & 1.48 & 1.44 & 1.64 & 1.32 & 1.19 & 1.10 & 1.01 & 1.08 \\
\hline Cs & 3.53 & 2.55 & 4.36 & 4.89 & 5.62 & 5.40 & 5.72 & 5.93 & 5.68 & 5.95 & 5.47 & 5.98 & 5.55 \\
\hline $\mathrm{Ba}$ & 790 & 662 & 744 & 675 & 680 & 748 & 725 & 715 & 666 & 784 & 702 & 777 & 725 \\
\hline La & 24.7 & 19.5 & 27.9 & 19.2 & 25.8 & 25.6 & 21.6 & 24.9 & 23.7 & 27.6 & 24.5 & 43.4 & 34.2 \\
\hline $\mathrm{Ce}$ & 48.8 & 42.7 & 50.0 & 40.2 & 46.9 & 51.3 & 48.0 & 52.8 & 54.6 & 58.1 & 74.2 & 63.2 & 56.0 \\
\hline Pr & 5.83 & 4.51 & 6.86 & 4.47 & 6.93 & 6.20 & 5.05 & 6.17 & 5.37 & 6.86 & 6.03 & 8.30 & 8.28 \\
\hline $\mathrm{Nd}$ & 22.1 & 16.6 & 25.4 & 16.4 & 27.1 & 23.3 & 19.1 & 23.5 & 20.4 & 26.0 & 22.2 & 28.4 & 31.1 \\
\hline Sm & 4.38 & 3.27 & 4.97 & 3.47 & 5.70 & 4.79 & 3.97 & 4.79 & 4.08 & 5.55 & 4.63 & 5.37 & 6.34 \\
\hline Eu & 0.98 & 0.89 & 1.10 & 0.89 & 1.10 & 1.04 & 0.98 & 0.77 & 1.07 & 1.10 & 1.01 & 1.23 & 1.22 \\
\hline Gd & 4.10 & 3.09 & 4.54 & 3.51 & 5.21 & 4.78 & 3.94 & 4.98 & 4.34 & 5.35 & 4.69 & 5.40 & 6.19 \\
\hline Tb & 0.62 & 0.45 & 0.64 & 0.56 & 0.79 & 0.71 & 0.64 & 0.77 & 0.68 & 0.84 & 0.72 & 0.85 & 0.96 \\
\hline Dy & 3.66 & 2.76 & 3.70 & 3.68 & 4.93 & 4.61 & 4.17 & 4.86 & 4.20 & 5.26 & 4.47 & 5.25 & 5.88 \\
\hline Ho & 0.73 & 0.55 & 0.70 & 0.78 & 0.97 & 0.95 & 0.84 & 0.99 & 0.84 & 1.09 & 0.94 & 1.09 & 1.17 \\
\hline $\mathrm{Er}$ & 2.12 & 1.63 & 1.97 & 2.31 & 2.86 & 2.84 & 2.58 & 3.00 & 2.61 & 3.24 & 2.74 & 3.18 & 3.39 \\
\hline $\mathrm{Tm}$ & 0.30 & 0.24 & 0.28 & 0.36 & 0.45 & 0.43 & 0.41 & 0.46 & 0.42 & 0.50 & 0.42 & 0.48 & 0.52 \\
\hline $\mathrm{Yb}$ & 1.98 & 1.52 & 1.80 & 2.44 & 3.03 & 3.04 & 2.62 & 3.13 & 2.54 & 3.26 & 2.78 & 3.09 & 3.42 \\
\hline Lu & 0.30 & 0.22 & 0.26 & 0.36 & 0.43 & 0.44 & 0.39 & 0.47 & 0.37 & 0.50 & 0.42 & 0.46 & 0.49 \\
\hline Hf & 3.13 & 2.54 & 2.24 & 3.04 & 3.09 & 3.08 & 3.10 & 3.34 & 3.61 & 3.38 & 3.64 & 3.55 & 3.20 \\
\hline $\mathrm{Ta}$ & 0.70 & 0.75 & 0.63 & 0.74 & 0.78 & 0.85 & 0.87 & 0.85 & 0.93 & 0.73 & 0.70 & 0.71 & 0.67 \\
\hline W & 1.00 & 0.65 & 0.78 & 1.21 & 1.29 & 1.18 & 1.24 & 1.47 & 1.36 & 0.83 & 0.85 & 0.87 & 0.85 \\
\hline $\mathrm{Ti}$ & 0.58 & 0.66 & 0.54 & 1.07 & 1.49 & 0.85 & 0.68 & 1.02 & 0.78 & 0.98 & 0.87 & 0.84 & 0.71 \\
\hline $\mathrm{Pb}$ & 14.5 & 13.2 & 12.6 & 10.1 & 16.6 & 11.3 & 11.9 & 12.7 & 13.7 & 15.7 & 16.8 & 8.55 & 9.38 \\
\hline Th & 11.6 & 10.1 & 9.73 & 9.67 & 12.0 & 10.9 & 11.1 & 11.9 & 11.9 & 11.6 & 12.6 & 13.1 & 11.3 \\
\hline U & 2.05 & 1.72 & 1.47 & 2.04 & 2.37 & 2.29 & 2.36 & 2.61 & 2.09 & 2.60 & 2.29 & 2.39 & 2.43 \\
\hline $\mathrm{Rb} / \mathrm{Sr}$ & 0.61 & 0.63 & 0.61 & 0.52 & 0.57 & 0.52 & 0.51 & 0.88 & & 0.61 & 0.62 & 0.46 & 0.58 \\
\hline $\mathrm{Zr} / \mathrm{Th}$ & 7.823 & 7.369 & 6.714 & 9.409 & 8.406 & 8.634 & 8.707 & 8.9247 & 8.6785 & 8.781 & 8.431 & 8.662 & 8.751 \\
\hline $\mathrm{Eu} / \mathrm{Eu}^{*}$ & 0.70 & 0.86 & 0.71 & 0.78 & 0.62 & 0.66 & 0.76 & 0.48 & 0.78 & 0.61 & 0.66 & 0.70 & 0.59 \\
\hline
\end{tabular}



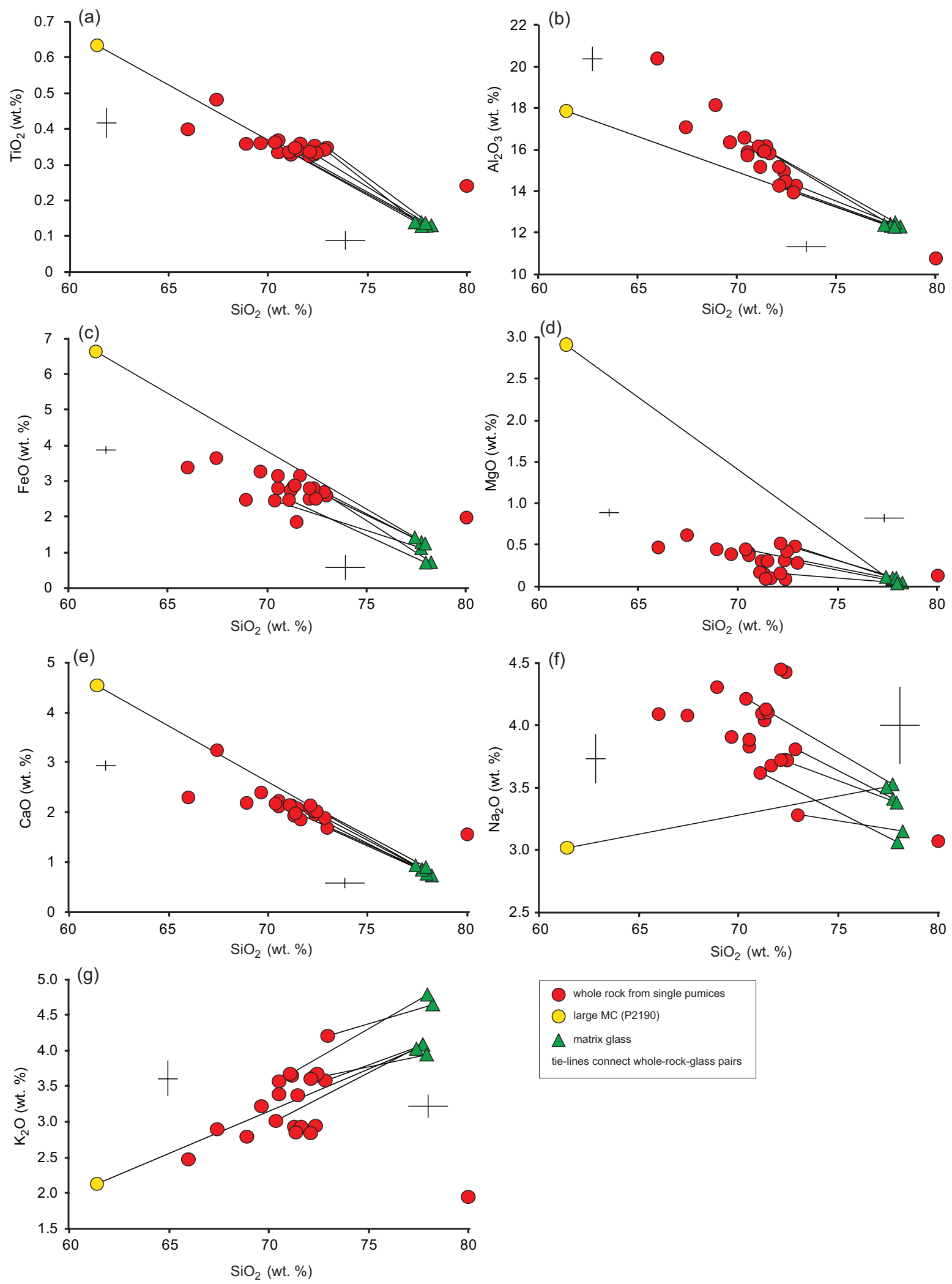

$$
\begin{aligned}
& \text { whole rock from single pumices } \\
& \triangle \text { large MC (P2190) } \\
& \text { matrix glass } \\
& \text { tie-lines connect whole-rock-glass pairs }
\end{aligned}
$$

Fig. 6.3. Plots of major oxides versus silica for whole-rock (red circles) and average matrix glass (green triangles) for all analysed Ongatiti single pumice clasts (total range shown in Figure 6.5). Yellow circle is a large MC (P2190) discussed in the text. Tie lines connect whole-rock-glass pairs. Crosses represent whole-rock 2 sd XRF uncertainties (left hand side) and 2 sd EPMA matrix glass uncertainties (right hand side). 
No significant differences in whole-rock major element concentrations between the lower (Eu I) and upper (Eu II) flows are present (Table 6.1). Minor distinctions in the $\mathrm{Zr} / \mathrm{Th}$ ratio are observed, which may be controlled by varying degrees of zircon crystallisation (Table 6.1). One large MC (P2190) has lesser-evolved compositions, with whole rock values of 61.4 wt. $\% \mathrm{SiO}_{2}, 6.6$ wt. \% FeO and 2.9 wt. \% $\mathrm{MgO}$ (Figure 6.3). However, average matrix glass compositions within this sample are the same (within analytical uncertainty) as pumice matrix glass. The whole rock-to-glass tie lines for this sample have similar gradients to normal pumice samples, apart from $\mathrm{MgO}$ and $\mathrm{Na}_{2} \mathrm{O}$. Pumice sample P2177 is unusual in appearance with a platy 'bamboo' texture and is a crystal poor end-member. This sample is highly siliceous ( 80 wt. \% $\left.\mathrm{SiO}_{2}\right)$ and is therefore likely to be vapour-phase altered. Average chondrite normalised rare-earth element (REE) whole-rock profiles show typical enrichments in LREE relative to HREE, but have a smaller negative Eu anomaly ( 0.69) in comparison to typical rhyolites (Figure 6.4), including the Kidnappers and Rocky Hill examples from Mangakino (Chapter 4). The small whole-rock Eu anomaly is a consequence of the crystal rich nature of pumices coupled with mineral assemblages dominated (70-90\%) by plagioclase, which has large positive Eu anomaly.

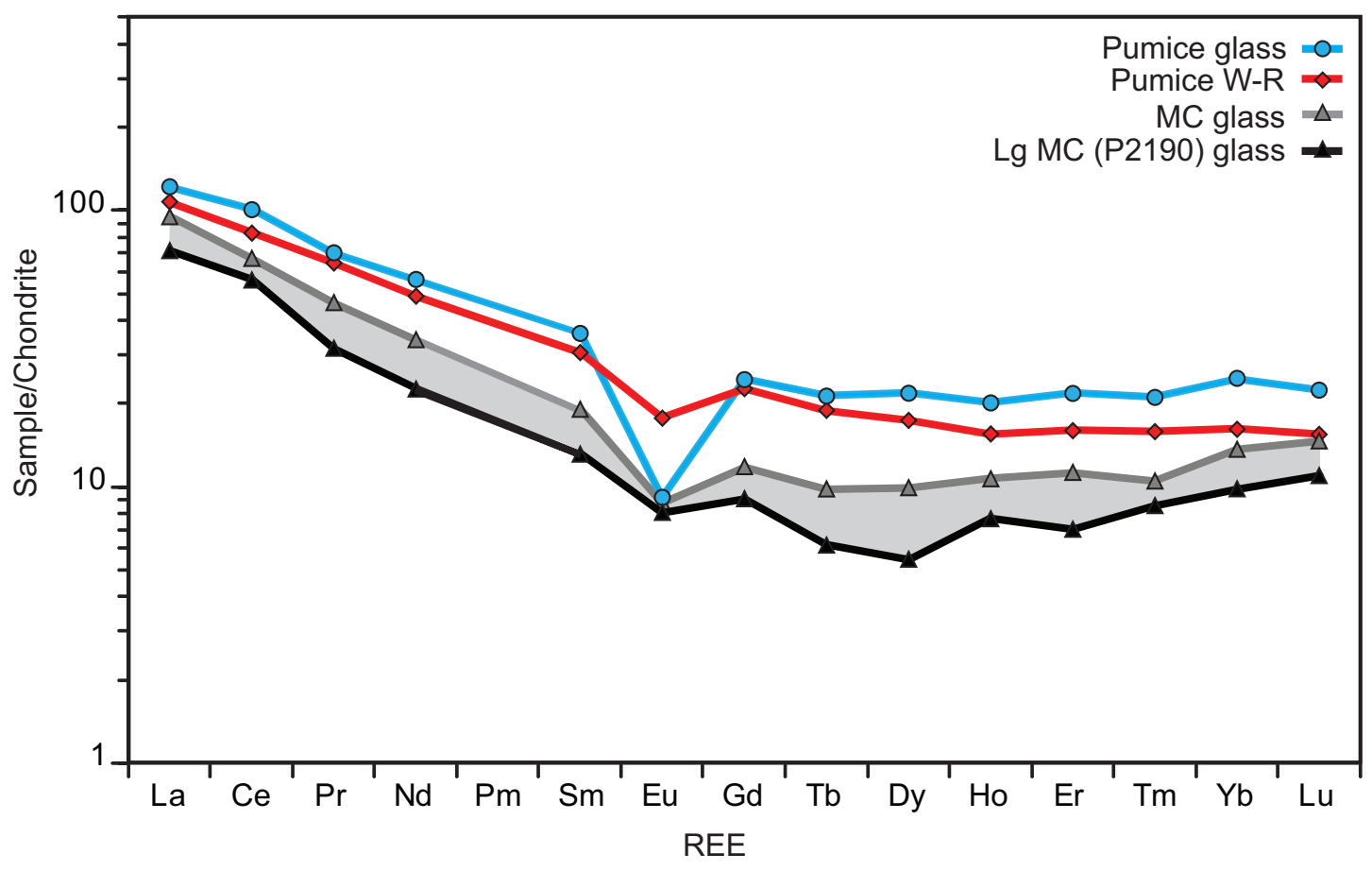

Fig. 6.4. Chondrite normalised rare earth element patterns for averages of pumice whole-rock, pumice matrix glass and microcrystalline clot (MC) glass. Shaded grey area is the typical range of $\mathrm{MC}$ glass. Note the larger negative $\mathrm{Eu} / \mathrm{Eu}^{*}$ in pumice glass compared with whole-rock values. Chondrite normalisation values are from Evensen et al. (1978). 


\subsubsection{Pumice matrix glass}

Matrix glass within Ongatiti pumices shows a variety of textures and vesiculation. Glass within dense pumices, particularly from the lower ignimbrite flows is partially devitrified, and therefore difficult to gain reliable and meaningful analyses from. Pumices from the upper flows containing fresh matrix glass were therefore targeted for EPMA and LA-ICPMS analysis. Average major and trace element glass data from pumices and MCs are presented in Table 6.2. Matrix glass from all analysed pumice samples has very similar chemistry (Figure 6.5). The range in matrix glass major element concentrations within each individual pumice overlap and average compositions are generally within analytical uncertainties. All matrix glass shards are in the range of 77.2-79.1 wt. \% $\mathrm{SiO}_{2}, 0.6-1.0$ wt. \% $\mathrm{CaO}$ and 0.2-1.5 wt. \% FeO (Figure 6.5). Compositions of pumice matrix glass are restricted with respect to the majority of trace elements, but variations outside of analytical uncertainty are present (Figure 6.6). $\mathrm{The} \mathrm{Rb} / \mathrm{Sr}$ and $\mathrm{Eu} / \mathrm{Eu}^{*}$ ratios (proxies of melt evolution) vary within pumice glass from 2.4-3.8 and 0.1-0.6 respectively (Figure 6.6a-c). Other trace element ratios, such as $\mathrm{Zr} / \mathrm{Y}, \mathrm{Ba} / \mathrm{La}, \mathrm{La} / \mathrm{Yb}$ and $\mathrm{Sr} / \mathrm{Y}$ have a very restricted range within pumice glass (Figure 6.6d). $\mathrm{Yb} / \mathrm{Gd}$, Th and $\mathrm{Zr}$ concentrations, however, show a larger range outside of analytical uncertainty. Two distinct groups based on Mn concentrations are present, at 90-210 ppm and 300-320 ppm. The low-Mn group covaries with Mg concentrations. The high-Mn group covers a similar range in Mg as MC glass and is at the low Mg end of the MC compositional array (670-890 ppm Mg) (Figure 6.6f). The average chondritenormalised REE matrix glass profile is similar to the whole-rock profile, but has a significantly larger negative $\mathrm{Eu}$ anomaly $\left(\mathrm{Eu} / \mathrm{Eu}^{*}\right.$ of $\left.\sim 0.32\right)$ implying significant plagioclase crystallisation from this melt has occurred, consistent with the whole-rock signature. The $\mathrm{Eu}$ anomaly is larger than within glass from the Kidnappers and Rocky Hill (average $\mathrm{Eu} / \mathrm{Eu}^{*}$ of $\sim 0.45$ ), suggesting higher degrees of plagioclase crystallisation and melt evolution within the Ongatiti.

\subsubsection{Microcrystalline clot matrix glass}

Glass within MCs was analysed to compare with matrix glass in the conventional pumices. The majority of MCs have glass compositions in the range of 77-78.4 wt. \% $\mathrm{SiO}_{2}, 0.8-1.0$ wt. \% $\mathrm{CaO}$ and 1.1-1.5 wt. \% FeO (Figure 6.5), which represents a slightly more restricted range than pumice matrix glass. 
Table 6.2. Average major (EPMA) and trace element (LA-ICP-MS) concentrations of matrix glass from each analysed pumice and microcrystalline clast. Major element concentrations are normalised to $100 \mathrm{wt}$. \% and Totals shown are uncorrected. Representative 2 sd uncertainties of both techniques are presented in Appendix 1.

\begin{tabular}{|c|c|c|c|c|c|c|c|c|c|c|c|c|c|c|c|}
\hline & \multicolumn{6}{|c|}{ Pumice glass } & \multicolumn{9}{|c|}{ Microcrystalline clots } \\
\hline & GC1 & P2023 & P2026 & P2027 & P2177 & P2184 & $\begin{array}{l}\text { Lg clast } \\
\text { P2190 }\end{array}$ & $\begin{array}{l}\text { clast } \\
\text { GC2 }\end{array}$ & $\begin{array}{l}\text { clast } \\
\text { GC10 }\end{array}$ & $\begin{array}{l}\text { clast } \\
\text { GC7 }\end{array}$ & $\begin{array}{l}\text { clast } \\
\text { GC9 }\end{array}$ & $\begin{array}{l}\text { clast } \\
\text { GC11 }\end{array}$ & $\begin{array}{l}\text { clast } \\
\text { GC16 }\end{array}$ & $\begin{array}{c}\text { clot } \\
\text { P2021 }\end{array}$ & $\begin{array}{c}\text { clot } \\
\text { P2022 }\end{array}$ \\
\hline \multicolumn{16}{|c|}{ Major elements by EPMA } \\
\hline $\mathrm{SiO}_{2}$ & 77.7 & 77.7 & 78.2 & 78.0 & 77.9 & 78.6 & 77.4 & 77.6 & 77.6 & 77.5 & 77.8 & 77.7 & 78.6 & 78.0 & 77.8 \\
\hline $\mathrm{TiO}_{2}$ & 0.13 & 0.14 & 0.13 & 0.13 & 0.14 & 0.13 & 0.14 & 0.12 & 0.15 & 0.12 & 0.14 & 0.13 & 0.14 & 0.14 & 0.13 \\
\hline $\mathrm{Al}_{2} \mathrm{O}_{3}$ & 12.3 & 12.4 & 12.3 & 12.5 & 12.3 & 12.2 & 12.4 & 12.4 & 12.3 & 12.4 & 12.2 & 12.3 & 12.4 & 12.2 & 12.3 \\
\hline $\mathrm{FeO}$ & 1.30 & 1.12 & 0.73 & 0.72 & 1.25 & 0.74 & 1.42 & 1.28 & 1.45 & 1.29 & 1.32 & 1.38 & 0.85 & 1.27 & 1.30 \\
\hline MnO & 0.04 & 0.03 & 0.01 & 0.01 & 0.04 & 0.02 & 0.04 & 0.04 & 0.03 & 0.04 & 0.04 & 0.04 & 0.02 & 0.04 & 0.03 \\
\hline $\mathrm{MgO}$ & 0.11 & 0.09 & 0.05 & 0.04 & 0.11 & 0.06 & 0.12 & 0.10 & 0.12 & 0.10 & 0.12 & 0.10 & 0.05 & 0.11 & 0.11 \\
\hline $\mathrm{CaO}$ & 0.85 & 0.86 & 0.74 & 0.77 & 0.91 & 0.79 & 0.94 & 0.85 & 0.94 & 0.85 & 0.90 & 0.84 & 0.87 & 0.94 & 0.90 \\
\hline $\mathrm{Na}_{2} \mathrm{O}$ & 3.41 & 3.53 & 3.15 & 3.06 & 3.38 & 3.32 & 3.51 & 3.53 & 3.55 & 3.61 & 3.62 & 3.40 & 3.97 & 3.44 & 3.51 \\
\hline $\mathrm{K}_{2} \mathrm{O}$ & 4.08 & 4.08 & 4.65 & 4.79 & 3.94 & 4.09 & 4.02 & 4.03 & 3.89 & 4.08 & 3.83 & 4.13 & 3.13 & 3.88 & 3.90 \\
\hline Total & 94.8 & 95.2 & 94.9 & 95.4 & 95.2 & 95.7 & 95.2 & 96.1 & 96.1 & 95.7 & 96.7 & 95.1 & 96.3 & 95.8 & 96.3 \\
\hline \multicolumn{16}{|c|}{ Trace elements by LA-ICPMS } \\
\hline $\mathbf{L i}$ & 35.8 & 50.4 & 58.9 & 48.1 & 43.5 & 47.1 & 28.7 & 44.8 & 36.9 & & & & & & \\
\hline Mg & 797 & 656 & 406 & 700 & 797 & 499 & 1177 & 754 & 1139 & & & & & & \\
\hline $\mathrm{Ca}$ & 5826 & 5940 & 4656 & 5570 & 6230 & 5486 & 6878 & 6140 & 7035 & & & & & & \\
\hline Sc & 13.3 & 15.1 & 12.4 & 13.4 & 14.5 & 15.6 & 13.5 & 12.5 & 10.7 & & & & & & \\
\hline $\mathrm{Ti}$ & 816 & 828 & 726 & 834 & 781 & 781 & 910 & 823 & 944 & & & & & & \\
\hline V & 1.73 & 3.06 & 1.21 & 2.60 & 1.93 & 2.62 & 7.60 & 1.54 & 2.96 & & & & & & \\
\hline Mn & 330 & 172 & 117 & 152 & 314 & 132 & 295 & 323 & 276 & & & & & & \\
\hline $\mathrm{Zn}$ & 31.6 & 28.1 & 25.2 & 43.4 & 43.4 & 30.3 & 38.3 & 35.4 & 37.2 & & & & & & \\
\hline $\mathrm{Ga}$ & 15.4 & 15.3 & 15.3 & 18.2 & 14.5 & 15.5 & 17.1 & 15.0 & 15.8 & & & & & & \\
\hline $\mathbf{R b}$ & 159 & 152 & 160 & 152 & 143 & 145 & 135 & 161 & 146 & & & & & & \\
\hline $\mathrm{Sr}$ & 53.3 & 53.3 & 49.5 & 49.8 & 54.5 & 54.2 & 71.2 & 54.9 & 62.1 & & & & & & \\
\hline$Y$ & 35.8 & 33.5 & 33.4 & 32.2 & 32.1 & 31.5 & 10.0 & 36.5 & 17.6 & & & & & & \\
\hline $\mathrm{Zr}$ & 137 & 128 & 135 & 135 & 130 & 124 & 182 & 143 & 197 & & & & & & \\
\hline $\mathrm{Nb}$ & 9.15 & 9.44 & 9.04 & 9.60 & 8.69 & 9.60 & 5.95 & 10.02 & 7.18 & & & & & & \\
\hline Mo & 1.99 & 1.78 & 1.20 & 0.70 & 2.12 & 2.73 & 1.55 & 2.00 & 1.23 & & & & & & \\
\hline Cs & 7.76 & 7.84 & 8.21 & 8.16 & 7.46 & 8.01 & 7.33 & 8.16 & 7.17 & & & & & & \\
\hline $\mathrm{Ba}$ & 936 & 888 & 920 & 853 & 852 & 831 & 848 & 958 & 916 & & & & & & \\
\hline La & 32.1 & 30.2 & 30.4 & 29.6 & 29.3 & 27.5 & 17.5 & 32.3 & 23.2 & & & & & & \\
\hline $\mathrm{Ce}$ & 69.3 & 64.7 & 65.7 & 64.9 & 62.7 & 59.3 & 35.7 & 67.1 & 42.8 & & & & & & \\
\hline $\mathrm{Pr}$ & 7.37 & 7.07 & 6.78 & 7.01 & 6.57 & 6.10 & 3.06 & 7.33 & 4.48 & & & & & & \\
\hline $\mathrm{Nd}$ & 28.2 & 26.7 & 27.2 & 28.0 & 26.7 & 24.7 & 10.7 & 28.5 & 16.2 & & & & & & \\
\hline Sm & 6.37 & 5.22 & 5.94 & 5.00 & 5.17 & 5.09 & 2.02 & 5.91 & 2.94 & & & & & & \\
\hline Eu & 0.56 & 0.53 & 0.50 & 0.51 & 0.60 & 0.48 & 0.47 & 0.50 & 0.51 & & & & & & \\
\hline Gd & 5.23 & 4.67 & 5.54 & 4.30 & 5.00 & 4.61 & 1.85 & 5.28 & 2.42 & & & & & & \\
\hline Tb & 0.92 & 0.84 & 0.74 & 0.72 & 0.76 & 0.76 & 0.23 & 0.90 & 0.37 & & & & & & \\
\hline Dy & 5.54 & 5.01 & 6.09 & 4.90 & 5.07 & 6.01 & 1.39 & 6.18 & 2.52 & & & & & & \\
\hline Ho & 1.37 & 1.16 & 1.20 & 1.05 & 1.09 & 1.01 & 0.44 & 1.32 & 0.62 & & & & & & \\
\hline $\mathrm{Er}$ & 4.06 & 3.60 & 3.70 & 3.50 & 3.23 & 3.52 & 1.17 & 3.96 & 1.87 & & & & & & \\
\hline $\mathrm{Tm}$ & 0.59 & 0.53 & 0.51 & 0.50 & 0.52 & 0.56 & 0.22 & 0.58 & 0.27 & & & & & & \\
\hline $\mathrm{Yb}$ & 4.20 & 4.00 & 4.39 & 3.93 & 3.82 & 3.98 & 1.62 & 4.36 & 2.26 & & & & & & \\
\hline Lu & 0.63 & 0.54 & 0.51 & 0.56 & 0.58 & 0.60 & 0.28 & 0.64 & 0.37 & & & & & & \\
\hline Hf & 4.19 & 3.89 & 4.38 & 4.00 & 3.91 & 3.89 & 4.24 & 4.45 & 4.97 & & & & & & \\
\hline $\mathrm{Ta}$ & 0.99 & 0.87 & 0.80 & 0.96 & 0.92 & 0.88 & 0.54 & 0.99 & 0.67 & & & & & & \\
\hline $\mathbf{W}$ & 1.61 & 2.66 & 2.37 & 1.53 & 1.89 & 6.08 & 1.24 & 1.85 & 1.29 & & & & & & \\
\hline $\mathbf{P b}$ & 21.8 & 16.1 & 17.0 & 14.2 & 20.4 & 17.2 & 16.3 & 19.5 & 19.1 & & & & & & \\
\hline Th & 16.9 & 14.7 & 15.5 & 15.0 & 15.0 & 14.1 & 10.9 & 17.1 & 12.6 & & & & & & \\
\hline $\mathbf{U}$ & 3.70 & 3.29 & 3.43 & 3.91 & 3.50 & 3.50 & 2.49 & 3.63 & 2.87 & & & & & & \\
\hline $\mathrm{Eu} / \mathrm{Eu}^{*}$ & 0.30 & 0.34 & 0.28 & 0.34 & 0.31 & 0.37 & 0.81 & 0.28 & 0.64 & & & & & & \\
\hline $\mathrm{Rb} / \mathrm{Sr}$ & 3.00 & 2.85 & 3.26 & 3.06 & 2.63 & 2.68 & 1.91 & 2.93 & 2.35 & & & & & & \\
\hline
\end{tabular}

Glass within one example of a $\mathrm{MC}(\mathrm{GC} 16)$ has a greater heterogeneity and higher $\mathrm{SiO}_{2}$ concentrations (78.0-79.2 wt. \% $\left.\mathrm{SiO}_{2}\right)$. Glass compositions within this clast fall into two groups based on $\mathrm{CaO}$ (Figure $6.5 \mathrm{c}$ ), $\mathrm{Na}_{2} \mathrm{O}$ and $\mathrm{K}_{2} \mathrm{O}$ concentrations. $\mathrm{CaO}$ groups are at $\sim 0.5$ and 1.0 wt. \% $\mathrm{CaO}$ and $\mathrm{FeO}$ concentrations extend to lower values $(0.36$ wt. \% $\mathrm{FeO}$ ) than in other samples (Figure 6.5d). Glass trace-element concentrations within some MCs are significantly different from pumice matrix glass (Figure 6.6), but one 
example has indistinguishable chemistry and overlaps the pumice glass compositional range on all plots. $\mathrm{Rb} / \mathrm{Sr}$ values are lower (1.5-2.5) and $\mathrm{Eu} / \mathrm{Eu}^{*}$ values are higher (0.41.2) in the other MCs, implying that their melts had less-evolved compositions. Trace element ratios $(\mathrm{Zr} / \mathrm{Y}, \mathrm{Ba} / \mathrm{La})$ are significantly elevated and span a larger range than within pumice matrix glass, but $\mathrm{Yb} / \mathrm{Gd}$ covers a similar range (Figure 6.6c) suggesting that similar levels of amphibole fractionation have occurred in both $\mathrm{MC}$ and pumice melts. $\mathrm{La} / \mathrm{Yb}$ and $\mathrm{Sr} / \mathrm{Y}$ values extend to higher values $(\mathrm{La} / \mathrm{Yb}=6-18 ; \mathrm{Sr} / \mathrm{Y}=1-10$; Figure 6.6d) which are typical of water rich magmas in which crystallisation of plagioclase is suppressed (Richards 2011; Chambefort et al. 2013). Higher Zr concentrations are found within MCs, suggesting less zircon has crystallised from these melts (Figure 6.5a). $\mathrm{Mg}$ concentrations extend to much higher values ( 700-1600 ppm) than in the pumice glass. In contrast to the main pumice compositional trend, Mn decreases with increasing $\mathrm{Mg}$ in $\mathrm{MC}$ glasses and there is a compositional gap between these groups.
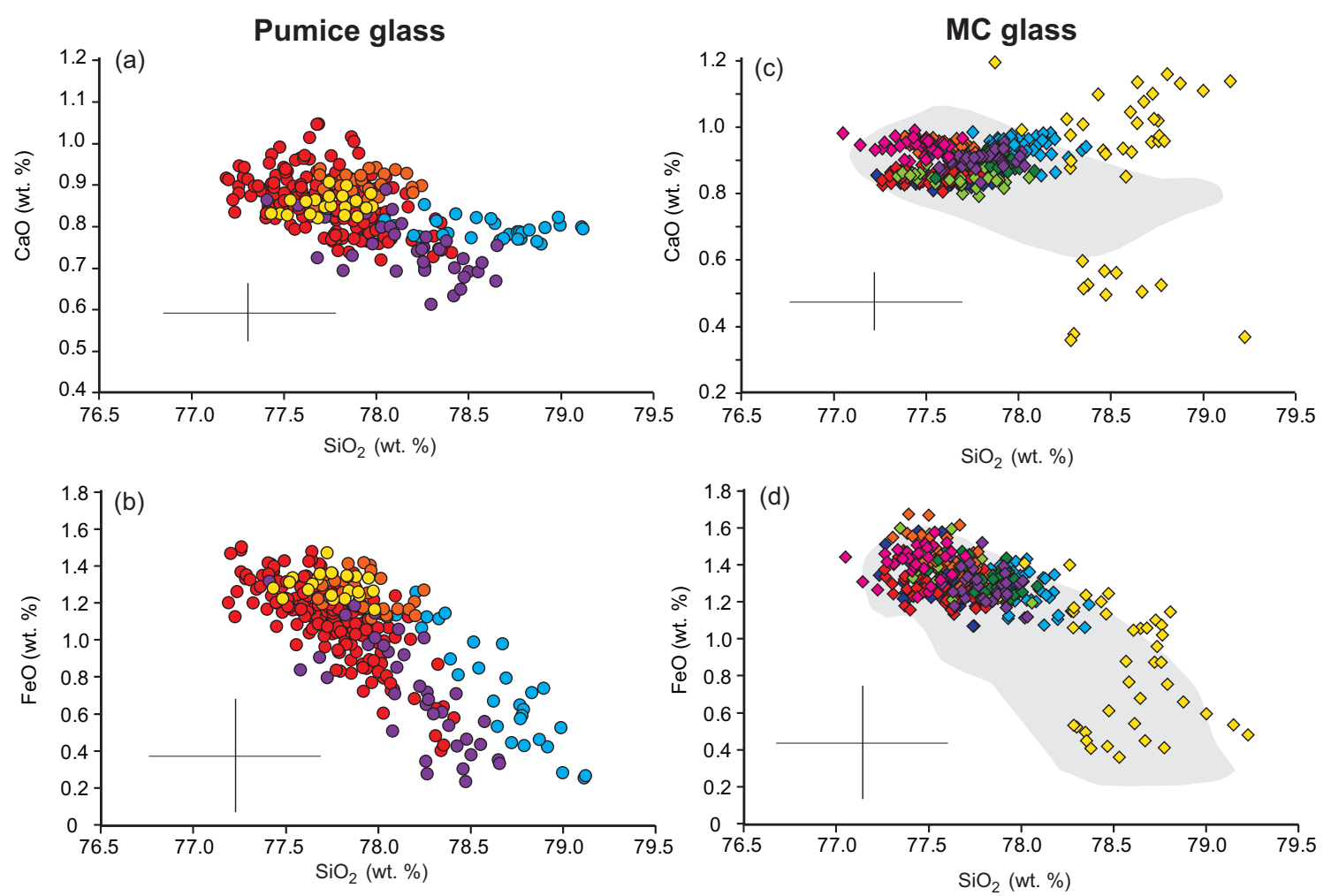

Fig. 6.5. $\mathrm{SiO}_{2}$ versus $\mathrm{CaO}$ and $\mathrm{FeO}$ of glass from Ongatiti pumices and $\mathrm{MC}$ fragments. Each data point represents a single matrix glass analysis and each colour represents a different individual sample. Grey shaded areas in (c) and (d) represent the compositional range of pumice glass. Crosses represent 2 sd uncertainties of glass analyses, calculated from the ATHO-G standard (presented in Appendix 1). 

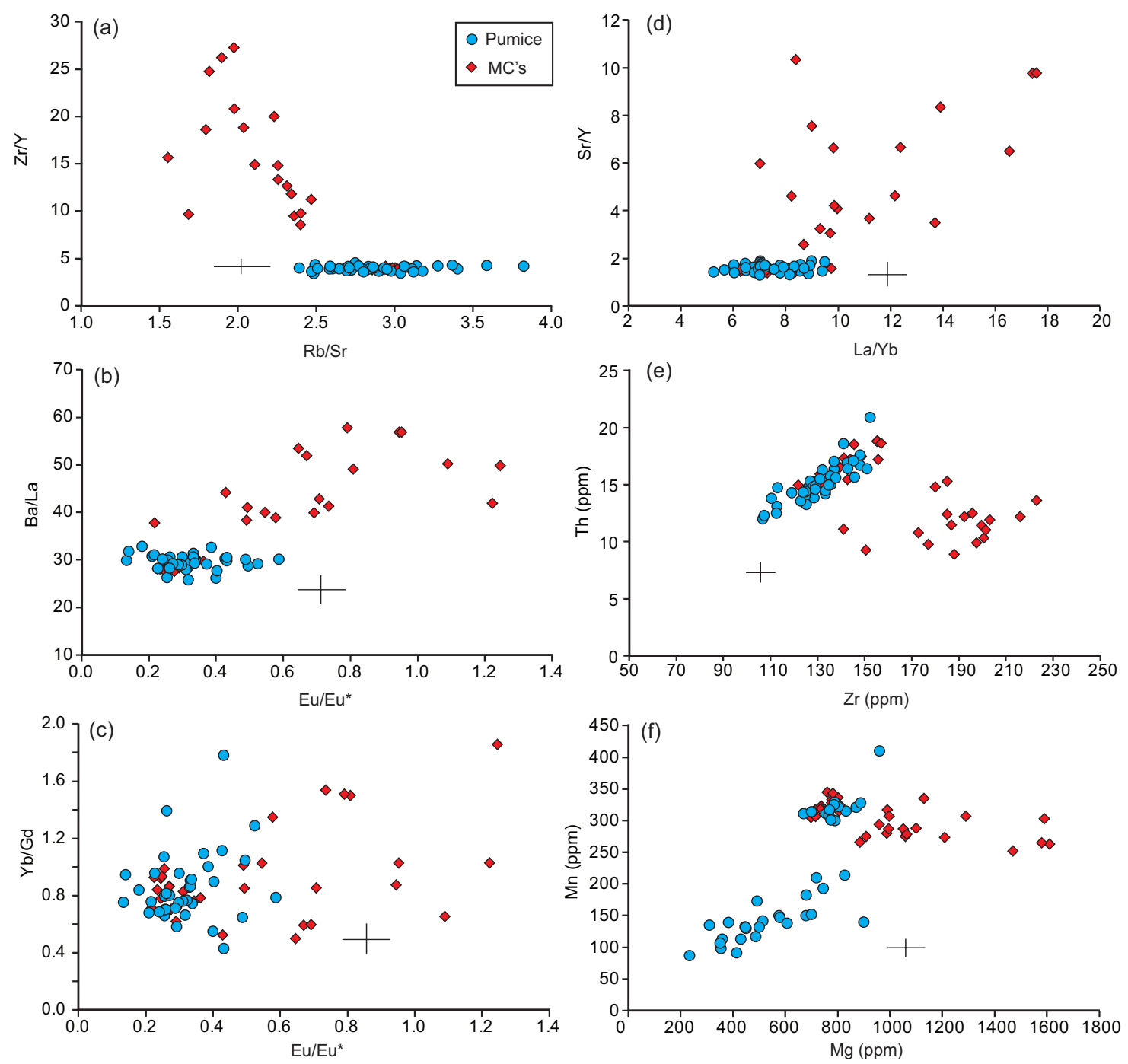

Fig. 6.6. Selected trace element plots of matrix glass from pumice and MC fragments. Each data point represents a single analysis.

Chondrite-normalised MC glass REE profiles are more depleted compared to pumice matrix glass (Figure 6.4), particularly in MREE (Gd to Tm). Such depletions in MREE are similar to those shown by andesitic REE profiles from the TVZ (Cole et al. 1983; Price et al. 2005). Fractionation of high-Al amphibole would be expected to reduce the middle REE content of the melt and has been proposed to occur as a general process within dacitic systems (Chambefort et al. 2013). Eu anomalies in the MC glasses are significantly less pronounced (average $\mathrm{Eu} / \mathrm{Eu}^{*}$ of $0.64-0.81$ ) than within pumice glasses, implying a less evolved origin for the MC melts, involving significantly less plagioclase crystallisation than their pumice glass counterparts. 


\subsubsection{Pumice crystal signatures}

To determine the magmatic history of the Ongatiti system, in situ major and trace element analysis of plagioclase, amphibole and orthopyroxene from large pumices were carried out by EPMA and LA-ICP-MS. These results will be discussed alongside the textural and zoning features of each mineral phase, which are summarised in Figure 6.7. Each crystal phase was divided into two populations based on core textures, which also have contrasting chemistries.

\subsubsection{Plagioclase}

Plagioclase within the pumices is divided into two populations based on texture. A dominant population ( $82 \%$ ) of grains have non-distinct cores, which are darker in BSE than rims. In contrast, a subordinate population (18\%) has bright and often resorbed cores (Figure 6.7). The intermediate domains and rims of both populations typically share a common texture with fine-scale oscillatory zoning. It is important to note that both populations of grains are present in broadly similar proportions within each individual pumice. Plagioclase cores display a large range in compositions from $\mathrm{An}_{21-57}$ and $\mathrm{Or}_{1.2-5.5}$, although the majority are between $\mathrm{An}_{21-32}$ and $\mathrm{Or}_{3.1-5.5}$ (Figure 6.8) and come from the grains with non-distinct dark cores (Figure 6.7). Those crystals with bright and resorbed cores form the scatter to higher An values. Rim compositions plot

within the middle of the total range of core compositions, in a tight cluster from $\mathrm{An}_{27-33}$ and $\mathrm{Or}_{2.9-4.0}$ (Figure 6.8). The dominant population of plagioclase grains (82\%; Figure 6.6) therefore show up-temperature (higher An) rims, implying increasing temperatures and/or water contents of the melt during later stages of crystallisation (Housh and Luhr 1991; Putirka 2005, 2008; Lange et al. 2009). Trends in trace element concentrations mirror those of the major elements. The dominant (82\%) plagioclase population has small core-to-rim increases in $\mathrm{Sr}, \mathrm{Mn}$ and a decrease in Ba. The subordinate (18 \%) population of grains show the reverse of this trend with a more scattered range of core concentrations, which have lower $\mathrm{Sr}$ and $\mathrm{Mn}$ and higher Ba concentrations than corresponding rims (Figure 6.8). 


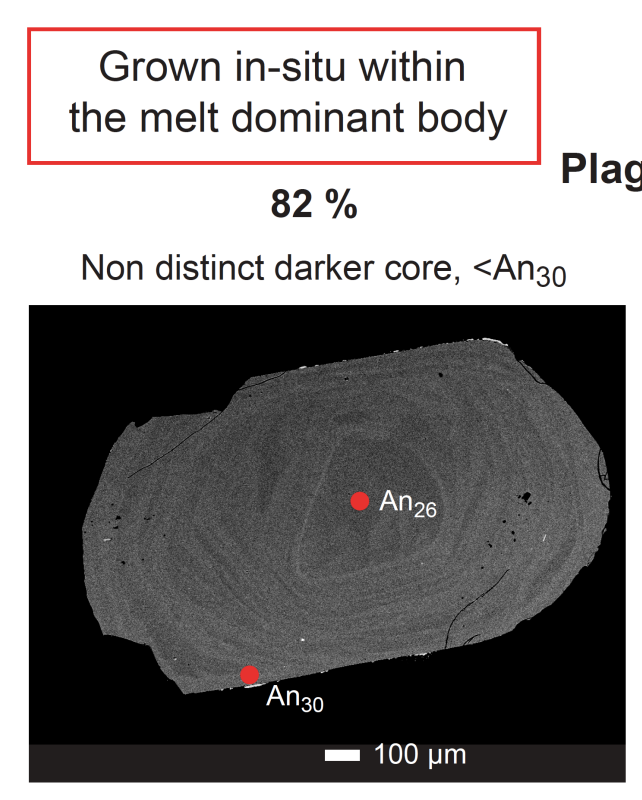

|

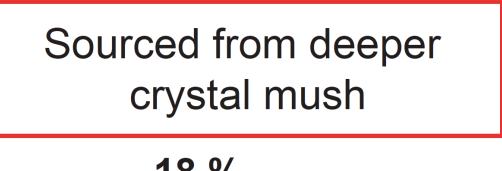

$18 \%$

Bright resorbed core, $>A n_{30-60}$

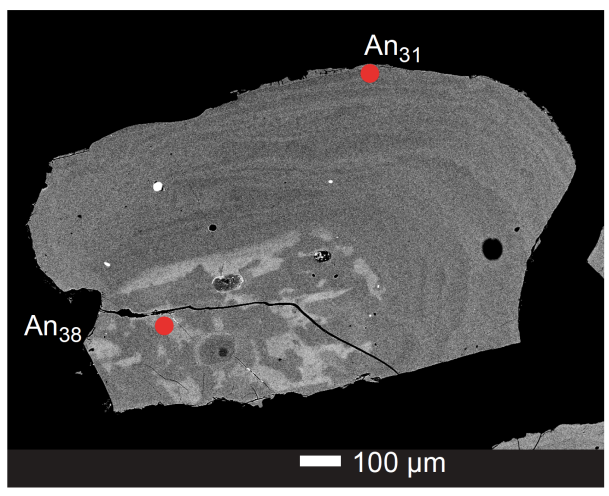

$17 \%$

Amphibole

$83 \%$

Non distinct core oscillatory outer zones

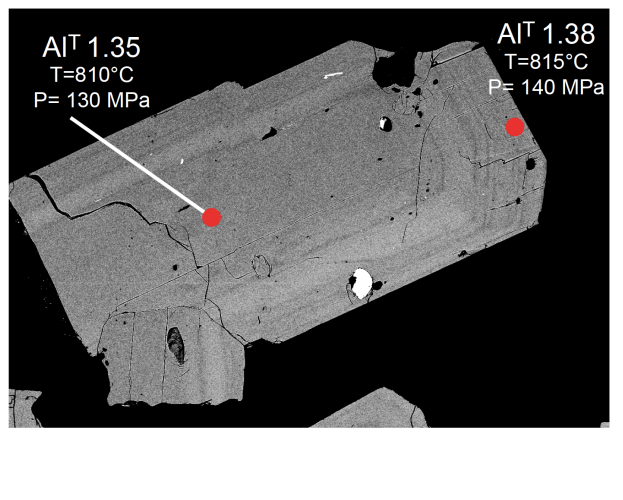
Dark and/or patchy core
oscillatory outer zones

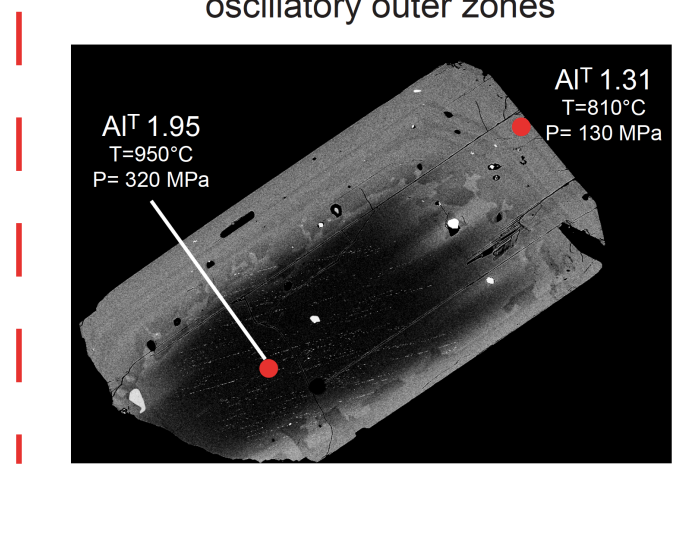

|

$88 \%$

weakly zoned

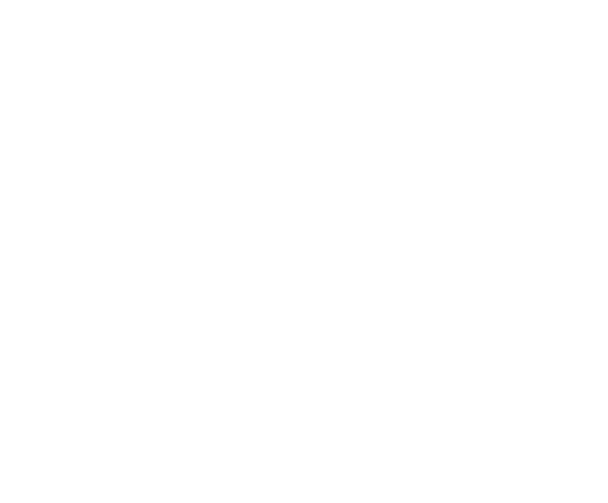

$12 \%$

Dark and/or patchy core

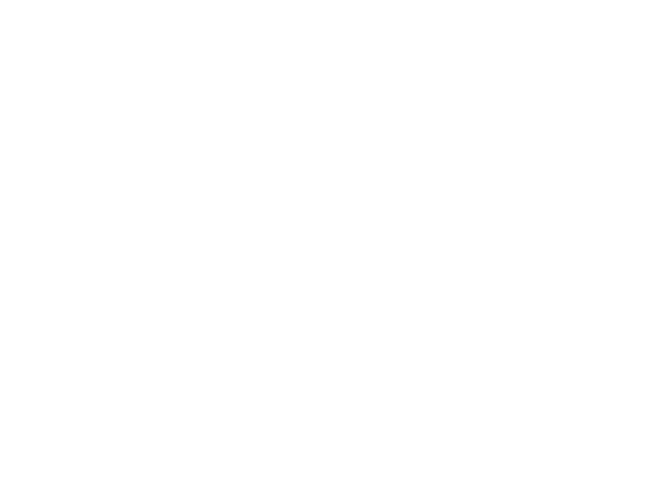

Fig. 6.7. Summary of textural features of Ongatiti plagioclase, amphibole and orthopyroxene. Each mineral phase is divided into two populations based on core textures and chemistries. 

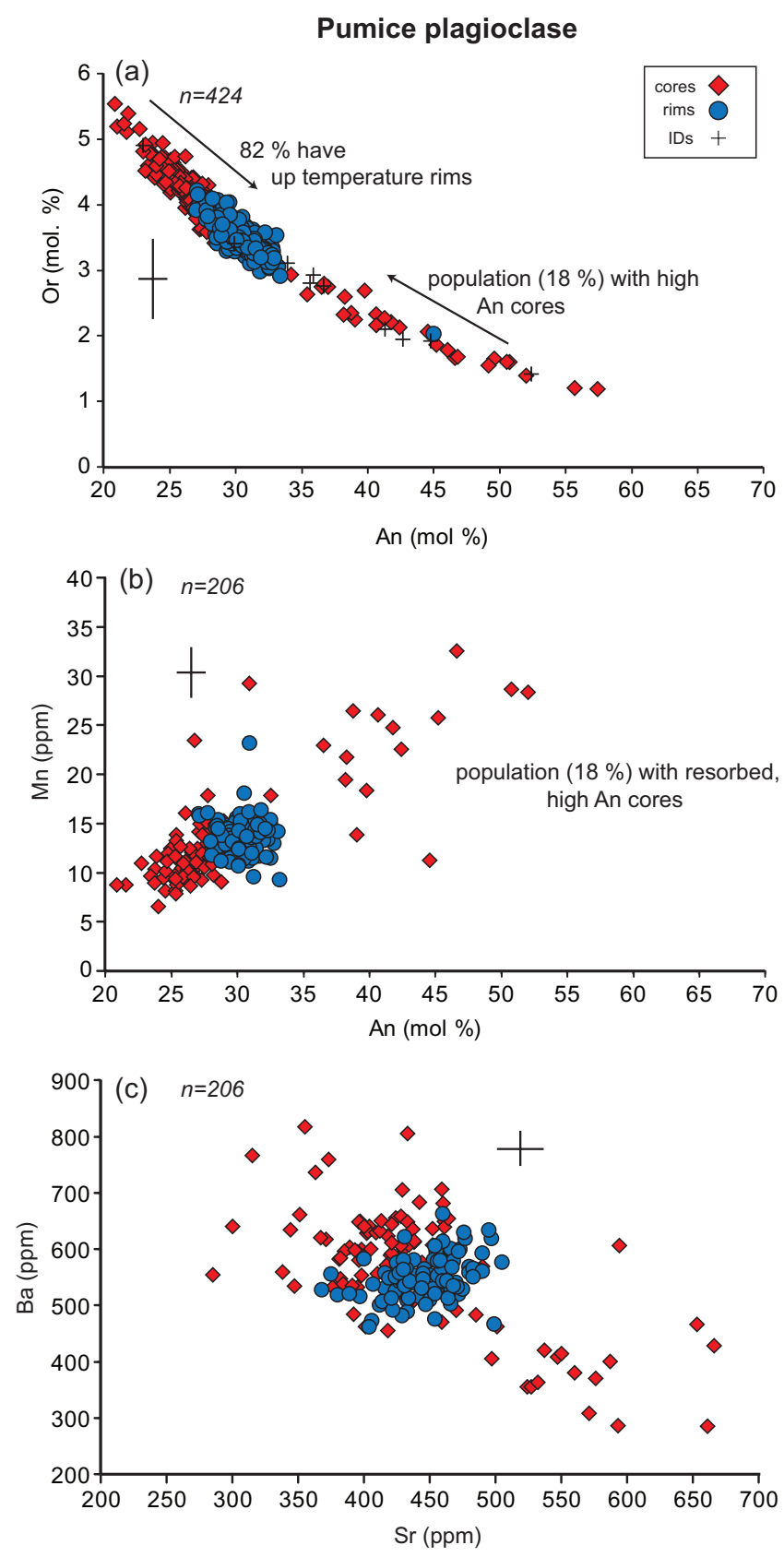

Fig. 6.8. Summary plots of in situ plagioclase compositions from Ongatiti pumice clasts.

To explore the zoning patterns of the two plagioclase populations (Figure 6.7) at a finer scale, a series on EPMA traverses were made with a spacing of $15 \mu \mathrm{m}$ between analytical spots (Figure 6.9a). Typically, grains with non-distinct cores and reverse zoning have a gradual rimward increase in An, with only small oscillations in An content. Few or no sharp compositional steps or boundaries are observed, in contrast to plagioclase and amphibole from the Fish Canyon Tuff, which typically display large spikes in elemental concentrations reflecting their inferred up-temperature evolution as 
a result of a series of rejuvenation events (Bachmann et al. 2002; Bachmann and Dungan 2002). Grains with high $A n\left(>A n_{35}\right)$ and often resorbed cores display a sharp drop in composition at the core boundary, followed by a similar, progressive increase in An towards the rim (Figure 6.9b).

(a) Low An cores - higher An rims (82 \%)
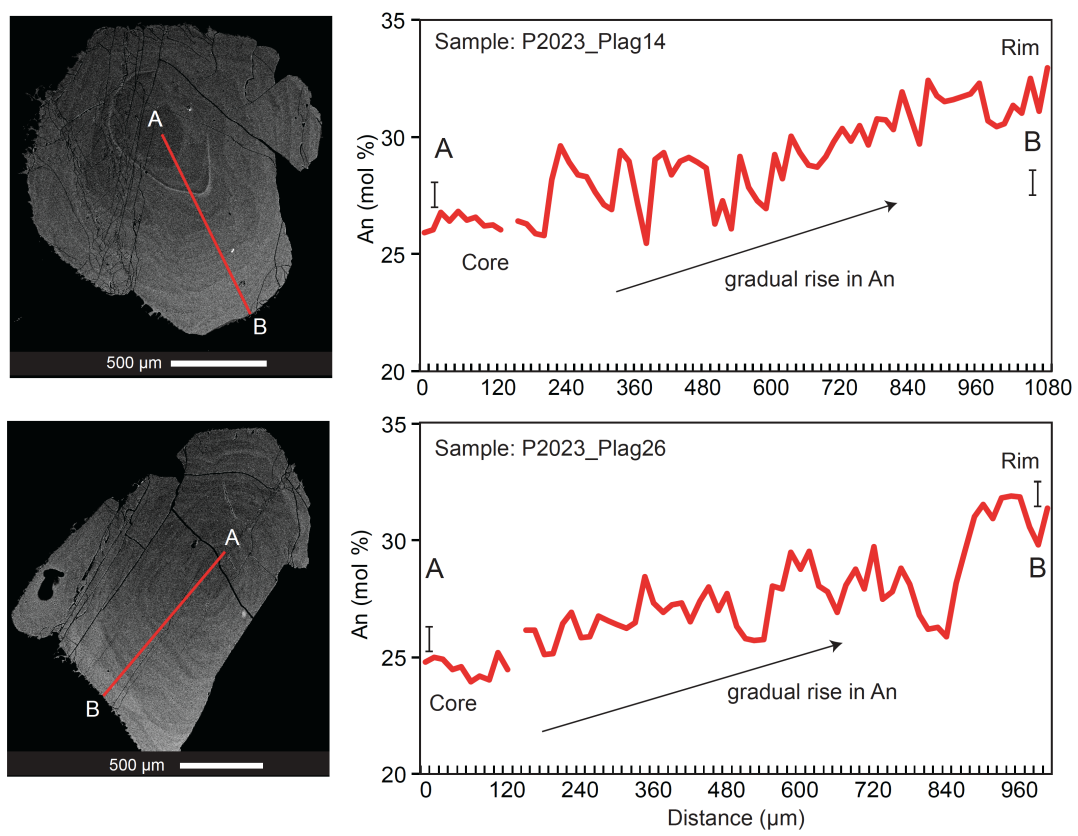

(b) High An cores - lower An rims (12\%)
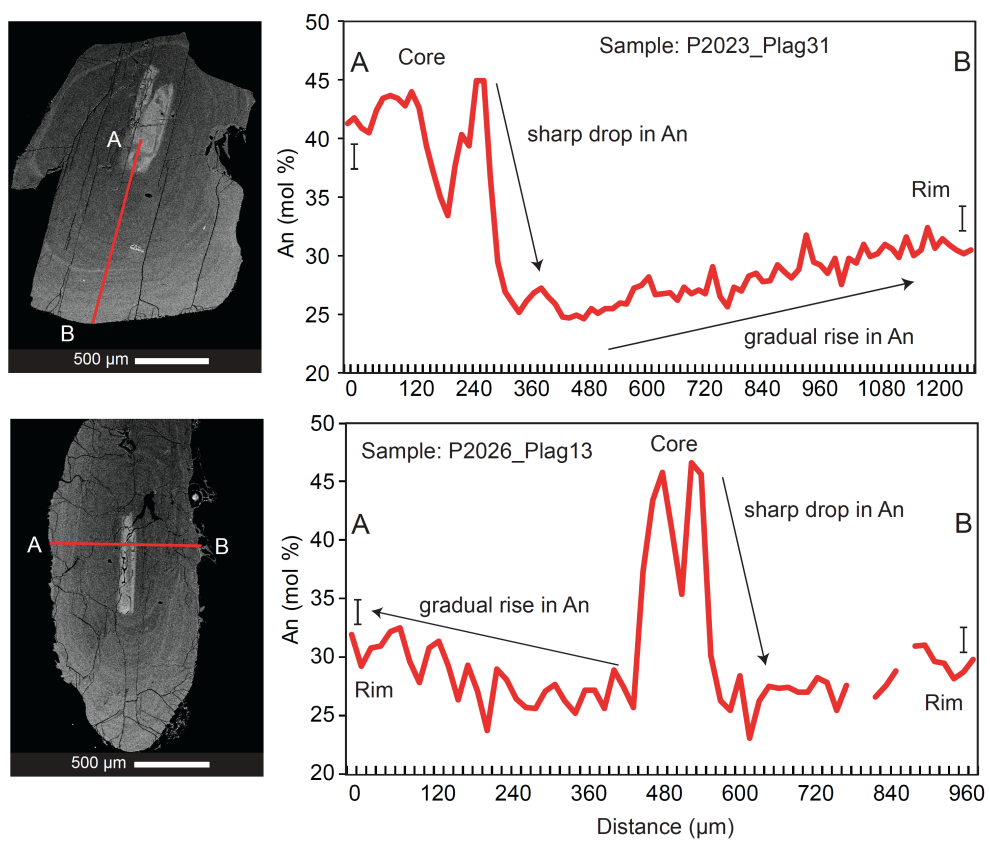

Fig. 6.9. Four core-to-rim EPMA traverses of Ongatiti plagioclase. Spot steps are at $15 \mu \mathrm{m}$. (a) Two profiles of plagioclase from sample P2023 with non-distinct, low An cores demonstrating a gradual rise in $\mathrm{An}$ content from $\sim \mathrm{An}_{25}$ to $\mathrm{An}_{30}$ from core to rim. (b) Two profiles of plagioclase from sample P2026 with bright, high An cores. The same gradual rise in An values from the outside of the core to the rim is observed. 


\subsubsection{Amphibole}

BSE imaging reveals that a high proportion (83\%) of amphiboles have resorbed, dark and/or patchy cores and a subordinate population (17\%) have a non-distinct core (Figure 6.7). Both populations display fine-scale oscillatory zoning in their intermediate and outer zones (Figure 6.7). Both populations of grains are present in similar proportions within each individual pumice (as is the case for plagioclase). The majority of amphiboles recorded within normal pumices have a magnesiohornblende composition, with a lesser proportion of tschermakite-pargasite grains (Electronic appendix). Major and trace element concentrations cover a significant range in amphibole cores, whereas rims have a very narrow range (Figure 6.10). Core $\mathrm{Al}^{\mathrm{T}}$ values are spread between 1.16 and 2.10, compared to a tight clustering in rims from 1.20-1.42. Core $(\mathrm{Na}+\mathrm{K})^{\mathrm{A}}$ values cover a larger range (0.27-0.69) than rims (0.27-0.49), as do $\mathrm{Mg} /\left(\mathrm{Mg}+\mathrm{Fe}^{3+}\right)$ values (0.50-0.77 compared to 0.30-0.62). Cores with $\mathrm{Al}^{\mathrm{T}}$ values $>1.4$ (dashed line in Figure 6.10) belong to the dominant population (83\%) of amphiboles with dark and/or resorbed cores (Figure 6.7). Trace element concentrations reveal greater compositional differences between amphibole cores and rims. A significant number of cores have $\mathrm{Eu} / \mathrm{Eu}^{*}$ from $\sim 0.3-0.9$, and display a large range in concentrations of Sr, Ba and $\mathrm{Mn}$. Sr drops from 200-30 ppm with decreasing $\mathrm{Eu} / \mathrm{Eu}^{*}$ between $\sim 0.9$ 0.4 , whereas rims form a very tight cluster at 0.15-0.20 Eu/Eu* and $\sim 30 \mathrm{ppm}$. The array of high $\mathrm{Eu} / \mathrm{Eu}^{*}(\sim 0.3-0.9)$ cores do not trend towards respective rim compositions with respect to $\mathrm{Sr}, \mathrm{Ba}$ and $\mathrm{Mn}$ (Figure 6.10). High $\mathrm{Eu} / \mathrm{Eu}^{*}$ cores have scattered $\mathrm{Ba}$ concentrations between 50 and $170 \mathrm{ppm}$, whereas rims have a tight distribution from 110-170 ppm Ba. The majority of amphiboles have lower Mn concentrations (1500$3000 \mathrm{ppm})$ in cores than rims (2700-3700 ppm). Sc concentrations are low (80-200 $\mathrm{ppm}$ ) in high $\mathrm{Eu} / \mathrm{Eu}^{*}$ cores and do not change with decreasing $\mathrm{Eu} / \mathrm{Eu}$ *. However, rim Sc concentrations show a large increase below $\sim 0.3 \mathrm{Eu} / \mathrm{Eu}^{*}$, and rims have 350-490 ppm Sc. Cores with $\mathrm{Eu} / \mathrm{Eu}^{*}$ values $>0.3$ belong to the dominant $(83 \%)$ amphibole population (Figure 6.7 ), whereas at $<0.3 \mathrm{Eu} / \mathrm{Eu}^{*}$ cores are non $\operatorname{distinct}(17 \%$ ) with similar compositions as corresponding rims.

There is a significant contrast in chondrite normalised REE profiles from amphibole cores and rims (Figure 6.11). Rim profiles cover a much smaller range and are generally more enriched than cores, in which concentration ratios vary by over an order of 
magnitude. Rims have a very large negative Eu anomaly, whereas dark and/or patchy cores with $\mathrm{Al}^{\mathrm{T}}$ values greater than $\sim 1.4$ (dashed line in Figure 6.10) have only a small negative Eu anomaly. These patterns suggest that the dominant $(83 \%)$ population of amphiboles originated from a lesser-evolved melt, which had undergone significantly less plagioclase crystallisation than the final melt from which all amphibole rims crystallised.
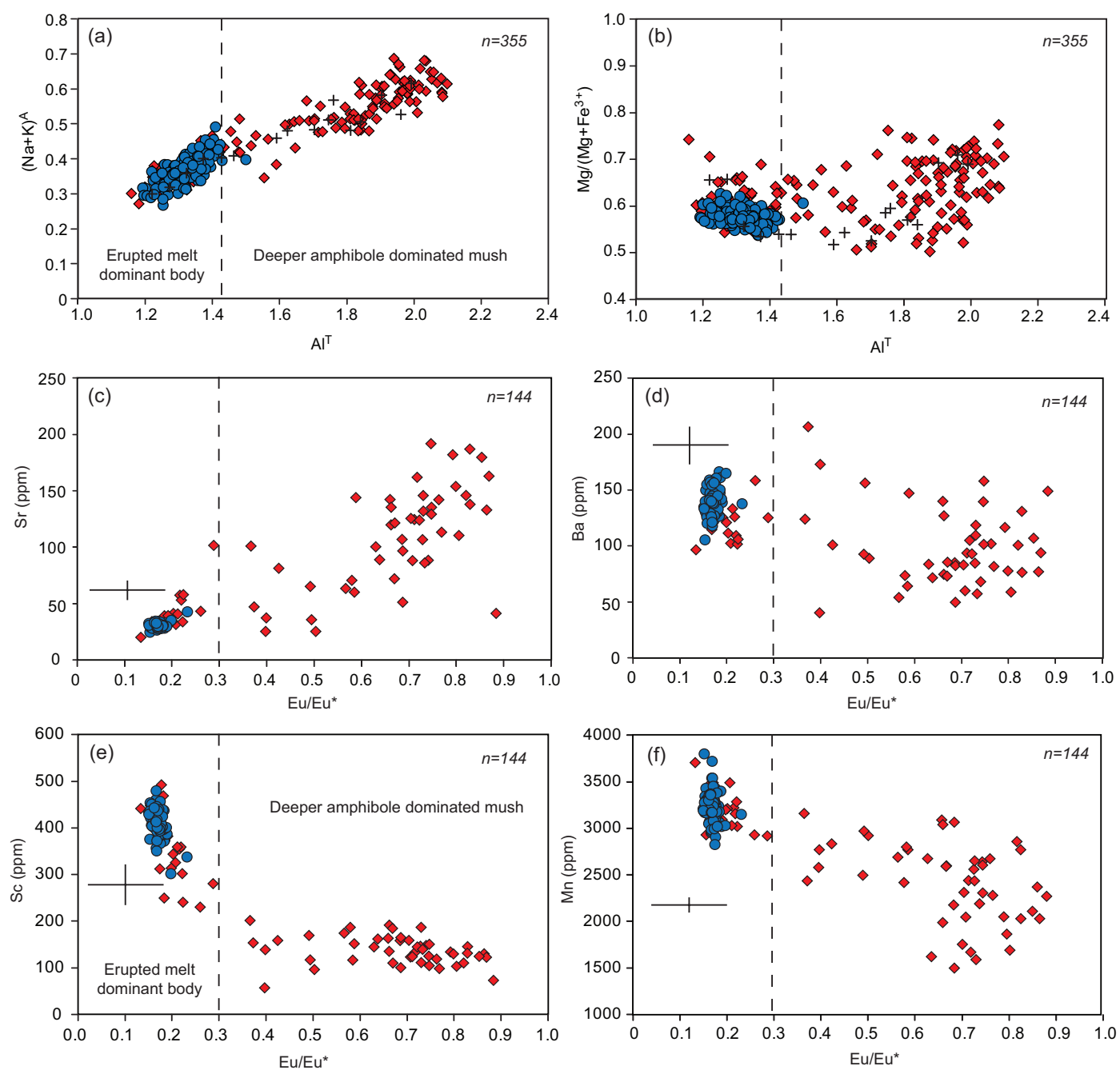

Fig. 6.10. In-situ major and trace element compositions of amphiboles from Ongatiti pumice clasts. In-situ, core-to-rim trace element concentrations in (c-f) are plotted against amphibole $\mathrm{Eu} / \mathrm{Eu}^{*}$ values, which are used as an index of evolution of the melt (low values $=$ more evolved; high values $=$ less evolved) at the time of crystallisation. Dashed line links the change in composition $\left(\mathrm{Al}^{\mathrm{T}}\right.$ and $\mathrm{Eu} / \mathrm{Eu}^{*}$ values) to the onset of crystallisation within the upper crustal magma body. 


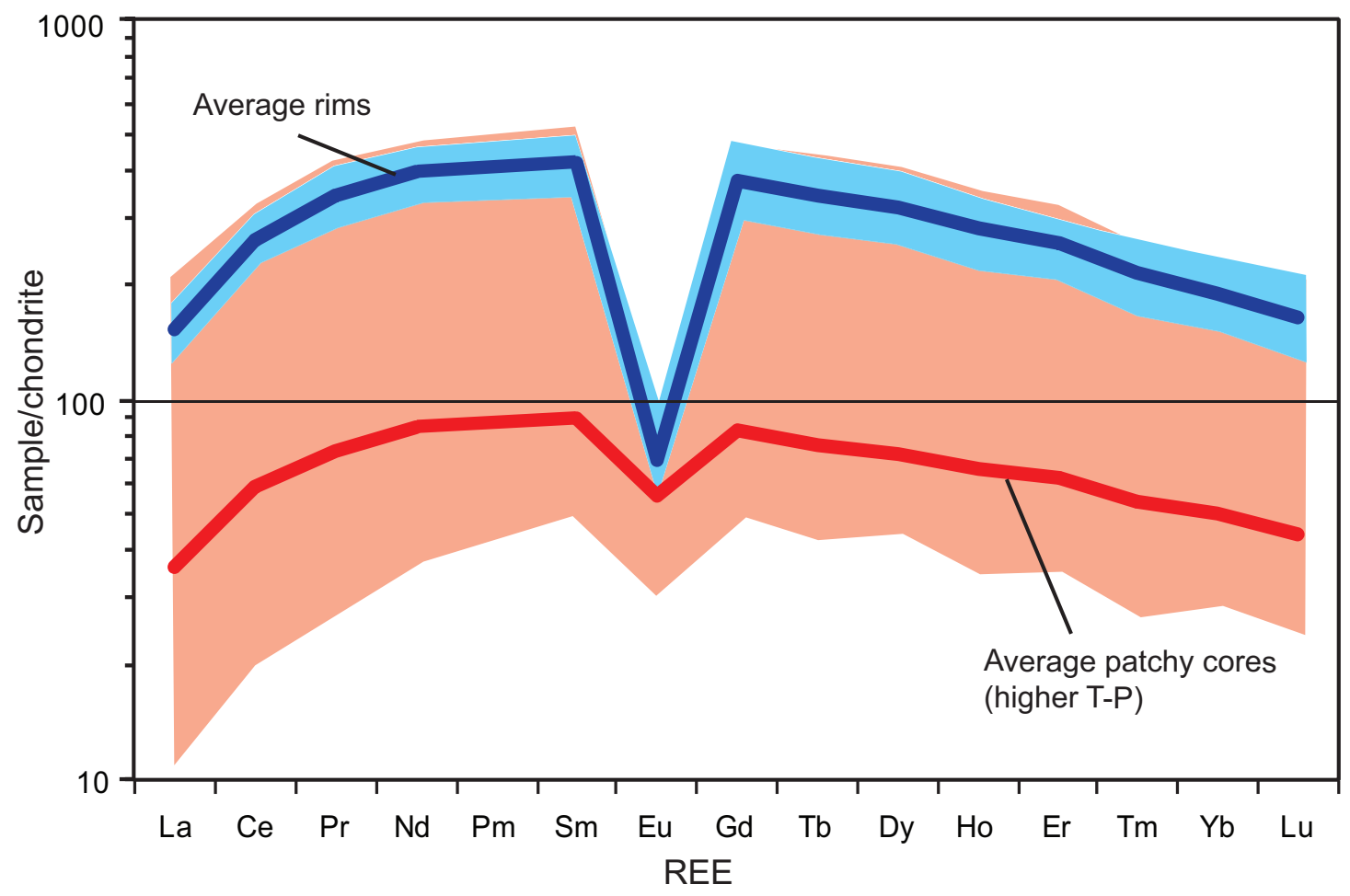

Fig. 6.11. Chondrite normalised rare earth element patterns for amphiboles from pumice clasts. The blue shaded area is the total range of rim values and the blue line is the average profile. The shaded red area is the total range in core values and the red line is the average profile from cores at $\mathrm{Eu} / \mathrm{Eu}^{*}$ values of $>0.4$, beyond the dashed line in Figure. 6.10. Note the much larger negative $\mathrm{Eu} / \mathrm{Eu}^{*}$ in amphibole rims compared with amphibole cores. Chondrite normalisation values are from Evensen et al. (1978).

\subsubsection{Pyroxene}

Orthopyroxene phenocrysts (up to $\sim 1 \mathrm{~mm}$ long) commonly have ragged terminations, similar to those seen in grains from the younger Kidnappers and Rocky Hill eruptions (Chapter 4). Unlike the plagioclase and amphibole, only a small proportion of orthopyroxenes have any significant zoning (Figure 6.7). Orthopyroxenes can be divided into two textural populations; the dominant population (88\%) displays weak zoning under BSE with slightly lighter and streaky intermediate domains; and a subordinate population (12\%) has dark and/or patchy cores. Both populations are present in similar proportions within each individual pumice (as is the case for plagioclase and amphibole). The majority of orthopyroxene cores (88 \%) have a small compositional range and cluster at $\mathrm{En}_{39-45}$ and $\mathrm{Wo}_{2.1-3.4}$ (Figure 6.12a) with a few scattered to higher values belonging to the $12 \%$ of grains with dark cores. Rims have a smaller range of $\mathrm{En}_{41-45}$ and $\mathrm{Wo}_{2.3-2.9}$ (Figure 6.12) and are consistent across textural 
populations. $\mathrm{Al}_{2} \mathrm{O}_{3}$ concentrations are very similar between cores and rims. The majority of rims tightly cluster at $1.4 \mathrm{wt} . \% \mathrm{Al}_{2} \mathrm{O}_{3}$, whereas cores scatter to slightly higher concentrations and have a mean of 1.5 wt. $\% \mathrm{Al}_{2} \mathrm{O}_{3}$ (Figure $6.12 \mathrm{~b}$ ). Ti concentrations in cores range from 450 to $1635 \mathrm{ppm}$, whereas all but one rim falls in a narrower range between 460 and 580 ppm (Figure 6.12c). V has the largest concentration difference between cores and rims (Figure 6.12d). Rims cluster at $20 \mathrm{ppm}$ $\mathrm{V}$, but the majority of cores have lower ( $\sim 10 \mathrm{ppm})$ at the same Ti concentrations (460$580 \mathrm{ppm})$.
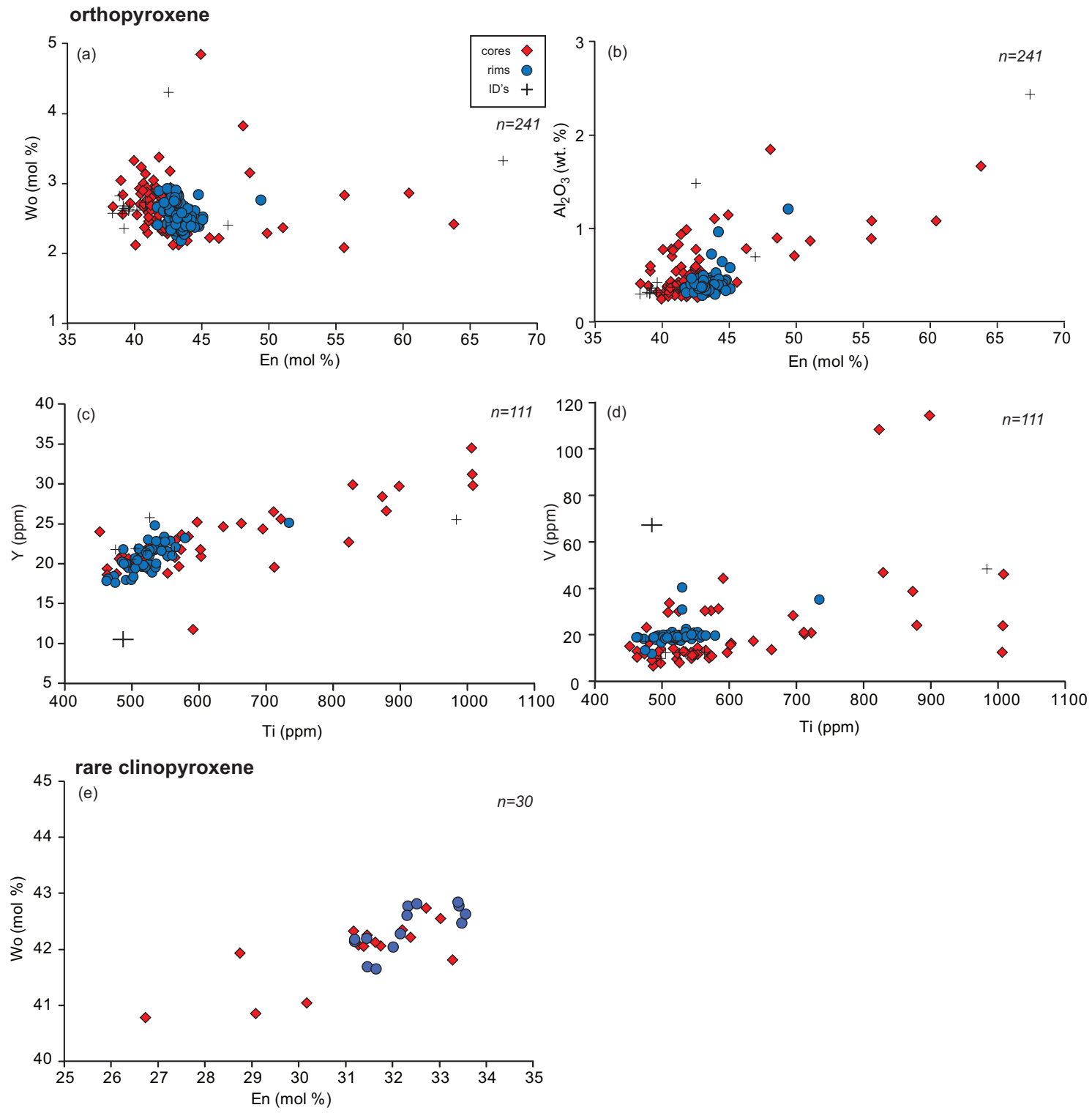

Fig. 6.12. In situ major and trace compositions of orthopyroxene (a-d) and rare clinopyroxene (e). Orthopyroxene cores with compositions greater than $\sim \mathrm{En}_{50}$ and $\sim 600 \mathrm{ppm}$ are those with dark cores in BSE imagery (Figure 6.7). 
Rare light green clinopyroxenes, up to $1 \mathrm{~mm}$ in length are found within a number of pumices and are variably fractured with a ragged appearance. A small number of clinopyroxene analyses were made in order to characterise these grains. Cores range from $\mathrm{En}_{26.7-33.3}$ and $\mathrm{Wo}_{40.8-42.7}$, and rims have a narrower range from $\mathrm{En}_{31.2-33.6}$ and

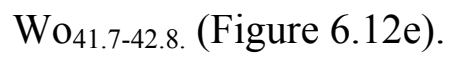

\subsubsection{Fe-Ti oxides}

Fe-Ti oxides within Ongatiti pumice samples are often corroded, especially within the lower flows. Therefore only fresh samples, mainly within the upper flow units, were considered reliable for in situ analysis. Magnetite and ilmenite pairs commonly occur as inclusions within orthopyroxenes and these were targeted for analysis. Magnetite inclusions are in the range of $\mathrm{Usp}_{21-43}$ with a mean of $\mathrm{Usp}_{34}$. Ilmenite has a narrow compositional range, falling between $\mathrm{Ilm}_{88-93}$ with a mean of $\mathrm{Ilm}_{89}$ (Electronic Appendix 11).

\subsubsection{Microcrystalline clot crystal signatures}

Minerals from a number of microcrystalline clasts and clots (MCs) were analysed to compare their geochemical signatures with the corresponding phases from normal pumices. Plagioclase and amphibole dominate the mineral assemblage in variable proportions within the MC material.

\subsubsection{Plagioclase}

Plagioclase within MCs display a range of sizes and textures including high aspect ratio skeletal grains and hopper textures (Figure 6.2; cf. Corrigan 1982; Nelson and Montana 1992). Plagioclase rims from small clasts and clots cover a very similar compositional range to normal pumices, clustering between $\mathrm{An}_{29-38}$ and $\mathrm{Or}_{2.7-3.9}$ (Figure 6.13a). In contrast to the dominant population of plagioclase within normal pumice, cores have higher An values than associated rims, and range between $\mathrm{An}_{29-63}$ and $\mathrm{Or}_{1.0-4.1}$. A comparison of core-to-rim An values between plagioclase from pumices and MCs is made in Figure 6.14. The dominant normal zoning and down temperature signal in the MC plagioclase is similar to those of the subordinate plagioclase population with light 
resorbed cores found within pumices. These trends imply that plagioclase within MCs first grew in a higher temperature and/or more water rich source, before crystallising under similar pre-eruptive conditions as the grains within pumices.
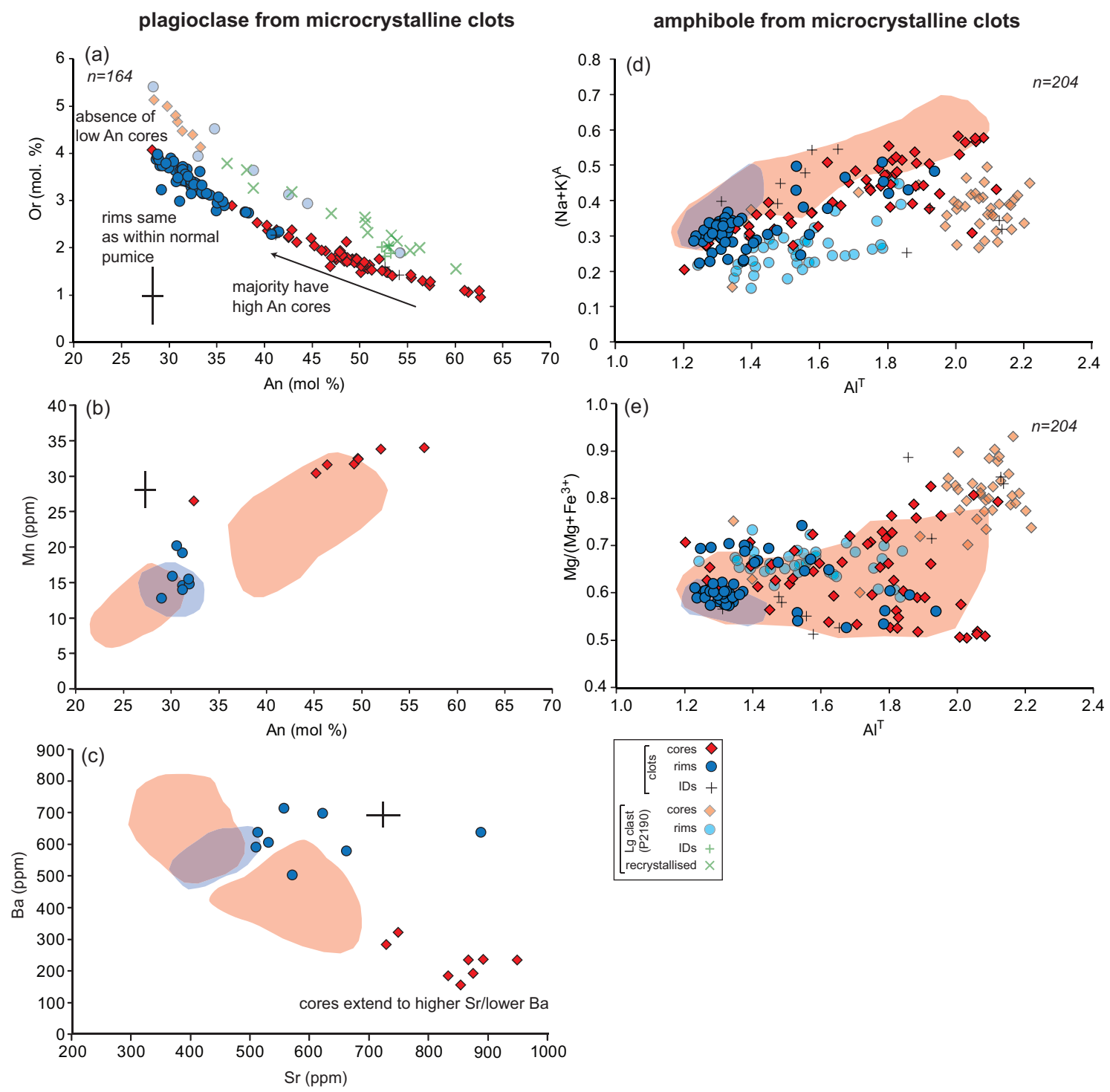

Fig. 6.13. Summary plots of in situ plagioclase (a-c) and amphibole (d \& e) compositions from microcrystalline clots (MCs) Shaded areas represent the compositional range of cores (red) and rims (blue) of plagioclase and amphibole from pumice clasts (Figures 6.8 and $6.10)$.

Plagioclase from a large MC (P2190) do not display coherent zoning and are commonly recrystallised and resorbed with sieve textures, which suggest a magma mixing and/or rapid decompression event (Nelson and Montana 1992; Humphreys et al. 2006). Grains from this MC clast (P2190) cover the same range in An as plagioclase from the other 
MCs, but Or values are significantly higher ( 1 mol. \% at the same An value) (Figure 6.13a). Grains from this clast therefore form a trend sub-parallel to the other plagioclase compositions and imply that the source of MC material had variable melt chemistries. $\mathrm{Mn}$ concentrations of MC plagioclase rims are similar to rims in pumices, but cores extend to slightly higher values than the light resorbed core population (Figure 6.13b). $\mathrm{Ba}$ and $\mathrm{Sr}$ rim concentrations are more variable, and cores extend to higher $\mathrm{Sr}(\sim 700$ $950 \mathrm{ppm})$ and lower $\mathrm{Ba}(\sim 100-300 \mathrm{ppm})$ than for plagioclase within pumice (Figure $6.13 \mathrm{c})$.
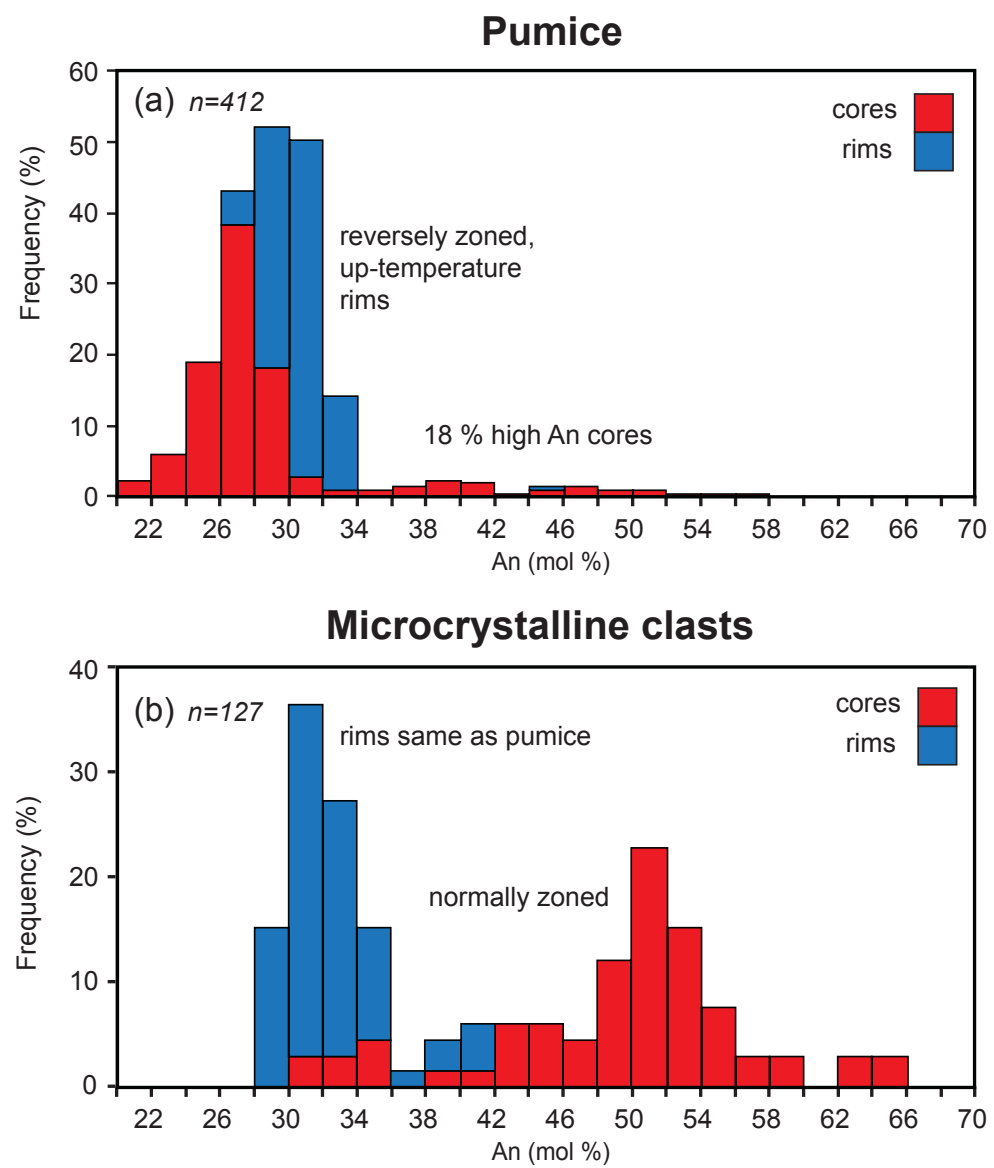

Fig. 6.14. Stacked histograms to summarise the contrasting compositional (An $\%$ ) relationships between plagioclase cores and rims from pumice and microcrystalline clots (MCs). Frequency \% values total $100 \%$ for each of the cores and rims separately.

\subsubsection{Amphibole}

A higher number of amphiboles with tschermakite-pargasite compositions (particularly cores) are present in MCs (Electronic Appendix 11). The major element chemistry of amphibole cores and rims show a greater scatter than that within normal pumice. This is 
particularly evident in plots of $\mathrm{Al}^{\mathrm{T}}$ versus $(\mathrm{Na}+\mathrm{K})^{\mathrm{A}}$ and $\mathrm{Mg} /\left(\mathrm{Mg}+\mathrm{Fe}^{3+}\right)$ (Figure 6.13d, e). The majority of rims within small MCs cover a similar compositional range to those in normal pumice, with some scatter to wider compositions. As with plagioclase, many of the amphibole grains within the large MC clast (P2190) display disequilibrium textures, such as sieve textured cores. Compositional trends within amphiboles from the large MC clast (P2190) are divergent from those in normal pumice and other MCs. Cores extend to higher $\mathrm{Mg} /\left(\mathrm{Mg}+\mathrm{Fe}^{3+}\right.$ ) values of $\sim 0.9$ at $2.2 \mathrm{Al}^{\mathrm{T}}$ (compared with $\sim 0.5$ in other grains), and lower $(\mathrm{Na}+\mathrm{K})^{\mathrm{A}}$ values of $\sim 0.3$, as compared to $\sim 0.5$. Rim compositions are also offset, with higher $\mathrm{Mg} /\left(\mathrm{Mg}+\mathrm{Fe}^{3+}\right)$ and lower $(\mathrm{Na}+\mathrm{K})^{\mathrm{A}}($ Figures $6.13 \mathrm{~d}, \mathrm{e})$.

\subsubsection{Intensive variables}

\subsubsection{Fe-Ti oxide temperature and oxygen fugacity}

Fe-Ti oxide magmatic model temperatures just prior to eruption were calculated using the method of Ghiorso and Evans (2008). Magnetite and ilmenite pairs included within the same host orthopyroxene were targeted to ensure textural equilibrium (Blundy et al. 2006), and all pairs were tested for equilibrium following the method of Bacon and Hirschmann (1988). Model temperature estimates form a unimodal distribution and are between 830 and $880{ }^{\circ} \mathrm{C}$, with a mean of $855^{\circ} \mathrm{C}$. Model $\log f \mathrm{O}_{2}$ estimates cover a range from -12.2 to -13.3 . These temperature and oxygen fugacity estimates straddle the NNO buffer curve (Figure 6.15). Caution must be placed on these estimates, as analytical totals for magnetites were high (100-106 \%) after recalculation for $\mathrm{Fe}_{2} \mathrm{O}_{3}$ and FeO (Carmichael 1967; Electronic Appendix 11), which may have had an effect on the absolute temperature estimates.

\subsubsection{Amphibole temperature and pressure}

Amphiboles have the potential to record magmatic temperature and pressure changes during growth of the crystal (Johnson and Rutherford 1989; Rutherford and Devine 2003). Apparent temperature and pressure estimates were made on amphiboles using the method of Ridolfi et al. (2010). Amphibole cores display a large and continuous range in apparent temperatures and pressures from $780-970{ }^{\circ} \mathrm{C}$ and $110-390 \mathrm{MPa}$ (Figure 6.16). Histograms of core model temperatures and pressures reveal two minor 

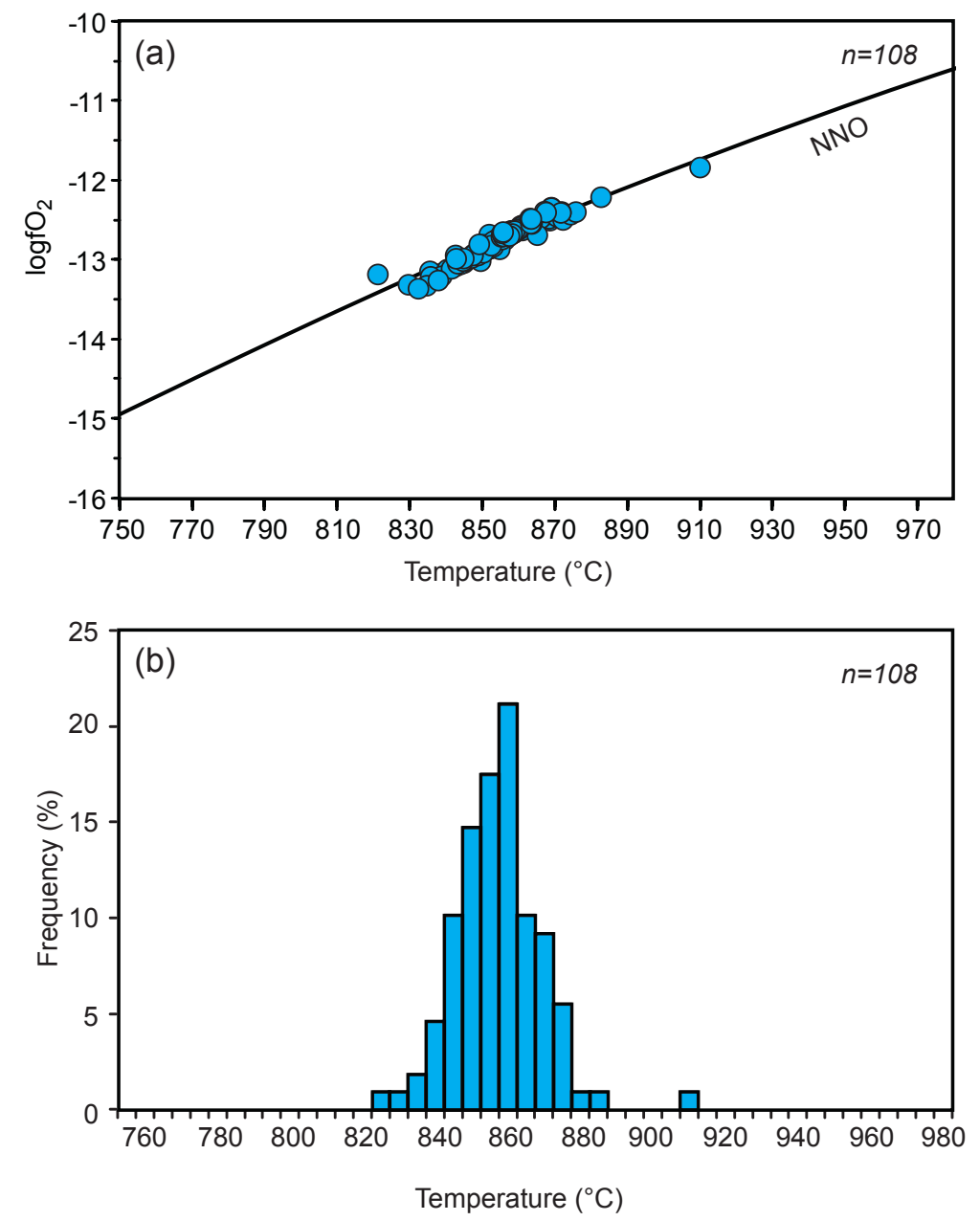

Fig. 6.15. Fe-Ti oxide model temperatures and oxygen fugacites calculated using the methods of Ghiorso and Evans (2008). (a) Data plotted to show close relationship to the nickel-nickel oxide buffer (NNO). (b) Histogram of individual model values.

peaks at 810 and $940{ }^{\circ} \mathrm{C}$, and 130 and $330 \mathrm{MPa}$. The lower temperature peak corresponds to the $17 \%$ of grains with non distinct cores and the higher temperature peak is related to the $83 \%$ population with dark, high Al-cores. Rim model temperatures and pressures are significantly restricted in comparison and form unimodal peaks, ranging from $780-840^{\circ} \mathrm{C}$ and $110-170 \mathrm{MPa}$ (Figure 6.16). These conditions correspond to depths of amphibole core crystallisation between $\sim 4-15 \mathrm{~km}$ and final preeruptive depths (crystallisation of rims) at shallower crustal levels between $\sim 4-6 \mathrm{~km}$ (Figure 6.17). 


\section{Pumice}
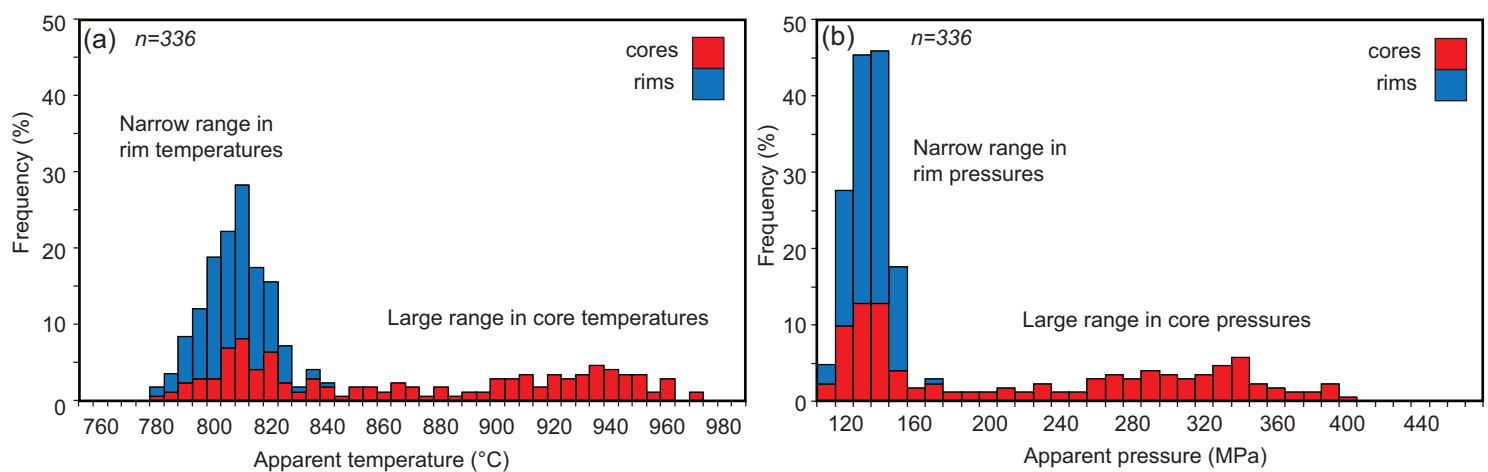

Microcrystalline clots
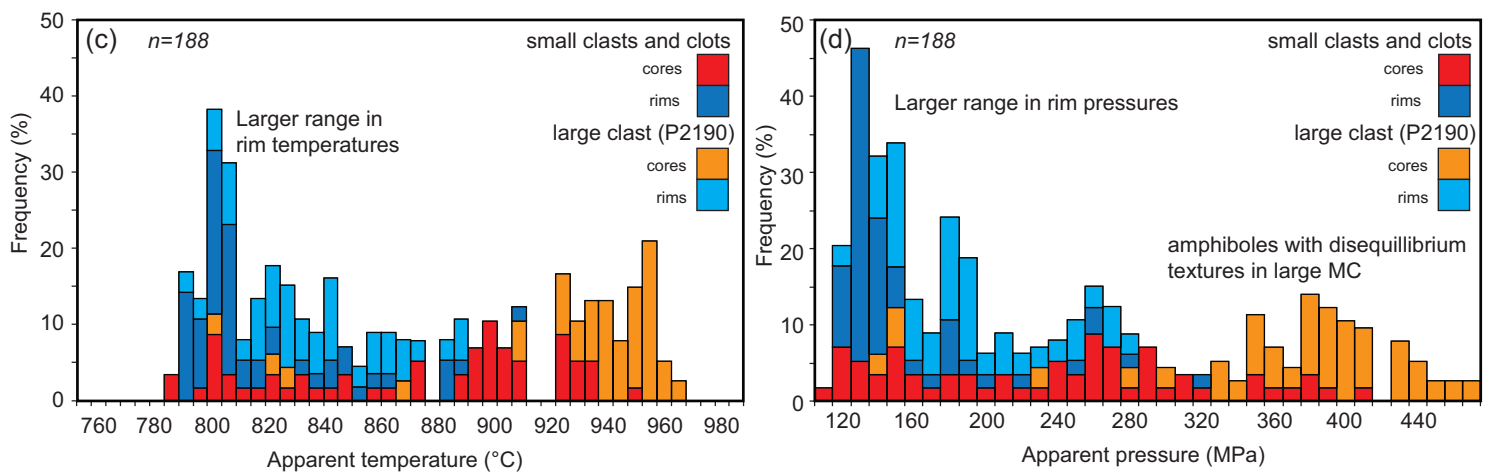

Fig. 6.16. Stacked histograms of amphibole core and rim apparent temperatures $\left({ }^{\circ} \mathrm{C}\right)$ and pressures $(\mathrm{MPa})$ from both pumices and microcrystalline clasts. Model amphibole temperatures and pressures were calculated using the method of Ridolfi et al. (2010). Frequency $\%$ values total $100 \%$ for each of the categories separately.

The range in modelled pre-eruptive conditions, and the contrast in modelled pressures and temperatures between rims and cores corresponds well with independently determined in-situ trace element concentrations. The lower depth of pre-eruptive conditions $(\sim 6 \mathrm{~km})$ is marked by a significant change in amphibole chemistry at $\mathrm{Al}^{\mathrm{T}}$ values of $\sim 0.4$ and $\mathrm{Eu} / \mathrm{Eu}^{*}$ of $\sim 0.3$ (dashed line in Figure 6.10 ). The maximum estimated depth of $\sim 15 \mathrm{~km}$ is consistent with the estimated depth $(\sim 16 \mathrm{~km})$ of the base of the quartzo-feldspathic crust beneath the central TVZ (Harrison and White 2004). The exact depth of the crust beneath Mangakino (to the northwest of modelled seismic arrays) is, however, not well constrained. The validity of model amphibole temperatures and pressures was assessed using cation abundances calculated following the method of Leake et al. (1997) (values presented in Electronic appendix). Evidence for both temperature (edenite and Ti-Tschermak) and pressure (Al-tschermak) sensitive atomic substitution mechanisms and, but to a lesser extent, plagioclase exchange are found within cores (cf. Bachmann and Dungan 2002; De Angelis et al. 2013). The consistency 
of amphibole rim concentrations (i.e. no temperature and pressure variations) results in little or no correlations between cation abundances (Electronic Appendix 11). Average pre-eruptive temperature estimates from amphibole rims are $\sim 40{ }^{\circ} \mathrm{C}$ lower than temperatures estimated from Fe-Ti oxides. This temperature difference may be an artefact of the two geothermometry methods, or due to high magnetite totals (discussed above), rather than a true distinction in magmatic temperatures.
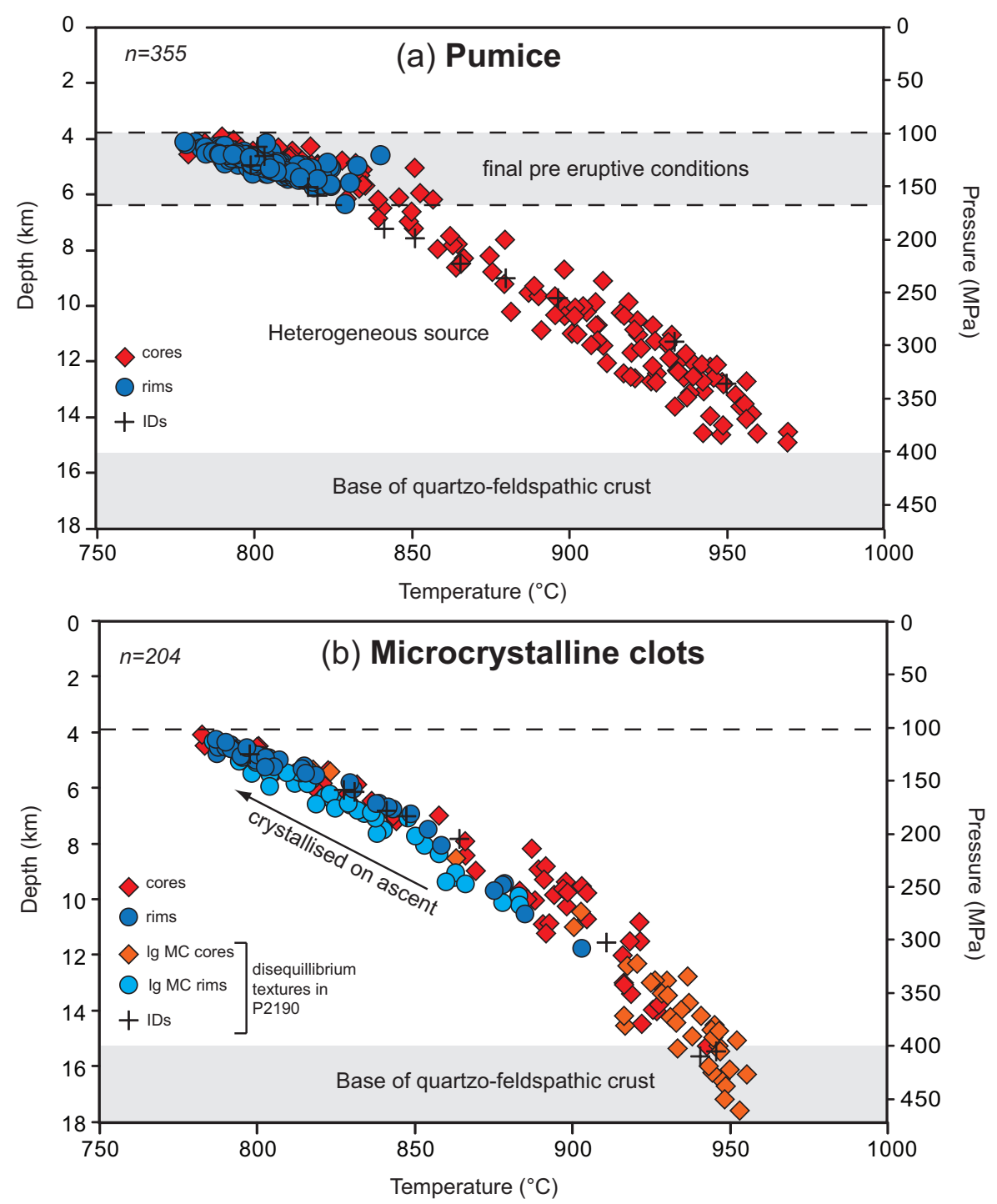

Fig. 6.17. Apparent temperatures $\left({ }^{\circ} \mathrm{C}\right)$, pressures $(\mathrm{MPa})$ and estimated depths from amphibole cores, intermediate domains and rims from both pumices and microcrystalline clasts. Dashed shaded area represents the depths at which rims crystallised and amphibole was stored prior to eruption. Note that estimated depths of amphibole cores from pumices stop at $\sim 15 \mathrm{~km}$, which is the approximate depth limit of the quartzofeldspathic crust beneath the central TVZ (e.g. Harrison and White 2006). 
Amphibole cores have a bimodal distribution in model melt $\mathrm{H}_{2} \mathrm{O}$ concentrations (Figure 6.18), which correspond to the two minor peaks in core apparent temperatures and pressures (Figure 6.16), and relate to the two crystal textural populations (Figure 6.7). Higher temperature $\left(870-970{ }^{\circ} \mathrm{C}\right)$ crystals with dark and/or patchy cores have higher estimations of melt $\mathrm{H}_{2} \mathrm{O}(\sim 6$ wt. \%) compared to $\sim 5$ wt. \% in lower temperature cores and rims. Uncertainties in melt $\mathrm{H}_{2} \mathrm{O}$ (wt. \%) estimates using amphiboles are large, and therefore significant weight cannot be placed on absolute modelled values.
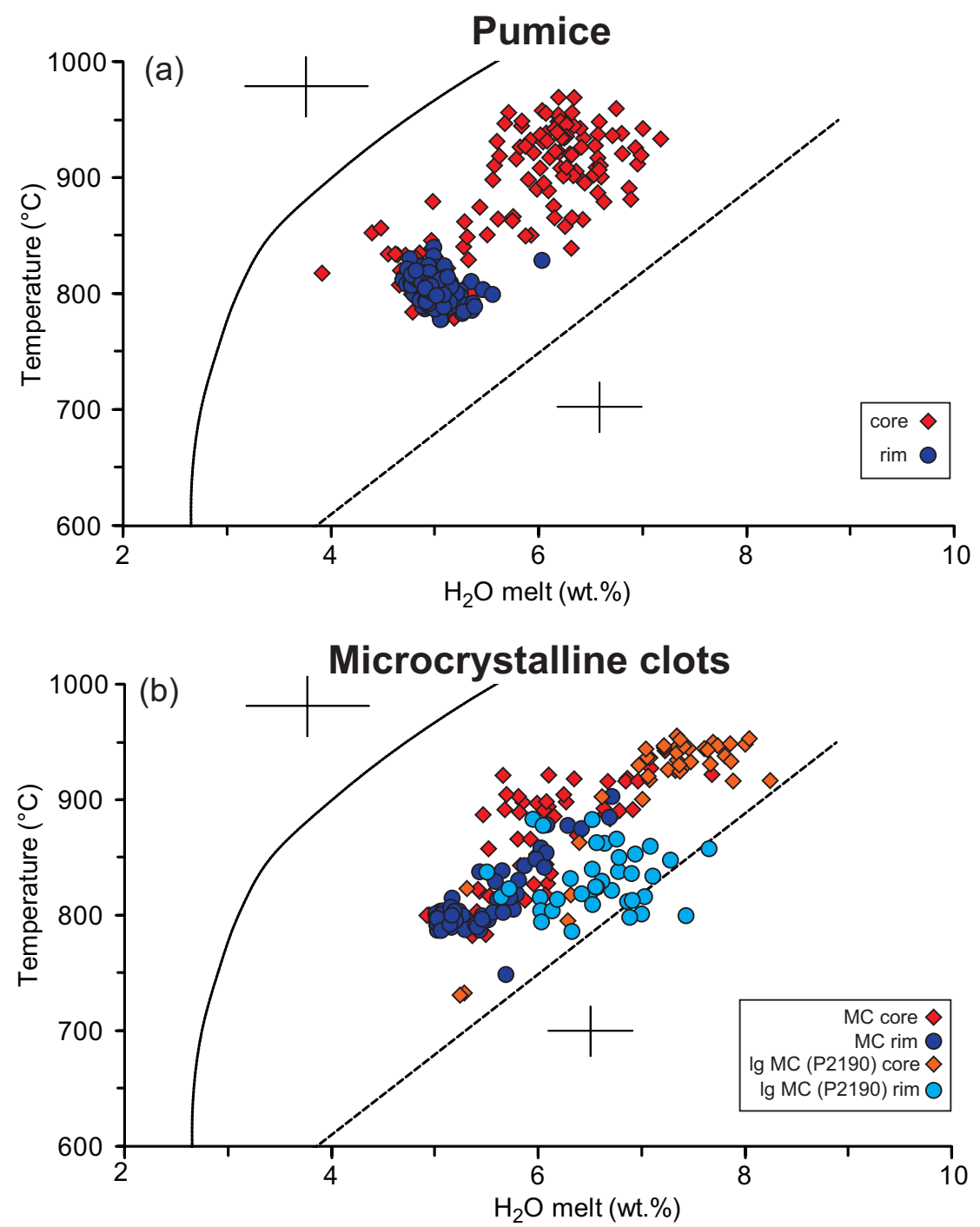

Fig. 6.18. Amphibole core and rim apparent temperatures $\left({ }^{\circ} \mathrm{C}\right)$ and model melt $\mathrm{H}_{2} \mathrm{O}$ contents (wt. \%) from Ongatiti pumices and microcrystalline clasts calculated using the method of Ridolfi et al. (2010). The maximum and minimum thermal stability of amphiboles are represented by the solid line and dashed line (Ridolfi et al. 2010). The lower cross indicates the $\sigma_{\text {est }}(0.4 \mathrm{wt}$. \%) error and the upper cross represents the maximum relative error (15\%) (Ridolfi et al. 2010). 
Amphiboles from individual MCs record similar temperature and pressure ranges to their counterparts from pumices (Figure 6.16). The majority of cores have temperatures from $780-950{ }^{\circ} \mathrm{C}$ and $110-410 \mathrm{MPa}$. Amphibole rims cover a larger range in temperatures $\left(790-910^{\circ} \mathrm{C}\right)$ and pressures $(120-320 \mathrm{MPa})$ than rims in normal pumice. The total range of conditions correspond to depths between $\sim 4$ and $15 \mathrm{~km}$, consistent with those seen in amphiboles from pumices. Amphiboles from these MCs show evidence for both temperature (edenite and Ti-tschermak) and pressure (Al-tschermak) sensitive atomic substitution mechanisms (Electronic Appendix 11). The tschermakitepargasite cores within the large MC clast (P2190) extend estimates to $970{ }^{\circ} \mathrm{C}$ and 470 MPa (up to $\sim 18 \mathrm{~km}$ ). However, cation abundances of amphiboles from this sample show little evidence for temperature (edenite and Ti-tschermak) or pressure (Altschermak) sensitive atomic substitution mechanisms (Electronic Appendix). Also, many amphibole grains from sample P2190 display disequilibrium textures and therefore the reliability of estimates are compromised in this case. Model melt $\mathrm{H}_{2} \mathrm{O}$ concentrations extend to higher water contents within the large MC clast (P2190) (5-8 $\%$; Figure 6.18) and are close to the limit of amphibole stability, which in turn may account for the observed disequilibrium textures.

\subsection{Discussion}

\subsubsection{The role of crystal mush in the development of the Ongatiti system}

Briggs et al. (1993) suggested that the variation in pumice chemistry found throughout the Ongatiti ignimbrite implied the magma body was originally stratified, but that this stratification was lost just prior to, or during eruption. Although a stratified magma chamber could explain the trends observed in whole rock chemistry, explaining the textural and chemical signatures of crystals with this model is problematic. If a chemically stratified magma body was in operation, it is likely that outer zones of phenocrysts would have varying chemistries and record varying magmatic conditions. However, the crystal rims within all crystal phases, from a range of pumices show very little compositional variability and suggest that the final erupted magma body was generally homogeneous. The Ongatiti U-Pb zircon age spectra indicate a protracted growth history, spanning $\sim 250 \mathrm{kyr}$, and peaking around $\sim 100 \mathrm{kyr}$ prior to eruption (Chapter 2). Maintaining a large melt-dominant body near its liquidus in the upper crust over such long timescales is difficult (Sparks et al. 1990; Mahood 1990), and therefore 
the zircon age record supports the notion of a large crystal-rich (mush) body with subordinate melt that was present for the $>10^{5}$ year period prior to eruption. The evidence presented within this chapter supports the idea for a magma system model involving large-scale crystal mushes (Figure 6.19) of varying composition at different depths within the crust. In this respect, the Ongatiti is similar to the Oruanui magma system, where the textural and chemical crystal signatures are interpreted to reflect processes in the formation of the melt-dominant body through the rapid extraction of melt and crystals from a zoned mush (depth of $\sim 6-10 \mathrm{~km}$ ) in a very short period (centuries) prior to eruption (Allan 2013; Allan et al. 2013). Within the Ongatiti magma system, however, the modelled pressures from high Al cored amphiboles suggest a crystal mush/source to depths close to the base of the quartzofeldspathic crust ( 15 km). The rapidly formed, crystal-poor Oruanui melt-dominant body was accompanied by rapid cooling $\left(\sim 50^{\circ} \mathrm{C}\right)$ as crystallisation continued (Allan et al. 2013). In contrast, the intermediate and outer zones of crystals in the Ongatiti suggest the erupted, crystal-rich (20-30 \%) magma body was not cooling, but warming and convecting in the final stages of development, prior to eruption (Figure 6.19). As with the Oruanui, evidence from the variation in amphibole chemistry and modelled temperatures and pressures between cores and rims are interpreted as showing that the large-scale crystal mush in the Ongatiti magma system was thermally and chemically zoned.

\subsubsection{Origin of textural and chemical signatures in the Ongatiti crystals}

To a first order the Ongatiti ignimbrite is relatively homogeneous, with restricted ranges in both whole-rock and glass compositions and no significant compositional gradients apparent between pumices from the earlier and later flows. In contrast to this large-scale homogeneity, the textural and chemical variations within individual crystals (particularly plagioclase and amphibole) record contrasting early growth histories and open system processes to suggest a dynamic magmatic system was in operation. Based on the textural and chemical signatures of the crystals, the mineral assemblage of the final erupted magma volume can be divided into two distinct populations. The first population, dominated by plagioclase, was grown in-situ in the melt-dominant body (Figure 6.19) and is represented by grains with non distinct cores ( $82 \%$ plagioclase, 88 $\%$ orthopyroxne and $17 \%$ amphibole: Figure 6.7 ). 


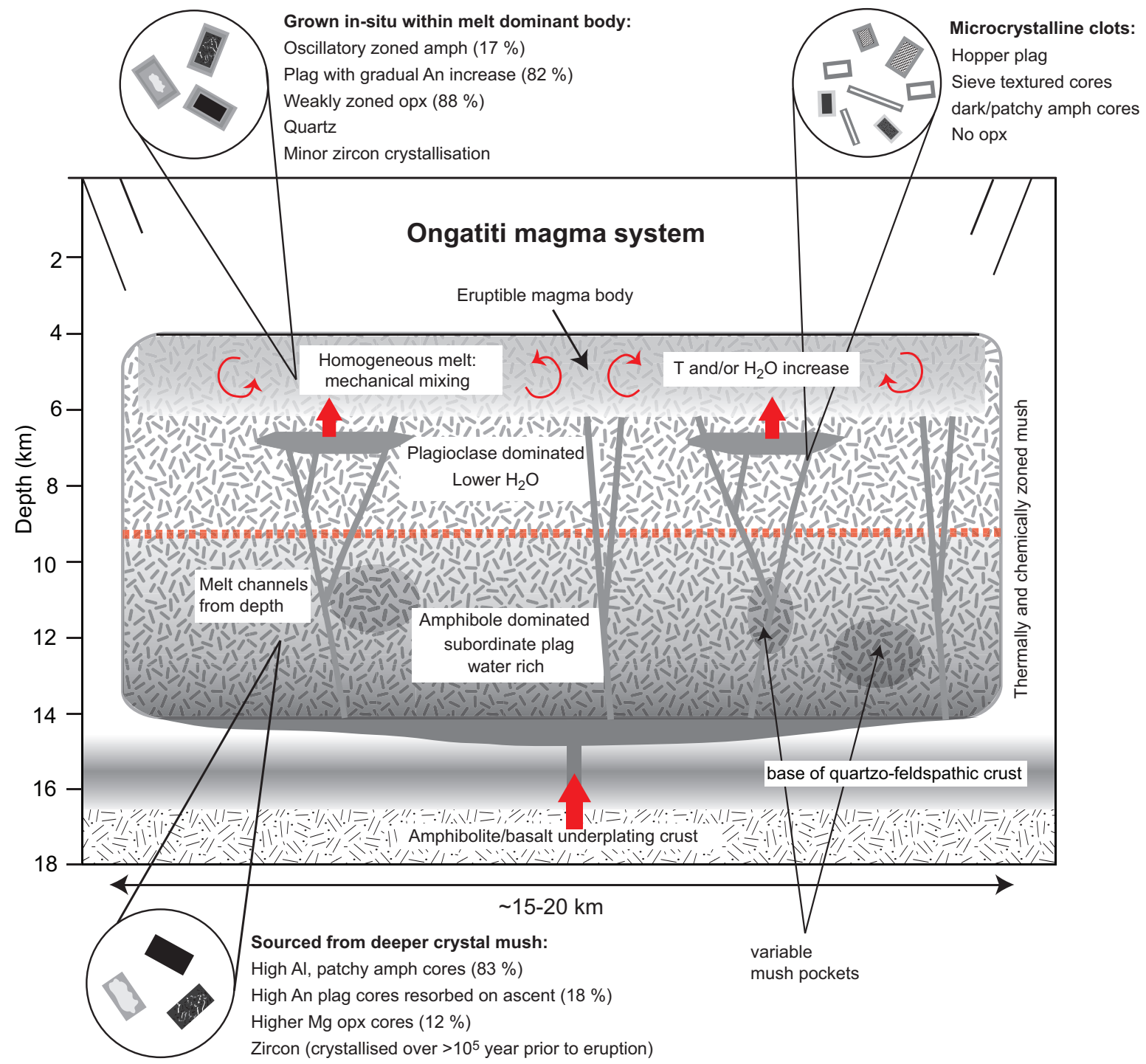

Fig. 6.19. Semi quantitative cross section of the Ongatiti magma system. The origin and formation of plagioclase and amphibole zoning populations (see Figure 6.7) within pumices, and the microcrystalline clots are shown. The dashed red line marks an approximate change from an amphibole dominated source to plagioclase dominated assemblages at shallower levels. Pervasive melt channels are present which allow for the rapid ascent of crystals and melt (forming microcrystalline clots) from depth. Depths are estimated from amphibole compositions using the method of Ridolfi et al. (2010). The horizontal extent of the system is approximate, but scaled to be consistent with the overall volume of the Ongatiti eruption deposits.

The second population, dominated by amphibole, was brought up from the deeper crystal mush (Figure 6.19) and is represented by crystals displaying lesser-evolved core compositions ( $83 \%$ amphibole, $18 \%$ plagioclase and $12 \%$ orthopyroxene: Figure 6.7 ). The crystallisation of amphibole and subordinate plagioclase and orthopyroxene within a deeper crystal mush is probably coincidental with the major crystallisation event from 1.30-1.32 Ma recorded in zircons (Chapter 2). Therefore the majority of zircons are 
antecrystic, inherited from the deeper source zone and only a limited proportion grew in-situ, within the pre-erupted magma body (Figure 6.19). The composition of the melt, and pre-eruptive model temperatures from both amphibole and $\mathrm{Fe}-\mathrm{Ti}$ oxides (total range of $\sim 800-860^{\circ} \mathrm{C}$ ) imply that the final erupted magma body was just below zircon saturation (Hanchar and Watson 2003; Boehnke et al. 2013). Under these conditions, the antecrystic zircon population that crystallised in the mush $\sim 100 \mathrm{kyr}$ prior to eruption would not be dissolved, but significant in-situ crystallisation of zircon within the magma body would be hindered. The origins and magmatic history of the plagioclase, amphibole and orthopyroxene, giving rise to the two overall contrasting populations are discussed in the following section.

\subsubsection{Plagioclase}

The dominance ( $82 \%$ ) of plagioclase with non-distinct, low-An cores are attributed to crystallisation entirely within an evolved crystal-rich, but melt-dominant body (Figure 6.19). Ongatiti plagioclase, which dominates the mineral assemblage (70-90\%), therefore records processes and changing magmatic conditions within the upper, highly evolved portion of the magmatic system (Figure 6.19). The subordinate (18\%) plagioclase population with higher An cores suggest an input of crystals grown in lesser-evolved melt, and/or at conditions of higher magmatic temperatures and water contents (Figure 6.19), when compared to the final erupted magma body. Core-to-rim plagioclase traverses show that all plagioclase crystals share a common history from the outside of cores to rims (Figure 6.7), implying that higher An plagioclase ascended and accumulated within the early development of the erupted magma body (Figure 6.19). Resorption of these cores, giving rise to their patchy appearance, may have occurred during ascent due to decreasing temperature and/or decreasing $\rho_{2} \mathrm{O}$ (Housh and Luhr 1991; Humphreys et al. 2006).

The composition of plagioclase is controlled by temperature, pressure, and melt composition coupled with a major dependence on $\mathrm{H}_{2} \mathrm{O}$ content (Rutherford and Devine 1988; Housh and Luhr 1991). A consistent and gradual core-to-rim reverse zoning trend from $\mathrm{An}_{25}$ to $\mathrm{An}_{30}$ therefore requires a progressive change in one or more of these parameters during crystallisation. Results from crystallisation experiments of A-type 
granites by Klimm et al. (2003) show that at temperatures of $800^{\circ} \mathrm{C}$ a rise from $\mathrm{An}_{25}$ to $\mathrm{An}_{30}$ requires a temperature increase of $\sim 50{ }^{\circ} \mathrm{C}$ or an increase in melt $\mathrm{H}_{2} \mathrm{O}$ of $\sim 0.5 \mathrm{wt}$. $\%$. These melt changes could be invoked by underplating of the crystal-rich mush by a less-evolved melt, with the potential to increase temperature and change melt chemistry and volatile content (increase in $\mathrm{Ca}$ and $\mathrm{H}_{2} \mathrm{O}$ ) (Bachmann et al. 2002; Bachmann and Bergantz 2006). It is likely that a $\sim 50{ }^{\circ} \mathrm{C}$ increase in temperature would be texturally and/or chemically recorded within the other crystal phases, in particular amphibole and orthopyroxene (cf. Chapter 4). Amphiboles, however, display no/minor evidence for core-rim increases in model temperatures (maximum $\sim 20^{\circ} \mathrm{C}$ : Figure 6.16). Therefore, in addition to temperature, the gradual rise in plagioclase An is strongly influenced by an increase in the $\mathrm{H}_{2} \mathrm{O}$ content (and other volatiles) of the melt during crystallisation.

\subsubsection{Amphibole}

The dominance of amphiboles with dark patchy cores (83\%), recording higher model temperatures and pressures, implies that there was a significant contribution of crystals from the zoned crystal mush to the zone of final pre-eruptive storage between 4-6 km depth. Amphiboles therefore have the potential to yield information on a deeper source than is recorded by the dominant plagioclase population grown within the final erupted magma body. Patchy and/or resorbed amphibole cores display a large range in major and trace element chemistries implying that their early crystallisation occurred within a source that was chemically variable and spanned a large range of temperatures, pressures and depths. This source region was significantly less evolved than the final erupted magma. $\mathrm{Eu} / \mathrm{Eu}^{*}$ values and $\mathrm{Sr}$ concentrations in patchy cores are higher and more variable than rims suggesting that significantly lower degrees of plagioclase crystallisation had occurred in the melt from which amphibole cores grew when compared with the final pre-eruptive melt. In comparison, within the Oruanui magma system, amphibole sourced from a crystal mush does not appear to have been stable beneath $\sim 10 \mathrm{~km}$ depths (Allan 2013). However higher melt $\mathrm{H}_{2} \mathrm{O}$ concentrations, lower thermal gradients, and/or higher concentrations of other volatiles such as $\mathrm{CO}_{2}$ would allow amphiboles crystallised under higher temperatures and pressures to remain stable at greater depths below the Ongatiti system (Ridolfi et al. 2010). Modelled water contents of the melt from patchy amphibole cores are $\sim 5$ to $7 \mathrm{wt} . \%$, that is, close to water saturated conditions, It is therefore inferred that within the Ongatiti magma 
system, an amphibole-dominated source was present in the mid to lower quartzofeldspathic crust, which supplied amphibole crystals (and subordinate plagioclase) to shallower levels (4-6 km) (Figure 6.19). The amphibole dominated midlower crust with high water contents may provide a source of $\mathrm{H}_{2} \mathrm{O}$, which could be transferred to the plagioclase dominated upper zone and the final erupted magma body, during ascent of crystals and melt.

A significant shift in the chemistry of amphiboles is recorded at $\sim 1.4 \mathrm{Al}^{\mathrm{T}}$ and $\sim 0.3$ $\mathrm{Eu} / \mathrm{Eu}^{*}$, which marks the point at which amphibole began to accumulate around 4-6 km depth and began crystallising alongside plagioclase. Amphibole compositions less than $\sim 1.4 \mathrm{Al}^{\mathrm{T}}$ and $\sim 0.3 \mathrm{Eu} / \mathrm{Eu}^{*}$ correspond to a period of stable growth of intermediate domains and rims, which have oscillatory zoned textures. The similarities between the oscillatory zoned plagioclase and amphibole suggest that both phases record a common history in the later stages of growth (Figure 6.19). The significant contribution of amphibole to the final erupted magma body from depth must therefore have occurred during its early development. This process was likely coincidental with the ascent of the subordinate population of plagioclase with resorbed cores, minor orthopyroxene with higher $\mathrm{Mg}$ cores and incorporation of the dominant zircon population with its $\sim 1.3 \mathrm{Ma}$ crystallisation peak.

\subsubsection{Orthopyroxene}

Orthopyroxenes within the Ongatiti system lack the complex crystallisation record preserved in plagioclase and amphiboles. Any oscillatory zonation visible under BSE (Fe-Mg zoning: Chapter 5) may have been lost over time through Fe-Mg interdiffusion. Only $12 \%$ of grains (dark, high En cores) show any significant shifts in chemistry implying that the majority of crystals (with weak zoning) crystallised under conditions similar to those just prior to eruption. Therefore it is assumed that the majority ( $88 \%$ : Figure 6.7) of orthopyroxene grew alongside plagioclase for its entire history and was not sourced to any significant extent from the amphibole dominated mush zone. 


\subsubsection{Origin of microcrystalline clots}

The MCs may provide direct samples of the mid to lower crustal source region of the Ongatiti magmatic system from where $82 \%$ of amphiboles within pumices originated. As the MC material is present both as individual clasts and as clots within pumices, and with no evidence for compositional gradients due to mixing, it can be inferred that limited mingling with the final erupted magma occurred (cf. Blake et al. 1992). There is a general absence of MCs within the lower flow units and therefore it can be inferred that the introduction of the MCs was syn-eruptive.

Glass within all but one $\mathrm{MC}$ (GC16) is indistinguishable in terms of major elements but significantly more depleted in REE than pumice glass. The disparity in the MCs between their high silica rhyolite major element compositions (77.5-79 wt. \% $\mathrm{SiO}_{2}$ ), and their less-evolved trace element signatures, is likely controlled by late-stage rapid crystallisation from a melt close to its eutectic. The REE patterns in MCs more resemble those of whole-rock andesite than they do rhyolite. The REE concentrations (and major elements within one MC) are variable between MCs and suggest a source with variable melt chemistries and/or variable proportions of crystallisation of the mineral assemblage (Figure 6.19). A considerably smaller Eu/Eu* anomaly implies that this melt was less evolved and had undergone less plagioclase crystallisation. Higher $\mathrm{Sr} / \mathrm{Y}, \mathrm{La} / \mathrm{Yb}$ and $\mathrm{Ba} / \mathrm{La}$ ratios further suggest lesser degrees of plagioclase crystallisation, which may be supressed by high water contents (Richards 2011; Chambefort et al. 2013). These observations are consistent with the signals recorded in high $\mathrm{Al}$ amphibole cores within the pumice, providing further support for a water rich zone that has undergone less plagioclase crystallisation. The $\mathrm{Yb} / \mathrm{Gd}$ ratio covers the same range as within pumices, suggesting that significant crystallisation of amphibole (relatively enriched in MREE/HREE: Sisson 1994) had already taken place from the lesser-evolved melt. These observations provide further evidence for an amphibole dominated source with high water contents. Mn concentrations of MC glass are higher than within pumice and increase with decreasing $\mathrm{Mg}$ concentrations (Figure 6.6f). This trend may be explained by a lack of crystallising orthopyroxene within the amphibole dominated source, or the breakdown of orthopyroxene (highly enriched in $\mathrm{Mn}$ ), alongside significant amphibole crystallisation (removal of $\mathrm{Mg}$ from the melt). Higher $\mathrm{Zr}$ concentrations within MC glass (Figure 6a, e) suggest lesser degrees of zircon crystallisation within this melt. 
The crystal assemblage of the MCs is entirely plagioclase and amphibole, with accessory Fe-Ti oxides. Amphiboles within the MC clasts (excluding P2190) have cores with a very similar range of chemistry and modelled temperatures and pressures as the patchy cored amphiboles in the normal pumices, implying that they may have originated from a common source under similar magmatic conditions. In addition, the majority of MC plagioclase cores span the same range in An values as the resorbed plagioclase cores in the normal pumices, providing further evidence for a common source region (Figure 6.19). The lack of orthopyroxene within MCs support the glass Mg versus Mn trends and imply no significant orthopyroxene crystallisation occurred at depth or that extensive and complete orthopyroxene breakdown occurred during ascent (cf. Allan et al. 2013), consistent with the low proportion (12\%) of high En orthopyroxene cores within normal pumices. A range of disequilibrium textures (sieve textures, high aspect ratio skeletal grains and hopper grains) is displayed by plagioclase, and to a lesser extent amphibole in the MC clasts. These textures are likely caused by rapid decompression, loss of $\mathrm{H}_{2} \mathrm{O}$ during ascent and cooling upon engulfment in the final erupted magma (Nelson and Montana 1992; Humphreys et al. 2006). The rapid ascent of this material just prior to or syn-eruptively from a crystal rich mush may have been aided by pervasive melt channels formed through regional rifting processes (Figure 6.19; cf. Allan 2013).

\subsubsection{Heterogeneity to homogeneity in the Ongatiti magma body}

The textural and compositional signatures from crystals suggest a highly evolved magma body was assembled from a large and diverse source from variable depths in the crust. Crystal rim compositions and the similarity of glass chemistries between pumices imply that the final erupted volume of melt was effectively homogeneous. The homogenisation of crystal-rich magma bodies is thought to arise through: (1) the addition of magma similar in composition to that of the growing reservoir, (2) significant mechanical mixing/convective stirring, (3) the hindering of crystal-melt separation or latent heat buffering (Bachmann and Bergantz 2008; Huber et al. 2009). The data presented here demonstrates that both open and closed system processes were involved in the accumulation and homogenisation of the melt-dominant magma body in the Ongatiti system. 
Crystal cores ( $83 \%$ amphibole, $18 \%$ plagioclase, $12 \%$ orthopyroxene) in pumices display evidence for a heterogeneous source/mush and earlier growth at variable depths and conditions, but was followed by a significant period of crystallisation of all phases at shallow crustal levels $(4-6 \mathrm{~km}$ ) prior to eruption (Figure 6.19). The majority of zircon can be considered antecrystic and crystallised within the source/mush $\sim 100 \mathrm{kyr}$ prior to eruption. There is no evidence that crystallisation led to cooling within the magma body during this period and the crystal-rich (20-30 \%) magma body did not approach a state where a crystal framework was formed. The outermost rims of all crystal phases are either the same or slightly less evolved than interiors and all plagioclase crystals have a gradual up-temperature (and/or $\mathrm{H}_{2} \mathrm{O}$ ) signal, suggesting the magma body was warming during crystallisation.

The initial mobilisation and extraction of melt and crystals from the crystal mush and subsequent ascent to 4-6 km may have been aided by the underplating of a lesser evolved magma. The gradual warming and/or input of $\mathrm{H}_{2} \mathrm{O}$ (and other volatiles) within the final erupted magma body may also have been caused by underplating of a waterrich (possibly saturated) magma within the underlying crystal mush. The microcrystalline clots are interpreted to provide an analogue for the composition of this lesser evolved melt, and aspects of their chemistry suggests that the underplating magma may have had a broadly andesitic composition. This magma is equivalent to the amphibole dominated mush/source from which crystals and melt were extracted to form the final magma body. The underplated magma provided a source of heat and volatiles, which initiated convection and mixing within the final erupted magma body (Couch et al. 2001; Rutherford and Devine 2003; Bachmann and Bergantz 2006). This convection or mechanical mixing would effectively homogenise the erupted magma. The consistent oscillatory zonation recorded in plagioclase and amphibole may therefore reflect convection and stirring of the magma body during crystallisation. The absence of significant steps in mineral compositions and disequilibrium textures suggest that the involvement of an underplated magma was a gradual process and did not occur as a distinct rejuvenation event (Murphy et al. 2000; Couch et al. 2001; Bachmann et al. 2002; Chapter 4). 
Apart from the syn-eruptive incorporation of microcrystalline clots, there is no evidence for the mixing of magmas with different compositions prior to eruption, which could cause significant shifts in chemistry of the melt and evidence for melting of crystals (cf. Chapter 4 and Bachmann et al. 2002), leading to compositional variations recorded within the erupted deposits.

The prominent negative Eu anomaly in pumice matrix glasses suggests that significant crystallisation of plagioclase has occurred within the erupted magma body. The significantly smaller values for the whole-rock negative Eu anomaly is explicable by nearly all plagioclase remaining suspended in the melt from which it crystallised and was quenched on eruption. The crystallisation of plagioclase, at least within the upper crustal magma body, represented a closed system process with no evidence for crystalliquid separation (Section 6.5.2.).

Within the Oruanui and Kidnappers/Rocky Hill magmatic systems, Fe-Mg diffusion modelling across core-rim zones in orthopyroxene demonstrates that the development of the melt-dominant bodies, through extraction of crystals and melt from a mush, occurred on rapid (centuries) timescales (Chapter 5; Allan et al. 2013). In this case, the timing of extraction cannot be determined by the same diffusion methods, as limited orthopyroxene was sourced from the crystal mush. The final erupted magma body within the Ongatiti system may have developed over a similarly short timescales, as there is no evidence for a long-lived melt-dominant body. The crystal mush itself, however, does record a protracted history, with significant crystallisation occurring $>10^{5}$ years prior to eruption (Chapter 2).

\subsubsection{Eruption of the Ongatiti magma body}

The textural and chemical signatures of the phenocryst assemblage within the Ongatiti show no clear evidence for singular rejuvenation events and/or trigger mechanisms. The overall increase in An content from cores to rims in plagioclase implies temperature and/or water contents of the melt gradually, rather than rapidly increased throughout crystal growth in the final erupted magma body. The crystals display oscillatory zonation in plagioclase and amphibole, coupled with weakly zoned orthopyroxene, with 
no or few large and abrupt shifts in chemistry. This evidence implies there were no sudden chamber wide magmatic perturbations, or any mixing of magmas with significantly contrasting chemistries in the immediate lead-up to eruption. The gradual evacuation of material from the deeper mush system and its subsequent heating may have arisen by magmatic underplating by lesser evolved melts, as has been suggested for the rejuvenation of mush at Soufrière Hills on Montserrat and the Fish Canyon Tuff (Murphy et al. 2000; Couch et al. 2001; Bachmann et al. 2002). The steady core-rim rise in plagioclase An content, but limited rise in model temperatures recorded in amphiboles implies that the gradual development of the upper crustal Ongatiti magma body was, in part, controlled by increasing melt $\mathrm{H}_{2} \mathrm{O}$. The transfer of $\mathrm{H}_{2} \mathrm{O}$ and additional volatiles, such as $\mathrm{CO}_{2}$ to aid in the rejuvenation of a mush may occur through 'gas sparging' or mafic 'wind' (Bachmann and Bergantz 2006) from underplated, lesser-evolved gas saturated magmas. Gas sparging, however, is also accompanied by an upward shift in temperature, a feature that would be expected to generate widespread and pronounced up-temperature signals in the phenocryst phases.

With no evidence for a triggering event recorded in the crystals, an external driving force, such as tectonics, may have controlled the evacuation of the large-scale magma body. Rifting related processes and localised faulting has been proposed to play a role in the triggering of eruptions both at Mangakino (Cooper et al. 2012 [Chapter 3]) and in the Oruanui eruption (Allan et al. 2012). Within the Oruanui magma system, channels/gashes through the mush zone are inferred to have been formed through rifting related processes, which allowed the extraction of melt and crystals from the mush zone on rapid timescales (Allan et al. 2013). Here, crystals within the less evolved microcrystalline clots record textures caused by rapid decompression or cooling on engulfment within the final erupted magma. This material may have rapidly ascended via extensional melt channels, degassing and rapidly crystallising, just prior to or during eruption. Pumices within the Ongatiti ignimbrite show no evidence for significant mixing or mingling between this magma and the final erupted magma body, suggesting incorporation of this lesser evolved magma occurred during eruption. The interaction of the lesser evolved magma can therefore not be the direct cause of the triggering of the eruption. 


\subsection{Conclusions}

Crystals from the Ongatiti record a complex history, providing evidence for the establishment of a crystal-rich, homogeneous magma body from a chemically heterogeneous source extending to the base of the quartzofeldspathic crust. The Ongatiti ignimbrite does not conform to either the crystal-rich 'monotonous intermediates' or the crystal-poor compositionally zoned rhyolites and demonstrates large-silicic magma systems can develop in a different fashion. The generation of the Ongatiti magmatic system can be explained through the following processes:

1. During a period from $\sim 1.32-1.30 \mathrm{Ma}$ (Chapter 2 ), the majority of zircons crystallised within a chemically variable, amphibole dominated mush zone (up to $15 \mathrm{~km}$ depth). Antecrystic zircons (crystallised 1.3 Ma), along with amphibole and subordinate plagioclase and orthopyroxene, were extracted from the crystal mush and ascended to final storage in a plagioclase dominated upper zone at depths between 4-6 km (Figure 6.19). The majority of plagioclase, and nearly all orthopyroxene were lost through decompression melting during ascent. In contrast, the majority of high $\mathrm{Al}$ amphibole cores and zircons survived, giving rise to the contrasting textural populations recorded within the cores of crystals within Ongatiti pumices.

2. The magma that was extracted from the crystal mush, ponded at 4-6 km depth. Significant crystallisation of plagioclase, alongside quartz, orthopyroxene, amphibole and only limited zircon occurred at these depths during a gradual rise in temperatures and/or water contents. During this stage the magma body can be thought of as a closed system, as little fractionation or removal of crystals (no crystal-melt separation), and no mixing with magmas of contrasting compositions occurred.

3. As crystallisation continued, homogenisation of the magma body occurred through convective stirring and gradually rising temperatures from underlying lesser-evolved magma. Underplating water rich magmas transferred volatiles, particularly $\mathrm{H}_{2} \mathrm{O}$ to the magma body without any physical exchange of melt and crystals. The increasing $\mathrm{H}_{2} \mathrm{O}$ and temperature of the melt is recorded by gradual increases in plagioclase $\mathrm{An}$ content $\left(\mathrm{An}_{25-30}\right)$. The final magma body, although crystal-rich, was dominated by melt and did not approach a state of 'lock-up'. 
4. No signals of a 'defrosting' or 'rejuvenation' event are recorded in the Ongatiti. Processes driven by rifting may have caused instability within the magma body, which ultimately triggered the eruption. These processes could have opened up melt channels through the mush, allowing lesser-evolved magma (represented by the microcrystalline clots) to rapidly ascend and incorporate within the final erupted magma during eruption. 
Chapter 7 


\section{Synthesis and Conclusions}

\subsection{Key findings}

This work illustrates the range of information on the dynamics of large-scale silicic systems that can be pieced together through the study of mineral phases, using three case studies from Mangakino volcanic centre, New Zealand. The $1.21 \pm 0.04 \mathrm{Ma}, \sim 500$ $\mathrm{km}^{3}$ (magma) Ongatiti, and the $\sim 1.0 \mathrm{Ma}, \sim 1200 \mathrm{~km}^{3}$ (magma) Kidnappers eruptions represent two of the four New Zealand examples of Quaternary supereruptions, and were studied to see how processes of magma generation and magma chamber development occurred in these large eruptions. The Rocky Hill eruption also dated at $\sim 1$ Ma, but of 'only' $200 \mathrm{~km}^{3}$ (magma) was also studied because of existing field and geochemical evidence to suggest a close temporal and genetic link to the earlier Kidnappers eruption. The minerals studied were extracted from pumices in the ignimbrites of all three eruptions, where crystal-glass-whole-rock compositional relationships could be measured, but where stratigraphic controls are limited. In addition, however, about two thirds ( $200 \mathrm{~km}^{3}$, magma) of the volume of the extracaldera deposits from the Kidnappers eruption is represented by a fine-grained phreatomagmatic fall deposit, which is lacking in pumice clasts but for which stratigraphic control is clear. For this fall deposit, a complementary approach of using mineral chemistry and glass compositions was used, which then allowed linkage to the pumice chemistry and mineralogy of the subsequent ignimbrite. Here, a summary of the findings of this research is presented in order to address the key questions raised in the Introduction (Chapter 1).

\subsubsection{Over what timescales did each of the magmatic systems at Mangakino accumulate and grow?}

In this study I have utilised zircon U-Pb age dating by SIMS to establish the timescales of zircon growth in each magmatic system. The zircon $\mathrm{U}-\mathrm{Pb}$ age spectra represent the growth of each magmatic system as a whole and the development of a crystal rich source or mush. U-Pb ages from each of the studied eruptions at Mangakino volcanic centre reveal protracted growth histories, spanning $200 \mathrm{kyr}$ in the Kidnappers and Rocky Hill and $\sim 250 \mathrm{kyr}$ in the Ongatiti system (Chapter 2 ). The majority of zircon within the Ongatiti system crystallised $\sim 100 \mathrm{kyr}$ prior to eruption in a crystal mush, 
ascended during the development of a crystal rich magma body and then remained stable with little additional crystallisation or signs of dissolution and instability. The extent of the disparity recorded in Ongatiti zircons between a peak crystallisation age from $\sim 1.32-1.30 \mathrm{Ma}$ and eruption at 1.21 Ma is unique within the zircon age record from New Zealand. The absence of significant zircon crystallisation immediately prior to eruption is due to a relatively hot (and wet) final erupted magma body, which was not zircon saturated.

Timescales from the Kidnappers and Rocky Hill eruptions cover the similar ranges, with a bimodal distribution in both, suggesting growth within a common system undergoing two major pulses of crystallisation. An earlier pulse, represented by a peak in crystallization ages around 1.1-1.2 Ma is inferred to relate to growth of a mush body during a period when eruptive activity at Mangakino was absent. A later pulse of crystallisation within the melt-dominant body just prior to eruption is represented by rapidly grown, high aspect ratio zircons within the Kidnappers. The establishment of the Kidnappers/Rocky Hill system occurred entirely in the timebreak after the Ongatiti eruption and few inherited grains from earlier systems (Ongatiti and Ahuroa, the latter studied by McCormack et al. 2009) are present.

There is a disconnect in all three systems between the growth and accumulation of the broader magmatic system (recorded in zircon U-Pb ages) and the establishment of the final erupted melt-dominant bodies (delineated by major-phase crystal textures). Within the Ongatiti the latter process is represented by the gradual rejuvenation of the crystal mush (Chapter 6), whereas in the Kidnappers/Rocky Hill system significant volumes of magma were extracted from a mush to form melt-dominant bodies within centuries of eruption (Chapter 2).

\subsubsection{What magmatic processes and varying source influences can be tracked by trace} elements in zircons?

Alongside U-Pb analyses for dating, in-situ trace element analyses by SIMS were undertaken to evaluate the potential of zircons to record geochemical processes. Zircons from all three systems record common magmatic processes that are dominated by their 
crystallising assemblages. Typical trends seen in changing $\mathrm{Eu} / \mathrm{Eu}^{*}$ with increasing evolution (measured, for example by increasing Hf concentrations) can be inferred to be governed by plagioclase co-crystallisation . Significant signals of amphibole crystallisation are also reflected in the zircon chemistry. Relative enrichments in HREE over MREE are often assumed to be governed by the presence of garnet in the source zone. Here, I propose that the relative enrichments in HREE over MREE and the trends in Sc concentrations seen in zircons from Mangakino are controlled by amphibole and its influence on the melt chemistry. These relationships are particularly evident in the Ongatiti, and supports evidence from the main crystal phases (Chapter 6) for an amphibole-dominated mid- to lower- quartzofeldspathic crust beneath Mangakino. In addition, it became apparent that single crystal geochemical variations can be governed by differing kinematic controls within sector-zoned crystals, as well as the sides and tips of high aspect ratio elongate (needle-shaped) grains. These crystal-specific variations, not previously recorded in the literature, may overprint the magmatic variations within zircon. These observations have implications for the use of zircons for tracking magmatic processes, particularly in techniques where CL zonation within crystals is not assessed and small analytical spot sizes cannot be achieved, such as with LA-ICP-MS. These observations also imply that the applicability of the widely used Ti-in-zircon thermometer may be compromised.

Unique U-Pb age spectra from both the Ongatiti and Kidnappers/Rocky Hill indicate both systems were newly built in the time-breaks after the previous large eruption from Mangakino volcanic centre (i.e. little or no inherited grains). Trace element variations defining three-component mixing, suggesting that multiple sources of grains contributed in each system. In the Ongatiti, two of these sources are defined by the presence or absence of co-crystallising amphibole, respectively, consistent with the geochemical signatures of magmatic evolution in amphibole and plagioclase (Chapter 6). 


\subsubsection{What information can we gain from variations in mineral chemistry and zoning}

patterns in crystals regarding the pre-eruptive crystal growth histories and changing magmatic conditions within large silicic systems?

This thesis underlines the value of crystal specific studies to unravel the complex dynamics of large-scale silicic systems at Mangakino volcanic centre. During this study it soon became clear that to gain meaningful insights from the chemical variations within crystal phases, textural classification to quantify populations of crystal phases was essential. A complex and unique magmatic history may be recorded within each mineral phase and/or textural population, which is a reflection of open system behavior and multiple processes in operation. Considering the complex zonation in each crystal, it is apparent that it is only in the final stages of growth (i.e. the crystal rims) that all the mineral phases are likely to have grown together that are now contained within a single pumice. It is from the composition of crystal rims and the associated matrix glass that I estimate the final chemistry and conditions within the melt-dominant bodies.

The majority of plagioclase and amphibole within the Ongatiti display distinct histories, which reveal the interaction of grains from two sources and the gradual defrosting of a crystal mush. Plagioclase typically shows a steady core to rim increase in An content (from $\sim \mathrm{An}_{25}$ to $\mathrm{An}_{30}$ ), which represents a gradual rise in temperature and/or increase in the water content of the melt. The low An values in the interior of grains suggests that the plagioclase was already highly evolved and likely stored at shallow levels in the crust ( 4-6 km). In contrast, the majority of amphiboles have darker cores and lighter rims when viewed under BSE, and the core-rim shifts in chemistry indicate a downtemperature and -pressure signature. These data indicate that amphiboles were sourced from deeper levels (mid-lower quartzofeldspathic crust), presumably grown and stored in a crystal mush, before extraction and migration to shallower levels. The migration upwards of hotter, less evolved melt with higher water contents containing a significant proportion of amphibole acted to rejuvenate a plagioclase richer mush to form an eruptible melt-dominant body at 4-6 $\mathrm{km}$ in which both phases were stored and continued to grow prior to eruption. 
Crystal signatures from the Kidnappers/Rocky Hill ignimbrites are more complex and reflect the establishment and growth of a total of four (two large $\left[>100 \mathrm{~km}^{3}\right]$ and two small $\left.\left[>10 \mathrm{~km}^{3}\right]\right)$ independent, melt-dominant bodies within the overall crustal magmatic system. Once pumice and glass compositional groups were established (e.g. Cooper et al. 2012 [Chapter 3]), I was able to quantify populations of crystal types within each group based on texture and composition. The relative proportions of crystal populations (in plagioclase, amphibole and orthopyroxene) between compositional groups then revealed that each host melt type underwent a distinct history and unique processes:

- Conditions (temperature, pressure, composition) in the largest independent body (Glass type A of Cooper et al. 2012 [Chapter 3]; pumice types Kidnappers KI-1 and Rocky Hill RH-1) remained constant for a period of time prior to eruption, reflected by little or no change in chemistry from interiors to rims.

- A greater fraction of grains within a second body (Glass type B of Cooper et al. 2012 [Chapter 3]; pumice types Kidnappers KI-2 and Rocky Hill RH-2) display down-temperature signals suggesting a significant proportion of crystals and melt moved to shallower levels prior to eruption.

- A significant proportion of crystals from a third independent body (pumice type Kidnappers KI-3) have up-temperature rims with significant shifts in crystal chemistry. These features are interpreted to represent the rejuvenation of this magma by intermixing of a lesser-evolved melt.

- A fourth melt type is only represented by the Kidnappers-C glass type in the fall deposit (Cooper et al. 2012 [Chapter 3]). No crystal phases can be uniquely linked to this melt composition, and it appears to have been wholly exhausted during the fall phase of the Kidnappers eruption and has no counterpart in the pumices from the succeeding ignimbrite (Chapter 4).

It is important to note that the cores and interiors of crystals within each of the independent bodies show no clear distinction and therefore all share a common source. It is only in the later stages of growth in which these distinct histories were established. 
7.1.4. Over what depths did each magmatic system operate, and what were the sizes and pre-eruptive states of the melt-dominant bodies prior to eruption?

Primarily, final pre-eruptive temperatures and oxygen fugacity were estimated using FeTi oxide equilibrium pairs, which is now a well established and long standing method. The calibration of Ghiorso and Evans (2008) was used as it has been widely adopted in recent studies and thus provides a direct comparison to other well-studied silicic systems. The amphibole thermobarometry methods of Ridolfi et al. (2010) were used to track a history of temperature and pressure changes, and the depths to which crystals were sourced within each system. For comparison, model temperatures were also calculated using the Ti-in-zircon thermometer (Ferry and Watson, 2007), plagioclasemelt (Putirka 2008) and orthopyroxene-melt (Putirka 2008) calibrations but were not used extensively due to the reasons discussed in Chapters 2 and 4. Even though there are disparities in the temperatures modelled using the different methods, with careful application the relative variations between compositional groups within each system can yield fairly consistent results.

There is a remarkably narrow range in the final pre-eruptive temperatures and pressures from the Ongatiti, which is also reflected in a narrow and consistent range of crystal rim compositions and textures. These observations imply that the melt-dominant body was not vertically stratified with respect to chemical compositions. Fe-Ti oxide temperatures are between $840-880^{\circ} \mathrm{C}$ and fall on the NNO buffer curve. Modelled temperatures from amphibole rims are cooler (between $780-840{ }^{\circ} \mathrm{C}$ ) and pressures fall between 120-160 $\mathrm{MPa}$. These conditions correspond to final pre-eruptive storage depths between 4 and 6 $\mathrm{km}$. In contrast, modelled temperature and pressure estimates from amphibole cores range from $780-960{ }^{\circ} \mathrm{C}$ and $120-400 \mathrm{MPa}$, suggesting that the earlier-grown parts of the amphiboles were sourced from up to $15 \mathrm{~km}$ depth, to the base of the quartzo-feldspathic crust.

The ranges in modelled temperature and pressures from amphibole cores within the Kidnappers/Rocky Hill system are more restricted, implying that the majority of crystals were crystallized from already more-evolved melts and stored in a mush at higher levels in the crust prior to formation of the melt-dominant bodies. Within the 
overall system, amphibole core temperatures and pressures range from $\sim 760-900{ }^{\circ} \mathrm{C}$ and $\sim 80-260 \mathrm{MPa}$ corresponding to depths up to $\sim 10 \mathrm{~km}$. Conditions in the final erupted melt-dominant bodies, represented by estimates from amphibole rims were between $\sim 760-840{ }^{\circ} \mathrm{C}$ and $\sim 80-160 \mathrm{MPa}$ corresponding to depths of 3.5-6.0 km. Each meltdominant body was held at slightly different conditions prior to eruption, but all estimates fall within this range. Total Fe-Ti oxide temperatures cover a larger range $\left(740-920^{\circ} \mathrm{C}\right)$ but are different between each body, and oxygen fugacity estimates fall on the NNO buffer curve.

7.1.5. What information can be obtained from the geochemisty and/or petrology of a fall deposit, and how does it compare to the record from ignimbrites?

There is a wide variability in the quality of material available to study compositional variations in large-scale silicic eruptions. Ideally, individual juvenile clasts (particularly pumice) are sampled from all stratigraphic levels. However, this is often not possible, particularly in the fine-grained products of phreatomagmatic eruptions, due to the scarcity of pumices large enough to analyse reliably, and the volumetric dominance of fine-grained widespread fall deposits that are prone to erosion. In contrast, ignimbrites commonly contain pumices that are large enough for individual study, but it is not always possible to determine the stratigraphic position of each pumice sample where exposures are limited. This is particularly an issue in the deposits from Mangakino volcanic centre, which are poorly exposed due to erosion and burial by the deposits of later volcanic activity. Therefore I used a novel approach to sampling in order to study time constrained geochemical variations to a level of detail that may be comparable to younger systems with well-preserved deposits.

A 4.0 m proximal section of the Kidnappers fall deposit, underlying the Kidnappers ignimbrite, was sampled for this study with the aim of tracking compositional variations through the first two thirds of the Kidnappers eruption. From the chemical variations in matrix glass shards and minerals through the deposit I was able to infer the existence of three horizontally separated melt-dominant bodies, which were systematically tapped during the eruption (Cooper et al. 2012 [Chapter 3]). The systematic evacuation of the magma bodies recorded in the proportions of different glass chemistries in the fall 
deposit implies that there was a tectonic triggering and linkage of eruptions. This interpretation would not be possible if only pumices from the overlying ignimbrite (lacking temporal control) were studied. However, large pumices within the ignimbrite provide an opportunity to study the textural and chemical variations of crystals with a definitive relationship to the associated mineral assemblage and the melt in which they grew (at least at the latest stages). The approach taken in this study parallels the methodologies used on glass chemistry in distal ash fall deposits from large ignimbrites (e.g. Perkins and Nash 2002, Cathey and Nash 2004, Nash and Perkins 2012), but the combination of glass and mineral chemistry opens up new possibilities where pumice clasts are not available.

\subsubsection{Do the Kidnappers and Rocky Hill ignimbrites share a common source and/or} magma chamber?

Mangakino volcanic centre provides a unique opportunity to study a caldera-related system from which one supervolcanic eruption was followed by a second large-scale silicic eruption in close succession. To a first order, the nature of pumices in the Rocky Hill ignimbrite and the presence of an erosional break between it and the underlying Kidnappers ignimbrite suggest the two deposits are from distinct events from the perspective of physical volcanology. However, the extensive studies of both units presented in this thesis provides unambiguous evidence for the evacuation of both deposits from a common magmatic system, which also shared in common the two largest melt-dominant bodies (Secion 7.1.3. above):

- $\mathrm{U}-\mathrm{Pb}$ age spectra are indistinguishable suggesting both events were sourced from the same broader crystal mush source which was established over a total time period of $\sim 200 \mathrm{kyr}$ prior to eruption at $\sim 1.0 \mathrm{Ma}$.

- Zircon trace element variations cover the same range, with evidence of threecomponent mixing in both eruptions, and common crystallisation trends.

- The major and trace element chemistries of matrix glass in the two Rocky Hill pumice types (RH-1 and $\mathrm{RH}-2$ ) overlie those from the pumice types representing the two largest melt-dominant bodies in the Kidnappers (KI-2 and KI-2: Chapter $4)$. 
- Major and trace element signatures and textural variations of major phases (plagioclase, orthopyroxene and amphibole) imply that significant proportions of the crystals in both eruptions are recording the same magmatic processes.

- Fe-Mg diffusion timescales in orthopyroxenes in the Rocky Hill deposits (see next section) suggest that rejuvenation of the Kidnappers melt-dominant bodies was occurring during the time-break between the two eruptions.

Small differences in the mineralogy of the Rocky Hill pumices (e.g. biotite less common and larger amphiboles than in the Kidnappers), and the presence of crystal clots with unique brown glass and whole-rock chemistry suggest that additional crystallisation, mixing and incorporation of marginal material occurred in the short time-break between the eruptions.

\subsubsection{What was the duration of the time break between the Kidnappers and Rocky Hill} eruptions and what processes, such as magma recharge and mixing occurred during this time break?

Determining the time interval between the Kidnappers and Rocky Hill eruptions is a conundrum. Typical absolute dating methods such as ${ }^{40} \mathrm{Ar} /{ }^{39} \mathrm{Ar}$ return identical ages within uncertainty (Houghton et al. 1995; Wilson et al. 1995b). Any possible eruptive age differences between the respective zircon $\mathrm{U}-\mathrm{Pb}$ age spectra are not discernible. Field evidence suggests that the time-break must be no more than a few thousand years, as the erosional surface between the ignimbrites has no well developed soil horizon and the associated distal correlative (Potaka Tephra) is interpreted to be a single composite deposit, consisting of Kidnappers and Rocky Hill material both primary and reworked. In addition, both eruptions are found within the upper period of the short Jaramillo subchron polarity interval. Therefore an unconventional approach was needed to estimate the time interval, which could be closer to a human, rather than a geological timescale. In order to accomplish this estimation, I utilised Fe-Mg diffusion in orthopyroxene to model timescales across zones common to crystals from both eruption deposits. The short time break between eruptions is estimated to be on the order of $\sim 20$ 40 yrs. This short time break highlights the rapidity at which magmatic rejuvenation occurred at Mangakino following the Kidnappers supereruption. Fe-Mg diffusion in orthopyroxene, modelled across core-rim boundaries also showed that significant 
additional extraction of crystals and melt occurred to rejuvenate the two largest eruptible melt-dominant bodies within the short time break. There is no evidence for significant mixing of magmas after the Kidnappers eruption, but incorporation of marginal material into the melt-dominant bodies occurred.

\subsubsection{Does the Ongatiti ignimbrite represent an erupted crystal mush, and if so, what} processes caused the transition into eruption?

To a first order, the Ongatiti ignimbrite is crystal rich and lacks evidence for compositional zoning, which is common of ignimbrites interpreted to represent erupted crystal mushes (e.g. the Fish Canyon Tuff; Bachmann et al. 2002; Bachmann and Dungan 2002). The protracted growth history recorded in Ongatiti zircons, with a peak in crystallisation $\sim 100 \mathrm{kyr}$ before the eruption also supports the idea of late stage rejuvenation of an older crystal mush in which zircon crystallised. Matrix glass chemistries do not significantly vary between pumices and can be considered as homogeneous. This homogeneity is reflected in a very narrow range of crystal rim compositions in all mineral phases, ruling against the possibility of a conventional zoned magma chamber. The majority of amphiboles in the Ongatiti pumices display abrupt down temperature and pressure core-rim signals, indicating their transport within an influx of melt and crystals from a chemically and thermally zoned mush in the midlower crust (6-15 km) to a plagioclase dominated zone at shallower levels ( 4-6 km). The ascent of this amphibole-dominated magma, with higher temperatures and water contents (and its population of zircon crystals), to shallower levels marks the establishment of a crystal rich (20-30 \%), but melt-dominant magma body. Plagioclase almost entirely crystallised at shallow levels and displays widespread gradual 'uptemperature' signatures, which are interpreted to signify a slow heating event and an increase in water contents. These core-rim chemical variations are, however, not abrupt as observed in the Fish Canyon Tuff (Bachmann et al. 2002; Bachmann and Dungan 2002) suggesting that rejuvenation did not occur as a singular event, or directly lead to an eruption. Homogenisation of the final erupted magma body likely arose through convective stirring and no significant crystal-melt separation wihtin the final stages prior to eruption. The establishment of the final erupted bodies within the Ongatiti magma system shows similarities to the Oruanui, in which a melt-dominant body was established through the extraction of crystals and melt from a zoned mush zone in rapid 
timescales ( $<1600$ yrs prior to eruption, Allan et al. 2013). The Ongatiti does therefore not represent a rejuvenated crystal mush, and like the Oruanui, implies that the final erupted magma bodies in large-scale silicic systems can be generated in an alternative fashion.

\subsection{Future perspectives}

In addressing the key research questions discussed above, a number of new questions and avenues for future work on the Mangakino volcanic centre have arisen during the course of this work. The approaches taken to unravel a complex story here have also opened up new possibilities for studying the deposits of other large-silicic systems worldwide.

Understanding of the Ongatiti ignimbrite would be greatly improved by further fieldwork to trace lateral variations within the deposit. Due to the limited exposures of the unit in the King Country, further work could concentrate on potential sections within shallow drill cores. It became apparent from the $\sim 100 \mathrm{kyr}$ difference between the peak of $\mathrm{U}-\mathrm{Pb}$ ages in the zircons and the ${ }^{40} \mathrm{Ar} /{ }^{39} \mathrm{Ar}$ eruption age estimates that the latter may need to be reviewed with recent advances in the technique. A sample from an ignimbrite correlated with the Ongatiti in the Tauranga-Kaimai area was dated at $1.32 \pm$ $0.01 \mathrm{Ma}$ using the ${ }^{40} \mathrm{Ar} /{ }^{39} \mathrm{Ar}$ method by Briggs et al. (2005). This age is different beyond analytical uncertainties from the widely cited age of $1.21 \pm 0.04 \mathrm{Ma}$ from Houghton et al. (1995), but is closely similar to the U-Pb age peak in this study. The possibility thus arises that the Tauranga-Kaimai ignimbrite might represent a separate, earlier eruption from the Ongatiti system. Repeating the age determinations on the main Ongatiti deposits would also help better constrain the timing of development of the magma body.

A logical step to follow on from the geochemical characterisation and crystal-specific work that I have carried out for this study would be the application of isotopes. In particular, single crystal $\mathrm{Sr}$ and $\mathrm{Pb}$ isotopic studies would allow further constraints to be placed on the sources of crystals assembled within the final erupted melt-dominant bodies and the evolution of the system as a whole. This work could be carried out on the 
same samples collected for this study from which the crystals have already been texturally and chemically characterised. Ideally these data could be coupled to an extensive isotopic and $\mathrm{U}-\mathrm{Pb}$ zircon dating study of the lithic types present in Mangakino deposits so that time periods of inter-caldera activity could be delineated and the relative contributions of the underlying greywacke terranes could be determined. The Waipapa composite terrane crops out west of the TVZ in the Mangakino area, whereas the Torlesse composite terrane underlies a significant proportion of, and crops out to the east of, the modern TVZ (e.g., Charlier et al. 2010; Leonard et al. 2010).

Reconnaissance whole-rock pumice $\mathrm{Pb}$ isotope work from this study hints at contamination from the Torlesse crust, implying the Torlesse must extend someway beneath the western margin of the old TVZ (cf. McCormack et al. 2009). Further isotope work has the potential to constrain this observation further, which would have wider implications on understanding the regional structure beneath the TVZ.

The study of melt inclusions could enhance and build upon the matrix glass chemistry I obtained for this study, in order to provide additional constraints on magmatic intensive parameters (notably contents of water and other volatile phases, and estimates of entrapment pressures). This information may be of particular importance within the Ongatiti in understanding the phase relationships within a mid-lower crustal source with an amphibole $>>$ plagioclase assemblage. Within the Kidnappers/Rocky Hill system, melt inclusions could be used to trace the evolution of each melt type as well as the changing conditions between the mush and melt-dominant bodies.

A remarkable range of vesicularity textures are observed in pumices from the ignimbrites from Mangakino. The Ongatiti contains very dense clasts within the lower flows and less dense pumices in the upper flows, which themselves cover a range in appearance and vesicularity. The cause of the highly variable textures is intriguing, particularly as there are no discernible differences in the textures and chemistries of the crystals contained within them. A comprehensive study of the pumice textures from the centimeter through to the micron scale would enhance our understanding of the physical processes occurring during these eruptions. 
The novel approach used in systematically sampling and analysing the material through the Kidnappers fall deposit to track compositional changes through time, may be applicable to other silicic systems where macroscopic clasts are not available. Alternatively, the systematic study of a co-ignimbrite fall deposit, representing the winnowed average of all compositions being erupted at any particular point in time, may prove to be a valuable counterpart to pumice specific studies in the ignimbrite itself. Such work has been undertaken on the Whakamaru system in New Zealand (Brown et al. 1998a ; Matthews et al, 2012c), but there is some room for doubt as to which of the ignimbrite deposits are represented in the co-eruptive Rangitawa Tephra. Similar studies have also been undertaken on vitric co-ignimbrite deposits of the Snake River Plain systems (e.g. Perkins and Nash 2002, Cathey and Nash 2004, Nash and Perkins 2012), where associated ignimbrites are highly welded and lack fresh pumice. Within this thesis I have highlighted the contrasting record from the Kidnappers fall deposit and overlying ignimbrite, and the importance of comparing each record to build a comprehensive picture of the magmatic behaviour. The Bishop, Lava Creek and Huckleberry Ridge tuffs may provide an avenue for similar comparisons, as their associated fall deposits are voluminous and extend across much of the western USA. 


\section{References}

Adams CJ, Mortimer N, Campbell HJ, Griffin WL (2009) Age and isotopic characterisation of metasedimentary rocks from the Torlesse Supergroup and Waipapa group in the central North Island, New Zealand. NZ J Geol Geophys 52:149-170

Allan ASR (2008) An elemental and isotopic investigation of Quaternary silicic Taupo Volcanic Zone tephras from ODP Site 1123: chronostratigraphic and petrogenetic applications. MSc thesis, Victoria University of Wellington, Wellington, New Zealand

Allan ASR (2013) The Oruanui eruption: insights into the generation and dynamics of the world's youngest supereruption. $\mathrm{PhD}$ thesis, Victoria University of Wellington, Wellington, New Zealand

Allan ASR, Baker JA, Carter L, Wysoczanski RJ (2008) Reconstructing the Quaternary evolution of the world's most active silicic volcanic system: insights from an $\sim 1.65$ Ma deep ocean tephra record sourced from Taupo Volcanic Zone, New Zealand. Quat Sci Rev 27:2341-2360

Allan ASR, Wilson CJN, Millet M-A, Wysoczanski RJ (2012) The invisible hand: tectonic triggering and modulation of a rhyolitic supereruption. Geology 40:563566

Allan ASR, Morgan DJ, Wilson CJN, Millet M-A (2013) From mush to eruption in centuries: assembly of the super-sized Oruanui magma body. Contrib Mineral Petrol 166:143-164

Alloway B, Westgate J, Pillans B, Pearce NJG, Newnham RM, Byrami M, Aarburg S (2004) Stratigraphy, age and correlation of middle Pleistocene silicic tephras in the Auckland region, New Zealand: a prolific distal record of Taupo Volcanic Zone volcanism. NZ J Geol Geophys 47:447-479

Alloway BV, Pillans BJ, Carter L, Naish TR, Westgate JA (2005) Onshore-offshore correlation of Pleistocene rhyolitic eruptions from New Zealand: implications for TVZ eruptive history and paleoenvironmental construction. Quat Sci Rev 24:1601-1622

Anders E, Grevesse N (1989) Abundances of the elements: meteoric and solar. Geochim Cosmochim Acta 53:197-214

Anderson AT, Davis AM, Lu F (2000) Evolution of Bishop Tuff rhyolitic magma based on melt and magnetite inclusions and zoned phenocrysts. J Petrol 41:449-473

Bachmann O (2010) The petrologic evolution and pre-eruptive conditions of the rhyolitic Kos Plateau Tuff (Aegean Arc). Cent Eur J Geosci 2:270-305 
Bachmann O, Bergantz GW (2003) Rejuvenation of the Fish Canyon magma body: A window into the evolution of large-volume silicic magma systems. Geology 31:789-792

Bachmann O, Bergantz GW (2004) On the origin of crystal-poor rhyolites: extracted from batholithic crystal mushes. J Petrol 45:1565-1582

Bachmann O, Bergantz GW (2006) Gas percolation in upper-crustal silicic mushes as a mechanism for upward heat advection and rejuvenation of near-solidus magma bodies. J Volcanol Geotherm Res 149:85-102

Bachmann O, Bergantz GW (2008) Deciphering magma chamber dynamics from styles of compositional zoning in large silicic ash flow sheets. Rev Mineral Geochem 69:651-674

Bachmann O, Dungan MA (2002) Temperature-induced Al-zoning in hornblendes of the Fish Canyon magma, Colorado. Am Mineral 87:1062-1076

Bachmann O, Dungan MA, Lipman PW (2002) The Fish Canyon magma body, San Juan volcanic field, Colorado: rejuvenation and eruption of an upper-crustal batholith. J Petrol 43:1469-1503

Bachmann O, Oberli F, Dungan MA, Meier M, Mundil R, Fischer H (2007) ${ }^{40} \mathrm{Ar} /{ }^{39} \mathrm{Ar}$ and $\mathrm{U}-\mathrm{Pb}$ dating of the Fish Canyon magmatic system, San Juan volcanic field, Colorado: evidence for an extended crystallization history. Chem Geol 236:134166

Bacon CR, Druitt TH (1988) Compositional evolution of the zoned calcalkaline magma chamber of Mount Mazama, Crater Lake, Oregon. Contrib Mineral Petrol 98:224-256

Bacon CR, Hirschmann MM (1988) Mg/Mn partitioning as a test for equilibrium between coexisting Fe-Ti oxides. Am Mineral 73:57-61

Baker J, Peate D, Waight T, Meyzen C (2004) Pb isotopic analysis of standards and samples using a ${ }^{207} \mathrm{~Pb}-{ }^{204} \mathrm{~Pb}$ double spike and thallium to correct for mass bias with a double-focusing MC-ICP-MS. Chem Geol 211:275-303

Barth AP, Wooden JL (2010) Coupled elemental and isotopic analyses of polygenetic zircons from granitic rocks by ion microprobe, with implications for melt evolution and the sources of granitic magmas. Chem Geol 277:149-159

Barth AP, Feilen ADG, Yager SL, Douglas SR, Wooden JL, Riggs NR, Walker JD (2012) Petrogenetic connections between ash-flow tuffs and a granodioritic to granitic intrusive suite in the Sierra Nevada arc, California. Geosphere 8:250264

Barth AP, Wooden JL, Jacobson CE, Economos RC (2013) Detrital zircon as a proxy for tracking the magmatic arc system: The California arc example. Geology 41:223-226 
Belousova EA, Griffin WL, O'Reilly SY, Fisher NI (2002) Igneous zircon: trace element composition as an indicator of source rock type. Contrib Mineral Petrol 143:602-622

Bergantz GW, Dawes R (1994) Aspects of magma generation and ascent in continental lithosphere. In: Ryan MP (Ed.) Magmatic Systems. Academic Press San Diego, 291-317

Bibby HM, Caldwell TG, Davey FJ, Webb TH (1995) Geophysical evidence on the structure of the Taupo Volcanic Zone and its hydrothermal circulation. J Volcanol Geotherm Res 68:29-58

Bindeman IN, Valley JW (2002) Oxygen isotope study of the Long Valley magmatic system, California: isotope thermometry and convection in large silicic magma bodies. Contrib Mineral Petrol 144:185-205

Bindeman IN, Schmitt AK, Valley JW (2006) U-Pb geochronology of silicic tuffs from the Timber Mountain/Oasis Valley caldera complex, Nevada: rapid generation of large volume magmas by shallow-level remelting. Contrib Mineral Petrol 152:649-665

Black TM (1992) Chronology of the Middle Pleistocene Kidnappers Group, New Zealand and correlation to global oxygen isotope stratigraphy. Earth Planet Sci Lett 109:573-584

Blake S, Wilson CJN, Smith IEM, Walker GPL (1992) Petrology and dynamics of the Waimihia mixed magma eruption, Taupo Volcano, New Zealand. J Geol Soc Lond 149:193-207

Blank HR (1965) Ash-flow deposits of the central King Country, New Zealand. NZ J Geol Geophys 8:588-607

Blundy J, Cashman K (2008) Petrologic reconstruction of magmatic system variables and processes. Rev Mineral Geochem 69:179-239

Blundy J, Cashman K, Humphreys M (2006) Magma heating by decompression-driven crystallization beneath andesite volcanoes. Nature 443:76-80

Boehnke P, Watson EB, Trail D, Harrison TM, Schmitt AK (2013) Zircon saturation rerevisited. Chem Geol 351:324-334

Briggs ND (1976) Recognition and correlation of subdivisions within the Whakamaru Ignimbrite, central North Island, New Zealand. NZ J Geol Geophys 19:463-501

Briggs RM, Gifford MG, Moyle AR, Taylor SR, Norman MD, Houghton BF, Wilson CJN (1993) Geochemical zoning and eruptive mixing in ignimbrites from Mangakino volcano, Taupo Volcanic Zone, New Zealand. J Volcanol Geotherm Res 56:175-203

Briggs RM, Houghton BF, McWilliams MO, Wilson CJN (2005) ${ }^{40} \mathrm{Ar} /{ }^{39} \mathrm{Ar}$ ages of 
silicic volcanic rocks in the Tauranga-Kaimai area, New Zealand: dating the transition between volcanism in the Coromandel Arc and the Taupo Volcanic Zone. NZ J Geol Geophys 48:459-469

Brophy JG (1991) Compositional gaps, critical crystallinity, and fractional crystallization in orogenic (calc-alkaline) magmatic systems. Contrib Mineral Petrol 109:173-182

Brown SJA, Fletcher IR (1999) SHRIMP U-Th dating of the preeruption growth history of zircons from the $340 \mathrm{ka}$ Whakamaru Ignimbrite, New Zealand: evidence for $>250$ k.y. magma residence times. Geology 27:1035-1038

Brown SJA, Smith RT (2004) Crystallisation history and crustal inheritance in a large silicic magma system: ${ }^{206} \mathrm{~Pb} /{ }^{238} \mathrm{U}$ ion probe dating of zircons from the $1.2 \mathrm{Ma}$ Ongatiti ignimbrite, Taupo Volcanic Zone. J Volcanol Geotherm Res 134:247257

Brown SJA, Wilson CJN, Cole JW, Wooden J (1998a) The Whakamaru group ignimbrites, Taupo Volcanic Zone, New Zealand: evidence for reverse tapping of a zoned silicic magma system. J Volcanol Geotherm Res 84:1-37

Brown SJA, Burt RM, Cole JW, Krippner SJP, Price RC, Cartwright I (1998b) Plutonic lithics in ignimbrites of Taupo Volcanic Zone, New Zealand: sources and conditions of crystallisation. Chem Geol 148:21-41

Broxton DE, Warren RG, Byers FM, Scott RB (1989) Chemical and mineralogic trends within the Timber Mountain-Oasis valley caldera complex, Nevada: evidence for multiple cycles of chemical evolution in a long-lived silicic magmatic system. J Geophys Res 94:5961-5985

Cambray FW, Vogel TA, Mills JG (1995) Origin of compositional heterogeneities in tuffs of the Timber Mountain Group: the relationship between magma batches and magma transfer and emplacement in an extensional environment. J Geophys Res 100:15793-15805

Cameron KL (1984) Bishop Tuff revisited: new rare earth element data consistent with crystal fractionation. Science 224:1338-1340

Carley TL, Miller CF, Wooden JL, Bindeman IN, Barth AP (2011) Zircon from historic eruptions in Iceland: reconstructing storage and evolution of silicic magmas. Mineralogy and Petrology 102:135-161

Carmichael ISE (1967) The iron-titanium oxides of salic volcanic rocks and their associated ferromagnesian silicates. Contrib Mineral Petrol 14:36-64

Carter L, Alloway BV, Shane P, Westgate JA (2004) Deep-ocean record of major late Cenozoic rhyolitic eruptions from New Zealand. NZ J Geol Geophys 47:481500

Cathey HE, Nash BP (2004) The Cougar Point Tuff: implications for thermochemical 
zonation and longevity of high-temperature, large volume silicic magmas of the Miocene Yellowstone hotspot. J Petrol 45:27-58

Chakraborty S (2008) Diffusion in solid silicates: a tool to track timescales of processes comes of age. Ann Rev Earth Planet Sci 36:153-190

Chambefort I, Dilles JH, Longo AA (2013) Amphibole geochemistry of the Yanacocha Volcanics, Peru: Evidence for diverse sources of magmatic volatiles related to gold ores. J Petrol 54:1017-1046

Chamberlain KJ, Wilson CJN, Wooden JL, Charlier BLA, Ireland TR (2013) New perspectives on the Bishop Tuff from zircon textures, ages and trace elements. $\mathrm{J}$ Petrol (under review)

Charlier BLA, Wilson CJN (2010) Chronology and evolution of caldera-forming and post-caldera magma systems at Okataina volcano, New Zealand from zircon UTh model-age spectra. J Petrol 51:1121-1141

Charlier BLA, Peate DW, Wilson CJN, Lowenstern JB, Storey M, Brown SJA (2003) Crystallisation ages in coeval silicic magma bodies: U-Th disequilibrium evidence from the Rotoiti and Earthquake Flat eruption deposits, Taupo Volcanic Zone, New Zealand. Earth Planet Sci Lett 206:441-457

Charlier BLA, Wilson CJN, Lowenstern JB, Blake S, van Calsteren PW, Davidson JP (2005) Magma generation at a large, hyperactive silicic volcano (Taupo, New Zealand) revealed by U-Th and U-Pb systematics in zircons. J Petrol 46:3-32

Charlier BLA, Bachmann O, Davidson JP, Dungan MA, Morgan DJ (2007) The upper crustal evolution of a large silicic magma body: evidence from crystal-scale $\mathrm{Rb}$ Sr isotopic heterogeneities in the Fish Canyon magmatic system, Colorado. J Petrol 48:1875-1894

Charlier BLA, Wilson CJN, Davidson JP (2008) Rapid open-system assembly of a large silicic magma body: time-resolved evidence from cored plagioclase crystals in the Oruanui eruption deposits, New Zealand. Contrib Mineral Petrol 156:799813

Charlier BLA, Wilson CJN, Mortimer N (2010) Evidence from zircon U-Pb age spectra for crustal structure and felsic magma genesis at Taupo volcano, New Zealand. Geology 38:915-918

Cherniak DJ, Watson EB (2003) Diffusion in zircon. Rev Mineral Geochem 53:113144

Chesner CA, Rose WI (1991) Stratigraphy of the Toba tuffs and the evolution of the Toba caldera complex, Sumatra, Indonesia. Bull Volcanol 53:343-356

Christensen JN, DePaolo DJ (1993) Time scales of large volume silicic magma systems- Sr isotopic systematics of phenocrysts and glass from the Bishop Tuff, Long Valley, California. Contrib Mineral Petrol 113:100-114 
Christiansen EH (2005) Contrasting processes in silicic magma chambers: evidence from very large volume ignimbrites. Geol Mag 142:669-681

Claiborne LL, Miller CF, Wooden JL (2010) Trace element composition of igneous zircon: a thermal and compositional record of the accumulation and evolution of a large silicic batholith, Spirit Mountain, Nevada. Contrib Mineral Petrol $160: 511-531$

Cole JW (1990) Structural control and origin of volcanism in the Taupo Volcanic Zone, New Zealand. Bull Volcanol 52:445-459

Cole JW, Lewis KB (1981) Evolution of the Taupo-Hikurangi subduction system. Tectonophysics 72:1-21

Cole JW, Cashman KV, Rankin PC (1983) Rare-earth element geochemistry and the origin of andesites and basalts of the Taupo Volcanic Zone, New Zealand. Chem Geol 38:255-274

Cole JW, Darby DJ, Stern TA (1995) Taupo Volcanic Zone and Central Volcanic Region: backarc structures of North Island, New Zealand. In: Taylor B (ed) Backarc Basins: Tectonics and Magmatism, vol. Plenum Press, New York, pp 128

Cole JW, Milner DM, Spinks KD (2005) Calderas and caldera structures: a review. Earth-Sci Rev 69:1-26

Coombs ML, Sisson TW, Bleick HA, Henton SM, Nye CJ, Payne AL, Cameron CE, Larsen JF, Wallace KL, Bull KF (2013) Andesites of the 2009 eruption of Redoubt Volcano, Alaska. J Volcanol Geotherm Res 259:349-372

Cooper GF, Wilson CJN, Millet M-A, Baker J, Smith EGC (2012) Systematic tapping of independent magma chambers during the 1 Ma Kidnappers supereruption. Earth Planet Sci Lett 213-214:23-33

Corrigan G (1982) The crystal morphology of plagioclase feldspar produced during isothermal supercooling and constant rate cooling experiments. Min Mag 46:433-439

Corfu F, Hanchar JM, Hoskin PWO, Kinny P (2003) Atlas of zircon textures. Rev Mineral Geochem 53:469-500

Costa F (2008) Residence times of silicic magmas associated with calderas. Developments in Volcanology 10:1-55

Costa F, Morgan D (2010) Time constraints from chemical equilibration in magmatic crystals. In: Dosseto A, Turner SP, Van Orman JA (eds) Timescales of magmatic processes: from core to atmosphere. Wiley, Chichester, 129-159

Costa F, Chakraborty S, Dohmen R (2003) Diffusion coupling between trace and major elements and a model for calculation of magma residence times using 
plagioclase. Geochim Cosmochim Acta 67:2189-2200

Costa F, Dohmen R, Chakraborty S (2008) Time scales of magmatic processes from modeling the zoning patterns of crystals. Reviews in Mineralogy and Geochemistry 69:545-594

Couch S, Sparks RSJ, Carroll MR (2001) Mineral disequilibrium in lavas explained by convective self mixing in open magma chambers. Nature Lond 411:1037-1039

Dalrymple GB, Grove M, Lovera OM, Harrison TM, Hulen JB, Lanphere MA (1999) Age and thermal history of the Geysers plutonic complex (felsite unit), Geysers geothermal field, California: $\mathrm{a}^{40} \mathrm{Ar} /{ }^{39} \mathrm{Ar}$ and U-Pb study. Earth Planet Sci Lett 173:285-298

Davis WJ (1985) Geochemistry and petrology of the Rotoiti and Earthquake Flat pyroclastic deposits. MSc Thesis, University of Auckland, New Zealand 1-142

Davy BW, Caldwell TG (1998) Gravity, magnetic and seismic surveys of the caldera complex, Lake Taupo, North Island, New Zealand. J Volcanol Geotherm Res 81:69-89

De Angelis SH, Larsen J, Coombs M (2013) Pre-eruptive magmatic conditions at Augustine Volcano, Alaska, 2006: evidence from amphibole geochemistry and textures. J Petrol (in press) doi:10.1093/petrology/egt037

Deering CD, Cole JW, Vogel TA (2011) Extraction of crystal-poor rhyolite from a hornblende-bearing intermediate mush: a case study of the caldera-forming Matahina eruption, Okataina volcanic complex. Contrib Mineral Petrol 161:129151

Devine J, Rutherford M, Norton G, Young S (2003) Magma storage region processes inferred from geochemistry of Fe-Ti oxides in andesitic magma, Soufriere Hills Volcano, Montserrat, WI. J Petrol 44:1375-1400

Dobson KJ, Stuart FM, Dempster TJ, EIMF (2008) U and Th zonation in Fish Canyon Tuff zircons: Implications for a zircon (U-Th)/He standard. Geochim Cosmochim Acta 72:4745-4755

Druitt TH, Bacon CR (1989) Petrology of the zoned calcalkaline magma chamber of Mount Mazama, Crater Lake, Oregon. Contrib Mineral Petrol 101:245-259

Druitt TH, Sparks RSJ (1984) On the formation of calderas during ignimbrite eruptions. Nature 310:679-681

Duffield WA, Ruiz J (1992) Compositional gradients in large reservoirs of silicic magma as evidenced by ignimbrites versus Taylor Creek Rhyolite lava domes. Contrib Mineral Petrol 110:192-210

Dunbar NW, Hervig RL (1992) Petrogenesis and volatile stratigraphy of the Bishop Tuff: evidence from melt inclusion analysis. J Geophys Res 97:15129-15150 
Evensen NM, Hamilton PJ, O'Nions RK (1978) Rare-earth abundances in chondritic meteorites. Geochim Cosmochim Acta 42:1199-1212

Fagan CJ (2007) Stratigraphy, hydrothermal alteration and evolution of the Mangakino geothermal system, Taupo Volcanic Zone, New Zealand. MSc Thesis, University of Auckland, New Zealand 1-142

Ferry JM, Watson EB (2007) New thermodynamic models and revised calibrations for the Ti-in-zircon and Zr-in-rutile thermometers. Contrib Mineral Petrol 154:429437

Finch RJ, Hanchar JM, Hoskin PWO, Burns PC (2001) Rare-earth elements in synthetic zircon: Part 2. A single-crystal X-ray study of xenotime substitution. Am Mineral 86:681-689

Folch A, Codina R, Martí J (2001) Numerical modeling of magma withdrawal during explosive caldera-forming eruptions. J Geophys Res 106:16163-16175

Folkes CB, de Silva SL, Wright HMN, Cas RAF (2011) Geochemical homogeneity of a long-lived, large silicic system; evidence from the Cerro Galán caldera, NW Argentina. Bull Volcanol 73:1455-1486

Francis PW, Sparks RSJ, Hawkesworth CJ, Thorpe RS, Pyle DM, Tait SR, Mantovani MS, McDermott F (1989) Petrology and geochemistry of volcanic rocks of the Cerro Galan caldera, northwest Argentina. Geol Mag 126:515-547

Freer R, Hauptman Z (1978) Experimental study of magnetite-titanomagnetite interdiffusion. Phys Earth Planet Int 16:223-231

Fridrich CJ, Mahood GA (1987) Compositional layers in the zoned magma chamber of the Grizzly Peak Tuff. Geology 15:299-303

Froggatt PC, Nelson CS, Carter L, Griggs G, Black KP (1986) An exceptionally large late Quaternary eruption from New Zealand. Nature 319:578-582

Fu B, Page FZ, Cavosie AJ, Fournelle J, Kita NT, Lackey JS, Wilde SA, Valley JW (2008) Ti-in-zircon thermometry: applications and limitations. Contrib Mineral Petrol 156:197-215

Gamble JA, Smith IEM, McCulloch MT, Graham IJ, Kokelaar BP (1993) The geochemistry and petrogenesis of basalts from the Taupo Volcanic Zone and Kermadec Island Arc, S.W. Pacific. J Volcanol Geotherm Res 54:265-290

Gamble JA, Woodhead JD, Wright IC, Smith IEM (1996) Basalt and sediment geochemistry and magma petrogenesis in a transect from oceanic island arc to rifted continental margin arc: the Kermadec-Hikurangi margin, SW Pacific. J Petrol 37:1523-1546

Gardner JN, Goff F, Kelley S, Jacobs E (2010) Rhyolites and associated deposits of the Valles-Toledo caldera complex. New Mex Geol 32:3-18 
Ghiorso MS, Evans BW (2008) Thermodynamics of rhombohedral oxide solid solutions and a revision of the Fe-Ti two-oxide geothermometer and oxygen-barometer. Am J Sci 308:957-1039

Ghiorso MS, Gualda GA (2013) A method for estimating the activity of titania in magmatic liquids from the compositions of coexisting rhombohedral and cubic iron-titanium oxides. Contrib Mineral Petrol 165:73-81

Girard G, Stix J (2009) Magma recharge and crystal mush rejuvenation associated with early post-collapse Upper Basin Member rhyolites, Yellowstone caldera, Wyoming. J Petrol 50:2095-2125

Girard G, Stix J (2010) Rapid extraction of discrete magma batches from a large differentiating magma chamber: the Central Plateau Member rhyolites, Yellowstone caldera, Wyoming. Contrib Mineral Petrol 160:441-465

Gradstein FM, Ogg JG, Schmitz M, Ogg G (2012) The Geologic Time Scale. Elsevier, Oxford, UK

Graham IJ, Cole JW, Briggs RM, Gamble JA, Smith IEM (1995) Petrology and petrogenesis of volcanic rocks from the Taupo Volcanic Zone: a review. J Volcanol Geotherm Res 68:59-87

Gravley DM, Wilson CJN, Leonard GS, Cole JW (2007) Double trouble: paired ignimbrite eruptions and collateral subsidence in the Taupo Volcanic Zone, New Zealand. Geol Soc Am Bull 119:18-30

Grimes CB, John BE, Cheadle MJ, Mazdab FK, Wooden JL, Swapp S, Schwartz JJ (2009) On the occurrence, trace element geochemistry, and crystallization history of zircon from in situ ocean lithosphere. Contrib Mineral Petrol 158:757783

Halliday A, Davidson JP, Hildreth W, Holden P (1991) Modelling the petrogenesis of high $\mathrm{Rb}$ /Sr silicic magmas. Chem Geol 92:107-114

Hammond PA, Taylor LA (1982) The ilmenite titano-magnetite assemblage - kinetics of reequilibration. Earth Planet Sci Lett 61:143-150

Hanchar JM, van Westrenen W (2007) Rare earth element behavior in zircon-melt systems. Elements 3:37-42

Hanchar JM, Watson EB (2003) Zircon saturation thermometry. Rev Mineral Geochem 53:89-112

Harrison AJ, White RS (2004) Crustal structure of the Taupo Volcanic Zone, New Zealand: stretching and igneous intrusion. Geophys Res Lett 31:L13615

Hellstrom J, Paton C, Woodhead JD, Hergt JM (2008) Iolite: software for spatially resolved LA-(quad and MC) ICPMS analysis. In: Sylvester P (Ed.) Laser Ablation ICP-MS in the Earth Sciences: Current Practices and Outstanding 
Issues. Mineral Association of Canada Short Course Series 40:343-348

Hildreth W (1979) The Bishop Tuff: evidence for the origin of compositional zonation in silicic magma chambers. Geol Soc Am Spec Pap 180:43-75

Hildreth W (1981) Gradients in silicic magma chambers: implications for lithospheric magmatism. J Geophys Res 86:10153-10192

Hildreth W (2004) Volcanological perspectives on Long Valley, Mammoth Mountain, and Mono Craters: several contiguous but discrete systems. J Volcanol Geotherm Res 136:169-198

Hildreth W, Wilson CJN (2007) Compositional zoning of the Bishop Tuff. J Petrol 48:951-999

Hinton RW, Upton BGJ (1991) The chemistry of zircon: Variations within and between large crystals from syenite and alkali basalt xenoliths. Geochim Cosmochim Acta 55:3287-3302

Hochstein MP (1995) Crustal heat transfer in the Taupo Volcanic Zone (New Zealand): comparison with other volcanic arcs and explanatory heat source models. J Volcanol Geotherm Res 68:117-151

Hoskin PWO, Schaltegger U (2003) The composition of zircon and igneous and metamorphic petrogenesis. Rev Mineral Geochem 53:27-62

Hoskin PWO, Kinny PD, Wyborn D, Chappell BW (2000) Identifying accessory mineral saturation during differentiation in granitoid magmas: an integrated approach. J Petrol 41:1365-1396

Houghton BF, Wilson CJN, McWilliams MO, Lanphere MA, Weaver SD, Briggs RM, Pringle MS (1995) Chronology and dynamics of a large silicic magmatic system: central Taupo Volcanic Zone, New Zealand. Geology 23:13-16

Housh TB, Luhr JF (1991) Plagioclase-melt equilibria in hydrous systems. Am Mineral $76: 477-492$

Huber C, Bachmann O, Manga M (2009) Homogenization processes in silicic magma chambers by stirring and mushification (latent heat buffering). Earth Planet Sci Lett 283:38-47

Huber C, Bachmann O, Dufek J (2010a) The limitations of melting on the reactivation of silicic mushes. J Volcanol Geotherm Res 195:97-105

Huber C, Bachmann O, Manga M (2010b) Two competing effects of volatiles on heat transfer in crystal-rich magmas: Thermal insulation vs defrosting. J Petrol 51:847-867

Huber C, Bachmann O, Dufek J (2012) Crystal-poor versus crystal-rich ignimbrites: A competition between stirring and reactivation. Geology 40:115-118 
Humphreys MC, Blundy JD, Sparks RSJ (2006) Magma evolution and open-system processes at Shiveluch Volcano: insights from phenocryst zoning. J Petrol 47:2303-2334

Johnson MC, Rutherford MJ (1989) Experimental calibration of the aluminium-inhornblende geobarometer with application to Long Valley caldera (California) volcanic rocks. Geology 17:837-841

Kahl M, Chakraborty S, Costa F, Pompilio M (2011) Dynamic plumbing system beneath volcanoes revealed by kinetic modelling, and the connection to monitoring data: an example from Mt. Etna. Earth Planet Sci Lett 308:11-22

Keller J (1969) Origin of rhyolites by anatectic melting of granitic crustal rocks; the example of rhyolitic pumice from the island of Kos (Aegean Sea). Bull Volcanol 33:942-959

Kennedy BM, Stix J (2007) Magmatic processes associated with caldera collapse at Ossipee ring dyke, New Hampshire. Geol Soc Am Bull 119:3-17

Kennedy BM, Jellinek AM, Stix J (2008) Coupled caldera subsidence and stirring inferred from analogue models. Nature Geosci 1:385-389

Kennedy B, Wilcock J, Stix J (2012) Caldera resurgence during magma replenishment and rejuvenation at Valles and Lake City calderas. Bull Volcanol 74:1833-1847

Klimm K, Holtz F, Johannes W, King P (2003) Fractionation of metaluminous A-type granites: an experimental study of the Wangrah Suite, Lachlan Fold Belt, Australia. Precamb Res 124:327-341

Krippner SJP, Briggs RM, Wilson CJN, Cole JW (1998) Petrography and geochemistry of lithic fragments in ignimbrites from the Mangakino volcanic centre: implications for the composition of the subvolcanic crust in western Taupo Volcanic Zone, New Zealand. NZ J Geol Geophys 41:187-199

Lange RA, Frey HM, Hector J (2009) A thermodynamic model for the plagioclaseliquid hygrometer/thermometer. Am Mineral 94:494-506

Leake BE, Woolley AR, Birch WD, Burke EA, Ferraris G, Grice JD, Hawthorne FC, Kisch HJ, Krivovichev VG, Schumacher JC (2004) Nomenclature of amphiboles: Additions and revisions to the International Mineralogical Association's amphibole nomenclature. Am Mineral 89:883-887

Leonard GS, Cole JW, Nairn IA, Self S (2002) Basalt triggering of the c. AD 1305 Kaharoa rhyolite eruption, Tarawera Volcanic Complex, New Zealand. J Volcanol Geotherm Res 115:461-486

Leonard GS, Begg JG, Wilson CJN (2010) Geology of the Rotorua area. Inst Geol Nucl Sci 1:250,000 geological map 5, 102 p. + 1 folded map. Lower Hutt, Institute of Geological \& Nuclear Sciences 
Lindsay JM, Schmitt AK, Trumbull RB, De Silva SL, Siebel W, Emmermann R (2001) Magmatic evolution of the La Pacana caldera system, central Andes, Chile: compositional variation of two cogenetic, large-volume felsic ignimbrites. J Petrol 42:459-486

Lipman PW (1984) The roots of ash flow calderas in western North America: windows into the tops of granitic batholiths. J Geophys Res 89:8801-8841

Lipman PW (2000) Calderas. In: Sigurdsson H (ed) Encyclopedia of Volcanoes. Academic Press, San Francisco, 643-662

Lipman PW, Dungan MA, Bachmann O (1997) Comagmatic granophyric granite in the Fish Canyon Tuff, Colorado: implications for magma-chamber processes during a large ash-flow eruption. Geology, Boulder 25:915-918

Liu Y, Anderson AT, Wilson CJN, Davis AM, Steele IM (2006) Mixing and differentiation in the Oruanui rhyolitic magma, Taupo, New Zealand: evidence from volatiles and trace elements in melt inclusions. Contrib Mineral Petrol 151:71-87

Lowe DJ (2011) Tephrochronology and its application: a review. Quat Geochronol 6: $107-153$

Ludwig KR (2008) Isoplot/Ex version 3.70, A geochronological toolkit for Microsoft Excel, revision of August 26, 2008. Berkeley Geochronology Center Spec Publ 4

Ludwig K (2009) SQUID 2: A User's Manual, revision of 12 April, 2009. Berkeley Geochronology Center Spec Publ 5

Luo Y, Ayers JC (2009) Experimental measurements of zircon/melt trace-element partition coefficients. Geochim Cosmochim Acta 73:3656-3679

Mahood G (1990) Second reply to comment of RSJ Sparks, HE Huppert and CJN Wilson on "Evidence for long residence times of rhyolitic magma in the Long Valley magmatic system: the isotopic record in the precaldera lavas of Glass Mountain”. Earth Planet Sci Lett 99:395-399

Marsh BD (1981) On the crystallinity, probability of occurrence, and rheology of lava and magma. Contrib Mineral Petrol 78:85-98

Marsh BD (2002) On bimodal differentiation by solidification front instability in basaltic magmas, part 1: basic mechanics. Geochim Cosmochim Acta 66:22112229

Marshall LA, Sparks RSJ (1984) Origin of some mixed-magma and net-veined ring intrusions. J Geol Soc Lond 141:171-182

Martin RC (1961) Stratigraphy and structural outline of the Taupo Volcanic Zone. NZ J Geol Geophys 4:449-478 
Martin VM, Morgan DJ, Jerram DA, Caddick MJ, Prior DJ, Davidson JP (2008) Bang! Month-scale eruption triggering at Santorini Volcano. Science 321:1178

Mason BG, Pyle DM, Oppenheimer C (2004) The size and frequency of the largest explosive eruptions on Earth. Bull Volcanol 66:735-748

Matthews NE, Pyle DM, Smith VC, Wilson CJN, Huber C, van Hinsberg V (2012a) Quartz zoning and the pre-eruptive evolution of the $\sim 340$-ka Whakamaru magma systems, New Zealand. Contrib Mineral Petrol 163:87-107

Matthews NE, Huber C, Pyle DM, Smith VC (2012b) Timescales of magma recharge and reactivation of large silicic systems from Ti diffusion in quartz. J Petrol 53:1385-1416

Matthews NE, Smith VC, Costa A, Durant AJ, Pyle DM, Pearce NJ (2012c) Ultra-distal tephra deposits from super-eruptions: examples from Toba, Indonesia and Taupo volcanic zone, New Zealand. Quat Int 258:54-79

Maughan LL, Christiansen EH, Best MG, Grommé CS, Deino AL, Tingey DG (2002) The Oligocene Lund Tuff, Great Basin, USA: a very large volume monotonous intermediate. J Volcanol Geotherm Res 113:129-157

Mazdab FK, Wooden JL (2006) Trace element analysis in zircon by ion microprobe (SHRIMP-RG): technique and applications. Geochim Cosmochim Acta 70:A405

McCormack KD, Gee MAM, McNaughton NJ, Smith R, Fletcher IR (2009) U-Pb dating of magmatic and xenocryst zircons from Mangakino ignimbrites and their correlation with detrital zircons from the Torlesse metasediments, Taupo Volcanic Zone, New Zealand. J Volcanol Geotherm Res 183:97-111

McCulloch MT, Kyser TK, Woodhead J, Kinsley L (1994) Pb-Sr-Nd-O isotopic constraints on the origin of rhyolites from the Taupo Volcanic Zone of New Zealand: evidence for assimilation followed by fractionation from basalt. Contrib Mineral Petrol 115:303-312

Metz JM, Mahood GA (1985) Precursors to the Bishop Tuff eruption: Glass Mountain, Long Valley, California. J Geophys Res 90:11121-11126

Metz JM, Mahood GA (1991) Development of the Long Valley, California, magma chamber recorded in precaldera rhyolite lavas of Glass Mountain. Contrib Mineral Petrol 106:379-397

Michael PJ (1983) Chemical differentiation of the Bishop Tuff and other high-silica magmas through crystallization processes. Geology 11:31-34

Miller CF, Wark DA (2008) Supervolcanoes and their explosive supereruptions. Elements 4:11-16

Miller JS, Wooden JL (2004) Residence, resorption and recycling of zircons in Devils Kitchen rhyolite, Coso Volcanic Field, California. J Petrol 45:2155-2170 
Miller JS, Matzel JEP, Miller CF, Burgess SD, Miller RB (2007) Zircon growth and recycling during the assembly of large, composite arc plutons. J Volcanol Geotherm Res 167:282-299

Mills JG, Saltoun BW, Vogel TA (1997) Magma batches in the Timber Mountain magmatic system, southwestern Nevada volcanic field, Nevada, USA. J Volcanol Geotherm Res 78:185-208

Milner DM, Cole JW, Wood CP (2003) Mamaku Ignimbrite: a caldera-forming ignimbrite erupted from a compositionally zoned magma chamber in Taupo Volcanic Zone, New Zealand. J Volcanol Geotherm Res 122:243-264

Morgan DJ, Blake S (2006) Magmatic residence times of zoned phenocrysts: introduction and application of the binary element diffusion modelling (BEDM) technique. Contrib Mineral Petrol 151:58-70

Morgan DJ, Blake S, Rogers NWB, DeVivo B, Rolandi G, Macdonald R, Hawkesworth CJ (2004) Time scales of crystal residence and magma chamber volume from modelling of diffusion profiles in phenocrysts: Vesuvius 1944. Earth Planet Sci Lett 222:933-946

Moyle AR (1989) Volcanic geology and geochemistry of the Rocky Hill Ignimbrite, Upper Waipa Valley. MSc thesis, University of Waikato, Hamilton

Murphy MD, Sparks RSJ, Barclay J, Carroll MR, Brewer TS (2000) Remobilization of andesite magma by intrusion of mafic magma at the Soufriere Hills volcano, Montserrat, West Indies. J Petrol 41:21-42

Nairn IA, Kohn BP (1973) Relation of the Earthquake Flat Breccia to the Rotoiti Breccia, Central North Island, New Zealand. NZ J Geol Geophys 16:269-279

Nairn IA, Shane PR, Cole JW, Leonard GJ, Self S, Pearson N (2004) Rhyolite magma processes of the $\sim$ AD 1315 Kaharoa eruption episode, Tarawera volcano, New Zealand. J Volcanol Geotherm Res 131:265-294

Nasdala L, Zhang M, Kempe U, Panczer G, Gaft M, Andrut M, Plotze M (2003) Spectroscopic methods applied to zircon. Rev Mineral Geochem 53:427-467

Nash BP, Perkins ME (2012) Neogene fallout tuffs from the Yellowstone hotspot in the Columbia Plateau Region, Oregon, Washington and Idaho, USA. PLoS ONE 7:e44205

Nelson ST, Montana A (1992) Sieve-textured plagioclase in volcanic rocks produced by rapid decompression. Am Mineral 77:1242-1249

Ninkovich D (1968) Pleistocene volcanic eruptions in New Zealand recorded in deepsea sediments. Earth Planet Sci Lett 4:89-102

Pallister JS, Hoblitt RP, Reyes AG (1992) A basalt trigger for the 1991 eruptions of Pinatubo volcano? Nature 356:426-428 
Pamukcu AS, Carley TL, Gualda GA, Miller CF, Ferguson CA (2013) The evolution of the Peach Spring giant magma body: evidence from accessory mineral textures and compositions, bulk pumice and glass geochemistry, and rhyolite-MELTS modeling. J Petrol 54:1109-1148

Pearce NJ, Denton JS, Perkins WT, Westgate JA, Alloway BV (2007) Correlation and characterization of individual glass shards from tephra deposits using trace element laser ablation ICP-MS analyses: current status and future potential. J Quat Sci 22:721-736

Perkins ME, Nash BP (2002) Explosive silicic volcanism of the Yellowstone hotspot: the ash fall tuff record. Geol Soc Am Bull 114:367-381

Perkins ME, Nash WP, Brown FH, Fleck RJ (1995) Fallout tuffs of Trapper Creek, Idaho- a record of Miocene explosive volcanism in the Snake River Plain volcanic province. Geol Soc Am Bull 107:1484-1506

Petford N (2003) Rheology of granitic magmas during ascent and emplacement. Ann Rev Earth Planet Sci 31:399-427

Phillips EH, Goff F, Kyle PR, McIntosh WC, Dunbar NW, Gardner JN (2007) The ${ }^{40} \mathrm{Ar} /{ }^{39} \mathrm{Ar}$ age constraints on the duration of resurgence at the Valles caldera, New Mexico. J Geophys Res 112:B08201

Price RC, Gamble JA, Smith IEM, Stewart RB, Eggins SM, Wright IC (2005) An integrated model for the temporal evolution of andesites and rhyolites and crustal development in New Zealand's North Island. J Volcanol Geotherm Res 140:1-24

Pritchard CJ, Larson PB (2012) Genesis of the post-caldera eastern Upper Basin Member rhyolites, Yellowstone, WY: from volcanic stratigraphy, geochemistry and radiogenic isotope modeling. Contrib Mineral Petrol 164:205-228

Putirka KD (2005) Igneous thermometers and barometers based on plagioclase + liquid equilibria: Tests of some existing models and new calibrations. Am Mineral 90:336-346

Putirka KD (2008) Thermometers and barometers for volcanic systems. Rev Mineral Geochem 69:61-120

Rampino MR, Self S (1993) Climate-volcanism feedback and the Toba eruption of $\sim 74,000$ years ago. Quat Res 40:269-280

Reid MR (2008) How long does it take to supersize an eruption? Elements 4:23-28

Reid MR, Vazquez JA, Schmitt AK (2011) Zircon-scale insights into the history of a supervolcano, Bishop Tuff, Long Valley, California, with implications for the Ti-inzircon geothermometer. Contrib Mineral Petrol 161:293-311

Rhodes JM, Dungan MA, Blanchard DP, Long PE (1979) Magma mixing at mid-ocean 
ridges: evidence from basalts drilled near $22^{\circ} \mathrm{N}$ on the mid-Atlantic ridge. Tectonophys 55:35-61

Richards JP (2011) High $\mathrm{Sr} / \mathrm{Y}$ arc magmas and porphyry $\mathrm{Cu} \pm \mathrm{Mo} \pm \mathrm{Au}$ deposits: Just add water. Econ Geol 106:1075-1081

Ridolfi F, Renzulli A, Puerini M (2010) Stability and chemical equilibrium of amphibole in calc-alkaline magmas: an overview, new thermobarometric formulations and application to subduction-related volcanoes. Contrib Mineral Petrol 160:45-66

Roeder PL, Emslie RF (1970) Olivine-liquid equilibrium. Contrib Mineral Petrol 29:275-289

Rogan AM (1982) A geophysical study of the Taupo Volcanic Zone, New Zealand. J Geophys Res 87:4073-4088

Rowland JV, Wilson CJN, Gravley DM (2010) Spatial and temporal variations in magma-assisted rifting, Taupo Volcanic Zone, New Zealand. J Volcanol Geotherm Res 190:89-108

Ruprecht P, Cooper KM (2012) Integrating the uranium-series and elemental diffusion geochronometers in mixed magmas from Volcán Quizapu, central Chile. J Petrol 53:841-871

Rutherford MJ, Devine JD (1988) The May 18, 1980, eruption of Mount St. Helens 3. Stability and chemistry of amphibole in the magma chamber. J Geophys Res 93:11949-11911

Rutherford MJ, Devine JD (2003) Magmatic conditions and magma ascent as indicated by hornblende phase equilibria and reactions in the 1995-2002 Soufriere Hills magma. J Petrol 44:1433-1453

Sano Y, Terada K, Fukuoka T (2002) High mass resolution ion microprobe analysis of rare earth elements in silicate glass, apatite and zircon: lack of matrix dependency. Chem Geol 184:217-230

Sauerzapf U, Lattard D, Burchard M, Engleman R (2008) The titanomagnetite-ilmenite equilibrium: new experimental data and thermo-oxybarometric application to the crystallization of basic to intermediate rocks. J Petrol 49:1161-1185

Saunders K, Blundy J, Dohmen R, Cashman K (2012) Linking petrology and seismology at an active volcano. Science 336:1023-1027

Sautter V, Jaoul O, Abel F (1988) Aluminum diffusion in diopside using the ${ }^{27} \mathrm{Al}(\mathrm{p}, \gamma)$

${ }^{28}$ Si nuclear reaction: preliminary results. Earth Planet Sci Lett 89:109-114

Schärer U (1984) The effect of initial ${ }^{230} \mathrm{Th}$ disequilibrium on young U-Pb ages: the Makalu case, Himalaya. Earth Planet Sci Lett 67:27-39 
Schipper CI (2004) Chemical and mineralogical characterization of pyroclastic deposits from the ca. 1 Ma Kidnappers and Rocky Hill eruptions, Taupo Volcanic Zone, New Zealand. Unpublished MSc thesis, University of Otago, Dunedin, New Zealand

Schuraytz BC, Vogel TA, Younker LW (1989) Evidence for dynamic withdrawal from a layered magma body: the Topopah Spring Tuff, southwestern Nevada. J

Geophys Res 94:5925-5942

Self S (2006) The effects and consequences of very large explosive volcanic eruptions. Phil Trans R Soc Lond A364:2073-2097

Self S, Sparks RSJ (1978) Characteristics of widespread pyroclastic deposits formed by the interaction of silicic magma and water. Bull Volcanol 41:196-212

Self S, Goff F, Gardner JN, Wright JV, Kite WM (1986) Explosive rhyolitic volcanism in the Jemez Mountains: vent locations, caldera development and relation to regional structure. J Geophys Res 91:1779-1798

Shane PAR (1994) A widespread, early Pleistocene tephra (Potaka tephra, $1 \mathrm{Ma}$ ) in New Zealand: character, distribution, and implications. NZ J Geol Geophys $37: 25-35$

Shane P, Smith VC, Lowe DJ, Nairn IA (2003) Re-identification of c. 15700 cal yr BP tephra bed at Kaipo Bog, eastern North Island: implications for dispersal of Rotorua and Puketarata tephra beds. NZ J Geol Geophys 46:591-596

Shane P, Martin SB, Smith VC, Beggs KF, Darragh MB, Cole JW, Nairn IA (2007) Multiple rhyolite magmas and basalt injection in the $17.7 \mathrm{ka}$ Rerewhakaaitu eruption episode from Tarawera volcanic complex, New Zealand. J Volcanol Geotherm Res 164:1-26

Shane P, Nairn IA, Martin SB, Smith VC (2008) Compositional heterogeneity in tephra deposits resulting from the eruption of multiple magma bodies: implications for tephrochronology. Quat Int 178:44-53

Shaw HR (1965) Comments on viscosity, crystal settling, and convection in granitic magmas. Am J Sci 263:120-152

Shaw HR (1985) Links between magma-tectonic rate balances, plutonism, and volcanism. J Geophys Res 90:11275-11288

Simon JI, Reid MR (2005) The pace of rhyolite differentiation and storage in an 'archetypical' silicic magma system, Long Valley, California. Earth Planet Sci Lett 235:123-140

Sisson TW (1994) Hornblende-melt trace-element partitioning measured by ion microprobe. Chem Geol 117:331-344 
Sisson TW, Bacon CR (1999) Gas-driven filter pressing in magmas. Geology 27:613616

Smith D, Barron BR (1991) Pyroxene-garnet equilibration during cooling in the mantle. Am Mineral 76:1950-1963

Smith RL (1979) Ash-flow magmatism. Geol Soc Am Spec Pap 180:5-27

Smith RL, Bailey RA (1968) Resurgent cauldrons. Geol Soc Am Mem 116:613-662

Smith VC, Shane P, Nairn IA (2004) Reactivation of a rhyolitic magma body by new rhyolitic intrusion before the 15.8 ka Rotorua eruptive episode: implications for magma storage in the Okataina Volcanic Centre, New Zealand. J Geol Soc Lond $161: 757-772$

Sparks RSJ, Sigurdsson H, Wilson L (1977) Magma mixing: a mechanism for triggering acid explosive eruptions. Nature 267:315-318

Sparks RSJ, Huppert HE, Wilson CJN (1990) Comment on: "Evidence for long residence times of rhyolitic magma in the Long Valley magmatic system: the isotopic record in pre caldera lavas of Glass Mountain", by AN Halliday, GA Mahood, P Holden, JM Metz, TJ Dempster and JP Davidson. Earth Planet Sci Lett 99:387-389

Sparks RSJ, Self S, Grattan JP, Oppenheimer C, Pyle DM, Rymer H (2005) Supereruptions: global effects and future threats. Report of a Geological Society of London working group. The Geological Society London 1-24

Speer JA (1982) Zircon. In: Ribbe PH (ed) Orthosilicates. Rev Mineral, vol 5. Mineral Soc Am, Chantilly, Virginia, pp 67-112

Spell TL, McDougall I, Doulgeris AP (1996) Cerro Toledo Rhyolite, Jemez Volcanic Field, New Mexico: ${ }^{40} \mathrm{Ar} /{ }^{39} \mathrm{Ar}$ geochronology of eruptions between two calderaforming events. Geol Soc Am Bull 108:1549-1566

Stacey JS, Kramers JD (1975) Approximation of terrestrial lead isotope evolution by a two-stage model. Earth Planet Sci Lett 26:207-221

Stern TA (1979) Regional and residual gravity fields, central North Island, New Zealand. NZ J Geol Geophys 22:479-485

Stix J, Gorton MP (1993) Replenishment and crystallization in epicontinental silicic magma chambers: evidence from the Bandelier magmatic system. J Volcanol Geotherm Res 55:201-215

Stix J, Goff F, Gorton MP, Heiken G, Garcia SR (1988) Restoration of compositional zonation in the Bandelier silicic magma chamber between two caldera-forming eruptions: geochemistry and origin of the Cerro Toledo Rhyolite, Jemez Mountains, New Mexico. J Geophys Res 93:6129-6147 
Streck MJ (2008) Mineral textures and zoning as evidence for open system processes. Reviews in Mineralogy and Geochemistry 69:595-622

Streck ML, Grunder AL (1997) Compositional gradients and gaps in high-silica rhyolites of the Rattlesnake Tuff, Oregon. J Petrol 38:133-163

Sutton A, Blake S, Wilson CJN (1995) An outline geochemistry of rhyolite eruptives from Taupo volcanic centre, New Zealand. J Volcanol Geotherm Res 68:153175

Sutton AN, Blake S, Wilson CJN, Charlier BLA (2000) Late Quaternary evolution of a hyperactive rhyolite magmatic system: Taupo volcanic centre, New Zealand. J Geol Soc Lond 157:537-552

Tanaka H, Turner GM, Houghton BF, Tachibana T, Kono M, McWilliams MO (1996) Palaeomagnetism and geochronology of the central Taupo Volcanic Zone, New Zealand. Geophys J Int 124:919-934

Tomiya A, Takahashi E (2005) Evolution of the magma chamber beneath Usu volcano since 1663: a natural laboratory for observing changing phenocryst compositions and textures. J Petrol 46:2395-2426

Trail D, Watson EB, Tailby ND (2011) The oxidation state of Hadean magmas and implications for early Earth's atmosphere. Nature 480:79-82

Trail D, Watson EB, Tailby ND (2012) Ce and Eu anomalies in zircon as proxies for the oxidation state of magmas. Geochim Cosmochim Acta 97:70-87

Turner S, Costa F (2007) Measuring timescales of magmatic evolution. Elements 3:267272

Vandergoes MJ, Hogg AG, Lowe DJ, Newnham RM, Denton GH, Southon J, Barrell DJA, Wilson CJN, McGlone MS, Allan ASR, Almond PC, Petchey F, Dabell K, Dieffenbacher-Krall AC, Blaauw M (2013) A revised age for the Kawakawa/Oruanui tephra, a key marker for the last Glacial Maximum in New Zealand. Quat Sci Rev 74:195-201

Vazquez JA, Reid MR (2002) Time scales of magma storage and differentiation of voluminous high-silica rhyolites at Yellowstone caldera, Wyoming. Contrib Mineral Petrol 144:274-285

Vazquez JA, Reid MR (2004) Probing the accumulation history of the voluminous Toba magma. Science 305:991-994

Venezky DY, Rutherford MJ (1999) Petrology and Fe-Ti oxide reequilibration of the 1991 Mount Unzen mixed magma. J Volcanol Geotherm Res 89:213-230

Vigneresse JL, Barbey P, Cuney M (1996) Rheological transitions during partial melting and crystallization with application to felsic magma segregation and transfer. J Petrol 37:1579-1600 
Wallace PJ, Anderson AT, Davis AM (1999) Gradients in $\mathrm{H}_{2} \mathrm{O}, \mathrm{CO}_{2}$, and exsolved gas in a large-volume silicic magma system: interpreting the record preserved in melt inclusions from the Bishop Tuff. J Geophys Res 104:20097-20122

Watson EB (1996) Surface enrichment and trace-element uptake during crystal growth. Geochim Cosmochim Acta 60:5013-5020

Watson EB, Harrison TM (2005) Zircon thermometer reveals minimum melting conditions on earliest Earth. Science 308:841-844

Watson EB, Wark DA, Thomas JB (2006) Crystallization thermometers for zircon and rutile. Contrib Mineral Petrol 151:413-433

Watts KE, Bindeman IN, Schmitt AK (2012) Crystal scale anatomy of a dying supervolcano: an isotope and geochronology study of individual phenocrysts from voluminous rhyolites of the Yellowstone caldera. Contrib Mineral Petrol $164: 45-67$

Wilson CJN (1986) Reconnaissance stratigraphy and volcanology of ignimbrites from Mangakino volcano. In: Smith IEM (ed) Late Cenozoic Volcanism in New Zealand, R Soc NZ Bull 23:179-193

Wilson CJN (2001) The 26.5 ka Oruanui eruption, New Zealand: an introduction and overview. J Volcanol Geotherm Res 112:133-174

Wilson CJN (2008) Supereruptions and supervolcanoes: processes and products. Elements 4:29-34

Wilson CJN, Charlier BLA (2009) Rapid rates of magma generation at contemporaneous magma systems, Taupo volcano, New Zealand: insights from U-Th model-age spectra in zircons. J Petrol 50:875-907

Wilson CJN, Hildreth W (1997) The Bishop Tuff: new insights from eruptive stratigraphy. J Geol 107:407-439

Wilson CJN, Rogan AM, Smith IEM, Northey DJ, Nairn IA, Houghton BF (1984) Caldera volcanoes of the Taupo Volcanic Zone, New Zealand. J Geophys Res $89: 8463-8484$

Wilson CJN, Houghton BF, Lloyd EF (1986) Volcanic history and evolution of the Maroa-Taupo area, central North Island. In: Smith IEM (ed) Late Cenozoic Volcanism in New Zealand, R Soc NZ Bull 23:194-223

Wilson CJN, Houghton BF, McWilliams MO, Lanphere MA, Weaver SD, Briggs RM (1995a) Volcanic and structural evolution of Taupo Volcanic Zone, New Zealand: a review. J Volcanol Geotherm Res 68:1-28

Wilson CJN, Houghton BF, Kamp PJJ, McWilliams MO (1995b) An exceptionally widespread ignimbrite with implications for pyroclastic flow emplacement. Nature 378:605-607 
Wilson CJN, Blake S, Charlier BLA, Sutton AN (2006) The 26.5 ka Oruanui eruption, Taupo volcano, New Zealand: development, characteristics and evacuation of a large rhyolitic magma body. J Petrol 47:35-69

Wilson CJN, Charlier BLA, Fagan CJ, Spinks KD, Gravley DM, Simmons SF, Browne PRL (2008) U-Pb dating of zircon in hydrothermally altered rocks as a correlation tool: application to the Mangakino geothermal field, New Zealand. J Volcanol Geotherm Res 176:191-198

Wilson CJN, Gravley DM, Leonard GS, Rowland JV (2009) Volcanism in the central Taupo Volcanic Zone, New Zealand: tempo styles and controls. In: Thordarson T, Self S, Larsen G, Rowland SK, Hoskuldsson A (ed) Studies in Volcanology: The Legacy of George Walker, vol 2. Special Publications of IAVCEI. Geological Society, London 225-247

Wilson CJN, Charlier BLA, Rowland JV, Browne PRL (2010) U-Pb dating of zircon in subsurface hydrothermally altered pyroclastic deposits and implications for subsidence in a magmatically active rift: Taupo Volcanic Zone, New Zealand. J Volcanol Geotherm Res 191:69-78

Wolff JA, Ramos FC, Davidson JP (1999) Sr isotope disequilibrium during differentiation of the Bandelier Tuff: constraints on the crystallization of a large rhyolitic magma chamber. Geology 27:495-498

Wolff JA, Brunstad KA, Gardner JN (2011) Reconstruction of the most recent volcanic eruptions from the Valles caldera, New Mexico. J Volcanol Geotherm Res 199:53-68

Woodhead JD, Hellstrom J, Hergt JM, Greig A, Maas R (2007) Isotopic and elemental imaging of geological materials by laser ablation inductively coupled plasma mass spectrometry. Geostand Geoanalyt Res 31:331-343 
Appendices 


\section{Appendix 1: Analytical Techniques}

\subsection{Whole rock major and trace element analyses}

\subsubsection{Whole rock sample preparation}

Pumice samples were scrubbed in tap water to remove any adhering foreign material. The clasts were then photographed to record textural characteristics before being cut into smaller blocks on a diamond saw, ensuring that any weathered surface material was removed. The blocks were then scrubbed and washed in milliRO 6 water to remove any contamination from the diamond sawing before being dried at $105^{\circ} \mathrm{C}$ for at least $24 \mathrm{~h}$. Samples were then allowed to re-equilibrate to atmospheric temperature and humidity for several days. Approximately $100 \mathrm{~g}$ of each pumice sample was reduced to chips $<20$ $\mathrm{mm}$ in size using a Boyd crusher, or mortar and pestle. Half of each sample was then crushed to a fine powder using an agate Tema mill. The agate mill was scrubbed and cleaned by milling a batch of quartz sand between samples to minimise the potential for sample cross-contamination.

\subsubsection{XRF major element analysis}

Whole-rock major element analysis $\left(\mathrm{SiO}_{2}, \mathrm{TiO}_{2}, \mathrm{Al}_{2} \mathrm{O}_{3}, \mathrm{Fe}_{2} \mathrm{O}_{3}, \mathrm{MnO}, \mathrm{MgO}, \mathrm{CaO}\right.$, $\mathrm{Na}_{2} \mathrm{O}, \mathrm{K}_{2} \mathrm{O}$, and $\mathrm{P}_{2} \mathrm{O}_{5}$ ) was carried out by X-Ray Fluorescence (XRF) spectrometry using a Philips PW2400 Sequential Wavelength Dispersive X-Ray fluorescence spectrometer at the University of Canterbury, Christchurch and Spectrachem Analytical (CRL Energy Ltd), Wellington. A ARL 8420+ dual goniometer WDXRF spectrometer was used at CESPAR, The Open University, UK. Loss on ignition (LOI) was determined at each institution by measuring the weight loss after heating the samples to $1000^{\circ} \mathrm{C}$ for $1 \mathrm{~h}$.

\subsubsection{Precision and accuracy of major element analyses}

To monitor the precision (i.e., reproducibility) and accuracy of the XRF analyses, two internal standards were each measured three times (three separate disks) for analyses at the University of Canterbury. Analyses of BCR-2 and BHVO-2 yielded precisions (2 
s.d.) that were generally $< \pm 5 \%$ (Tables A1.1 and A1.2). The major element data for BCR-2 and BHVO-2 were in close agreement $(<2.5 \%$ offset $)$ with the preferred reference values in the GeoReM online database (http://georem.mpchmainz.gwdg.de/sample_query_pref.asp) (Tables A1.1 and A1.2).

Table A1.1. XRF precision and accuracy for the BCR-2 standard.

\begin{tabular}{ccccccccc}
\hline & UC & UC & UC & OU & & & \\
BCR-2_1 & BCR-2_2 & BCR-2_3 & BCR_1 & Mean & 2sd (\%) & Preferred & \% diff \\
\hline $\mathbf{S i O}_{2}$ & 54.5 & 54.4 & 54.4 & 54.1 & 54.3 & 0.55 & 54.1 & 0.5 \\
$\mathrm{TiO}_{2}$ & 2.28 & 2.26 & 2.27 & 2.26 & 2.27 & 0.44 & 2.26 & 0.3 \\
$\mathbf{A l}_{2} \mathbf{O}_{3}$ & 13.3 & 13.7 & 13.6 & 13.7 & 13.6 & 2.50 & 13.5 & 0.4 \\
$\mathrm{Fe}_{2} \mathbf{O}_{3} \mathbf{T}$ & 13.7 & 13.6 & 13.6 & 13.7 & 13.7 & 0.70 & 13.8 & -0.9 \\
$\mathbf{M n O}$ & 0.20 & 0.19 & 0.20 & 0.20 & 0.20 & 4.48 & 0.20 & -1.9 \\
$\mathbf{M g O}$ & 3.66 & 3.64 & 3.62 & 3.63 & 3.64 & 0.71 & 3.59 & 1.3 \\
$\mathbf{C a O}$ & 7.10 & 7.06 & 7.05 & 7.08 & 7.07 & 0.52 & 7.12 & -0.7 \\
$\mathbf{N a}_{2} \mathbf{O}$ & 3.31 & 3.26 & 3.29 & 3.1 & 3.2 & 4.93 & 3.16 & 2.5 \\
$\mathbf{K}_{2} \mathbf{O}$ & 1.75 & 1.74 & 1.76 & 1.80 & 1.76 & 2.51 & 1.79 & -1.5 \\
$\mathbf{P}_{2} \mathbf{O}_{5}$ & 0.19 & 0.21 & 0.19 & 0.35 & 0.23 & 55.94 & 0.35 & -49.6 \\
Total & 99.14 & 99.88 & 99.64 & 99.91 & 99.64 & 0.71 & 99.87 & -0.2 \\
\hline Oxide abundances in wt. \%, normalised to 100\% volatile free, Totals are original (uncorrected).
\end{tabular}

Table A1.2. XRF precision and accuracy for the BHVO-2 standard.

\begin{tabular}{|c|c|c|c|c|c|c|c|c|}
\hline & $\begin{array}{c}\text { UC } \\
\text { BHVO-2_1 }\end{array}$ & $\begin{array}{c}\text { UC } \\
\text { BHVO-2_2 }\end{array}$ & $\begin{array}{c}\text { UC } \\
\text { BHVO-2 } 3\end{array}$ & $\begin{array}{c}\text { OU } \\
\text { BHVO-2 }\end{array}$ & Mean & 2sd (\%) & Preferred & $\%$ diff \\
\hline $\mathrm{SiO}_{2}$ & 49.67 & 49.60 & 50.00 & 49.72 & 49.75 & 0.70 & 49.90 & -0.3 \\
\hline $\mathrm{TiO}_{2}$ & 2.72 & 2.74 & 2.75 & 2.70 & 2.73 & 1.76 & 2.73 & -0.1 \\
\hline $\mathrm{Al}_{2} \mathrm{O}_{3}$ & 13.79 & 13.72 & 13.17 & 13.68 & 13.59 & 4.20 & 13.50 & 0.7 \\
\hline $\mathrm{Fe}_{2} \mathrm{O}_{3} \mathrm{~T}$ & 12.12 & 12.16 & 12.20 & 12.30 & 12.19 & 1.23 & 12.30 & -0.9 \\
\hline MnO & 0.17 & 0.17 & 0.17 & 0.17 & 0.17 & 0.49 & 0.17 & -0.6 \\
\hline MgO & 7.30 & 7.33 & 7.38 & 7.18 & 7.30 & 2.30 & 7.23 & 0.9 \\
\hline $\mathrm{CaO}$ & 11.31 & 11.34 & 11.35 & 11.28 & 11.32 & 0.54 & 11.40 & -0.7 \\
\hline $\mathrm{Na}_{2} \mathrm{O}$ & 2.29 & 2.27 & 2.28 & 2.19 & 2.26 & 4.04 & 2.22 & 1.7 \\
\hline $\mathrm{K}_{2} \mathrm{O}$ & 0.52 & 0.54 & 0.54 & 0.51 & 0.53 & 5.45 & 0.52 & 1.0 \\
\hline $\mathbf{P}_{2} \mathrm{O}_{5}$ & 0.12 & 0.14 & 0.16 & 0.27 & 0.17 & 78.33 & 0.27 & -57.1 \\
\hline Total & 99.87 & 99.92 & 99.58 & 100.12 & 99.87 & 0.45 & 100.24 & -0.37 \\
\hline
\end{tabular}

Repeated analyses of a single pumice from the $1.8 \mathrm{ka}$ Taupo eruption (MF-1) were carried out in order to establish an internal rhyolite standard and to monitor its reproducibility (Table A1.3). Uncertainties (2 s.d.) of major element analyses for the Taupo pumice are $<10 \%$, apart from $\mathrm{MgO}$ which has a larger uncertainty, which is likely due to instrumental differences of machines and their operators between the three institutions. Repeat analyses of a Kidnappers pumice were also performed as a check for reproducibility, both within the same batch of analyses and between instruments (Table A1.4). Precision of the major element analyses on this material is $< \pm 5 \%$ for the majority of elements for pumice samples P1655, P2015, and P2006. Analyses of sample P17XX exhibit slightly worse reproducibility (Table A1.4), which is due to the natural geochemical variability within this pumice sample (see Chapter 4). 
Table A1.3. XRF reproducability for the Taupo pumice (MF-1) internal standard.

\begin{tabular}{|c|c|c|c|c|c|c|c|c|c|c|c|}
\hline & $\begin{array}{c}\text { UC } \\
\text { MF_1 }\end{array}$ & $\begin{array}{c}\text { UC } \\
\text { MF_2 }\end{array}$ & $\begin{array}{c}\text { UC } \\
\text { MF_3 }\end{array}$ & $\begin{array}{c}\text { UC } \\
\text { MF_4 }\end{array}$ & $\begin{array}{c}\text { UC } \\
\text { MF_5 } \\
\end{array}$ & $\begin{array}{c}\text { UC } \\
\text { MF_6 }\end{array}$ & $\begin{array}{c}\text { SC } \\
\text { MF_A }\end{array}$ & $\begin{array}{c}\text { SC } \\
\text { MF_A }\end{array}$ & $\begin{array}{c}\text { OU } \\
\text { MF_1 }\end{array}$ & Mean & 2sd (\%) \\
\hline $\mathrm{SiO}_{2}$ & 73.70 & 73.26 & 74.14 & 73.39 & 73.60 & 73.93 & 74.28 & 74.20 & 73.51 & 73.78 & 1.01 \\
\hline $\mathrm{TiO}_{2}$ & 0.29 & 0.28 & 0.28 & 0.28 & 0.28 & 0.29 & 0.28 & 0.28 & 0.31 & 0.29 & 7.12 \\
\hline $\mathrm{Al}_{2} \mathrm{O}_{3}$ & 14.12 & 14.50 & 13.74 & 14.47 & 14.19 & 13.81 & 13.47 & 13.47 & 13.75 & 13.95 & 5.60 \\
\hline $\mathrm{Fe}_{2} \mathrm{O}_{3} \mathrm{~T}$ & 2.35 & 2.40 & 2.34 & 2.37 & 2.37 & 2.39 & 2.41 & 2.43 & 2.63 & 2.41 & 7.32 \\
\hline MnO & 0.09 & 0.09 & 0.09 & 0.09 & 0.09 & 0.09 & 0.09 & 0.09 & 0.10 & 0.09 & 3.15 \\
\hline MgO & 0.28 & 0.29 & 0.27 & 0.29 & 0.29 & 0.29 & 0.32 & 0.33 & 0.36 & 0.30 & 19.75 \\
\hline $\mathrm{CaO}$ & 1.61 & 1.64 & 1.63 & 1.61 & 1.66 & 1.66 & 1.70 & 1.73 & 1.85 & 1.68 & 9.06 \\
\hline $\mathrm{Na}_{2} \mathrm{O}$ & 4.67 & 4.71 & 4.69 & 4.69 & 4.70 & 4.71 & 4.54 & 4.53 & 4.70 & 4.66 & 3.12 \\
\hline $\mathrm{K}_{2} \mathrm{O}$ & 2.88 & 2.82 & 2.81 & 2.80 & 2.80 & 2.82 & 2.84 & 2.87 & 2.73 & 2.82 & 3.08 \\
\hline LOI & 3.08 & 3.20 & 3.27 & 3.19 & 3.06 & 3.11 & 3.21 & 3.22 & 3.40 & 3.19 & 6.53 \\
\hline Total & 100.02 & 99.96 & 100.14 & 99.94 & 100.06 & 99.91 & 99.54 & 99.45 & 99.85 & 99.87 & 0.47 \\
\hline
\end{tabular}

Table A1.4. Repeated XRF analyses of pumice samples

\begin{tabular}{|c|c|c|c|c|c|c|c|c|c|c|}
\hline & $\begin{array}{c}U C \\
1655\end{array}$ & $\begin{array}{c}U C \\
P 1655 B\end{array}$ & & & & $\begin{array}{c}\text { UC } \\
P 2015 A\end{array}$ & $\begin{array}{c}\text { UC } \\
\text { P2015 }\end{array}$ & $\begin{array}{c}\text { UC } \\
P 2015 \mathrm{C}\end{array}$ & & \\
\hline Sample & $\begin{array}{c}\text { P1655_A } \\
7158\end{array}$ & $\frac{\text { P1655_B }}{7072}$ & Mean & $2 \mathrm{sd}(\%)$ & & P2015_A & P2015_B & P2015_C & Mean & 2 sd (\%) \\
\hline $\mathrm{SiO}_{2}$ & 71.58 & 70.72 & 71.15 & 1.71 & & 75.15 & 74.76 & 75.18 & 75.03 & 0.63 \\
\hline $\mathrm{TiO}_{2}$ & 0.40 & 0.40 & 0.40 & 2.27 & & 0.17 & 0.18 & 0.18 & 0.18 & 6.94 \\
\hline $\mathrm{Al}_{2} \mathrm{O}_{3}$ & 14.48 & 15.33 & 14.90 & 8.02 & & 13.66 & 14.03 & 13.57 & 13.75 & 3.59 \\
\hline $\mathrm{Fe}_{2} \mathrm{O}_{3} \mathrm{~T}$ & 2.98 & 3.01 & 2.99 & 1.04 & & 1.60 & 1.59 & 1.59 & 1.59 & 0.39 \\
\hline $\mathrm{MnO}$ & 0.07 & 0.07 & 0.07 & 1.40 & & 0.04 & 0.04 & 0.04 & 0.04 & 0.45 \\
\hline $\mathrm{MgO}$ & 0.58 & 0.59 & 0.58 & 1.10 & & 0.21 & 0.22 & 0.21 & 0.21 & 5.23 \\
\hline $\mathrm{CaO}$ & 2.53 & 2.58 & 2.55 & 3.18 & & 1.61 & 1.58 & 1.61 & 1.60 & 2.23 \\
\hline $\mathrm{Na}_{2} \mathrm{O}$ & 3.69 & 3.69 & 3.69 & 0.18 & & 3.25 & 3.24 & 3.28 & 3.26 & 1.16 \\
\hline $\mathrm{K}_{2} \mathrm{O}$ & 3.67 & 3.57 & 3.62 & 3.83 & & 4.30 & 4.35 & 4.33 & 4.32 & 1.21 \\
\hline LOI & 3.30 & 2.40 & 2.85 & 44.66 & & 2.27 & 2.51 & 2.49 & 2.42 & 10.99 \\
\hline \multirow[t]{2}{*}{ Total } & 99.50 & 99.56 & 99.53 & 0.09 & & 100.00 & 99.98 & 99.78 & 99.92 & 0.24 \\
\hline & UC & SC & SC & & & UC & SC & OU & & \\
\hline Sample & P2006 & P2006 & P2006 & Mean & $2 \mathrm{sd}(\%)$ & P17XX & P17XX & P17XX & Mean & $2 \mathrm{sd}(\%)$ \\
\hline $\mathrm{SiO}_{2}$ & 76.49 & 76.51 & 76.57 & 76.52 & 0.11 & 70.3 & 70.8 & 70.5 & 70.54 & 0.77 \\
\hline $\mathrm{TiO}_{2}$ & 0.15 & 0.15 & 0.15 & 0.15 & 2.51 & 0.41 & 0.38 & 0.42 & 0.40 & 9.19 \\
\hline $\mathrm{Al}_{2} \mathrm{O}_{3}$ & 12.98 & 12.89 & 12.95 & 12.94 & 0.70 & 15.82 & 15.35 & 15.6 & 15.58 & 3.04 \\
\hline $\mathrm{Fe}_{2} \mathrm{O}_{3} \mathrm{~T}$ & 1.36 & 1.35 & 1.36 & 1.35 & 0.88 & 3.43 & 3.41 & 3.50 & 3.45 & 2.86 \\
\hline MnO & 0.03 & 0.03 & 0.03 & 0.03 & 2.56 & 0.06 & 0.06 & 0.07 & 0.06 & 9.50 \\
\hline MgO & 0.18 & 0.20 & 0.19 & 0.19 & 8.70 & 0.60 & 0.57 & 0.61 & 0.59 & 5.82 \\
\hline $\mathrm{CaO}$ & 1.10 & 1.15 & 1.11 & 1.12 & 4.52 & 2.40 & 2.31 & 2.41 & 2.37 & 4.57 \\
\hline $\mathrm{Na}_{2} \mathrm{O}$ & 3.05 & 3.01 & 2.99 & 3.02 & 2.05 & 3.33 & 3.18 & 3.20 & 3.23 & 5.07 \\
\hline $\mathrm{K}_{2} \mathrm{O}$ & 4.64 & 4.70 & 4.64 & 4.66 & 1.51 & 3.65 & 3.88 & 3.70 & 3.74 & 6.56 \\
\hline LOI & 2.54 & 2.29 & 2.55 & 2.46 & 11.98 & 2.91 & 3.20 & 3.45 & 3.19 & 16.96 \\
\hline Total & 99.89 & 99.37 & 99.84 & 99.70 & 0.57 & 99.97 & 99.50 & 99.67 & 99.71 & 0.48 \\
\hline
\end{tabular}

\subsubsection{Sample preparation for trace element analysis}

Samples for trace element and isotopic analyses were prepared in the ultra-clean geochemistry laboratory facility at Victoria University of Wellington. The ultra-clean laboratory was positively pressured with air filtered to class 100 . A PicoTrace Class 10 laminar flow workstation is used to minimise the risk of contamination. Water used within the laboratory was filtered Millipore ${ }^{\circledR} \mathrm{H}_{2} \mathrm{O}$ (Milli-Q) with a resistivity of $>18.2$ $\mathrm{M} \Omega$. SeaStar ${ }^{\mathrm{TM}}$ (SS) grade ultra-pure acids were used for trace element and $\mathrm{Pb}$ isotope sample preparation. Analytical Reagent (AR) grade acids distilled to produce sub-boiled (SB) distilled acids were also used. 
Before use in sample preparation, Savillex Teflon beakers were cleaned extensively. Beakers were first wiped with methanol and rinsed with Milli-Q $\mathrm{H}_{2} \mathrm{O}$ before soaking in $6 \mathrm{M} \mathrm{HCl}$ for $\sim 24 \mathrm{~h}$ on a hotplate at $120^{\circ} \mathrm{C}$ in a $5 \mathrm{~L}$ glass beaker. The Savillex beakers were then rinsed three times in Milli-Q $\mathrm{H}_{2} \mathrm{O}$ and soaked in $7 \mathrm{M} \mathrm{HNO}_{3}$ for a further $24 \mathrm{~h}$ on a hotplate at $120{ }^{\circ} \mathrm{C}$. The beakers were again rinsed in Milli-Q $\mathrm{H}_{2} \mathrm{O}$ three times before being filled with $\sim 5 \mathrm{~mL}$ of $\sim 6 \mathrm{M} \mathrm{SB} \mathrm{HNO}_{3}$, sealed, and refluxed on a hotplate for at least $24 \mathrm{~h}$. The acid was then discarded and the beakers were rinsed three times with Milli-Q $\mathrm{H}_{2} \mathrm{O}$. This step was then repeated using $\sim 7 \mathrm{M} \mathrm{SS} \mathrm{HNO}_{3}$. The beakers were then dried before use. For $\mathrm{Pb}$ isotope work, the beakers were subjected to an additional cleaning step using $\sim 6 \mathrm{M} \mathrm{SS} \mathrm{HCL}$ for at least $24 \mathrm{~h}$ before use.

The same sample powders used prepared for major element XRF analyses analysis (Section 9.1.2.) were used for whole rock trace element analyses. Approximately $50 \mathrm{mg}$ of sample powders and international reference materials (BHVO-2 and BCR-2) were weighed into pre-cleaned $23 \mathrm{~mL}$ Savillex beakers on a high precision balance with a weighing uncertainty of $\pm 0.0001 \mathrm{~g}$. Sample powders were then digested in $\sim 2 \mathrm{~mL}$ of concentrated hydrofluoric acid (29M HF) and $\sim 0.5 \mathrm{~mL}$ of nitric acid $\left(14 \mathrm{M} \mathrm{HNO}_{3}\right)$ in sealed Savillex beakers on a hotplate at $120{ }^{\circ} \mathrm{C}$ for $3-4 \mathrm{~d}$. The samples were then evaporated to incipient dryness. Samples were then attacked twice with concentrated $\mathrm{HNO}_{3}$ and evaporated each time to incipient dryness. To check if the samples were completely dissolved, each sample was refluxed in $\sim 5 \mathrm{~mL}$ of $6 \mathrm{M} \mathrm{HCL}$ for $\sim 24 \mathrm{~h}$. The HCL was then evaporated and samples were re-dissolved in concentrated $\mathrm{HNO}_{3}$ for at least $24 \mathrm{~h}$. Samples were once again evaporated and re-dissolved in $9 \mathrm{~mL}$ of $1 \mathrm{M} \mathrm{HNO}_{3}$ for several days. These solutions were transferred into $10 \mathrm{~mL}$ polyethylene centrifuge tubes and weighed on a high precision balance. A $60 \mu \mathrm{L}$ aliquot of sample was transferred to another centrifuge tube and weighed before dilution with $6 \mathrm{~mL}$ of $1 \%$ $\mathrm{HNO}_{3}$. Procedural blanks were prepared with each batch of samples so that any blank contribution from sample preparation could be monitored and, if necessary, corrected for. 


\subsubsection{ICP-MS solution trace element analysis}

Whole-rock trace element analysis was carried out by solution inductively coupled plasma mass spectrometry (ICP-MS). Measurements were made on an Agilent 7500cs ICP-MS at Victoria University of Wellington. Forty-three elements were analysed: Ca, Li, B, Mg, Sc, Ti, V, Cr, Mn, Co, Ni, Cu, Zn, Ga, Rb, Sr, Y, Zr, Nb, Mo, Cs, Ba, La, Ce, Pr, Nd, Sm, Eu, Gd, Tb, Dy, Ho, Er, Tm, Yb, Lu, Hf, Ta, W, Tl, Pb, Th, and U. Sample and standard solutions were introduced to the ICP-MS by free aspiration through a wet spray chamber. The ICP-MS was tuned using a $10 \mathrm{ppb}$ multi-element Agilent tuning solution to optimise relative standard deviations (RSDs) of the isotopes in that standard $\left({ }^{7} \mathrm{Li},{ }^{59} \mathrm{Co},{ }^{89} \mathrm{Y},{ }^{140} \mathrm{Ce},{ }^{205} \mathrm{Tl}\right)$. The plasma torch was tuned so that the production of oxides, as monitored by $\mathrm{CeO}^{+} / \mathrm{Ce}^{+}$, was $<2 \%$. BHVO-2 was used as the calibration and primary standard, and BCR-2 and Taupo Pumice (MF-1) were used as secondary standards. Each sample was measured for $120 \mathrm{~s}$. The ICP-MS was then washed out in Milli-Q for $30 \mathrm{~s}$ followed by $1 \mathrm{wt}$ \% $\mathrm{SS} \mathrm{HNO}_{3}$ for $90 \mathrm{~s}$ before measuring the background whilst aspirating analytical blanks. Sample-standard bracketing was undertaken in a repeated sequence that consisted of measuring the primary standard (BHVO-2), followed by two unknown samples, a secondary standard (BCR-2 or MF-1), two more unknown samples, and then the primary standard again.

Trace element concentrations in samples were calculated by the sample-standard bracketing method, and using ${ }^{43} \mathrm{Ca}$ as an internal correction, utilising $\mathrm{CaO}$ concentrations of samples previously determined by XRF. The mean background counts were subtracted from the average count rates measured whilst aspirating the samples using Igor Pro v. 6.21 and the Iolite v. 6.23 software add-on (Hellstrom et al., 2008). The background-corrected count rates for each sample were converted into concentrations based on mean background-corrected count rates for the bracketing standards and its known trace element concentration (std ref. value) using the following equation:

$$
\text { Sample } C_{\mathrm{i}}=\left(\operatorname{sample}_{\mathrm{CPS}} / \mathrm{std}_{\mathrm{CPS}}\right) \times\left(\text { sample }_{\mathrm{Dil}} / \mathrm{std}_{\mathrm{Dil}}\right) \times(\text { std ref. value })
$$

The sample concentrations were then internally corrected using $\mathrm{Ca}$ :

$$
\text { Sample } C_{i}=\left(\text { Sample } C_{i} \text { from eq. } 1\right) \times\left(C_{C a} X R F / C_{C a} I C P-M S\right)
$$


where $\mathrm{C}_{\mathrm{i}}$ and $\mathrm{C}_{\mathrm{Ca}}$ are concentrations of a given element (i) or Ca, respectively. $\mathrm{X}_{\mathrm{CPS}}$ is the average counts per second of a given element on either a sample or standard (std). $\mathrm{X}_{\mathrm{Dil}}$ is the concentration of material in the final measured aliquot. All standard reference values used were taken from GeoRem preferred reference values (http://georem.mpchmainz.gwdg.de/) and are displayed in Tables A.5 and A.6.

Table A1.5. Summary of solution ICP-MS data acquired for international rock powder standards (BHVO-2, BCR-2) and the internal Taupo Pumice (MF-1) standard.

\begin{tabular}{|c|c|c|c|c|c|c|c|c|c|c|c|}
\hline \multirow[b]{2}{*}{$\begin{array}{c}\text { Mass } \\
\text { monitored }\end{array}$} & \multicolumn{5}{|c|}{ BHVO-2 rock powder standard } & \multicolumn{4}{|c|}{ BCR-2 rock powder standard } & \multicolumn{2}{|c|}{ Taupo Pumice (MF-1) } \\
\hline & & $\begin{array}{c}\text { Average } \\
n=6\end{array}$ & $\begin{array}{l}\text { Preferred } \\
\text { value }\end{array}$ & 2sd (\%) & $\%$ diff & $\begin{array}{c}\text { Average } \\
n=8\end{array}$ & $\begin{array}{l}\text { Preferred } \\
\text { value }\end{array}$ & 2sd (\%) & $\%$ diff & $\begin{array}{c}\text { Average } \\
n=3\end{array}$ & 2sd (\%) \\
\hline 7 & $\mathrm{Li}$ & 6.10 & 4.80 & 53.4 & 21.3 & 8.28 & 9 & 32.7 & -8.7 & 28.0 & 91.8 \\
\hline 25 & $\mathbf{M g}$ & 43651 & 43599 & 0.834 & 0.1 & 21248 & 21649 & 5.25 & -1.9 & 1804 & 4.4 \\
\hline 25 & Sc & 31.9 & 32.0 & 1.60 & -0.3 & 33.2 & 33.0 & 2.54 & 0.5 & 11.4 & 2.1 \\
\hline 47 & $\mathrm{Ti}$ & 17009 & 16300 & 13.4 & 4.2 & 14200 & 13500 & 12.2 & 4.9 & 1687 & 3.0 \\
\hline 51 & v & 320 & 317 & 3.53 & 0.9 & 421 & 416 & 3.93 & 1.2 & 2.1 & 10.5 \\
\hline 53 & $\mathrm{Cr}$ & 280 & 280 & 0.891 & 0.0 & 15.2 & 18.0 & 7.60 & -18.7 & 0.5 & 98.0 \\
\hline 55 & Mn & 1318 & 1318 & 0.592 & 0.0 & 1542 & 1520 & 1.60 & 1.4 & 719 & 1.7 \\
\hline 59 & Co & 44.9 & 45.0 & 1.65 & -0.2 & 37.6 & 37.0 & 1.89 & 1.7 & 0.5 & 1.6 \\
\hline 60 & $\mathrm{Ni}$ & 119 & 119 & 0.947 & 0.2 & 12.5 & 13.0 & 4.03 & -4.3 & 0.3 & 11.4 \\
\hline 63 & $\mathrm{Cu}$ & 126 & 127 & 0.932 & -0.4 & 19.5 & 21.0 & 2.18 & -7.8 & 2.6 & 3.4 \\
\hline 66 & $\mathrm{Zn}$ & 104 & 103 & 1.53 & 0.7 & 131 & 127 & 1.91 & 3.3 & 69.6 & 4.9 \\
\hline 71 & $\mathrm{Ga}$ & 21.9 & 22.0 & 1.41 & -0.4 & 22.9 & 23.0 & 2.65 & -0.3 & 17.2 & 0.5 \\
\hline 85 & $\mathbf{R b}$ & 9.18 & 9.11 & 2.27 & 0.7 & 47.9 & 46.9 & 9.80 & 2.1 & 98.4 & 8.5 \\
\hline 88 & $\mathrm{Sr}$ & 397 & 396 & 1.97 & 0.1 & 342 & 340 & 1.12 & 0.6 & 156.2 & 5.2 \\
\hline 89 & $Y$ & 25.9 & 26.0 & 1.81 & -0.5 & 35.7 & 37.0 & 3.06 & -3.7 & 33.7 & 3.4 \\
\hline 90 & $\mathrm{Zr}$ & 172 & 172 & 1.09 & -0.1 & 189 & 184 & 1.70 & 2.4 & 229 & 3.2 \\
\hline 93 & $\mathrm{Nb}$ & 32.9 & 18.1 & 127 & 45.1 & 24.1 & 12.6 & 99.3 & 47.8 & 8.8 & 1.2 \\
\hline 95 & Mo & 3.53 & 4.00 & 34.6 & -13.4 & 310 & 250 & 35.8 & 19.5 & 1.5 & 31.6 \\
\hline 133 & Cs & 0.099 & 0.100 & 5.95 & -0.5 & 1.21 & 1.10 & 11.0 & 8.9 & 5.1 & 2.5 \\
\hline 137 & $\mathrm{Ba}$ & 130 & 131 & 2.37 & -0.4 & 676 & 677 & 5.67 & -0.2 & 620 & 4.9 \\
\hline 139 & La & 15.2 & 15.3 & 2.64 & -0.4 & 25.0 & 24.9 & 2.57 & 0.3 & 25.8 & 3.9 \\
\hline 140 & $\mathrm{Ce}$ & 37.3 & 37.8 & 1.29 & -1.3 & 53.3 & 52.9 & 2.81 & 0.8 & 55.5 & 5.2 \\
\hline 141 & Pr & 5.32 & 5.35 & 2.16 & -0.6 & 6.84 & 6.70 & 3.15 & 2.1 & 6.6 & 4.7 \\
\hline 146 & $\mathrm{Nd}$ & 24.4 & 24.4 & 2.36 & 0.1 & 28.6 & 28.7 & 3.49 & -0.5 & 25.8 & 3.2 \\
\hline 147 & $\mathrm{Sm}$ & 6.01 & 6.03 & 4.41 & -0.3 & 6.56 & 6.58 & 4.62 & -0.2 & 5.6 & 3.7 \\
\hline 153 & Eu & 2.07 & 2.07 & 1.25 & 0.2 & 2.07 & 1.96 & 2.25 & 5.3 & 1.3 & 3.9 \\
\hline 157 & Gd & 6.23 & 6.23 & 1.93 & 0.0 & 6.84 & 6.75 & 3.38 & 1.3 & 5.7 & 5.3 \\
\hline 159 & Tb & 0.913 & 0.920 & 2.71 & -0.8 & 1.04 & 1.07 & 2.59 & -3.2 & 0.9 & 6.2 \\
\hline 163 & Dy & 5.28 & 5.3 & 2.34 & -0.4 & 6.43 & 6.41 & 4.15 & 0.3 & 5.6 & 4.1 \\
\hline 165 & Ho & 0.971 & 0.980 & 2.39 & -0.9 & 1.29 & 1.28 & 3.11 & 0.9 & 1.2 & 4.3 \\
\hline 166 & $\mathrm{Er}$ & 2.51 & 2.55 & 2.34 & -1.3 & 3.66 & 3.88 & 4.20 & -5.9 & 3.5 & 5.1 \\
\hline 169 & $\mathrm{Tm}$ & 0.334 & 0.330 & 3.35 & 1.3 & 0.524 & 0.540 & 5.16 & -3.1 & 0.5 & 4.0 \\
\hline 172 & $\mathrm{Yb}$ & 1.95 & 1.96 & 5.67 & -0.1 & 3.34 & 3.38 & 4.98 & -1.2 & 3.5 & 2.4 \\
\hline 175 & Lu & 0.273 & 0.274 & 5.60 & -0.2 & 0.492 & 0.503 & 3.21 & -2.3 & 0.5 & 4.8 \\
\hline 178 & Hf & 4.37 & 4.36 & 1.79 & 0.2 & 4.90 & 4.90 & 2.75 & 0.0 & 6.0 & 3.2 \\
\hline 181 & $\mathrm{Ta}$ & 2.39 & 1.14 & 190 & 52.2 & 2.12 & 0.74 & 121 & 65.2 & 0.7 & 26.6 \\
\hline 208 & $\mathrm{~Pb}$ & 1.96 & 1.60 & 49.3 & 18.6 & 13.5 & 11.0 & 48.5 & 18.3 & 19.7 & 5.8 \\
\hline 232 & Th & 1.22 & 1.22 & 2.90 & 0.2 & 5.97 & 5.70 & 2.51 & 4.6 & 10.4 & 5.0 \\
\hline 248 & $\mathbf{U}$ & 0.408 & 0.403 & 5.20 & 1.2 & 1.62 & 1.69 & 3.42 & -4.2 & 2.4 & 2.2 \\
\hline
\end{tabular}

\subsubsection{Precision and accuracy of solution trace element analyses}

BHVO-2 and BCR-2 were measured during each analytical session to monitor the precision and accuracy of the trace element analyses. The analytical precision on each measured element for BHVO-2 was generally $< \pm 5 \% 2$ sd (Table A1.5 and Figure A1.1). Exceptions include $\mathrm{Li}, \mathrm{Nb}, \mathrm{Mo}, \mathrm{Ta}$, and $\mathrm{Pb}$, which show significant offsets in concentrations between analytical sessions (Table A1.5). The measured concentrations of these elements are also somewhat offset from the published reference values. The accuracy of the other trace elements is generally better than $2 \%$. BCR-2 has slightly 
worse reproducibility, but is still generally $< \pm 6 \%$. However, $\mathrm{Li}, \mathrm{Ti}, \mathrm{Rb}, \mathrm{Nb}, \mathrm{Mo}, \mathrm{Cs}$, $\mathrm{Ta}$, and $\mathrm{Pb}$ show significant variability between analytical sessions and/or between different dilutions (Table A1.5 and Figure A1.1). The measured BCR-2 trace element concentrations are generally within $5 \%$ of published values with the exception of $\mathrm{Li}$, $\mathrm{Cr}, \mathrm{Ni}, \mathrm{Cu}, \mathrm{Nb}, \mathrm{Mo}, \mathrm{Cs}$, $\mathrm{Ta}$, and $\mathrm{Pb}$, which are less accurate. Repeated measurements of the MF-1 internal standard show comparable precision to the analyses of BHVO-2 and BCR-2.

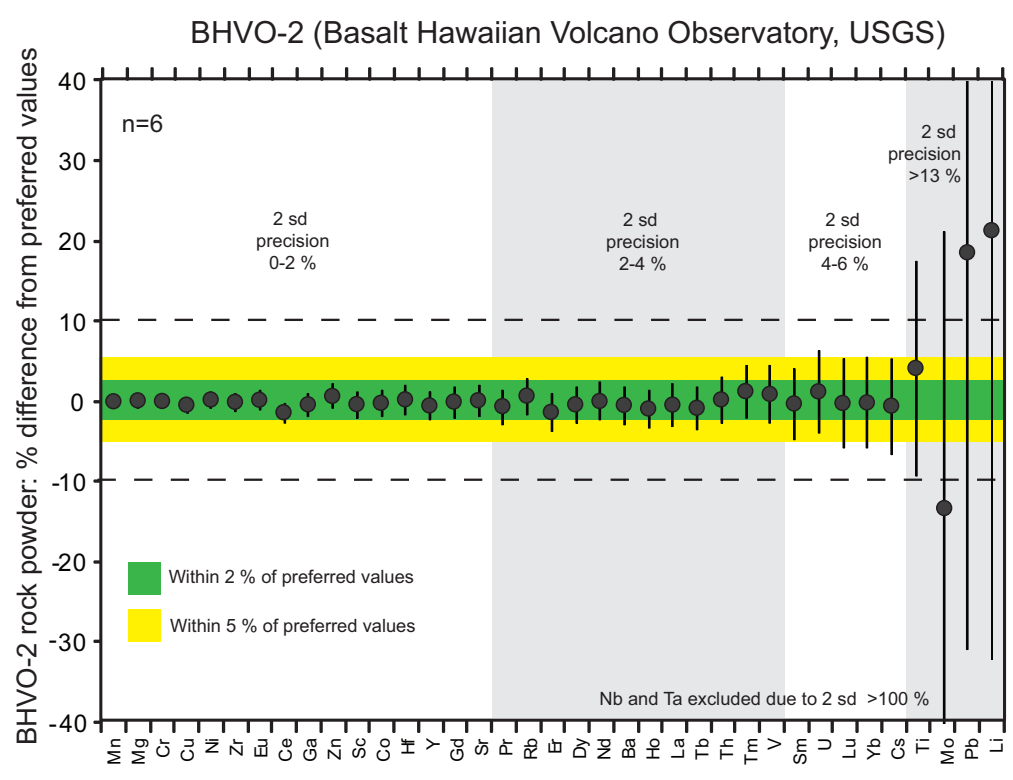

BCR-2 (Basalt Columbia River, USGS)

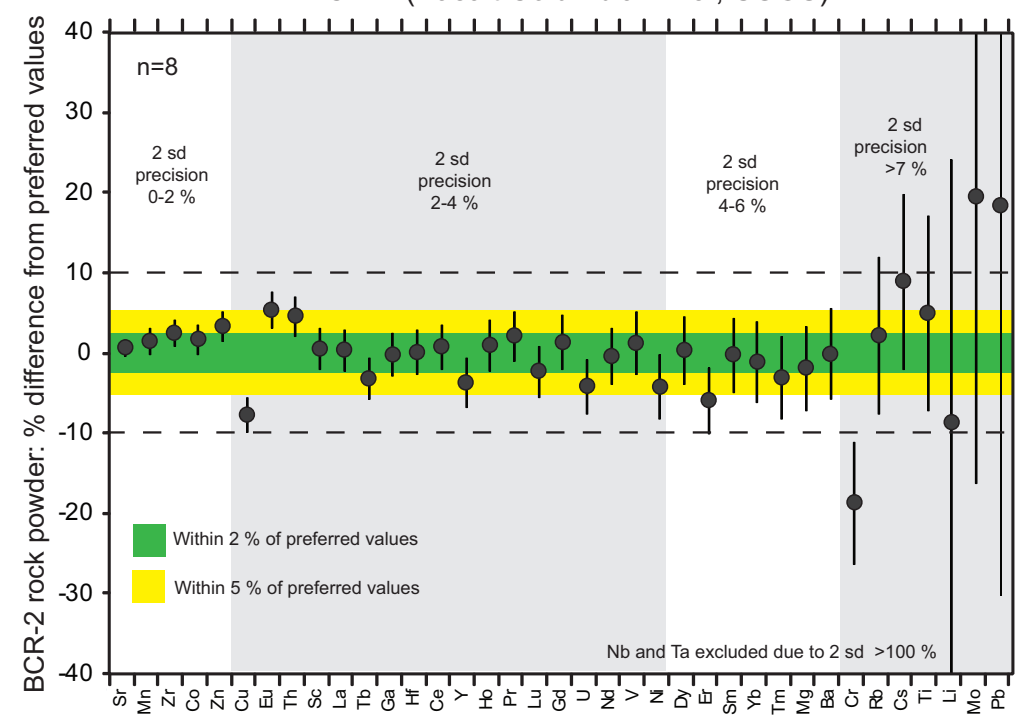

Figure A1.1. Summary of solution ICP-MS data for rock powder standards. Elements are listed from left to right in order of the most precise to least precise measurements. 


\subsection{In-situ major and trace element analyses}

\subsubsection{Sample preparation}

Pumice clasts to be used for in situ glass chemistry, mineral chemistry, and isotopic work were selected on the basis of major element chemistry and textural characteristics in order that a full range of pumice types was represented. Cleaned pumice was first coarsely crushed with a hydraulic press, before being gently crushed with a mortar and pestle or a Boyd Crusher to release crystals from the matrix glass. The samples were then dry sieved into $>1 \mathrm{~mm}, 1 \mathrm{~mm}-500 \mu \mathrm{m}, 500-250 \mu \mathrm{m}, 250-125 \mu \mathrm{m}, 125-63 \mu \mathrm{m}$ and $<63 \mu \mathrm{m}$ fractions. Matrix glass was floated off in water to provide an initial separation of glass and minerals. Plagioclase, quartz, amphibole, orthopyroxene, and biotite crystals were handpicked from the $>1 \mathrm{~mm}$ and $1 \mathrm{~mm}-500 \mu \mathrm{m}$ sieve fractions under a binocular microscope. Fe-Ti oxide (ilmenite and magnetite) equilibrium pairs contained as inclusions within orthopyroxene and amphibole were targeted for electron probe microanalysis (EPMA).

At least 25 grains of each mineral phase from each pumice sample were mounted in 32 $\mathrm{mm}$ wide and $5 \mathrm{~mm}$ thick epoxy resin blocks. Epoxy mounts were made using Epotec $®$ epoxy and polished using 400-2400 grit silicon carbide paper until the phenocrysts were exposed and then polished to a high finish using $3 \mu \mathrm{m}$ and $1 \mu \mathrm{m}$ diamond suspension. Glass shards from the $250-125 \mu \mathrm{m}$ sieve fraction were mounted into six pre-drilled holes within each epoxy block. Pumice chips $<25 \mathrm{~mm}$ in size were mounted in epoxy and polished. This method was used where the petrographic relationships between the crystals and glass were of interest, but the sample was not large enough to produce a thin section. A $25 \mathrm{~nm}$ thick carbon coating was applied to each polished epoxy block before EPMA analysis.

\subsubsection{Electron probe (EPMA) major element analyses}

Back-scattered electron (BSE) imaging, cathodoluminescence (CL) imaging, and quantitative major element analysis of glass and crystals were carried out using a JEOL JXA-8230 Superprobe at Victoria University of Wellington by wavelength dispersive spectrometry. Minerals were analysed with a $15 \mathrm{kV}$ accelerating voltage and a $12 \mathrm{nA}$ focused $(\sim 1 \mu \mathrm{m})$ electron beam. Glass shards were analysed with a $15 \mathrm{kV}$ accelerating 
voltage and a beam current of $8 \mathrm{nA}$ with a defocused beam $(20 \mu \mathrm{m})$. Measurements of $30 \mathrm{~s}$ on the peak and $15 \mathrm{~s}$ on backgrounds either side of the peak were used for the majority of analyses. When analysing $\mathrm{Na}_{2} \mathrm{O}$ in glass, the peak and background times were reduced to 10 seconds and $\mathrm{Na}_{2} \mathrm{O}$ and $\mathrm{K}_{2} \mathrm{O}$ were included in the first analytical scan (of 2) to minimise alkali loss caused by the electron beam. Standardisation of element oxide concentrations and count rates was achieved using a combination of natural and synthetic standards and concentrations of the unknowns calculated using the ZAF correction method.

\subsubsection{Precision and accuracy of EPMA major element analyses}

Plagioclase (NMNH 115900), Engels' amphibole, hypersthene (USNM 746), magnetite (NMNH 96189), ilmenite (NMNH 96189), and rhyolite glass (ATHO-G) were used as standards. Generally, if measured major element oxide totals were $>2.5 \%$ different from published values then a re-calibration of standards was performed before continuing the run. Compiled raw major element data from these secondary standards collected over the course of $\sim 1$ yr are shown in Tables A1.6 and A1.7. The reproducibility of standards are generally $< \pm 6 \%$ on elements with concentrations $>1$ wt. \%. The reproducibility decreases for elements with concentrations $<1 \mathrm{wt} . \%$. Elements with concentrations $>1$ wt. \% exhibit a high degree of accuracy, and are all within $0.7 \%$ of the published reference values. Measured $\mathrm{TiO}_{2}$ concentrations in most (low- $\mathrm{TiO}_{2}$ ) minerals also shows an offset as compared with published reference values. This is likely a consequence of the matrix differences between the synthetic $\mathrm{TiO}_{2}$ standard used for EPMA calibration and the analysed natural minerals

During the first year of this research (collection of data for Chapter 3), the concentration of $\mathrm{Na}_{2} \mathrm{O}$ in the rhyolite glass standard (ATHO-G) showed a consistent offset that was 15-17\% lower than the published reference value. Even though measurement times were reduced (10 seconds) for glass analyses, an offset was caused by alkali migration under the electron beam. The $\mathrm{Na}_{2} \mathrm{O}$ concentrations of measured glass shards during this period were normalised using the consistent offset between the measured $\mathrm{Na}_{2} \mathrm{O}$ contents of ATHO-G in each run and the reference value for this standard. This $\mathrm{Na}_{2} \mathrm{O}$ offset was investigated further and it was found that by separating the $\mathrm{Na}_{2} \mathrm{O}$ peak search and 
analytical scan during the standardisation procedure, any migration could be severely reduced. The difference in the measured ATHO-G standard are shown in Table A1.6.

Table A1.6. EPMA precision and accuracy of the ATHO-G glass standard

\begin{tabular}{|c|c|c|c|c|c|c|c|c|}
\hline \multirow[t]{2}{*}{ (a) } & \multicolumn{4}{|c|}{$\begin{array}{c}\text { ATHO-G (rhyolitic glass) } \\
n=334\end{array}$} & \multicolumn{4}{|c|}{$\begin{array}{l}\text { ATHO-G (rhyolitic glass) } \\
n=60\end{array}$} \\
\hline & Mean & $2 s d(\%)$ & Ref. Value & $\%$ diff & Mean & $2 \mathrm{sd}(\%)$ & Ref. Value & $\%$ diff \\
\hline$\overline{\mathrm{SiO}_{2}}$ & 75.57 & 2.72 & 75.60 & 0.0 & 75.05 & 1.20 & 75.60 & -0.7 \\
\hline $\mathrm{TiO}_{2}$ & 0.24 & 12.69 & 0.26 & -8.5 & 0.24 & 11.73 & 0.26 & -7.6 \\
\hline $\mathrm{Al}_{2} \mathrm{O}_{3}$ & 12.27 & 1.82 & 12.20 & 0.5 & 12.11 & 1.30 & 12.20 & -0.7 \\
\hline $\mathrm{FeO}$ & 3.29 & 10.16 & 3.27 & 0.7 & 3.19 & 7.48 & 3.27 & -2.5 \\
\hline MnO & 0.08 & 125.78 & 0.11 & -37.5 & 0.10 & 23.82 & 0.11 & -8.2 \\
\hline MgO & 0.10 & 32.14 & 0.10 & 0.8 & 0.10 & 20.68 & 0.10 & -2.8 \\
\hline $\mathrm{CaO}$ & 1.69 & 4.08 & 1.70 & -0.3 & 1.72 & 4.27 & 1.70 & 1.1 \\
\hline $\mathrm{Na}_{2} \mathrm{O}$ & 4.51 & 4.81 & 3.75 & 16.9 & 3.74 & 5.89 & 3.75 & -0.4 \\
\hline $\mathrm{K}_{2} \mathrm{O}$ & 2.63 & 3.58 & 2.64 & -0.5 & 2.61 & 6.48 & 2.64 & -1.2 \\
\hline Total & 100.38 & 2.20 & 99.24 & 1.1 & 98.85 & 1.09 & 99.24 & -0.4 \\
\hline
\end{tabular}

(a) Total ATHO-G measured over $\sim 1 \mathrm{yr}$. (b) ATHO-G measured after $\mathrm{Na}_{2} \mathrm{O}$ offset had been addressed. See text for discussion

Table A1.7. Summary of EPMA data for mineral standards collected over $\sim 1$ year.

\begin{tabular}{|c|c|c|c|c|c|c|c|c|}
\hline & \multicolumn{4}{|c|}{ Plagioclase (NMNH 115900) } & \multicolumn{4}{|c|}{ Engels Amphibole } \\
\hline & \multicolumn{3}{|c|}{$n=552$} & \multirow[b]{2}{*}{$\%$ diff } & \multicolumn{4}{|c|}{$n=458$} \\
\hline & Mean & $2 \mathrm{sd}(\%)$ & Pref* & & Mean & 2sd (\%) & Pref** & $\%$ diff \\
\hline $\mathrm{SiO}_{2}$ & 51.16 & 2.11 & 51.25 & -0.2 & 42.00 & 1.89 & 42.14 & -0.3 \\
\hline $\mathrm{TiO}_{2}$ & 0.03 & 88.01 & 0.05 & -85.6 & 0.92 & 14.59 & 0.94 & -2.3 \\
\hline $\mathrm{Al}_{2} \mathrm{O}_{3}$ & 30.83 & 2.27 & 30.91 & -0.3 & 12.08 & 5.15 & 12.09 & -0.1 \\
\hline $\mathrm{FeO}$ & 0.46 & 19.30 & 0.46 & -0.2 & 19.01 & 3.74 & 19.05 & -0.2 \\
\hline MnO & & & & & 0.67 & 16.45 & 0.63 & 6.6 \\
\hline MgO & 0.14 & 20.89 & 0.14 & -0.6 & 8.73 & 5.32 & 8.67 & 0.7 \\
\hline $\mathrm{CaO}$ & 13.64 & 1.71 & 13.64 & 0.0 & 11.56 & 2.03 & 11.56 & 0.0 \\
\hline $\mathrm{Na}_{2} \mathrm{O}$ & 3.46 & 5.64 & 3.45 & 0.4 & 1.61 & 11.94 & 1.63 & -1.2 \\
\hline $\mathrm{K}_{2} \mathrm{O}$ & 0.12 & 24.94 & 0.18 & -44.6 & 0.92 & 9.24 & 0.91 & 1.3 \\
\hline Total & 99.84 & 1.53 & 100.17 & -0.3 & 97.51 & 1.04 & 97.62 & -0.1 \\
\hline & & ersthene & JSNM 72 & & & & & \\
\hline & & $n=3$ & & & & & & \\
\hline & Mean & $2 \mathrm{sd}(\%)$ & Pref* & $\%$ diff & & & & \\
\hline $\mathrm{SiO}_{2}$ & 53.94 & 1.69 & 54.09 & -0.3 & & & & \\
\hline $\mathrm{TiO}_{2}$ & 0.08 & 32.45 & 0.16 & -88.9 & & & & \\
\hline $\mathrm{Al}_{2} \mathrm{O}_{3}$ & 1.23 & 10.77 & 1.23 & 0.2 & & & & \\
\hline $\mathrm{FeO}$ & 15.16 & 3.28 & 15.22 & -0.4 & & & & \\
\hline MnO & 0.49 & 10.78 & 0.49 & 0.5 & & & & \\
\hline MgO & 26.90 & 2.96 & 26.79 & 0.4 & & & & \\
\hline $\mathrm{CaO}$ & 1.51 & 11.63 & 1.52 & -0.6 & & & & \\
\hline $\mathrm{Na}_{2} \mathrm{O}$ & 0.01 & 158.56 & 0.05 & -237.3 & & & & \\
\hline $\mathrm{Cr}_{2} \mathrm{O}_{3}$ & 0.67 & 22.26 & 0.75 & -11.2 & & & & \\
\hline Total & 100.12 & 1.65 & 100.25 & -0.1 & & & & \\
\hline
\end{tabular}




\subsubsection{LA-ICP-MS trace element analyses}

The trace element concentrations of minerals and matrix glass shards were determined using a New Wave deep ultraviolet (193 nm solid state) laser ablation system coupled to an Agilent 7500cs ICP-MS at Victoria University of Wellington. After analysis by EPMA, the carbon coating on the epoxy blocks was removed with methanol. Laser ablation analysis sites within minerals were chosen on the basis of major element concentrations and zoning. The same glass shards analysed by EPMA were targeted for trace element analysis, where shard sizes permitted, major element concentrations were determined for each spot by EPMA prior to LA-ICP-MS analysis. The majority of data were acquired as static spot analyses with a beam diameter of $35 \mu \mathrm{m}$ (reduced to $25 \mu \mathrm{m}$ for some glass shards), a laser repetition rate of $5 \mathrm{~Hz}$, and $85 \%$ laser power. Helium was used as the carrier gas. NIST612 was used as the calibration standard for calculating trace element abundances of rhyolitic glass and plagioclase.

BCR-2 was used as the calibration standard for analyses of amphibole and orthopyroxene. ATHO-G and BHVO-2-G were analysed as secondary standards during each analytical session when the instrument was calibrated using NIST 612 and BCR-2, respectively. Each spot was ablated for $60 \mathrm{~s}$ with a $90 \mathrm{~s}$ washout of the ablation cell between ablations. Two analyses of the calibration standard were typically measured for every 10 analyses of minerals and/or glass samples.

All LA-ICP-MS raw data files (csv) were processed using Igor Pro v. 6.21 and the Iolite v. 6.23 software add-on (Hellstrom et al., 2008). The trace element with internal standard Data Reduction Scheme (DRS) was used (Woodhead et al., 2007). All standard reference values used were the GeoRem preferred reference values (http://georem.mpch-mainz.gwdg.de/). After correction for backgrounds the trace element concentrations of the unknown (sample) can be calculated by reference to count rates on the internal standard, following the relationship:

$$
\begin{aligned}
& C_{\mathrm{unk}}^{\mathrm{el}}=C_{\mathrm{rm}}^{\mathrm{el}}\left(C P S_{\mathrm{rm}}^{\mathrm{el}} / C P S_{\mathrm{rm}}^{\mathrm{l} . S .}\right) \times\left(C P S_{\mathrm{unk}}^{\mathrm{el}} / C P S_{\text {unk }}^{\mathrm{l} . \mathrm{S}_{\dot{\mathrm{r}}}}\right) \\
& \times\left(C_{\mathrm{unk}}^{\mathrm{l} . \mathrm{S}} / C_{\mathrm{rm}}^{\mathrm{l} . \mathrm{S}}\right)
\end{aligned}
$$


where $\mathrm{C}=$ concentration, $\mathrm{el}=$ analyte element, I.S. = element used as internal standard, $\mathrm{rm}=$ in the reference material, unk $=$ in the sample being analysed and CPS $=$ counts per second (Pearce et al., 2007). The isotopes ${ }^{29} \mathrm{Si}$ (for orthopyroxene, plagioclase and glass) and ${ }^{43} \mathrm{Ca}$ (for amphibole) were used as internal standards for the respective crystal phases.

Table A1.8. Summary of LA-ICP-MS data aquired for glass standards thoughout this research

\begin{tabular}{|c|c|c|c|c|c|c|c|c|c|c|c|c|c|}
\hline \multirow{3}{*}{$\begin{array}{r}\text { Mass } \\
\text { montored }\end{array}$} & \multirow{3}{*}{ Element } & \multicolumn{4}{|c|}{ ATHO-G (rhyolite glass) } & \multicolumn{4}{|c|}{ BCR-2G (Basaltic glass) } & \multicolumn{4}{|c|}{ BHVO 2G (Basaltic glass) } \\
\hline & & \multicolumn{4}{|c|}{$n=24$} & \multicolumn{4}{|c|}{$n=44$} & \multicolumn{4}{|c|}{$n=27$} \\
\hline & & Mean & 2 sd (\%) & Pref & $\%$ diff & Mean & 2 sd (\%) & Pref & $\%$ diff & Mean & $2 \mathrm{sd}(\%)$ & Pref & $\%$ diff \\
\hline 7 & $\mathrm{Li}$ & 35.6 & 31.7 & 28.6 & 20 & 9.41 & 6.06 & 9 & 4.3 & 4.26 & 11.82 & 4.80 & -12.7 \\
\hline 25 & $\mathrm{MgO}$ & 0.12 & 5.90 & 0.10 & 11 & 3.32 & 3.76 & 3.59 & -8.3 & 7.52 & 4.42 & 7.229 & 3.9 \\
\hline 44 & $\mathrm{CaO}$ & 1.67 & 13.2 & 1.70 & -1.6 & - & - & - & - & - & - & - & - \\
\hline 45 & Sc & 14.5 & 12.9 & 5.00 & 65 & 33.4 & 5.98 & 33.0 & 1.1 & 31.1 & 5.97 & 32.0 & -3.0 \\
\hline 47 & $\mathrm{TiO}_{2}$ & 0.27 & 7.03 & 0.26 & 4.7 & 2.27 & 4.27 & 2.25 & 0.9 & 2.79 & 4.69 & 2.7 & 2.6 \\
\hline 51 & V & 3.36 & 20.1 & 3.91 & -17 & 405 & 3.82 & 416 & -2.7 & 321 & 7.41 & 317 & 1.3 \\
\hline 53 & $\mathrm{Cr}$ & 3.41 & 90.7 & 6.10 & -79 & 15.6 & 11.3 & 18 & -15.1 & 316 & 10.6 & 280 & 11.5 \\
\hline 55 & MnO & 0.10 & 3.76 & 0.11 & -7.0 & 0.19 & 3.05 & 0.2 & -4.6 & 0.18 & 3.69 & 0.2 & 5.0 \\
\hline 59 & Co & 1.59 & 48.7 & 2.13 & -34 & 36.2 & 4.27 & 37 & -2.3 & 45.9 & 7.14 & 45.0 & 1.9 \\
\hline 60 & $\mathrm{Ni}$ & 14.0 & 119 & 13.0 & 6.9 & 11.1 & 5.55 & 13 & -16.9 & 135 & 11.2 & 119 & 12.1 \\
\hline 63 & $\mathrm{Cu}$ & 16.3 & 7.97 & 18.6 & -14 & 17.1 & 9.09 & 21 & -23.0 & 166 & 18.8 & 127 & 23.7 \\
\hline 66 & $\mathrm{Zn}$ & 128 & 18.9 & 141 & -11 & 133 & 5.66 & 127 & 4.3 & 96.65 & 10.3 & 103 & -6.6 \\
\hline 71 & $\mathrm{Ga}$ & 21.6 & 20.9 & 25.3 & -17 & 23.0 & 5.37 & 23 & 0.0 & 22.0 & 13.5 & 22 & 0.2 \\
\hline 85 & $\mathbf{R b}$ & 63.7 & 4.94 & 65.3 & -2.5 & 47.5 & 4.30 & 46.9 & 1.3 & 9.09 & 9.25 & 9.11 & -0.3 \\
\hline 88 & $\mathrm{Sr}$ & 88.9 & 5.03 & 95.1 & -6.9 & 319 & 4.92 & 340 & -6.6 & 408 & 4.80 & 396 & 3.0 \\
\hline 89 & $Y$ & 87.5 & 8.69 & 94.5 & -8.0 & 34.0 & 7.06 & 37 & -8.7 & 25.3 & 10.5 & 26.0 & -2.8 \\
\hline 90 & $\mathrm{Zr}$ & 495 & 10.7 & 512 & -3.5 & 177 & 6.65 & 184 & -3.8 & 167 & 7.76 & 172 & -3.3 \\
\hline 93 & $\mathrm{Nb}$ & 64.2 & 15.7 & 62.4 & 2.8 & 12.3 & 4.94 & 12.6 & -2.6 & 18.1 & 6.98 & 18.1 & 0.1 \\
\hline 133 & Cs & 0.98 & 15.3 & 1.08 & -10 & 1.12 & 8.36 & 1.1 & 1.4 & 0.11 & 44.5 & 0.10 & 9.4 \\
\hline 138 & $\mathrm{Ba}$ & 530 & 5.31 & 547 & -3.3 & 639 & 4.37 & 677 & -6.0 & 136 & 4.79 & 131 & 3.6 \\
\hline 139 & La & 52.0 & 7.93 & 55.6 & -6.9 & 23.6 & 6.11 & 24.9 & -5.5 & 15.0 & 6.30 & 15.3 & -1.4 \\
\hline 140 & $\mathrm{Ce}$ & 120 & 3.89 & 121 & -1.0 & 50.2 & 3.77 & 52.9 & -5.3 & 38.9 & 4.03 & 37.8 & 2.7 \\
\hline 141 & $\mathrm{Pr}$ & 13.6 & 6.43 & 14.6 & -7.1 & 6.41 & 5.45 & 6.7 & -4.4 & 5.37 & 6.70 & 5.35 & 0.4 \\
\hline 146 & Nd & 58.8 & 8.02 & 60.9 & -3.6 & 27.0 & 6.34 & 28.7 & -6.4 & 25.0 & 7.68 & 24.4 & 2.3 \\
\hline 147 & Sm & 14.1 & 13.4 & 14.2 & -0.9 & 6.24 & 6.97 & 6.58 & -5.4 & 6.19 & 11.7 & 6.03 & 2.6 \\
\hline 151 or 153 & $\mathrm{Eu}$ & 2.61 & 9.20 & 2.76 & -5.9 & 1.89 & 6.42 & 1.96 & -3.6 & 2.09 & 9.17 & 2.07 & 1.1 \\
\hline 157 & Gd & 14.2 & 11.3 & 15.3 & -7.7 & 6.49 & 8.89 & 6.75 & -4.1 & 6.03 & 12.9 & 6.23 & -3.3 \\
\hline 159 & $\mathrm{~Tb}$ & 2.31 & 16.1 & 2.51 & -8.7 & 0.97 & 9.17 & 1.07 & -11 & 0.90 & 12.0 & 0.92 & -1.8 \\
\hline 163 & Dy & 16.2 & 12.5 & 16.2 & -0.1 & 5.95 & 8.22 & 6.41 & -7.7 & 5.26 & 10.8 & 5.30 & -0.8 \\
\hline 165 & Ho & 3.32 & 13.0 & 3.43 & -3.3 & 1.21 & 7.84 & 1.28 & -5.5 & 0.98 & 14.4 & 0.98 & 0.3 \\
\hline 166 & $\mathrm{Er}$ & 9.94 & 15.6 & 10.3 & -3.6 & 3.49 & 7.60 & 3.88 & -11 & 2.59 & 13.3 & 2.55 & 1.6 \\
\hline 169 & $\mathrm{Tm}$ & 1.47 & 12.8 & 1.52 & -3.6 & 0.52 & 9.86 & 0.54 & -4.1 & 0.33 & 17.5 & 0.33 & 0.3 \\
\hline 172 & $\mathrm{Yb}$ & 9.87 & 11.3 & 10.5 & -6.4 & 3.28 & 9.85 & 3.38 & -3.0 & 2.04 & 17.2 & 1.96 & 4.1 \\
\hline 175 & Lu & 1.47 & 18.4 & 1.54 & -5.1 & 0.50 & 8.81 & 0.50 & 0.0 & 0.28 & 23.4 & 0.27 & 1.3 \\
\hline 178 & $\mathrm{Hf}$ & 12.6 & 12.3 & 13.7 & -8.9 & 4.62 & 8.10 & 4.90 & -6.1 & 4.36 & 14.2 & 4.36 & 0.0 \\
\hline 181 & $\mathrm{Ta}$ & 3.90 & 12.7 & 3.90 & -0.1 & 0.76 & 9.59 & 0.74 & 2.5 & 1.12 & 13.0 & 1.14 & -2.0 \\
\hline 182 & $\mathbf{W}$ & 8.71 & 10.1 & 9.30 & -6.8 & 0.52 & 25.0 & 0.50 & 3.4 & 0.23 & 49.5 & 0.23 & 1.0 \\
\hline 208 & $\mathrm{~Pb}$ & 5.08 & 16.8 & 5.67 & -12 & 10.7 & 6.42 & 11.0 & -2.8 & 1.76 & 13.3 & 1.60 & 9.2 \\
\hline 232 & Th & 7.23 & 8.74 & 7.40 & -2.3 & 5.62 & 9.18 & 5.70 & -1.4 & 1.20 & 10.1 & 1.22 & -1.9 \\
\hline 238 & $\mathbf{U}$ & 2.23 & 10.8 & 2.37 & -6.1 & 1.63 & 7.98 & 1.69 & -3.8 & 0.43 & 19.7 & 0.40 & 5.7 \\
\hline
\end{tabular}

\subsubsection{Precision and accuracy of LA-ICP-MS trace element analyses}

The precision and accuracy of LA-ICP-MS trace element data were routinely monitored by repeated analyses of secondary standards (ATHO-G, BCR-2G and BHVO-2G). The precision of measured concentrations broadly varies with atomic mass within each standard. Generally, ATHO-G concentrations are reproducible to $< \pm 15 \%$ (2 s.d.), with reproducibilities being on average slightly higher for rare earth elements (Table A1.8 and Figure A1.2). Sc, V, Cs, Sm, Eu, Tm, and W are less reproducible than the other elements. BCR-2 concentrations are generally reproducible to $< \pm 9 \%$ ( 2 s.d.), but have 
higher offsets to the GeoRem preferred values than BHVO-2. Trace element analyses of BHVO-2 exhibit worse reproducibility than BCR-2 and are generally $< \pm 15 \%( \pm 4-23 \%$ for rare earth elements) (Table A1.8 and Figure A1.2). The measured trace element concentrations are generally within 5\% of the published BHVO-2 reference values, with the exception of $\mathrm{Cr}, \mathrm{Ni}, \mathrm{Cu}, \mathrm{Zn}, \mathrm{W}$ and $\mathrm{Pb}$ (Table A1.8 and Figure A1.2).

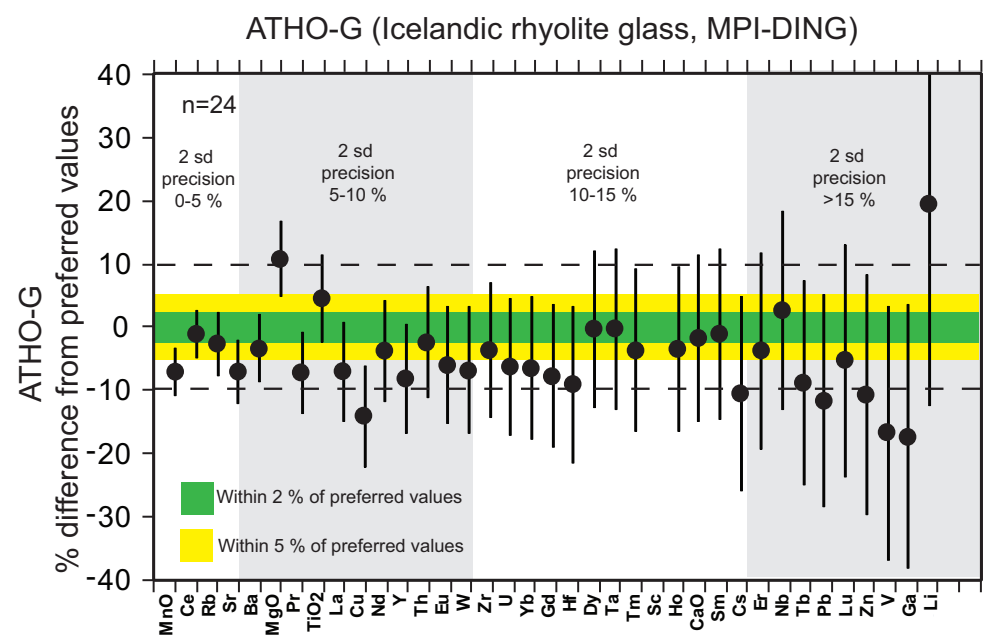

BCR-2G (Basalt Columbia River, USGS)
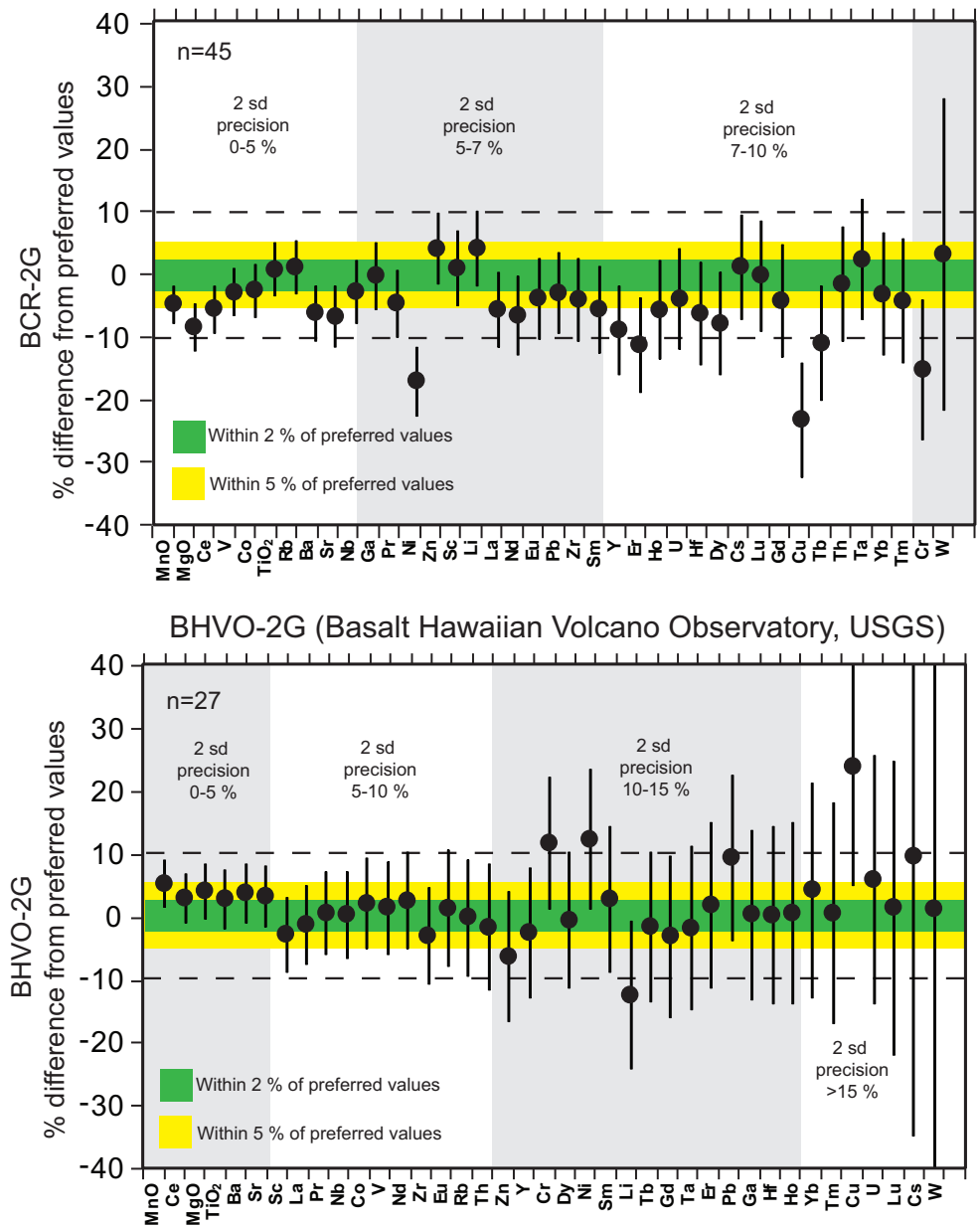

Figure A1.2. Summary of LA-ICP-MS data for ATHO-G, BCR-2, BHVO-2 glass standards. 


\subsection{Pb isotopic analyses}

\subsubsection{Sample preparation}

Isotopic analyses were carried out on the same powders used for whole rock major and trace element analyses. Approximately $150 \mathrm{mg}$ of each sample powder was weighed into cleaned Savillex beakers. Sample powders were then acid leached to remove any anthropogenic $\mathrm{Pb}$ contamination, by leaching twice in $2 \mathrm{~mL}$ of $1 \mathrm{M} \mathrm{HCl}(\mathrm{SS}$ ) on a hotplate at $120{ }^{\circ} \mathrm{C}$ for $20 \mathrm{~min}$. Between each acid leaching step, the samples were centrifuged at $2000 \mathrm{rpm}$ for $4 \mathrm{~min}$, the acid leachate was discarded, and the sample was rinsed three times with Milli-Q $\mathrm{H}_{2} \mathrm{O}$. After the final leaching step, the residual sample was rinsed three times with Milli-Q $\mathrm{H}_{2} \mathrm{O}$ before being refluxed on a hotplate at $120{ }^{\circ} \mathrm{C}$ for 3-4 days in $\sim 2 \mathrm{~mL}$ of $29 \mathrm{M} \mathrm{HF}$ and $\sim 0.5 \mathrm{~mL}$ of $14 \mathrm{M} \mathrm{HNO}_{3}$. The acid was then evaporated and subsequently attacked twice with $14 \mathrm{M} \mathrm{HNO}_{3}$. Samples were then dissolved in $3 \mathrm{~mL}$ of $0.8 \mathrm{M} \mathrm{HBr}$ for $24 \mathrm{~h}$, evaporated, and then re-dissolved in $1.5 \mathrm{~mL}$ of $0.8 \mathrm{M} \mathrm{HBr}$ prior to chemical separation of $\mathrm{Pb}$.

\subsubsection{Chemical separation of $P b$}

$\mathrm{Pb}$ was separated from sample solutions by two passes through AG1-X8 anion exchange resin (Figure A1.3). Columns were made by inserting polypropylene frits into the end of $1 \mathrm{~mL}$ pipette tips, and cleaned in $2 \mathrm{M} \mathrm{HCl}$ for approximately 1 week before being rinsed three times with Milli-Q $\mathrm{H}_{2} \mathrm{O}$ just prior to use. A $\sim 5 \mathrm{~mm}$ thick resin bed was added to each column, which was then cleaned three times with alternating volumes of Milli-Q $\mathrm{H}_{2} \mathrm{O}$ and $7 \mathrm{M} \mathrm{HCl}(\mathrm{SS})$. Sample matrix was eluted with $\mathrm{HBr}$ and $\mathrm{Pb}$ collected in $7 \mathrm{M} \mathrm{HCl}$ (Figure A1.3). Following this first pass, the sample was redissolved in $1.5 \mathrm{~mL}$ of $0.8 \mathrm{M} \mathrm{HBr}$ for a second pass through the $\mathrm{Pb}$ columns following the same method. After the second pass, the Pb sample was dissolved in $2 \mathrm{~mL}$ of $0.5 \%$ $\mathrm{HNO}_{3}(\mathrm{SS})$ for MC-ICP-MS isotopic analysis. 


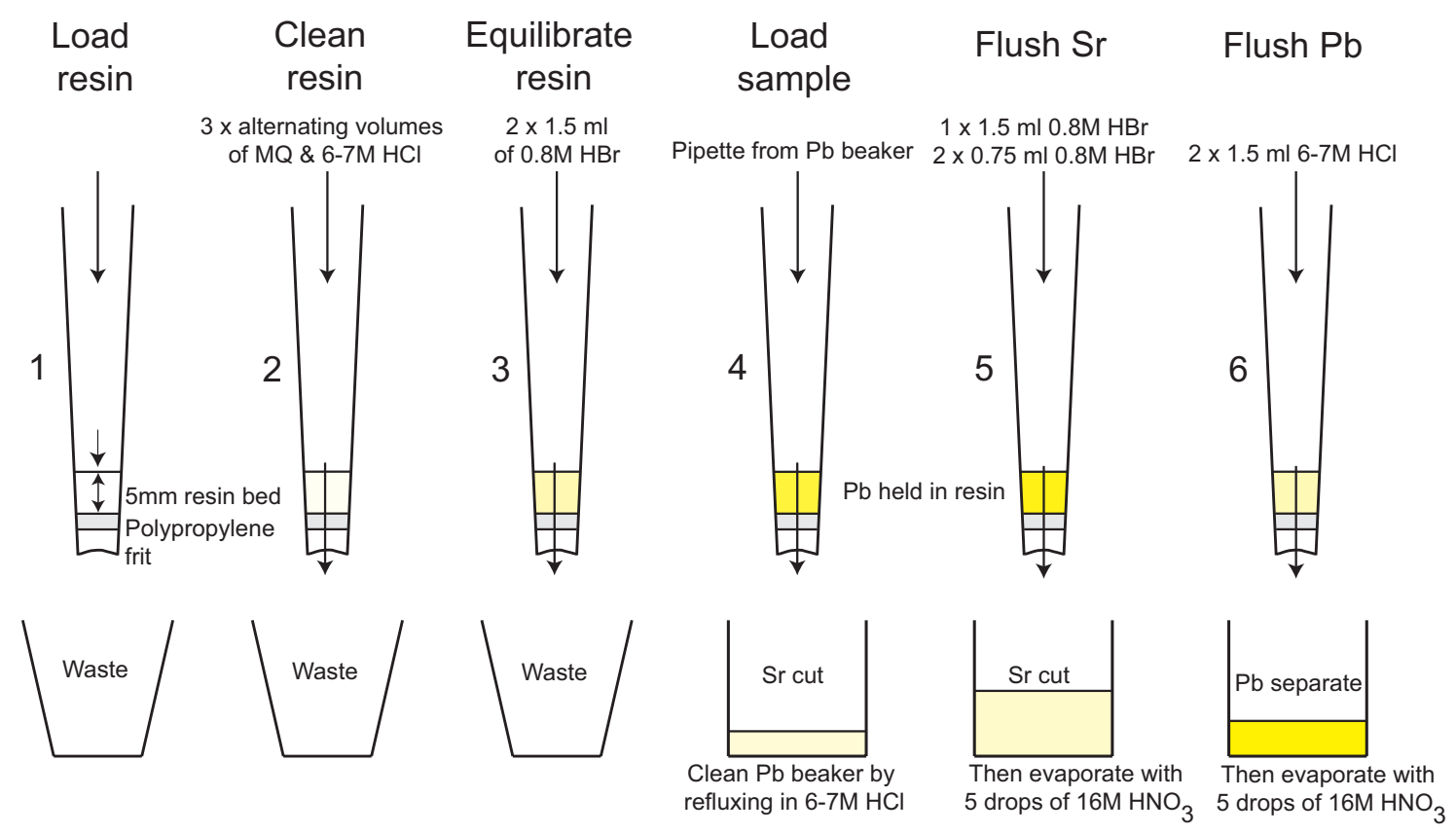

Figure A1.3. Schematic diagram to illustrate the procedure of $\mathrm{Pb}$ separation from a digested sample. This procedure is repeated (second pass) using the same resin bed.

\subsubsection{Mass spectrometry procedures for Pb isotope analysis}

$\mathrm{Pb}$ isotopic ratios were measured using a Nu-Plasma multiple-collector inductively coupled plasma mass spectrometer (MC-ICP-MS) at Victoria University of Wellington. $\mathrm{Pb}$ samples were introduced into the MC-ICP-MS via a desolvating nebuliser system (DSN-100). The instrument was tuned with a $30 \mathrm{ppb}$ solution of SRM981 Pb standard. Each sample was diluted in acid-cleaned micro-centrifuge tubes with $0.5 \% \mathrm{HNO}_{3}$ so that the ${ }^{208} \mathrm{~Pb}$ yielded an ion beam of $\sim 8 \mathrm{~V}$. Pb isotopic data were collected in $50 \mathrm{x} 5 \mathrm{~s}$ integrations. The baseline was measured 60 seconds prior to sample measurements, and automatically subtracted from the measured signal. The interference of ${ }^{204} \mathrm{Hg}$ on ${ }^{204} \mathrm{~Pb}$ was corrected for by measuring ${ }^{202} \mathrm{Hg}$ and applying the natural ${ }^{202} \mathrm{Hg} /{ }^{204} \mathrm{Hg}$ ratio to calculate the concentration of ${ }^{204} \mathrm{Hg}$ interfering on ${ }^{204} \mathrm{~Pb}$. Raw $\mathrm{Pb}$ isotope measurements were corrected for instrumental mass bias by sample-standard bracketing using bracketing analyses of SRM-981 $\left({ }^{208} \mathrm{~Pb} /{ }^{204} \mathrm{~Pb}=36.7262,{ }^{207} \mathrm{~Pb} /{ }^{204} \mathrm{~Pb}=15.5000\right.$ and ${ }^{206} \mathrm{~Pb} /{ }^{204} \mathrm{~Pb}=16.9416$ : Baker et al., 2004). Errors from bracketing standards were propagated into analyses using the following equation:

$$
2 \sqrt{\left(\sigma_{\text {sample }}^{2}+\frac{\sigma_{\text {before }}{ }^{2}}{2}+\frac{\sigma_{\text {after }}{ }^{2}}{2}\right)}
$$


where $\sigma$ is the analytical precision of the sample and the standards before and after this sample.

International rock standard JB-2 from the Geological Survey of Japan was used as a secondary standard to monitor the accuracy and precision of $\mathrm{Pb}$ isotopic data. $\mathrm{Pb}$ procedural blanks were measured with each batch of samples processed for $\mathrm{Pb}$ isotopes and $\mathrm{Pb}$ concentrations were always insignificant $(<0.03 \mathrm{ppb})$.

\subsubsection{Precision and accuracy of $P b$ isotope data}

$\mathrm{Pb}$ isotope ratios are reported relative to SRM981 values given above, from Baker at al. (2004). Four analyses of the JB-2 standard were measured during each analytical session to monitor data quality (Table A1.9). All $\mathrm{Pb}$ isotopic analyses of JB-2 are within analytical uncertainties of the reference values published by Baker et al. (2004) and reproducibility (2 s.d.) is $109 \mathrm{ppm}$ for ${ }^{208} \mathrm{~Pb} /{ }^{204} \mathrm{~Pb}, 93 \mathrm{ppm}$ for ${ }^{207} \mathrm{~Pb} /{ }^{204} \mathrm{~Pb}$ and $50 \mathrm{ppm}$ for ${ }^{206} \mathrm{~Pb} /{ }^{204} \mathrm{~Pb}$.

Table A1.9. Precision and accuracy of the JB-2 standard

\begin{tabular}{|c|c|c|c|c|c|c|c|c|c|c|c|}
\hline & \multicolumn{4}{|c|}{ Session 1 (single pass) } & \multicolumn{4}{|c|}{ Session 2 (double pass) } & \multirow[b]{2}{*}{ Mean } & \multirow[b]{2}{*}{ JB2 ref* } & \multirow[b]{2}{*}{ 2sd (ppm) } \\
\hline & JB-2 & JB-2 & JB-2 & JB-2 & JB-2_a & JB-2_a & JB-2_b & JB-2_b & & & \\
\hline $208 \mathrm{~Pb} / 204 \mathrm{~Pb}$ & 38.2697 & 38.2652 & 38.2680 & 38.2753 & 38.2764 & 38.2762 & 38.2693 & 38.2726 & 38.2716 & 38.2784 & 109 \\
\hline $2 s i g$ & \pm 26 & \pm 26 & \pm 33 & \pm 31 & \pm 26 & \pm 22 & \pm 24 & \pm 22 & \pm 29 & \pm 50 & \\
\hline $207 \mathrm{~Pb} / 204 \mathrm{~Pb}$ & 15.5601 & 15.5582 & 15.5590 & 15.5616 & 15.5622 & 15.5620 & 15.5600 & 15.5609 & 15.5605 & 15.5619 & 93.2 \\
\hline $2 s i g$ & \pm 11 & \pm 10 & \pm 13 & \pm 13 & \pm 11 & \pm 9 & \pm 10 & \pm 9 & \pm 12 & \pm 16 & \\
\hline $206 \mathrm{~Pb} / 204 \mathrm{~Pb}$ & 18.3413 & 18.3393 & 18.3399 & 18.3416 & 18.3412 & 18.3407 & 18.3392 & 18.3398 & 18.3404 & 18.3435 & 50.3 \\
\hline $2 s i g$ & \pm 13 & \pm 11 & \pm 15 & \pm 13 & \pm 11 & \pm 10 & \pm 11 & \pm 10 & \pm 13 & \pm 17 & \\
\hline
\end{tabular}

\subsection{Ion probe $\mathrm{U}-\mathrm{Pb}$ geochronology and trace element analysis of zircon}

\subsubsection{Zircon separation and mount preparation}

Only large pumice clasts were chosen for zircon extraction so that enough zircon grains could be obtained for ion probe work. The pumice was crushed to chips $<20 \mathrm{~mm}$ in size using a Boyd Crusher before being briefly crushed in a Tema mill (tungsten carbide). The crushed sample was dry sieved into size fractions $<250 \mu \mathrm{m}$ and $>250 \mu \mathrm{m}$. All material $<250 \mu \mathrm{m}$ was then wet sieved at $60 \mu \mathrm{m}$ and the fraction between 250 and 60 
$\mu \mathrm{m}$ was retained. The majority of glass from this fraction was floated off in water and the sample was dried. A hand magnet was initially used to remove (titano)magnetite before mineral separation with heavy liquids. Firstly, the sample was introduced to filtered lithium heteropolytungstate (LST) at a density of $2.60-2.85 \mathrm{~g} / \mathrm{mL}$ in a $1 \mathrm{~L}$ separating funnel. The sample was stirred to ensure material $>2.60 \mathrm{~g} / \mathrm{mL}$ would sink in this solution. The heavy fraction with a density $>2.60 \mathrm{~g} / \mathrm{mL}$ was then washed with distilled water and dried. This heavy fraction typically contained orthopyroxene, Fe-Ti oxides, zircon, apatite, and some multi-minerallic fragments. The heavy fraction was passed through a Frantz magnetic separator to remove orthopyroxene. The remaining, non-magnetic, minerals were then further separated using methylene iodide, with a solution density of $3.30 \mathrm{~g} / \mathrm{mL}$, in a $50 \mathrm{~mL}$ separating funnel. The heavy fraction from this separation step was typically $>90 \%$ zircon grains, and was washed with acetone to remove any adhering methylene iodide, and dried. Zircon grains were mounted in Epofix $^{\mathrm{TM}}$ epoxy resin and polished to expose the grains. The mounts were then photographed in reflected light and imaged by CL on a JEOL LV5600 Scanning Electron Microscope. The mount was rinsed in dilute EDTA at Stanford or petroleum spirits at $\mathrm{ANU}$, and then rinsed in $1 \mathrm{M} \mathrm{HCl}$ for 5 min to remove any surficial $\mathrm{Pb}$ contamination prior to gold coating.

\subsubsection{Zircon U-Pb geochronology and trace element analytical techniques}

The SIMS techniques used for zircon U-Pb age determinations and trace element analysis are discussed in detail within Chapter 2 (section 2.5). The precision and accuracy of zircon trace element data are shown within Table A1.10. The analytical uncertainties on zircon trace element data generally vary with atomic weight. The majority of measured elements reproduce to $< \pm 10 \%$ ( 2 s.d.; Table A1.10). Exceptions include light elements ( $\mathrm{Li}, \mathrm{Be}, \mathrm{F}$, and $\mathrm{Na}$ ), which show worse reproducibilities $( \pm 45-66$ $\%)$ and elements with low concentrations ( $<5 \mathrm{ppm})$ such as $\mathrm{Ca}, \mathrm{La}$, and $\mathrm{Eu}$. Measured zircon trace element concentrations for the MAD standard are generally within $2 \%$ of reference values (Mazdab and Wooden 2006) except for $\mathrm{Be}, \mathrm{Na}, \mathrm{Ca}, \mathrm{La}, \mathrm{Eu}$, and $\mathrm{Pb}$ (Table A1.10). 
Table A.10. Summary of data from the MAD zircon standard, measured by SHRIMP.

\begin{tabular}{|c|c|c|c|c|c|}
\hline \multirow{2}{*}{$\begin{array}{c}\text { Mass } \\
\text { monitored }\end{array}$} & \multicolumn{5}{|c|}{ MAD $n=25$} \\
\hline & Element & Average & Ref. value ${ }^{*}$ & $2 \mathrm{sd}(\%)$ & $\%$ diff* \\
\hline 7 & $\mathrm{Li}$ & 15.0 & 15 & 65.9 & -0.3 \\
\hline 9 & $\mathrm{Be}$ & 1.6 & 1.5 & 54.7 & 5.2 \\
\hline 19 & $\mathbf{F}$ & 34.2 & - & 50.8 & - \\
\hline 23 & $\mathrm{Na}$ & 4 & 4 & 45.3 & 2.1 \\
\hline 27 & Al & 17.6 & 18 & 14.4 & -2.0 \\
\hline 31 & $\mathbf{P}$ & 172 & 172 & 9.05 & -0.1 \\
\hline 40 & $\mathrm{Ca}$ & 3 & 3 & 65.1 & 5.0 \\
\hline 45 & Sc & 10.6 & 10.6 & 14.1 & 0.3 \\
\hline 48 & $\mathrm{Ti}$ & 25.8 & 25.6 & 7.02 & 0.8 \\
\hline 89 & $\mathbf{Y}$ & 962 & 960 & 6.54 & 0.2 \\
\hline 93 & $\mathrm{Nb}$ & 65.3 & 65 & 13.1 & 0.4 \\
\hline 139 & La & 0.041 & 0.04 & 38.1 & 2.1 \\
\hline 140 & $\mathrm{Ce}$ & 140 & 139 & 7.12 & 0.5 \\
\hline 146 & Nd & 2.20 & 2.18 & 10.4 & 0.9 \\
\hline 147 & Sm & 4.39 & 4.36 & 10.8 & 0.7 \\
\hline 153 & Eu & 0.367 & 0.362 & 13.3 & 1.3 \\
\hline 157 & Gd & 26.1 & 26 & 6.72 & 0.4 \\
\hline 165 & Ho & 32.0 & 32 & 7.04 & -0.1 \\
\hline 159 & $\mathrm{~Tb}$ & 8.24 & 8.25 & 7.33 & -0.1 \\
\hline 163 & Dy & 84.9 & 85 & 8.05 & -0.1 \\
\hline 166 & $\mathrm{Er}$ & 152 & 153 & 7.70 & -0.4 \\
\hline 169 & $\mathrm{Tm}$ & 35.9 & 36 & 8.24 & -0.3 \\
\hline 172 & $\mathrm{Yb}$ & 324 & 325 & 9.26 & -0.4 \\
\hline 175 & Lu & 59.8 & 60 & 8.67 & -0.4 \\
\hline 180 & Hf & 16204 & 16280 & 4.51 & -0.5 \\
\hline 206 & $\mathbf{P b}$ & 318 & 356 & 13.6 & -11.8 \\
\hline 238 & $\mathbf{U}$ & 4180 & 4196 & 10.4 & -0.4 \\
\hline 232 & Th & 1162 & 1166 & 9.25 & -0.4 \\
\hline
\end{tabular}




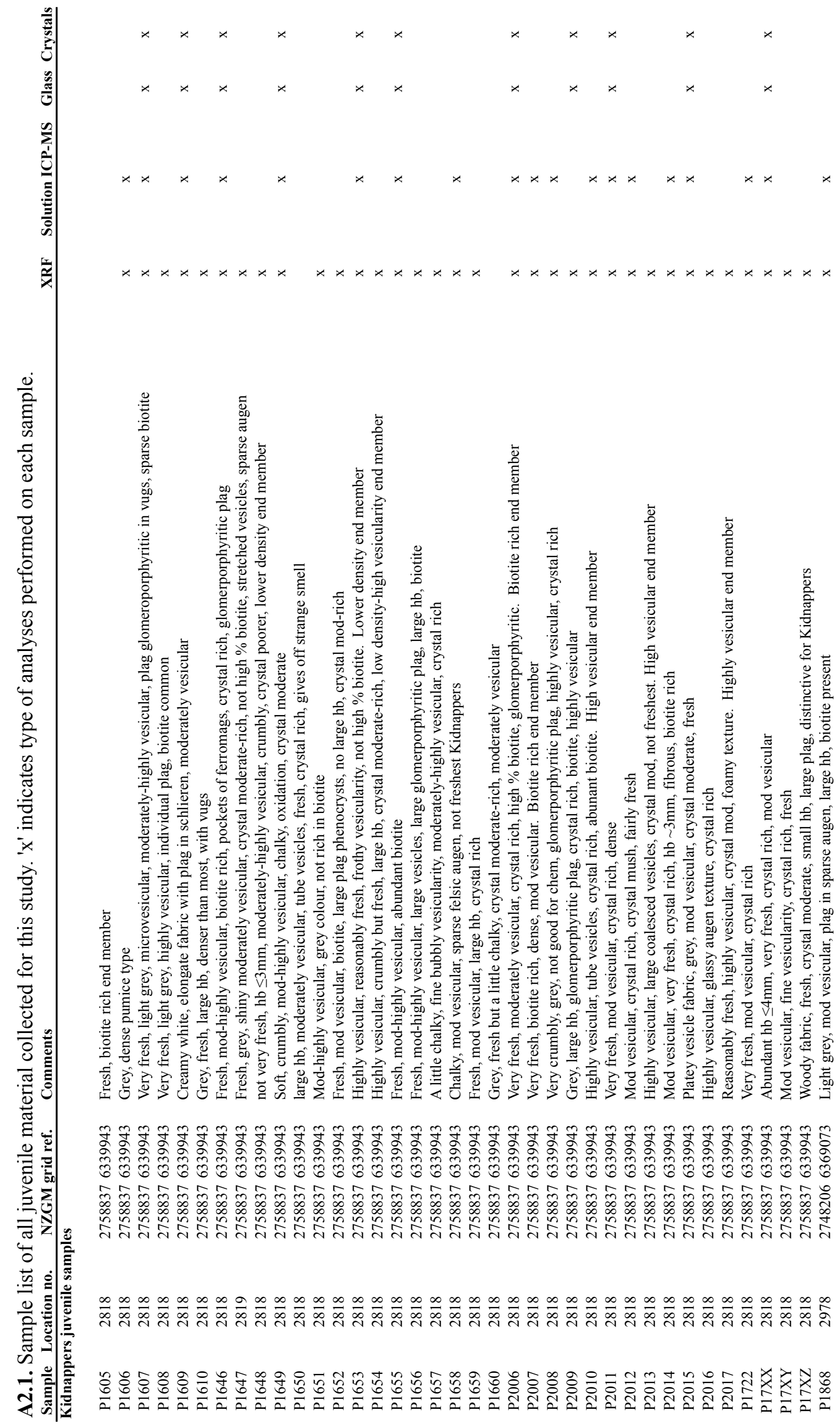




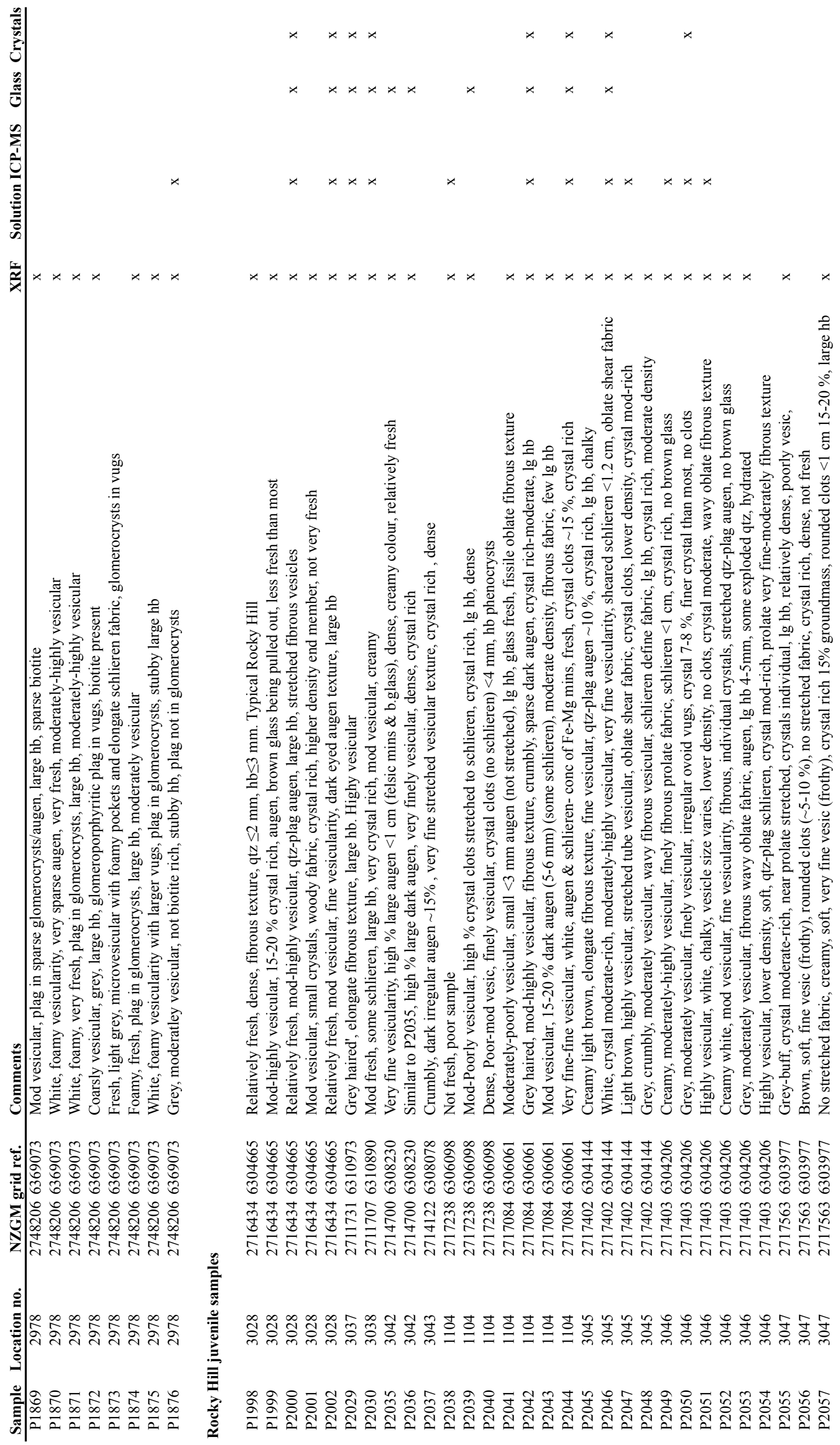




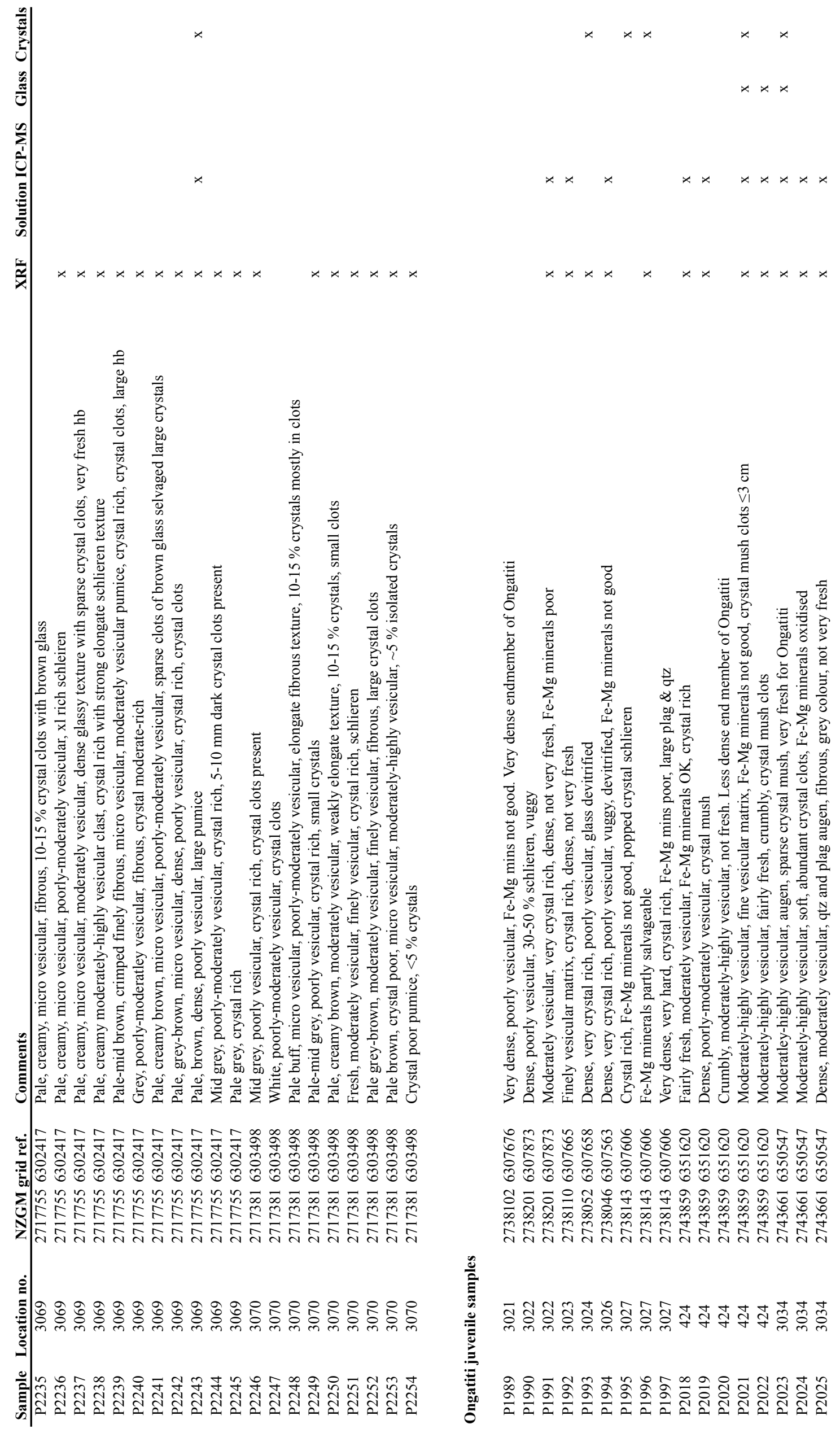




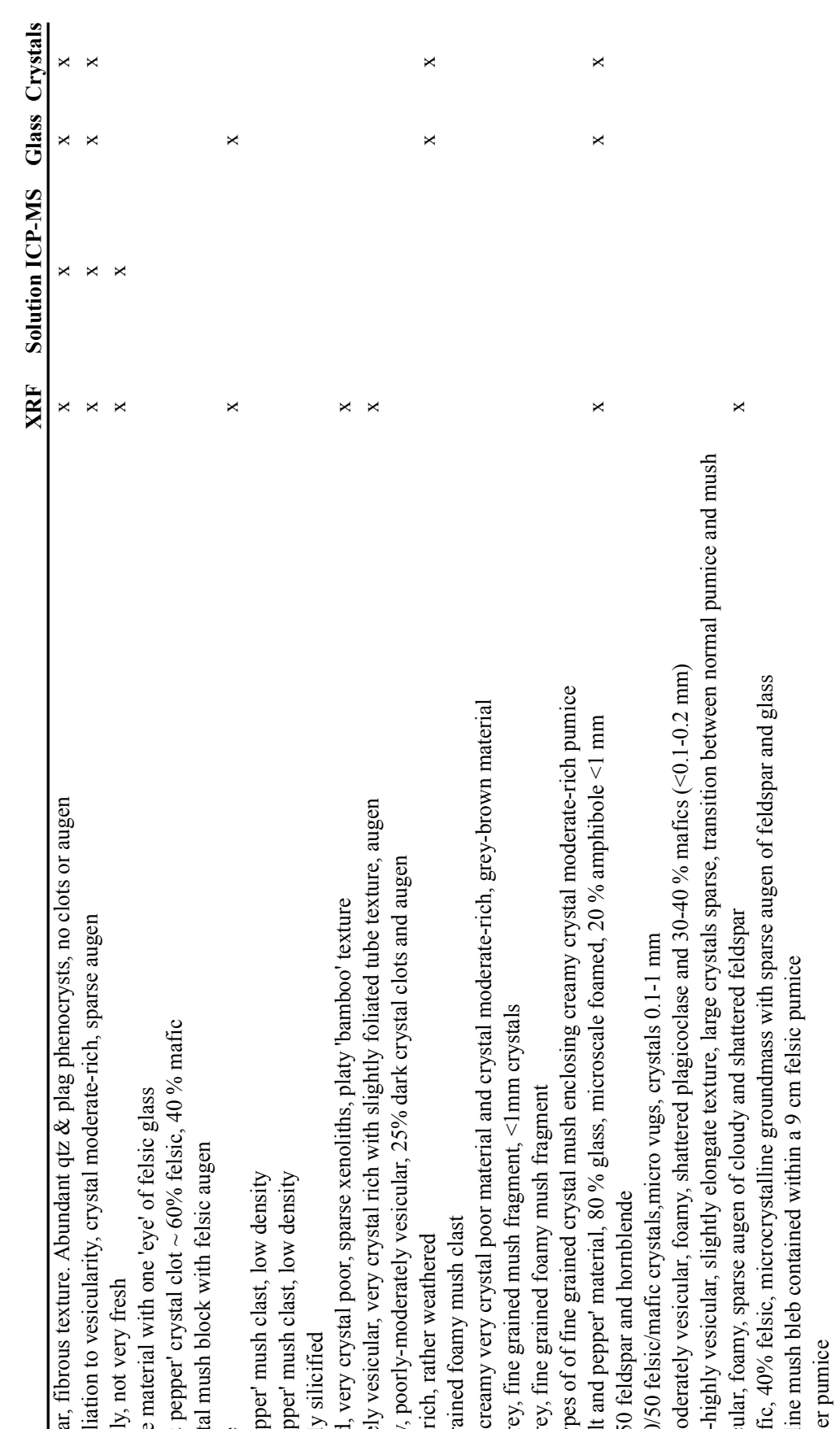

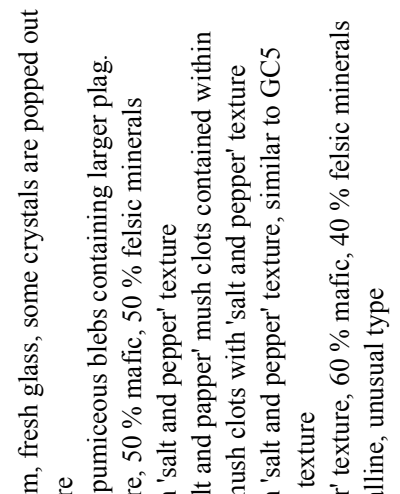

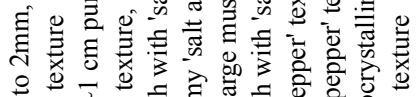

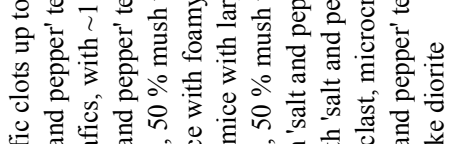

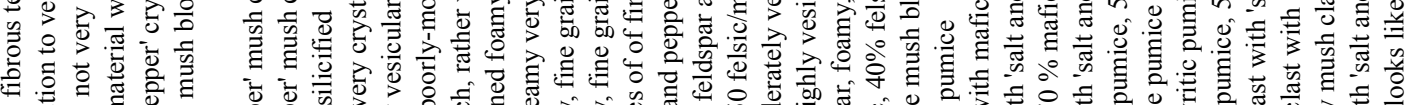

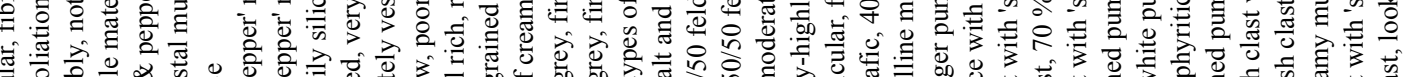

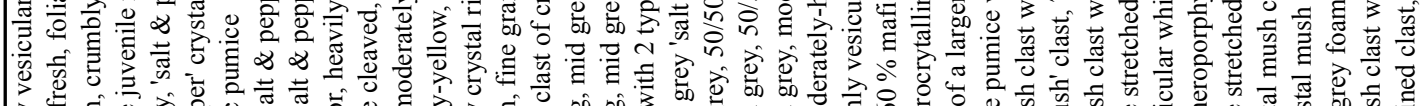

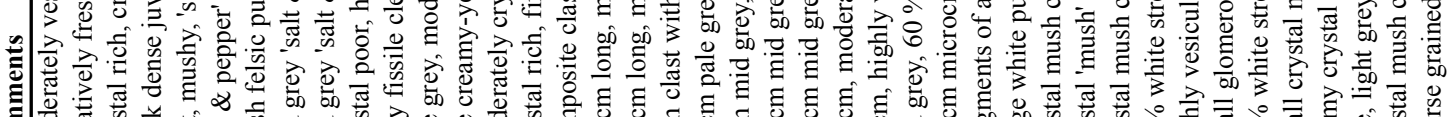

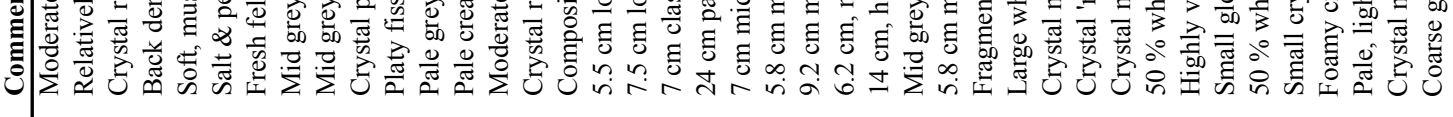

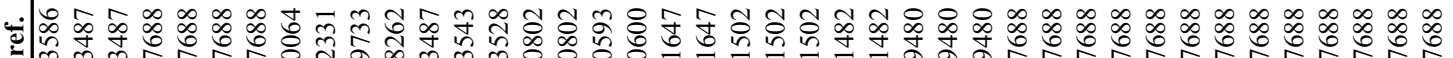

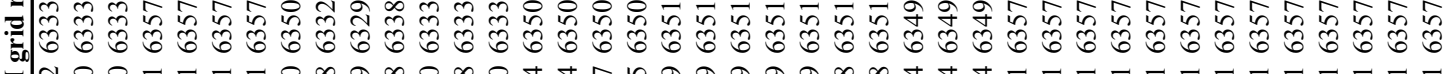

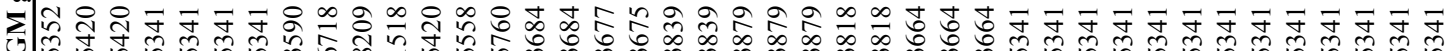

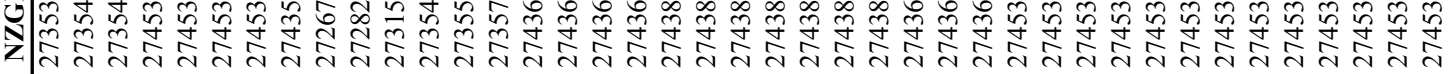
$\dot{\leftrightarrow}$

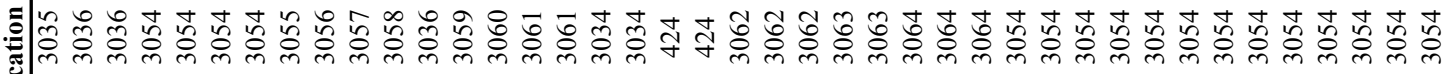

言| 


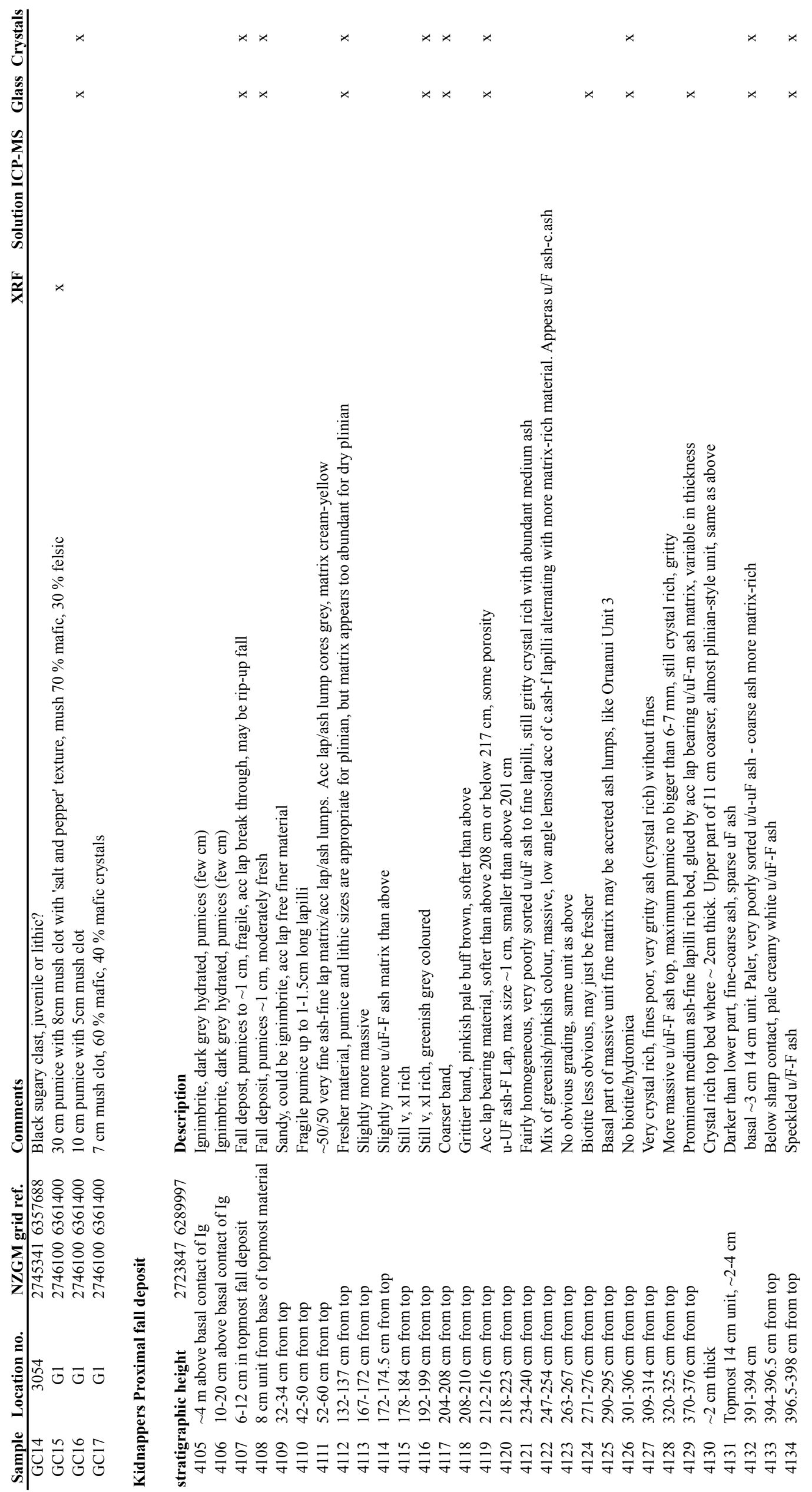




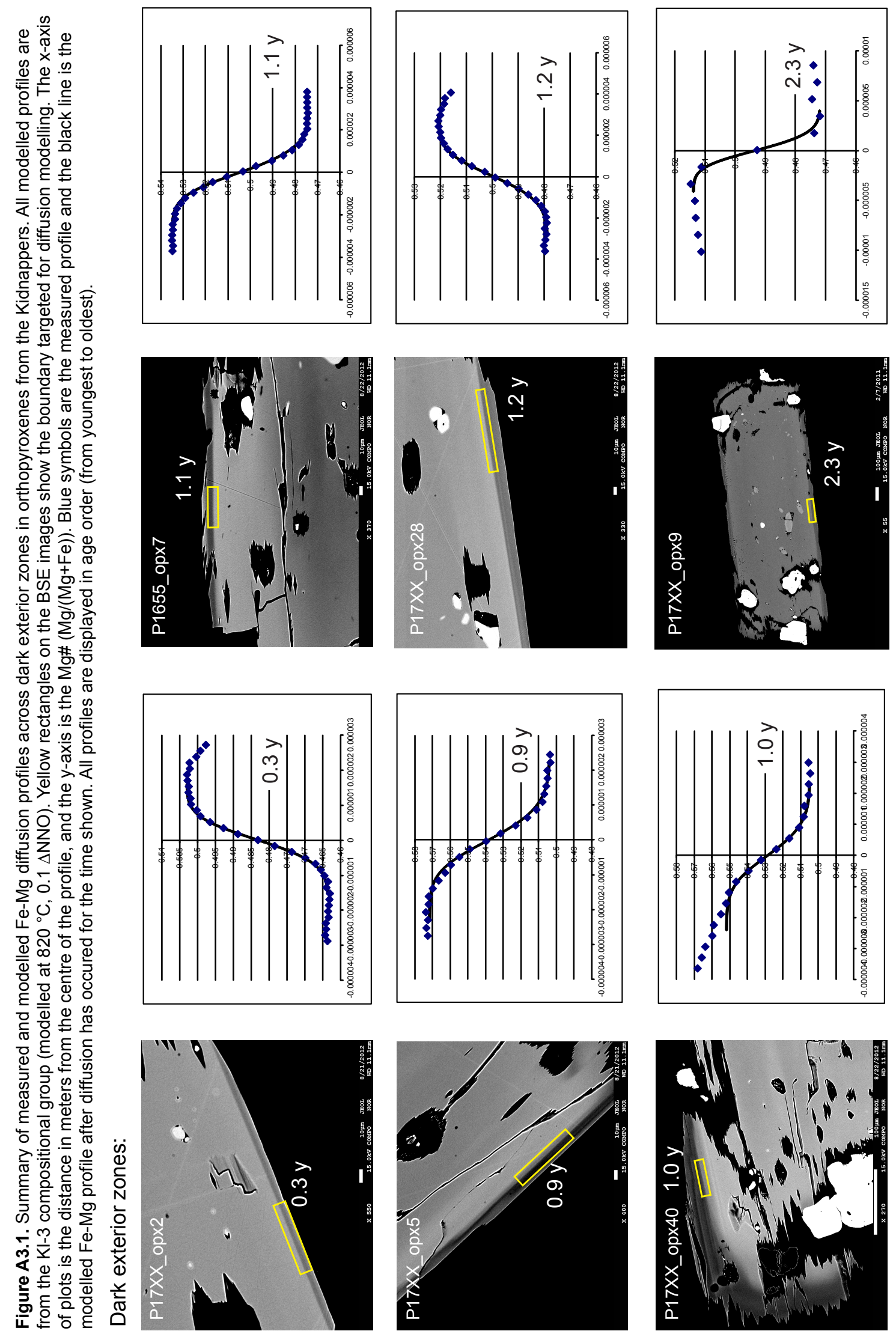



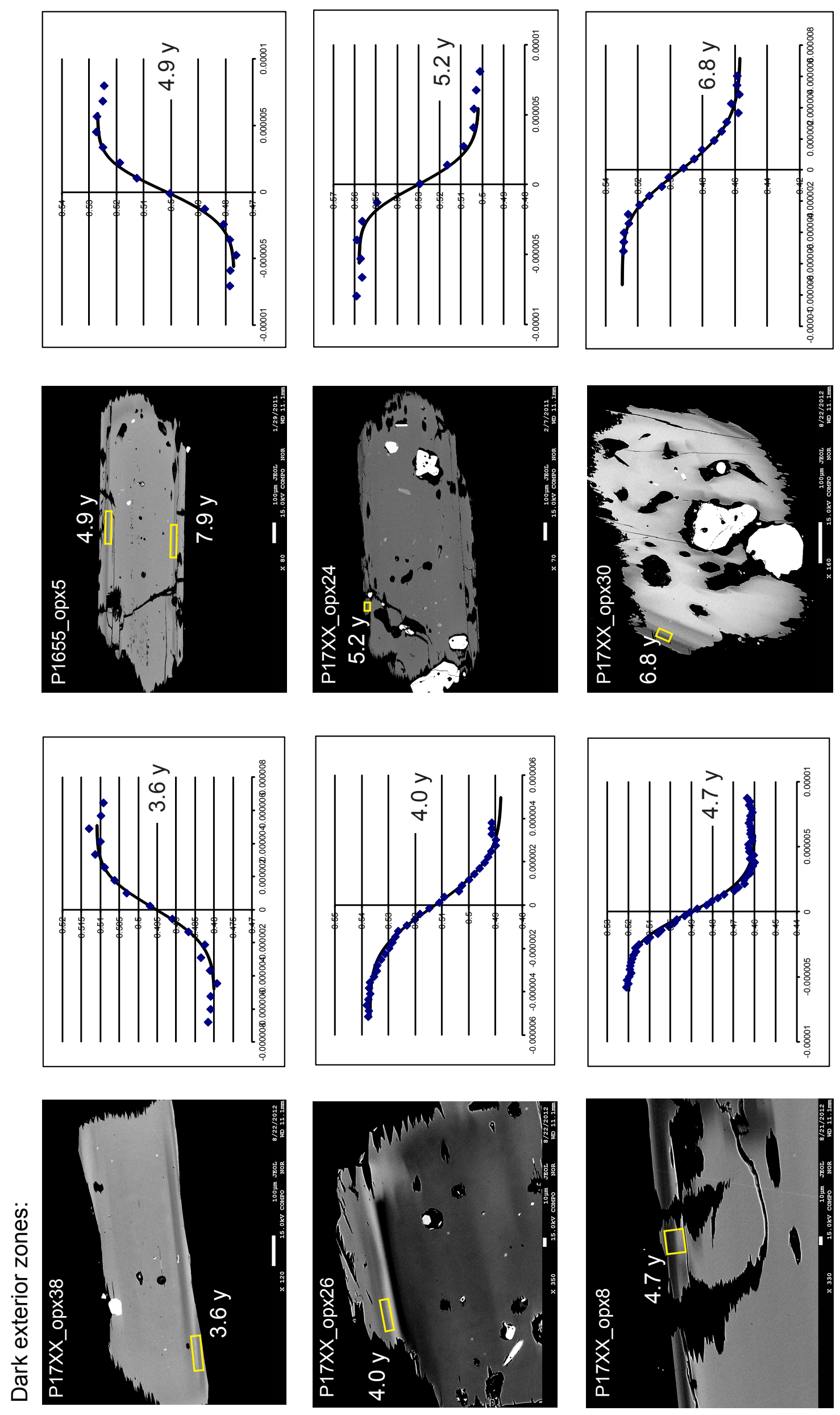

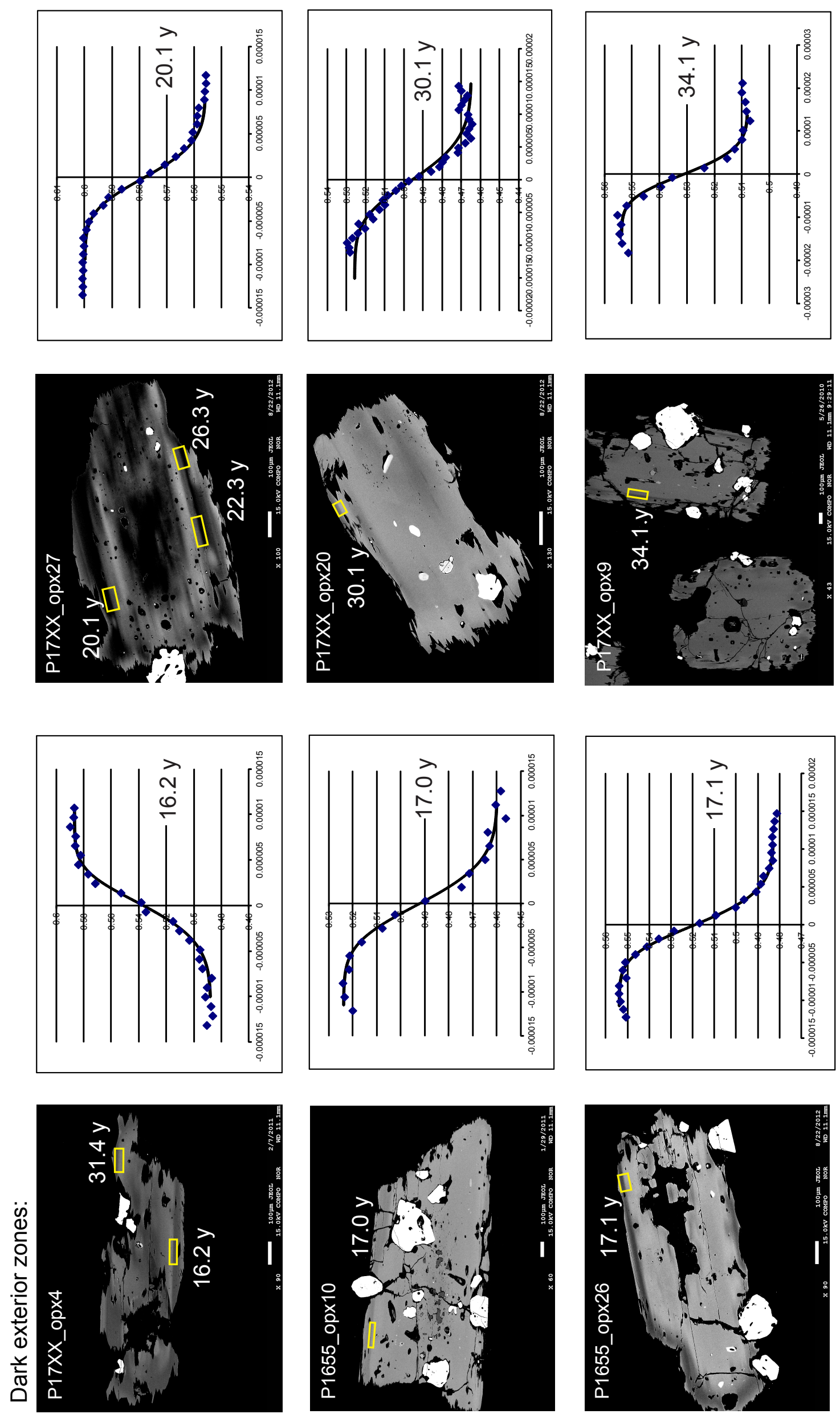

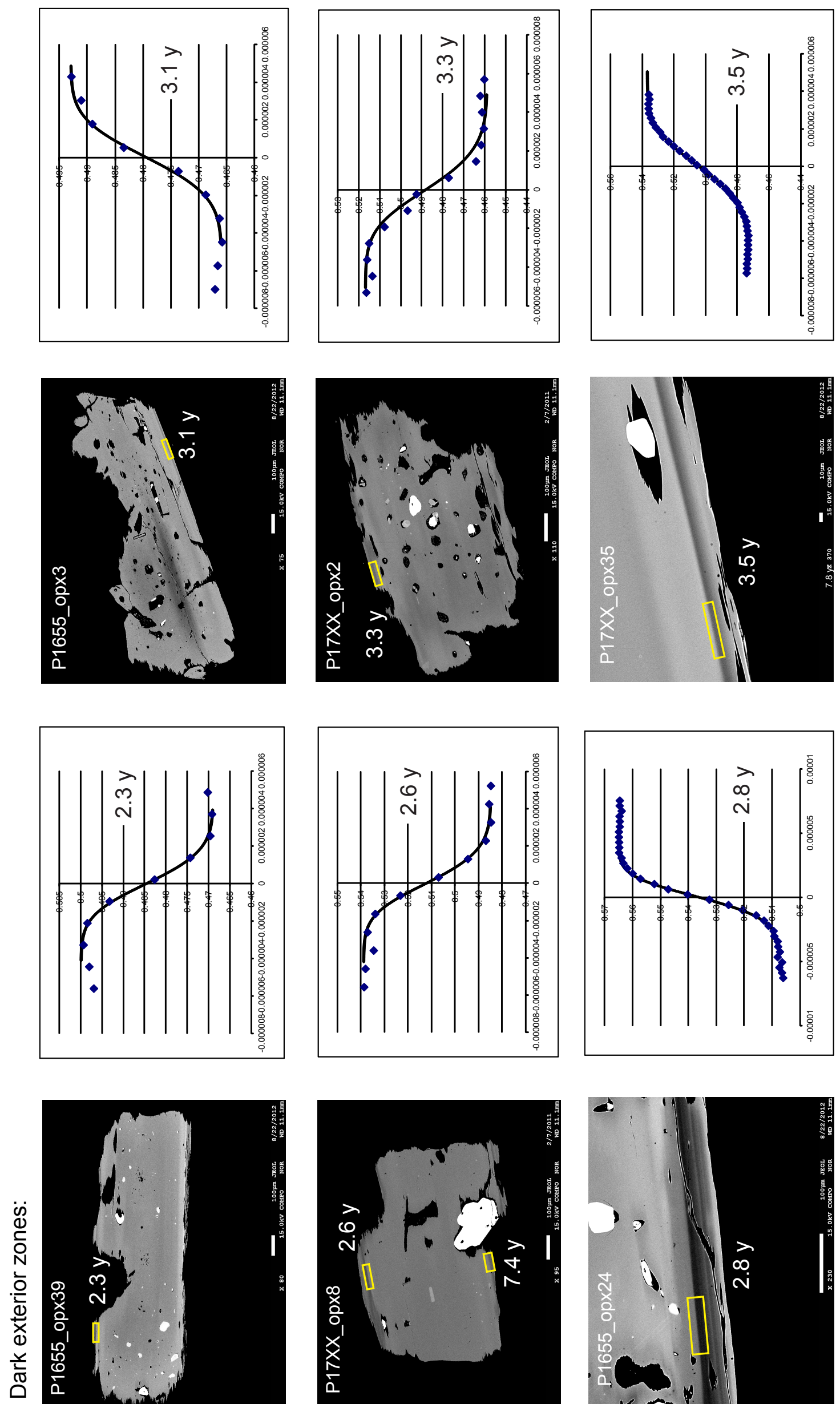

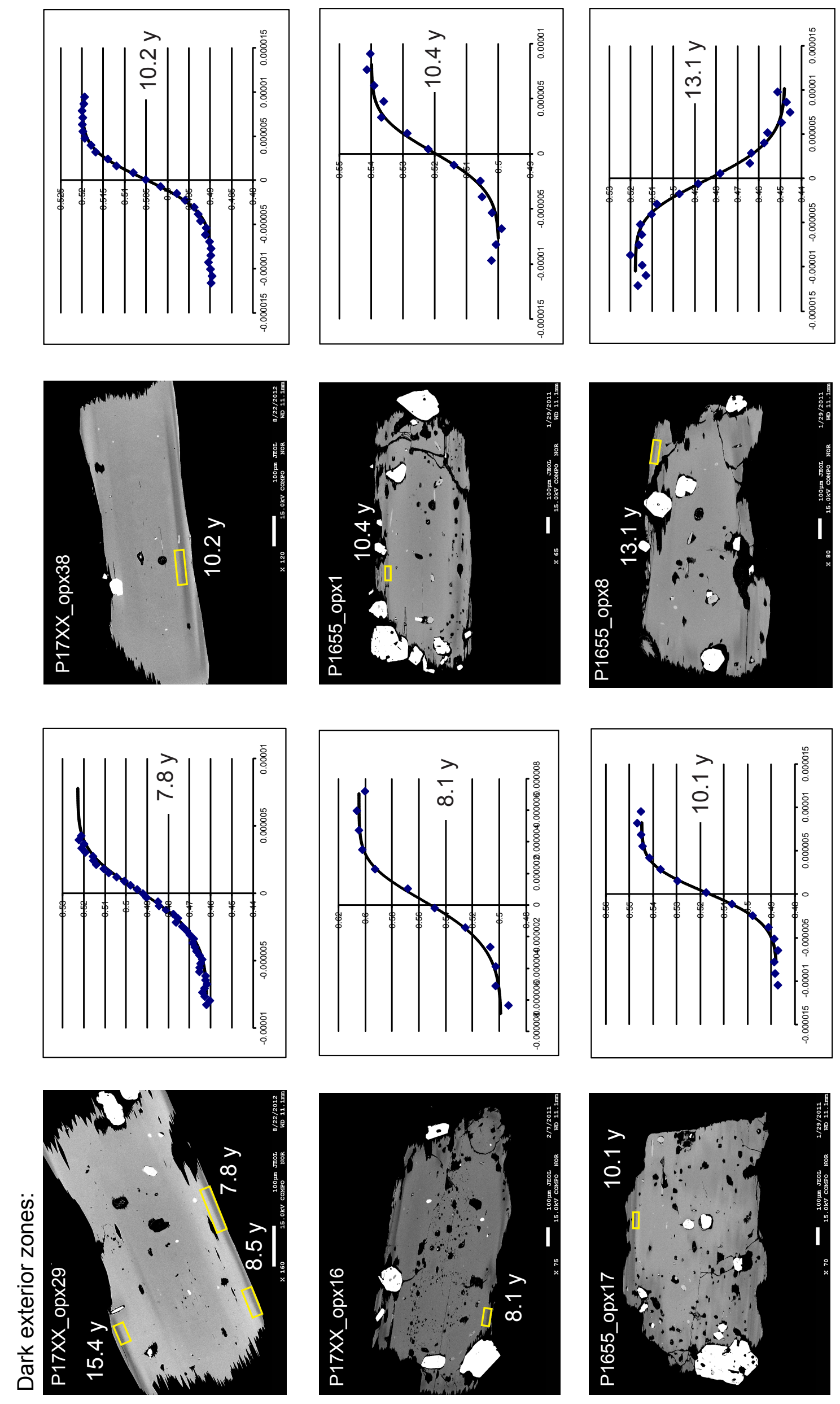

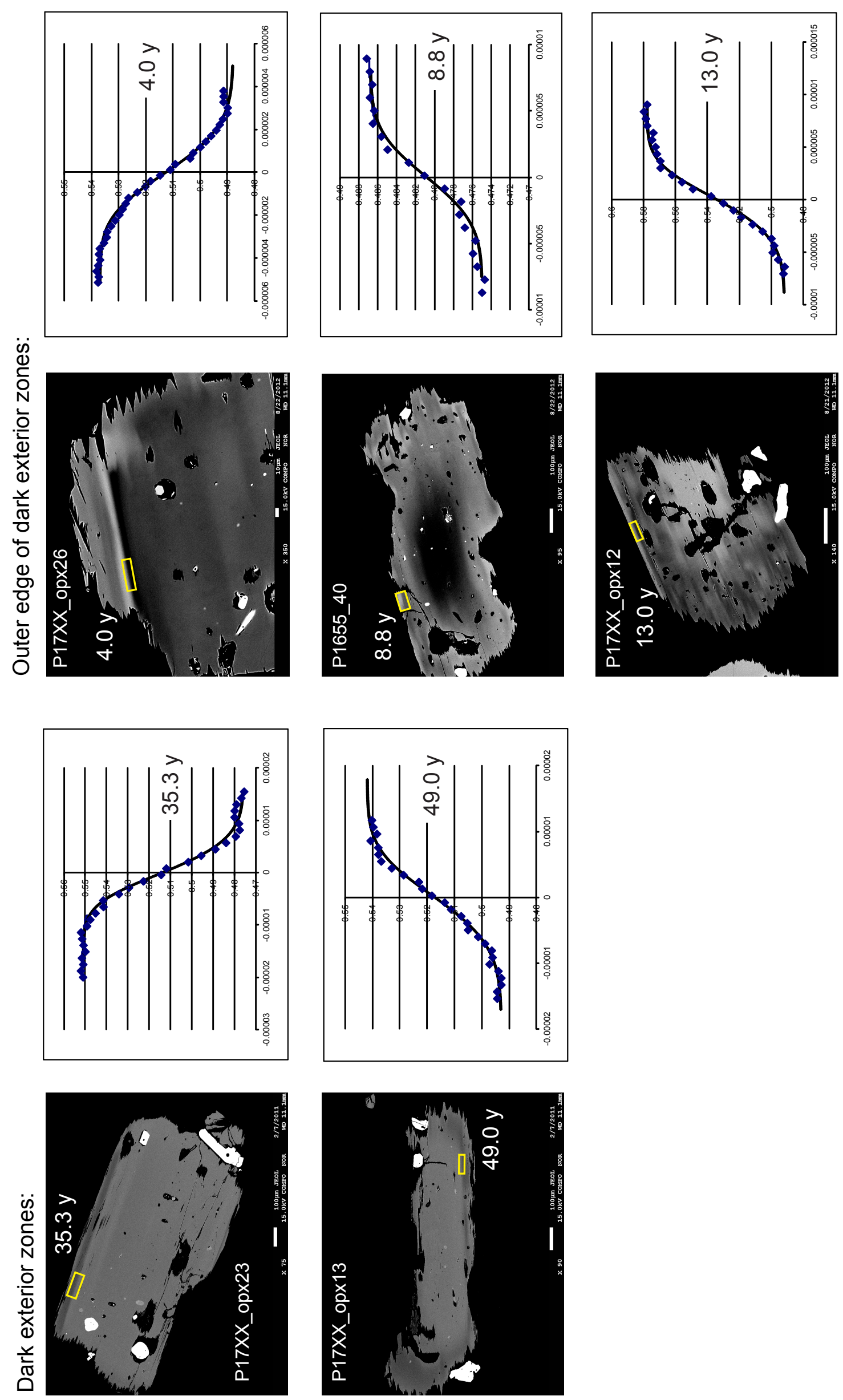

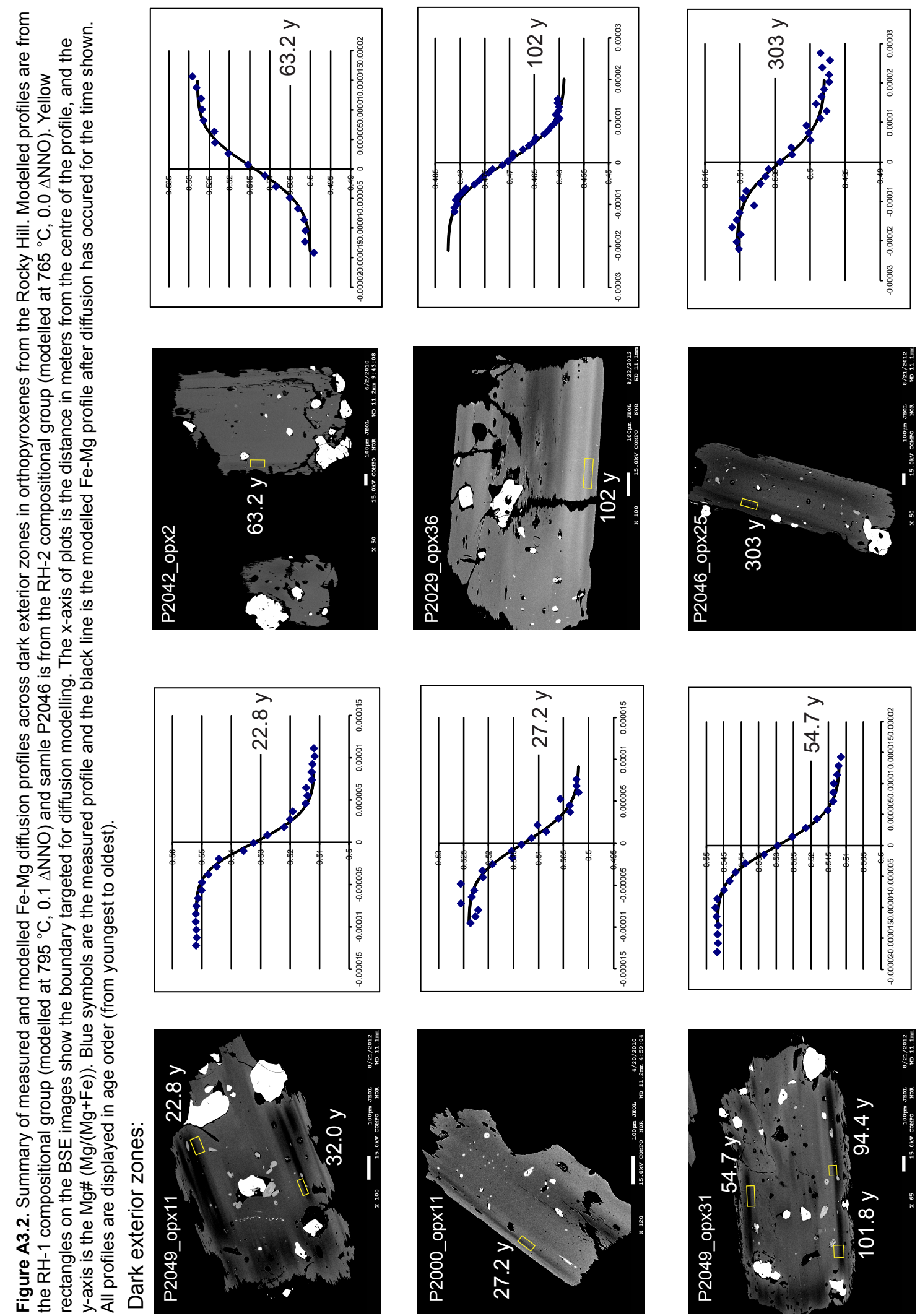

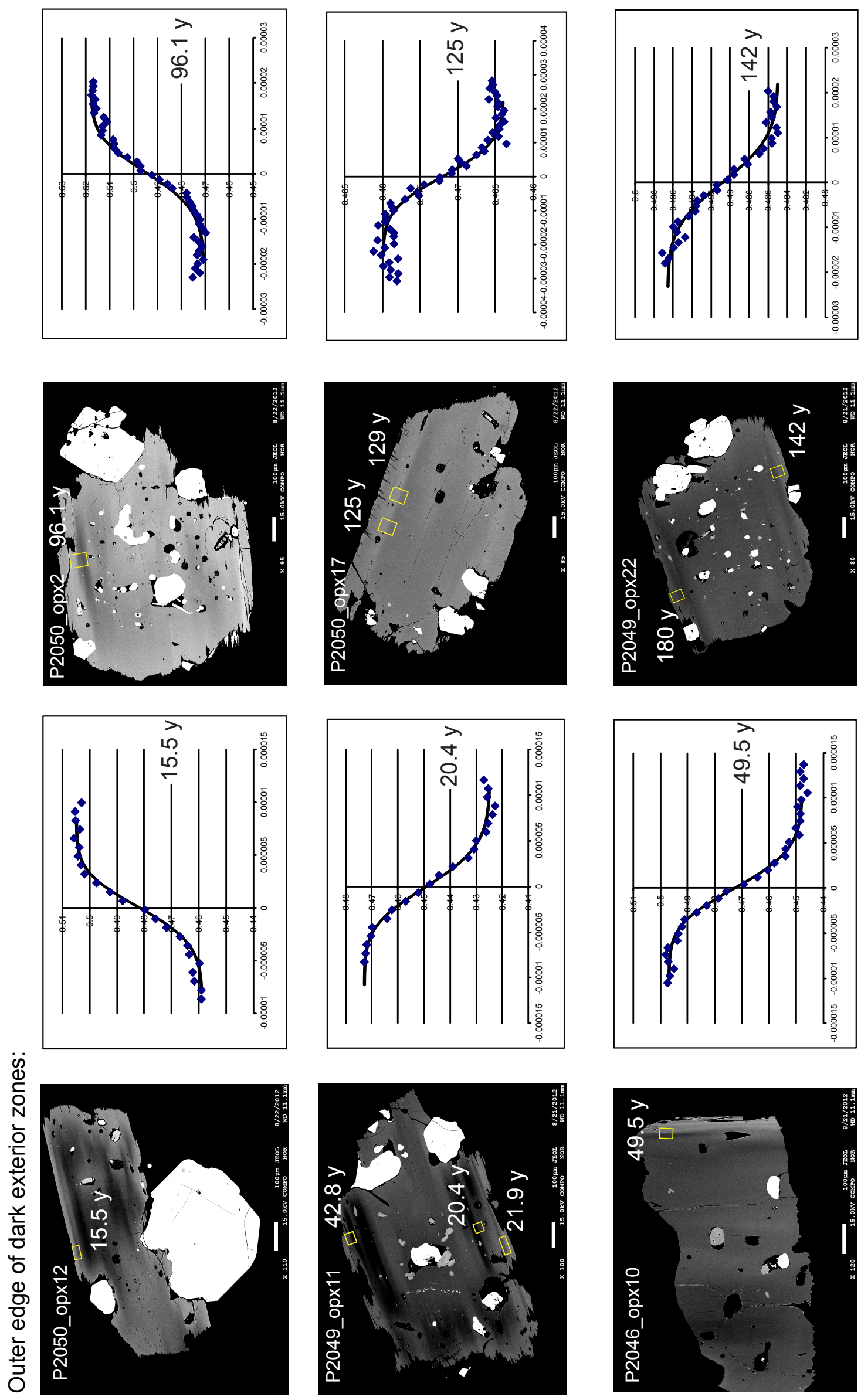

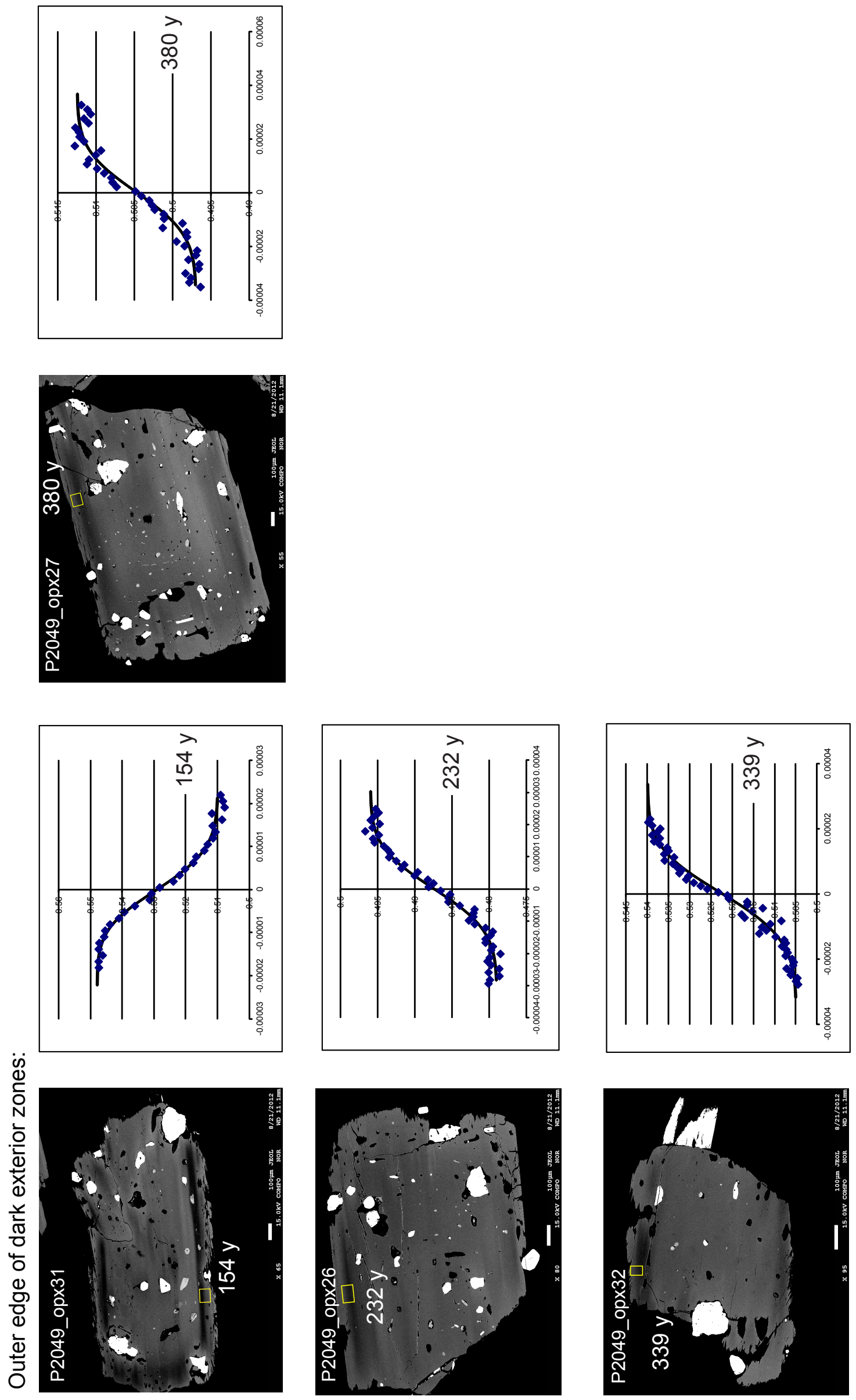

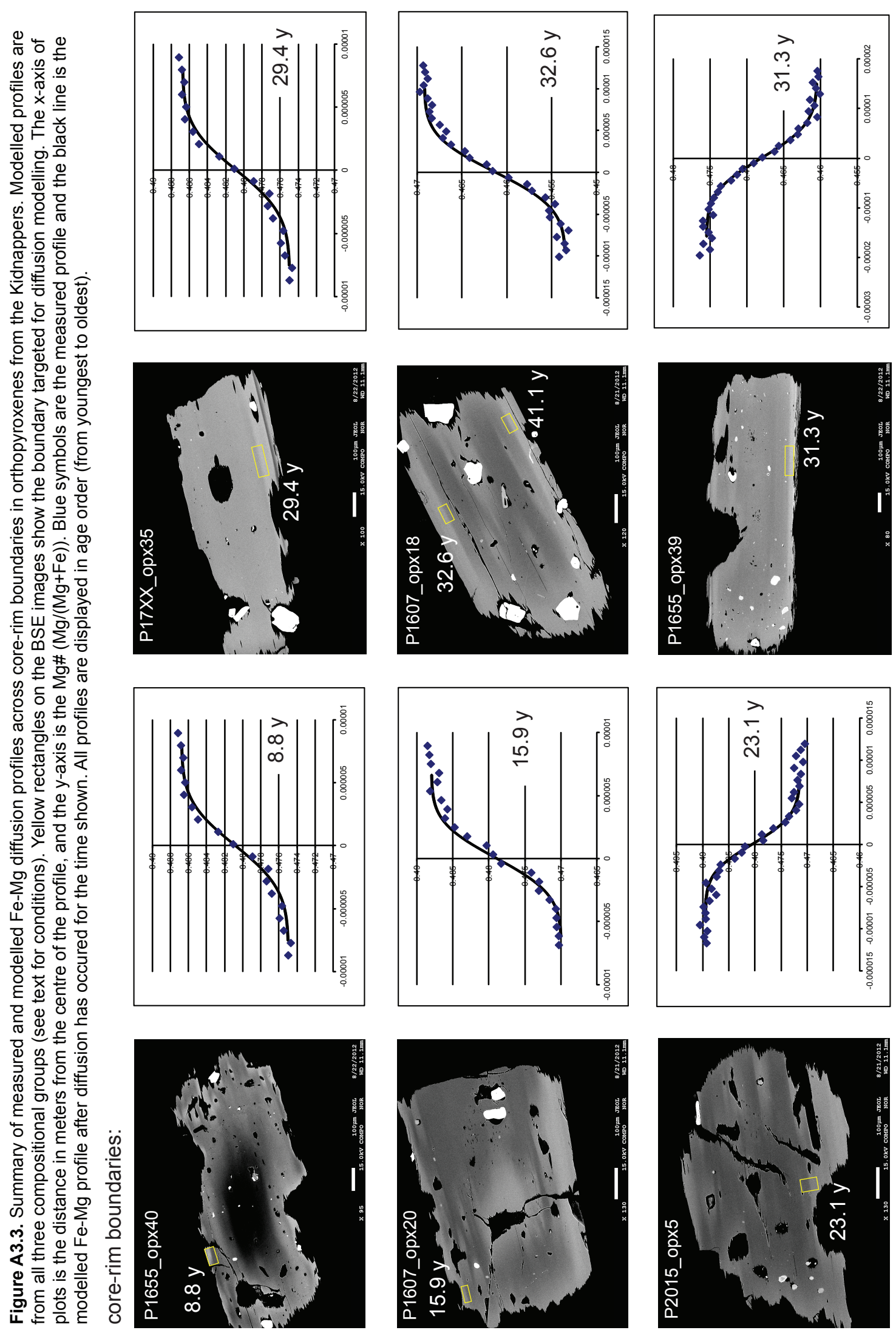

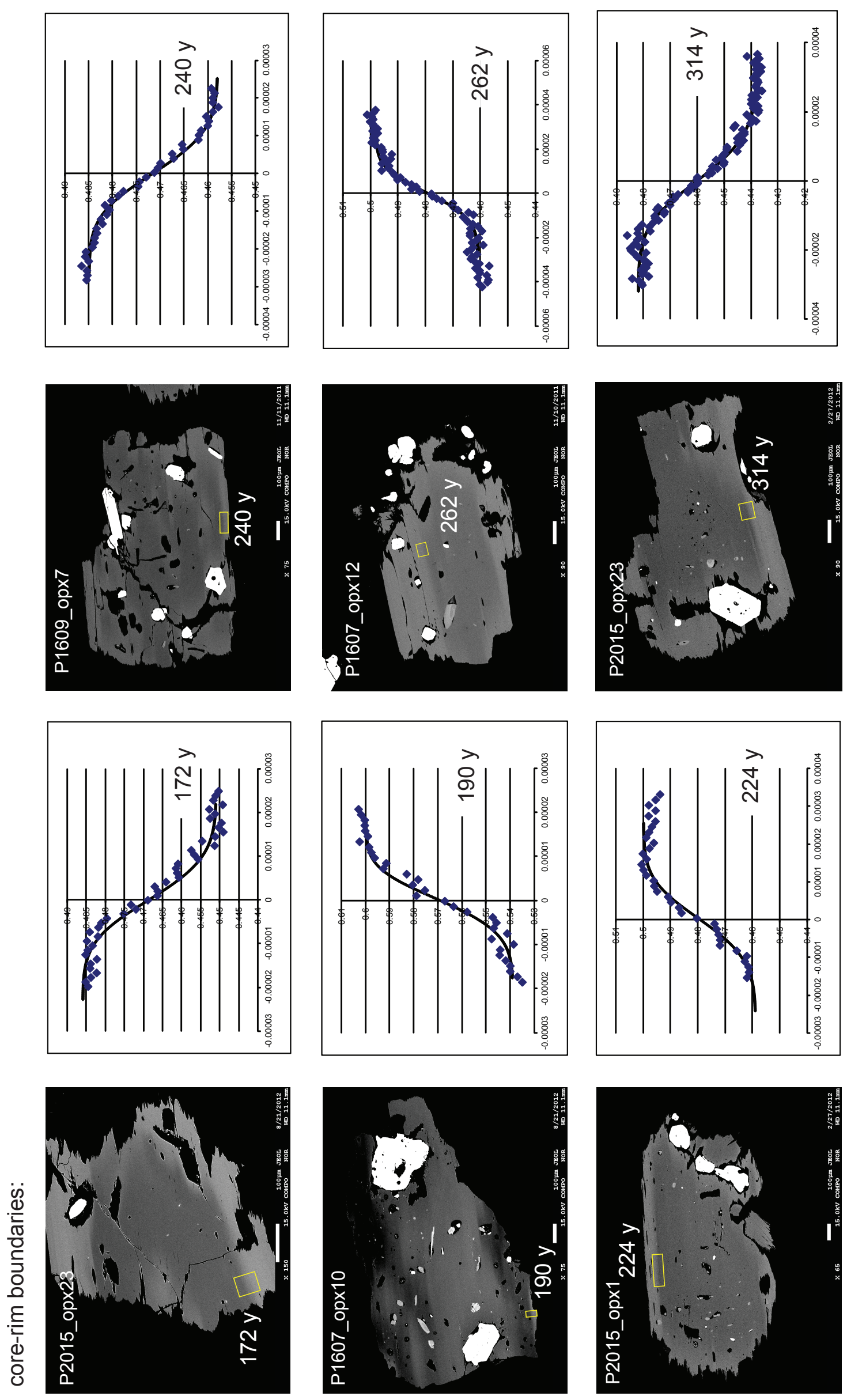

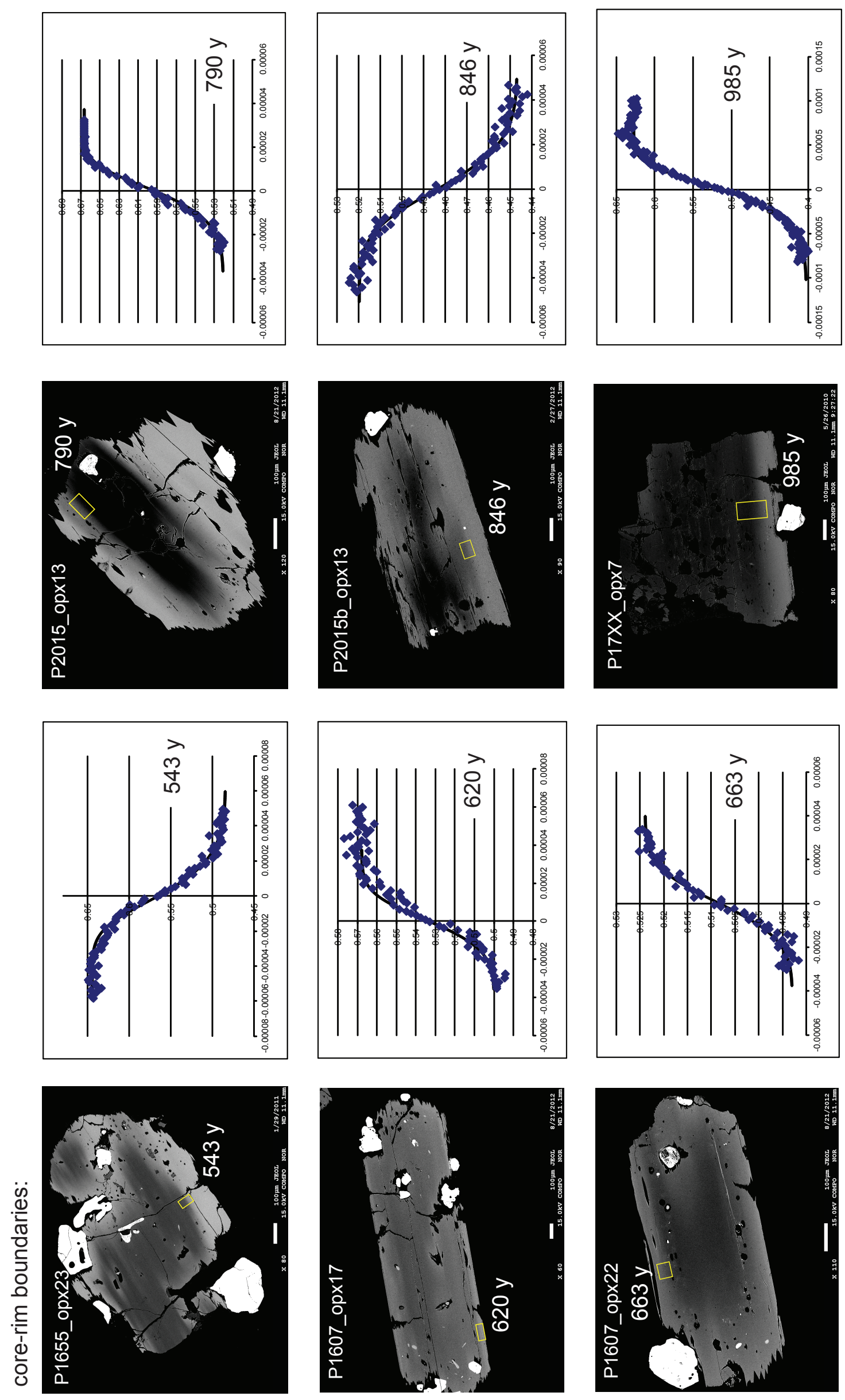

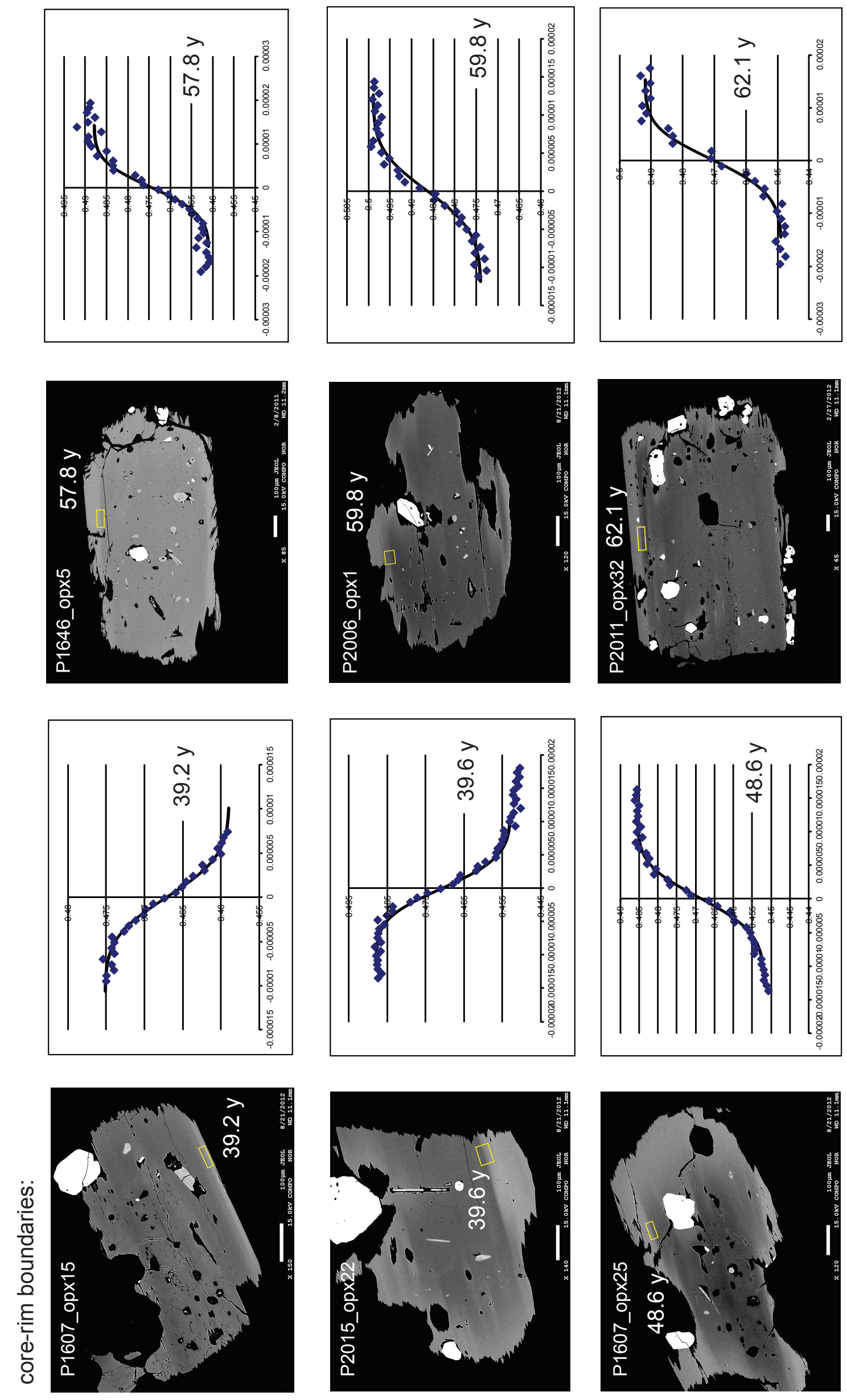

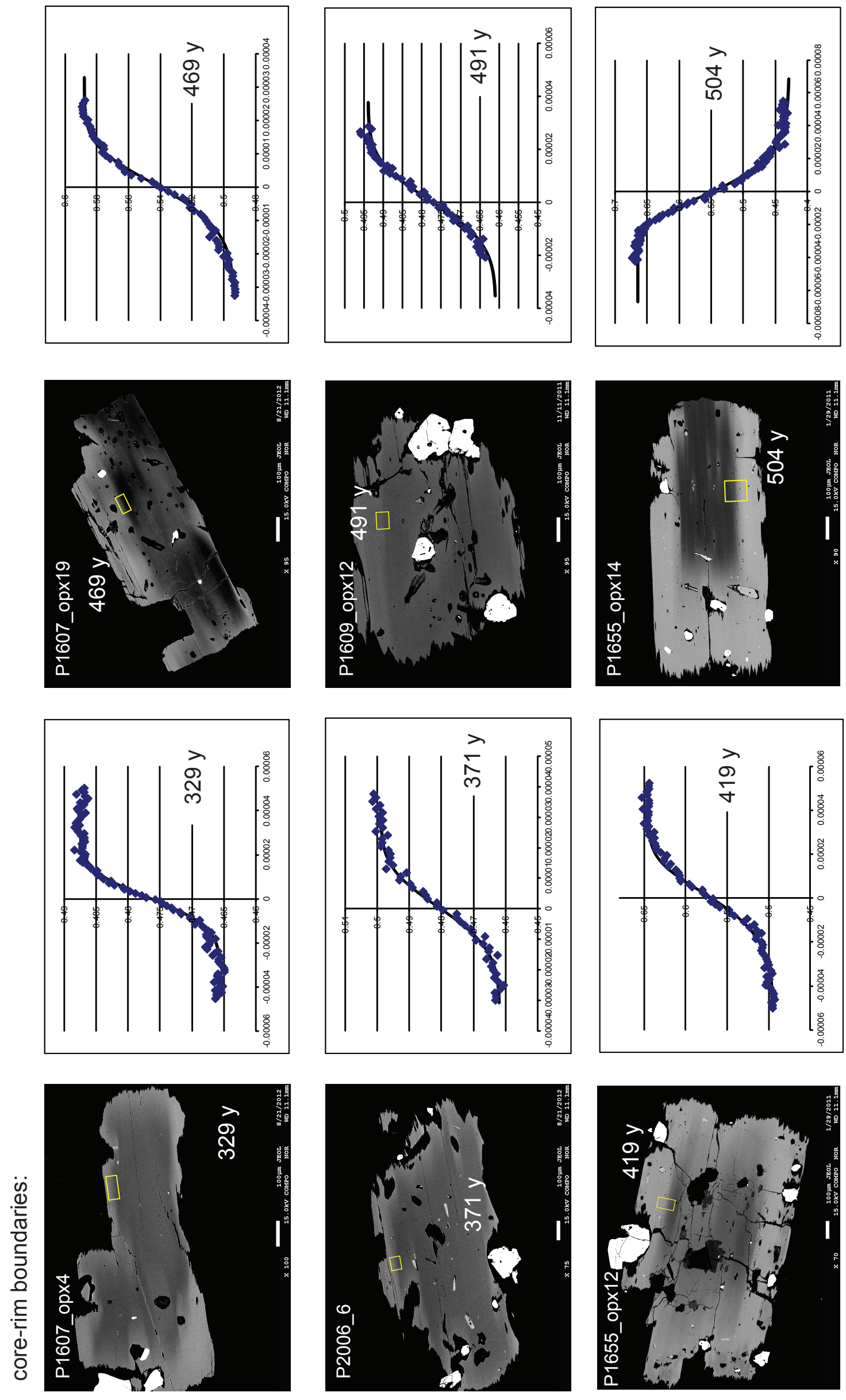


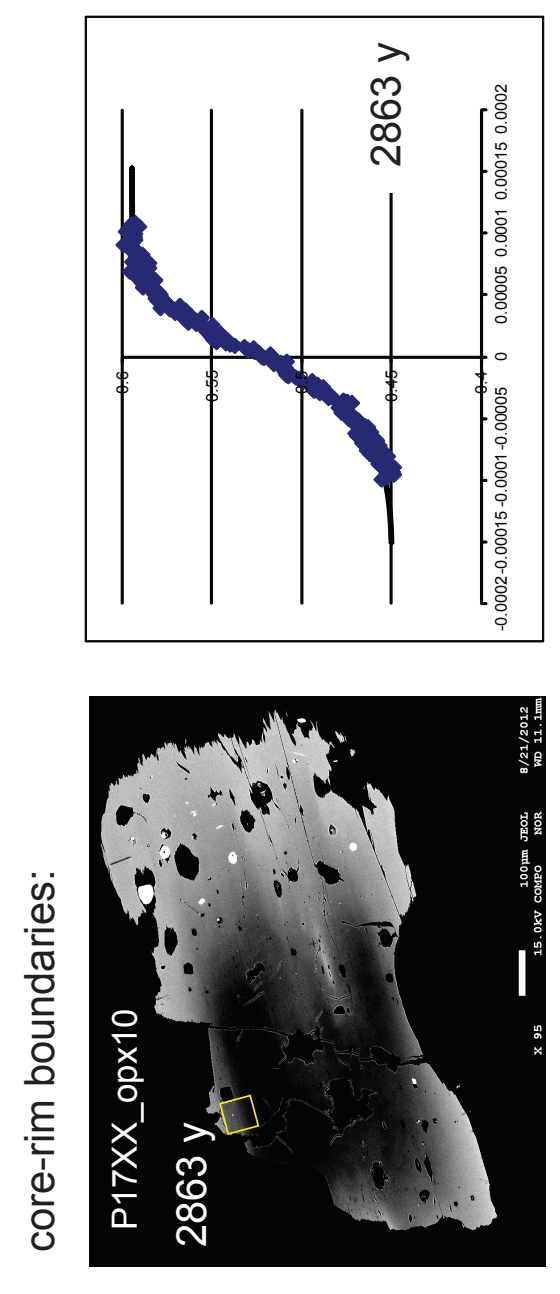



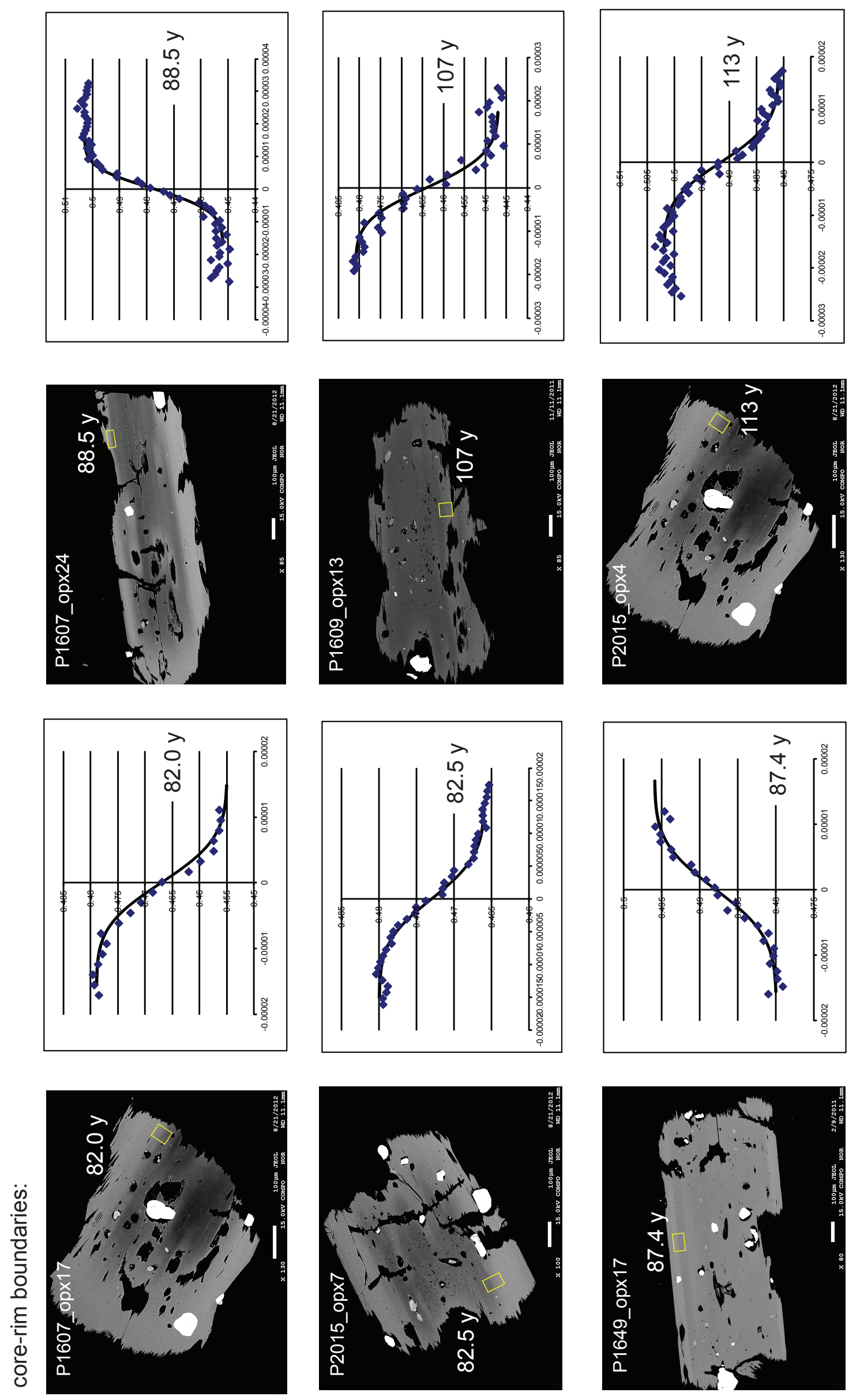

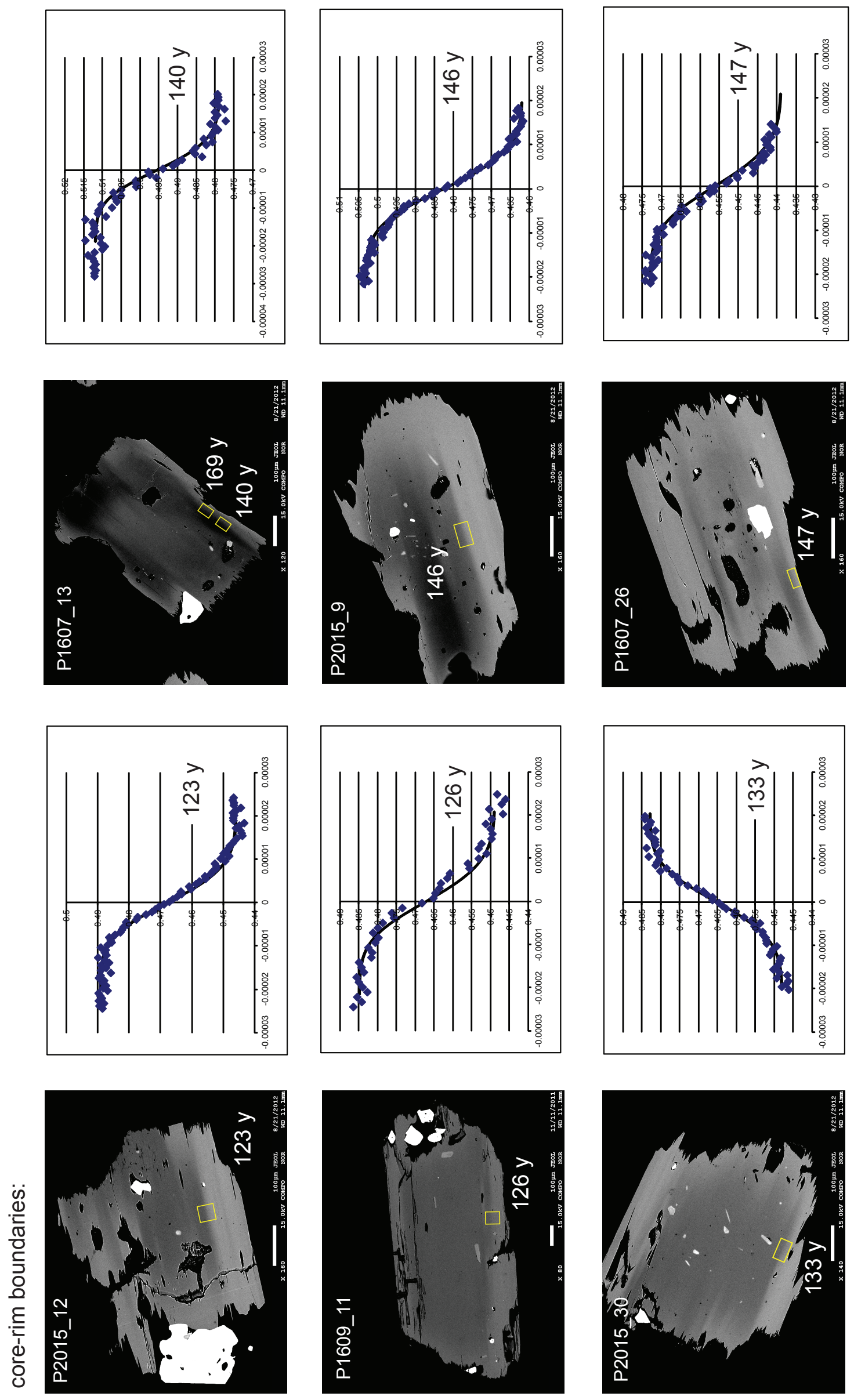


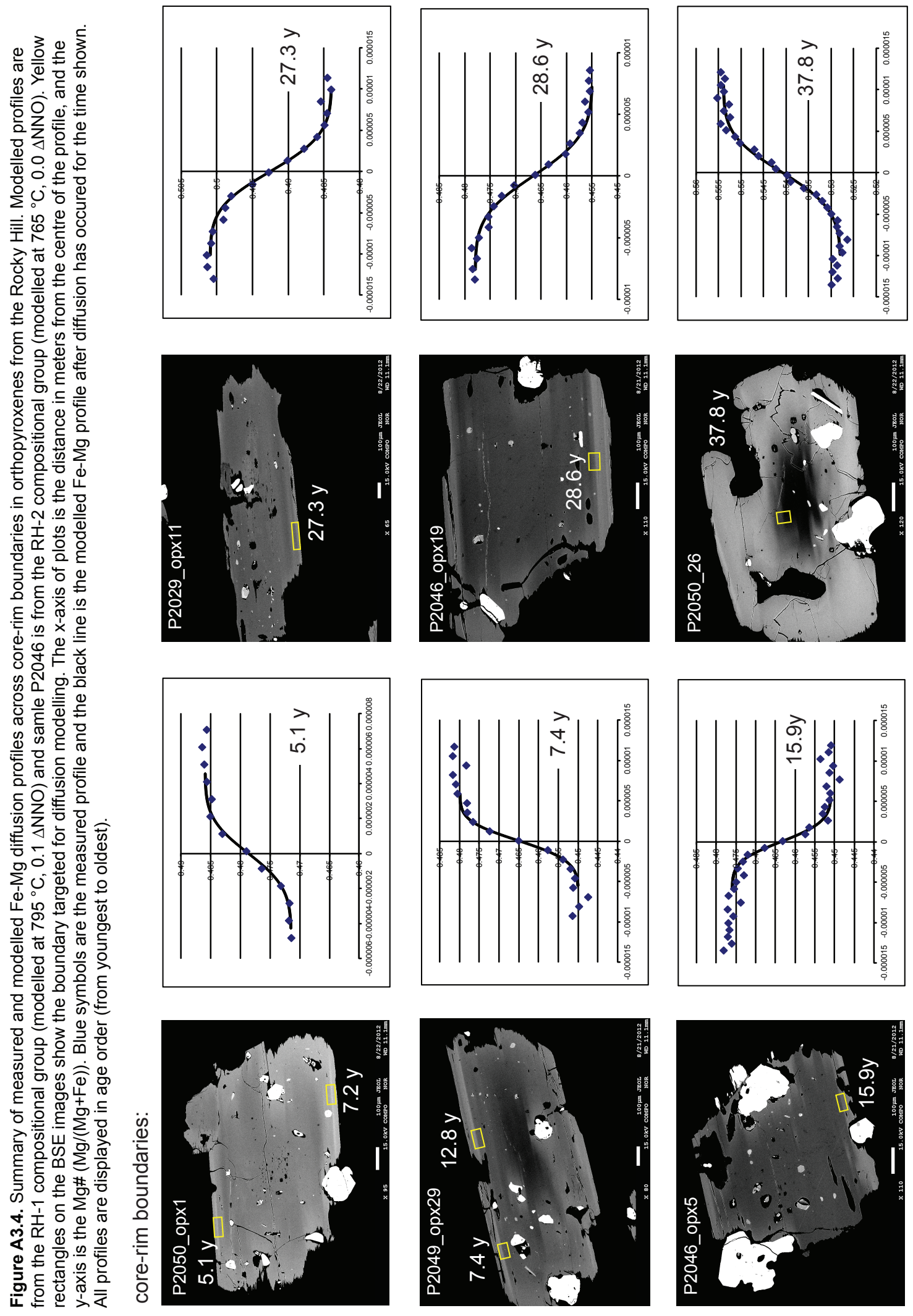



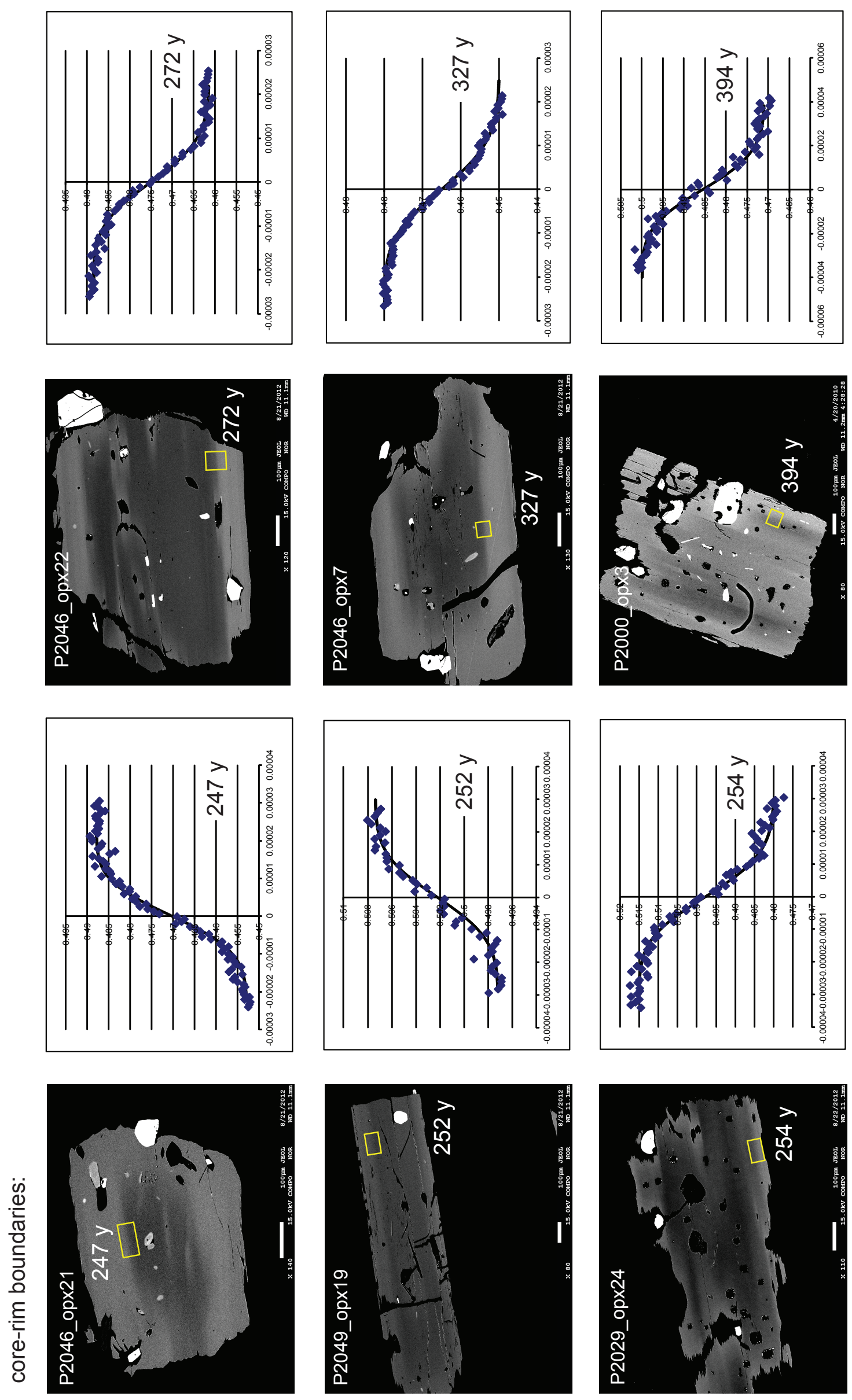


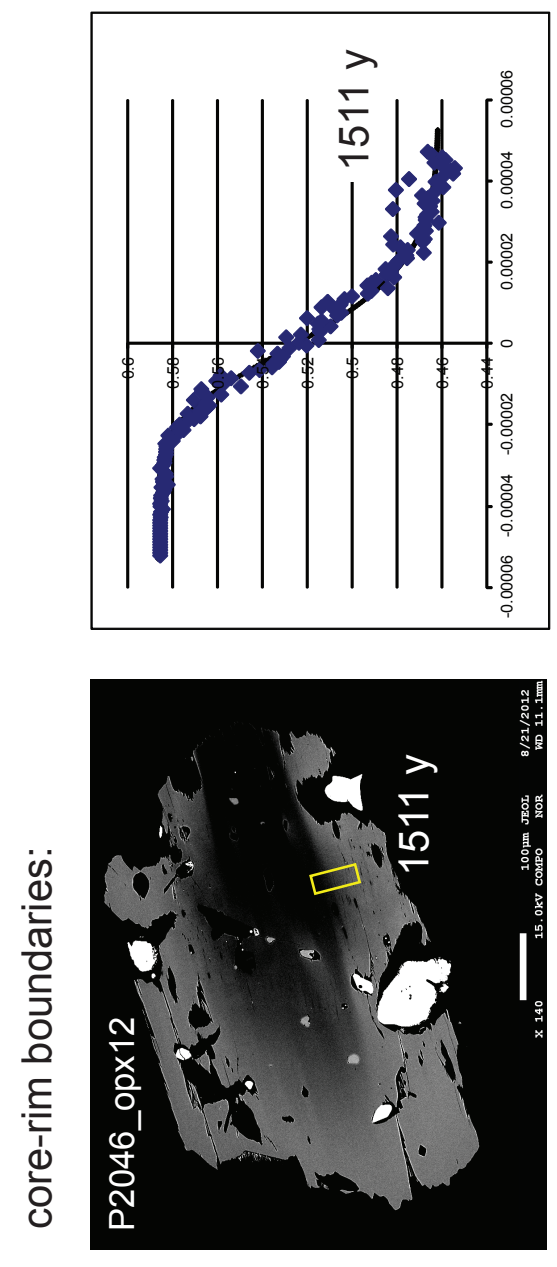



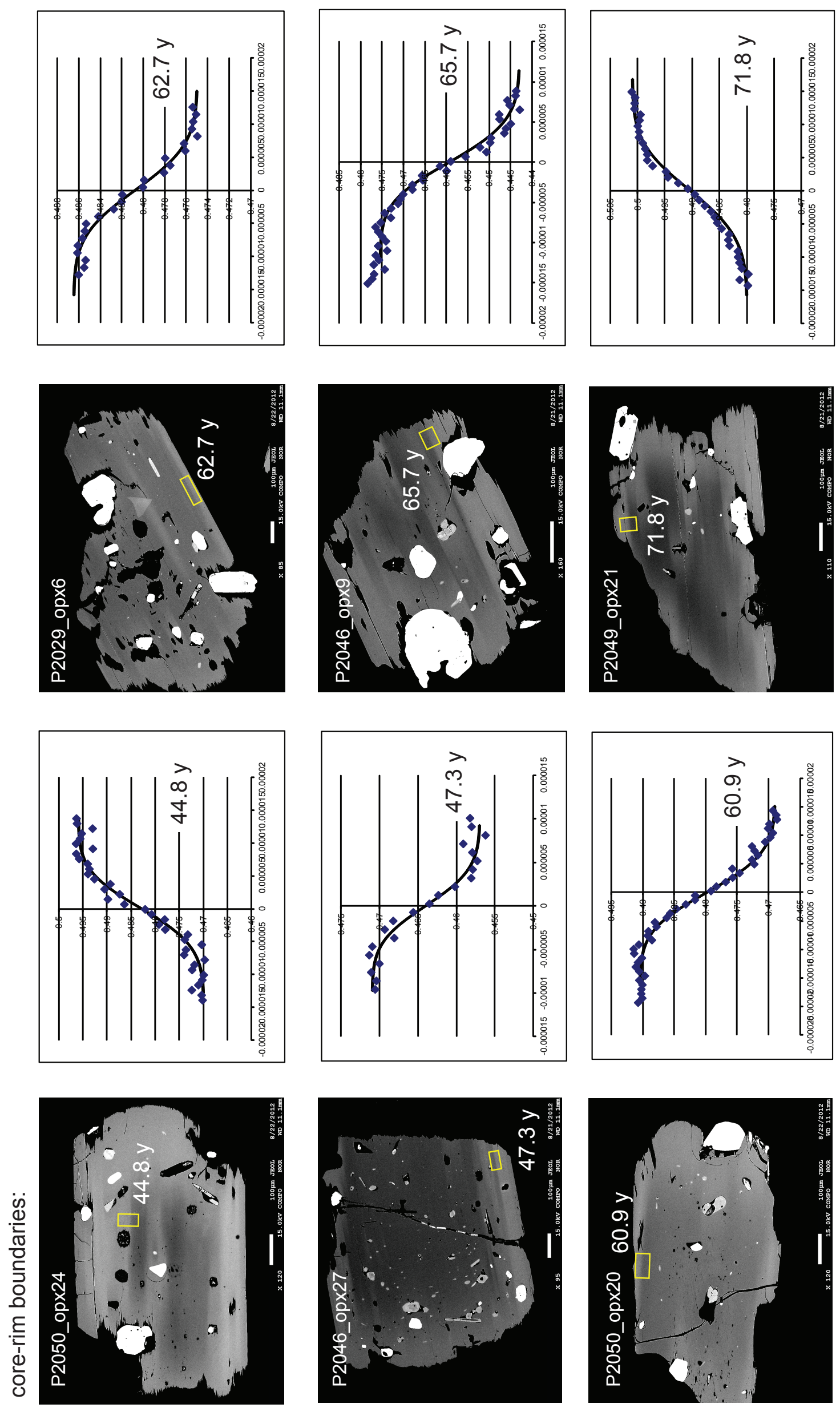

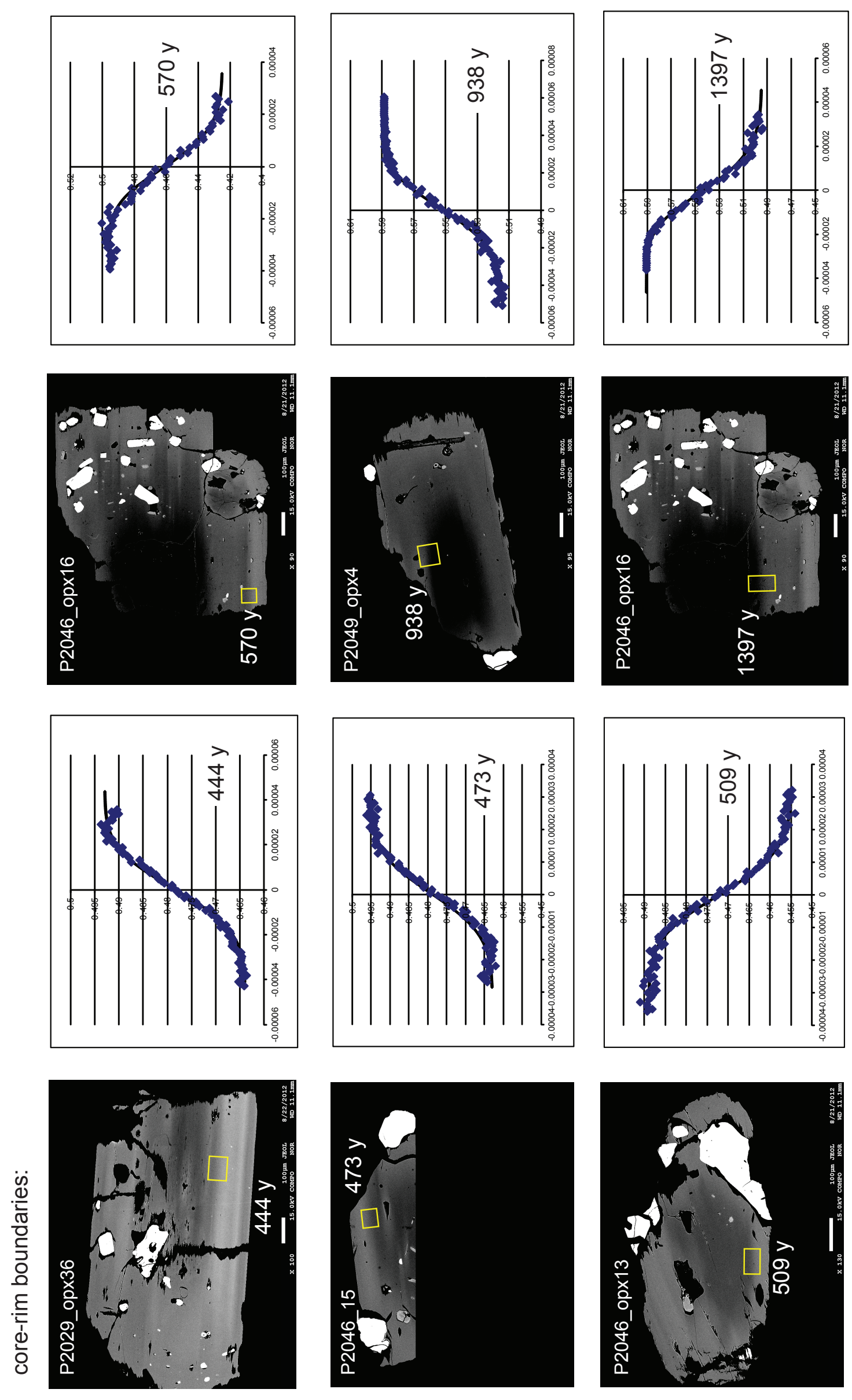

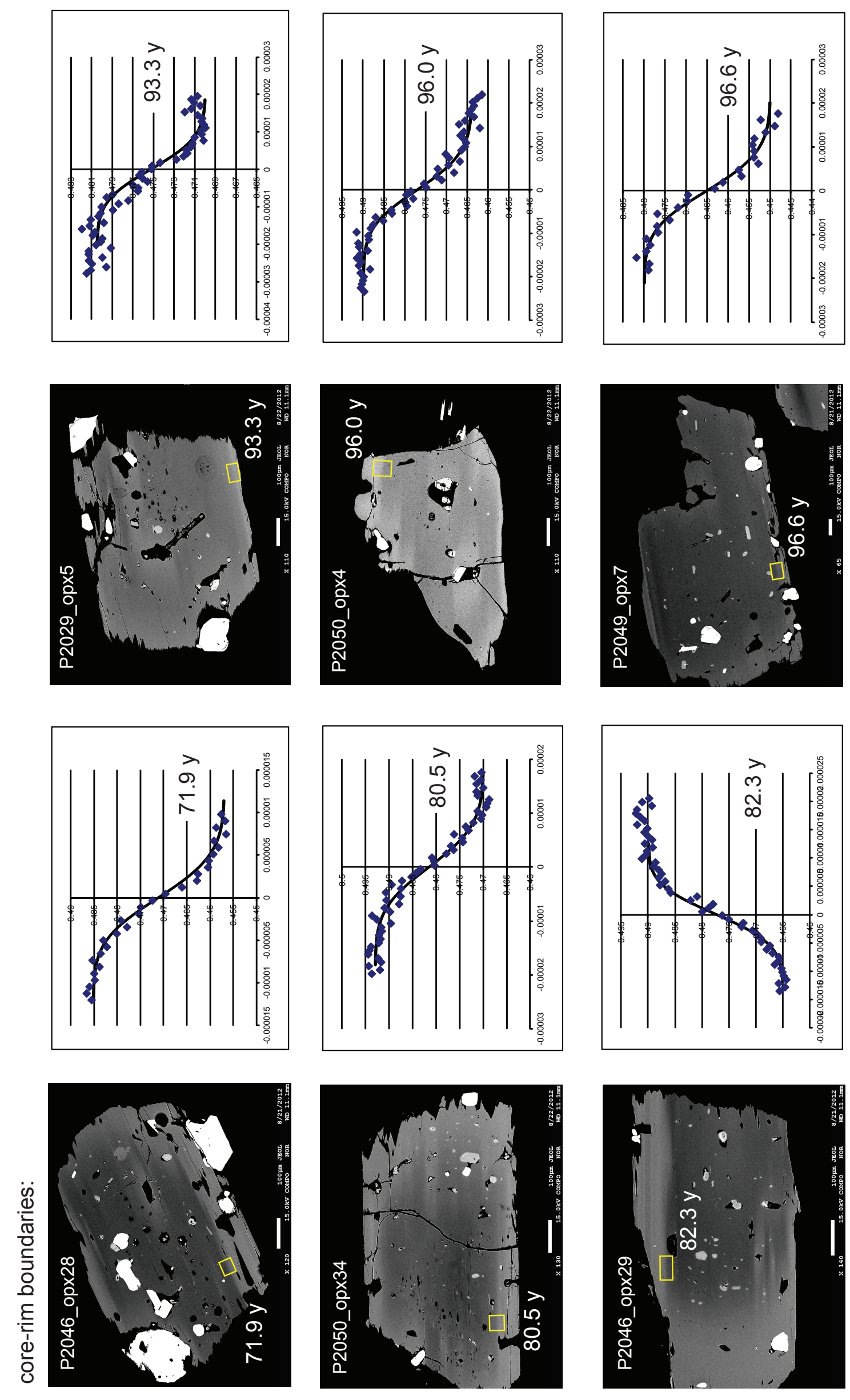

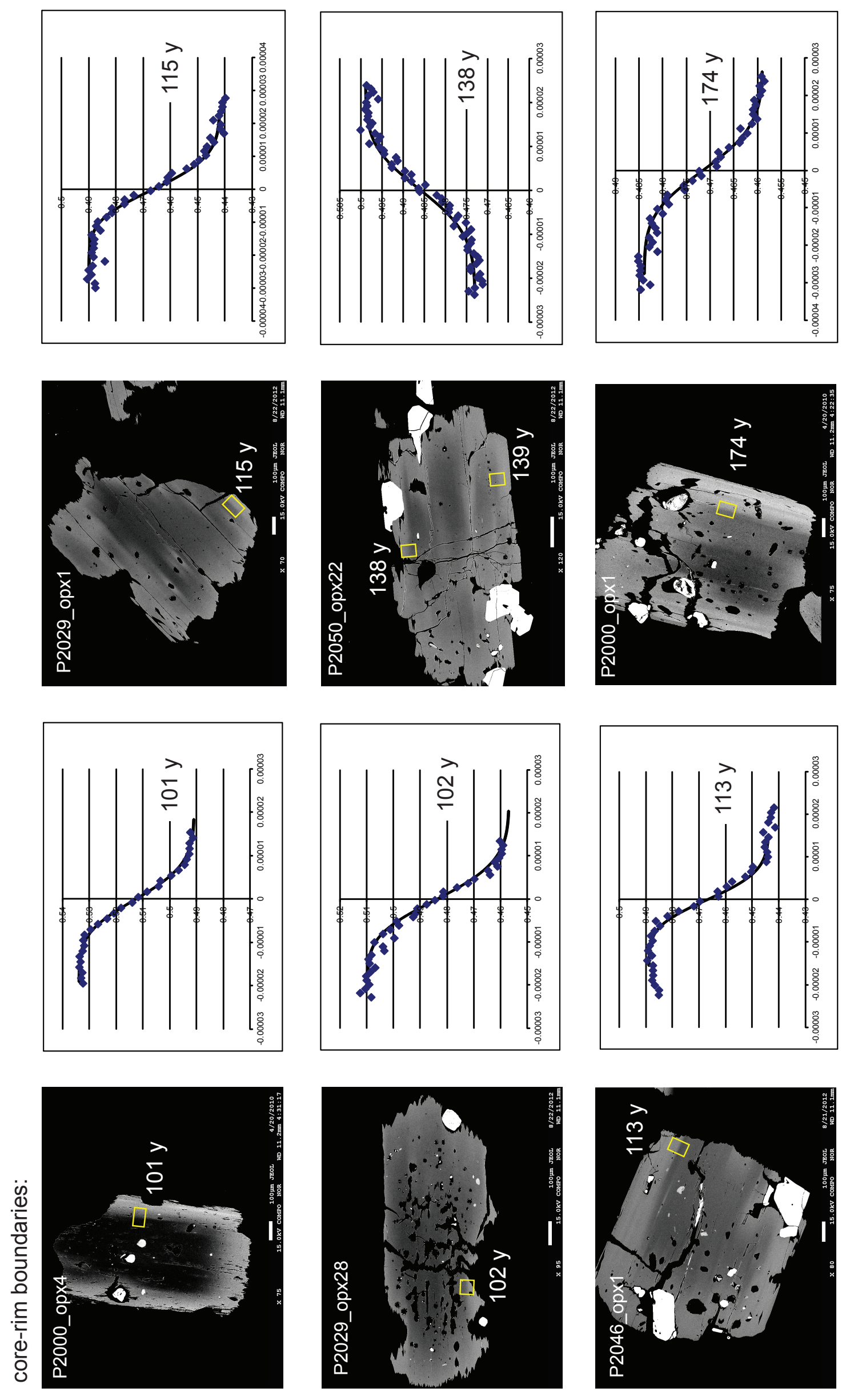
